\title{
Assessing governance assessments; the case of Mozambique : governance assessments in the context of aid effectiveness discourse
}

Citation for published version (APA):

Torvinen, L. (2013). Assessing governance assessments; the case of Mozambique : governance assessments in the context of aid effectiveness discourse. [Doctoral Thesis, Maastricht University]. Boekenplan. https://doi.org/10.26481/dis.20131121lt

Document status and date:

Published: 01/01/2013

DOI:

10.26481/dis.20131121lt

Document Version:

Publisher's PDF, also known as Version of record

Please check the document version of this publication:

- A submitted manuscript is the version of the article upon submission and before peer-review. There can be important differences between the submitted version and the official published version of record.

People interested in the research are advised to contact the author for the final version of the publication, or visit the DOI to the publisher's website.

- The final author version and the galley proof are versions of the publication after peer review.

- The final published version features the final layout of the paper including the volume, issue and page numbers.

Link to publication

\footnotetext{
General rights rights.

- You may freely distribute the URL identifying the publication in the public portal. please follow below link for the End User Agreement:

www.umlib.nl/taverne-license

Take down policy

If you believe that this document breaches copyright please contact us at:

repository@maastrichtuniversity.nl

providing details and we will investigate your claim.
}

Copyright and moral rights for the publications made accessible in the public portal are retained by the authors and/or other copyright owners and it is a condition of accessing publications that users recognise and abide by the legal requirements associated with these

- Users may download and print one copy of any publication from the public portal for the purpose of private study or research.

- You may not further distribute the material or use it for any profit-making activity or commercial gain

If the publication is distributed under the terms of Article 25fa of the Dutch Copyright Act, indicated by the "Taverne" license above, 
Assessing Governance Assessments;

The Case of Mozambique

Governance Assessments in the Context of Aid Effectiveness Discourse 
(C) 2013, Laura Torvinen

ISBN 9789086663163

NUR 740

Publisher: Boekenplan, Maastricht

www.boekenplan.nl

www.booxstore.nl

All rights reserved. No part of this publication may be reproduced, stored in a retrieval system, or transmitted in any form, or by any means, electronic, mechanical, photocopying, recording or otherwise, without the prior permission in writing, from the author. 


\title{
Assessing Governance Assessments; \\ The Case of MozambiQue
}

\author{
Governance Assessments in the Context of \\ Aid Effectiveness Discourse
}

\begin{abstract}
Dissertation
to obtain the degree of Doctor at the Maastricht University, on the authority of the Rector Magnificus Prof. Dr. L. L. G. Soete in accordance with the decision of the Board of Deans, to be defended in public on Thursday 21 November 2013, at $16.00 \mathrm{hrs}$




\section{Promoter:}

Prof. Dr. Adam Szirmai

\section{Assessment Committee:}

Prof. Dr. Chris de Neubourg (Chairperson)

Dr. Håkan Edström

Prof. Dr. Wil Hout, International Institute of Social Studies, Erasmus University Rotterdam

Prof. Dr. Juhani Koponen, University of Helsinki

Dr. Katrin Kriz, Emmanuel College, Boston

The cover photo shows an advertisement of a radio programme on governance and anti-corruption issues broadcasted in the Province of Cabo Delgado. Photo taken by the author on September 11, 2010 in Pemba. 


\section{Table of Content}

Acknowledgements $\quad$ xi

List of Boxes xiv

List of Figures $\quad$ xv

List of Tables $\quad$ xvi

Maps xvii

Abbreviations $\quad$ xviii

1 Introduction 1

1.1. Background to the Research 1

1.2. Purpose of the Research 5

1.3. Research Questions 6

1.4. Definition of Key Concepts 8

$\begin{array}{ll}\text { 1.5. } & \text { Structure of the Dissertation } \\ \end{array}$

2 Framing the Research: The Puzzle of Development, Aid Effectiveness and Governance

2.1. Role of Aid in Development 16

2.1.1. Aid as Source of Investment and Capital Accumulation 17

2.1.2. Emerging Poverty Focus 19

2.1.3. Structural Adjustment as Key to Growth and Development 21

2.1.4. Poverty Reduction with "Good Governance" 23

2.1.5. Concluding Remarks 26

2.2. Shifting Paradigm of Aid Effectiveness 27

2.2.1. Methodological Challenges 28

2.2.2. "Aid Contributes to Poverty Reduction and Development - at MicroLevel” 29

2.2.3. "Impact of Aid - Harmful if Any" 30

2.2.4. "Aid Contributes to Growth - Marginally" 32

2.2.5. "Aid Contributes to Growth and Development - In Good Policy Environment" 33

2.2.5.1. Aid in Support of the Millennium Development Goals 36

2.2.6. Partnership as Key to Aid Effectiveness 37 
2.2.7. Concluding Remarks 38

2.3. Conceptual Approaches to Governance 39

2.3.1. Governance in the Context of International Development Cooperation 40

2.3.2. Governance, Good Governance or Good Enough Governance? $\quad 47$

2.3.3. Governance Assessments in Practice 50

2.3.4. Concluding Remarks 54

2.4. The Puzzle of Development, Aid Effectiveness and Governance Conclusions $\quad 54$

$3 \quad$ Methodological Approach and Data $\quad 57$

3.1. Case Study on Assessing Governance Assessment in Mozambique $\quad 58$

3.1.1. Units of Analysis $\quad 59$

3.1.2. Data Sources 60

3.2. Positionality and Ethical Considerations 63

3.2.1. Position as a Foreign Researcher in Mozambique 63

3.2.2. Ethical Considerations 65

3.3. Aspects of Validity and Reliability $\quad 68$

3.3.1. Validity of the Research Findings 68

3.3.2. Reliability of the Research Findings 70

4 Setting the Scene: Historical Context of Governance in Mozambique $\quad 73$

4.1. Achieving Independence in the Shadow of War 75

4.2. The Political, Economic and Social Context at Independence, $1975 \quad 78$

4.2.1. Political Context at Independence $\quad 78$

4.2.2. Economic Context at Independence 81

4.2.3. Social Sectors at Independence 82

4.3. Building Socialism under Single-Party Rule, 1975-1985 83

4.3.1. Building the Party-State Organization 83

4.3.2. Transforming the Economy under Single-Party Rule 84

4.4. Transition to a Market-Oriented Economy and Multiparty Democracy, 1985-1992 87

4.5. Political and Economic Transformation since 1992

4.5.1. Political Transformation 91

4.5.1.1. "Voting for Peace" - First Multi-Party Elections in 199491 
4.5.1.2. Consolidating Democracy - Elections in 1999, 2004 and 2009

4.5.1.3. Towards Decentralization and Local Democracy 95

4.5.1.4. Multi-party Democracy with Single-party Dominance 97

4.5.2. Economic Transformation 98

$\begin{array}{ll}\text { 4.5.2.1. Fight against Poverty } & 100\end{array}$

4.5.2.2. Facing the Debt Crisis 104

4.5.3. Other Socio-Economic Development Trends 105

4.6. Mozambique as a Success Story - Concluding Remarks 107

5 Evolving Aid Architecture; “Who Sits in the Driver's Seat?" 111

5.1. Aid Flows to Mozambique; An Overview 112

$\begin{array}{lll}\text { 5.2. } & \text { First Decade of Aid } & 115\end{array}$

5.3. Aid Architecture in the Aftermath of the Economic Recovery Programme

5.4. Aid Architecture during the Post-War Period

5.5. Aid Profile of the "Top Ten" Donors in Mozambique 121

5.5.1. Towards New Modalities of Aid 123

5.5.1.1. Governance in the Context of the New Aid Modalities $\quad 126$

5.6. Contribution of Aid to Mozambique's Development 129

$\begin{array}{ll}\text { 5.6.1. Intended Outcomes } & 129\end{array}$

$\begin{array}{ll}\text { 5.6.2. Unintended Outcomes } & 131\end{array}$

6 Governance Assessments by the “Top Ten” Donors 135

6.1. Worldwide Governance Indicators; The World Bank Institute 136

6.2. Country Policy and Institutional Assessment; The World Bank 143

6.3. Country Policy and Institutional Assessment;

$\begin{array}{ll}\text { The African Development Bank } & 156\end{array}$

6.4. Governance Profile; The European Union 164

6.5. Millennium Challenge Scorecard; The USA 170

6.6. Country Governance Analysis; The United Kingdom 180

6.7. Strategic Governance and Corruption Analysis; The Netherlands 187

6.8. Power Analysis; Sweden 194

6.9. Concluding Remarks 200 
7 Consistency of the Assessments of Governance in Mozambique

7.1. Comparing the Results of Governance Assessments Comparing Pears with Apples? 207

$\begin{array}{ll}\text { 7.2. Comparison Methods } & 210\end{array}$

7.2.1. Comparison of Results as Reported by Aid Agencies 210

7.2.2. Comparison of Results Based on Quantification 211

7.2.2.1. Rescaling the Original Scores 213

7.3. Quality of Governance in Mozambique: Quantitative Assessments 214

7.3.1. Worldwide Governance Indicators 214

7.3.2. Country Policy and Institutional Assessment (The World Bank) 219

7.3.3. Country Policy and Institutional Assessment (The African Development Bank) 222

7.3.4. The Millennium Challenge Scorecard 227

7.4. Quality of Governance in Mozambique: Qualitative Assessments 232

7.4.1. Governance Profile 232

7.4.2. Country Governance Analysis 237

7.4.3. Strategic Governance and Corruption Analysis 242

7.4.4. Power Analysis 247

7.5. Consistency of the Assessment Results: The Emerging Landscape 254

7.6. Consistency of the Results Based on Quantification 256

7.7. Inconsistencies in the Assessment Results; An Attempt of Explanation 262

7.8. Consistency of the Results of Governance Assessments - Concluding Remarks 264

8 Donor Governance Assessments: Mozambican Perceptions 267

$\begin{array}{lll}\text { 8.1. } & \text { Field Study } & 268\end{array}$

8.1.1. Data Collection 268

8.1.2. Data Analysis 276

8.2. Relevance of Donor Governance Assessments 279

8.2.1. Meaning of Governance in the Mozambican Context 279

8.2.1.1. Interpretation of Governance in the Context of Mozambique 279

8.2.1.2. Perceptions on "Good" and "Bad" Governance 293

8.2.1.3. Greatest Challenges of Governance for Mozambique $\quad 305$

8.2.2. Knowledge of Donor Governance Assessments 314

8.2.3. Relevance of Donor Governance Assessments in Mozambique 322

8.3. Impact of Donor Governance Assessments 329 
8.4. Mozambican Perceptions on Donor Governance AssessmentConcluding Remarks

9.1. Context-Specificity with Local Participation 340

9.1.1. Joint Review of the General Budget Support 346

9.1.2. African Peer Review Mechanism 351

9.2. Revisiting Donor Governance Assessments; Donor Perspectives 357

9.3. Ways Forward - Concluding Remarks 366

10 Conclusions $\quad 369$

10.1. Conceptual and Operational Approaches to Assessing Governance 370

10.2. Consistency of the Results of the Governance Assessments 371

10.3. Perceptions about the Relevance of the Governance Assessments 373

10.4. Perceptions about the Impact of Governance Assessments 375

10.5. Relevance of the Research 376

10.6. Emerging Questions for Future Research 379

$\begin{array}{ll}\text { References } & 383\end{array}$

$\begin{array}{lr}\text { Annexes } & 399\end{array}$

Annex 1. CPIA Cluster D 399

Annex 2. Interview Guide: Key Informants and Focus Group Discussants $\quad 405$

Annex 3. Interview Guide: Donor Representatives 408

$\begin{array}{ll}\text { Summary in Dutch - Samenvatting } & 409\end{array}$

$\begin{array}{ll}\text { Curriculum Vitae } & 415\end{array}$

MGSoG Dissertation Series $\quad 417$ 



\section{Acknowledgements}

The realization of this research project has been made possible through the inspiration, encouragement and guidance that I have received from many individuals and institutions. Amongst all the colleagues and friends who have contributed to my research, my greatest gratitude belongs to my supervisor, Professor Adam Szirmai of Maastricht University. Without his constant professional and personal support, the completion of the dissertation would probably have remained an unfulfilled dream. His firm belief in my research and willingness to read my drafts has been invaluable. I would also like to thank the Assessment Committee, Prof. Dr. Chris de Neuburg (chair), Dr. Håkan Edstöm, Prof. Dr. Wil Hout, Prof. Dr. Juhani Koponen and Dr. Katrin Kriz, for constructive criticism which guided the finalization of the manuscript.

I am deeply indebted to my respondents in Mozambique who shared their time and thoughts with me. Although burdened with many responsibilities, all the key informants and focus group discussants were willing to engage in long discussions on governance issues in general and the governance assessments in particular. Without their insightful inputs the research questions, which I set to answer, could not have been answered. In this context, I would also like to extend my sincere thanks to Humberto Ossemane, Ritva Parviainen and Pauliina Sarvilahti-Jimenez from the Finnish NGO KEPA for their guidance when organizing the field work. Finally, without the excellent transcription of all the interviews by Ms. Neide John and Ms. Lotta Wilkman, the analysis of the field data would simply not have been possible. Special thanks to you both. I am also grateful to all the colleagues at the Embassy of Finland to Mozambique for the warm welcome and support during my field trips to the country.

The GPAC programme of the Maastricht Graduate School of Governance, Maastricht University, has provided an ideal environment for learning and research: structured, yet sufficiently flexible, to allow for combining full-time work with studies. I am grateful to all the academic and non-academic staff responsible for the smooth running of the GPAC programme. My special thanks to Dr. van de Laar, Prof. Dr. Neuburg and Dr. Edström for their guidance and critical questions which have helped me to stay on track. Shifting the mindset of an aid practitioner to that of a researcher is a challenging task for all involved! I would also like to extend my gratitude to Dr. Kriz of Emmanuel College, Boston, for her advise in the various phases of the field work. 
The GPAC programme is, however, more than just a programme to pursue a degree: the GPAC is the micro-cosmos of the United Nations. I feel privileged for having had the opportunity to learn from and exchange ideas with my fellow students from all parts of the world, and for having developed lasting friendships. Special thanks to Joe Abah, Christiane Arndt, Dennis Gyllenspörre, Sepideh Yousefzadeh and Manos Sfakianakis, who have all successfully completed their "PhD marathons", for their support, inspiring debates and, most importantly, warm friendship.

In addition to the GPAC programme, I have greatly benefitted from the inspiring $\mathrm{PhD}$ Seminars, led by Professor Juhani Koponen, at the Institute of Development Studies (IDS) of the University of Helsinki. My sincere thanks to Professor Koponen for his professional support as well as for allowing me to attend the PhD Seminars as a visiting student, and to share my work with other PhD students at the IDS. The IDS has been my second academic home over the years, and I am grateful for the support and friendship of, in particular, Professors Jeremy Gould, Liisa Laakso and Lauri Siitonen. Special thanks also to my fellow PhD candidates Minna Hakkarainen, Markku Malkavaara, Anja Onali, Sirpa Rovaniemi and Maria Suolahti for their support in the earlier stages of the research.

I am very grateful for the financial support that I have received from my employer, the Ministry for Foreign Affairs, and from the Finnish Graduate School in Development Studies (DEVESTU). Among the many colleagues at the Ministry for Foreign Affairs who have supported my research aspirations, I would like to thank, in particular, Ms. Leena Aalto, Mr. Jorma Julin, Ms. Sirpa Mäenpää and Ms. Anneli Vuorinen.

On a personal level, my warmest thanks to Dr. Liisa Torvinen for encouragement and inspiration when I was still contemplating whether or not to embark upon a doctoral programme. I am also grateful to Ms. Tuuli Huovila for her never ceasing interest in my research - and for all the literature on research methods that she has given me over the years! I am also indebted to Ms. Elisa Mikkola for sharing her knowledge and understanding not only of Mozambique but also of the process of doing research. Furthermore, I have truly appreciated her regular phone calls to check on my well-being!

In Mozambique I owe thanks to far too many people to list here. As I am not able to name my respondents I can only express, once again, my sincere thanks to all of you. I would, however, like to express my gratitude to Dr. Isabel Casimiro and Dr. Terezinha da Silva for sharing your deep understanding of the many realities in Mozambique and for your long-standing, delightful friendship over the past decades. I am also deeply indebted to my former colleague and friend Ms. Helena Chivite for broadening my horizon beyond the luxury life of the expatriate community in Mozambique. Special thanks to my Portuguese teacher, Mr. Joaquim Salvador, for the eye-opening 
discussions and debates about the past and future of Mozambique. I have never before benefitted so much from language lessons!

Last but not least, my warmest thanks and love to Maria and Michael who have borne the heaviest burden of my "project" as this dissertation has come to be known within the family. As Maria put it, just in passing on a beautiful summer evening: "vaikka sä oot kotona, niin et sä kuitenkaan oo täällä" ("although you are at home, you are not really here"). I am deeply grateful for your patience. You may have had your doubts about my capacity to complete the "project", alongside my work-related globe-trotting, but you have wisely kept your own counsel. In my moments of doubt, you have encouraged me to continue. You have been there to support, as you Michael have said numerous times. Special thanks to you also for the careful proof-reading and language checking of the manuscript. My debt to both of you is enormous. 


\section{List of Boxes}

Box 2.1 | Focus of Governance Assessment Tools 52

Box 3.1 | The Relationship between Research Questions, Data Sources and Methods

Box 6.1 | The CPIA Clusters and Criteria 146

\begin{tabular}{l|l} 
Box 6.2 The CPIA (A-C) Clusters and Criteria & 158
\end{tabular}

\begin{tabular}{l|ll} 
Box 6.3 & The CPIA (D) Cluster and Criteria & 158
\end{tabular}

Box 6.4 Operational Guidance Note: Assessing the Quality of Public Administration $\quad 160$

Box 6.5 | Focus of the MCC Country Performance Assessment 172

Box 6.6 | Focus of the CGA 182

Box 6.7 | Focus of the SGACA 189

Box 6.8 | Focus of the Power Analysis 196 


\section{List of Figures}

Figure 2.1 | Global Net ODA Disbursements 1960-2006 16

Figure 2.2 | Governance in the Context of Aid Effectiveness 55

Figure 4.1 | Annual Growth of GDP in 1999-2009 99

Figure 5.1 | Net ODA Disbursements and Net ODA to GNI ratio in 1975-2008 112

Figure 5.2 | ODA per capita in 1975-2008 113

Figure 5.3 | Total ODA Net Disbursements; Bilateral and Multilateral Agencies 1980-2009 114

\begin{tabular}{l|l} 
Figure 5.4 | Total Net ODA Disbursements 1975-1984 & 115
\end{tabular}

Figure 5.5 | Total Net ODA Disbursements 1985-1994 118

Figure 5.6 | Total Net ODA Disbursements; Bilateral (DAC and non-DAC) and Multilateral Agencies 1985-1994 119

Figure 5.7 | Total Net ODA Disbursements 1995-2009 120

Figure 5.8 | Total Net ODA and ODA Excluding Debt Relief by OECD DAC Countries and Multilateral Aid Agencies 1995-2009 120

Figure 5.9 | Total Net ODA Disbursements by Ten Largest Donors (5-year average 2005-2009) 123

Figure 6.1 | Performance-Based Allocation System; IDA14 (2006-2008) 152

Figure 6.2 | Performance-Based Allocation System; IDA15 (2009-2011) 153

Figure 7.1 | Governance Performance 2007 and 2010; WGI Percentile Ranking 217 


\section{List of Tables}

Table 4.1 | Global Social Product 1975-1982 85

Table 4.2 | The Growth of GNP 1985-1991 88

Table 4.3 | Presidential and Parliamentary Elections in Mozambique in 1994, 1999, 2004, 2009

Table 4.4 | Presidential and Parliamentary Elections $2009 \quad 94$

Table 4.5 | Provincial Elections 2009

Table 4.6 | National Household Surveys of 1996/97, 2002/03 and 2008/09 103

Table 7.1 | Governance Performance; WGI Scores 2007 and $2010 \quad 215$

Table 7.2 | Governance Performance - Mozambique and SADC LICs;

WGI 2007 and $2010 \quad 218$

Table 7.3 | Governance Performance - Mozambique, SADC LICs and IDA-eligible countries; World Bank CPIA 2007 and $2010 \quad 220$

Table 7.4 | Governance Performance - Mozambique, SADC LICs and ADF-eligible countries; The AfDB CPIA 2007 and 2010223

Table 7.5 | Governance Performance; The World Bank and the AfDB CPIA for 2007 and 2010

Table 7.6 | Governance Performance - Mozambique and SADC LICs; Millennium Challenge Scorecard 2007 and 2010229

Table 7.7 | Quality of Governance in Mozambique on the Scale from 1 to 6; Average Scores per Aggregate Indicator by Assessment Tool 257

Table 7.8 | Quality of Governance in Mozambique on the Scale from 1 to 6; Scores for Key Focus Areas by Assessment Tool 259

Table 8.1 | Breakdown of the Respondents: Key Informants 269

Table 8.2 | Breakdown of the Respondents: Focus Groups 271

Table 8.3 | Breakdown of Respondents: Donor Agencies 273 


\section{Maps}

Map 1 | Map of the Republic of Mozambique 


\section{Abbreviations}

ACP

AfDB

AfDF

AMA

APRM

AU

BRICS

CGA

CIP

CMI

CNE

CPIA

CSO

$\mathrm{DAC}$

DFID

DRC

EC

EITI

EU

FEIMA

FLEGT

FRELIMO

African, Caribbean and Pacific

African Development Bank

African Development Fund

Associação do Meio Ambiente (Environmental Association)

African Peer Review Mechanism

African Union

Brazil, Russia, India, China, South Africa

Country Governance Analysis

Centro de Integridade Publica (Centre for Public Integrity)

Chr. Michelsen Institute

Comissão Nacional de Eleições (National Elections Commission)

Country Policy and Institutional Assessment

Civil Society Organization

Development Assistance Committee

Department for International Development of the UK Government

Democratic Republic of Congo

European Commission

Extractive Industries Transparency Initiative

European Union

Feira de Artesanato, Flores e Gastronomía de Maputo (Maputo handicraft, flower and food market)

Forest Law Enforcement, Governance and Trade

Frente de Libertação de Moçambique (Mozambique Liberation Front)

GBS General Budget Support

GDP Gross Domestic Product

GNI Gross National Income

GPA General Peace Agreement

GSP Global Social Product

GMD Grupo Moçambicano de Dívida (Mozambican Debt Group)

GoM Government of Mozambique

G19 Group of 19 GBS donors

HIPC Highly Indebted Poor Countries (debt relief initiative) 
HIV/AIDS Human Immunodeficiency Virus/Acquired Immune Deficiency Syndrome

IAF Inquérito aos Agregados Familiares (Hoiisehold Survey)

IDA International Development Association

IDS Institute of Development Studies, University of Sussex

IESE Instituto de Estudos Sociais e Economicos (Institute for Social and Economic Studies)

ILO International Labour Organization

IMF International Monetary Fund

INE Instituto Nacional de Estatistica (National Statistics Institute)

LDC Least Developed Country

LIC Low Income Country

LOLE

MANU

Lei de Orgãos Locais (Law and Local Organs)

MCC

MCS

Makonde African National Union

MDG

Millennium Challenge Corporation

Millennium Challenge Scorecard

MDRI

Millennium Development Goal

MNR

Multilateral Debt Relief Initiative

MONAP

Mozambican National Resistance

$\mathrm{MoU}$

MPD

Mozambique-Nordic Agricultural Programme

Memorandum of Understanding

Ministério do Plano e Desenvolvimento (Ministry of Planning and Development)

MT Metical

NEPAD New Partnership for Africa's Development

NIE

NGO

New Institutional Economics

ODA

OECD

Non-Governmental Organization

Official Development Assistance

OJM

Organization for Economic Cooperation and Development

Organização da Juventude Moçambicana (Mozambican Youth Organization)

OMM Organização da Mulher Moçambicana (Mozambican Women’s Organization)

OTM Organização de Trabalhadores Moçambicanos-Central Sindical (Mozambican Labour Organization)

PCA Power and Change Analysis

PAF

Performance Assessment Framework

PAPS

Programme Aid Partners (GBS donors)

PARPA Plano de Acção para a Redução da Pobreza Absoluta (Action Plan for the Reduction of Absolute Poverty)

PES

Plano Económico e Social (Economic and Social Plan) 
PESOD Plano Económico e Social (District Economic and Social Plan)

PRE Programa de Reabilitação Economica (Economic Recovery Programme)

PRSP Poverty Reduction Strategy Paper

RENAMO Resistência Nacional de Moçambique (Mozambique National Resistance)

RoM Republic of Mozambique

SADC Southern Africa Development Community

SDR Special Drawing Righ

SGACA Strategic Governance and Corruption Analysis

SIDA Swedish International Development Agency

SWAP Sector wide approach

UDENAMO União Democrática Nacional de Moçambique (National Democratic Union of Mozmabique)

UK United Kingdom

UN United Nations

UNAMI União Nacional de Moçambique Independente (National Union for Independent Mozambique)

UNDP United Nations Development Programme

UPC União Provincial dos Camponeses (Provincial Peasants' Union)

USAID United States Agency for International Development

USD United States Dollar

WB World Bank

WBI World Bank Institute

WGI Worldwide Governance Indicators 


\section{Introduction}

\subsection{Background to the Research}

"Good governance is perhaps the single most important factor in eradicating poverty and promoting development."

(United Nations Secretary-General Kofi Annan, 1998)

Contemporary development discourse continues to battle with questions concerning the relationships between the quality of governance, aid effectiveness and development. While there is a broad consensus among academics and development aid agencies on the importance of governance for the impact of aid interventions, and for the achievement of development goals, there is no consensus as to what governance means, how it can be assessed, or how the quality of governance affects aid effectiveness and development in specific country settings. Regardless of the multiple, and often parallel, governance assessments conducted by aid agencies in a given developing country, the understanding of the country-level perceptions of the relevance and potential impact of the assessments on governance remains limited. This research aims to contribute to the discourse by examining what governance assessments conducted by aid agencies entail in the specific country context of Mozambique, and how those assessments are perceived from the Mozambican perspective.

The notion of governance was brought to the centre of the development agenda by the World Bank in its 1989 report Sub-Saharan Africa: From Crisis to Sustainable Growth, which concluded that "Underlying the litany of Africa's development problems is a crisis of governance. " (World Bank, 1989, p. 60). Since then, the belief in governance as one of the key pillars of development has been a central element in the discourse amongst other multilateral and bilateral development aid agencies and, increasingly amongst the developing countries themselves (Gisselquist, 2012). This belief is crystallized in an often cited quote from a speech by the former Secretary-General of the United Nations, Kofi Annan: "good governance is perhaps the single most important factor in eradicating poverty and promoting development" (UN 1998).

Along with a growing emphasis on governance as one of the building blocks for development, the notion of governance has also come to be seen as a key determinant for the effectiveness of development aid (Riddell, 2007, p. 372). This view can be traced to the influential research on the impact of aid on economic growth in developing countries carried out by Burnside and Dollar in the late 1990s. This research concluded that aid contributes to growth and thereby to wider socio-economic development in 
good policy environments (Burnside and Dollar, 1997, 2000; World Bank, 1998) ${ }^{1}$. The initial findings have since been revisited and challenged by several researchers (see e.g. Hansen and Tarp, 2000; 2001; 2006, 2010; Lensink and White, 2000; Guillaumont and Chauvet, 2001; Easterly, Levine and Roodman D., 2003; Clemens, Radelet and Bhavnani, 2004; Collier and Dollar, 2004; McGillivray, 2004; Addison, Mavrotas and McGillivray, 2005; Doucouliagos and Paldam, 2005). However despite this academic controversy, the belief among aid agencies in a good policy and institutional environment as a fundamental precondition for effective aid remains firm. As stated by Riddell "...governance and commitment to governance are now regarded as the central concepts which account for all, or almost all, of the performance of aid - both successes and failures" (Riddell, 2007, p. 370). In other words, "good governance" has become the "new paradigm for aid effectiveness" (Finland's Development Policy Committee: State of Finland's Development Policy III, 2007, p. 13).

The emphasis on governance has led to significant changes in the policies guiding international development cooperation and the allocation of aid resources. Building on the assumption that countries with sound macro-economic policies, well-functioning institutions and administrative frameworks can utilise aid resources most effectively, and are thus more likely able to achieve the expected development objectives, both multilateral and bilateral aid agencies have developed various tools to assess the quality of governance for guiding their aid programming (Arndt and Oman, 2006; Arndt, 2009; OECD, 2009). Countries performing well in these governance assessments are rewarded for their performance by having better access to external assistance compared to countries with poor performance. The results of such governance assessments further influence the choice of instruments to be used in providing assistance.

The shared belief among aid agencies in the importance of governance for the impact of aid and the achievement of development objectives has not resulted in a shared understanding of what governance means or how it can be assessed in a specific country setting. As stated by the World Bank: “... while empirical research links governance-related institutions and development, there is not yet a consensus as to how to approach governance and its measurement" (World Bank, 2006a, p. 11). The multitude of the interpretations of governance reflects, on one hand, different theoretical approaches to governance, and on the other, aid agencies' differing policy objectives and priorities. Hence, developing countries are subjected to multiple governance assessments which build on aid agencies' diverse interpretations of the notion of governance and diverse operational approaches to assessing governance. The multitude of approaches

1. The variables used for assessing the quality of a policy environment included political and institutional variables, budget surplus, inflation rate and trade openness (Burnside and Dollar, 1997). 
to assessing the quality of governance in a given country may result in conflicting perceptions of the governance situation of the country giving thus conflicting signals to policy-makers both among aid agencies and in the developing country itself. In view of the absence of a coherent body of governance theory, the multitude of theoretical and operational approaches applied by the aid agencies is in itself understandable. However, from the point of view of a developing country, the lack of a unified approach is problematic because the quality of governance, as perceived through the governance assessments, is commonly used by aid agencies as a criterion for determining the volume of aid and the modalities for providing aid to a given country.

Against this background, the main purpose of my research is to examine what the governance assessments conducted by aid agencies actually assess in the specific country setting of Mozambique. Since Mozambique gained independence in 1975 it has received substantial amounts of assistance from both multilateral and bilateral aid agencies, and continues to be dependent on external aid to implement its development strategies. Consistent with the belief in the quality of governance as the key determinant of effective aid, Mozambique has been subjected to several governance assessments carried out by the different aid agencies present in the country. As Mozambique's access to external assistance is largely determined by the results of the various governance assessments, the question of what the assessments actually try to capture is of central importance to the Government of Mozambique and to the society at large. From this perspective I will focus on three sets of questions: first, how aid agencies operating in Mozambique define and assess governance; second, how consistent the outcomes of the different governance assessments are; and third, how governance assessments are perceived by Mozambican stakeholders.

My motivation to embark upon this research project derives from my more than 30 years' of involvement in international development cooperation. As a development aid practitioner, with experience from several aid agencies and several developing countries, I have found this growing emphasis on governance to be both inspiring and discomforting. While the belief in "good governance" as a basic ingredient for development seems in itself to be fully plausible, this view turns problematic when looking at the multiple ways with which aid agencies approach governance in developing countries, and increasingly use the governance assessments as criteria for aid allocation. The attempts by aid agencies to assess the quality of governance often seem to build on their pre-conceived notions of good governance without paying much attention to the country-specific governance challenges. Furthermore, despite the donor rhetoric on the importance of country ownership, the participation of local stakeholders in designing and implementing the governance assessments remains limited. 
I have chosen Mozambique as the focus of my research primarily for the reasons that follow. Firstly, I have had the opportunity to work in Mozambique for nearly ten years, on different assignments and over very distinct periods of history of the country. When I first arrived in Mozambique in 1988 it was a country at war with much interference by outside forces, including both by countries within the region and by some of the major players of the Cold War. Mozambique was classified as the poorest, most indebted and most aid-dependent country of the world (World Bank, 1990). My second posting to Mozambique in the mid-1990s coincided with the country's transition to peace, a market economy and multi-party democracy. There was a strong sense of a new beginning with political stability and promising economic prospects. Mozambique has been able to establish itself as an example of a successful post-conflict country, and has achieved the highest sustained rate of economic growth during that period amongst African oil-importing countries (http://www.worldbank.org/ida/country/mozambique.html). During my latest assignment to Mozambique in 2011/2012, the development prospects of the country changed again when Mozambique's natural resource wealth started to attract significant amounts of new foreign direct investments. Confirmed coal deposits and natural gas reserves not only open new opportunities for economic growth and poverty reduction but also present new governance challenges, particularly in terms of public financial management and natural resource management (IMF, 2013, Press Release No. 13/231). In-between my longer-term assignments in Mozambique I have visited the country on numerous occasions in relation to my work in the field of development cooperation. Over the course of the past two decades I have been able to gain some, albeit still limited, insight into and understanding of the dynamics of the Mozambican society and the role of the aid agencies in Mozambique's transformation.

Secondly, over the years of my involvement with Mozambique, the landscape of development cooperation in the country has altered significantly reflecting the country's political and economic transformation as well as the changing paradigm of development cooperation. Support from the former socialist countries of Eastern Europe largely dried up with end of the Cold War and the collapse of the Soviet Union. At the same time, the Bretton Woods Institutions together with the USA, the European Union, and the aid agencies of Western European countries, have become the main players in the donor community. Furthermore, in line with the evolving aid paradigm, the development agendas of the aid agencies operating in Mozambique have undergone significant change. The notion of governance and the quality of governance have gained increasing attention in the development policy dialogue, not only globally but also in Mozambique between the aid agencies, the Government of Mozambique and other local stakeholders. A gradual shift in the modalities of development aid from largely project-based aid to programme-based aid instruments, such as general budget support and sector-wide support programmes, has contributed to the increasing significance of governance issues in the aid policy dialogue in Mozambique. As a result 
of these shifting modalities Mozambique has been, and continues to be, subject to governance assessments by the different aid agencies present in the country.

In other words I have had the possibility to closely follow Mozambique's emergence from decades of war to become one of the best-performing, politically stable economies in Sub-Saharan Africa. As an aid practitioner I have seen, and to some extent taken part in, the changing landscape of development cooperation in the country, including the increasing emphasis on governance in the aid policy dialogue. The choice of Mozambique as the focus of my research thus seemed justified for personal reasons as well as from a perspective of the noticeable country-level implications of the shifting paradigm within development cooperation.

\subsection{Purpose of the Research}

This research builds on the contemporary development discourse on the relationship between governance, aid effectiveness and the achievement of development objectives. As discussed above, while there is a broad consensus among academics and aid agencies on the importance of governance for the impact of aid and the achievement of developmental goals, there is no consensus as to what governance means, how it should be assessed, or how the quality of the governance affects aid effectiveness and development in specific country settings. Furthermore, in spite of aid agencies' commitment to respect "country ownership", as enshrined in the Paris Declaration on Aid Effectiveness ${ }^{2}$, the involvement of developing countries themselves in the governance assessment processes has remained weak, and the understanding of the perceptions of the relevance and potential impact of the assessments from the perspective of local stakeholders is limited.

In an attempt to contribute to this discourse, the main purpose of this case study on Mozambique is to explore what aid agencies actually assess when they assess the quality of governance in a specific country setting, and how these governance assessments are perceived by the local stakeholders. This research does not aim to assess the quality of governance in Mozambique itself but seeks to understand what the governance assessments conducted by aid agencies mean in the specific setting of Mozambique.

2. The Paris Declaration on Aid Effectiveness was adopted in 2005 by close to 100 countries including developed and developing countries, 30 international aid organizations as well as by 15 international civil society organizations. The notion of "Ownership", which is one of the five guiding principles aimed at enhancing the effectiveness of aid, is defined as follows: "Partner countries exercise effective leadership over their development policies, and strategies and co-ordinate development actions." (OECD 2005, p. 3, www.oecd.org/dac/effectiveness/parisdeclaration). 
In the context of this research, the term "governance assessment" is used to refer to tools applied by aid agencies to assess the quality of governance in the specific country setting of Mozambique. The research will focus on the governance assessments carried out over the period of 2006-2010 by the ten largest aid agencies (by volume of aid) operating in Mozambique, which jointly account for approximately $70 \%$ of the all aid flows to the country. ${ }^{3}$ These include the following tools:

1. Worldwide Governance Indicators (the World Bank/the World Bank Institute)

2. Country Policy and Institutional Assessment (the World Bank)

3. Country Policy and Institutional Assessment (the African Development Bank)

4. Governance Profile (the European Union)

5. Millennium Challenge Scorecard (the USA)

6. Country Governance Analysis (the UK)

7. Strategic Governance and Corruption Analysis (the Netherlands)

8. Power Analysis (Sweden)

The term "local stakeholder" refers to Mozambican citizens, grouped in six stakeholder groups:

- Members of Parliament

- Senior Civil Servants in Public Administration

- Private Sector Actors

- Media

- Academia

- Civil Society Organizations

The justification for the selection of the above governance assessment tools and the stakeholder groups will be discussed in more detail in Chapter 3 (Methodological Approach and Data) and Chapter 8 (Donor Governance Assessments; Mozambican Perspectives).

\subsection{Research Questions}

The broad statement on the purpose of the research can be narrowed down to the following research questions:

1. How do aid agencies operating in Mozambique define and assess governance?

2. How consistent are the results of the governance assessments conducted by different aid agencies?

3. Of ten largest donors operating in Mozambique Denmark, Norway and Germany have not developed their own tools to assess governance (at the time of the writing of this research report). 
3. Are the governance assessments perceived by the Mozambican stakeholders as succeeding in addressing governance issues that are considered relevant in the specific governance context of Mozambique?

4. Are the governance assessments perceived as contributing to improved governance in Mozambique?

By seeking answers to the first two research questions this research aims at increasing knowledge and understanding of the various conceptual and operational approaches applied by aid agencies in assessing governance, and the potential implications of the different approaches for the emerging perceptions of the quality of governance in Mozambique. The latter two questions aim at contributing to the understanding of the relevance and potential impact of the assessments from the point of view of country-led efforts to improve governance in Mozambique.

The initial expectations with regard to the key answers to the research questions can be formulated as follows:

- The aid agencies define and assess governance in a multitude of ways which reflect more agency-specific interpretations of governance, and agency-specific priorities, rather than attempting to build on a country-specific analysis of the governance context and governance challenges in Mozambique.

- The aid agencies' different conceptual and operational approaches to assessing governance will lead to inconsistent results regarding the quality of governance in Mozambique.

- The governance assessments conducted by the aid agencies are driven by the agencies' own definitions of the notion of governance, and by their perceptions of governance concerns in Mozambique. As a result they fail to capture country-specific interpretations of governance and the governance concerns considered relevant by local stakeholders.

- The governance assessments carried out by aid agencies without the involvement of the local stakeholders are not likely to contribute to enhanced aid effectiveness and to improving governance in Mozambique.

The research questions, and the underlying expectations, are derived from voluminous research literature and policy debate among aid agencies on the inter-linkages between development, aid effectiveness and governance. The research aims at bridging the knowledge gaps concerning, in particular, the actual use of governance indicators, particularly by "internal" stakeholders, and the impact of the use of governance indicators on the quality of governance in a developing country (Arndt 2009, p. 288; see also IDS, 2010; Booth, 2011; Grindle, 2011 ). From the perspective of the aid agencies, the research thus aims at contributing to the attempts to improve governance assessments by exploring the country-level perceptions on the relevance and potential impact of 
the assessments. Within the Mozambican context, the research aims at providing an input to the dialogue between aid agencies and local stakeholders - whether the Government of Mozambique or non-state actors - on the challenges related to governance, as well as to the joint efforts to improve governance as a fundamental precondition for ensuring political stability and sustainable economic and social development.

\subsection{Definition of Key Concepts}

This research addresses governance within the framework of international development cooperation and, more specifically, in relation to the debate on aid effectiveness. The research builds on a number of core concepts which are widely used in the development cooperation discourse and warrant a definition as a basis for the discussion in the chapters that follow. At the outset, the following concepts will be discussed:

- governance

- official development assistance (ODA)

- "donors and partners": the twin concepts of donor agency/developed country and partner country/developing country

- aid effectiveness

\section{$\square$ Governance $^{4}$}

As the point of departure for this research, the following definition of the concept of governance, formulated by the World Bank Institute, has been chosen to guide the discussion:

"By governance we mean the traditions and institutions by which authority in a country is exercised for the common good. This includes the process by which those in authority are selected, monitored and replaced; the government's capacity to effectively manage its resources and implement sound policies; and the respect of citizens for the country's institutions." (Kaufman, Kraay and Zoido-Lobatón, 1999, p. 1)

The above definition underlies the governance assessment tool, known as the Worldwide Governance Indicators ${ }^{5}$ (WGI), which has been developed by the World Bank Institute within the framework of its research programme on governance. The WGI definition of governance has been criticized for lacking theoretical foundation (Arndt

4. The concept of governance will be discussed in more detail in Chapter 2.

5. The World Governance Indicators will be discussed in more detail in Chapter 6 . 
and Oman, 2006; Thomas 2007; Andrews, 2008; Arndt, 2009; Langbein and Knack, 2010). It has been argued that the WGI indexes to measure governance derived from this definition lack "concept validity" (Langbein and Knack, 2010, p. 351) and are merely "personal ideas of governance" (Thomas, 2007, p. 10) of the people who have developed the indicators. Despite the scholarly critique, the use of the WGI definition as the starting point for the discussion in this research can be justified on several accounts. First, within the context of development policy discourse, the WGI represents one of the most widely referenced governance assessment tools. Second, the governance definition adopted by the WGI underlies several other governance assessment tools developed and applied by other multilateral and bilateral aid agencies. As noted by Andrews (2008, p. 381), "they [the WGI] have been instrumental in mainstreaming discussion and treatment of corruption, regulatory ailments and governmental weaknesses in development". The third justification for adopting this definition is its relatively comprehensive approach to governance which takes into account political, economic, social and institutional dimensions of governance.

\section{Official Development Assistance}

Within the context of this research, the OECD DAC ${ }^{6}$ definition of Official Development Assistance (ODA), and the statistical data on ODA as reported by the OECD DAC, will be used as the basis for discussion unless otherwise stated. ODA is defined by the OECD DAC as those flows to countries and territories on the DAC List of ODA Recipients and to multilateral development institutions which are:

i. provided by official agencies, including state and local governments, or by their executive agencies; and

ii. each transaction of which:

a) is administered with the promotion of the economic development and welfare of developing countries as its main objective; and

b) is concessional in character and conveys a grant element of at least 25 per cent (calculated at a rate of discount of 10 per cent)

Source: OECD DAC Statistical Reporting Directives, DCD/DAC, 2008

6. The Development Assistance Committee (DAC) of the Organisation for Economic Cooperation and Development (OECD) was created in 1961 with the mandate to "consult on the methods for making national resources available for assisting countries and areas in the process of economic development and for expanding and improving the flow of long-term funds and other development assistance to them" (http://www.oecd.org/dac (see also OECD, The Story of Official Development Assistance, Führer, 1996). 
The DAC List of Aid Recipients defines all countries that are eligible for Official Development Assistance. These consist of all low- and middle-income countries, classified on the basis of Gross National Income (GNI) per capita as published by the World Bank, with the exception of G8 members, European Union (EU) members and countries with a firm accession date for entry into the EU. The list also includes all of the Least Developed Countries (LDCs) as defined by the United Nations (UN). The list is revised every three years. Countries that have exceeded the high-income threshold for three consecutive years at the time of the review are removed from the list (http://www.oecd.org/dac).

In international development discourse, the terms development aid, or in short aid, and development cooperation ${ }^{7}$ are commonly used in parallel with Official Development Assistance. However, it is worth noting that the term development aid is in fact a broader concept which also includes assistance provided by non-state actors such as non-governmental organizations, private organizations and foundations or individuals. As the OECD DAC definition of ODA only refers to concessional financial flows and technical assistance provided through governmental agencies and multilateral development institutions, aid flows raised and allocated by non-state actors and countries outside the DAC are excluded from the statistical data collected by the DAC. The DAC statistics therefore fail to provide a comprehensive picture of all development assistance channelled for development purposes, e.g., much of the aid channelled by non-governmental organizations directly to developing countries (Riddell, 2007). Furthermore, data on aid flows from countries that are not members of the DAC are not fully captured in the DAC statistics. For example, the emerging economies such as Brazil, Russia, India, China and South Africa, i.e. the BRICS, are not members of the OECD DAC and therefore are not obliged to regularly report their aid flows to DAC. In view of the increasingly important role of the BRICS in international development cooperation and their significant amount of financial and technical assistance to many developing countries, including to Mozambique, the lack of reporting constitutes a major weakness for the DAC statistics.

\section{$\square$ Donors and Partners or Developed and Developing Countries}

In the context of international development cooperation, the terms aid agency, donor agency, donor country and developed country are often used as synonyms. The terms aid agency and donor agency can refer either to a multilateral or bilateral aid organization

7. Development aid and development cooperation are generally used synonymously although in contemporary development discourse the term development cooperation is given preference as a less paternalistic term (Siitonen, 2005, p. 18). 
whereas a donor country or a donor refers to any state that provides development assistance. Multilateral organizations are international institutions with governmental membership. They include organizations to which contributions by individual donor countries may be reported, either in whole or in part, as multilateral ODA, as well as by organizations that serve only as channels for bilateral ODA (OECD, 2010). Bilateral aid organizations are generally agencies established by individual donor countries with a specific mandate to carry out development cooperation on behalf of the respective government.

The term donor country is generally used in reference to the 26 OECD DAC members ${ }^{8}$ that provide the bulk of the total ODA. For example, according to DAC statistics for 2011, the total net ODA provided by the DAC members amounted to USD 134 billion compared to an estimated USD 9,7 billion provided by the non-DAC countries (OECD, 2012). However, as pointed out earlier, the group of countries providing aid exceeds the number of DAC members with the BRICS constituting the most important group of donors outside the DAC.

The precise definition of the term developed country, while widely used in the development discourse, is problematic as it is based not only on a country's Gross National Income per capita but also on a judgment of the developmental status of a given country. For example, the World Bank classification of high income countries makes a distinction between high income countries and high income OECD members (in all 71 and 31 countries respectively in 2012). In this research, the term developed country is used in reference to the latter group of countries, which excludes a number of high income small-island states and oil-producing countries. The terms donor country and developed country will be used synonymously unless otherwise stated.

For the purpose of this research, the term developing country is used in a manner consistent with the DAC List of ODA Recipients discussed above. In other words, the term refers to low- and middle-income countries that are eligible for official development assistance (http://www.oecd.org/dac).

8. The OECD DAC members are: Australia, Austria, Belgium, Canada, the Czech Republic (joined in May 2013), Denmark, European Union, Finland, France, Germany, Greece, Iceland (joined in March 2013), Ireland, Italy, Japan, Korea, Luxembourg, New Zealand, the Netherlands, Norway, Portugal, Spain, Sweden, Switzerland, United Kingdom and United States. Seven members of the OECD are not members of the DAC, but have full observer status and participate in DAC meetings. They are the Hungary, Mexico, Poland, the Slovak Republic and Turkey. The main reason why these countries are not DAC members is that they do not have major aid programmes. Many of them are currently expanding their aid programmes and considering DAC membership (http://www.oecd.org/dac). 
In the international development discourse, the terms developing country, partner country and recipient country are often used synonymously. Reflecting attempts to redefine the nature of the relationship between aid-giving and aid-receiving countries, the term partner country has largely replaced the references to a recipient country in the OECD DAC dialogue. Although the term partner country already featured in the influential report Partners in Development of 1969 by the Pearson Committee, the heightened focus on developing country ownership since the late 1990s has given a more specific meaning to this term (Pearson L. and others, 1969). For example, the Paris Declaration on Aid Effectiveness adopted in $2005^{9}$, which constitutes an important milestone in the aid effectiveness discourse, builds entirely on the twin concepts of donors and partners.

\section{$\square$ Aid Effectiveness}

At the outset, aid effectiveness seems a relatively straightforward concept. It is used with reference to the questions whether, and to what extent, development aid contributes to the achievement of development objectives. The most common meaning of aid effectiveness is perhaps the one that is derived from the empirical aid-economic growth literature where a positive coefficient on the aid variable is interpreted as evidence that aid was effective in increasing growth (Morrissey, 2004, p. 155). However, in the course of the history of development cooperation, the focus of the aid effectiveness discourse has shifted reflecting the evolving understanding of the constraints to economic growth and other development outcomes, as well as of the role of aid in overcoming these constraints. The criteria used to assess the effectiveness of aid have changed accordingly which makes the definition of the concept in precise terms more problematic (Cassen et Associates, 1985; Cassen 1993; Riddell 1987; Riddell 2007).

For the purpose of this research, aid effectiveness is defined generally in terms of the contribution of aid to accelerating economic growth and achieving the expected development objectives in a given country. This definition follows the purpose-based definition of aid adopted by Cassen and Associates in their pioneer research on the impact of aid (Cassen and Associates, 1985; Riddell, 2007). The discussion further builds on the broader approach to aid effectiveness, embedded in the Paris Declaration of Aid Effectiveness of 2005 which highlights the nature of the relationship between the donor and partner countries as a key component of the aid effectiveness debate.

The aid effectiveness discourse forms an integral part of the evolving international aid architecture which will be discussed in more detail in Chapter 2. The World Bank

9. http://www.oecd.org/dac/effectiveness/parisdeclarationandaccraagendaforaction.htm 
defines aid architecture "as the set of rules and institutions governing aid flows to developing countries" (World Bank, 2008a, p. 1, Aid Architecture; An Overview of the Main Trends in Official Development Assistance Flows). The OECD DAC approaches aid architecture from a wider perspective, which also includes questions such as conflict and fragility, gender and environment, as well as matters related to evaluation of development cooperation (http://www.oecd.org/dac/aid-architecture/). Unless otherwise stated, this research builds on the more narrow definition of the World Bank.

\subsection{Structure of the Dissertation}

The dissertation consists of 10 chapters which are structured in the following way. This first Chapter, Introduction, describes the background of the research, outlines the main purpose of the research and defines the research questions which the dissertation aims at answering. The introductory chapter also introduces some of the core concepts which are widely used in the development cooperation discourse in general and form the starting point for this research.

Chapter 2 outlines the conceptual framework of the research. It provides an overview of the changing paradigm of the development discourse so as to create a basis for understanding why the notion of governance has emerged as one, if not the key, determinant for effective aid. The first section of the chapter explores the evolving thinking of the role of aid in the development process of a given country, the second section focuses on the shifts in the aid effectiveness debate, and the third section addresses the question of the multitude of conceptual and operational approaches adopted by the donors for assessing governance.

Chapter 3 introduces the methodological approach and primary data sources chosen for conducting the research. This chapter also discusses questions of positionality and ethical considerations as well as aspect of validity and reliability related to this research. The methods for data collection and data analysis will be described in more detail in the Chapters 6 to 9, which address the specific research questions.

Chapters 4 and 5 set the scene for the research by sketching the evolution of the context of governance as well as the development of the aid architecture in Mozambique since independence in 1975. The main objective of the chapters is to describe the reallife context within which the current governance discourse and the governance assessments take place. Focus is on the post-war period since 1992. 
The main chapters for answering the research questions, and analyzing the data, are Chapters 6 to 9. Chapter 6 explores the research question of how aid agencies operating in Mozambique define and assess governance. The discussion focuses on the governance assessments conducted over the period of $2006-2010$ by the ten largest donors which provide the bulk of all external assistance to Mozambique and therefore play a significant role in its policy-making, including in the field of governance.

Chapter 7 aims at answering the research question concerning the consistency of the results of the selected governance assessments. The results of the governance assessment by the various donors are analysed and compared with the objective of establishing whether the assessments arrive at similar conclusions on the quality of governance in Mozambique. This analysis is done in two phases: first, on the basis of the original reports made available by the aid agencies themselves; and second, on the basis of quantified results using a standardized numeric scale as the benchmark for analyzing all assessment reports.

Chapter 8 examines the governance assessments from the Mozambican perspective. It aims at answering the research questions concerning the relevance of the donor governance assessments and their impact on reforming governance as perceived by Mozambican stakeholders. To answer these questions, a field study was carried out in Mozambique. Its objective was to explore the views of local stakeholders about the relevance and potential impact of the donor governance assessments on improving governance in the country.

In Chapter 9 an attempt is made to sketch some recommendations for improving the current donor practices for assessing governance in a specific country context. The discussion draws on the data gathered through the field study.

Finally, Chapter 10 presents a summary of the key findings of the research, discusses the relevance of the findings of the research and, finally, suggests some areas for further research. 


\section{Framing the Research: The Puzzle of Development, Aid Effectiveness and Governance}

The purpose of the Chapter 2 is to outline the theoretical discussions and concepts that frame this research. This entails addressing three interrelated discourses which underlie the aid agencies' increasing emphasis on governance, and the drive for assessing the quality of governance in developing countries. These are: first, the discourse on the potential role of aid in the process of socio-economic development; second, the discourse on aid effectiveness; and third, the governance discourse within the context of international development cooperation. The first section of the chapter aims at providing a brief overview of the evolving thinking of the role of aid in the development process of a given country, the second focuses on the shifts in the aid effectiveness debate, and the third addresses the question of the multitude of conceptual and operational approaches adopted by the donors for assessing governance. At the outset it needs to be emphasized that a comprehensive critique of the interrelated discourses on the role of aid in development, the effectiveness of aid and the importance of governance is beyond the scope of this research.

To set the stage for the discussion, an overview of the trends of the ODA during the period of 1960-2010, as recorded by the OECD DAC, is presented in Figure 2.1.

As the data on ODA indicate, the volume of aid has increased significantly, in nominal terms, since the launch of the First UN Decade for Development in 1961 (from USD 37,9 billion in 1960 to USD 136,7 billion in 2010; in constant 2006 USD). However, the share of ODA in relation to the developed countries' Gross National Income (GNI) has declined since the beginning of the statistical reporting by the OECD DAC. Hence, the commitment made in 1970 by the industrialized countries to provide $0.7 \%$ of their GNI as ODA remains an unfulfilled promise. ${ }^{10}$ From the perspective of the developing country economies, ODA represents a relatively small percentage of GNI. According to Tarp's analysis covering the period from 1996 to 2005, for most aid receiving countries with populations of more than 2 million, ODA accounted for $1.8 \%$ of their GNI

10. The $0.7 \%$ target was formally adopted through the UN General Assembly Resolution of 1970 stating that "Each economically advanced country will progressively increase its official development assistance to the developing countries and will exert its best efforts to reach a minimum net amount of $0.7 \%$ of its gross national product at market prices by the middle of the Decade." (UN General Assembly Resolution 2626 (XXV), 24 October 1970, paragraph 43). 
with a median of $3.2 \%$ (Tarp, 2010, p. 23, 26). In some countries, such as Mozambique, the ODA to GNI ratio has been much higher (in Mozambique the average ODA/GNI ratio over the period 1996-2005 was $28.6 \%$ ), and continues to be high, as will be discussed in Chapter 5.

\section{Figure 2.1 | Global Net ODA Disbursements 1960-2006}

NET ODA Disbursement 1960 - 2010

USD billion, constant 2006 prices

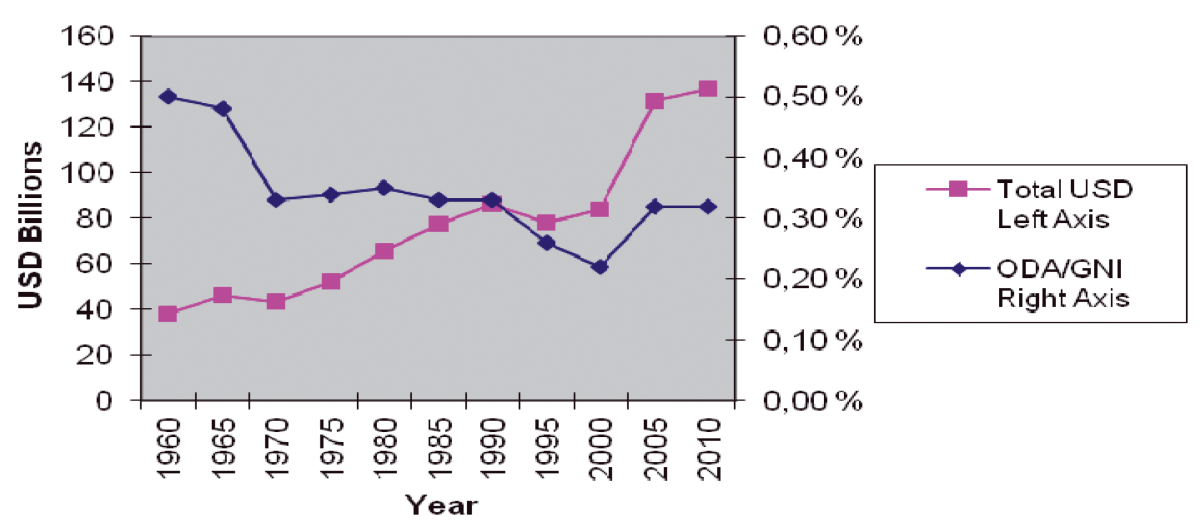

Source: OECD DAC, 2011 (adapted by the author). Note: ODA/GNI is the un-weighted average of the share of ODA in donor country GNI.

\subsection{Role of Aid in Development}

The relationship between aid, economic growth and wider socio-economic development has been subject to academic research and policy debate since the beginnings of international development cooperation in the late 1940s and early 1950s. ${ }^{11}$ The understanding of the role of aid in the development process has evolved significantly over the years, largely in response to the controversial empirical evidence of the impact of aid on achieving the expected development outcomes.

11. Governments and voluntary organizations had provided aid to developing countries already earlier. However, two events occurred in the late 1940s, which laid the basis for the expansion and institutionalisation of international development cooperation. First, the "historically unprecedented" aid initiative known as Marshall Plan, launched in 1949 to support the reconstruction of Europe after the World War II and, second, the speech held by US President Harry Truman in 1949 in which he outlined the rationale and a mechanism for providing aid. (Riddell, 2007, p.24). 
In light of the evolution of the development discourse, four broad periods can be identified (Szirmai, 2005; Browne, 2006; Riddell 2007; Tarp 2010):

1. Aid as source of investment and capital accumulation; period from the mid-1950s to late 1960s

2. Emerging poverty focus; period from the 1970 s to early $1980 \mathrm{~s}$

3. Structural adjustment as key to growth and development; period from the $1980 \mathrm{~s}$ to mid-1990s)

4. Poverty reduction with "good governance"; period from the mid-1990s onwards

In reality, the periods overlap as the changes in development research and in the practice of development cooperation take place gradually. However, this simplified categorization helps to illustrate the shifting paradigm of the development discourse and its impact on aid policies.

\subsubsection{Aid as Source of Investment and Capital Accumulation}

The theoretical foundations for providing aid to developing countries were formulated in the 1950s and 1960s. Among the pioneering development economists were A. Lewis (1954), W.W. Rostow (1956), M.F. Millikan and W.W. Rostow (1957), P. N. Rosenstein-Rodan (1961) and H. Chenery and A. Strout (1966). The formulation of the first theories on development aid coincided with the expansion of official development assistance. According to the early theories, growth in developing countries was constrained, primarily, by a lack of capital, a shortage of skills and infrastructural weaknesses (Rostow, 1956; Millikan and Rostow, 1957; Rosenstein-Rodan, 1961; Chenery and Strout, 1966). Aid in the form of foreign capital and technical assistance could promote economic growth by contributing to increased investment in infrastructure and capital accumulation.

Rostow was among the first scholars to attempt a theoretical justification for giving aid to developing countries. Aid in the form of capital could play a critical role by creating the conditions for the "take off" through increasing the rate of investment (Rostow, 1960). ${ }^{12}$ In addition, aid provided as technical assistance would be needed to ensure the effective use of newly available resources (Millikan and Rostow, 1957). Another major contribution to the emerging theory of the role of aid in development process

12. As a modernization theorist Rostow believed that the transformation of societies from traditional to modern would take place through five stages: "traditional society", "preconditions to take-off", "take-off", "drive to maturity" and "mass consumption society". The crucial stage to reach the final stage of "mass consumption" is the period of "take off" (Rostow, 1960). 
was made by Rosenstein-Rodan. In his view, foreign capital was needed to increase the rate of domestic capital formation "up to a point where satisfactory rate can be achieved on a self-sustaining basis" (Rosenstein-Rodan, 1961, p. 107). The main function of external assistance was to allow developing countries to make the transition from stagnation to self-sustaining growth rather than to directly raise the standards of living. The "two gap model" developed by Chenery and Strout (1966) presents perhaps the most complete theoretical formulation of the role of aid in development among the first development scholars. Building particularly on the work of Rosenstein-Rodan they argued that economic growth in developing countries is constrained by a "savings gap" and a "foreign exchange gap" which lead to under-utilization of domestic resources. Foreign aid could reduce these gaps and allow better utilization of domestic resources and thereby accelerate economic growth until the stage of self-sustaining growth is achieved (Chenery and Strout, 1966, p. 608; Szirmai, 2005, p. 601-603). While the theories developed by the early development scholars have since been challenged both on theoretical and empirical grounds, they have nevertheless guided the thinking about the role of aid in development.

From the point of view of this research, it is important to note that the early scholars of aid did not view the link between aid and economic growth in terms of a simplistic chain of causality. Rather they stressed the importance of the domestic policy environment for making effective use of the external assistance. The notion of governance was introduced to the development discourse already by Rostow who emphasized the need for "political, social and institutional changes" as one of the necessary preconditions for the "take off" (Rostow, 1956, p.25). The concluding remark in his often quoted article can be traced in contemporary development discourse even though the phraseology has changed over the decades: "In the end the 'take off' requires that a society finds a way to apply effectively to its own peculiar resources..." (Rostow, 1957, p. 48). Rosenstein-Rodan argued similarly that the role of aid in promoting growth was conditional to the efforts made by the aid receiving country: "The principal element in this transition must be the efforts that the recipient countries themselves make to bring this about. Without these efforts, outside capital will be wasted." (Rosenstein-Rodan, 1961, p. 107). Rosenstein-Rodan's views about national ownership, the catalytic role of aid, the predictability of aid, and most importantly from the point of view of this research, his emphasis on the aid-receiving country's administrative and organizational capacity are also echoed in contemporary debate on aid effectiveness (Rosenstein-Rodan, 1961, p. 109). The domestic policy environment of the aid-receiving country was highlighted as a critical factor for aid effectiveness by Chenery and Strout also (Chenery and Strout, 1966, p. 703). They further emphasized the need to promote institutional change and to enhance the human capacity in developing countries as necessary components of aid aimed at accelerating growth and development. 
The theoretical understanding of the role of aid in development was mirrored in the aid policies of the time. Aid was provided mainly as support to infrastructural development and as technical assistance. Building on the Keynesian growth theories of the time, the role of the state was considered fundamental in accelerating economic growth, and therefore much of the aid was targeted at the public sector (World Bank, 2005). Despite the emphasis on the domestic policy environment and national ownership as key conditions for effective use of aid, these aspects were largely ignored in the development cooperation of the time (Riddell, 1987; 2007).

It is worth noting that the primary goal of aid was initially not defined in terms of poverty reduction. The prevailing assumption among the early development scholars was that measures targeted at accelerating economic growth would overcome poverty in developing countries (Jolly 2005, Riddell 2007). For example, the UN General Assembly Resolution 1701 of 1961 launching the beginning of the First Development Decade, called for intensified efforts to mobilize support to "accelerate progress towards self-sustaining economic growth of the economy of the individual nations and their social advancement" (A/RES/1701 (XVI), adopted December 19, 1961, www.un.org). Similarly, the Commission on International Development, set up by the World Bank to assess the results of the development cooperation of the previous decade, made no explicit reference to poverty reduction (Pearson et al. 1969).

\subsubsection{Emerging Poverty Focus}

The notion of poverty emerged as an important issue in international development discourse in the early 1970s, driven by the increasing understanding, amongst the donors, of the scale of poverty in developing countries, and the realization that economic growth by itself did not lead to wide-spread socio-economic development and poverty reduction (Szirmai, 2005; Browne, 2006; Riddell, 1987; 2007).

The research carried out mostly under the auspices of the International Labour Organization (ILO) and the World Bank was instrumental in bringing about the change in development thinking. The ILO's "basic-needs approach" (ILO, 1976) ${ }^{13}$ and the World Bank's "redistribution with growth approach" (Chenery, Ahluwalia, Bell, Duloy and

13. The notion of "basic needs" was defined broadly as comprising the minimum requirements of a family for private consumption, services provided by and for the consumption of a community at large, as well as the right by people to participate in decisions affecting them. The satisfaction of basic needs thus was seen in the wider framework of human rights, which were seen both as ends in themselves and as means to achieve other goals (ILO, 1976, p. 32). 
Jolly, 1974) ${ }^{14}$ both argued that while economic growth was necessary to reduce poverty, measures focusing on accelerating growth and promoting structural and institutional changes were insufficient to improve the well-being of the poor. Poverty, in particular the extreme forms of poverty, had to be addressed directly with specific policies that take into account the specific socio-economic characteristics of the poor population groups (Chenery et al., 1974; ILO, 1976).

The shift in focus took place against the backdrop of the disappointing poverty impact of the period of rapid economic growth that was experienced in the 1960s in most developing countries (Pearson et al., 1969, p. 27; Riddell, 1987, p. 144-145). As noted by Chenery: "Although the average per capita income of the Third World has increased by 50 percent since 1960, the growth has been very unequally distributed among countries, regions within countries, and socio-economic groups. Paradoxically, while growth policies have succeeded beyond the expectations of the first development decade, the very idea of aggregate growth as a social objective has increasingly been called into question" (Chenery et al., 1974, p. xiii). Economic growth tended to be concentrated in relatively limited parts of the economy, mostly those using capital-intensive techniques without creating opportunities for productive employment in the traditional rural and informal urban sectors where most people were engaged. The central thesis of the development discourse of the 1960s, that external assistance targeted at accelerating economic growth would "trickle down" and so also benefit the poor, was thus strongly questioned (ILO, 1976).

The emphasis on poverty reduction embedded in the basic needs and redistribution of growth approaches led to changes in the practices of development cooperation. Project-based aid with heavy reliance on foreign technical assistance became the dominant aid modality, and aid was targeted increasingly towards poverty-oriented development strategies aimed at expanding employment opportunities, improving access to health, education, housing and other basic services, as well as towards equitable distribution of income and wealth (Riddell, 1987; Riddell, 2007).

The notion of governance was deeply ingrained both in the basic needs and the redistribution of growth approaches. Political commitment to poverty-oriented and distributional development strategies came to be seen as critical factors for poverty-focused

14. The "redistribution with growth" approach, formulated by Chenery, Ahluwalia, Bell, Duloy and Jolly distinguished four basic policy approaches for raising the income of the poor populations groups: 1) maximizing GNP growth through increased savings and more efficient allocation of resources to benefit all population groups; 2) redirecting investments towards the poor in the form of education, access to credit and public services etc.;3) redistributing income to the poor through fiscal transfers and other distributive policies; and 4) transferring assets, such as land, to the poor (Chenery et al., 1974, p. 223-235). 
development. Enhanced attention was given to challenges related to creating the enabling political coalitions and policy environments that were deemed necessary for the implementation of any basic needs or distributional strategies (Chenery et al., 1974; ILO, 1976).

\subsubsection{Structural Adjustment as Key to Growth and Development}

In the early years of the 1980s, the focus of the development discourse turned back to macro-level questions of economic growth from micro-level poverty concerns. The shift was motivated by the disappointing evidence arising from development results on the ground, particularly in Africa. Following the oil crisis of 1973, the growth of the world economy as a whole had slowed down and the differences in economic patterns in various parts of the world increased. By the early 1980s, almost all African economies were confronted with serious economic crises characterized by falling average growth rates, declining agricultural production, increasing foreign exchange shortages and deteriorating debt situations (ILO, 1986). In the aftermath of the debt crisis of 1982 economic growth also stagnated in Latin America - in this case for a decade (Szirmai, 2005). Hence, a new approach was needed to address these challenges.

While the goal of poverty alleviation remained the central development goal, the thinking about the issues underlying poverty and the approach to decrease poverty changed. According to Riddell, the question "how can the poor be assisted more rapidly?", dominant in the discussion in the 1970s, was replaced by the question "how can the preconditions be altered so that economic development can get started again?" (Riddell, 1987, p. 95). To answer this question, the approach which came to be known as "structural adjustment" was formulated with the leadership of the Bretton Woods Institutions. This approach was later cemented in the so-called Washington Consensus. ${ }^{15}$

The structural adjustment approach was initially outlined in the World Bank publication Accelerated Development in Sub-Saharan Africa: An Agenda for Action, published in 1981, as a response to the economic crisis in Africa. In analyzing the growth performance of Sub-Saharan African countries in comparison with the performance of countries in other parts of the developing world, the World Bank concluded that the

15. The Washington Consensus, as originally outlined by Williamson, referred to the following set of policy instruments to be deployed as a response to the debt crisis in Latin America: fiscal discipline, prioritisation of public expenditures, tax reform, interest rates, exchange rates, trade liberalisation, foreign direct investment, privatisation, deregulation and property rights. The term Washington Consensus has since developed multiple meanings, many of which Williamson has tried to distance himself from (Williamson, 2002). 
poor performance of African economies was primarily due to the domestic policies pursued by their governments, rather than to external factors affecting the developing world generally. African governments were criticized for biases against private sector development through overextended state intervention in the economy, against exports through overvalued exchange rates and restrictions on trade, and against agricultural development through inappropriate pricing policies and protection of the manufacturing sectors of the economy (World Bank, 1981).

The reforms advocated by the World Bank and the IMF, and supported through structural adjustment lending, comprised generally four broad components: first, the restructuring of incentives (pricing, tariffs, taxation, subsidies, interest rates); second, the revision of public investment priorities; third, improvement in budget and debt management; and fourth, the strengthening of institutions, in particular public enterprises. The assumption underlying the reforms was that markets rather than the state provide a more efficient mechanism for planning and allocating resources in an economy (Abrahamsen, 2000; Riddell, 2007). The structural adjustment approach also entailed a new type of conditionality. The policy dialogue conducted by the World Bank and the IMF with their partner countries broadened from questions related to the expected outcome of specific aid interventions to wider macro-level issues, such as the role of the state in the economy, privatization of state-owned enterprises and trade liberalization.

Despite its focus on Sub-Saharan Africa, the policy recommendations of the 1981 World Bank report, together with the broadened agenda of conditionality, gained prominence in the wider development discourse as well as in the policies applied by other multilateral and bilateral aid agencies. Hence, support to developing countries became increasingly conditioned to reforms aimed at reducing the role of the state in the economy, cutting public expenditures, and enhancing the role of markets through private sector development (World Bank, 1981; World Bank, 1990; Browne, 2006; Riddell, 2007).

The structural adjustment approach with tight policy conditionality has come to be one of the most contested approaches to development both among academics and policy-makers. While the World Bank's first major review of the adjustment programmes concluded that adjustment programmes had a favourable impact on economic performance, and that adjustment "helps raise living standards overall and especially for the poor" (World Bank, 1989, p. iii), a pioneering study on the social impact of adjustment conducted for UNICEF around the same time argued that the programmes "tend to increase aggregate poverty, or in other words the number of people - and of children - living below the poverty line" (Cornia, Jolly and Stewart, 1987, p. 66; see also Mosley, Harrigan and Toye, 1991). Even the World Bank itself has come to acknowledge the 
limitations, if not outright failure, of structural adjustment: “The 'one size fits all' policy reform approach to economic growth and the belief in 'best practices' exaggerated the gains from improved resource allocation and their dynamic repercussions, and proved to be both theoretically incomplete and contradicted by the evidence" (World Bank, 2005, p. 11).

\subsubsection{Poverty Reduction with "Good Governance"}

In response to the controversial impact of structural adjustment on developing countries, in particular on the poorest people, the attention of the development discourse, and of development cooperation, turned towards the role of the state in enhancing economic growth, providing basic services for citizens and creating the enabling environment for private sector. With the emphasis on the role of the state, governance emerged as a key element in the discussion.

The notion of "governance" was brought to the core of the development agenda by the World Bank in its report Sub-Saharan Africa: From Crisis to Sustainable Growth (World Bank, 1989). Based on its analysis of the failure of the structural adjustment programmes to foster economic growth and alleviate poverty in Africa, the Bank argued that "Underlying the litany of Africa's development problems is a crisis of governance." (World Bank, 1989, p. 60). The key message of the report was that sound macroeconomic policies and efficient infrastructure, while essential for creating the conditions for productive use of resources, are not sufficient to transform the structure of African economies, and therefore major efforts are needed to enhance the social and institutional frameworks within which development can take place. The report explicitly aligned itself with the human-centred development strategy advocated earlier, for example, in the UNICEF report Adjustment with a Human Face of 1987 and the UN Economic Commission for Africa's Khartoum Declaration Towards a Human-Focused Approach to Socio-Economic Recovery and Development in Africa adopted in 1988 (World Bank, 1989).

The World Bank report itself refrained from using the notion of "good" governance in discussing the root causes for the weak economic performance in Africa. However, the term appeared in the foreword to the report, written by Barber B. Conable, the then president of the Bank. While acknowledging the importance of the private sector and market mechanisms for development, Conable emphasized that "they must go handin-hand with good governance - a public service that is efficient, a judicial system that is reliable, and an administration that is accountable to its public" (ibid, p. xii, underlining by the author). 
The report of the World Bank is seen as having paved the way for a "new paradigm for development" which defines governance as the fundamental pillar for growth and sustainable socio-economic development. The role of the state re-emerged as an important factor in creating the conditions for such broad-based development. Although quoting the former President of Senegal, Abdou Diouf, who argued that "Africa needs not just less government but better government", the Bank emphasized the vital role of the state in establishing a predictable and honest administration of the regulatory framework, assuring law and order, and fostering a stable and transparent judicial system (World Bank 1989, p. 55). ${ }^{16}$ The central role of the state as a catalyst and facilitator of the development process was further endorsed by the results of the research conducted for the World Development Report (WDR) entitled The State in a Changing World (World Bank 1997). Emphasising that there is no unique model of "good government" the report called for building on the relative strengths of the state, the market and civil society to improve state's effectiveness (World Bank 1997, p. 25-27, see also World Bank 1998 and 2002).

The new agenda set by the World Bank with governance as a fundamental building block for poverty reduction and development was soon endorsed by other multilateral and bilateral aid agencies. Economic conditionality characteristic to the era of structural adjustment started being replaced by political conditionality, which put emphasis on the quality of government and governance in the aid recipient countries. The focus among donors shifted towards a new realm of conditionality which ties aid to promoting democracy, human rights and good governance (Moore, 1993; Abrahamsen, 2000; Browne, 2007; Arndt, 2009). For example, the European Council resolved that the respect for human rights and the existence of political institutions, which are effective, accountable and enjoy democratic legitimacy, are the basis for equitable development, while the OECD concluded that aid should favour countries promoting democratic reforms and transition to a market economy. The good governance agenda thus marked a significant broadening of "development" to include not only the traditional focus on economic reforms, but also on explicit political demands (Moore, 1993, p. 8).

The renewed emphasis on governance, and the role of state as the critical actor for enhancing governance, cannot be understood in isolation from the end of the Cold War which changed the political context of development aid. As argued by Smith: "The collapse of the Soviet Union made it no longer necessary for the West to support authoritarian regimes because they were anti-Communist. It also encouraged the view

16. Interestingly, from my personal point of view as a Finnish citizen, the World Bank report points at the "Nordic development paradigm", characterized by relatively clear division of labour between the state and the markets, as an example of a successful path to development (World Bank, 1989, p. 187). 
that political liberalisation was a necessary condition for economic liberalization and growth" (Smith, 2007, p. 2).

This shift in the development discourse coincided with the findings from research on the role of institutions in development. The new institutional economics (NIE), most directly associated with Douglas North, emphasized the role of institutions and forms of governance in development. According to North, economic performance is determined by institutions which define "the rules of the game". Institutions are made up of formal rules, informal norms and the enforcement characteristics of both. While the formal rules can be changed overnight, the informal norms, which provide legitimacy to the formal rules, change only gradually, and therefore, "revolutionary" change is never as revolutionary as anticipated. He stressed the importance of democratic governance for long-term development by stating that "while economic growth can occur in the short run with autocratic regimes, long-run economic growth entails the development of the rule of law and the protection of civil and political freedoms (North, 1995, p. 25; North 2005).

Alongside the increasing emphasis on good governance and well-functioning institutions as basic ingredients for a sustainable development strategy, poverty reduction as the primary goal for development cooperation gained new momentum. The World Bank's World Development Report of 2000/2001, entitled Attacking Poverty, served as an important input in broadening the understanding of poverty as a multidimensional phenomenon. The report, which was based on extensive research by the World Bank on the nature of poverty in developing countries, clearly illustrated that poverty means not only low income levels but also lack of education and employment opportunities, poor access to health, insecurity, and importantly, lack of voice, power and possibilities to participate in decision-making in the society. ${ }^{17}$ The report argued that while economic growth is essential for poverty reduction, "poverty is an outcome of economic, social and political processes that interact with and reinforce each other" and therefore, "attacking poverty requires promoting opportunities, facilitating empowerment and enhancing security at local, national and global levels" (World Bank 2000a, p. 37).

The broad approach to poverty with emphasis on governance adopted by the World Bank reflected the international development discourse that had taken place within the framework of the UN and the OECD DAC. As pointed out by Voipio, the UNDP

17. The background research for World Development Report 2000/2001 included extensive collection of data on poor people's views and their experiences of poverty. More than 60000 men and women living in poverty in 60 countries were interviewed. The results of the study, entitled "Voices of the Poor" were published in three separate books (Voice of the Poor (1): Can Anyone Hear Us?; Voices of the Poor (2): Crying Out for Change; Voices of Poor (3): From Many Lands, World Bank, 2000). 
had advocated a multi-dimensional interpretation of poverty with its annual Human Development Reports since 1990, that is, a decade earlier than the World Bank. The Poverty Reduction Guidelines developed by the OECD DAC Poverty Network (published in 2001) contributed to the emerging consensus on poverty as the primary goals for development (OECD DAC 2001). The shift in the development discourse was influenced also by the writings of eminent scholars such as the Nobel Laureate Amartya Sen who argued that poverty reduction is identical to development, which entails not only freedom of starvation, ill-health etc. but also right to political participation, freedom of expression, etc. (Voipio, 2011, p. 118, 120; Sen 1999).

The new development agenda focusing on poverty reduction with governance as its key pillar culminated in the adoption of the UN Millennium Declaration and the related eight Millennium Development Goals (MDGs) in 2000 (http://www.un.org/millenniumgoals). This Declaration commits developed countries to providing support to developing countries for achieving the specific targets set for each MDG by 2015. It further commits developed and developing countries alike to a "global partnership for development" which entails, inter alia, good governance both nationally and internationally. The Millennium Declaration states that the "Success in meeting these objectives (creating an environment conducive to development and poverty reduction, added by the author) depends, inter alia, on good governance within each country." (UN A/RES/55/2, 2000).

\subsubsection{Concluding Remarks}

The shifting focus of the development discourse reflects the evolving understanding of what drives - and hinders - economic growth, poverty reduction and wider socio-economic development, and what role development aid can play in supporting the achievement of development objectives. The narrow focus on economic growth as the key to development amongst first generation development scholars and policy-makers has been replaced by an increasingly broad approach that includes elements such as institution building, private sector development, poverty as a multi-dimensional phenomenon and strengthening governance as foundations for sustainable socio-economic development. The development agenda that has emerged from the decade-long discourse is enshrined in the Millennium Declaration and the time-bound MDGs which provide the contemporary framework for international development cooperation.

However, the Millennium Declaration is not a roadmap for achieving the shared development goals. In other words, while there is now a wide-spread consensus among academics and policy-makers that economic growth is a necessary, albeit insufficient, precondition for poverty reduction and sustainable socio-economic development, 
there is no consensus as to how to best support developing countries to achieve their development objectives. As stated by Stiglitz: "If there is a consensus today about what strategies are likely to help the development of the poorest countries in the world, it is this: there is no consensus except that the Washington Consensus did not provide the answer" (Stiglitz, 2008, p. 41).

\subsection{Shifting Paradigm of Aid Effectiveness}

Since the expansion of development cooperation in the early 1960s, the questions of whether, and to what extent, external aid does actually contribute to the achievement of development objectives has been a central item in development discourse. The question is obviously not only of academic interest. It is also a highly political issue as aid is financed primarily out of donor government budgets. In other words, politicians and aid administrators in the developed countries - and increasingly also in the aid-receiving countries - are constantly called upon to justify and account for the use of "tax payers' money".

Following the enhanced political commitment by developed countries to increase aid in support of the achievement of the MDGs by 2015, the debate about the impact of aid has gained additional momentum. The outcomes of the successive international conferences on development financing and aid effectiveness, notably the UN Conference on Financing for Development held in Monterrey in 2002, the Rome Declaration on Aid Harmonization of 2003 and the Paris Declaration on Aid Effectiveness of 2005, have served to cement aid effectiveness as the core issue in international development cooperation. The UN Conference on Financing for Development of 2002 was followed by the second International Conference on Financing for Development in 2005 in Doha, whereas the conference culminating in the adoption of the Paris Declaration of Aid Effectiveness was followed by the Third and Fourth High-Level Forums on Aid Effectiveness, held in 2008 and 2011 (in Accra and Busan respectively) (www.un.org/esa/ffd/ffdconf/; www.oecd.org/dac/effectiveness/parisdeclarationandaccraagendaforaction.htm).

However, in the absence of a clear understanding of what drives growth, poverty reduction and wider socio-economic development, and how aid can contribute to these processes, any attempt to draw firm conclusions about the impact of aid is problematic. The primary role of aid in promoting development, and the criteria used for assessing its impact, have varied overtime reflecting the shifting paradigm of development discourse. Furthermore, aid to developing countries has been, and continues to be, motivated by various factors not all of which are linked either to poverty reduction or wider 
socio-economic development. For example, during the Cold War period, one of the primary rationales for providing aid was to strengthen the governments of "friendly" countries for political reasons. This tended to undermine concerns about the impact of aid on socio-economic development. Data and methodological problems have made the efforts to provide evidence on the impact of aid even more challenging. Nevertheless, the significant flow of financial resources and technical assistance from developed countries to developing countries over the past decades justifies the intense efforts by academics and policy-makers to answer the question whether or not "aid works".

In this section an attempt is made to provide an overview, on the basis of existing literature, of the diverse views concerning the impact of aid. While a thorough review of the voluminous body of this literature is well beyond the scope of this research, the discussion aims at sketching the shifting landscape of the debate on aid effectiveness. This is done with the objective of tracing the emergence, today, of the question of the quality of governance of developing countries as one the key - or perhaps the key determinant of aid effectiveness. The discussion starts with a brief overview of the methodological issues related to assessing aid effectiveness.

\subsubsection{Methodological Challenges}

The attempts to assess the impact of aid are confronted with a number of methodological challenges. First, as discussed in the introductory chapter, the statistical data on aid provided by donors, as recorded by the OECD DAC, are not comprehensive. In addition, the data on growth and other development trends in aid-receiving countries - whether at aggregate, sectoral or local levels - are often inaccurate or non-existent. Second, the focus of the assessment can vary from project level assessments to country and cross-country level assessments, or concentrate on short-term impact without addressing the sustainability of aid interventions and long-term development outcomes. Third, the difficulties related to separating the impact of aid interventions of one donor from that of other donors hamper the possibilities of assessing the precise impact of a specific intervention. Fourth, in most developing countries aid accounts for only a relatively small share of government resources and its precise impact on development cannot be isolated from the impact of other factors. Fifth, due to the dynamic nature of the development process, and to the lack of sufficient base-line data, the questions related to the causality linking aid to economic growth and other development outcomes often remain unresolved. In the realm of development cooperation, the possibility of scientific experiments with counter-factual is limited (see e.g. Cassen and Associates 1986 and 1994; Riddell 1987; Riddell 2007, Tarp 2010). 
Bearing in mind these limitations, the existing evidence on the impact of aid is summarized below. At the risk of oversimplification, the discussion is structured according to the following lines of argumentation: 1) "aid contributes to poverty reduction and development - at micro-level"; 2) "the impact of aid is harmful - if any"; 3) "aid contributes to economic growth, albeit marginally"; and 4) "aid contributes to growth and wider development outcomes in good policy environment". The last section of the chapter looks at the impact of aid in light of the progress made towards achieving the MDGs.

\subsection{2. "Aid Contributes to Poverty Reduction and Development - at Micro-Level"}

The study Does Aid Work? by Robert Cassen and his team, published nearly three decades ago, was one of the first attempts to present an overview of the impact of aid (Cassen and Associates, 1986). In light of its findings, the answer to the question was generally positive. Looking at aid provided in the form of individual projects, programmatic support and technical assistance, Cassen et al. concluded that most aid had been successful in terms of achieving its developmental objectives. However, a number of failures and weaknesses were also identified. For example, the effectiveness of policy dialogue between aid-giving and aid-receiving countries, particularly the impact of structural adjustment programmes and the related donor-imposed conditionality in inducing reforms, was questioned. Hence, despite its positive tone, the report concluded that "the precise degree of the effectiveness of aid is in the end unknowable" (Cassen 1986, p. 8). Cassen's updated version of the study (1994) confirmed the generally positive conclusions.

The overview by Cassen et al. was followed by Riddell (1987) who focussed on the impact of aid on poverty reduction. The key questions addressed by Riddell related to "whether aid can reach the poor" and whether "aid has to be specifically poverty-focussed to benefit the poor", mirroring the objectives set for aid at the time. Based on the available evidence, Riddell concluded that poor people can benefit from aid interventions even if the aid is not directly targeted at them. He further argued that aid contributes to poverty reduction even in difficult political environments although political constraints in developing countries constitute a critical factor for the impact of aid (Riddell 1987). The most recent study by Riddell of 2007, which is based on an extensive review of more recent research findings, comes to the same broadly positive conclusions (Riddell 2007). According to Riddell, the available evidence suggests that clearly a majority of aid projects have achieved their immediate objectives, although "the evidence is far from comprehensive and is likely to be biased in favour of a more flattering picture of the impact of project aid than is probably deserved" (Riddell 2007, 
p. 193). Furthermore, Riddell seemed to confirm the "micro-macro paradox" identified by Mosley two decades earlier by pointing out the insufficient evidence to draw conclusions about the wider impact of aid, or about the cumulative effects of groups of projects across different sectors. The findings by Mosley had suggested that while aid seems to be effective at micro-level, the positive impact cannot be identified and captured by macro-level data (Mosley 1987).

\subsection{3. "Impact of Aid - Harmful if Any"}

In 2009, the book with a provoking title Dead Aid by Dambisa Moyo shook the international development community by calling on donors to stop providing aid. The book was not written as an academic paper or for an academic audience, but it succeeded in stirring up an intense debate among academics and policy-makers alike by arguing that "aid has helped make the poor poorer, and the growth slower" (Moyo 2009, p. xix). Although the debate around the book did not last long, it certainly exceeded the media threshold, even beyond the English-speaking world, and thereby reinforced the anti-aid argumentation (see e.g. Wahlroos, Suomen Kuvalehti 19.3.2010).

On theoretical grounds, the positive contribution of aid to development had been most forcefully challenged much earlier by the dependency theories which originated in the far-reaching debate on the problems of "underdevelopment" in Latin America in the 1960s and 1970s. The seminal research by Prebisch and Singer in the late 1940s on the deterioration of the terms of trade between primary goods and manufactured goods played an instrumental role in conceptualizing the dependency approach to development. While comprising different intellectual traditions, the dependency theories saw aid as an element in the unequal relationship between the centre (developed countries) and the periphery (developing countries) (Blomström and Hettne, 1984; Szirmai 2005, Riddell 2007). In this relationship, aid was seen as an instrument for enhancing the dominance of the centre over the periphery. Furthermore, as the state in developing countries was seen as being controlled by the elite, donor support to the state served to reinforce the elite's position without addressing the critical issue of power relations within the developing countries. ${ }^{18}$ Among the most influential scholars who contributed to the conceptual approach underpinning the "dependency school", as it has come to be known in the development discourse, are C. Furtado

18. As argued by Baran: "That they ('monarchs, military-fascist dictatorships, or republics of the Kuomintang variety') have been able to stay in business - for business is, indeed, their sole concern - in most Latin America and in the Near East, in several 'free' countries of Southeast Asia and in some similarly 'free' countries of Europe, is due mainly if not exclusively to the aid and support that was given to them 'freely' by Western capital and Western governments acting on its behalf" (Baran, 1972, cited in Alavi and Shanin, 1982, p. 203). 
(1965), T. Dos Santos (1967), O. Sunkel (1967), F. H. Cardoso and E. Faletto (1969), and perhaps most importantly, A. Gunder Frank (1967). The dependency school had close ties with the UN Economic Commission for Latin America (ECLA) which was founded in 1948, in Chile. The dependency approach was, however, not limited to one academic tradition in Latin America but has greatly influenced development thinking globally. Outside Latin America, scholars such as S. Amin (1957), P. A. Baran (1957), P.M. Sweezy (1972), H. Bernstein (1973), and I. Wallerstein (1979) have contributed to the conceptualization of the "development of underdevelopment" through various means, including aid (Roxborough, 1983; Frank, 1981; Blomström and Hettne, 1984, Alavi and Shanin, 1985).

The influence of the dependency school in development discourse reached its peak in the 1970s and has since gradually faded away. The criticism of the entire international order, and of unequal power relations between developed and developing countries, has however gained momentum with the increasing economic and political role of the emerging economies, albeit without the militant tone characteristic of the dependency school. This is reflected, for example, in the spirit of the Millennium Declaration (2000), the Monterrey Consensus (2002) and, more recently, in the processes to reform the governance structures of the International Monetary Fund and the World Bank.

In addition to the dependency theories, the rationale for development cooperation has been challenged by orthodox neo-liberalism which has its roots in the work by Hayek and Friedman. The neo-liberal criticism of development cooperation stems from the view that aid hinders economic growth and development by maintaining inefficient government intervention and thus constraining the development of dynamic market relationships. From this perspective, state intervention is seen as distorting the efficient allocation resources and obstructing dynamic and competitive market expansion. Development aid which is channelled to governments in developing countries strengthens the role of those governments in the economy and allows them to pursue policies which hamper the competitive sectors of the economy (Szirmai 2005, p. 614617). One of the influential scholars questioning the role of aid for development is Bauer. In his view, markets are the driver of growth and countries succeed in achieving economic growth if they have the right skills, attitudes and institutions at their disposal. That is, the right conditions for development. External aid cannot create the necessary conditions. On the contrary, it can allow local elites to pursue policies that undermine growth and development (Bauer 1981). Bauer's argument can be summarized by the following quote: "If the conditions for development other than capital are present, the capital required will be either generated locally or be available commercially from abroad to governments or to businesses. If the required conditions are not present, then aid will be ineffective and wasted." (Bauer, 1981, p. 100). Although the 
neo-liberal criticism of development cooperation has become less vocal since its peak in the 1980s and early 1990s, its key messages remain influential in today's debate on aid effectiveness.

\subsection{4. "Aid Contributes to Growth - Marginally"}

In parallel with the research focusing on the effectiveness of aid at micro-level, i.e., on the impact of specific aid interventions, extensive research has been conducted to provide evidence of aid's macro-level impact on economic growth across countries. Orienting oneself in this vast and expanding literature, which is applying increasingly sophisticated econometric techniques, is a daunting task, particularly, for a non-econometrician like myself (see also Roodman 2007). For the purpose of this research, the recent overview by Tarp (2010) of the cross-country studies on the relationship between aid and growth ${ }^{19}$ has been used as guidance in an attempt to distil the key, often contradictory, findings emerging from the debate (Tarp 2010).

According to Tarp, the studies on the impact of aid on economic growth can be classified into three generations, with a fourth generation emerging (Hansen and Tarp 2000; Tarp 2009; Tarp 2010, p. 36). ${ }^{20}$ The first generation studies, based on the growth models formulated by Harrod-Domar and the Chenery-Strout, focussed primarily on the relationship between aid and savings. The second generation studies concentrated on the relationship between aid, investment and economic growth, while the third generation studies introduced institutional and policy variables into the growth models, in addition to the more traditional macro-economic variables. The meta-analysis by Doucouliagos and Paldam (2005), covering 97 empirical macro-level studies conducted over the period 1968-2004, followed a somewhat similar classification ${ }^{21}$ dividing the individual studies into three main groups: 1) the impact of aid on savings and investment; 2) impact of aid on growth; and 3) impact of aid on growth in "good policy environment" (Doucouliagos and Paldam 2005, p. 7). The focus of cross-country studies has thus also changed over time mirroring the debates and discussions about aid's overall impact, as discussed in the previous chapter.

19. The "narrow" focus on the aid-growth nexus can be justified in view of the contemporary development paradigm which defines economic growth as a necessary, albeit not sufficient, condition for poverty reduction and wider socio-economic development.

20. According to Tarp, a fourth generation of research has emerged with studies conducted by Rajan and Subramanian after 2005. A leading paper within this tradition, published in 2008, concluded that the impact of aid on growth is either non-existent or negative (Rajan and Subramanian, 2008).

21. Doucouliagos and Paldam divide the individual studies into three main groups: 1 ) the impact of aid on savings and investment; 2) impact of aid on growth; and 3) impact of aid on growth in "good policy environment" (Doucouliagos and Paldam, 2005, p. 7). 
The first generation of cross-country studies, conducted in the early 1970s, built on the then prevailing assumption that aid accelerates economic growth by bridging the savings or foreign exchange gap. The findings of these first generation studies indicated that aid did not lead to increased savings (Enos and Griffin 1970; Weisskopf 1972; cited by Doucouliagos and Paldam, 2005, p. 15). However, these findings were later challenged by Hansen and Tarp (2000) who found, on the basis of their detailed survey of the first generation studies that, in fact, the majority of the studies concluded that aid contributes to increased savings, albeit by less than the amount of the aid flow (Arndt, Jones and Tarp 2009, p. 2).

The second generation studies, conducted during the 1980s and early 1990s, focussed on the contribution of aid to investments, and thereby to economic growth. According to an analysis by Hansen and Tarp, the findings of the studies consistently indicate a positive relationship between aid and investment (Arndt, Jones and Tarp 2009, p. 2). However, several other scholars have not found evidence of a link between aid and growth (Mosley et al. 1987; Boone 1994, 1996). For example, a study by Mosley et al. (1987) failed to establish any statistically significant relationship between aid inflows and real GDP growth in developing countries, and pointed out the possibility of aid leaking into non-productive public sector spending or changing relative prices in ways that adversely affect the private sector. Boone (1994) concluded, on the basis of his analysis of the aid-growth link covering 117 studies over the period of 19711990, that aid does not correlate with factors causing economic growth (Boone 1994, cited in Clemens et al 2004, p. 7). The contradictory results of the second generation studies have been explained by weaknesses in underlying theoretical assumptions and techniques used for empirical analysis, including the failure to address the question of endogeneity of aid (Arndt et al 2009, p. 3).

A third generation of cross-country studies emerged in the early 1990s giving rise to a new line of argumentation: aid contributes to growth but only in countries with a "good policy framework". The third generation studies, which have brought the governance debate to the core of the aid effectiveness agenda, will be discussed in the next section.

\subsection{5. "Aid Contributes to Growth and Development - In Good Policy Environment"}

The argument that aid works in countries with good policies can be traced back to the research conducted under the auspices of the World Bank in the late 1990s. The pioneering research paper, which came to shift the focus of the development discourse, and the practice of development towards governance, was written by Burnside and 
Dollar in 1997. Looking at the growth performance of 56 low-income countries over the period of 1970-93, Burnside and Dollar concluded that, on average, aid has had little impact on growth but, in a good policy environment, aid has had a positive impact (Burnside and Dollar, 1997, p. 32). Three years later Burnside and Dollar confirmed the findings using a new database and concluded that "aid has a positive impact on growth in developing countries with good fiscal, monetary, and trade policies but has little effect in the presence of poor policies" (Burnside and Dollar, 2000, p. 847). Along with Burnside and Dollar, a number of other researchers examined the aid-policy interaction. For example, Dollar and Svensson (1998), Dollar (1998) and Collier and Dollar $(2001,2002)$ argued that aid must be directed to poor countries with sound policies advocating the so called "poverty efficient allocation" which would take into account the policy environment in the aid-receiving countries. Dollar and Easterly (1999) looked at the relationship between aid and the policy environment specifically in Africa in an effort to analyse further the findings by Burnside and Dollar (1997). They found that the linkages between aid, investment and growth in Africa are not very robust, but there is a strong relationship between pursuit of "sound" economic policy and growth.

The Burnside-Dollar argument has been challenged in several subsequent studies. Hansen and Tarp $(2000,2001)$ found that aid had a significant impact on growth, regardless of the policy environment, "as long as the aid to-GDP ratio is not excessively high" (Hansen and Tarp 2000, p. 389). Dalgaard and Hansen (2001) go further arguing that, on the basis of exactly the same data as used by Burnside and Dollar, "if anything, good policy is likely to reduce the growth effect of aid because they act as substitutes in the growth process" (Dalgraad and Hansen 2001, p. 37-38). Easterly, Levine and Roodman (2003) extended Burnside and Dollar's study up to 1997 and found that the aid-policy interaction variable became insignificant, even when only low income countries were studied. Bosworth and Collins (2003) found that sound macroeconomic policy is not a significant determinant of growth but initial conditions and sound institutions, such as control of corruption and protection of property rights are. Guillaumont and Chauvet (2001) found little support for a link between aid and policy and concluded that "aid's contribution to growth depends significantly on the environment" (Guillaumont and Chauvet 2001, p. 67). Clemens et al. (2004) contributed to the debate by arguing that "all aid is not alike" (Clemens et al 2004, p.10). By focussing on aid flows targeted at stimulating economic growth in the short term, the so called "short impact aid", they found a very strong, positive relationship between aid and growth regardless of recipient countries' income levels or quality of institutions and policies. However, "all else being equal, stronger institutions, more open trade, lower inflation and lower budget deficits are associated with faster economic 
growth (Clemens et al 2004, p. 39-41) 22. Regardless of the diverse findings concerning the impact of the policy framework on aid effectiveness, both "groups of researchers" seem to agree that aid generally contributes to economic growth (Addison et al. 2005, p. 990).

Despite the academic controversy, the conclusions about the positive relationship between the impact of aid and a good policy framework were summarized in two World Bank reports: Assessing Aid: What Works, What Doesn't and Why (1998) and The Role and Effectiveness of Development Assistance (2002). The key message of both reports was that aid is effective in good policy and institutional environment, in other words in countries committed to macro-economic stability, institutional strengthening and poverty reduction. The message of the reports, backed by the powerful position of the World Bank, came to influence the thinking in the wider donor community contributing to the enhanced emphasis on the quality of governance in aid-receiving countries as a "guarantee" of the effective use of aid resources. Governance emerged as the new conceptual framework for the aid agencies' policy and decision-making concerning the selection of partner countries, country-specific allocation of aid and choice of aid instruments (Hout 2007).

In addition to the contested evidence about the positive relationship between the impact of aid and the policy environment in developing countries, the assumption that a good policy and institutional framework is a precondition for achieving growth and wider socio-economic development results has been challenged. For example Khan concludes, on the basis of his analysis of the WGI data sets for the period of 19902003, that "the data suggests very weak positive relationship between the quality of governance and economic growth", and that nothing can be said about the direction of causality (Khan, 2006a, p. 10; Khan 2006). Khan argues that the diversity of the policy measures through which Asian countries accelerated their growth performance demonstrates that "while there is clearly no single set of governance requirements to ensure that interventions for catching up are effective, the governance capabilities have to be appropriate for ensuring that the growth-enhancing interventions are effectively implemented and enforced (ibid, p. 19). His critique, however, primarily focuses on the limitations of the "market-enhancing governance" agenda supported by the international financing institutions, rather than on the argument about the importance of governance for economic development (ibid.).

22. The "short impact aid" was defined as comprising balance of payments support/budget support, investments in infrastructure and productive sectors such as agriculture leaving our, for example, humanitarian aid and support to social sectors (Clemens et al., 2004, p. 39-41). 


\subsubsection{Aid in Support of the Millennium Development Goals}

The progress made by developing countries towards the achievement of the MDGs provides one perspective for assessing the impact of aid. While using the MDGs as the criteria for assessing aid effectiveness may be questioned for many of the methodological reasons discussed above, from an aid-practitioner's perspective, the MDGs provide a legitimate benchmark for assessing the impact of aid effectiveness. Since 2000, the MDGs have served as the shared agenda for development cooperation with time-bound targets for poverty reduction and explicit emphasis on good governance. Furthermore, the adoption of the MDGs has led to increased aid flows and a renewed sense of partnership between the developed and developing countries. Hence, the progress, or lack of, towards the MDGs can be interpreted as one indication of a relationship between aid and development.

From the perspective of the MDGs, the impact of aid on poverty reduction and wider socio-economic development is encouraging. Both the Millennium Development Goals 2012 Report by the United Nations (UN, 2012) and the joint Global Monitoring Report 2013 by the World Bank and the IMF (World Bank, 2013) indicate that three of the MDG targets have, at global level, been met well ahead of the deadline. These include targets related to reducing extreme poverty, providing access to improved drinking water and reducing the number of slum dwellers in urban areas. For the first time since records on poverty began, the number of people living in extreme poverty has fallen in every developing region, including sub-Saharan Africa. Accordingly, the proportion of people whose income is less than $\$ 1.25$ a day decreased from $43.1 \%$ in 1990 to $23.1 \%$ in 2010. Similarly, the proportion of people without sustainable access to safe drinking water has been halved from the $24 \%$ estimated for 1990 . The share of slum dwellers in urban areas declined from 39\% in 2000 to $33 \%$ in 2012. Progress is also significant in terms of primary school completion rates and gender equality in primary and secondary education. The latest available data suggest that these two development goals will probably be reached by the year 2015 .

On the other hand, both reports point out that progress has been slow with regard to the achievement of health-related MDGs. Global targets related to infant and maternal mortality and, albeit to a lesser extent, access to basic sanitation are significantly off-track. Particular areas of concern relate to persistent undernourishment, including slow progress in reducing child under-nutrition, and only slow decrease in levels of vulnerable employment (defined as the share of unpaid family workers and own-account workers in total employment).

At the regional level progress toward the MDGs is diverse. In Sub-Saharan Africa, the region with the largest number of low-income countries, developments have been 
slower than in other regions, and the region lags behind on most MDGs. However, even Sub-Saharan Africa has achieved more than $60 \%$ of the targets set for gender parity, primary school completion, access to safe water, and extreme poverty. This evidence is based on statistical data collected at country-level and compiled by the UN and the Bretton Woods Institutions.

According the World Bank-IMF analysis, progress made in achieving the MDGs is related to income and institutions. Hence, the World Bank-IMF report points out that countries in fragile and conflict situations lag considerably behind - a finding which is in line with the argumentation about the importance of a good policy framework. The UN points at the recent global financial crisis and natural disasters as the main factors slowing down the progress towards achieving the MDGs. Both reports argue that meeting the remaining targets remains possible, albeit challenging, but only if the governments of developed and developing countries respect the commitments they made over a decade ago (World Bank, 2013; United Nations, 2012). In other words, the central role of the state in achieving the expected development objectives is highlighted in both reports.

\subsubsection{Partnership as Key to Aid Effectiveness}

In parallel with the shifts in the conceptualization of the role of aid in development processes, the question of the nature of the relationship between aid-giving and aid-receiving countries has come to be seen a central aspect of aid effectiveness. The OECD DAC policy document Shaping the $21^{\text {st }}$ Century: The Contribution of Development Cooperation of 1996 (OECD DAC, 1996) marked an important step towards a partnership approach in development cooperation. It stressed the responsibility of the developing countries for planning and pursuing their development strategies, and argued that donor support must be integrated into these strategies. The lack of donor coordination and the proliferation of aid agencies were identified as key constraints to aid effectiveness. It was pointed out that donors at best can play only a supportive or catalytic role in enhancing the efforts taken by the developing countries themselves. The need for a change in the donor-partner country relationship was also highlighted in the World Bank reports from 1998 and 2002 (World Bank, 1998, World Bank, 2002).

This call for a partnership approach to development cooperation with emphasis on developing country ownership was not, as such, new. Rather it was a rediscovery of the old truth advocated already by early development scholars and policy-makers, such as Rosenstein-Rodan (1961), Chenery and Strout, (1966); Pearson et al. (1969); Brandt, (1980, 1983); Cassen et al., (1986); Cassen, (1994) and Riddell (1987; 2007). Following the adoption of the Paris Declaration on Aid Effectiveness (2005), the subsequent 
Accra Agenda for Action (2008), and the Busan Partnership for Effective Development Co-operation (2011), the nature of the relationship between donor and partner countries has become a core issue in the aid effectiveness debate (www.oecd.org/dac).

\subsubsection{Concluding Remarks}

Despite the evidence of the positive impact of aid at project level, the impact of aid at macro-level remains contested, in particular among many development scholars. The uncertainty can be explained, firstly, by the fact that there is not enough understanding of what causes growth and poverty reduction to allow the tracing of a link from aid to its impact on various macro-economic variables. Secondly, the statistical relationships between aid and growth aggregates fail to explain the causality between the variables or to show whether the observed relationship is due to other external influence. Thirdly, the wider impact of aid is crucially linked to the context within which aid is provided. Yet, the degree of ownership by the aid-receiving countries and their commitment to poverty reduction and development, which are considered as fundamental prerequisites for effective aid, cannot easily be included in the studies using aggregate quantitative data.

The progress made by developing countries towards the MDGs provides a more promising outlook for the impact of aid on development. Since the adoption of the MDGs as a common agenda for development, significant steps have been taken towards achieving the targets. Perhaps most importantly from the perspective of the primary objective of development cooperation, the target set for the reduction of extreme poverty by half has been met ahead of the time limit of 2015 (using the 1990 poverty rate as the baseline). While the progress made towards the MDGs cannot be attributed directly to aid, it can be argued that the increased aid has played a role in supporting developing countries in creating the conditions for economic growth, and thereby has reinforced their own efforts to achieve the MDGs.

Finally, the findings by Burnside and Dollar on the positive relationship between the quality of the policy and institutional framework and the impact of aid, albeit widely challenged in academic literature, have remained firm on the donor agenda contributing to the emergence of a new "paradigm on aid effectiveness" based on the notion of "good governance". The increasing emphasis on governance has led to an intense debate, among both academics and policy-makers, on the dynamics between governance, aid effectiveness and development outcomes. It has also resulted in a multitude of conceptual and operational approaches for assessing governance in developing country contexts. The key messages emerging from this "governance discourse" will be outlined in the next section. 


\subsection{Conceptual Approaches to Governance}

Governance is a vague term for complex social phenomena which escapes universally agreed definition. According to Bevir, "at the most general level, governance refers to theories and issues of social coordination and the nature of all patterns of rule" (Bevir, 2011, p. 1). The concept of governance appears in different academic disciplines including, inter alia, political science, economics, sociology, international relations, public administration etc. which all tend to approach governance from the perspective of a given academic tradition. Even if initially equated with government referring to the system of ruling by government ${ }^{23}$, in contemporary usage the concept of governance encompasses the multiple interrelationships and networks between various government institutions, private sector actors and non-governmental organizations. Governance has also become a central concept in international relations.

The 2011 SAGE Handbook of Governance provides an overview of ten new theoretical approaches to governance (underlining by the author), which have evolved over the course of the twentieth century in an attempt to shed light on the changing nature of relationship between the state and the society at large (Bevir, 2011). The conceptualization of governance has evolved significantly, in particular, since the 1980s. In contrast with earlier approaches to governance the new theories - each divided into several lines of thinking - put emphasis on markets and networks, reflecting the development of new forms of public management, increasing importance of public-private partnerships, other policy networks involving non-state actors, and the greater impact of supranational and sub-national organizations (Rhodes, 1997; Pierre and Peters, 2000; Kjaer, 2004; Heywood, 2007; Bevir, 2011). A distinction can also be made between theories that view governance primarily as a structure, and theories that view governance as a process. Approaching governance as a structure entails an analysis of the political and economic institutions that have been created to address governance issues in a society, whereas a process approach to governance shifts the attention from institutional arrangements to the outcomes of a of variety political, economic and

23. The origin of the concept of governance extends well before the twentieth century and can be traced back to the ancient Greek political philosophers, such as Plato's and Aristotle's works on ideal forms state and government. The classical typology of the six forms of government based on questions "who rules?" and "who benefits from the rule?", devised by Aristotle in the fourth century $\mathrm{BC}$, has influenced the thinking on state, government and governance for over two thousand years. Advocating democracy - "ruling by many to the benefit of all" - as the best form of government Aristotle laid foundations to the development of the political system and model of governance in the western societies. Governance was also at the heart of the thinking in Age of Enlightenment, in the $17^{\text {th }}$ and $18^{\text {th }}$ century, among the early advocates of liberalism such as such as J. Locke and C-L. Montesquieu. The principle of the separation of powers between the "executive, legislative and judicial", introduced by Montesquieu in the eighteenth century, is considered as one of the defining characteristics of liberal democratic government (see Heywood, 2007; Hyden and Court 2002). 
social actors (Pierre and Peters, 2000). In the absence of one coherent body of governance theory, it is no wonder that the concept of governance is defined in different ways, each rooted in a specific academic tradition. As noted by Keefer, "there is no agreed definition of governance that would provide a convenient device for organizing the literature" (Keefer, 2009, p. 439).

While any attempt to present an overview of the vast literature on governance is well beyond the scope of this research, the evolution of the interpretation of the concept of governance within the context of development cooperation merits further discussion as a background to an analysis of the governance assessments under consideration in this research.

\subsubsection{Governance in the Context of International Development Cooperation}

As argued earlier, the World Bank report entitled Sub-Saharan Africa: From Crisis to Sustainable Growth (World Bank, 1989) was instrumental in bringing governance to the centre of the development discourse by defining governance as the fundamental pillar for growth and sustainable socio-economic development. Despite extensive research on governance, and an emerging consensus on its importance for aid effectiveness and development, there is no agreement as to what the concept of governance means, how governance relates to development and aid effectiveness, how it can be measured and, finally, how - or if - it can be strengthened through aid. Bilateral and multilateral aid agencies apply different definitions of governance which are rooted in diverse academic traditions and which impact upon their aid policies and approaches in assessing governance in specific country contexts. The World Bank, the UN and the European Union, which are the largest multilateral aid providers, and which play a leading agenda setting role for international development cooperation ${ }^{24}$, have adopted somewhat different interpretations of governance. The diversity of interpretations is not limited to these three multilateral actors, but is characteristic of the governance discourse among other multilateral and bilateral aid agencies. The OECD DAC Survey on Donor Approaches to Governance Assessment of 2009, which covers 30 selected aid agencies, indicates that all agencies interpret the concept of governance somewhat

24. According to the OECD DAC data from 2009, the DAC members channel $81 \%$ of their multilateral aid into five main clusters of multilaterals. These are (in the order of aid volume): the EU 37\%, (EDF and EU budget); the World Bank 21\% (IDA); the UN 10\% (UN Funds and Programmes); the African and Asian Development Banks (5\% and 3\% respectively), and the Global Fund (6\%). Only $18 \%$ of multilateral aid goes to the remaining over 200 multilateral organizations (OECD DAC, 2011, p. 31). 
differently (OECD DAC, 2009, p. 22-24, underlining by the author). By expanding the selection of donors, the number of definitions is likely to increase.

The complexity of the governance discourse deepens when moving from the essentially neutral concept of governance to the normative notion of "good" governance. The good policy framework, as initially outlined by Burnside and Dollar, has been progressively broadened to include a number of other attributes which refer to both governance processes and governance outcomes. Hence, the emerging good governance agenda advocated by aid agencies covers a wide range of issues from the nature of the political and economic system, status of socio-economic development and quality of public administration, to the international relations of a given developing country. The emphasis placed on the different aspects of good governance has shifted over time, and continues to vary between and within the aid agencies (Grindle, 2002; 2011; Hyden, Court and Mease, 2004; Booth 2011).

In view of the influential role of the World Bank, the UN and the European Union in setting the donor governance agenda globally and in Mozambique, the conceptual approaches adopted by these agencies will be briefly discussed below. As to the UN agencies, the discussion will focus on the United Nations Development Programme (UNDP) which plays a primary role among the UN agencies in supporting governance at the country level. The discussion starts from the World Bank, which tends to set the tone of the development debate among other multilateral and bilateral aid agencies as well as at the level of developing countries.

\section{The World Bank ${ }^{25}$}

The World Bank's approach to governance has evolved through three stages from the focus on the quality of government (between the mid-1980s and mid-1990s) to the emergence of governance as a key pillar of poverty reduction (from the mid-1990s through the mid-2000s), and finally to the contemporary emphasis of governance as a bank-wide strategic priority (World Bank, 2011, p. 3).

25. The World Bank Group consists of five institutions: the International Bank for Reconstruction and Development (IBRD), the International Finance Institutions (IFC), the International Development Association (IDA), the Multilateral Investment Guarantee Agency (MIGA) and the International Centre for Settlement of Investment Disputes (ICSID). The World Bank Institute (WBI) as such is not a separate institute but serves as one of the Bank's main instruments for capacity building in developing countries. All the five institutions including the WBI are headed by the President of the World Bank Group. 
During the first stage, governance was defined as "the manner in which power is exercised in the management of a country's economic and social resources for development" (World Bank, 1992, p. 52). Following from this definition, which was outlined in the Bank's first report devoted entirely on governance, three distinct aspects of governance were identified: the form of the political regime; the manner by which authority is exercised in the management of a country's economic and social resources for development; and the capacity of government to design formulate and implement policies and discharge functions. The Bank's initial approach thus reflected the findings of its research on the development challenges in Sub-Saharan African countries. The perceived "crisis of governance", which was identified as the root cause underlying the problems in Africa, was defined in terms of power relations. In response to the crisis, the Bank called for a "political renewal" involving concerted action against corruption, greater accountability, rule of law, free press, increased grassroots participation and empowerment of people, in particular of women (World Bank 1989, p. 60).

During the second stage, governance was brought to the centre of the debate on poverty reduction. The World Development Report of 2000/2001, Attacking Poverty (World Bank, 2000), identified governance as the key pillar in poverty reduction and broadened the interpretation of the political dimension of governance. Stating that poverty is an outcome of interacting economic, social and political processes, and "in particular, of the accountability and the responsiveness of state institutions", the report called for promoting democratic policies so as to foster economic growth (World Bank 2000, p. 99). In other words, transparency, accountability and participatory democracy were brought to the centre of the Bank's agenda.

The World Bank's contemporary approach to governance was outlined in the first bank-wide Governance and Anti-Corruption Strategy of 2007 which defined governance as "the manner in which public officials and institutions acquire and exercise the authority to shape public policy and provide public goods and services" (World Bank, 2007, p. i). The 2012 update of this strategy builds on the same definition while putting enhanced emphasis on the importance of country-specific approaches and, in particular, on supporting citizenship and citizens' participation in policy-making (World Bank, 2012, p. 8).

Although the World Bank's current definition of the concept of governance appears rather neutral, the Bank's operational approach to governance, as outlined in the 2012 update of the Governance and Anti-Corruption Strategy, entails a number of normative elements. According to the update, "Governance is about what the state can do and how it does it" which in turn "is determined by its capacity, its legitimacy, and its authority" (World Bank, 2012, p. 9). The state capacity, legitimacy and authority are further specified as follows: 
"Capacity is the ability of the state to procure and deliver goods and services, design and implement policies, build infrastructure, collect revenue, dispense justice, and maintain a conducive environment for the private sector. Legitimacy is simply whether citizens feel the government has the right to govern - and whether they trust the government. Authority is the ability of the state to govern its territory effectively, reach all citizens regardless of their location, gender, or ethnicity, maintain law and order and protect citizens from predation and violence. It is the ability of the laws and rules of the state to trump all other laws and rules."(World Bank, 2012, p. 9-10, underlining by the author)

In addition to the key concepts of capacity, legitimacy and authority, the strategy calls for "building capable, transparent and accountable country institutions", for enhancing the "voice for citizens in decisions affecting their access to basic services and economic opportunities" and for "closer interaction among citizens, the private sector and the state" (ibid. p. 1). Hence, from the Bank's perspective, the foundation of good governance is a state that is capable, transparent and accountable, and which creates space for citizen and private sector participation. While the emphasis on political aspects of governance, highlighted already in the Bank's pioneering report of 1989, has remained strong in the Bank's conceptual approach to governance, it is not fully reflected in its operational approach to assessing governance (see Chapter 6).

\section{․ United Nations Development Programme (UNDP)}

UNDP's approach to governance was initially laid out in the policy document Governance for Sustainable Human Development, adopted in 1997, which explicitly confirmed governance as a specific area for aid programming within the UNDP. According to the document, governance refers to "the exercise of economic, political and administrative authority to manage a country's affairs at all levels. It comprises the mechanisms, processes and institutions through which citizens and groups articulate their interests, exercise their legal rights, meet their obligations and mediate their differences" (UNDP 1997, p. 12). The three key dimensions of governance are economic, political and administrative. Economic governance includes decision-making processes that affect a country's economic activities and its relationships with other economies, political governance refers to the process of decision-making to formulate policy, and administrative governance refers the system of policy implementation (ibid. p. 12).

From the UNDP's perspective, the main actors of governance at a country level include the state, the private sector and civil society: "Governance encompasses the state, but it transcends the state by including the private sector and civil society organizations" (ibid. p. 4). The state, comprising political and public sector institutions, creates the 
political and legal environment conducive to human development. The private sector, consisting of private enterprises and the informal sector actors, generates jobs and income. The role of the civil society in governance is to facilitate political and social interaction and mobilise groups to participate in economic, social and political activities. Civil society itself comprises individuals and groups (organised or unorganised) interacting socially, politically and economically - regulated by formal and informal rules and laws (ibid.).

From the perspective of the UNDP, good governance is participatory, transparent, accountable, effective and equitable. It promotes the rule of law. Good governance also "ensures that political, social and economic priorities are based on broad consensus in society and that the voices of the poorest and the most vulnerable are heard in decision-making over the allocation of development resources" (ibid., p. 4).

The UNDP's approach to governance has broadened since the late 1990s. Since the adoption of the Millennium Declaration in 2000, the notion of democratic governance emerged into the UNDP vocabulary (underlining by the author, see also the UNDP Strategy Note on Governance for Human Development, 2000). In terms of aid programming, democratic governance entails fostering inclusive participation, strengthening responsive governing institutions and aligning democratic governance with international principles. UNDP's contemporary work on governance seems to build solely on the notion of democratic governance which includes a wide range of topics from human rights, democracy and rule of law to public administration, control of corruption and conflict issues (www.undp.org/governance/).

\section{The European Union}

The EU's approach to governance, with specific reference to development cooperation, was first outlined in the Commission Communication on Governance and Development of $2003 .{ }^{26}$ Echoing the World Bank, governance is defined in general terms as "the state's ability to serve the citizens" and more specifically as follows:

26. The objectives of the EU's development cooperation are laid down in the successive EU Treaties which form the legal basis for European Union action in this field. The Lisbon Treaty, signed in 2007 and ratified in December 2009, states that the Union's action on the international scene shall be guided by the principles which have inspired its own creation, development and enlargement, and which it seeks to advance in the wider world: democracy, the rule of law, the universality and indivisibility of human rights and fundamental freedoms, respect for human dignity, the principles of equality and solidarity, and respect for the principles of the United Nations Charter and international law. (EC 2008, OJ C115/Lisbon Treaty, Article 21). 
"Governance refers to the rules, processes, and behaviour by which interests are articulated, resources are managed, and power is exercised in society... As the concepts of human rights, democratisation and democracy, the rule of law, civil society, decentralised power sharing, and sound public administration gain importance and relevance, a society develops into a more sophisticated political system and governance evolves into good governance."(Commission Communication on Governance and Development, COM (2003) 615, p. 3).

The Commission Communication of 2006 on Governance in the European Consensus for Development - Towards a harmonised approach within the European Union (COM 2006, 421 final of 2006) broadened the EU's approach to governance. Following the terminology adopted by the UNDP, it builds on the notion of "democratic governance", which is defined in terms of a long list of "good things", although it refrains from using the notion of "good" governance:

"It [democratic governance] includes: respect of human rights and fundamental freedoms (including freedom of expression, information and association); support for democratisation processes and the involvement of citizens in choosing and overseeing those who govern them; respect for the rule of law and access for all to an independent justice system; access to information; a government that governs transparently and is accountable to the relevant institutions and to the electorate; human security; management of migration flows; effective institutions, access to basic social services, sustainable management of natural and energy resources and of the environment, and the promotion of sustainable economic growth and social cohesion in a climate conducive to private investment (COM 2006, 421 final, p. 3).

From the point of view of this research, an important element introduced by the 2006 Communication relates to the new financing instrument, the so called Governance Initiative, aimed at enhancing governance reforms in developing countries. The Governance Initiative will be discussed in more detail in Chapter 6.

The Partnership Agreement ACP-EC, signed in Cotonou 2000, which provides the legal base for the EU cooperation with 79 African, Caribbean and Pacific countries including Mozambique, builds on a similar approach to governance. However, the Partnership Agreement makes an explicit reference to the notion of "good" governance as "the transparent and accountable management of human, natural, economic and financial resources for the purpose of equitable and sustainable development". ${ }^{27}$

27. The ACP-EC Agreement, generally known as the Cotonou Agreement, was signed between the ACP Group of States, apart from Cuba, and the EU member states in 2000 in Cotonou. The Agreement covers the period 2000-2020. The Agreement states that "In a context of a political and 
Other multilateral and bilateral aid agencies have developed their own definitions of governance. However, the definitions adopted by such other agencies echo, to a greater or lesser degree, those of the World Bank, UNDP and the EU. Multilateral development banks, such as the African Development Bank, tend to follow the approach adopted by the World Bank whereas bilateral donor agencies align themselves more with the UNDP and the EU (OECD DAC 2009). Common for most of the definitions is that the notion of governance is multi-dimensional comprising political, economic, social, institutional and cultural dimensions. The national governance system is generally perceived as a network which includes the central government and public sector institutions, the private sector and civil society actors which operate at different levels, including at national, regional and local levels. As summarized by Court, a consensus seems to have emerged on three issues: first, the concept of governance extends beyond the government of a given state; second, governance refers to the pattern of rules that regulate the public sphere where the state and other societal actors interact; and third, governance refers to both the processes of governance and the outcomes of governance (Court 2006).

As to the aid agencies' interpretation of good governance, a number of common areas of interest can also be identified. Most definitions of good governance agree on the importance of a capable state that respects the rule of law. Furthermore, according to most definitions, effective governance calls for mutual accountability between the state apparatus, private sector and civil society. According to Smith, the common elements include ten focus areas: political accountability; human rights; the rule of law; decentralization of political power; political pluralism; participation; eradicating corruption; transparent and accountable public administration; efficient public management; economic reform and poverty alleviation (Smith, 2007). The UNDP lists the common elements of the good governance agenda somewhat differently, perhaps aiming at a less normative set of attributes: participation; fairness; decency; accountability; transparency; and efficiency. ${ }^{28}$ The first three aspects are perceived to refer to the

institutional environment that upholds human rights, democratic principles and the rule of law, good governance is the transparent and accountable management of human, natural, economic and financial resources for the purpose of equitable and sustainable development. It entails clear decisionmaking procedures at the level of public authorities, transparent and accountable institutions, the primacy of the rule of law in the management of resources and capacity building for elaborating and implementing measures aiming in particular to preventing and combating corruption" (Cotonou Partnership Agreement 2000, article 9.3).

28. Participation: the degree of involvement by affected stakeholders.

Fairness: the degree to which rules apply equally to everyone in society.

Decency: the degree to which the formation and stewardship of the rules is undertaken without humiliating or harming people.

Accountability: the extent to which political actors are responsible to society for what they say and do. Transparency: the degree of clarity and openness with which decisions are made. 
relationship between the state and the society at large whereas the latter three seem to refer to operational aspects of the state (Hyden, Court and Mease, 2004, p. 3).

From the point of view of this research, the key question concerns the relevance of the diverse attributes of good governance in the specific country context of Mozambique. This question will be addressed in Chapter 8 .

\subsubsection{Governance, Good Governance or Good Enough Governance?}

The governance approaches adopted by the international development agencies have been challenged both on conceptual and operational grounds. According to Hyden and Court (2002), aid agencies define governance in a way that suits their own specific mandates and programmatic needs. Governance has therefore become a "catch-all concept" which fails to make distinctions between governance, policy and administration (ibid., p. 18). Furthermore, the conceptualization of governance by donors is perceived to be ethnocentric, i.e. building on "the idea that good governance is a reflection of what works in Western democracies". Good governance has come to mean liberal democracy, competitive market economy, free trade, decentralization and a minimalist state (Leftwich 2000; Hyden, Court and Mease, 2004; Court 2006). In other words, achieving good governance in developing countries would entail adopting the best practices that have evolved overtime in developed countries.

The normative agenda of good governance has been challenged not only because of a lack of conceptual clarity, but also because of its ambition level. In view of the wide range of issues embedded in the notion of good governance - some referring to policies and processes and some to development outcomes - it has become difficult to distinguish governance from development itself. As argued by Grindle already in 2002:

"Getting good governance calls for improvements that touch virtually all aspects of the public sector - from institutions that set the rules of the game for economic and political interaction, to organizations that manage administrative systems and deliver goods and services to citizens, to human resources that staff government bureaucracies, to the interface of officials and citizens in political and bureaucratic arenas." (Grindle, 2002, p. 1).

Highlighting the problems related to the implementation of such a broad agenda Grindle calls for an agenda for "good enough governance" that shifts attention to the 
"minimal" conditions of governance necessary to allow political and economic development to occur. The good enough governance agenda requires an understanding of the evolution of institutions and government capabilities of a given country, and builds on what works rather than focusing only on governance gaps. Hence, the roadmap towards good enough governance in developing countries entails strategic prioritization and the sequencing of interventions to strengthen governance as well as the identification of the key, context-specific actors to implement the necessary reforms (Grindle, 2002; 2011).

Donor approaches to governance have also been criticized for a lack of understanding, and outright ignorance, of the formal and informal governance structures rooted in the social fabric and power relations in developing countries. It has been argued that instead of promoting an ethnocentric good governance agenda, aid agencies should build upon the existing notions of accountability and moral obligations with the objective of strengthening these governance structures (Kelsall, 2008). For example, the report by the Commission for Africa of $2005^{29}$ noted, with specific reference to Somaliland, that "outside prescriptions only succeed when they work with the grain of African ways of doing things" stressing the importance of using existing forms of governance as the starting point for enhancing governance (Commission for Africa, 2005, p. 35).

This line of thinking is developed further in research programme by the Centre for Future States (Institute of Development Studies, University of Sussex) which questions the aid agencies' emphasis on reforming governance through strengthening formal, rules-based institutions (IDS, 2010). In view of the evidence of the limited impact of donor interventions focusing on formal institutions and state-building, the Centre for Future States programme calls for "an upside-down view of governance" that builds on informal institutions and personalized relationships. It is argued that "informal institutions and personalized relationships are pervasive and powerful and can contribute to progressive outcomes in poor countries" (IDS, 2010, p. 70), and therefore, should be seen as part of the solution to reform governance rather than problems for governance. Instead of putting emphasis on reforming formal institutions aid agencies should look beyond these institutions and analyse the structures, relationships, interests and incentives that underpin them (IDS, 2010).

The governance discourse - and the perceived failure by donors to contribute to reforming governance in developing countries - can also be analyzed within the conceptual framework developed by Ferguson (1994) in his case study on a large-scale

29. Our Common Interest: The Report of the Commission for Africa, published in 2005. The Commission was set up by the UK Government under the premiership of Tony Blair. 
rural development programme in Lesotho, the Thaba-Tseka Development Project. ${ }^{30}$ Although focused on a specific programme in Lesotho, the study opens new perspectives for analyzing the impact, and the unintended consequences, of the evolving development discourse. According to Ferguson, the development institutions generate their own form of discourse which creates a structure of knowledge around a given phenomenon of interest. Aid interventions are then organized on the basis of this structure of knowledge, and while failing to achieve the intended objectives, the interventions contribute to significant structural changes. As argued by Ferguson, "ideas and discourses have important and very real social consequences" and the production of certain ideas by the development institutions, or by the "development apparatus", plays an important role in the production of structural changes (Ferguson, 1994, p. xv). According to the findings by Ferguson, the development discourse generated by the development institutions turned sensitive political issues, such as access to resources, public service provision, decision-making procedures etc. into technical "development issues" which remained outside the realm of politics. This in turn led to the de-politicization of the political debate, and to the expansion and strengthening of the bureaucratic power by the state (ibid., p. 256).

From this perspective, the governance discourse, generated by the development institutions in their attempt to ensure the effective use of aid resources and the achievement of intended development objectives, may have brought about significant structural changes despite failing to achieve the intended objectives. Following Ferguson's argumentation, the donor governance discourse may lead to the de-politicization of the country-specific governance debates translating them into a technical development discourse which is context-independent and standardized.

Despite the controversy related to the donor discourse on governance, the belief that "governance matters" remains firm among the aid agencies. This is reflected in their efforts to assess the quality of governance in developing countries. The donor approaches to assessing governance in practice will be discussed in the next section.

30. Tracing the evolution of the Thaba-Tseka Development Project and its impact on the political, economic and social structures in Lesotho, Ferguson found that while the programme failed to achieve its intended objectives, that is increased agricultural production, decentralization, and enhanced community level popular participation, it led to the expansion of the state bureaucracy, and to the de-politicization of all economic and social issues encountered by the people in the district. Ferguson concludes that the "development apparatus" in Lesotho depoliticized "everything it touches...while performing, almost unnoticed, its own pre-eminently political operation of expanding bureaucratic state power" (Ferguson, p. xv). 


\subsubsection{Governance Assessments in Practice}

The enhanced interest among donors in governance, and in promoting good governance in developing countries, has resulted in a significant increase in the number of governance assessment tools and indicators used to measure the quality of governance. The seemingly endless development of new instruments is driven not only by the aid agencies' search for good governance but reflects also the concerns about governance issues by developing country governments, civil society organizations and private sector actors. The attempts to translate the ambiguous and multi-faceted agenda of good governance into practice have thus lead to a myriad of different operational approaches to assessing governance.

The multitude of different governance assessments is illustrated by the UNDP in the handbook on governance of 2007, Governance Indicators - User's handbook which provides a list of 35 governance assessment tools that meet the criteria of having a clear governance data aspect, are publicly available in English, enable cross-national comparisons and provide information about their methodology (UNDP, 2007a, p. vi, underlining by the author). These assessment tools differ in terms of the stated purpose of the assessment, sources of data, the frequency, thematic and geographic focus of the assessment, methodology for conducting the assessment, format of reporting the results, as well as in terms of the use of the assessments. The handbook lists another 22 assessment tools which fail to meet the set criteria. In view of the wide range of questions addressed through the various assessments it seems that "all issues related to social coordination and patterns of rule" (see Bevir 2011, p. 1) are covered (www.undp.org/oslocentre).

The restrictive criteria applied by the UNDP leave out not only all assessment tools produced in other languages than English but also most of the tools that are tailored by different aid agencies to meet their specific governance concerns and programmatic needs. The survey conducted in 2008 by the OECD DAC Governance Network ${ }^{31}$ opens another perspective to the realm of governance assessments by providing information on governance assessment tools "actually applied" by selected bilateral and multilateral aid agencies (21 and 9 agencies respectively) at the time of the survey (OECD, 2008, p. 8-9, underlining by the author). Based on the responses provided by 27 of the selected 30 agencies/countries, the survey arrives at 36 different governance assessment tools actually in use in $2008^{32}$.

31. The OECD DAC Governance Network is one of the DAC's subsidiary bodies. Its members include representatives from DAC member and observer countries. The Network aims at enhancing donor support to democratic governance by providing a forum to exchange experiences and lessons, identify and disseminate good practice, and develop policy and analytical tools (OECD, 2010, p. 26).

32. Bilateral agencies/countries: Australia, Austria, Canada, Denmark, Finland, France, Germany, Greece, Ireland, Japan, Luxembourg, Netherlands, New Zealand, Spain, Sweden, United Kingdom, United States; 
The assessment tools under preparation at that time were not included in the survey. Of the agencies/countries responding to the survey, only 5 bilateral agencies did not have their own governance assessment tools. In view of the volunteer nature of responding, the number of assessment tools applied by the agencies may be even higher. In other words, the majority of the members of the OECD DAC have developed their own tools for assessing the quality of governance in their partner counties. ${ }^{33}$

Like the UNDP's handbook on governance mentioned above, the OECD DAC survey also looks at the differences and similarities in the various assessment tools in terms of their stated purposes, choices of data sources, methodologies, frequency, as well as thematic and geographic foci. However, the analysis by the OECD DAC goes beyond that of the UNDP and explores the diverse conceptual approaches underlying each assessment tool and the involvement of the local actors (representing the state, private sector or civil society) in the assessment process.

As to the conceptual approaches to governance underpinning the various governance assessment tools, the OECD DAC identifies five "different perspectives on governance": 1) traditional public administration; 2) new public management; 3) network governance; 4) power and political economy perspectives; and 5) historical perspectives. The conceptual approach of a given governance assessment tool is deemed central in determining the focus and methodology of that tool. According to the findings by the OECD DAC, most of the 36 governance assessment tools included in the survey "explicitly or implicitly measure or assess governance against the standards that represent the combination of the first three perspectives", namely of traditional public administration, new public management and network governance (OECD, 2009, p. 12). Less than half of the governance assessment tools included in the survey contain elements of the power and political economy or historical approach to governance (ibid. p. 25). The analysis of the involvement of the local actors in the governance assessment processes indicates that in most cases $(26$ out of 36) the governance assessments are conducted by the aid agencies with little or no

Multilateral agencies: African Development Bank, Asian Development Bank, European Commission, Inter-American Development Bank, International Monetary Fund, OECD/DAC, Office for the High Commissioner for Human Rights (UN), World Bank. The survey also included an assessment tool known as the Public Expenditure and Financial Accountability (PEFA) developed jointly by the OECD, World Bank and the IMF in collaboration with some developing countries.

33. Making a distinction between general and thematic governance assessment tools, the OECD DAC identifies 18 general and 18 thematic assessment tools, with several agencies conducting both types of assessments in parallel (OECD, 2008, p. 10; OECD, 2009, p. 5). General governance assessment refers to an assessment which aims at addressing the quality of the governance in a country in general terms whereas thematic assessment aims at addressing specific issues such as human rights, corruption, conflict and so forth. The distinction between general and thematic governance assessment is not clear-cut and the assessments tend to overlap because thematic issues often constitute a sub-set of a general governance assessment (ibid., p. 8). 
participation by local stakeholders. Only 4 of governance assessment tools entail a joint assessment process (ibid. p. 25). ${ }^{34}$

The OECD DAC survey also looks at the issues addressed in the donor governance assessments and identifies four main focus areas. These are the quality of the political system, public administration, social policies (including gender), and the environment for private sector development. Within each of the four areas, a number of specific aspects of governance, ranging from broad topics such as human rights to well-defined questions concerning public procurement, can be identified. The outcome of the survey is summarized in Box 2.1:

\section{Box 2.1 | Focus of Governance Assessment Tools}

\begin{tabular}{|c|c|}
\hline Focus Area & Specific Aspects \\
\hline Political System & $\begin{array}{l}\text { Human Rights } \\
\text { Elections } \\
\text { Rule of Law } \\
\text { Decentralisation } \\
\text { Conflict }\end{array}$ \\
\hline Public Administration & $\begin{array}{l}\text { Corruption } \\
\text { Public Financial Management } \\
\text { Public Procurement }\end{array}$ \\
\hline Social Policies & $\begin{array}{l}\text { Revenue Mobilization } \\
\text { Service Delivery } \\
\text { Gender } \\
\text { Environmental Sustainability }\end{array}$ \\
\hline Business Environment & Regulatory Framework for Private Sector and Trade \\
\hline
\end{tabular}

Source: OECD DAC 2009, p. 15

The complexities related to donor governance assessments are not limited to the multitude of the existing assessment tools with diverse conceptual underpinnings and operational approaches. Each of the governance assessment tools comprises numerous individual indicators aimed at measuring specific areas of governance such as electoral processes, corruption, human rights, public service delivery, civil society, gender equality, etc. All of this adds to the difficulty of getting an overview of what is being assessed, how and by whom. As pointed out by the UNDP, "there exists a plethora of governance indicators,

34. As discussed by Rakner and Wang (2007), the governance assessments can be distinguished in a number of different ways, for example, according to the agencies behind the various initiatives, the role of national stakeholders in the assessment processes or according the main purpose of the assessments (Rakner and Wang, 2007, p. 3). 
which are used by governments, development agencies, non-governmental organizations, media, academic institutions and the private sector... intended to inform users on business investment, allocation of public funds, civil society advocacy or for academic research" (UNDP, 2007a, p. 1). ${ }^{35}$ The indicators vary from perception-based to facts-based indicators, from process indicators to output indicators, from narrow "actionable" indicators to broad indicators, from country-specific to cross-country indicators etc., depending on the data source used to support a given indicator and the purpose of the assessment (Arndt, 2009, unpublished document; see also UNDP, 2007a).

As convincingly argued by Arndt and Oman, the different governance assessment tools with hundreds of indicators are confronted with a number of problems (Arndt and Oman, 2006). Based on a systematic analysis of some of most widely used indicator datasets, such as the Worldwide Governance Indicators, Country Policy and Institutional Assessment, Corruption Perception Index and Freedom House, Arndt and Oman conclude that the indicators lack transparency, comparability over time and suffer from selection bias. They point out the likelihood of correlation of errors among the data sources, and note that the margin for error - if or when reported - is generally ignored by those who use these measurements. Hence, the differences in governance scores between countries, or overtime, are often cited as "real" differences although they are not statistically significant. According to Arndt and Oman, the indicators are not well suited to help developing countries identify how effectively to improve the quality of local governance. The critical analysis is developed further by Arndt in her doctoral dissertation, completed in 2009, which confirms the earlier findings (Arndt 2009, see also Hoyland, Moene and Willumsen, 2009). Several other researchers have questioned the reliability of the data sources which underlie the governance indicators pointing out that change in the choice of data sources used impacts upon the conceptual and statistical precision of the indicator (Knack, 2006). Finally, many of the governance indicator datasets are based on globally standardized benchmarks and therefore fail to capture context-specific governance concerns. The World Governance Assessment research programme, initiated under the auspices of the United Nations University in 1999, presents an attempt to overcome the lack of context-specificity by combining data collected at country level from local stakeholders with an analysis of a common set of governance indicators (Hyden, Court, and Mease 2004; Hyden, Mease, Foresti and Fritz, 2008). The approach adopted by the World Governance Assessment allows for cross-country comparison by focusing primarily on quantitative data while also capturing qualitative inputs from local stakeholders.

35. Other publicly available datasets of governance indicators are listed by, for example, the World Bank Institute, the Inter-American Development Bank and the OECD DAC. In all, the datasets amount to hundreds of governance indicators (www.worldbank.org/wbi/governance/govdatasets/; www.iadb.org); www.oecd-ilibrary.org). 
While the development of tools and indicators to assess the quality of governance in developing countries has been driven, primarily, by the interests of donors and private sector organizations in developed countries, a number of assessment tools have been formulated by organizations and agencies based in the developing countries. In the Mozambican context, the best known are the African Peer Review Mechanism (APRM), initiated within the framework of NEPAD in 2003 (AU/NEPAD, 2003) and the survey-based instruments Afrobarometer (www.afrobarometer.org/) and the Mo Ibrahim Index (www.moibrahimfoundation.org). Although still in a minority, the emergence of country or even continent-led assessment tools indicates the interest by the African countries themselves in interpreting and addressing governance from the perspective of the challenges confronted in their own countries.

\subsubsection{Concluding Remarks}

In conclusion, while the formal definitions of governance by aid agencies may seem like "variations on a theme", they hide more fundamental differences which come to the surface in the aid agencies' operational approaches to assessing governance in practice. Reflecting the underlying differences, the governance assessments tend to put emphasis on different aspects of governance. Most agencies address governance from the perspectives of traditional public administration, new public management and networks focusing on economic and institutional aspects without paying much attention to the power and political economy or historical perspectives to governance. The lack of a shared interpretation of the concept of governance, and of a harmonized approach to assessing governance, results in vast number of governance indicators being used to measure governance. Although many of these indicators lack transparency and comparability over time, suffer from selection bias, and fail to address country-specific governance concerns, they are widely used by aid agencies to guide their aid policy dialogue with developing countries.

\subsection{The Puzzle of Development, Aid Effectiveness and Governance - Conclusions}

The shifting paradigm of the development discourse illustrates that the notion of development has been a moving target generating progressively more demands for new approaches to support the developing countries. The narrow focus on economic growth as the key to development of the first development decade of the 1960s has been replaced by a broad agenda aimed at poverty eradication and sustainable socio-economic development, as enshrined in the UN Millennium Declaration and the related 
Millennium Development Goals of 2000. The primary objectives of development aid have been defined in multiple ways from contributing to savings and investments to the eradication of multi-dimensional poverty, in reflection of the changing focus of the development discourse. Accordingly, the criteria for assessing the impact of aid have shifted in line with the shifting expectations about the contribution of aid to development.

While the notion of governance as one determinant of aid effectiveness can be traced back to the early years development research, it was not until the late 1980s and early 1990s that the concept of governance was explicitly introduced to the development discourse. Since the publication of the World Bank report Sub-Saharan Africa: From Crisis to Sustainable Growth (1989), governance has remained a central element in the debate on aid effectiveness contributing to the emergence of the "new paradigm on aid effectiveness". The emphasis on governance - or good governance in normative terms - has led to the development of a multitude of tools and indicators to assess the quality of governance in developing countries. The assessment tools differ not only in terms of the conceptual approach underpinning the assessments, but also in terms of their objectives, foci, sources of data and methodological choices. The range of issues addressed in governance assessments seems to touch upon all aspects of the social phenomena referred to as governance. An attempt to illustrate the central role of governance in contemporary discourse on aid effectiveness, as outlined by Bourguignon and Sundberg (2007), is presented in Figure 2.2.

\section{Figure 2.2 | Governance in the Context of Aid Effectiveness}

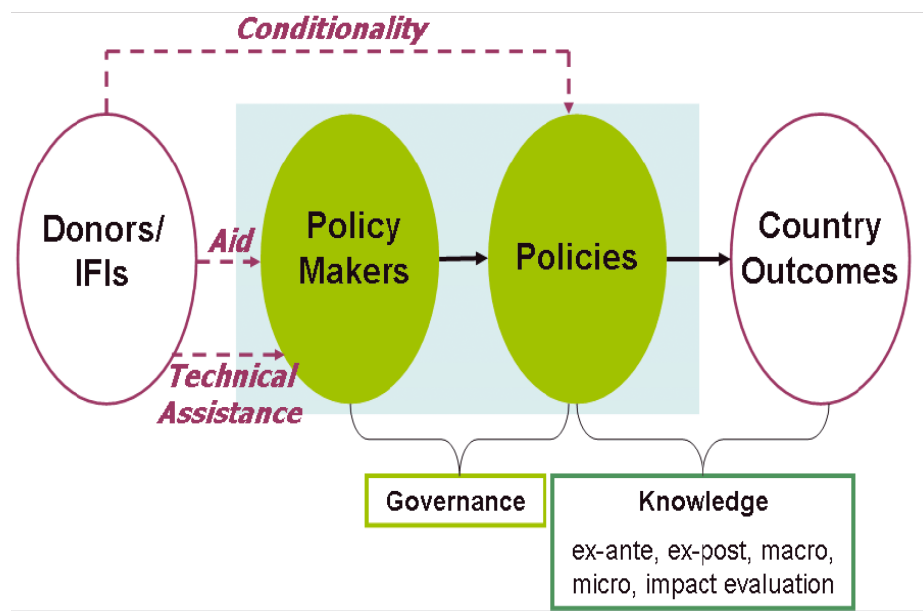

Source: Bourguignon and Sundberg (2007) Aid Effectiveness - Opening the Black Box. (unpublished document) 
Within the above framework of the debates about the dynamics between development, aid effectiveness and governance, this research aims at opening the "black box" of governance by exploring what the governance assessments conducted by aid agencies operating in Mozambique actually assess.

Finally, in this contested field of development discourse and development cooperation, I would like to outline my position as a researcher and aid practitioner. The choice of the topic of the research and the formulation of the research questions are informed by my experience as aid practitioner. I align myself with those who view development cooperation as one instrument that can contribute to poverty reduction and wider socio-economic development. I support the argument that good governance, characterized by broad-based participation, fairness, decency, accountability, transparency and efficiency in a society, is a basic ingredient for sustainable socio-economic development and can contribute to the effectiveness of development aid. However, good governance cannot be imported: strengthening governance to the benefit of all population groups requires country-specific approaches that build on existing formal and informal structures in a given society. 


\section{Methodological Approach and Data}

The nature of the research problem and the research questions largely determine the methodology of a given research project. Qualitative research typically seeks to reveal what lies behind a phenomenon about which little is known, or to shed new light on something about which some common understanding exists (Strauss and Corbin, 1990, p. 19; Mason, 1996, p. 4). The research questions concerning diverse conceptual and operational approaches to assessing governance in the context of Mozambique, the consistency of the assessment results, and the perceived relevance and potential impact of the assessments on reforming governance from the Mozambican perspective, lend themselves rather naturally to a qualitative research approach.

Qualitative research, however, tends to mean different things to different people. ${ }^{36} \mathrm{It}$ comprises several approaches or strategies which can be distinguished, inter alia, by the focus of the research, the academic discipline underpinning the research, data collection and data analysis methods, as well as by the general structure of the research process (Creswell, 2013, p. 104-106). In the absence of a common definition of what constitutes qualitative research, Creswell presents the following "working definition":

"Qualitative research begins with assumptions and the use of interpretive/theoretical frameworks that inform the study of research problems addressing the meaning individuals or groups ascribe to a social or human problem. To study this problem, qualitative researcher uses an emerging qualitative approach to inquiry, the collection of data in natural setting sensitive to the people and places under study, and data analysis that is both inductive and deductive and establishes patterns or themes. The final written report or presentation includes voices of participants, the reflexivity of the researchers, a complex description and interpretation of the problem and its contribution to the literature or a call for change." (Creswell, 2012, p. 44)

In most general terms, qualitative research can be characterized as having three components: 1) data, obtained most commonly through documents, observations and interviews; 2) different analytic and interpretive procedures used for conceptualizing the data and for arriving at research findings; and 3) reports that are presented in written and verbal formats. The collection and analysis of data are intertwined in the

36. Qualitative research is determined by certain philosophical assumptions about the nature of reality (ontology), nature of knowledge and evidence (epistemology), the role of values in the research (axiology) and about the research process itself (methodology) (Mason, 1996, p. 10-13; Creswell 2012, p. 19-23). 
research process (Strauss and Corbin, 1990; Mason, 1996; Silverman, 2010; Creswell, 2013).

\subsection{Case Study on Assessing Governance Assessment in Mozambique}

In seeking answers to the research questions outlined above, the case study approach ${ }^{37}$ has been adopted. Yin defines the case study method "as an empirical inquiry that investigates contemporary phenomenon in depth and within its real-life context, especially when the boundaries between the phenomenon and context are not evident" (Yin, 2009, p. 18). ${ }^{38} \mathrm{He}$ further states that the case study method "relies on multiple sources of evidence" and "benefits from the prior development of theoretical propositions to guide data collection and data analysis case." (ibid. p. 18; see also Creswell, 2013, p. 97). The case study method has, according to Yin, a distinct advantage when seeking answers to questions "how" and "why" about a contemporary set of events over which the researcher has little or no control (Yin, 2009, p. 13).

From the perspective of this research, the case study method as defined by Yin seemed best suited for answering questions about how aid agencies define and assess the quality of governance in the specific context of Mozambique, how consistent the results of the assessments are and how the assessments are perceived by the Mozambican stakeholders. While the case study method does not entail survey-based data collection and, therefore, is often criticized for providing a limited basis for scientific generalization, it does allow for a context-specific, interpretative analysis of the phenomenon of interest in a real life situation (Yin, 2009, p. 14-16). Within the framework of this research, the use of the method entails an in-depth analysis of the selected governance assessments, including their perceived relevance, that have been conducted by aid agencies in the real-life context of Mozambique. It further entails an analysis of the country-specific situation within which the contemporary governance discourse takes place, with focus on the evolution of the governance context and the role of aid agencies in Mozambique. To accomplish this, the analysis relies on multiple sources

37. The terms "case study approach", "case study method" and "case study strategy of inquiry" are used somewhat inter-changeably. For example, Creswell uses the term case study approach whereas Yin refers to case study as a method or strategy of inquiry (Creswell, 2013, p. 5; Yin, 2009).

38. The case study method can be defined in several ways as discussed by Gerring (2004). Gerring proposes to define the method as "an intensive study of a single unit for the purpose of understanding a larger class of (similar) units" (ibid, p. 342). However, Gerring notes that there is no harm in continuing to refer to a case study method in the various ways, as long as the researcher is aware of the methodological trade-offs between single-unit versus cross-unit study research designs. 
of information, i.e. different types of written documentation such as academic literature, documents and internet-based information as well as data generated through interviews with the Mozambican stakeholders and donor agency representatives. The case study on Mozambique, while initially motivated by the researcher's relationship with the country, is methodologically justified in view of the fact that as an aid-dependent country Mozambique has been subject to multiple donor governance assessments which provide data for seeking answers to the research questions.

\subsubsection{Units of Analysis}

As discussed by Creswell (2013), Silverman (2010) and Yin (2009), case study research begins with the identification of a specific case/multiple cases for analysis, in other words, a unit or units of analysis which can be defined and described within certain parameters. The selection of the unit of analysis is guided by the research questions, although the phenomenon being studied may extend beyond the parameters of the primary units of analysis (Yin, 2009, p. 30). However, as pointed out by Yin "the boundaries between the case/cases and the context are not likely to be sharp" (ibid., p. 46). Within the framework of this research, the data generated through the stakeholder interviews on the Mozambican and donor perceptions about the governance assessments broaden the analysis beyond the specific assessments to wider context of governance in the country. Therefore, the analysis of the selected governance assessments on Mozambique sheds light on the wider governance discourse taking place at the country level.

For the purpose of this research, the units of analysis are the governance assessment tools developed and applied by the ten largest aid agencies in Mozambique over the period of 2006-2010. As mentioned in the Introduction, these assessments are:

1. Worldwide Governance Indicators (the World Bank/The World Bank Institute)

2. Country Policy and Institutional Assessment (the World Bank)

3. Country Policy and Institutional Assessment (the African Development Bank)

4. Governance Profile (the European Union)

5. Millennium Challenge Scorecard (the USA)

6. Country Governance Analysis (the UK)

7. Strategic Governance and Corruption Analysis (the Netherlands)

8. Power Analysis (Sweden)

The justification for limiting the scope of the analysis to the governance assessment tools of the ten largest aid agencies operating in Mozambique lies in the fact that these agencies jointly account for approximately $70 \%$ of all ODA channelled to Mozambique 
and, therefore, they play an influential role in the country, including in the governance discourse.

The rationale for the focus on the period of $2006-2010$ is two-fold: firstly, while the assessments based on the Worldwide Governance Indicators, the Country Policy and Institutional Analyses and the Millennium Challenge Scorecard are conducted annually, the rest of the assessments are conducted only on an ad hoc basis. During the period of 2006 - 2010, four ad hoc assessments were conducted by donors belong to the group of the ten largest aid agencies: the Power Analysis (Sweden) was completed in 2006, the Country Governance Analysis in 2007 (the UK), and the Governance Profile as well as the Strategic Governance and Corruption Analysis in 2008 (the EU and the Netherlands respectively). Secondly, Mozambique's latest presidential, parliamentary and municipal elections took place in 2009 in the midst of intense debate among both the aid agencies and the Mozambican electorate about the transparency of the electoral process. This led to a temporary freeze of aid disbursements by several of the aid agencies conducting governance assessments. The question to what extent the selected governance assessments capture this type of county-specific developments, particularly in the field of political governance, can thus be discussed in light of the 2010 assessment results. The inclusion of the year 2010 is justified also by the fact that the field work for this research was carried out, primarily, in 2010.

\subsubsection{Data Sources}

This research builds primarily on two main types of data sources. First, in an attempt to answer the research question concerning the conceptual and operational approaches of the selected governance assessment tools, and the consistency of the results of the different assessments, I have relied on the written documentation and internet-based material provided, for the most part, by the aid agencies themselves. The written documentation has been complemented by data collected through interviews with the representatives of the respective aid agencies. For the purpose of the research 11 donor representatives have been interviewed.

As to the research questions concerning the country-level perceptions of the relevance of the assessments, and the impact of the assessments on reforming governance in Mozambique, I have collected data through semi-structured interviews and focus group discussions with the various stakeholder groups. Based on the UNDP's definition of the key actors involved in governance in a country-specific context, the following six Mozambican stakeholder groups were identified:

- Members of Parliament (MP) 
- Senior Civil Servants in Public Administration (SCS)

- Private Sector Actors (PS)

- Media (MED)

- Academia (ACA)

- Civil Society Organizations (CSO)

In all, 28 key informant interviews and 8 focus group interviews/discussions, involving 58 discussants, were conducted with Mozambican stakeholders.

One of the main issues which impacts upon qualitative research relates to the question of the relationship between theory and data. Depending on the role of a theory or conceptual framework underlying and guiding the process of data analysis, three approaches can be distinguished: 1) theory-based approach; 2) data based approach; and 3) theory-guided approach (Eskola 2001, 2007). Theory-based approach to data analysis, typically applied in the research tradition of the natural sciences, starts from an existing theory or conceptual framework which guides the classification, reduction and interpretation of the data. The ultimate purpose of the data analysis is to test the underlying theory or concepts in a new context (Tuomi and Sarajärvi, 2012, 97-98). The data-based approach puts emphasis on data, and the process of analysis starts from organizing, analyzing and interpreting the data. Rather than testing an existing theory, or hypothesis derived from existing theoretical concepts, a data-based approach aims at building a new theory. In its "purest" form the data-based method is referred to as grounded theory, which can be defined as "a qualitative research method that uses a systematic set of procedures to develop an inductively derived grounded theory about a phenomenon" (Strauss and Corbin 1990, p. 23; Glaser and Strauss, 1967). ${ }^{39}$ The theory-guided approach to data analysis can be characterized as an approach falling in the middle ground between the theory-based and data-based approaches (Eskola, 2001, 2007). The starting point for the analysis is data, but the process is guided by what is already known of the phenomena of interest, and the findings derived from the empirical data are linked with this existing knowledge. In the case of theory-guided approach, the existing theoretical concepts are thus used to support and enhance the analysis and interpretation of the data with the objective of opening new avenues for understanding the phenomena of interest (Tuomi and Sarajärvi, 2012, p. 96-97).

In view of the purpose of this research the theory-guided approach seemed best suited for seeking answers to the research questions. The data obtained through written

39. Data-based research in absolute terms is not considered to be possible as the formulation of research questions, the choice of research methods and the observations in themselves are oriented by the researcher's previous knowledge (Alasuutari, 1994, 1996; Eskola, 2001, 2007; Tuomi and Sarajärvi, 2012). As pointed out by Silverman "simplistic inductivism is at best a convenient myth which ignores the theory-saturated nature of any observation" (Silverman, 2010, p. 98). 
documentation and interviews are used as the starting point of the analysis, but the process of data analysis is informed by the existing knowledge of governance discourse and the concepts used for analyzing the donor governance assessments. Hence, the analysis of the selected governance assessment tools is guided by the conceptual framework developed by the OECD DAC Governance Network. The data generated through the field work is analyzed using the method of contents analysis building on the concepts formulated within the framework of the research programme on Worldwide Governance Indicators. In other words, the data analysis is supported by what is already known, and the findings are related to the existing concepts applied in the governance discourse.

The relationships between the research questions, primary sources of data and the methods of data analysis are summarized in Box 3.1:

\section{Box 3.1 | The Relationship between Research Questions, Data Sources and Methods}

\begin{tabular}{|l|l|l|}
\hline \multicolumn{1}{|c|}{ Research Questions } & \multicolumn{1}{|c|}{ Data Sources } & \multicolumn{1}{c|}{ Method of Analysis } \\
\hline $\begin{array}{l}\text { How do aid agencies operating in } \\
\text { Mozambique define and assess } \\
\text { governance? }\end{array}$ & $\begin{array}{l}\text { Documents, reports and internet based } \\
\text { material; } \\
\text { Semi-structured interviews with donor } \\
\text { representatives. }\end{array}$ & $\begin{array}{l}\text { Desk study of written documentation } \\
\text { guided by the OECD DAC analytical } \\
\text { framework; } \\
\text { Content analysis of interview data. }\end{array}$ \\
\hline $\begin{array}{l}\text { How consistent are the results of the } \\
\text { governance assessments which are } \\
\text { conducted by different aid agencies? }\end{array}$ & $\begin{array}{l}\text { Documents, reports and internet based } \\
\text { material. }\end{array}$ & $\begin{array}{l}\text { Qualitative and quantitative desk } \\
\text { analysis of the results of the selected } \\
\text { governance assessments. }\end{array}$ \\
\hline $\begin{array}{l}\text { Are the governance assessments per- } \\
\text { ceived by the Mozambican stakeholders } \\
\text { as succeeding in addressing governance } \\
\text { issues that are considered relevant } \\
\text { in the specific governance context of } \\
\text { Mozambique? }\end{array}$ & $\begin{array}{l}\text { Semi-structured interviews and focus } \\
\text { group discussions with local stake- } \\
\text { holder groups. }\end{array}$ & $\begin{array}{l}\text { Content analysis of data obtained } \\
\text { through key informant interviews and } \\
\text { focus group discussions. }\end{array}$ \\
\hline $\begin{array}{l}\text { Are the governance assessments } \\
\text { perceived as contributing to improved } \\
\text { governance in Mozambique? }\end{array}$ & $\begin{array}{l}\text { Semi-structured interviews and focus } \\
\text { group discussions with local stake- } \\
\text { holder groups as well as with donor } \\
\text { representatives. }\end{array}$ & $\begin{array}{l}\text { Content analysis of data obtained } \\
\text { through key informant interviews and } \\
\text { focus group discussions. }\end{array}$ \\
\hline
\end{tabular}

The sources of data and methods of data collection and analysis will be discussed in more detail in Chapters 7 and 8. 


\subsection{Positionality and Ethical Considerations}

As I have described in the Introduction, I have worked in Mozambique on various assignments in the 1980s, 1990s and in the new millennium. Over the years, I have developed a strong affiliation to the country and some understanding of the dynamics of the society, albeit still very limited. From the point of view of conducting the research, my relationship with Mozambique entails both merits and disadvantages. These have impacted not only upon the formulation of the research questions, but also upon the choices concerning the methods of data collection and data analysis. The questions arising from my position as a foreign researcher in Mozambique, and ethical issues related to my research, will be discussed below.

\subsubsection{Position as a Foreign Researcher in Mozambique}

First, one of the merits of my previous experience from Mozambique links to my relatively extensive social and professional network, developed over the years, in the country. This greatly facilitated the initial research on the country context and, in particular, the organization of the field work. Despite the major political, economic and social transformations that Mozambique has gone through over the past decades, it was not a terra incognito for me when I embarked upon this research project and started the field work in 2010. While the selection of the local stakeholder groups to be interviewed was guided by literature, the identification of the respondents was made easier because of my existing networks. I would, however, stress that the respondents were not selected on the basis of any personal relationships but, as will be described in the Section 7.1.2. on Data Collection, on the basis of their assumed specific knowledge of or role in the governance discourse in Mozambique.

Second, the fact that I had lived in Mozambique during the final years of the war in the 1980's, and again during the promising period of the transition to peace and multi-party democracy in the mid-1990's, made the data collection easier as it seemed to create a certain sense of trust and rapport with the respondents. As jokingly said by some of the respondents, I was almost an "old war veteran", antigo combatante, which is a truly respectful status granted for the real war veterans. Obviously I do not qualify for that. The sense of trust is reflected in the openness of the respondents, which certainly surprised me knowing that, only a few years ago, Mozambique was a country at war with a highly authoritarian regime. The permission given by all the Mozambican respondents to tape-record the interviews was unexpected, and seemed even more astonishing in the course of the interviews when many of the respondents expressed very critical views about the government and the political processes in the country. Third, although I don't speak any of the some 20 local languages spoken in 
Mozambique (http://www.portaldogoverno.gov.mz/Mozambique), I was able to conduct all the interviews with local stakeholders in Portuguese, the official language of the country, without interpretation, which smoothened the discussions with the respondents.

From the point of view my research on Mozambique, the long-standing relationship with the country has also its disadvantages. First of all, despite the fact that I have lived and worked in Mozambique for many years, I am an outsider with limited understanding of the cultural and informal structures and rules that underlie the governance context of the country. My perception of the society is narrow, shaped by the experience of a relatively luxurious life in the capital. Through social and professional relations I have gained some glimpses of the reality of life for the majority of Mozambicans but my perspective remains, for the most part, the perspective of a member of an expatriate elite.

The second disadvantage is closely related to the first: although I have worked in Mozambique in different positions and for different employers, including working in the state apparatus, I have always been associated with the international development cooperation and the donor community. Even in my role as a researcher I was probably still seen by most of the respondents as a member of the donor world. This setting constitutes an asymmetrical power relationship between the respondents and myself, and may have influenced the discussions with the respondents as most of them are very aware of Mozambique's dependence on external assistance. Being conscious of the setting, I have repeatedly clarified my role to the respondents as a researcher who has no financial or other resources to offer in exchange of interviews. In fact there were times when I felt uncomfortable because the respondents confided in me with information about governance issues which might have called for interventions that I could not engage in. In other words, the interviews may have created expectations among the respondents that I could not fulfil. However, it needs to be said that the question of rewarding the respondents did not come up at all.

Third, it may be argued that an objective analysis and interpretation of the data is undermined by my own perceptions and experiences of the subject matter, that is, of the governance situation in the country. While this may of course be true, I have made a conscious effort to mitigate this risk by giving a voice to the respondents and allowing the data to speak. As will be discussed in more detail in the section on Data Analysis, the analysis of the interviews relies on extensive use of quotes from the interviews, and the interpretation of the data is guided by the concepts derived from the literature on governance assessments. As in the case of all qualitative research, the organization and interpretation of the data has also been informed by my previous knowledge of the governance concerns, and of the processes of assessing governance in Mozambique. 
Finally, with regard to the interviews with the selected donor representatives, my position remained somewhat ambivalent. On the one hand, my role as a researcher was acknowledged by all respondents who, without exception, made themselves available for the interviews showing genuine interest in the topic of my research. Again to my surprise, many of the donor representatives engaged in very open and often critical discussions about their own governance assessments and their perceptions of governance in Mozambique. On the other hand, I was clearly associated by the donors not only with their community in general but with the Nordic countries which have a long-standing relationship with Mozambique. My experience from Mozambique, dating back to the period of the Cold War, was generally much longer than that by any of the respondents which seemed to enhance their views about the special Nordic relationship with the country. To some extent, my credibility as a researcher was strengthened because of my relatively long term interest in Mozambique. In other words, from the perspective of the donors I was seen as wearing two hats, one of a researcher and one of a donor.

\subsubsection{Ethical Considerations}

In qualitative research, the question of research ethics ${ }^{40}$ has been approached from different perspectives. For some scholars, research ethics concerns mainly the choices made by the researcher during the phase of the field work. Other scholars understand research ethics as comprising all phases of research starting from the choice of the research topic to the choices concerning the methods of data collection, data analysis and reporting the research findings. Silverman, for example, seems to approach the question of research ethics from a more narrow perspective with focus on the issues related to the phase of field work. Accordingly, he lists the following five principles as the core code of ethical research: 1) voluntary participation and the right to withdraw; 2) protection of research participants; 3 ) assessment of potential benefits and risks to the participants; 4) obtaining informed consent; and 5) the principle of "not doing harm" (Silverman 2010, pp. 153-154). Creswell broadens the code of ethical research by stressing that a researcher needs to remain sensitive to ethical issues throughout the research process, although there is "a common misconception that these issues only surface during data collection" (Creswell, 2013, p. 56). According to Creswell, ethical

40. According to Haaparanta and Niiniluoto, research ethics is shaped by 5 questions:

- what constitutes good research?

- is research, or the search for knowledge, acceptable in all circumstances?

- how are the research topics chosen?

- what kind of research results should be sought (for example, is research aimed at developing more efficient military weapons acceptable)?

- what kind of research methods are acceptable? (Source: Haaparanta L. and Niiniluoto I., 1991) 
issues in qualitative research need to be considered prior to conducting the research, in the beginning of the research, in data collection, in data analysis, in reporting the data and in publishing the research results (Creswell 2013, p. 57). This broader approach, also shared, for example, by Tuomi and Sarajärvi, 2012 (p. 128-129), has guided the consideration of ethical issues encountered in this research.

First a few words about the ethics concerning the choice of my research topic with focus on what donor governance assessments entail, and how they are perceived by local stakeholders in the case of Mozambique. As discussed in the Introduction, governance assessments conducted by donor agencies have significant implications for Mozambique because of its dependence on external assistance. The discussion on the evolving relationship between the donors and the Government of Mozambique (Chapters 4 and 5) illustrates that donors have had a major impact on Mozambique's development trajectory contributing to fundamental political, economic and social changes in the country since independence. In view of the fact that the results of governance assessments have actually been used by donors to guide their dialogue and cooperation policies with Mozambique, the topic of my research can be considered legitimate.

Second, the topic and the research design to answer my research questions, or "the logical plan from getting from here to there" (Yin, 2009, p. 26), has been approved by the University of Maastricht. While no formal research permission was required by the Mozambican authorities, a Letter of Introduction was provided by my supervisor to facilitate the organization of the field work.

Third, prior to the first field visit, some of the key informants including both local stakeholders and donors were contacted by e-mail to seek their preliminary willingness to be interviewed for the research. At this stage an abstract of the research project, outlining the purpose of the research and the research questions, was shared with prospective respondents for information. Although a prior contact with all key informants and focus group discussants was not feasible, all respondents were explained the overall purpose of the research, the specific objectives of the interviews and how the interview data will be used. As the topic of my research, with focus on governance, entails potentially sensitive issues from the local stakeholders' point of view, a special effort was made to stress, in the beginning of each interview and focus group discussion, that the purpose of my research is not to assess the quality of governance in Mozambique, but to seek an understanding of what governance means in the Mozambican context, and how the governance assessments conducted by the selected donor agencies are perceived by the Mozambican stakeholders. I have therefore refrained from drawing any conclusions or general statements about the quality of Mozambique's governance on the basis of the interview data, although the respondents seemed to share their 
experiences very freely during the course of the interviews. As an introduction to the interviews and focus group discussions, respondents were told, in general terms, about the desk analysis that I had done of the donor governance assessments prior to the field work. The donor representatives were further informed that the main purpose for interviewing them was to complement the desk analysis of their governance assessment tools, and thereby to enhance my understanding of these assessments.

Fourth, in line with the general principles of ethical research, I made it very clear to all respondents that the participation in the interview or focus group discussion is voluntary. In addition, a permission to tape-record the interviews was obtained prior to each interview. While all of the selected Mozambican respondents agreed to be tape-recorded, the permission to tape-record the interviews was denied in the case of two donor representatives. However, as pointed out by Silverman, a researcher seeking consent from people with different cultural background needs to be extremely sensitive to the social setting due to the potentially imbalanced power relations between the researcher and the respondents (Silverman, 2010, p. 163). As a foreign researcher representing - unintentionally - the donor world, I remained very sensitive to the problems arising from this social setting. In the case of my research, the risk of the respondents giving a consent without being truly willing to participate seemed limited as most of the selected respondents were themselves actively involved in governance discourse in the country, and to varying degrees familiar with collaboration with foreigners, including representatives of donor agencies. As to the donor representatives, the social setting did not entail similar sensitivities.

Fifth, concerning the confidentiality of the interviews, the respondents were assured that the data collected through the interviews will be used only for the purpose of the research, and that the anonymity of the respondents will be protected. The trust expressed by the respondents, reflected in their willingness to share their views and experiences of the governance problems in Mozambique, enhances the importance of adhering to the ethical principles guiding the processes of data collection, data analysis and reporting of the research findings. Accordingly, the identity of the individual respondents has not been disclosed even in the case of direct citations. In the case of the respondents representing donor agencies, the anonymity of the respondents has also been protected, although the agencies concerned may in some cases be identified. While the identification of the donor agencies may be considered problematic, it is to some extent unavoidable as the interviews concerned the agency-specific governance assessments. It is also worth noting that, in the case of the interviews with the donor representatives, the relationship between the researcher and the respondents seemed to be very equal. The fact that two of the donor representatives denied the permission to tape-record the interviews can be seen as an indication of the balanced social setting. Furthermore, in view of the openness of the debate of governance assessments 
among the donor agencies in Mozambique, the possibility of the interviews doing harm either to the individuals or to the agencies seems very limited, even if the agencies can be identified.

Sixth, the data analysis has been informed by the conceptual framework guiding the desk analysis of governance assessments and the concepts derived from existing research on assessing governance.

\subsection{Aspects of Validity and Reliability}

The questions of validity and reliability of research findings constitute fundamental aspects of the quality of any research project over and above the considerations related to the researcher's positionality and the research ethics discussed above. The following sections will address the questions of validity and reliability from the perspective of this research.

\subsubsection{Validity of the Research Findings}

The importance of validation in qualitative research, the definition of validity, the terms used to describe it, and the procedures for validation, have all been approached from several different perspectives (see, for example, Creswell 2013, Silverman 2010, Tuomi and Sarajärvi 2012). The lack of a common approach reflects, to some extent, the multitude of intellectual and disciplinary traditions underlying qualitative research. Despite the academic debates, the question of how to assess the "trustworthiness" (Guba and Lincoln, 1994) in qualitative research remains a crucial challenge. ${ }^{41}$

To address this challenge, several validation strategies have been formulated. According to Creswell, the validity of a research project can be considered in terms of an attempt to assess the "accuracy" of the research findings as they are described by the researcher. He suggests eight different validation strategies of which at least two should be applied in any given study:

- prolonged engagement in the field

41. The importance of validation within qualitative research has also been questioned because the concept has its origin in quantitative research and is seen as corresponding, primarily, to the needs of quantitative research. It has been argued that the concept of validation is based on assumptions that there is one concrete reality, and that there is objective knowledge of this reality. In other words, epistemological and ontological assumptions impact upon the considerations about validity in qualitative research (Tuomi and Sarajärvi, 2012, p. 136). 
- triangulation by using multiple and different data sources and methods

- peer review or peer debriefing to provide and external check of the research process

- negative case analysis

- clarifying researcher's position

- member checking based on soliciting participants' views of the credibility of findings

- rich, thick description

- external audits allowing an external actor to examine both the process and the end product

(Creswell, 2013, p. 250-253).

Following the approach suggested by Creswell, I will address the question of validity in terms of four validation strategies: prolonged engagement in the field, clarification of researcher's position, triangulation by using of multiple and different data sources, and presenting a research report with "thick description".

The questions related to my prolonged engagement, and position as a researcher in Mozambique, have been elaborated in the Introduction. I have gained a certain understanding of the dynamics of the country, including the role of donors, because of my long-standing experience in the country. While this has helped me to create a rapport with the respondents, it has also impacted upon my position and my perceptions as a researcher. For example, for some of the respondents I represented the "rich donor world" even though I was very explicit about my role as a researcher. At the same time my own experience from the period of the war, and the transition to a multi-party system made me pay special attention to the respondents' perceptions of governance trends during the post-war period, and to the prevailing governance structures in the country.

As to triangulation ${ }^{42}$ amongst different data sources, I have used several data sources and methods to answer the research question concerning how aid agencies define and assess governance in the specific context of Mozambique. An initial analysis of the selected governance assessment tools was undertaken on the basis of written documentation and internet-based data with the objective of identifying the conceptual and operational approaches underpinning these assessments. This initial analysis has been complemented by field data collected through semi-structured interviews with the representatives of the donor agencies. To address the research question regard-

42. According to Denzin, four different types of triangulation can be identified: 1) triangulation among different data sources; 2) triangulation among different researchers; 3) theoretical triangulation; and 4) methodological triangulation. Within the framework of this research, triangulation has entailed the use of different data sources and different methods for exploring the phenomenon under consideration (Denzin, 1978). 
ing the consistency of the results of the governance assessments, the results of the selected assessments have been analyzed and compared in light of the original assessment reports, as presented by the aid agencies, as well as in light of the summarized assessment reports. The results, based on the summarized reports, have been quantified using a single numeric scale so as to allow for more systematic comparison. The methods used for comparing the results have been described.

In order to seek answers to the research questions concerning the relevance and impact of the donor governance assessments, I have conducted a field study with the objective of collecting data on the perceptions by various groups of local stakeholders. Semi-structured interviews and focus group discussions involving a broad range of Mozambican men and women with diverse professional and geographic backgrounds have resulted in a rich data base for analyzing the views about donor governance assessments from the Mozambican perspective. The characteristics of the respondents have been discussed with some detail while protecting their anonymity. Although the data analysis has been supported by concepts derived from previous research on governance, I have also relied on extensive use of direct quotes from the interviews and focus group discussions. By using several quotes on each of the key messages emerging from the data, I have made an attempt to minimize the problem of anecdotalism (Silverman 2010, p. 270).

Finally, my research report builds on a detailed description of the political, economic and social developments in Mozambique which have shaped the contemporary governance context in the country. The evolution of the aid architecture in Mozambique is also discussed in some detail with the objective of creating a basis for understanding why governance has emerged as a central component in the aid policy dialogue.

\subsubsection{Reliability of the Research Findings}

The reliability of the research findings poses another challenge in qualitative research. The common methods suggested, for example, by Creswell (2013), Silverman (2010) and Tuomi and Sarajärvi (2012), include tape-recording and transcribing interview material as well as using external researchers for the analysis of data.

For the purpose of enhancing the reliability of the findings of this research, the interviews have been taped subject to the respondents' permission, and all taped interviews have been transcribed verbatim. As pointed out earlier, the permission to tape the interviews was granted by all interviewees apart from two donor agency respondents. In addition, the tape-recording of 3 of the interviews with local stakeholders (2 key informants, one focus group discussion) proved to be unsuccessful because of external 
factors such as outside noise. The initial transcription was done by two research assistants, one Mozambican and one Finnish assistant, both of whom are fluent in Portuguese and familiar with the country context. The transcriptions have been rechecked by the author.

The use of external analysts, which would have enhanced the objectivity of the analysis, was not considered feasible for various reasons. First, the use of external analysts in Mozambique might have undermined the confidentiality of the interviews, second, identifying analysts with sufficient language skills in Finland would have been problematic, and third, hiring external analysis would have increased the costs of the research considerably. From the point of view of reliability it is therefore important to repeat that, although the data analysis was informed by concepts derived from earlier research on governance, the interpretation of the data and the conclusions drawn upon the analysis reflect my personal perceptions and biases. I entered into the field with the preconceived notion that the donor governance assessments are imposed on Mozambique by the donors as an attempt to enhance the effectiveness of their aid interventions and to contribute to governance reforms. I further assumed that the governance assessments reflect a governance agenda that responds to the needs of the donors themselves and fails to capture those governance issues that are considered relevant at the country level. My biased views were shaped, primarily, by the existing research on governance assessments.

The reliability of the research findings could have been enhanced by increasing the number of respondents in the various local stakeholder groups. In particular, the number of respondents from medium to large scale enterprises remained very limited despite several efforts to broaden their participation. At the same time, the number of micro and small scale entrepreneurs is relatively large, in particular, bearing in mind that subsistence and family sector farmers are in fact private sector actors. It is also worth repeating that the respondents belonging to civil society organizations are, to some extent, overrepresented in the sample. However, in my view this is justified because of the crucial role of the CSOs play as interlocutors between the state, the donors and the communities in Mozambique. The use of a variety of data sources and methods of analysis enhances the reliability of the research, and allows for cautious generalization of the findings beyond the case of Mozambique. 



\section{Setting the Scene: Historical Context of Governance in Mozambique}

The purpose of this chapter is to give an overview of the major changes and trends in Mozambique's political, economic and institutional development since the country's independence in 1975. In this, the objective is to lay down the context within which the current governance discourse takes place. The discussion focuses on the politico-economic transformation process which began in the late 1980s and paved the way for ending the destabilization cum civil war in the country. Since the signing of the General Peace Agreement in 1992 Mozambique has become one of the fastest growing, politically most stable economies in Sub-Saharan Africa. While Mozambique still remains one of the poorest countries in the world with high levels of absolute poverty, the progress it has made can be considered remarkable in light of the country's history.

Mozambique's post-independence history can be divided into periods in various ways depending on the key questions framing the research. For the purpose of this research focusing on governance, the following broad periodization is used to highlight the most fundamental changes in Mozambique's political and economic orientations that have shaped the country's contemporary governance context:

1. Achieving independence in the shadow of the war

2. Political, economic and social context at independence in 1975

3. Building socialism under single party rule, 1975-1985

4. Transition towards market economy and multiparty democracy, 1985-1992

5. Political and economic transformation since 1992

One of the key factors underpinning, and to a large extent driving, Mozambique's political and economic transformations relates to the destabilization cum civil war that Mozambique was drawn into soon after independence, and which came to an end only in 1992. In view of its fundamental impact on Mozambique's development trajectory and the emerging governance context, the key factors underlying the war and its impact on Mozambique's development will be discussed in the first section of the chapter.

The discussion draws on the existing research which has been carried out on Mozambique's post-independence development. ${ }^{43}$

43. For primary research and more comprehensive overviews, see for example: Abrahamsson H. and Nilsson A. (1994): Moçambique em Transição: Um Estudo da Historia de Desenvolvimento durante o Periodo 1974-1992; Hall M. and Young T. (1997): Confronting the Leviathan: Mozambique Since Independence; Hanlon J. (1984): The Revolution under Fire: Mozambique; Hanlon J. (1991): Who Calls the Shots?; Hanlon J. (2008) Há mais bicicletas - mas há mais desenvolvimento?; Isaacman 


\section{Map 1 | Map of the Republic of Mozambique}

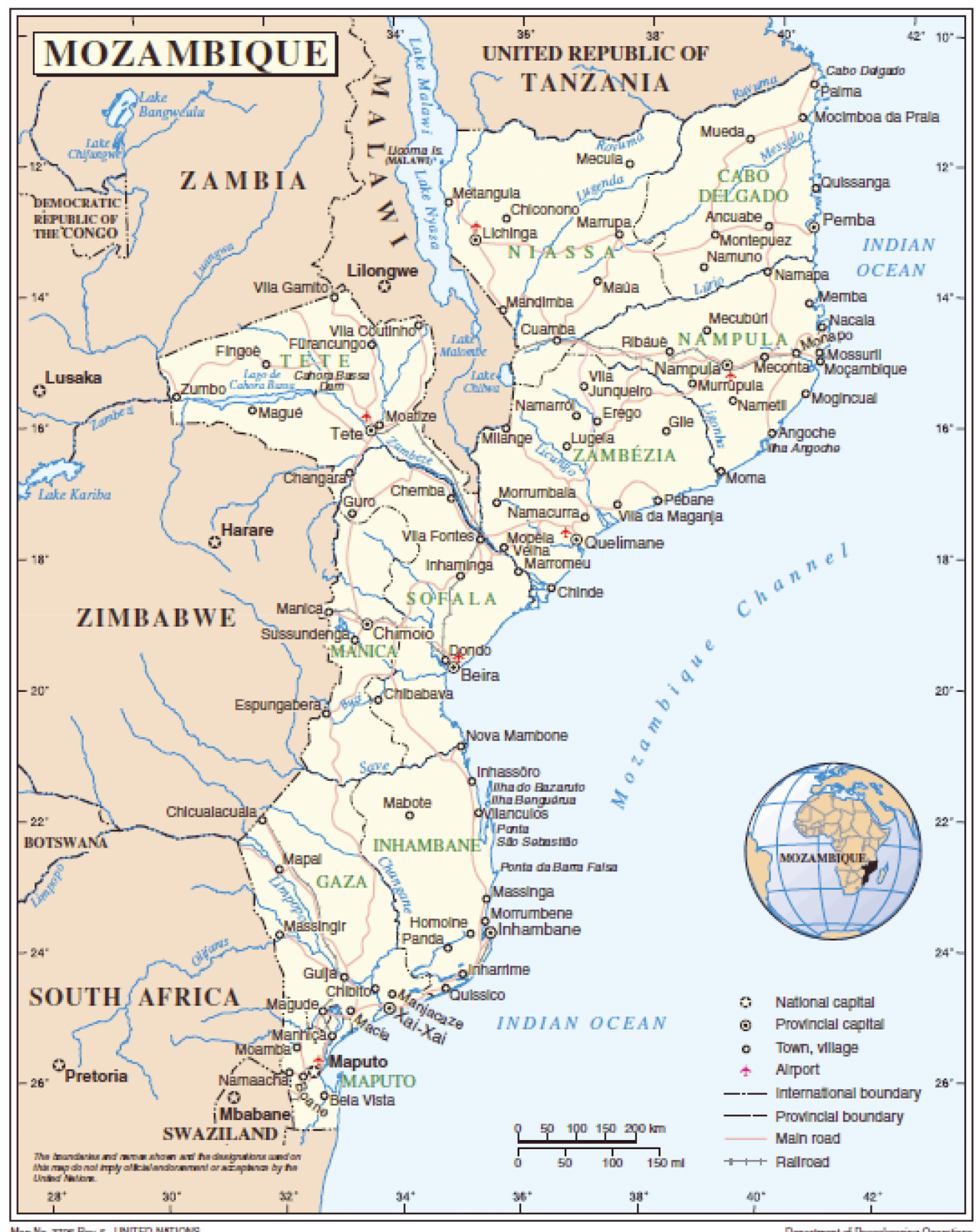

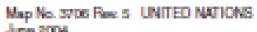

Source: United Nations, Retrieved March 2, 2011 from the World Wide Web: www.un.org/Depts/Cartographic/map/profile/mozambiq.pdf.

Land Area: $799.380 \mathrm{~km}^{2}$, Population 20.4 million (2007)

Source: http://www.portaldogoverno.gov.mz/Mozambique 


\subsection{Achieving Independence in the Shadow of War}

The war in Mozambique, which is often referred to as a destabilization cum civil war, lasted nearly two decades and had a fundamental impact on Mozambique's post-independence political and economic development trajectory setting the parameters for the government's policy-making both internally and internationally. Despite the successful peace process, the shadow of the war remains very vivid in the minds of the Mozambicans and continues to impact upon, among others, the governance discourse in the country.

At independence, Mozambique was not engaged in any open conflict with its neighbours. However, two years following the end of the war for national liberation Mozambique was drawn into another war which was triggered by the on-going fight for independence in the neighbouring Rhodesia. This war had its roots in the early 1970s when Zimbabwean liberation movements had been allowed to carry out guerrilla operations in eastern Rhodesia from Frelimo-controlled areas of Mozambique. Upon Mozambique's independence, they were allowed to establish bases within Mozambican territory, and more than 150000 Zimbabweans were resettled in refugee camps inside the country. In retaliation, the Mozambican National Resistance (MNR) was created in 1976 by the Rhodesian Central Intelligence Organization (CIO) to fight Zimbabwean rebels operating from Mozambique, and to undermine the Frelimo Government (Isaacman and Isaacman, 1983, p. 173). The MNR was later to be known by its Portuguese-based acronym Renamo (Resistencia Nacional de Moçambicana) which will be used in this study. ${ }^{44}$

Initially Renamo incorporated various groups from the local militias formed by the Portuguese secret police (PIDE), Portuguese settlers and soldiers from the Portuguese army, as well as deserters from the Frelimo army (Isaacman and Isaacman, 1983, p. 176; Minter, 1994, p. 33 and p. 124). From the beginning of the war Renamo also had some internal support among those population groups that were discontented with Frelimo's political and economic orientations, which were formulated during the liberation struggle and the immediate post-independence period. Frelimo's negation of traditional authorities, including local institutions and practices of governance, together with its policy of resettling peasants in communal villages, caused a negative

B. and Isaacman A. (1983): Mozambique from Colonialism to Revolution; Manning C. L. (2002): The Politics of Peace in Mozambique: Post-Conflict Democratization 1992-2000; Minter W (1994): Apartheid's Contras: An Inquiry into the Roots of War in Angolan and Mozambique; Newitt M (1995): History of Mozambique.

44. The English-based acronym, MNR, was replaced by the Portuguese-based acronym Renamo (Resistencia Nacional Moçambicana) in the early 1980s with the objective of stressing the Mozambican identity of the orgnization (Minter, 1994, p. 42). 
backlash (Geffray, 1991; Abrahamsson and Nilsson, 1994; Manning, 2002). Furthermore, as argued by Manning, the fact that Frelimo was perceived as a southern movement dominated by the people from the Gaza province caused distrust, particularly in the central and central northern regions of the country. The distrust coincided with the early ideological splits within Frelimo about the political and economic orientation for an independent Mozambique. The drastic economic decline from the early 1980s onwards, particularly in the rural areas, created increasing discontent towards Frelimo and made the "opportunity costs of joining Renamo lower" (Manning, 2002, p. 56).

With the independence of Zimbabwe in 1980, the patronage of Renamo passed to South Africa which gave Renamo access to much greater resources and allowed the war to be extended to the whole of the national territory. South Africa's primary purpose in supporting Renamo was to destabilize Mozambique and thereby to demonstrate to its own African population that independence under African leadership was not viable. As argued by Minter, "The operative goal of Renamo's patrons was never, as far as can be determined, to put it in power in Mozambique. ...Support for Renamo was subordinated to the "total strategy of defending the white regime's security" (Minter, 1994, p. 134).

The war in Mozambique can be fully understood only against the background of the geo-political battle of the Cold War. During the liberation struggle, and increasingly after independence, Frelimo received political, economic and military support mainly from the former Soviet Union and the socialist countries of Eastern Europe, whereas Renamo gained support in the Western bloc led by the USA. Already in 1977 the US Congress had imposed a ban on bilateral aid to Mozambique ${ }^{45}$, motivated primarily by the USA's policy of supporting the minority-rule South Africa which was seen as the main US ally in southern Africa. During President Reagan's administration the pro-Renamo lobby in the US gained strength and the US support to Renamo was intensified. The main initial result of the US policy was to encourage South Africa to escalate its destabilization operations in Mozambique (Minter, 1994, p. 157).

Following a period of intensified warfare during 1981-83, the Nkomati Accord on "non-aggression and good neighbourliness" between South Africa and Mozambique was signed in 1984 with the objective of ending the hostilities. In Mozambique, the Nkomati Accord was celebrated by the then President Samora Machel as "another victory in our socialist policy of peace" (AIM Bulletin, 1984, No 94, p. 1). For South Africa the signing of the agreement was part of the implementation of its "total strategy" marking a shift from destabilization to détente (Davies, O’Meara and Dlamini, 1984). In spite of

45. The US ban on non-emergency aid to was lifted only in 1984 when Mozambique joined the IMF and the World Bank (Buur and Baloi, 2009, p. 22). 
the non-aggression pact Renamo operations in Mozambique continued to escalate with increasing military, logistical and financial support from South Africa, as later admitted by South Africa’s political and military leaders (de Klerk, 1998, p. 117). Although active in brokering the Nkomati Accord as part of the policy of "constructive engagement", the US did not put any pressure on South Africa to stop supporting Renamo and to thereby stop violating the Accord. The attempts by the Frelimo government to enhance relations with the US government in order to obtain political support to end the war, and to gain economic support, remained largely unsuccessful (Minter, 1994, p. 166).

In 1988, without any sign of either Frelimo or Renamo being able to achieve military victory, first talks to end the war were initiated. Changes in the international geo-political setting in the late 1980s contributed to creating conditions for successful peace negotiations. The fall of the Berlin Wall in 1989, and the subsequent ending of the Cold War, undermined the primary rationale for proxy wars in developing countries.

Formal peace talks between Frelimo and Renamo began in 1990, and after two years of successive rounds of negotiations, the General Peace Agreement (GPA) was signed in Rome in October 1992. The implementation of the GPA was to be overseen and supported by a UN peacekeeping and observation mission (United Nations Observation Mission in Mozambique, ONUMOZ), with significant participation by donors to Mozambique. The donor community provided financial support to facilitate the demobilization and reintegration of demobilized soldiers back into civilian life. In addition, significant funding was given to Renamo to support its transformation into a political party, as well as to other smaller opposition parties, to support their campaigning costs. According to the initial timetable set for the implementation of the GPA, the various tasks were to be completed within one year, with the peace process culminating in first multi-party elections in October 1993. This deadline was later postponed to October 1994 (Manning, 2002, p. 28-30).

The estimates of the impact of the war on Mozambique vary. By the end of the 1988, more than one third of the rural health clinics had been destroyed or forced to close, and by the end of 1989 , more than half of the primary schools had been forced to close. The rural transport and commercial network suffered significant losses. More than $50 \%$ of the population was dependent on food aid (Hanlon, 1991, p. 40-41; Abrahamsson and Nilsson, 1994, p. 176-178; Minter, 1994, p. 3 and p. 192-193). Some 1 million people, half of them children under the age of five years, died from war and war-related causes such as famine and disease (UNICEF, 1987, p. 21). Approximately 1 million Mozambicans lived as refugees outside the country, mainly in the neighbouring Malawi, Zimbabwe, Zambia and South Africa, while the number of internally displaced people was estimated to reach 2 million (Hanlon, 1994, p. 38). All of this from a total population of approximately 16 million in 1992. 
While both sides of the conflict, the Mozambican Armed Forces and Renamo, were accused of violence against civilian population, Renamo became the symbol for widespread terror among civilians. A formal investigation commissioned by the US State Department of the atrocities during the war, based on interviews with refugees and ex-Renamo soldiers, held the group responsible for $95 \%$ of the abuses of civilians in the war. This report, published in 1988, somewhat contributed to a change in the US government position vis-à-vis Renamo (Minter, 1994, p. 206, for detailed accounts, see Gersony, 1988).

The war overshadowed Mozambique's post-independence development for 15 years, from 1977 until 1992, and set the parameters for its policy choices internally, regionally and internationally. Although the war was sparked off by regional actors, which were seen as Western allies in the Cold War geo-political setting, notably by Rhodesia and South Africa, it was fuelled by the internal social and political splits in Mozambican society. Renamo's emergence and evolution over time was rooted in the ethnic, regional and ideological splits within Frelimo, and by the increasing confrontation between Frelimo and the wider Mozambican society in the immediate post-independence period (Minter, 1994; Hall and Young, 1997). The failure of Frelimo's state-centred agricultural policies certainly undermined its credibility, and over the years, the war seemed to gain a momentum of its own exploiting the prevailing social crisis and economic collapse in rural area (Clarence-Smith, 1989; Geffray, 1991; Hanlon 1991; Manning, 2002).

\subsection{The Political, Economic and Social Context at Independence, 1975}

\subsubsection{Political Context at Independence}

Mozambique became independent in the aftermath of the 1974 coup détat in Portugal, following a protracted colonial war with Portugal. The war that had been launched a decade earlier by the Mozambican Liberation Front (Frente de Libertação de Moçambique, Frelimo,) ended in September 1974 with the signing of the Lusaka Peace Accords between Frelimo and the new Portuguese Government. A joint transitional government, with representatives from Frelimo and from the Portuguese Government, was formed to prepare for independence. In June 1975, Mozambique was proclaimed independent by President Samora Machel, the then President of Frelimo (Newitt 1995; Hall and Young 1997; Manning 2002). 
According to the Constitution, the People's Republic of Mozambique was to be steered according to the political orientation defined by Frelimo which was "the leading force of the state and of the society" (República Popular de Moçambique, 1975; Constituição da República Popular de Moçambique, 1975, original in Portuguese, translated by the author). Frelimo was defined as the legitimate representative of the Mozambican people, with the President of Frelimo being the President of the Republic and the Head of State. Mozambique was thus founded as a one-party state governed by Frelimo.

The Constitution contained key elements of Frelimo's political orientation, which had been formulated in the midst of intense internal conflicts during the years of the liberation war. Frelimo itself was formed in 1962 in Tanzania, under the leadership of Eduardo Mondlane, by merging three nationalist independence movements operating in exile. ${ }^{46}$ These movements, each with somewhat different background and different regional base, had diverse views about the strategy towards independence, and about the future political and economic structures of an independent Mozambique (Hall and Young, 1997, p. 12-13; Abrahamsson and Nilsson, 1994, p. 32-33, p. 35).

Despite the formal unification of the three movements, there were sharp ideological differences within Frelimo which culminated in the question of its role as an African nationalist movement aiming at capturing the colonial state, or as a revolutionary movement aiming at transforming fundamentally the political, social and economic relations of the society. The conflict between the two positions, the "reactionary line" and the "revolutionary line", as referred to in Frelimo documents of the time, carried within it several other contested issues related to traditional governance structures, ethnicity, religion, etc. over which there was no consensus. The Second Party Congress, held in 1968, confirmed the "revolutionary" political orientation of Frelimo and put an end to the debate over the developmental model for independent Mozambique. However, the ideological conflict, together with many of the other contested issues, remained unresolved and were to re-emerge soon when the post-independence war broke out (Abrahamsson and Nilsson, 1994, p. 35).

Frelimo's leadership of the national liberation war had positioned it as the successor of the Portuguese colonial state, and the Lusaka Accords granted unconditional power to

46. The National Democratic Union of Mozambique (União Democrática Nacional de Moçambique (UDENAMO), National African Union for Mozambican Independence (União Nacional de Moçambique Independente (UNAMI) and Makonde African National Union (MANU, later Mozambique African National Union). The supporters of UDENAMO, based in then Rhodesia, were mainly Mozambicans from the southern part of the country, UNAMI had been established by Mozambican migrants in the neighbouring Tanzania, Kenya, Rhodesia and Malawi, whereas MANU's initial support came from Makonde-speaking Mozambican migrants working in Kenya and Tanzania. 
Frelimo in the transitional government. The assumption of the power of the state by Frelimo was, however, contested by a number of groups. These included Portuguese settler organizations as well as groups led by Mozambicans who had been sidelined or expelled from the Frelimo leadership during the liberation war (Manning, 2002, p. $47-48)^{47}$. Frelimo's direct influence within the country was largely limited to the "liberated zones" in the northern provinces of Cabo Delgado and Niassa, covering only about one third of the total land area with less than $10 \%$ of the total population, which was estimated at 10,4 million at independence (Francisco 2011, p. 239). Most other parts of the country had not been directly affected by the war (Abrahamsson and Nilsson, 1994, p. 30). During the crucial transition and immediate post-independence period, Frelimo was thus confronted with a relatively weak legitimacy and a lack of political organization.

To entrench Frelimo's political authority over the entire national territory, a network of so called "Grupos Dinamizadores" - literally translated as "dynamising groups" - was formed. ${ }^{48}$ The dynamising groups played a central role also in running state administration and economy after the mass exodus of the Portuguese. In rural communities, the dynamising groups took on several functions which during the colonial administration had been carried out by traditional African authorities, the so called "regulos". Although some of the traditional chiefs enjoyed legitimacy among the population, many had been appointed to their positions of local authority by the colonial administration, and therefore, had become an integral part of the colonial administration (Meneses and de Sousa Santos, 2009). According to de Brito, the dynamising groups established themselves both as instruments for political and social control by Frelimo, and as a space for political participation by the population (de Brito, 2010). ${ }^{49}$

The replacement of the traditional governance structures with the new administrative system was considered necessary for the construction of the new independent Mozambique. However, the measures taken by Frelimo in creating the new institutions

47. Attempts by a small group of Portuguese settlers, with some support from non-Frelimo Mozambicans, to seize power during the transition period failed (Manning 2002, p. 48).

48. The "dynamising groups" were popularly elected groups of 8-10 people comprising Frelimo activists and supporters at the level of neighbourhoods, work places etc.

49. Along with the dynamising groups, the Mozambique Women's Organization (Organização de Mulheres Moçambicanas, OMM), established already during the liberation war, played an important role in building Frelimo's political base after independence. Later on, several other "mass democratic organizations" were established to serve as a link between the party and the different population groups (Isaacman and Isaacman, 1983, p. 127). Of major significance were the Mozambican Youth Organization (Organização de Juventude de Moçambique, OJM), Mozambican Workers Organization, (Organização de Trabalhadores de Moçambique, OTM), National Teachers' Organization (Organização Nacional dos Professores, ONP), Hall and Young, 1997). Many of these organizations continue to play a central role in the political governance of the country. 
were considered authoritarian, which contributed to building the internal support to anti-Frelimo actions in years to come (Geffray, 1991; Meneses and Sousa Santos, 2009; Brito, 2010).

\subsubsection{Economic Context at Independence}

At independence the Mozambican economy was characterized by four distinct features: first, its economic integration with the Southern African region, notably with South Africa and Rhodesia; secondly, the production of primary commodities and related processing industries destined for exports; third, the production of consumer goods and intermediary products for the settler economy, and forth, the existence of the large peasant population engaged in cash crop production and subsistence farming supplemented by seasonal agricultural work on plantations and settler farms (Wuyts 1989, p. 24-26). Approximately $90 \%$ of the total population lived in rural areas (Isaacman and Isaacman 1983, p. 148).

Apart from subsistence farming, the economy was in the hands of the Portuguese settlers, and of Portuguese, South-African and British investors. The commercial network in rural areas, which was of key importance not only to the Portuguese settlers but also to the peasant cash crop farming, was controlled by Portuguese and Asian-origin traders (Abrahamsson \& Nilsson 1994, p. 46). Alarmed by the liberation war, the majority of the Portuguese settlers left the country. The Portuguese community is estimated to have shrank from 250000 to 20000 between the years 1974 and 1977 (Wield 1983, p. 85; Isaacman \& Isaacman 1983, p. 145). The mass exodus, together with the systematic damage of the fixed assets by the departing settlers, affected every sector of the economy, creating an acute shortage of administrative and technical skills (Wield, 1983; Isaacman and Isaacman, 1983). In the early 1970s, an estimated 30\% of Mozambican children of primary school age attended school, and only approximately $1 \%$ of the students received post-primary education (Ferreira 1974, p.87). At independence there were some 40 Mozambican university graduates in the whole country (Hall and Young, 1997, p. 51).

Faced with such a crisis, the transitional government, and subsequently the post-independence Frelimo government, had to adopt immediate policy measures to gain control of the economy. The State Intervention Act of 1975 allowed the takeover of abandoned companies to keep them running and to prevent the sabotage. ${ }^{50}$ Land ownership was nationalized, and plantations and farms abandoned by settlers were con-

50. The state intervention in the economy was initially not driven by an explicit policy of nationalization but rather dictated by the chaotic circumstances of this period. 
solidated into state farms and cooperatives, and to a lesser degree, distributed to local residents, i.e. peasants. Despite opposition, peasants were urged to move to communal villages. In response to the breakdown of the rural commercial network, on which the Mozambican peasant cash crop production had strongly depended, state shops and consumer cooperatives were established (Abrahamsson and Nilsson, 1994; Hall and Young, 1997).

Upon independence, Mozambique's position within the regional economy changed dramatically with South Africa diverting its cargo away from Mozambican ports and cutting back the number of migrant workers from Mozambique. For example, the number of Mozambicans recruited for the mines in South Africa fell from 115000 in 1975 to 45000 in 1976 (Wield, 1983, p. 94). Mozambique's decision in 1976 to take part in the UN sanctions against Rhodesia by closing the border between the two countries resulted in significant losses of transport and tourism revenue as well as employment opportunities for migrant labour (Hanlon 1991, p. 11).

The economic and social breakdown of the colonial economy caused a significant decline in economic activity. According to estimates based on relatively limited data, the Gross Material Product declined by 27\% between 1973 and 1975..$^{51}$ The marketed output of agriculture, notably cash crops production, fell by an estimated $40 \%$, and the output of subsistence farming increased by an estimated 12\% (Wyuts, 1983, p. 71-73).

\subsubsection{Social Sectors at Independence}

In social sectors the Frelimo government opted for immediate nationalization and achieved some major successes. ${ }^{52}$ At independence, the literacy rate was less than $15 \%$ among the total population. Within five years, the illiteracy rate had dropped to approximately 75\%. Between 1974 and 1981, the number of children attending primary school nearly doubled from 700000 to close to 1.4 million, and secondary school enrolments went up from 20000 to 135 000. A vaccination campaign, completed in 1979, reached more than $90 \%$ of the total population. By 1978 more than 160 000 indigenous Mozambicans had been relocated into urban residences previously reserved for Europeans (Abrahamsson and Nilsson, 1994; p. 44, Isaacman and Isaacman, 1983, p. 139; Hanlon, 1991, p. 8-9; Hall and Young 1997, p.56-58).

51. Gross Material Product refers to total of gross product of agriculture, industry (mining, manufacturing, construction and energy), productive services (transport, storage and trade). The lack of accuracy of the statistical data is explicitly pointed out by Wuyts (1983, p. 71-72).

52. Within a year of independence education, health, housing and legal services as well as funeral services were nationalized with the explicit aim to break away from the colonial policy of limiting access to these services along racial lines (Abrahamsson and Nilsson, 1994, p. 44). 
Albeit successful, the new social programmes generated problems of their own. Due to lack of resources to meet the drastic increase in the number of school children, the quality of education suffered. The health care system was seriously understaffed often operating without even minimal medical supplies, and the nationalized housing system provided opportunities for wide-spread corruption (Isaacman and Isaacman, 1983, p. 138-139).

\subsection{Building Socialism under Single-Party Rule, 1975-1985}

\subsubsection{Building the Party-State Organization}

The strategy for socialist development, embedded in the 1975 Constitution, was explicitly laid out by the Third Congress of Frelimo in 1977. The alliance of workers and peasants was declared to be the political base of people's democratic power and Frelimo was defined as a Marxist-Leninist vanguard party (Isaacman and Isaacman, 1983, p. 121; Hanlon, 1991, p. 13; Hall and Young, 1997, p. 70-71).

The implementation of political and economic orientations of the Third Congress started immediately. On the political front, a national campaign was initiated by Frelimo to create party cells throughout the country. A new governing structure for the state was established with the creation of local, district, provincial and municipal assemblies with the national-level People's Assembly (Assembleia Popular) (the national parliament) as the highest legislative body.

The first elections were carried out in 1977. The representatives for the local and municipal assemblies were elected by direct popular vote, whereas the district and provincial assemblies were indirectly elected from the ranks of the lower level legislatures. The deputies of the People's Assembly were nominated by the Frelimo Central Committee amongst those serving at the provincial assemblies.

Despite deficiencies in the electoral processes, the first elections succeeded in engaging almost the entire adult population in nascent democratic processes aimed at enhancing "people's democratic power", as called for by the 1975 Constitution. However, as has been argued in several studies (see e.g. Isaacman and Isaacman, 1983; Hanlon 1991; Hall and Young 1997), the different legislatures failed to provide a space for political participation and their role as a channel for exercising people's democratic power remained debatable. The governing structure was highly centralized under the 
President who appointed directors to the different levels of legislature. The Frelimo party and the government were effectively merged with the provincial governors and district administrators serving also as party secretaries. As argued by Hanlon, despite Frelimo's rhetoric concerning the need to "learn from the people", the local party cells and local assemblies, including the mass organizations, became bodies to transmit instructions from above (Hanlon, 1991, p. 13-15). The low level of education of deputies and directors at all levels hampered the functioning of the new state apparatus. Even many of the members of the parliament were illiterate (Isaacman and Isaacman, 1983, p. 132).

\subsubsection{Transforming the Economy under Single-Party Rule}

The formation of the National Planning Commission in 1977-78 provided the institutional structure for the building of a centrally planned economy. The key sectors of the economy, i.e., agriculture, industry, commerce, transport and finance, were brought under the direct control of the state. In many cases this process involved only de jure nationalization of the commercial enterprises and plantations which de facto had been subjected to state intervention during the immediate post-independence period (Wuyts, 1989, p. 57; Hall and Young, 1997, p. 98) ${ }^{53}$. In line with the policy measures, the state sector grew rapidly during the period 1977-81. Within agriculture, the state sector came to account for more than $50 \%$ of the total marketed output while the share of the peasant producers amounted to some $40 \%$. The rest was produced by private farmers. The state sector also became dominant in other sectors of the economy accounting for $65 \%$ of the total output in industry, $85 \%$ in transportation and communications, $90 \%$ in construction and 40\% in commerce (Wuyts, 1989, p. 59 and 61; Hall and Young, 1997, p. 95).

The first ten-year National Plan covering the period 1980-90 targeted an annual rate of economic growth of close to $15 \%$, to be achieved through growth in industrial production which was to be financed by agricultural exports (Arndt, Jones and Tarp, 2006, p. 9). Mechanization, with emphasis on the expansion of cultivation on state farms, was seen as the key to increasing agricultural production and productivity. Accordingly, investments in the agricultural sector were targeted to the state farms to the extent that, in the period 1978-82, more than $90 \%$ of agricultural investment went to the state sector while cooperatives received only $2 \%$ and the small-scale family agriculture received virtually none (Wuyts 1989, p. 60).

53. The formal structure of the state enterprises was initially laid down by a decree in 1977 and, subsequently formalized by legislation in 1981 . 
The establishment of communal villages and cooperatives, based on collective production, was seen as the cornerstone in the transformation of the social organization of the peasantry. However, the policy of resettling peasants in communal villages failed to take into account the existing forms of political and social organization and patterns of land tenure in rural communities (Hall and Young, 1997, p. 85). Furthermore, as discussed by Wuyts, communal villages and cooperatives were seen as being of secondary importance compared to the state farms, and were therefore, largely deprived of state support (Wuyts 1989, p. 56). The imposition of communal villages, and the lack of state support to develop them, meant that the policy failed. By 1983 only some 1.4 million people were estimated to be living in the communal villages, instead of the targeted 6 million. At the same time of the planned 15000 cooperatives only 350 had started operating (Abrahamsson and Nilsson, 1994, p. 215).

The trends of Mozambique's economic development during the period 1975-82 are summarized in Table 4.1 below. The data compiled by the National Planning Commission on Mozambique's Global Social Product ${ }^{54}$ illustrates that, despite the collapse of the service and construction sectors at independence, the aggregate value of production increased during the first years after independence. However, towards the end of the period, the growth trend turned negative, in particular due to significant falls in agricultural and industrial production.

Table 4.1 | Global Social Product 1975-1982

\begin{tabular}{|l|c|c|c|}
\hline \multicolumn{1}{|c|}{ Sector } & $\begin{array}{c}1975-1977 \\
\text { (\% change) }\end{array}$ & $\begin{array}{c}1977-1981 \\
\text { (\% change) }\end{array}$ & $\begin{array}{c}\text { 1981-1982 } \\
\text { (\% change) }\end{array}$ \\
\hline Agriculture & 17.2 & 8.8 & -2.4 \\
\hline Industry & 5.3 & 13.8 & -13.9 \\
\hline Transport & -14.4 & 15.4 & -6.6 \\
\hline Commerce, construction, other unspecified & -7.4 & 11.4 & 0 \\
\hline Total GSP & 5.5 & 11.6 & -6.9 \\
\hline
\end{tabular}

Source: Adapted from Wuyts, 1989, p. 73; see also Hall and Young, 1997, p. 107.

The downward trend in the economy was caused by several factors. As argued by Arndt, Jensen and Tarp, "Mozambique lacked the necessary human and capital

54. Global Social Product (GSP) is the aggregate gross value of production used in centrally planned economies where the allocation of resources is organized by material balances. As described by Wuyts " in aggregating GSP, the value of the productive consumption of raw material and auxiliary materials as well as intermediary products is not netted out" (Wuyts 1989, p. 74). 
resources to achieve growth rates of such magnitudes (as envisaged in the first tenyear National Plan), and since investments did not yield expected economic returns, a critical foreign debt burden started accumulating" (Arndt, Jensen and Tarp, 2000, p. 301). In 1983, the government was faced with a balance of payment deficit for the first time since independence, largely due to increasing subsidies paid to the state owned enterprises and consumers (Abrahamsson and Nilsson, 1994, p. 46-47). The declining trend of the economy was exacerbated by the escalation of South Africa's destabilization policy, combined with a series of natural disasters affecting agricultural production and transport infrastructure (Wuyts, 1989, p. 59-61; Hall and Young, 1997, p. 95; Arndt, Jensen and Tarp, 2000, p. 302; Arndt, Jones and Tarp 2006, p. 11).

The Fourth Congress of Frelimo, held in 1983, called for major reorientation in the government's development strategy, and agreed upon radical reforms to halt the expansion of the state sector and to enhance the role of the private sector in economy (Abrahamsson and Nilsson 1994, p. 47-48; Wuyts 1989, p. 67-68). The new policies were never implemented as planned, largely due to the escalation of the war from the early 1980 s onwards. By the mid 1980s, Mozambique was at the edge of economic collapse. Officially marketed agricultural output fell by $50 \%$ during the period 1981-86, and local agricultural production succeeded in meeting only $10 \%$ of the demand for food. Industries operated at a level of 20-30\% of their capacity, and by 1986, total industrial output had declined to less than half of the level of 1981. The exchange rate became grossly overvalued and prices in the parallel markets were 20 to 40 times higher than the official prices. Over the period 1981-1986, the GDP fell 5\% per year in real terms (Abrahamsson and Nilsson, 1994, p. 48; Arndt, Jensen and Tarp 2000, p. 302).

In 1984 Mozambique joined the World Bank and the International Monetary Fund (IMF) with the objective of halting the economic crisis and gaining access to financial resources from Western donors - after having been turned down for membership in the CMEA (Council of Mutual Economic Assistance) in 1981. ${ }^{55}$ Three years later, in 1987, the government agreed upon an Economic Recovery Programme (Programa de Reabilitação Economica, PRE) backed by the World Bank and the IMF. The economic recovery programme marked a fundamental change in Frelimo's economic policy setting in motion not only the transition from a centrally planned economy towards market economy but also a transition from a single-party rule towards multi-party-democracy.

55. Mozambique's application to join the CMEA (Council of Mutual Economic Assistance) was vetoed by the then USSR in 1981 (Hanlon, 1991, p. 28). 


\subsection{Transition to a Market-Oriented Economy and Multiparty Democracy, 1985-1992}

The Economic Rehabilitation Programme, known in Mozambique by its Portuguese-based acronym PRE, entailed both stabilization and adjustment measures. The stabilization measures included devaluation of the national currency, drastic cuts in public expenditures and attempts to increase government revenue whereas the adjustment measures aimed at increasing the productivity and efficiency of the economy through the elimination of price controls, privatization and trade liberalization, as well as the reduction of state subsidies to social sectors (Abrahamsson and Nilsson, 1994; Arndt, Jensen and Tarp, 2000; Arndt, Jones and Tarp, 2006; Eronen, Palmujoki and Virtanen, 2007).

Successive devaluation of the currency took place from 1987 onwards bringing the metical from approximately USD $1=40$ meticais at the beginning of 1987 to USD 1 = 11000 by 1997 (Ministry for Foreign Affairs of Finland, 2002, p. 22; Arndt, Jensen and Tarp 2000, p. 307). Spending on social sectors and public administration was drastically reduced: for example, the combined share of education and health in the state budget fell from $24 \%$ in 1986 to $3.2 \%$ in 1991. In public administration the spending cuts were implemented through strict limits on wages and salaries of civil servants (Arndt, Jensen and Tarp, 2000, p. 307; Eronen, Palmujoki and Virtanen, 2007, p. 109).

During the early years of PRE, the impact of fiscal adjustment measures, such as the reform of the custom administration and introduction of a value added tax, remained marginal and external assistance was essential for financing public expenditure. Over the period from the mid 1980s until 2004 external financing equalled, in value, to approximately $50 \%$ of total government expenditure, and to over $100 \%$ of government investment (Arndt, Jones and Tarp, 2006, p. 29). As part of the adjustment, price controls were gradually removed to the extent that the share of products with fixed prices decreased, as percentage of GDP, from 70\% in 1986 to 30\% in 1989. Trade liberalization implied the abolishment of quantitative restrictions on imports and exports, simplification of licensing procedures and reduction in the number and average level of tariffs (Arndt, Jensen and Tarp 2000, p. 303-304, see also Abrahamsson and Nilsson 1994).

The privatization of state enterprises was started in 1989. By 1990, about 200 stateowned enterprises and intervened firms - less than $20 \%$ of all state enterprises - had been privatized (Castel-Branco, Cramer and Hailu, 2001). According to Castel-Branco et al., the process was "delayed by lobbying and competition for cheap state assets, ambiguities in the criteria for selecting buyers, together with financial and managerial weaknesses among state enterprises" (ibid., p. 3). In the early 1990s, the process 
accelerated rapidly when privatization became a key conditionality for the IMF and the World Bank support. By 1996 the privatization programme was considered as one of the largest in Africa with more than 1400 companies having been privatized (ibid., p. 3-4). The PRE entailed also privatization of the two state-owned commercial banks and institutional reform of the commercial financial sector. The privatization of the Banco Commercial de Moçambique (BCM) and Banco Popular de Desenvolviment $(B P D)$ took place in 1996 and 1997 respectively. ${ }^{56}$

The initial economic and social impact of the PRE was highly contentious. Firstly, although the Mozambican economy experienced a brief period of growth in 1987-89, the trend turned negative in 1990. The GNP growth trends, as recorded by Abrahamsson and Nilsson, are presented in Table 4.2 below:

Table 4.2 | The Growth of GNP 1985-1991

\begin{tabular}{|l|c|c|c|c|c|c|c|}
\hline \multicolumn{1}{|c|}{ GNP Growth (\%) } & 1985 & 1986 & 1987 & 1988 & 1989 & 1990 & 1991 \\
\hline Total GNP & -7.2 & 1.1 & 3.8 & 5.5 & 5.1 & -1.3 & -0.2 \\
\hline Agriculture & 0.8 & -0.6 & 7.0 & 7.2 & 4.0 & 1.1 & 1.9 \\
\hline Industry & -18.6 & -4.3 & 8.9 & 7.5 & 6.8 & -9.9 & -5.6 \\
\hline Construction & -4.4 & -4.8 & -16.0 & 0.1 & 3.0 & 1.5 & 3.0 \\
\hline Transport & -11.8 & 1.7 & -9.8 & 6.2 & 10.2 & 0.5 & -2.3 \\
\hline Commerce & -6.8 & -0.7 & 3.5 & 4.5 & 4.0 & 2.5 & 2.0 \\
\hline GNP Growth/capita (\%) & -11.2 & -1.7 & 1.9 & 2.8 & 2.7 & -1.3 & -1.8 \\
\hline
\end{tabular}

Source: Abrahamsson and Nilsson, 1994, p. 51

Secondly, the rapid privatization programme created losers and winners. Due to the lack of a strategic framework, and the limited government capacity to regulate the process, "assets were sold off almost indiscriminately" (Castel-Branco et al., 2001, p. 1). Pre-existing community rights to land and resources were ignored in the process of breaking up state farms, and members of cooperatives were sidelined in the selling of the cooperatives' assets to private buyers.

56. By 2001, both banks had entered into insolvency, largely due to non-performing loans given first to finance the loss-making state enterprises during the period of central planning, and later on, to finance the privatization of the state owned enterprises. The banking crisis involved accusations of large-scale fraud and corruption. Two individuals investigating the cases, Carlos Cardoso and António Siba-Siba were assassinated, in 2000 and 2001 respectively. The assassinations led to a temporary withdrawal of aid by some donors in 2002 as an attempt to put pressure on the government to proceed with the investigation of the murders (Hanlon and Smart, 2008, p. 248-249). 
Thirdly, the measures to reduce public expenditure hit both the working population and poor population groups hard. During 1987-1992 real wages are estimated to have declined by more than $20 \%$. In 1988, after the lifting of price controls and elimination of food subsidies, the prices of maize, rice and sugar increased by between $300 \%$ and $600 \%$ (Manning, 2002, p. 123). Access to social services was affected by cuts in public expenditure (Hall and Young, 1997, p. 228-229). According to some estimates, the proportion of the urban population living in absolute poverty increased from 15\% in 1980 to $50 \%$ in 1989. In rural areas, only those with larger farms who were able to benefit from the privatization of state farms, increased access to credit and other inputs, were considered to be better off. As concluded in a survey carried out by the National Planning Commission, "the only beneficiaries of PRE in rural areas are few professionals linked to modern sectors, such as shopkeepers, high officials and private farmers" (Comissão Nacional do Plano 1990, quoted in Hanlon, 1991, p. 149-151). In 1989, in response to the negative consequences of the recovery programme, policy measures to mitigate the high social costs of adjustment were expanded and the programme itself was renamed the "Social and Economic Recovery Programme" (Programa de Reabilitação Economica and Social, PRES).

Furthermore, as argued by Hall and Young (1997) and even more forcefully by Hanlon $(1991,2006)$, as the economic policy measures were largely financed by external assistance, they contributed to increased corruption by creating new possibilities for personal enrichment for the political elite. According to Hall and Young "the conjunction of difficult economic circumstances with the legitimation of private gains has exposed officials to temptations while privatization in its various guises offered great rewards" (Hall and Young, 1997, p. 230). Hanlon goes further and argues that the increasing phenomenon of corruption was caused not only by the acute deprivation faced by many people in the aftermath of PRE, but that it was fuelled by donors (Hanlon, 1991, p. 238).

The launch of the PRE, which implied de facto transition to a market economy, contributed to far-reaching political and legislative changes. Together with the amounting pressures to end the war, the economic transition created the basis for the adoption of the new Constitution in 1990 and the subsequent political transition. The demand for political reforms had gained momentum during the course of the debates preceding the Fifth Congress of Frelimo, held in 1989, and in early 1990 a proposal to alter the Constitution of 1975 was presented for public debate. ${ }^{57}$ Following wide debates by the different legislatures, in the media, at work places etc., the new Constitution was adopted by the parliament in November 1990. This meant a fundamental change

57. The first proposal to alter the 1975 Constitution was made public already in 1988. It entailed only relatively small modifications in the political system and failed to raise wider debate. 
from a single-party system to a multi-party political system (Abrahamsson and Nilsson 1994, p. 64-68).

With the new Constitution, the People's Republic of Mozambique was renamed as the Republic of Mozambique. The Constitution contained the principles of a multi-party system, separation of powers, guarantees for human rights and fundamental freedoms. While the new Constitution acknowledged the role of Frelimo as the leader of the liberation struggle and founder of independent Mozambique, it aimed to detach Frelimo as a party from the state. The shift from centrally-planned economy to market economy, already underway since the launch of PRE, was formalized (República de Moçambique 1990).

The shift from single-party system to multi-party system, the separation of the party from the state, and the formal shift to market economy were all contested issues. First, the debates preceding the constitutional reform indicated that the majority of rural population seemed to prefer the existing single-party rule. ${ }^{58}$ Second, the separation of the party from the state implied that many people holding high positions both within the party and the state apparatus would lose the privileges that came along with the posts. Third, while the economic policy embedded in PRE had already implied a de facto transition to a market economy, the formal acknowledgment of Mozambique's changing economic orientation proved to be problematic. According to Hanlon, reference to Mozambique as a "market economy", which was included in the draft Constitution approved by Frelimo Central Committee, was cancelled after intense debates in the parliament, and replaced with a more vague reference to "the economic order based on market forces" (Hanlon 1994, p. 241).

The new Constitution, together with the changing international political setting, created the conditions for ending the protracted war in Mozambique. The signing of the General Peace Agreement in 1992 marked the beginning of a new era in Mozambique's political and economic development. The peace agreement addressed both the formal resolution of the hostilities and the establishment of a new political system as the basis for political stability. The main development trends during the post-war period will be discussed in the following sections.

58. The explanations for this varied. Some argued that more than one party would divide the country. For some the multi-party system meant coexistence with Renamo which in itself was considered unacceptable. Despite the opposition, the Frelimo Central Committee decided to move ahead with the reform, arguably in fear that Frelimo would split apart if opposition parties were not allowed (Manning, 2002, p. 127). 


\subsection{Political and Economic Transformation since 1992}

\subsubsection{Political Transformation}

The 1990 Constitution of Mozambique provided the framework for the multiparty democracy founded on periodic elections on the basis of universal, direct, secret and equal suffrage. The President, members of the Assembly of the Republic, Assembleia da Republica (with the new Constitution the name of the national parliament was changed from Assembleia Popular to Assembleia da Republica) and members of the Provincial Assemblies are elected for five-year terms of office. For the legislative elections, electing the 250 members of the Assembly of the Republic, there are 13 constituencies corresponding to the 11 provinces (the City of Maputo has the status of a province), and 2 constituencies out of the country. The members of the Assembly of the Republic and the members for the Provincial Assemblies are drawn from party lists following a proportional representation system. Only the two members of the Assembly of the Republic representing the expatriate voters are elected by simple majority (Constituição da República, 1990).

\subsubsection{1. "Voting for Peace” - First Multi-Party Elections in 1994}

The first multi-party presidential and parliamentary elections, held in October 1994, have come to be seen as the defining moment in the transition from war to peace and from single party to multi-party rule. The elections were declared free and fair by the UN observation mission as well as by other international and domestic election observers. Most importantly, the results were accepted by all parties, including Renamo, albeit with some hesitation. The voter turnout reached nearly $90 \%$. This was remarkable taking into consideration the fact that freedom of movement was still limited and the country was still practically divided into Renamo and Frelimo-controlled areas (Manning 2002, p. 170)..$^{59}$

Frelimo's candidate, Joaquim Chissano, the incumbent president at the time, was re-elected with $53 \%$ of the vote. Renamo's candidate, Afonso Dhlakama, received 34\% of the votes. The other ten candidates together received $12.47 \%$ of the votes. Frelimo also won a majority in the 250 -member parliament with 129 deputies. Renamo won 112 seats. In addition, 9 representatives of three smaller parties that formed the Democratic

59. Based in Mozambique at the time of the first multi party elections, the author of this research had the opportunity to participate in the elections as a UN Election Observer. 
Union (UD) were voted in (EISA Mozambique Election Archive. Retrieved April 15, 2010, from the World Wide Web: http://www.eisa.org.za/WEP/mozelectarchive.htm).

Even though the first elections have been, characterized, first and foremost, as the "vote for peace", the results did show that Renamo had strong internal support in the country. The "armed bandits", bandidos armados, as Renamo had been referred to by the Frelimo government and in the government-controlled media up to the final period prior to the beginning of the peace talks in the late 1980s, had emerged as a legitimate political party and a serious contester to Frelimo's power. The results further confirmed the fact that the country was divided along regional lines between Frelimo and Renamo supporters: Frelimo won the majority in the southern provinces (Maputo, Gaza, Inhambane, and the City of Maputo) as well as in the two northernmost provinces (Niassa and Cabo Delgado) whereas Renamo emerged as the winner in five central provinces (Sofala, Manica, Tete, Zambezia and Nampula) which had been largely under its control during the war. The elections also highlighted a clear urban-rural demarcation with Frelimo winning votes amongst the urban population and Renamo primarily amongst the rural population (Manning, 2002, p. 170-171).

\subsubsection{Consolidating Democracy - Elections in 1999, 2004 and 2009}

Since 1994 successive presidential and parliamentary elections have been held in 1999, 2004 and 2009 in accordance with the 1990 Constitution (and its revised version of 2004). In 2009, simultaneously with the presidential and legislative vote, the Provincial Assembly members were also elected, for the first time through a popular vote, in line with the legislation approved by the Assembly of the Republic in 2007 (Law 10/2007) ${ }^{60}$.

Despite the concerns about the transparency of the electoral process and the impartiality of the National Electoral Commission, CNE (Comissão Nacional de Eleições), all elections have so far been declared free and fair by international and domestic observers. Furthermore, although the results of the succeeding elections have all initially been challenged by the losing parties, in the end they have been accepted not only by the country's Constitutional Council but also by the opposition. The results of the post 1994-elections follow, by and large, similar regional and rural-urban divisions between the supporters of Frelimo and opposition as the first elections. Frelimo has succeeded

60. While the election of the provincial assemblies 'through universal, direct, equal, secret and harmonious suffrage" was foreseen already in the 1990 Constitution (Constituição da República, article 142), and the first elections had been scheduled for 2007, they had been postponed twice because of the lack of time and resources for the preparation of the elections (Buur, 2009, p. 2). 
in consolidating its political power by winning the majority in all elections, albeit with a very small margin in 1999.

Since the transition to multi-party rule, the 2009 elections have been the most contested because of some pre-election decisions by the CNE and the Constitutional Council limiting the participation by the opposition parties. ${ }^{61}$ Amongst rumours of Frelimo's ties to both the Constitutional Council and CNE, the donor community voiced unified concern regarding the transparency of Mozambique's multi-party elections and called for reforms in the electoral processes (see, for example, the final report of the EU Election Observation Mission, 2009). The shortcomings of the 2009 electoral process emerged as one of the concerns in the dialogue between the Government of Mozambique and the donors providing general budget support (see Chapter 5).

The outcome of the presidential and parliamentary election held in 1994, 1999, 2004 and 2009 is summarized in Table 4.3 below:

Table 4.3 | Presidential and Parliamentary Elections in Mozambique in 1994, 1999, 2004, 2009

\begin{tabular}{|c|c|c|c|c|c|c|c|c|}
\hline \multirow[b]{2}{*}{$\begin{array}{l}\text { Year } \\
\text { (turnout\%) }\end{array}$} & \multicolumn{4}{|c|}{$\begin{array}{l}\text { Presidential Elections } \\
\text { ( } \% \text { of votes) }\end{array}$} & \multicolumn{4}{|c|}{$\begin{array}{l}\text { Parliamentary Elections } \\
\text { (\% of votes) }\end{array}$} \\
\hline & $\begin{array}{c}1994 \\
(88 \%)\end{array}$ & $\begin{array}{l}1999 \\
(70 \%)\end{array}$ & $\begin{array}{c}2004 \\
(37 \%)\end{array}$ & $\begin{array}{c}2009 \\
(44.5 \%)\end{array}$ & $\begin{array}{c}1994 \\
(88 \%)\end{array}$ & $\begin{array}{c}1999 \\
(79 \%)\end{array}$ & $\begin{array}{l}2004 \\
(37 \%)\end{array}$ & $\begin{array}{c}2009 \\
(44.4 \%)\end{array}$ \\
\hline Frelimo & 53.3 & 52.6 & 63.7 & 75.0 & 44.3 & 48.5 & 62.0 & 74.7 \\
\hline Renamo & 33.7 & & 31.7 & 16.4 & 37.8 & & 29.7 & 17.7 \\
\hline Renamo-UE & & 47.7 & & & & 38.8 & & \\
\hline MDM & - & - & - & 8.6 & & - & - & 3.9 \\
\hline Others & 13 & & 4.5 & & 17.9 & 12.7 & 8.3 & 3.7 \\
\hline
\end{tabular}

Sources: EISA Mozambique Election Archive. Retrieved April 15, 2010, from the World Wide Web: http://www.eisa.org.za/WEP/mozelectarchive.htm.

The distribution of seats between the different parties in the Assembly of the Republic, following the 2009 parliamentary elections is presented below in Table 4.4:

61. Of the 24 parties and five coalitions that submitted their candidacies to National Electoral Commission, 10 parties were rejected by the Commission completely, and 17 parties in some of the constituencies. Only Frelimo and Renamo had their lists accepted by CNE in all constituencies. The rejection of MDM in 7 out of the 11 constituencies gave rise to accusations of political bias against $\mathrm{CNE}$ and the Constitutional Council. 
Table 4.4 | Presidential and Parliamentary Elections 2009

\begin{tabular}{|l|c|c|c|c|}
\hline \multicolumn{1}{|c|}{ Party } & Votes & Votes (\%) & Seats & Seats (\%) \\
\hline Frelimo & 2907335 & 74.66 & 191 & 76.4 \\
\hline Renamo & 688782 & 17.69 & 51 & 20.4 \\
\hline MDM & 152836 & 3.93 & 8 & 3.2 \\
\hline Others ${ }^{62}$ & 144905 & 3.72 & 0 & 0 \\
\hline Total & 3893858 & 100 & 250 & 100 \\
\hline
\end{tabular}

Source: EU Election Observation Mission to Mozambique 2010, Retrieved April 15, 2011 from the World Wide Web:

http://www.cip.org.mz/election2009/ndoc2009/294_Final_Report_EU_EOM_en.pdf.

The results of the first elections for the provincial assemblies are summarized in the Table 4.5 below. The distribution of seats between Frelimo and Renamo confirms the regional divisions which have been apparent since the first elections in 1994.

Table 4.5 | Provincial Elections 2009

\begin{tabular}{|l|c|c|c|c|c|}
\hline \multirow{2}{*}{ Province } & \multicolumn{5}{|c|}{ Number of Seats } \\
\cline { 2 - 6 } & Frelimo & Renamo & MDM $^{63}$ & PDD $^{64}$ & Total \\
\hline Niassa & 66 & 2 & 2 & - & 70 \\
\hline Cabo Delgado & 73 & 8 & - & - & 81 \\
\hline Nampula & 77 & 12 & 2 & - & 91 \\
\hline Zambézia & 57 & 31 & 0 & 2 & 90 \\
\hline Tete & 75 & 5 & - & - & 80 \\
\hline Manica & 61 & 19 & - & - & 80 \\
\hline Sofala & 59 & 1 & 20 & - & 80 \\
\hline Inhambane & 80 & 0 & 0 & - & 80 \\
\hline Gaza & 80 & - & - & - & 80 \\
\hline Maputo & 75 & 5 & - & - & 80 \\
\hline Total seats & $\mathbf{7 0 3}$ & $\mathbf{8 3}$ & $\mathbf{2 4}$ & $\mathbf{2}$ & $\mathbf{8 1 2}$ \\
\hline \% of seats & $\mathbf{8 6 . 6}$ & $\mathbf{1 0 . 2}$ & $\mathbf{3}$ & $\mathbf{0 . 2}$ & $\mathbf{1 0 0}$ \\
\hline
\end{tabular}

Source: EU Election Observation Mission to Mozambique 2010, Retrieved April 15, 2011 from the World Wide Web:

http://www.cip.org.mz/election2009/ndoc2009/294_Final_Report_EU_EOM_en.pdf.

62. Includes 16 parties each of which received less than $1 \%$ of the votes.

63. Movimento Democrático de Mocambique

64. Partido para Paz, Democracía e Desenvolvimento 
The outcome of the 2009 presidential, parliamentary and provincial elections further reinforced the political dominance of Frelimo, which gained control of all political organs from central to provincial level. While Renamo continues to be the largest opposition party, MDM has emerged as a third political force. The strong regional division of the country between Frelimo and Renamo supporters can still be identified although Renamo's support has been declining: Frelimo is practically the only party in the three southern provinces (Maputo, Gaza, Inhambane) as well as in the two northernmost provinces (Niassa and Cabo Delgado), while the central provinces continue to be the strongholds for Renamo and its break-off party MDM.

The participation of women in political life, rooted in the prominent of role of the OMM during the liberation struggle and the early post-independence period, has remained strong. Frelimo has traditionally used a 30\% quota for women in their candidate lists. In the 2009 elections, Renamo stated that about $20 \%$ of its candidates would be women, while MDM pursued a target of $45 \%$ of women candidates. As a result of the 2009 elections, a total of 98 women were elected as members of the Assembly of the Republic representing about $39 \%$ of all elected members. The share of women in the parliament is well above the average of 19\% in Sub-Saharan Africa, and in 2011 Mozambique ranked in the top 10 of countries for women representation in parliament (Inter-Parliamentary Union, IPU, Retrieved April 15, 2011 from the World Wide Web: http://www.ipu.org/wmn-e/classif.htm).

\subsubsection{Towards Decentralization and Local Democracy}

The 1990 Constitution provided also the basis for the establishment of local governance structures in line with the principles of democratic participation. The first legislation concerning local elections had already been adopted in 1994, before the first multi-party elections. Under the 1994 law, all 128 districts of Mozambique were meant to be municipalities but, for fear of fragmentation of the country, this legislation was subsequently revoked. A new legal framework, based on a model of gradual decentralization, was approved in 1997. The Municipal Law 2/1997 made provision for the election of municipal assemblies and mayors only in 33 municipalities in urban and peri-urban settings (Manning, 2002, p. 190).

In 1998, the first municipal elections for the 33 municipal assemblies and mayors of the major cities were held. Because of widespread boycotts by Renamo and other smaller opposition parties, the voter turnout remained very low at the level of $15 \%$ of registered eligible voters. Frelimo won the majority in municipal assemblies, and the positions of mayor in all 33 municipalities (Hanlon and Smart, 2008, p. 204). The second local elections involving again 33 municipalities took place in 2003. The total 
voter turnout reached the level of $24 \%$ of registered voters, and in some municipalities close to $50 \%$. Frelimo won 28 mayoral positions and the majority in 29 municipal assemblies, while Renamo won 5 mayoral positions and the majority in 4 municipal assemblies. In the third round of local elections including this time 43 municipalities, held in 2008, Frelimo gained 42 of the 43 mayoral positions (Hanlon and Smart, 2008, p. 204).

The process of gradual decentralization entailed the strengthening of democratic participation in rural areas through various forms of participatory mechanisms for representation and consultation, and a transfer of responsibility to lower levels of administration within the state sector. An important step in this process was the approval of the Law of Local State Authorities (Lei das Órgãos Locais do Estado, LOLE) in 2003. The new legal framework designated the district as the main territorial unit of decentralised state administration. At district level, local councils, known as the Consultative Councils (Conselhos Consultivos), were to be established to serve as the official interlocutor between the central level state administration and the local communities. To enhance the financial autonomy of the Consultative Councils, a separate fund for local investments initiatives was established within the state budget (Orçamento de Investimento de Iniciativas Locais, OIIL) (Forquilha, 2010, p. 32-34). ${ }^{65}$

The merits and shortcomings of the decentralization process are subject to intense debate by Mozambican academics. According to Forquilha, political decentralization has taken place at municipal level, while, at district level decentralization has merely meant administrative decentralization. The creation of the Consultative Councils has been characterized by the control of the state, in particular by Frelimo, and therefore the setting up of Councils has resulted in re-centralization of power in the hands of the dominant party. The space for local participation, created by the legislation, is thus seen as being captured by the political elite. Furthermore, the value of the Councils is perceived to be undermined because of their role as consultative rather than decision-making bodies (Forquilha, 2010, p. 46-47). Buur raises similar concerns, based on case studies in two of Mozambique's northern provinces, Niassa and Nampula, and argues that the emergence of the participatory mechanism for representation and consultation at local level has to be seen in light of the attempted party-state capture of nearly all societal domains in Mozambique (Buur, 2009, p.1).

As will be discussed in Chapter 8, the criticism by the academics about Frelimo dominance of the Consultative Councils, and the limited space for local participation in the

65. In the 2006 budget, these funds were set as a lump sum amounting to 7 million Meticais, approximately USD 300,000 at the time (Forquilha, 2010, p. 32-34). 
Councils, seems to be shared by most of the civil society and community level actors interviewed for this research.

Mozambican civil society organizations and other non-state actors constitute an important component in the development of local democracy. Many nonpartisan civil society groups have emerged since the adoption of the 1990 Constitution, and they do play an increasingly important role in local governance. The more prominent groups include, for example, the Human Rights League (Liga dos Direitos Humanos, LDH), the Centre for Public Integrity (Centro de Integridade Publica, CIP) and a private-sector lobby organization, (Comissão de Trabalho das Associações, CTA). Some of the old "mass democratic organizations" such as the Mozambican Workers Organization (Organização de Trabalhadores Moçambicanos, OTM) and the Mozambican Women's Organization (Organização de Mulheres Moçambicanas, OMM) have been able to gain more independence from Frelimo and are also assuming the role of a "watch dog" visà-vis the government (Francisco 2010, p. 51).

\subsubsection{Multi-party Democracy with Single-party Dominance}

The post-war developments of the political system in Mozambique indicates that the transition from war to peace and from a single-party to a multi-party system has been successful. However, with Frelimo emerging as the winner in all successive elections, apart from some municipalities, Mozambique has evolved into a multi-party political democracy with one dominant party. As noted by Hanlon, this is not, in itself, a sign of lack of democracy but it involves risks which may undermine the democratic development of the country (Hanlon 2008). The overwhelming majority of Frelimo at all levels of political governance raises questions about state-citizen accountability and the capture of the state by the party in power. According to de Brito, the development of pluralistic democratic society in Mozambique has been hampered by the fact that the process of the political transition was negotiated by Frelimo and Renamo which were the two warring parties. This has polarized the political space from the very beginning. As argued by de Brito, "democracy was confiscated by the two parties without allowing the participation and expression of interests by other actors including the civil society" (de Brito, 2010, p. 23 , translated from the original in Portuguese by the author).

Manning argues, in a similar fashion, that the 1994 elections established certain patterns of interaction which have characterized all subsequent elections. First, the main opposition party, Renamo, does not accept that the elections can be managed by the government, which is seen by Renamo as a warring party rather than a legitimate authority. Second, despite the existence of several political parties, the contested issues would have to be solved between Frelimo and Renamo while the other parties remain 
in the margin. According to Manning, "the nominally multi-polar setting turns into a bipolar setting" which is largely dependent on an informal negotiation processes between the two parties, and therefore tends to be very fragile (Manning, 2002, p. 186).

The bipolar nature, with Frelimo as the ruling party and Renamo as the only significant opposition party, has continued largely unchanged since the first elections. The emergence of MDM as a third force in the political arena may bring an end to the historical bipolarization of the Mozambican political setting. As a new contester MDM can mitigate the fragility of the current multi-party system characterized by the overwhelming dominance of Frelimo at all levels of governance.

\subsubsection{Economic Transformation}

Since the end of the war in 1992, Mozambique's economic recovery has accelerated considerably. Initially, economic growth was driven largely by three factors: high levels of external assistance; the "peace dividend"; and an increasing inflow of foreign direct investment. Net ODA has accounted for more than half of the state budget during the post-war period. The peace dividend was realized, in particular, through successful resettlement of refugees and the return of rural population to productive activities in agriculture and other sectors of the economy. Furthermore, since the mid1990's, Mozambique has succeeded in attracting increasing amounts of foreign private capital thanks largely to economic liberalization and post-war political stability (Buur and Baloi, 2009, p. 9).

During the ten-year period, 1999-2009, the average annual GDP growth has achieved $7.6 \%$, despite the floods in 2000 which slowed GDP growth to $1.5 \%{ }^{66}$ The GDP growth per capita shows a similar positive trend: during the period 1989-99, the average annual growth of GDP per capita was 2.3\%, and reached the level of 5\% during the ten-year period from 1999 to 2009. In terms of US dollars, GDP per capita has increased from USD 130 per capita in 1992 to USD 475 per capita in 2009 (at current prices) (AfDB, 2012; IMF 2010 and 2013, World Bank 2010). Mozambique's annual GDP growth during the period 1999-2009 is illustrated in the graph below:

66. In 2010, the real GDP growth rate remained at the level of reached $6.8 \%$ but reached the level of 7,8\% in 2011. According to IMF projections, the GDP grow is estimated to reach $7.5 \%$ in 2012. 
Figure 4.1 | Annual Growth of GDP in 1999-2009

Annual GDP Growth $1999-2009, \%$

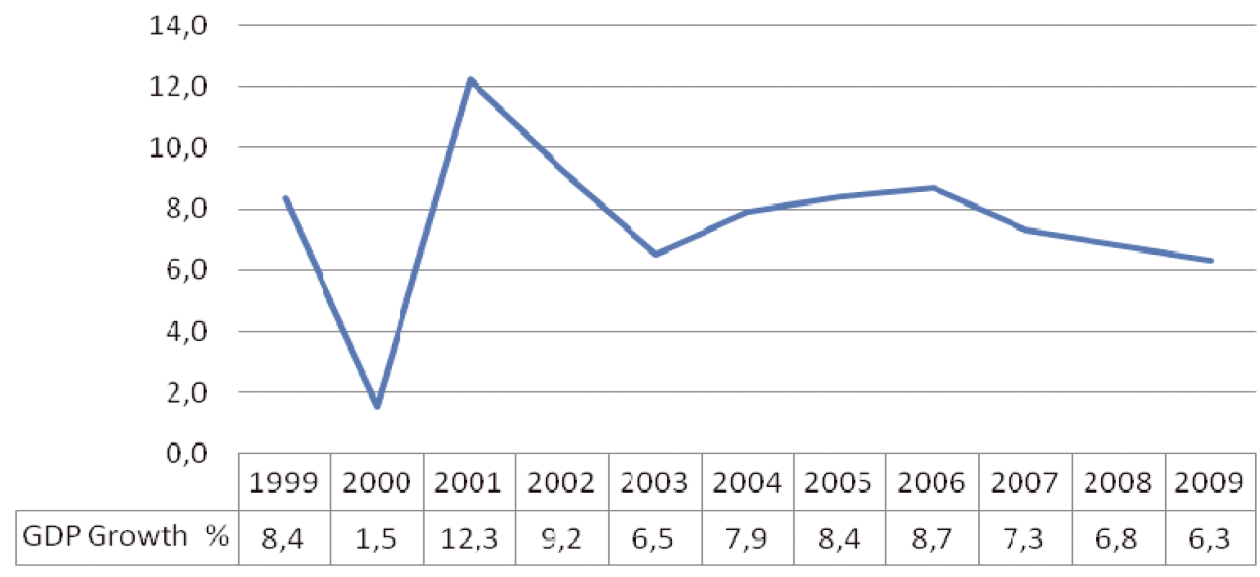

Source: Adapted from the IMF World Economic Outlook, 2010

Despite Mozambique's sustained economic growth during the post-war period, the economy remains vulnerable due to its high dependence on external assistance and foreign private investment. Approximately $50 \%$ of the state budget is financed by external assistance, and foreign private capital represents up to $90 \%$ of the total private investments in Mozambique (Castel-Branco, 2010, p. 141). While aid funding has been largely targeted towards financing public sector expenditures, particularly in social sectors, foreign direct investment has concentrated heavily on large scale "mega-projects" in three sectors, energy, minerals and gas. The mega-projects account for most of the growth in industrial production and exports constituting also the main source of the overall economic growth. As argued by Castel-Branco, the total industrial production in Mozambique has increased by ten-fold during the period 1999-2009, but the overwhelming part of the growth is explained by one company, the Mozal aluminium smelter, located near the capital city of Maputo (Castel-Branco, 2010, p. 148 -150,underlining by the author).

The composition of Mozambique's exports reflects the same pattern with aluminium accounting for nearly 50\% of total exports during the period of 1999-2009. The share of export revenue originating from all other sources of industrial or primary production has remained marginal, apart from the sale of electricity and prawns which each contribute $7 \%$ to the total of Mozambique's exports. The share of other primary products, which since the time of colonial administration have been major export products, have become marginal accounting for 1-2\% of total exports (Castel-Branco 2010, 150-153). 
In other words, the structure of the Mozambican economy, traditionally largely dominated by agriculture and service provision, has radically changed with the high concentration of the foreign direct investment. As discussed by Buur and Kyed, the growth in agricultural sector has not gone beyond the "one-off peace dividend" which took place immediately after the end of the war. While overall annual agricultural growth has averaged 6\%, increases in the food and cash-crop sub-sectors grew primarily through the expansion of land under cultivation and the increase in labour force, rather than through increased productivity and development of agro-industries. In view of the fact that agriculture accounts for the livelihood of some $70 \%$ of the population, the limited broadbased growth of the agricultural sector is a major concern (Buur and Kyed 2009, p. 10).

\subsubsection{Fight against Poverty}

The impact of Mozambique's rapid and sustained economic growth on poverty reduction in the country has been significant. The results of the first national household survey (Inquérito aos Agregados Familiares, IAF) measuring poverty and inequality in 1996/97 showed that $69.4 \%$ of Mozambicans lived below a poverty line measured by consumption (World Bank, 2003, p. 1). Regional differences were large with the central provinces ranking as poorer than the northern and southern provinces. The City of Maputo ranked as the richest province. ${ }^{67}$

In response to the survey results, a poverty reduction strategy was adopted by the Government of Mozambique in 1999 (GoM 1999, Plano Acção para a Erradicação da Pobreza Absoluta, PARPA). The adoption of the first poverty reduction strategy coincided with the introduction of the then new planning instrument by the Bretton Woods Institutions, namely the Poverty Reduction Strategy Paper (PRSP) approach. ${ }^{68}$ The government's strategy was endorsed by the BWIs as an "interim PRSP" which was later developed into a full PRSP for the period 2001-2005. In Mozambique, the PRSP became known by its Portuguese-based acronym PARPA.

According to PARPA, the "central objective of the Government of Mozambique is a substantial reduction in the levels of absolute poverty in Mozambique through the

67. The six main determinants of poverty identified by the survey included: 1) slow growth of the economy until the beginning of the 1990s; 2) low levels of education in the working age population, particularly of women; 3 ) high dependency rates in households; 4) low productivity in the family agriculture sector; 5) lack of employment opportunities within and outside of the agricultural sector; and 6) poor infrastructure, especially in rural areas (Inquérito aos Agregados Familiares 1996/97).

68. The PRSP approach was closely linked to the implementation of the debt relief mechanism for poor countries, the HIPC (Heavily Indebted Poor Countries), launched by the BWIs in 1996. All countries that were to benefit from debt relief under HIPC initiative were required to prepare a PRSP. 
adoption of measures to improve the capacities of, and the opportunities available to all Mozambicans, especially the poor" (GoM, 2001, p. 1). Emphasis was put on economic growth, institutional reforms to accelerate private sector development and investments in human capital and productive infrastructure. The specific objective was to reduce the incidence of absolute poverty to less than $60 \%$ by 2005 and to less than $50 \%$ by the end of 2010 (ibid).

The implementation of PARPA, with significant financial and technical assistance from the international donor community, seemed to bring positive results: by 2003, when the second household survey was conducted, the poverty headcount rate had fallen from $69.4 \%$ to $54.1 \% .^{69}$ The poverty reduction target set in PARPA had thus been achieved two years ahead of target. The results indicated that both the percentage of the population below the poverty line had fallen, and the average consumption by those who remain below the poverty line had improved (GoM, 2004, p. 19-20). However, the poverty trends varied greatly between different provinces: the largest reduction in consumption poverty was registered in Sofala where the poverty rate fell from $87.9 \%$ in $1996 / 97$ to $36.1 \%$ in $2002 / 03$. The rate of poverty also reduced in Nampula (by 16.3\%), Zambézia (23.5\%), Tete (22.5\%), Manica (19.0\%), Inhambane (1.9\%) and Gaza (4.5\%). On the contrary, the rate of poverty increased in Cabo Delgado (5.8\%), Maputo Province (3.7\%) and City of Maputo (5.8\%) (ibid., p. 20).

On the national scale, the level of inequality measured by the Gini coefficient ${ }^{70}$ increased only slightly from 0.40 in $1996 / 97$ to 0.42 2002/03 (change statistically not significant). This suggests that the rapid economic growth had been relatively broadbased despite the high concentration of investments and industrial production. A considerable increase in inequality was recorded in Maputo City where the Gini coefficient increased from 0.44 in 1996-67 to 0.52 in 2002-2003 (James, Arndt and Simler, 2005, p. 14-17).

The second Poverty Reduction Strategy Paper for 2005-2009 (PARPA II) was prepared by the Government in line with the priorities set in its Five Year Programme for the period. ${ }^{71}$ The three main pillars for poverty reduction were defined as gov-

69. Mozambique's development trend is monitored annually also through the government's Economic and Social Plan (Plano Económico e Social,PES), and related progress report (Balanço do Plano Económico e Social) which are prepared by the government.

70. The Gini coefficient remains in the interval of 0 to 1 , where zero represents no inequality, and with increasing inequality, the indicator approaches one.

71. The elaboration of the PARPA II was preceded by the government's long-term vision, Agenda 2025, which was prepared in 2003 by a civil society group, known as the Committee of Advisers, with support from several donors. The Agenda 2025 contributed to setting the broad, long-term development goals for Mozambique. 
ernance, human capital and economic development, to be supported by sound macro-economic and pubic financial management. Although PARPA II built on the first poverty reduction strategy, it also indicated a shift from the social sectors towards stronger emphasis on creating the conditions for economic growth and private sector development. The need to control market failures and increased regulation was acknowledged, particularly, with regard to agricultural and rural marketing. As part of the institutional reforms related to public administration and the judiciary, enhanced attention was to be paid to fighting corruption. The priorities related to investments in human capital were aligned with the MDGs (GoM, 2005).

Contrary to the positive trend in poverty reduction during the period 1996/97$2002 / 03$, which largely coincided with the implementation of first PARPA I, the poverty impact of PARPA II was disappointing. The results of the third household survey (Inquérito sobre Orçamento Familiar, previously called Inquérito aos Agregados Familiares), published in 2010 , indicate that the poverty rate (poverty headcount rate) had increased from $54.1 \%$ in $2002-3$ to $54.7 \%$ in $2008-09 .{ }^{72}$ Rural poverty increased from $55.3 \%$ to $56.9 \%$ whereas urban poverty decreased from $51.5 \%$ to $49.6 \%$. While neither of the changes is statistically significant they indicate a reversing trend in Mozambique’s poverty reduction (GoM, 2010, p. 25).

The geographically disaggregated data show statistically significant changes in poverty rates, measured by consumption, in the northern, central and southern regions of the country. The results for the northern provinces of Niassa and Cabo Delgado as well as for the southern province of Inhambane showed a significant decrease in consumption poverty whereas the central provinces of Sofala and Zambézia experienced an increase in poverty levels. The most significant increase in consumption poverty had taken place in the centre of the country (Zambezia), where poverty rose from $44.6 \%$ in $2002 / 03$ to $70.5 \%$ in 2008/09. In Maputo City poverty had dropped from $53.6 \%$ to $36.2 \%$ during the period under consideration (INE 2010, p. 26).

The third survey did not indicate statistically significant changes in the level of inequality at the national level or within urban and rural areas: at national level the Gini coefficient in 2008/09 was estimated 0.414 compared to 0.415 in 2002-03. In urban areas the level of inequality was higher with the Gini coefficient of 0.48 compared to that of 0.37 in rural areas. There were effectively no changes within urban and rural zones during that period (at 95\% confidence level) (GoM, 2010, p. 56-57).

72. The 2008/09 household survey was conducted by National Statistics Institute (Instituto Nacional de Estatistica, INE), and is comparable with surveys of 1996/97 and 2002/03 concerning measuring consumption poverty at a given point in time (Arndt, Azhar, Jones, Nhate, Tarp, Thurlow 2010). 
Concerning trends in non-monetary poverty indicators, the third household survey results give a mixed picture. Enrolment rates in both primary and secondary education indicated positive developments. The illiteracy rate among women decreased significantly from $54 \%$ to $40.8 \%$. Indicators on health services showed improvement in rural areas, but deterioration in urban areas. Access to clean water remained generally unchanged, except for significant improvement in urban areas in the south. Indicators on access to electricity and ownership of household goods showed positive trends. One of the main concerns relates to continued high rates of malnourishment. The survey indicates that $46.4 \%$ of children under five years suffer from moderate chronic malnourishment and $23 \%$ suffer from severe chronic malnourishment. The situation is worse in rural areas compared to urban areas (GoM, 2010, p.26). According to the household survey, child malnutrition is not falling and may be getting worse. The results of the household surveys of 1996/97, 2002/03 and 2008/09 are summarized in Table 4.6.

Table 4.6 | National Household Surveys of 1996/97, 2002/03 and 2008/09

\begin{tabular}{|c|c|c|c|c|c|c|}
\hline \multicolumn{5}{|c|}{ Rate of Poverty } & \multicolumn{2}{|c|}{ Difference (\%) } \\
\hline & Area & $1996 / 97$ & $2002 / 03$ & $2008 / 09$ & $\begin{array}{c}1996 / 97- \\
2002 / 03\end{array}$ & $\begin{array}{c}2002 / 03- \\
2008 / 09\end{array}$ \\
\hline \multirow[t]{3}{*}{ National } & National & 69.4 & 54.1 & 54.7 & -15.3 & 0.6 \\
\hline & Urban & 62.0 & 51.5 & 49.6 & -10.5 & -1.9 \\
\hline & Rural & 71.3 & 55.3 & 56.9 & -16 & 1.6 \\
\hline \multirow[t]{3}{*}{ Regional } & North & 66.3 & 55.3 & 46.5 & -11 & -8.8 \\
\hline & Centre & 73.8 & 45.5 & 59.7 & -28.3 & 14.2 \\
\hline & South & 65.8 & 66.5 & 56.9 & 0.7 & -9.6 \\
\hline \multirow[t]{11}{*}{ Provincial } & Niassa & 70.6 & 52.1 & 31.9 & -18.5 & -20.2 \\
\hline & Cabo Delgado & 57.4 & 63.2 & 37.4 & 5.8 & -25.8 \\
\hline & Nampula & 68.9 & 52.6 & 54.7 & -16.3 & 2.1 \\
\hline & Zambézia & 68.1 & 44.6 & 70.5 & -23.5 & 25.9 \\
\hline & Tete & 82.3 & 59.8 & 42.0 & -22.5 & -17.8 \\
\hline & Manica & 62.6 & 43.6 & 55.1 & -19 & 11.5 \\
\hline & Sofala & 87.9 & 36.1 & 58.0 & -51.8 & 21.9 \\
\hline & Inhambane & 82.6 & 80.7 & 57.9 & -1.9 & -22.8 \\
\hline & Gaza & 64.6 & 60.1 & 62.5 & -4.5 & 2.4 \\
\hline & Maputo Province & 65.6 & 69.3 & 67.5 & 3.7 & -1.8 \\
\hline & Maputo City & 47.8 & 53.6 & 36.2 & 5.8 & -17.4 \\
\hline
\end{tabular}

Source: GoM/Ministry of Planning and Development Poverty and Wellbeing in Mozambique: Third National Poverty Assessment 2010, p.26) 
Although the 2008/09 household survey provides evidence of significant progress across a range of non-monetary poverty indicators, the trend in poverty headcount rates is a cause for concern. It has fuelled the debate of the "paradox of the Mozambican economy": how to explain the lack of change or even deterioration in poverty in an economy with high rates of economic growth over the past decade (Hanlon and Smart, 2008). From the perspective of Mozambique's political stability, the regional trends in poverty reduction represent a serious challenge to the government and the ruling party because the provinces in the central region, those with greatest increases in poverty rates, are the traditional strongholds of Renamo, as discussed above in the section on Mozambique's post-war political transformation.

According to the IMF, economic growth in Mozambique has been less "pro-poor" than in other countries with comparable high and sustained growth, and the growth pattern has become less inclusive over time. The results of 2008/09 household survey suggest that the high rate of growth between 2002/03 and 2008/09 has not benefitted the poorest populations groups. Bearing in mind that more than $70 \%$ of the population is engaged in small-scale agriculture, growth in the agricultural sector is crucial for poverty reduction. With most of Mozambique's arable land still uncultivated, there is potential for increasing agricultural production. However, sustainable use of land and other natural resources requires enhanced management of those resources. The IMF further argues that investments are needed to develop labour intensive industries, as opposed to the investments in capital intensive "mega-projects", to create employment opportunities for the new entrants into the labour markets (IMF, 2011, p. 57).

\subsubsection{Facing the Debt Crisis}

The development of the Mozambican economy during the post-war period cannot be discussed without reference to the debt burden that the country started to accumulate from the 1980s onwards. Mozambique's development strategy in the immediate post-independence period aimed at a rapid modernisation of the agricultural and industrial sectors led to the accumulation of substantial foreign debt. Following the serious deterioration of economic growth in the mid-1980s, largely caused by the war, the debt burden became unsustainable. The war also led to high military debts to the Soviet Union. The debt crisis forced the government to enter into negotiations with the Paris Club creditors and to join the Bretton Woods institutions in 1984. The first agreement on debt rescheduling with the Paris Club creditors was reached in 1984 (Abrahamsson and Nilsson, 1992). 
In 1998, the World Bank and the IMF agreed, along with other creditors $^{73}$, to provide nearly USD 3 billion (in nominal terms) to Mozambique as debt-service relief under the Heavily Indebted Poor Countries Initiative (HIPC). The debt relief represented over 70\% of Mozambique's GDP in 1997. The stock of debt in net present value (NPV) terms was reduced to $200 \%$ of exports, compared to $466 \%$ prior to debt relief, while debt service payments were reduced to below $20 \%$ of export earnings. In its press release announcing the decision on debt relief, the IMF referred specifically to the "one of the most successful privatization programmes in Africa, including the banking sector" (IMF Press Release No. 98/12, 1998). As discussed earlier, the privatization programme has in fact been one of the controversial elements of the economic recovery programme.

In 2000 Mozambique qualified for additional debt relief amounting to USD 600 million under the enhanced HIPC Initiative. Following the two debt relief packages, agreed upon within the framework of the original and the enhanced HIPC, Mozambique's total debt reduction has amounted to USD 4.3 billion which was equivalent to $72 \%$ of the net present value of its total outstanding debt in 1998 (IMF Press Release No. 00/28, 2000). Since debt relief is recorded by the OECD DAC as official development assistance, the two debt relief packages are reflected in a sudden peak in aid flows to Mozambique in 2002 (see Chapter 5).

Finally, as result of the 2005 agreement by the G8 countries on a complementary debt relief mechanism, the Multilateral Debt Relief Initiative (MDRI), Mozambique's debt to the IMF, the World Bank and the African Development Bank was written off (debt contracted prior to 2005). Hence, in 2005, all of Mozambique's IMF debt, worth USD 153 million, was cancelled. A year later the World Bank announced the cancellation of its Mozambican debt, amounting to USD 1.3 billion, and the African Development Bank wrote off its debt of USD 370 million (World Bank 2003, 2007).

\subsubsection{Other Socio-Economic Development Trends}

When assessing Mozambique's socio-economic development against the MDGs, the prospects of Mozambique achieving the goals by 2015 are somewhat promising. Mozambique is likely to achieve the goals of reducing by half the proportion of people living in absolute poverty and suffering from hunger, eliminating gender disparity in primary and secondary education, reducing the under-five mortality rate, and reversing the incidence of malaria and other major diseases. Furthermore, the goals

73. Other Paris Club creditors, including the Russian Federation as Mozambique's single largest creditor. 
of providing universal primary education and environmental sustainability may still be within Mozambique's reach. However, the specific target set for providing universal access to HIV/AIDS treatment by 2010 was not reached (GoM 2011, Report on the Millennium Development Goals, Mozambique).

According to the 2011 Human Development Index (HDI) Mozambique ranks as number 184 out of 187 countries with a score of $0.322^{74}$. Compared with the HDI of Sub-Saharan Africa as a region with the score of 0.463 , Mozambique ranks below the regional average (UNDP, Mozambique Country Profile of Human Development Indicators, Retrieved April 29, 2011 from World Wide Web: http://hdrstats.undp.org/en/ countries/profiles/MOZ.html). HIV/AIDS is a serious threat to Mozambique's development prospects. According to the estimates by UNAIDS, in 2009, the HIV prevalence rate among the age group from 15 to 49 years was between $10.6 \%$ to $12.2 \%$. More than 130,000 children up to 14 years are estimated to live with HIV, and up to about 670,000 children, aged 0 to 17 years, have lost their parents to AIDS-related illnesses (UNAIDS 2009, Country Fact Sheet on Mozambique).

Corruption is perceived to be endemic in Mozambique and presents a serious problem for the government, private sector, donors and, in particular, for ordinary citizens. Over the past decade, several initiatives have been undertaken by the government to fight corruption but little progress has been made. Mozambique's relatively poor results in various international corruption indexes can be seens as an indication of the magnitude of the problem. For example, according to the World Bank Institute's Worldwide Governance Indicators, Mozambique has scored between -0.61 and -0.41 , on scale from -2.5 to +2.5 , over the period from 2005 to 2009 . While the changes over the years are not statistically significant, the scores indicate that Mozambique falls into the category of highly corrupt countries (http://info.worldbank.org/governance/wgi/index.asp). Similarly, the Transparency International Corruption Perception Index ranks Mozambique among the countries with a corruption score between $2.0-2.9$ on the scale from zero ("highly corrupt") to 10 ("very clean"). Mozambique's score has got steadily worse over recent years, declining from 2.8 in 2005 to 2.5 in 2009, giving it a rank 130 out of the 180 countries surveyed in 2009 countries (http://www.transparency.org). In the Mo Ibrahim index for 2008/9, Mozambique scored 52.1 which places it $20^{\text {th }}$ out of 53 African countries (http://www.moibrahimfoundation.org). In 2005, Mozambique was ranked number 23 with a score of 55.8. Contrary to the above rankings, the World Bank's Country Policy and Institutional Assessment (CPIA) paints a somewhat

74. The HDI, developed by the UNDP, is a composite measure of three basic dimensions of human development: health, education and income. The HDI sets a minimum and a maximum for each dimension, called goalposts, and then shows where each country stands in relation to these goalposts, expressed as a value between 0 and 1. (http://hdr.undp.org/en/statistics/hdi/) 
better picture of the situation: over the period of 2005-2009, Mozambique scored 3, on a scale from 1 to 6 . The specific indicator, which is used to measure corruption (transparency, accountability and corruption in the public sector), does not show any changes over the past few years (http://siteresources.worldbank.org/IDA/Resour ces/73153-1181752621336/3878278-1277241699178/moz.pdf).

\subsection{Mozambique as a Success Story - Concluding Remarks}

Since independence in 1975, Mozambique has gone through drastic economic and political changes. As suggested by Åkesson and Nilsson, "Mozambique has been in a state of unfinished transitions since 1974" (Åkesson and Nilsson, 2007, p. 34). The changes have been driven by both internal and external forces, not least by the war which set the parameters for Mozambique's post-independent development trajectory for nearly two decades.

The Constitution of the newly independent People's Republic of Mozambique defined Frelimo as "the leading force of the state and the society" (Constituição da República Popular de Moçambique, 1975). The traditional local governance structures were dismantled by Frelimo because of their perceived collaboration with the former colonial administration. Although losing their formal position, the traditional leaders continued, to some extent, as legitimate leaders in the realm of local communities. The marginalization of the traditional leaders is considered to be one of the internal factors which contributed to the protracted destabilization cum civil war. As argued by White, "the heritage of the period of revolutionary struggle and the problems it encounters in the post-revolutionary era of 'socialist construction' constitute part of the basis dynamics of such societies" (White, 1983, p. 5).

The end of the Cold War, the transition to a market-oriented economy and the adoption of the new Constitution in 1990 based on a multi-party political system created the conditions for ending the war in 1992. Since then Mozambique has sustained the highest growth rate among oil-importing African countries, albeit still ranking near the bottom on the Human Development Index. Political stability has been cemented by the successive elections of 1994, 1999, 2004 and 2009 which have been declared free and fair by international and domestic observers. The election results have consolidated Frelimo's political power at all levels of state administration, although the decreasing number of voters participating in the elections somewhat undermines Frelimo's legitimacy. The process of gradual decentralization has provided for the election of municipal assemblies in 43 municipalities, and for the establishment of new local 
governance bodies, the Consultative Councils, at the district level. Despite shortcomings, the decentralization process has broadened the space for community level participation in the country's governance. The decentralization process has also contributed to Frelimo's legitimacy at community level.

As a result of the far-reaching economic and political transitions, Mozambique has come to be seen by the international donor community as a prime example of successful post-conflict political stabilization, transition to democracy and sustained socio-economic development. It is seen as satisfying the three criteria that define a "turn-around" from a conflict and post-conflict stage to a sustainable development path: a durable cessation of violent conflict; sustained economic growth; and sustained improvements in human development indicators (Kulipossa, 2007). However, despite undeniable economic and political achievements during the post-1992 period, Mozambique is still confronted with deep-rooted risks which may undermine its longterm sustainable development.

As argued by Collier, the countries where the "bottom billion" of the world's population live can be characterized by four "traps" which prevent them from breaking out of extreme poverty and from improving the quality of life for their citizens. These traps include "conflict trap", the "natural resource trap", the trap of being "land-locked with bad neighbours", and the "bad governance trap" of a small country (Collier 2007, p. 5). Using Collier's traps as guideposts, the following concluding remarks can be made about Mozambique's development opportunities and development challenges.

Mozambique's sustained rapid economic growth and political stability imply that the country seems to have overcome the first of Collier's traps, namely the "conflict trap". Furthermore, with its diverse resource base comprising energy, mining, agriculture, fisheries and forestry, as well as a long coast line with three major ports, Mozambique avoids the traps associated with dependence on a single natural resource or being landlocked.

In view of the perceived capture of the state apparatus by Frelimo, the party in power since independence, and the widespread corruption, the most significant threat to Mozambique's political and socio-economic development may be - following Collier's argumentation - the "bad governance trap". In comparison to the political and economic record of many other countries in Sub-Saharan Africa, Mozambique performs well, as widely acknowledged by the international community. However, its political stability can eventually be compromised by a limited space for political pluralism which results from the increasing political dominance of the ruling party. As argued by Astill-Brown and Weimar, "there are signs that democratic space is being monopolized, as an elite element within the ruling party consolidates its political and economic 
hold on power" (Astill-Brown and Weimar 2010, unnumbered page). Similar arguments about the intertwining of Mozambique's political elite and economic elite are put forward by Hanlon and Smart (2008) and Hanlon and Mosse (2010).

In an environment of limited transparency and political competition, corruption has become endemic. Growing popular concern about both high-level and petty corruption, as well as other implications of bad governance, may combine with frustrations over the government's inability - or lack of commitment - to address these issues. Riots in February 2008 and again in September 2010, sparked off by sharp rises in food and transportation costs, highlighted the level of frustration, particularly among the growing numbers of urban youth. The outbreak of violent conflicts suggests increasing discontent with the political leadership that seems unable to provide and ensure adequate livelihoods and equal opportunities to education, health and employment.

The challenges related to political governance render Mozambique vulnerable to the "bad governance trap". This vulnerability was acknowledged by President Guebuza who was quoted saying that the uprisings in North Africa "...serve as a warning for all of us. A warning that we have to take the needs of our people into account, and we have to intensify dialogue with the people" (Hanlon, 2011, Mozambique News Reports \& Clippings, Number 178, Retrieved on March 12, 2011 from the World Wide Web: http://tinyurl.com/mozamb). Addressing political governance is thus critical for ensuring the deepening of democracy, accountability, harnessing resources for development, and realizing Mozambique’s significant economic potential. 



\section{Evolving Aid Architecture;}

"Who Sits in the Driver's Seat?"

Mozambique's economic and political transformation has been supported by the international donor community which, over the years, has channelled significant amounts of financial and technical assistance to Mozambique. Through external assistance, the donor community has also impacted upon the country's policy choices and policy-making processes. The donor assessments of the quality of governance in Mozambique can be seen as one instrument for influencing these choices.

The purpose of this chapter is to sketch the evolution of the aid architecture in Mozambique and the role of donor agencies in shaping Mozambique's development trajectory. The focus will be on the period after the signing of the General Peace Agreement in 1992 which also marked a new era in Mozambique's aid relationships. The post-war period, which largely coincides with the emergence of the "governance paradigm" in international development cooperation, has witnessed several major changes in the role of donors in Mozambique.

The data on aid flows are based on the OECD DAC statistics which provide the most comprehensive and comparable data sets on ODA provided by bilateral and multilateral donors to developing countries over time. ${ }^{75}$ However, as pointed out in the introduction, the OECD DAC statistics only capture aid flows by the DAC member states and multilateral organizations. The increasing volume of external assistance provided by the non-DAC emerging economies, such as China, Brazil and India which are important players in Mozambique, is not systematically recorded by the DAC. Further, the DAC statistics do not fully capture aid provided by non-governmental organizations (NGO) as the DAC only records NGO aid as reported by the DAC members and multilateral organizations themselves. Hence, financial and other resources mobilized and channelled to Mozambique directly by NGOs, which are major sources of aid to Mozambique, do not enter into the OECD DAC statistics.

75. As discussed by Hanlon (2008) and Arndt et al (2006), the statistics concerning aid flows to Mozambique vary depending on the data source. For example, in their analysis of the impact of aid to Mozambique, Arndt et al. use three data sources: government's Balance of Payments statistics, fiscal accounts and OECD DAC data which all provide somewhat different estimates of the aid flows. 


\subsection{Aid Flows to Mozambique; An Overview}

The volume of external assistance to Mozambique has increased significantly since the early years of independence, and in particular since the mid-1980's. During the first ten year period after independence, the net ODA to GNI ratio recorded by the OECD DAC remained below 10\%. With the launch of PRE in 1987 the net ODA to GNI ratio increased to $30 \%$, and reached a peak in 1992 when net ODA amounted to $80 \%$ of the Gross National Income (GNI). In terms of gross aid, including debt relief, ODA reached over 92\% of GNI in 1992 following the debt relief under the enhanced HIPC initiative. ${ }^{76}$ During the ten year period from 1998 to 2008 , the net ODA to GNI ratio has fluctuated within the range from $19 \%$ to $26 \%$ with the exception of the year 2002, when net ODA reached 55\% of the GNI (OECD 2011, Retrieved in April 17, 2011 from World Wide Web: www.oecd.org/dac/stats/idsonline).

Figure 5.1, below, illustrates the trends in aid flows to Mozambique and the country's dependence on foreign aid as measured by the net ODA to GNI ratio during the post-independence period.

\section{Figure 5.1 | Net ODA Disbursements and Net ODA to GNI ratio in 1975-2008}

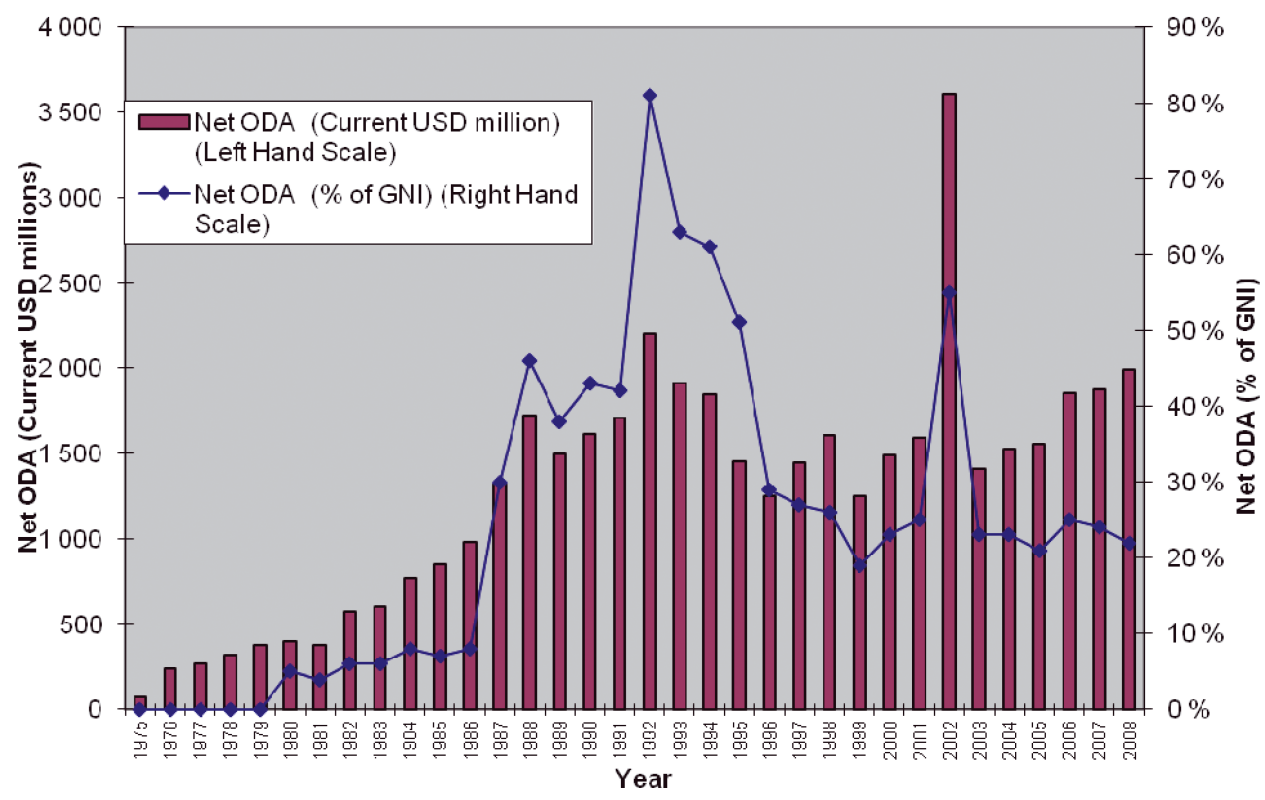

Source: www.oecd.org/dac/stats/idsonline, adapted by the author.

76. The 1992 and 2002 temporary peaks are explained by the influx of aid in the aftermath of the end of the war and the HIPC debt relief respectively. 
Aid flows measured in terms of ODA (net disbursements) per capita reflect similar trends. During the first decade after independence, ODA per capita gradually increased to USD 22 in 1985 (in current prices). In 1987-1991, following the introduction of PRE, ODA per capita amounted to an average of USD 65 reaching again a peak in 1992, the year of the signing of the General Peace Agreement, with USD 102 per capita. During the ten-year period from 1999 until 2009, ODA per capita has gradually doubled from USD 46 to USD 88 (in current prices) apart from another temporary peak in 2002. The trend of ODA per capita during the post-independence period is illustrated in Figure 5.2 below:

\section{Figure 5.2 | ODA per capita in 1975-2008}

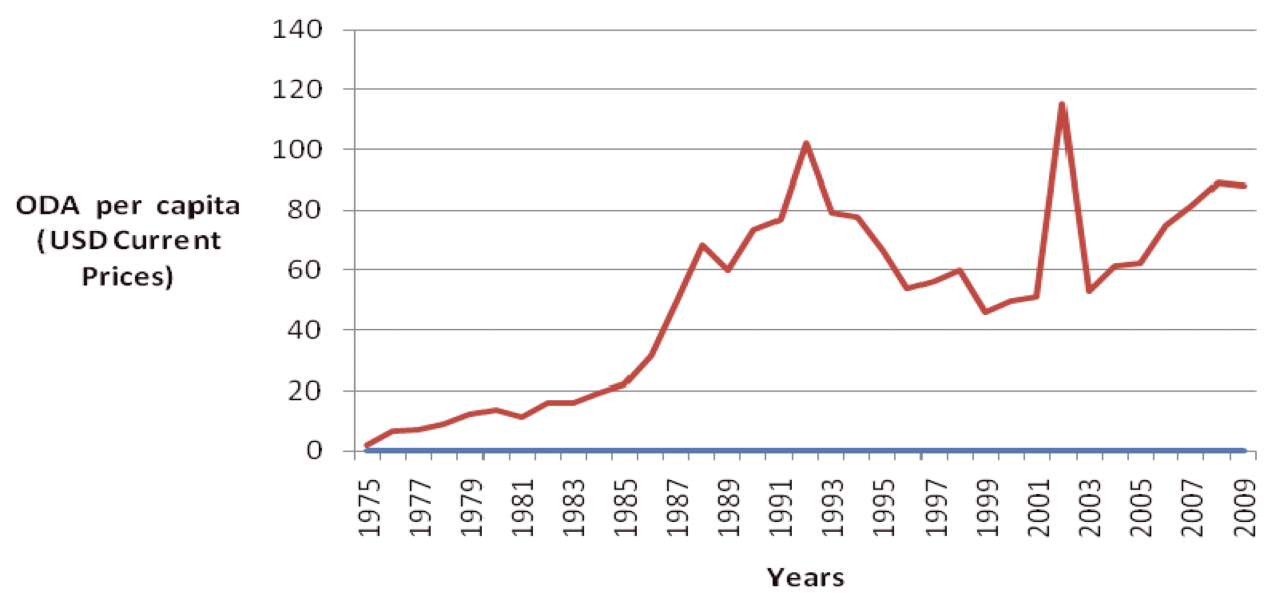

Source: www.oecd.org/dac/stats/idsonline, adapted by the author.

It is important to bear in mind that, from the early to mid 1980s, Mozambique's economic situation declined rapidly, and the country was faced with an unsustainable debt burden. Consequently, in the late 1980 s, over $50 \%$ of gross aid was used to pay back debt obligations due to the rapid increase in the debt burden and debt service obligations (Arndt et al., 2006, p. 28).

An analysis of the aid flows disaggregated according to various donor groups, that is by the OECD DAC member countries, the non-DAC countries reporting to DAC, and the multilateral aid agencies, shows that the contribution of the multilateral aid agencies has gradually increased. While the bilateral DAC countries continue as the largest aid providers, their relative share of total ODA to Mozambique shows a declining trend. As mentioned above, the peaks in bilateral financing in 1999 and 2002 are explained 
by the debt relief provided to Mozambique within the framework of the HIPC and multilateral debt relief initiatives. The international financial institutions, particularly the World Bank and the IMF, have emerged as the most important multilateral donors, followed by the African Development Bank. The aid flows disaggregated by donor groups are illustrated in Figure 5.3 below:

Figure 5.3 | Total ODA Net Disbursements; Bilateral and Multilateral Agencies 1980-2009

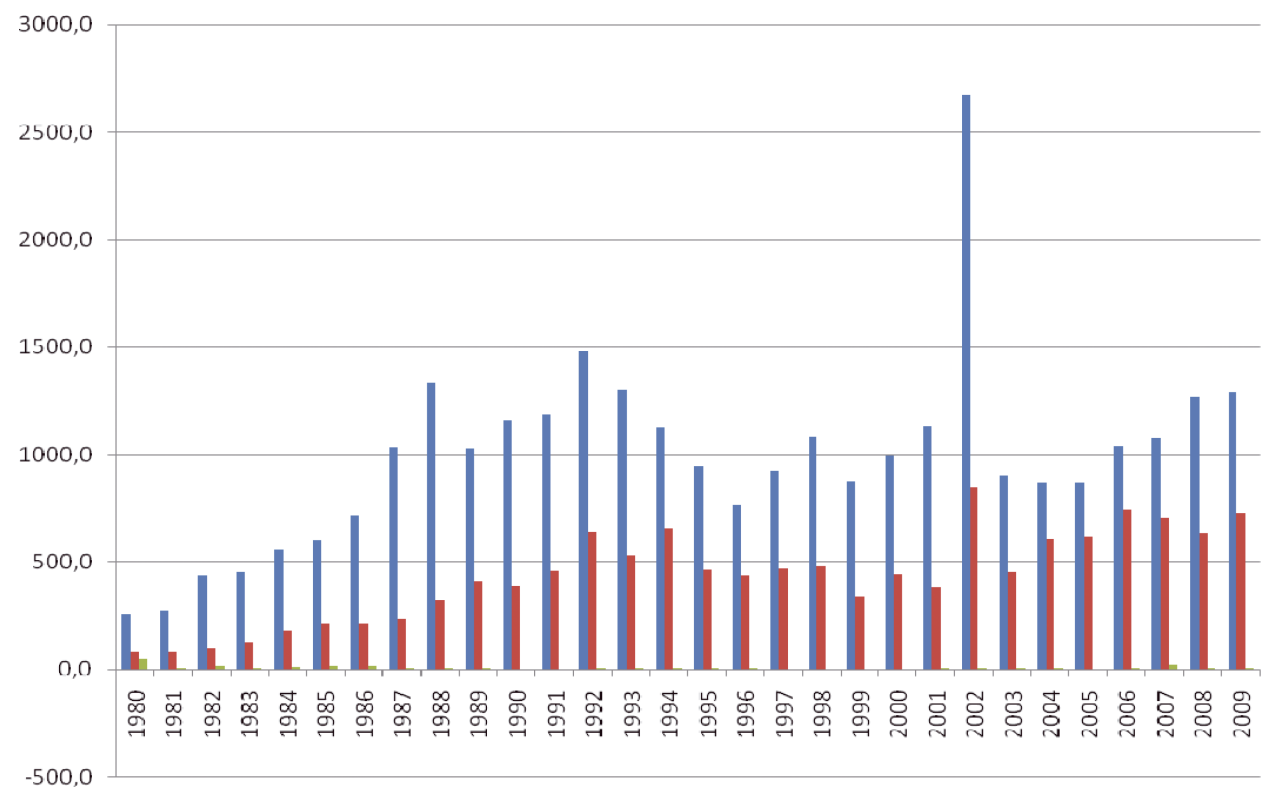

In constant 2009 USD, million

Blue bars: aid flows by bilateral DAC members

Red bars: aid flows by multilateral agencies

Green bars: aid flows by bilateral non-DAC members

Source: www.oecd.org/dac/stats/idsonline, adapted by the author.

The nature of the aid relationships between Mozambique and the international donor community can be divided into three broad periods which largely coincide with main trends in the country's political and economic development after independence (de Renzio and Hanlon, 2006). The main characteristics the three periods above will be discussed in the following sections. 


\subsection{First Decade of Aid}

During the first ten-year period after independence from 1975 to the mid-1980s, the era of central planning under one-party rule, Mozambique received external assistance mainly from the socialist countries of Eastern Europe as well as from the Nordic countries and Italy. They were later joined by the Netherlands, Switzerland and Canada. During the first decade of aid, the relationship between Mozambique and its donors was characterized by strong government leadership. Donor support was provided in line with Mozambique's development strategies at the time (de Renzio and Hanlon, 2006).

Detailed statistics on external assistance to Mozambique during the first years after independence are scarce, largely due to the fact that during the immediate post-independence period only few countries reporting to the OECD DAC provided aid to Mozambique. Based on the OECD DAC data, the total net ODA disbursements from all donors increased more than ten-fold from USD 68 million to USD 738 million (in constant 2009 prices) during the period of 1975 until 1984. The Figure below illustrates the growing trend in aid disbursements to Mozambique.

Figure 5.4 | Total Net ODA Disbursements 1975-1984

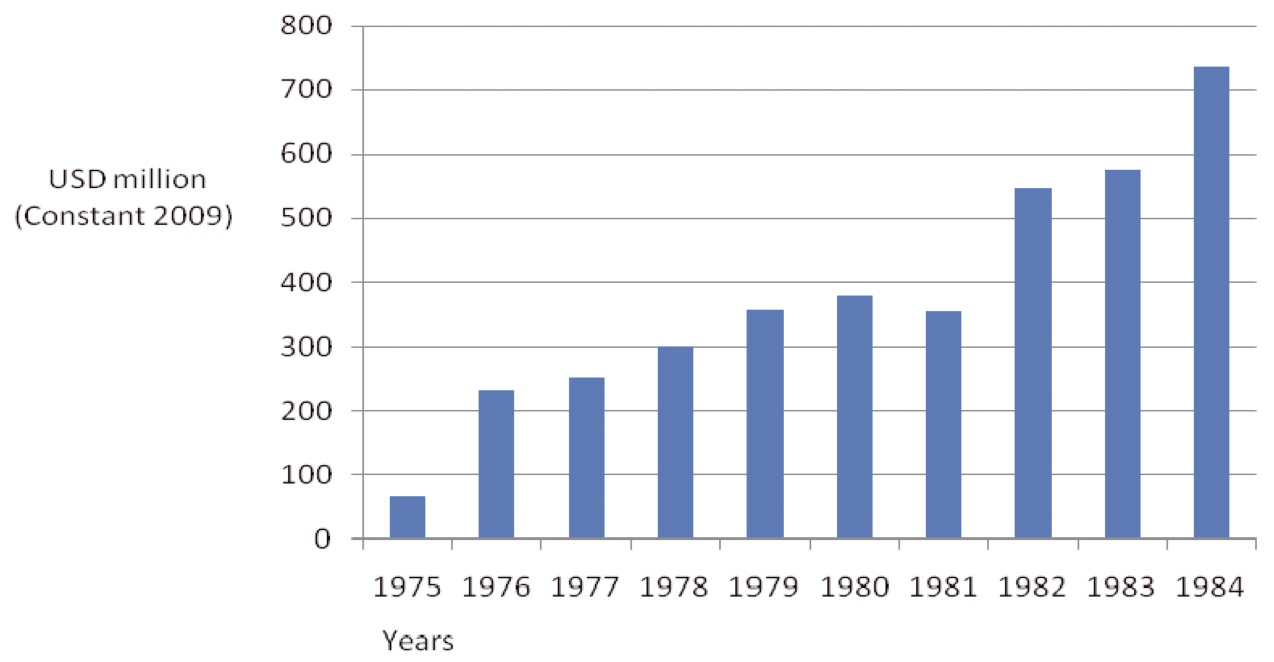

Source: www.oecd.org/dac/stats/idsonline, adapted by the author.

Mozambique's collaboration with the former Soviet Union and other socialist countries had its roots in the liberation struggle and the Cold War when Mozambique received 
military aid from the Eastern bloc. Apart from military aid, which is not counted as ODA, the Soviet Union and its allies provided technical assistance and machinery, in particular agricultural equipment. Much of the assistance was provided in the form of long-term loans which were paid back through exports. Scholarship programmes and employment schemes constituted an important component of the cooperation with the socialist countries including Cuba. As of 1982, more than 900 Mozambicans were studying and working in East Germany, and some 1,200 students were in Cuba. ${ }^{77}$ Apart from the cooperation with the Soviet-led socialist countries, Mozambique had well-established relations with the People's Republic of China which targeted its support mainly to health and agriculture (Isaacman and Isaacman, 1983, p. 182).

The support by the Nordic countries to Mozambique dates back to their long-standing cooperation with the liberation movements in Southern Africa including Frelimo (Sellström, 2002). During the immediate post-independence years, the bulk of the aid from the non-socialist countries was technical assistance and project aid. The Nordic countries were the main supporters in the agricultural sector through the joint Nordic agricultural programme, the Mozambique-Nordic Agricultural Programme (MONAP), initiated in 1977. It is estimated that in the early years after independence approximately $80-90 \%$ of the foreign currency budget of the Ministry of Agriculture was provided through MONAP. In 1989, MONAP still accounted for some $30 \%$ of the Ministry's foreign exchange resources (SIDA 1991, p. 39) ${ }^{78}$ In addition, the Nordic countries provided financing in the form of import support and balance of payment support. Emergency food aid started to play an important role as of the mid-1980s, in the face of the disruption of agricultural production caused by war and severe drought.

Many UN agencies established representation in Mozambique following its decision to join in the implementation of UN sanctions against Rhodesia in 1976. By the early 1980's, the UNDP programme in Mozambique was one of its largest programmes in Africa. Other UN agencies with operations in Mozambique included the UN Children's Fund (UNICEF), the office of the UN High Commissioner for Refugees (UNHCR), the UN Industrial Development Organization (UNIDO) and the Food and Agricultural Organization (FAO) as well as the World Food Programme (WFP) (Hanlon, 1991, p. 57).

77. These programmes came to an abrupt end with the collapse of the Soviet Union and the subsequent unification of Germany when thousands of Mozambicans had to return at a very short notice from the former East Germany (based on the author's own records).

78. The programme, initiated in 1977 and phased out as joint Nordic programme in 1989 consisted of technical, material and financial support amounting to a total of around USD 192 million (SEK 1.18 billion). The programme comprised agriculture, livestock, fisheries, forestry and research projects with focus on small scale agricultural and rural development (SIDA 1991, p. 27-30). 
During this period, the international financial institutions, notably the World Bank and the IMF, as well as the European Commission and the USA played a very limited role as donors. Mozambique was not party to the Lomé Convention, the main development cooperation agreement between the EU and the African, Caribbean and Pacific countries. Only in 1984 did Mozambique sign the then Lomé III Convention (Cotonou Agreement as of 2000).

In addition to official development assistance through governments and multilateral agencies, a number of non-governmental organizations, which had supported Frelimo already during the liberation struggle, continued providing assistance to the newly independent country. ${ }^{79}$

\subsection{Aid Architecture in the Aftermath of the Economic Recovery Programme}

The period extending from 1986 until the signing of the General Peace Agreement entailed drastic changes in Mozambique's aid architecture. In the mid-1980s, Mozambique initiated negotiations with the USA in an attempt to end the war as well as to gain economic support. In 1984 Mozambique joined the World Bank and the IMF. The introduction of the economic recovery programme in 1987, endorsed by the BWIs, led to a major increase in the flow of aid funds also from a larger group of bilateral donors. Over the period from 1984 to 1994, the total annual ODA (net disbursements, in constant 2009 USD) more than doubled from just over USD 800 million to USD 1.780 million. The increase of aid flows to Mozambique during the ten-year period from 1984-1994 is illustrated in Figure 5.5 below.

79. In Finland, for example, the first nationwide fund-raising campaign involving most of Finnish secondary school pupils in 1969, the so called Taksvärkki Campaign, mobilized funds for the Mozambique Institute which had been established in 1963 in Dar-es-Salaam, Tanzania, to support Mozambican refugees (Soiri and Peltola, 1999, p. 35). 
Figure 5.5 | Total Net ODA Disbursements 1985-1994

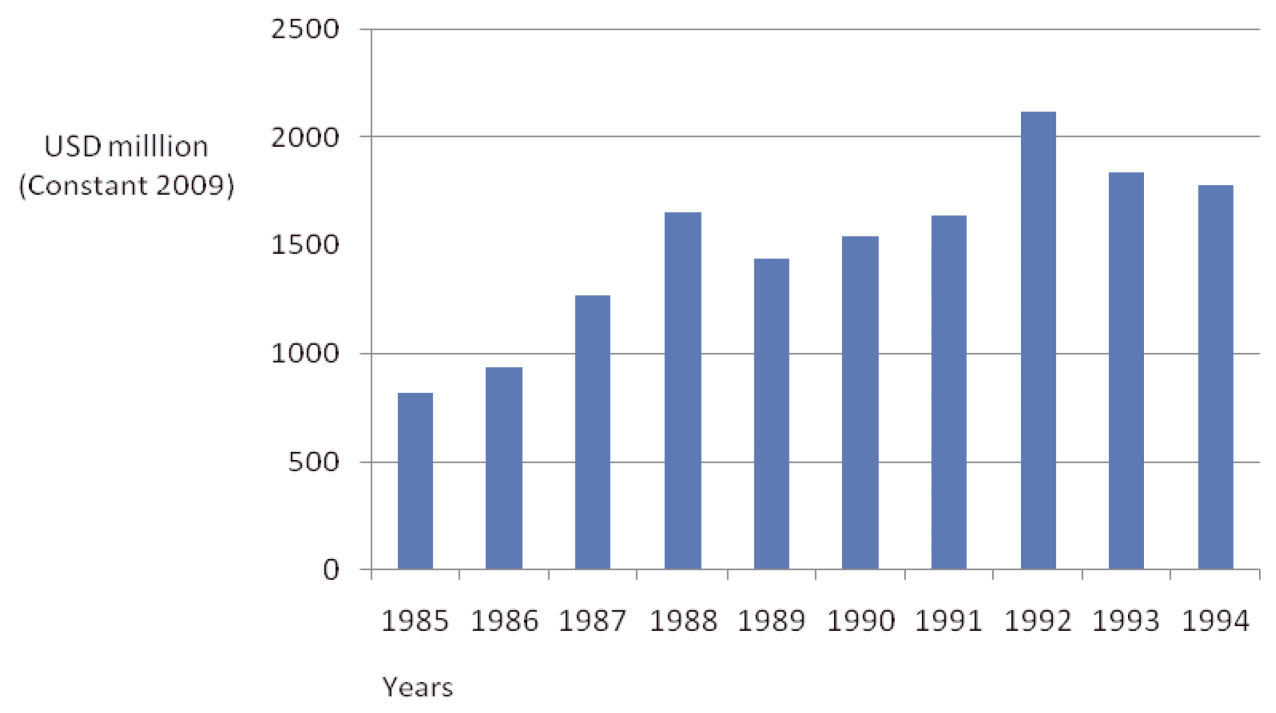

Source: www.oecd.org/dac/stats/idsonline, adapted by the author.

During the second decade of aid, the BWIs emerged as very visible partners for Mozambique, playing an important role in planning, financing and implementing various economic policy reforms. In 1987 Mozambique received its first structural adjustment loan, followed by an agreement in 1990 with the IMF on the enhanced structural adjustment facility (ESAF), which imposed tighter restrictions on subsidies and social expenditure. According to Hanlon, in the early 1990s IMF pressure over fiscal policy was so acute that bilateral donors issued a public statement criticizing the Fund for the cap it had imposed on public expenditure (Hanlon, 2002). Assistance was provided in the form of balance of payment support for the implementation of PRE as well as in project aid. Between 1989 and 1996 import support, food aid, debt relief and sector support accounted for more than $20 \%$ of total aid, reaching the level of more than $50 \%$ in 1992, the year of the signing of the peace agreement (Batley, Bjornestad and Cumbi, 2006, p. 13).

While the OECD DAC countries featured as the largest aid providers accounting for two thirds of the total ODA to Mozambique, assistance provided by the multilateral agencies more than tripled from approximately USD 200 million to USD 650 million (constant 2009 prices) during this period. The share of non-DAC donors declined from USD 15 million to a mere USD 3 million. The increasing role played by the multilateral agencies is illustrated in the Figure below, which indicates the share of the aid provided by the OECD DAC member countries, multilateral agencies as well as by the 
non-DAC countries during this period (the share of non-DAC countries being barely visible).

Figure 5.6 | Total Net ODA Disbursements; Bilateral (DAC and non-DAC) and Multilateral Agencies 1985-1994

USD million

(Constant 2009)

DAC Countries, Total

Multilateral Agencies,

Total

- Non-DAC Countries,Total

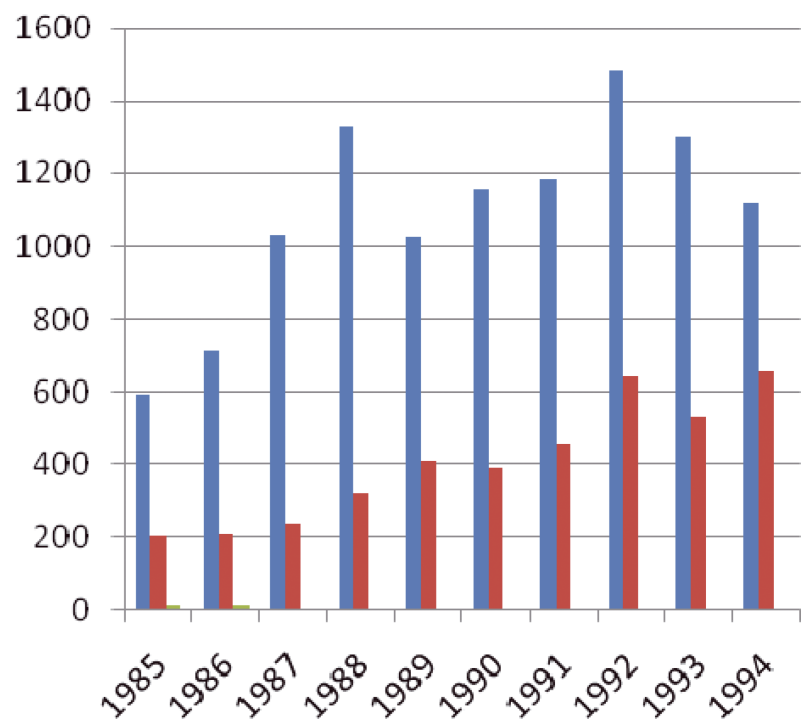

Source: www.oecd.org/dac/stats/idsonline, adapted by the author.

As argued by de Renzio and Hanlon, following the rapid influx of donor agencies with different development agendas the Government of Mozambique largely lost its policy control over aid. Furthermore, the balance of power among the aid agencies changed dramatically. With the decline of the support from the Soviet Union and Eastern European countries, and increasing aid from the BWIs and the USA, "the centre of the donor power moved from Europe to Washington" (de Renzio and Hanlon, 2006, p. 6).

\subsection{Aid Architecture during the Post-War Period}

The post-war period has cemented Mozambique's status as one of the "darlings" of the international donor community. Aid flows have stabilized at the level of USD 1.5 to USD 2 billion with a slightly increasing trend, apart from the peak in 2002, when net ODA disbursements exceeded USD 3,5 million (in constant 2009 prices). The trend of the total net ODA disbursements is illustrated in graph 5.7. 
Figure 5.7 | Total Net ODA Disbursements 1995-2009

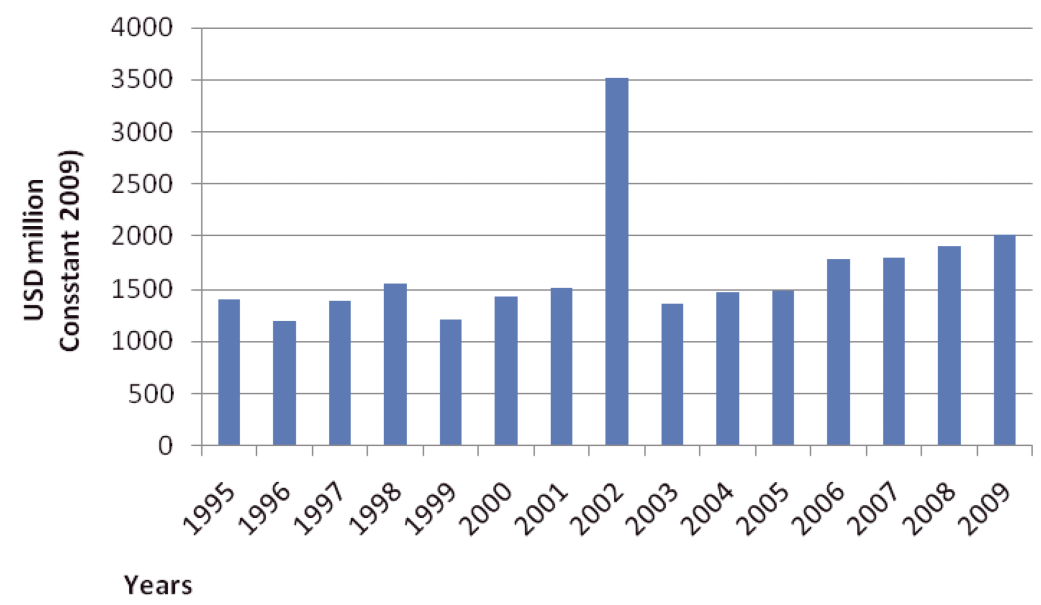

Source: www.oecd.org/dac/stats/idsonline, adapted by the author.

The 2002 peak in aid flows reflects the debt relief provided to Mozambique after it had reached the HIPC completion point, which was financed primarily by bilateral donors. This is clearly illustrated in the graph below which shows aid flows both in terms of the total ODA and ODA excluding debt relief provided by the DAC countries and by multilateral aid agencies. External assistance provided by the non-DAC countries remained marginal throughout this period and, for clarity reasons, is left out from graph 5.8 .

Figure 5.8 | Total Net ODA and ODA Excluding Debt Relief by OECD DAC Countries and Multilateral Aid Agencies 1995-2009

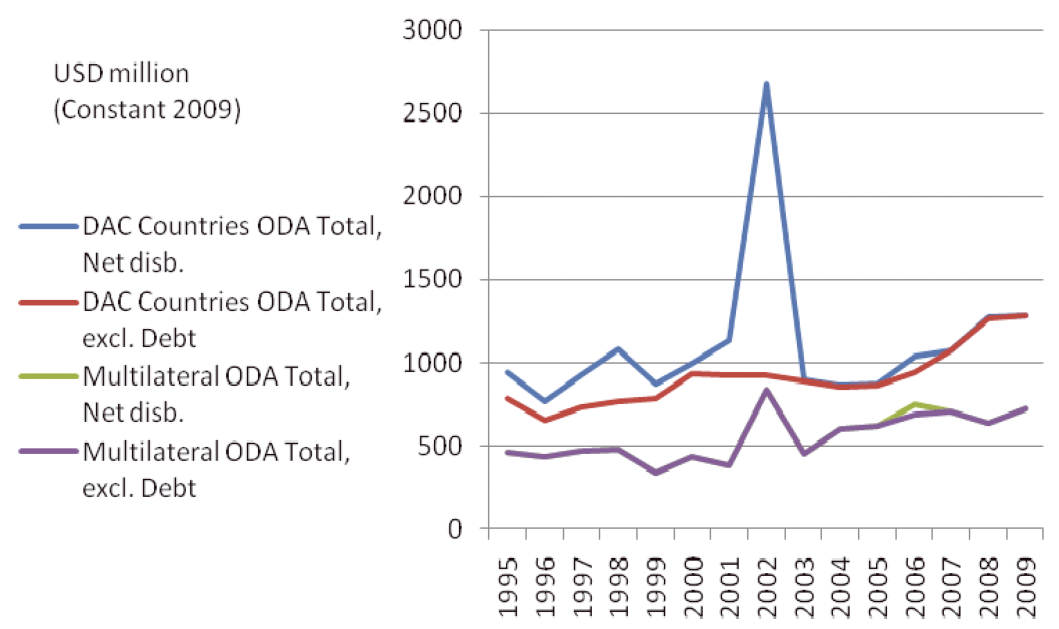

Source: www.oecd.org/dac/stats/idsonline, adapted by the author. 
Most of the aid to Mozambique from the OECD DAC countries and multilateral agencies has been provided in the form of grants. Over the past ten-year period, the financing in terms of both grants and loans show a similar pattern of growth with the amount of net loans representing about a quarter of the amount of grants provided to Mozambique. After the peak in 2002, aid provided as debt relief has played a marginal role. The temporary increase in debt relief grants in 2006 is explained by the cancellation of all multilateral debt, committed prior to 2005, under the Multilateral Debt Relief Initiative (MDRI), which was agreed in 2005.

According to de Renzio and Hanlon, the third post-war period can be been characterized as a "period of accommodation" (ibid., 2006, p. 6). The Government of Mozambique and the international donor community have gradually developed a relationship based on a partnership where the government is, at least formally, "in the driver's seat" setting policy priorities for foreign aid. The aid agencies for their part are committed to the principles of respecting country ownership, alignment, harmonization, mutual accountability and results-based management of aid, as laid out in the Paris Declaration on Aid Effectiveness adopted in 2005. ${ }^{80}$

\subsection{Aid Profile of the “Top Ten” Donors in Mozambique}

Following the above analysis of the general trends in external assistance to post-independent Mozambique, this section will focus on the ten largest donors operating in the country as measured by the volume of aid. The purpose of this discussion is to highlight the role of the "top ten" donors in bringing governance to the core of the dialogue between the donors and the Government of Mozambique, partly by moving forward with new modalities of development assistance.

The focus on the "top ten" donors can be justified on two accounts. First, despite the large number of donors active in the country, the ten largest donors have accounted for, on average, approximately $70 \%$ of all ODA to Mozambique over the five-year period

80. Ownership: Partner Countries exercise effective leadership over their development policies and strategies, and co-ordinate development actions.

Alignment: Donors base their overall support on partner countries' national development strategies, institutions and procedures.

Harmonization: Donors' actions are more harmonized, transparent and collectively effective.

Management for Development Results: Managing resources and improving decision-making for results. Mutual Accountability: Donors and partners are accountable for development results. (OECD 2005, p. 3-8). 
2005 to 2009 (World Bank and OECD DAC, www.aidflows.org, with calculation by the author) $)^{81}$. Second, the group of the "top ten" largely corresponds with the list of donors whose governance assessments have been selected as units of analysis for this research. The discussion will be limited to the period of 2005-2009 which largely coincides with the period during which the selected governance assessments have been carried out.

According to OECD DAC data on average aid volumes during the period 2005-2009, the following ten donors emerge as the largest donors in Mozambique (listed according to the volume of aid): the World Bank (IDA), the EU, the USA, the UK, Sweden, the African Development Bank (the African Development Fund), Norway, Denmark, the Netherlands and Germany. The group has remained largely unchanged although the ranking order has somewhat varied. While the $\mathrm{UN}$ with its different agencies plays a central role in the aid policy dialogue in Mozambique, in financial terms the assistance provided by the UN family is relatively small, and therefore none of the UN agencies is included in the group of "top ten". The emerging donors, such as China, Brazil and India, which are increasingly visible in Mozambique, are not included in the analysis because of the lack of comparable data. As mentioned earlier, these countries do not systematically report their aid flows to the DAC. In fact, the data on aid flows from these countries are generally very scarce, as pointed out even by the authorities of the Government of Mozambique (information based on personal communication).

During the five-year period 2005-2009, the total net disbursements (in constant 2009 prices) of the World Bank exceeded, on average, USD 250 million per year, followed by the EU with approximately USD 200 million per year. In the case of the USA, total net disbursements amounted to approximately USD 170 million annually. The UK, Sweden and the African Development Fund provided, on average, some USD 100 million per year each. They were followed by Denmark, Norway and the Netherlands each of which provided some USD 90 million annually. Assistance provided by Germany averaged some USD 70 million per year. The aid flows (total net disbursements) by the top ten donors is illustrated in Figure 5.9 below:

81. There are over 20 bilateral governmental aid agencies and some 20 multilateral agencies, including the various UN agencies, several so called vertical funds and close to 300 foreign NGOs with numerous interventions in the country (Appolinario, 2010, p. 14, see also www.odamoz.org). 
Figure 5.9 | Total Net ODA Disbursements by Ten Largest Donors (5-year average 20052009)

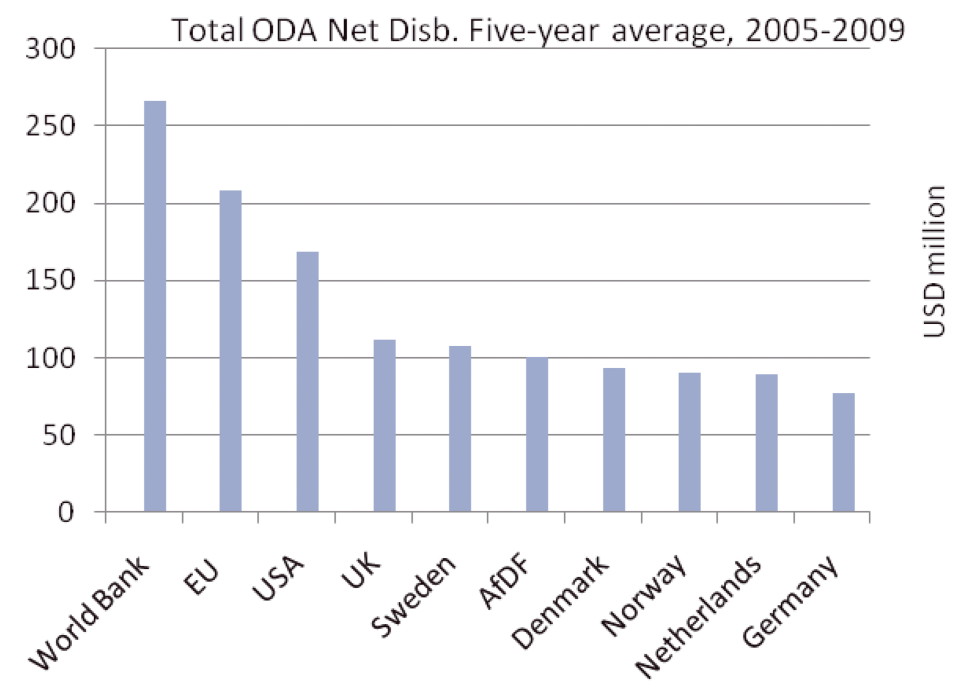

Constant 2009 USD

Source: www.aidflows.org (World Bank and OECD DAC), compiled by the author.

An analysis of the sectoral allocation of aid by the ten largest donors during the period 2005-2009 indicates that apart from debt relief, aid has been targeted at building economic infrastructure and supporting social sector development. With the gradual shift from project- to programme-based aid modalities, programme aid is becoming the single largest sector (World Bank and OECD DAC, www.aidflows.org). ${ }^{82}$

\subsubsection{Towards New Modalities of Aid}

In parallel with the increasing volume of aid, the modalities of aid used by the ten largest donors have broadened from project-specific assistance to coordinated, programme-based assistance such as sector-wide programmes and general budget

82. Limiting the analysis to a 3-year period from 2007 until 2009, the list of "top ten" donors remains the same whereas the sectoral allocation of aid changes, in particular, because debt relief has no longer been needed following the cancellation of Mozambique's multilateral debt in 2005. General budget support maintains its position as the single biggest sector (27\% of total ODA), followed by assistance towards social sector development, notably to health (20\%), education (10\%) and other social infrastructure (18\%). Support to economic infrastructure accounted for $13 \%$ of total ODA while some $7 \%$ of aid was targeted at production sectors (World Bank, OECD DAC, www.aidflows.org). 
support. ${ }^{83}$ In Mozambique, the transition from isolated project interventions towards programme-based assistance was initiated in the mid-1990s as an attempt to enhance the effectiveness of aid. With the new aid modalities governance has become a key component of the dialogue between the donors and the Government of Mozambique, as well as with other Mozambican stakeholders.

The first formal coordination mechanism for general budget support, the Common Framework Agreement for the Joint Donor Programme for Macro-Financial Support, was signed between six bilateral donors (Denmark, Netherlands, Norway, Sweden, Switzerland, UK) and the Government of Mozambique in 2000. The main rationale for the agreement was to enhance the donor support for the implementation of the government's poverty reduction strategy, PARPA. With regard to policy conditionality, the agreement required the government to prioritize poverty reduction according to PARPA (Harding and Gerster, 2004, p. 8). It is worth noting that, apart from Switzerland, the bilateral donors signing up to the first coordination mechanism belong to the contemporary group of the ten largest donors. ${ }^{84}$

The Common Framework Agreement has been superseded by a Memorandum of Understanding (MoU), agreed upon in 2004 and further revised in 2009. The elaboration of the $2004 \mathrm{MoU}$ with a detailed performance assessment mechanism was motivated by the temporary freeze of budget support disbursements by some donors in 2002, in the aftermath of the banking crisis and the related assassinations in Mozambique. The Government of Mozambique, supported by the IMF, requested that the conditions for budget support disbursements by donors be clarified (Batley, Bjørnestad and Cumbi, 2006, p. 18).

The $2004 \mathrm{MoU}$, and its revised version of 2009, outlines the commitments by all parties, the administrative structure and procedural arrangements for general budget support. A joint planning and monitoring mechanism for general budget support was established. The MoU further led to the elaboration of a Performance Assessment Framework (PAF) to be used as the joint instrument for assessing government's performance and for deciding donors' commitments for the following year. The

83. General budget support is defined as a method of financing a partner country's budget through a transfer of resources from a donor to a partner government's treasury, to be managed in accordance with the partner country's budgetary procedures. This definition also includes sector budget support (OECD 2006). General budget support in Mozambique consists of a programme of non-earmarked financial support to the government's economic and social programme (PES) and poverty reduction strategy, PARPA.

84. In 2012, the Government of the Netherlands made a decision to stop providing general budget support as of 2013. However, within the framework of this research, the Netherlands is still counted as one of the budget support donors. 
Performance Assessment Framework builds on the core principles of Paris Declaration while the indicators for measuring progress are derived from the government's development strategies, notably PARPA and the Economic and Social Programme (Programa Económico and Social, PES). The MoU introduced also a number of conditions related to the political governance in Mozambique (www.pap.org.mz). ${ }^{85}$

The number of donors providing general budget support under the framework of the MoU has increased from the original 6 agencies to 19 agencies by 2010. While formally named as the Programme Aid Partners (PAP), in common parlance the PAP donors are referred to as the "G19", based on the number of donors belonging to the group. The ten largest donors are all either full or associate members of the G19. Reflecting the growing number of the G19, the share of general budget support of total ODA to Mozambique has raised from about 2.7\% in 2000 to about 28\% of in 2009 (net disbursements) (www.pap.org.mz). ${ }^{86}$

The systematic collaboration within the framework of general budget support has made the G19 the most influential donor group. With the USA and the UN joining the group as associate members, its role has been further strengthened. The most important donors outside the G19 are the non-DAC donors, such as China, India and Brazil, as well as some large private foundations and global funds (e.g. Bill and Melinda Gates Foundation and the Global Fund for Aids, Tuberculosis and Malaria). ${ }^{87}$ The information on the contents and the scale of operations by the non-DAC donors and global funds remains scarce. According to an evaluation report on the implementation of the Paris Declaration in Mozambique, commissioned by the Ministry of Planning and Development, "the lack of knowledge among central ministries (and donors) about their activities was remarkable" (KPMG/Government of Mozambique, 2010, p. 25). The report referred specifically to vertical funds.

85. The MoU covers also non-earmarked sector budget support. With regard to project aid and technical assistance, the MoU states that "successively, in pace with their development, these modalities will be directly executed by the GoM using its financial management systems" (MoU 2009, p. 82). This implies that the PAP donors are committed, within the framework of the MoU, to follow the core principles of Paris Declaration in terms of all modalities of aid.

86. In 2010, the donors belonging to the Programme Aid Partners are: Austria, African Development Bank, Belgium, Canada, Denmark, United Kingdom, European Commission, Finland, France, Germany, Ireland, Italy, the Netherlands, Norway, Portugal, Spain, Sweden, Switzerland and World Bank. The USA and UN have joined as associate members and the IMF has "ex-officio" membership in the PAP. - As of 2013, the Netherlands no longer formally belongs to the G19.

87. The Development Partners Group (DPG), chaired jointly by the World Bank and the UN, is seen by many to be more of a forum for discussion. It does not have a regular government counterpart in the same way that the G19 does. However, the DPG includes non-traditional donors, such as China, Brazil and Vietnam, and therefore, might be a possible vehicle for developing a more inclusive aid architecture in the future (KPMG/ Ministry of Planning and Development 2010). 
The G19 coordinates a large number of working groups (a total of 30 working groups in 2010), chaired or co-chaired by representatives of the government. Most of the working groups have representatives also from the Mozambican civil society organizations. The working groups are organized thematically according to the key pillars of PARPA and contribute to the annual Joint Reviews and Mid-Year Reviews within their specific thematic areas (www.pap.org.mz). Amongst the general budget support donors, the coordination is based on an annually rotating troika format with one donor assuming the role of the presidency. On the government side, the Ministry of Planning and Development and the Ministry of Finance are the key focal points for the PAP, whereas the Ministry of Foreign Affairs coordinates the overall development cooperation policy. Line ministries are involved in discussions on sector-specific issues (information based on personal communication, see also www.pap.org.mz).

The elaborate coordination framework built for the general budget support has been criticized both by the Government of Mozambique and the donors themselves for the increased administrative burden and related transaction costs. It has also been argued that the space for substantive debate has been reduced with the dialogue focusing on the annual administration of the multi-layered coordination as an end in itself. However, it has also been pointed out that the coordination framework allows the government to deal with a large number of donors as a group rather than on individual basis (Killick, Castel-Branco and Gerster, 2005; KPMG/GoM, 2010, discussions by the author with the representatives of PAP donors, the Government of Mozambique and academics).

Despite the relatively rapid increase of programme-based aid modalities including general budget support and sector wide programmes, more than $50 \%$ of aid to Mozambique is still provided in the form of project aid and technical assistance (GoM, Ministry of Planning and Development 2010).

\subsubsection{Governance in the Context of the New Aid Modalities}

As a result of the programme-based modalities of aid, the notion of good governance has been brought to the core of the policy dialogue between the donors and the Government of Mozambique. The enhanced emphasis on good governance is embedded also in the government's poverty reduction strategies which define good governance as a fundamental condition for successful implementation of the poverty reduction strategy. Both PARPA I and PARPA II highlight the role of the state as the key actor in promoting good governance and emphasize the accountability of the state vis-à-vis its citizens and private sector actors (Republic of Mozambique/PARPA, 2001 and Republic of Mozambique/PARPA II 2006). As stated in PARPA II: "the proper functioning of State institutions and the State's ability to bring services to the citizens, inclusion of 
forms of participative democracy in public administration, and a respect for the value of traditional instruments for conflict resolution are extremely important in reducing poverty" (Republic of Mozambique, 2006, p. 70).

While the specific components of good governance as outlined in PARPA II are limited to public sector reform, decentralization, and reform of the justice system ${ }^{88}$, the governance agenda addressed by the G19 is much broader and includes issues of political governance. The key issues related to the broader governance agenda are outlined as the "underlying principles" in the Memorandum of Understanding. According to the $2009 \mathrm{MoU}$ :

"The GoM and the PAPs are agreed that the GoM's commitments, through the Constitution and international agreements, to the following underlying principles of governance are the basis for their cooperation, and in the context of this $\mathrm{MoU}$, for the provision of Budget Support": 1) safeguarding peace and promoting free, credible and democratic political processes, independence of the judiciary, rule of law, respect for human rights, good governance and probity in public life, including the fight against corruption; 2) prioritising fighting poverty through its policies and plans and in its patterns of public expenditure; and 3) pursuing sound macro-economic policies and public financial management systems" (Memorandum of Understanding, 2009, p. 6). ${ }^{89}$

The underlying principles constitute the most powerful set of conditions for the G19 donors as the MoU clearly states that "the violation of an underlying principle is understood as being above and beyond concerns raised about under-performance against indicators and targets expressed in the Government of Mozambique's PAF" (MoU, 2009, para 21, p. 7). The MoU further notes that, in the case of the violation of the underlying principles, "PAPs reserve the right to unilaterally or jointly withhold disbursements" if an amicable solution cannot be reached through the dispute settlement mechanism outlined in the MoU (MoU, 2009, para 22, p. 7).

The influential role of the G19 has raised concerns about the government's ownership of aid policies, and Mozambique's development strategies in general. Although the

88. In accordance with the PARPA II, the three thematic working groups under the governance pillar are: the working groups on "public sector reform", on "decentralization" and on "justice and legality" (www.pap.org.mz).

89. Two of the PAP donors, namely the EC and the World Bank, introduced exceptions related to the "underlying principles" as defined in the MoU, and thereby, de facto refused to adhere to the MoU on these issues. For the EC, the MoU "remains subject to the provisions of the Cotonou Agreement or any subsequent framework for the European Commission-Mozambique cooperation". The World Bank makes reference to its Articles of Agreement according to which the World Bank "shall not interfere in the political affairs of any member; nor shall they be influenced in their decisions by the political character of the member or members concerned. Only economic considerations shall be relevant to their decisions..." (MoU 2009, p. 78). 
2005 evaluation of the impact of general budget support in Mozambique indicated a "moderately positive effect in increasing core governmental ownership of the budgetary process" (Batley et al., 2006, p. 5), it has also been pointed out that general budget support has allowed the donors to get deeply involved in the core budgeting and policy-making processes of the government at central and sectoral levels (Killick, Castel Branco and Gerster, (2005); Batley et al., 2006; de Renzio and Hanlon, 2007; Hanlon and Smart, 2008; Castel-Branco, 2011). The intensive donor participation may undermine national ownership, especially when the government's capacity is weak. The fact that the government may write its own development strategies and exercise formal leadership of donor coordination does not necessarily signify government ownership (KPMG/Government of Mozambique, 2010). It has also been argued that over the years of collaboration with donors, the Government of Mozambique has become aware of their expectations and is able to shape its policies accordingly (de Renzio and Hanlon, 2007; Hanlon and Smart, 2008; Castel-Branco 2011).

The enhanced political conditionality introduced in the MoU is another cause for concern from the point of view of government ownership. With the underlying principles that involve broad political conditionality, such as "promoting free, credible and democratic political processes", the principle of mutual agreement in assessing the government's performance has become a contested issue. This was reflected in the debates about the temporary suspension of general budget support disbursements by some of the G19 donors who questioned the transparency of the electoral process prior the 2009 parliamentary elections (Africa Confidential, March 19, 2010, Vol. 51, No. 6). From the government's point of view, a mere suspicion of a violation of the underlying principles led to an immediate suspension of funding without referring the case first to the dispute settlement mechanism provided for in the MoU. The government has pointed out that donors seem far more prone to react on the basis of the underlying principles than on the regular PAF indicators. The G19, for its part, argued that its strong action was justified as a defence of good governance that includes the political rights of the citizens. The donors had the last word, and to overcome the freeze in disbursements, the government was requested to present a detailed reform plan, a Governance Action Plan (GAP). ${ }^{90}$ The incidence implies that the G19 and the government interpret the notion of ownership differently. It has further contributed to growing scepticism within the government about the donors' commitment to the principle of ownership (KPMG/Government of Mozambique, 2010).

Finally, the partner country ownership of the Paris Declaration is in itself a vague notion. The Paris Declaration defines ownership as the "partner countries exercising

90. The implementation of the GAP was to be followed up at a political level between the G19 ambassadors and the GoM ministers. 
effective leadership over their development policies and strategies, and co-ordinate development actions" (OECD, 2005, p. 3-8).

The definition is not limited to government ownership but refers to wider national ownership, which includes other national stakeholders such as the parliament and civil-society actors. In Mozambique, the parliament has played a minor role in the development of national poverty reduction strategies, and its role in aid management and decision-making remains limited. The civil society has been more actively invited to participate in the formulation and monitoring of PARPA as well as the general budget support programme, but limited capacity and resources undermine its role to engage in policy dialogue. Nevertheless, there are influential CSO groups including the Poverty Observatories (renamed as Development Observatories) which contribute to the debates about the implementation of general budget support and of PARPA in general.

\subsection{Contribution of Aid to Mozambique's Development}

As discussed in Chapter 2, the question whether aid contributes to development seems to remain a contested issue, at least among academics. In this section, the focus is on the impact of aid on Mozambique. While a comprehensive analysis of the role of aid in Mozambique's post-independent political and socio-economic development is beyond the scope of this research - and would in any case be very problematic due to the lack of a counterfactual, as well as for other methodological reasons - an attempt is made to identify some of the key developments that can be attributed to the sustained high flows of aid. A distinction will be made between the intended and the unintended outcomes of aid. ${ }^{11}$

\subsubsection{Intended Outcomes}

According to a study by Arndt, Jones and Tarp (2006) covering the period from 1980 to 2004, external assistance to Mozambique promoted the strengthening of the country's macro-economic framework, supported an expansion of health and education services and the rehabilitation of transport network, and thereby contributed to the sustained growth of the economy. Linking the achievement to aid is justified by the fact that more than $50 \%$ of the government's public expenditure, and close to $100 \%$ of

91. This discussion draws primarily on the following studies: Arndt et al. (2006), Batley et al., 2006, Lawson et al., 2006, Lawson et al., 2008, KPMG/Government of Mozambique, 2010. 
public investment, were financed through aid during the period under consideration. Without the additional resources provided by donors, the implementation of the policy reforms launched with the economic recovery programme (PRE), and the significant investments in social and physical infrastructure, could not have been carried out. Based on a detailed analysis of the macro-economic policy reforms comprising fiscal, financial and public sector reforms, Arndt et al. conclude that "the available evidence suggests that external donors have been instrumental in these policy developments" and further that "whilst these reforms are still ongoing it remains clear they have reduced economic distortions and provided a much improved basis for macroeconomic management" (Arndt et al., 2006, p. 34).

The impact of aid on enhancing Mozambique's public financial management system, and the institutional capacity of government institutions, has been evidenced in several evaluations (see for example Batley et al., 2006, Lawson et al., 2006, Lawson et al., 2008, KPMG/Ministry of Planning and Development, 2010). These studies, albeit more technical in their approach, identify significant improvements in the key indicators of Mozambique public financial management. ${ }^{92}$ As the strengthening of public financial management has been one of the main priorities of the donors, in particular of the BWIs and the PAPs, it can be argued that the achievements are largely related to donor support.

Concerning social sector development, particularly health and education, Arndt et al. provide evidence of the significant expansion of service delivery and improved access to health and education services which has led to positive trends in social development indicators. During the period 1992-2004, primary school enrollments increased by $174 \%$ and the secondary school enrollments by $537 \%$. According to Arndt et al. the increase in school enrollment was made possible by the donor-financed expansion of the education system (Arndt et al., 2006, p. 40). The positive trends in social sector indicators are largely confirmed by the successive household surveys carried out in 1995/96, 2002/03 and 2008/09. Although the household survey results cannot be directly attributed to donor support, the fact that external funding continues to account for the bulk of public expenditure in social sectors indicates a positive correlation between aid and development in these sectors.

The results of the investments in the rehabilitation of the roads network, which is of fundamental importance for both the domestic economy and export industries, show

92. Following the Public Expenditure and Financial Accountability (PEFA) methodology, the key indicators used to assess the public financial management system include: credibility of budget, comprehensiveness and transparency of the budget, policy-based budgeting, revenue collection and management, cash management, payroll, procurement and internal controls, accounting, recording and reporting, external scrutiny and auditing. 
similar positive trend. These achievements can be largely attributed to external assistance, due to the fact that the expenditures in the roads rehabilitation were financed up to $75 \%$ by donors (Arndt et al., 2006, p. 48). Again, the household survey data indicate similar trends: access to basic infrastructure, including water and sanitation, has improved between 2002/03 and 2008/09 (the period between the two latest household surveys).

The impact of aid on development in the agricultural sector remains more questionable in light of both the analysis by Arndt et al. and the household survey data. Although the development in the sector has been relatively good since the end of the war in 1992, donor support, that accounts for some $80 \%$ of total spending in the sector, has been characterized by a lack of consistency and common understanding of priority needs. It is therefore concluded that "it is difficult to link the contribution of donor support/government activity to the increased agricultural production and rural incomes observed over the past decade" (Arndt et al., 2006, p. 52). Similar conclusions have been drawn on the basis of the results of the household surveys.

The international donor community has also played an instrumental role in Mozambique's political transformation, particularly, in supporting the peace process and the transition to multi-party democracy. Apart from providing financial support for the peace negotiations, and the subsequent demobilization and reintegration of the soldiers of both armies, significant financing was provided, first and foremost, to Renamo to facilitate its transformation into a political party (Manning, 2002). The organization of the first elections in 1994, as well as the successive elections in 1999, 2004 and 2009 have all been financially supported by the donor community. In addition, the funding by donors to Mozambican civil society organizations has contributed to enhancing their voice and capacity to hold the government accountable.

In conclusion, as argued by Arndt et al.:"Without sustained aid at a high level there is no way in which Mozambique would have been able to: (i) establish peace so smoothly; (ii) manage the challenge of post-war stabilization; and (iii) carry out widespread reconstruction" (Arndt et al., 2006, p. 79).

\subsubsection{Unintended Outcomes}

The steadily increasing volumes of aid and the number of donor agencies operating in Mozambique have also led to unintended outcomes which can be considered detrimental to the development of the country. Among the most obvious unintended outcomes is the country's continued high dependency on external assistance, and related to that, the limited space for independent policy formulation. The most controversial 
accusations concerning the impact of aid are linked to a weakening institutional framework and increasing corruption in the public sector.

In terms of the net ODA per capita in 2009, Mozambique ranked as the $7^{\text {th }}$ most aid-dependent country in Africa (World Bank, World Economic Indicators. Retrieved June 15, 2010 from the http://data.worldbank.org/indicator/DT.ODA.ODAT.PC.ZS). Despite the government's somewhat successful efforts to decrease its financial dependency, the share of external assistance is estimated to have amounted to $11 \%$ of GDP in 2011. ${ }^{93}$ Donor-financed investments in the social sectors and public infrastructure have also created long-term fiscal implications which will, potentially, reinforce Mozambique's aid dependency beyond the current financing requirements.

Dependency on external assistance to carry out economic reforms has impacted upon Mozambique's policy choices. While the economic recovery programme (PRE) was initially designed by the government of Mozambique, the final planning of the policy reforms was largely in the hands of the BWIs. Hence, many of the policy reforms introduced under the economic recovery programme (PRE), such as the rapid privatization of state-owned enterprises and significant cuts in public expenditure, were initiated and implemented in response to donor pressure. The space for independent policy-making was largely limited (Arndt, Jensen and Tarp, 2000).

The role of the donors in influencing political changes is perhaps not as obvious. The pressure to change the Constitution to allow for multi-party democracy was driven by the Frelimo government's growing desire to end the war, but this transition was widely advocated and supported by Western donors in the aftermath of the Cold War. Without creating a space for Renamo to participate in the political arena, the peace negotiations would not have succeeded. As discussed earlier, the change of the political system was one of the key elements of the 1992 General Peace Agreement. Yet, the implementation of the peace agreement, with the demobilization of the armed forces and the organization of the first elections, was made possible by significant flows of aid.

The evolution of the aid architecture in Mozambique, characterized by an increasing number of aid agencies entering to the country, has also led to a number of unintended outcomes. Despite the efforts to increase donor coordination within the framework of general budget support and sector-wide programmes, the bulk of aid is still channelled in the form of projects. Project-based assistance is often provided outside the government structures which has contributed to institutional fragmentation and weakening

93. The share of external assistance in the GoM's budget has decreased from 53\% in 2009 to $44 \%$ in 2011 (budget estimate for 2011). 
of the government's capacity to plan investments coherently at central and sectoral level (Arndt et al., 2006, p. 59). The fragmentation of the institutional framework is exacerbated by the fact that many donors continue to provide funding outside the government's budget. According to the Ministry of Planning and Development, approximately $83 \%$ of aid flows are reported in the government budget (KPMG/Government of Mozambique, 2010, p. 27). The amount of "off-budget" funding is, however, likely to be larger as the data by the Ministry of Planning and Development do not fully capture the aid provided through the non-governmental organizations.

Despite the good intentions, the transition to new aid modalities, in particular, to general budget support, entails also several unexpected consequences which can be considered detrimental to Mozambique's own policy space and domestic accountability. As has been described above, the general budget support donors are involved in the key planning and policy-making processes at the highest level of the government. It has been suggested that the budget support donors have better access to government documents than national stakeholders, such as the parliament and civil society actors. The close relationship and intensive policy dialogue between the general budget support donors and the government seem to have created perverse accountability relations: instead of being accountable, in the first place, to the parliament and the citizens, the government seems to respond more swiftly to the accountability requirements set by the donors (Killick et al., 2006, Batley et al. 2006). As argued by Hodges and Tibana, "the high aid dependence means that the budget process essentially involves only two actors, the executive and foreign donors. Accountability to donors is much stronger than it is to Mozambican society". (Hodges and Tibana, 2004, p. 8). The risk of developing the complex general budget support structures into a shadow government structure has been mentioned by the donors themselves (Mozambique Political Process Bulletin, 2009).

One of the most controversial issues linked to external assistance in Mozambique is the role of aid in promoting corruption. Corruption is highlighted as a serious problem in several international and domestic assessments, and there are indications that corruption is increasing. However, whether external assistance has contributed to increased corruption is subject to an intense debate among the policy-makers and academics. On the one hand, various evaluations have shown that the enhanced emphasis by donors on prudent public financial management has resulted in improved longterm financial planning, budgeting and budget execution both at central and sectoral levels. On the other hand, it has also been argued that high flows of aid have fuelled corruption. The evidence of extremely low levels of corruption during the immediate post-independence era has been contrasted against wide-spread high-level and petty corruption in the public sector, in particular, in the aftermath of the launch of the economic recovery programme and the subsequent influx of aid. For example, already 
in 1991 Hanlon accused aid workers of creating a "culture of corruption" by offering bribes and gifts even when they were not asked to do so. Hanlon further argued that aid agencies "weaken state structures, steal government staff, create complex parallel structures, and block the creation of monitoring systems which make it impossible for Mozambique to stop corruption" (Hanlon 1991, p. 238). The drastic cuts in public expenditure, including salary cuts, imposed as part of the economic recovery programme, created a situation where informal fees for public services became the norm. The large-scale privatization of state-owned enterprises was promoted by donors, in particular by the World Bank and the IMF, as an integral component of the economic recovery despite the signs of non-transparent financing arrangements (Castel-Branco et al., 2001; Hanlon 2004).

Over the past decade, the question of donors promoting corruption in Mozambique has become even more complex. It has been argued that having invested substantial amounts of aid in Mozambique's post-conflict reconstruction, transition to multiparty democracy and socio-economic development, donors have created a vested interest in maintaining the myth of Mozambique as a "success story", and therefore avoid confronting the government on corruption systematically. According to de Renzio and Hanlon, "the donors' need to support Mozambique as a success story is contradictorily part of the 'pathological equilibrium..." to the extent that part of Frelimo has been allowed to enrich itself through corruption (de Renzio and Hanlon, 2006, p. 21). Donors have had a common interest with the highly concentrated political and economic elite of the government and the ruling party in supporting political stability and economic growth of Mozambique (Hanlon 2004; Hanlon and Mosse, 2010). It has been pointed out that the rapid transformation from the socialist economy under-single party rule towards market-oriented multi-party system has taken place without equivalent changes in the ruling elite which has its roots in the liberation struggle. ${ }^{94}$

Therefore while no firm evidence-based conclusions can be made about the role of donors in promoting corruption intentionally, it can be argued that the policies pushed by the donors have greatly influenced the political, economic and institutional dynamics of the Mozambican society, and have contributed to creating conditions and during the initial years of PRE even the need - for corrupt practices. Within the framework of general budget support, with the central government as the main counterpart of the donors, the position of the government and the ruling elite has been enhanced. The changing nature of the donor-government partnership aimed at enhanced effectiveness of aid has thus, unintentionally, contributed to the emerging state-capture and institutionalized corruption in the society.

94. The President holding the office in 2010, and the previous Presidents, were all members of the Frelimo leadership already before independence. 


\section{Governance Assessments by the “Top Ten” Donors}

Following the above overviews of the historical context of governance (Chapter 4) and the evolution of the aid architecture in Mozambique (Chapter 5), this chapter turns the discussion to the governance assessments conducted by the largest donors in Mozambique. The chapter aims to answer the research question of how aid agencies operating in Mozambique define and assess governance by analyzing the governance assessment developed and applied by the largest donors which provide the bulk of all external assistance to Mozambique, and therefore play a significant role in its policy-making, including in the field of governance.

Amongst the various instruments applied by the largest agencies, the following general governance assessment tools have been selected as units for analysis in this research: ${ }^{95}$ 1. Worldwide Governance Indicators (the World Bank/The World Bank Institute)

2. Country Policy and Institutional Assessment (the World Bank)

3. Country Policy and Institutional Assessment (the African Development Bank)

4. Governance Profile (the European Union)

5. Millennium Challenge Scorecard (the USA)

6. Country Governance Analysis (the UK)

7. Strategic Governance and Corruption Analysis (the Netherlands)

8. Power Analysis (Sweden)

The selection of two different assessment tools developed under the auspices of the World Bank is justified by the fact that both the Worldwide Governance Indicators (World Bank Institute) and Country Policy and Institutional Assessment (World Bank) are widely used by other multilateral and bilateral aid agencies, and so influence the governance discourse in Mozambique beyond the World Bank itself. It is also worth noting that as members of the World Bank and the African Development Bank, bilateral donors are also involved in designing the governance assessments tools developed by these agencies. Bilateral donors tend to use the World Bank's tools for reference when developing their own assessment tools. The discussion starts from the governance assessment tools developed by the multilateral agencies, followed by the analysis of the tools developed by the bilateral aid agencies.

95. Only Denmark, Norway and Germany of the ten largest agencies have not developed their own instruments for the purpose of general governance assessment. Many of the largest donors also used instruments to assess governance in specific thematic areas. 
The analysis of the above donor assessments tools builds on the conceptual framework developed by the Governance Network of the OECD DAC as an attempt to address the theoretical and policy-related discussion concerning the multitude of donor assessments. The analysis is structured as follows:

1. Conceptual approach ${ }^{96}$

2. Stated purpose

3. Focus of assessment

4. Methodology

5. Reporting and dissemination of results

6. Partner country ownership

The main purpose of the analysis is thus to shed light on questions related to the conceptual approach and motivation underlying the different assessment tools, their key focus areas and methodological choices as well as their reporting and dissemination practices. Finally, the question of partner country ownership in the design and implementation of the various tools will be addressed.

\subsection{Worldwide Governance Indicators; The World Bank Institute ${ }^{97}$}

The Worldwide Governance Indicators (WGI) are based on a research programme initiated by the World Bank Institute ${ }^{98}$ in the late 1990s. The initial objective of the WGI was to provide data on the quality of governance that allow for cross-country comparisons and for the tracking of changes in the quality of governance over time. Since the beginning of the research programme, the WGI have come to be seen as the most rigorously constructed set of governance indicators which are regularly updated, publicly available and cover a large number of countries over a long period of time

96. As described in Section 2.3.3, the Governance Network of the OECD DAC has identified five different conceptual approaches to governance which underpin donor governance assessments. These are: 1) traditional public administration, 2) new public management, 3) network governance, 4) power and political economy perspectives and 5) historical perspectives. The conceptual approach of a specific governance assessment is based on a set of assumptions that influence the focus and the methodological choice of the assessment process (OECD 2009, p. 10-14).

97. The discussion on the WGI builds on the voluminous debate on the WGI, and in particular on the in-depth analysis by Arndt and Oman (2006) and by Arndt (2009).

98. The World Bank Institute is the research arm of the World Bank. The research on the WGI was initiated by Daniel Kaufman and Aart Kraay, with the assistance of Pablo Zoido-Lobatón (1999, 2001) and further developed by Kaufmann, Kraay and Massimo Mastruzzi (2004, 2005, 2006, 2007, 2008, 2009, 2010). Hence the World Governance Indicators are sometimes referred to as the KKZ indicators (Arndt, 2009). 
(Arndt and Oman 2006). The governance assessments based on the WGI have been carried out every two years between 1996 and 2004, and since then on an annual basis, covering over 200 countries (www.govindicators.org). Mozambique has been subject to the WGI assessment since 1996.

\section{ㄷ Conceptual Approach}

The Worldwide Governance Indicators define governance as "the traditions and institutions by which authority in a country is exercised. This includes the process by which governments are selected, monitored and replaced; the capacity of the government to effectively formulate and implement sound policies; and the respect of citizens and the state for the institutions that govern economic and social interactions among them." (Kaufman, Kraay and Zoido-Lobatón, 1999, p. 1; World Bank, 1992; World Bank 2007a). Building on this definition, the WGI defines governance as encompassing three broad dimensions including the political, economic and the institutional dimension. Within the WGI framework, the three broad dimensions of governance are captured by six composite indicators (World Bank 2006) which are:

Political Dimension

Voice and Accountability

Political Stability and Absence of Violence

Economic Dimension

Government Effectiveness

Regulatory Quality

Institutional Dimension

Rule of Law

Control of Corruption

Each of the above six aggregate indicators is based on several hundreds of individual variables measuring perceptions of some aspects of the broader notion of governance. As argued by Arndt, the concept of governance is defined by the meaning embodied in these different variables rather than based on any explicit theory of governance (Arndt, 2009, p. 87). Based on the OECD DAC analysis of the conceptual approaches to governance assessments, the WGI has its roots, primarily, in public administration, new public management and political economy approaches to governance. The emphasis on institutional aspects further reflects the influence of the new institutional economics as one of its theoretical underpinnings (OECD, 2009, p. 14). 


\section{$\square$ Stated Purpose}

The development of the WGI as a tool for assessing the quality of governance was motivated by four inter-related reasons: first, the lack of robustness of cross-country comparisons using different individual data sources; second, difficulties in interpreting cross-country differences; third, difficulties in comparing regional survey results with broader cross-country surveys; and fourth, the need to develop summary indicators for measuring governance (Arndt and Oman, 2006). The main purpose of the WGI is to provide robust and publicly available data on the quality of governance worldwide that permits cross-country comparisons and tracking of changes in governance over time. Although the WGI is one of the general governance assessment tools developed under the auspices of the World Bank Group, the WGI are not formally used by the World Bank to determine allocation of the World Bank's aid resources or for any other official purposes.

\section{$\square$ Focus of Assessment}

The WGI attempt to assess the quality of governance in terms of three dimensions: political, economic and institutional dimensions of governance. For each dimension, two aggregate indicators are constructed resulting in six clusters of governance which constitute the focus of the assessment: 1) Voice and Accountability; 2) Political Stability and Absence of Violence; 3) Government Effectiveness; 4) Regulatory Quality; 5) Rule of Law; and 6) Control of Corruption. The meaning of governance embodied in each of the six aggregate indicators is described as follows (World Bank, 2006b, 2-3):

\section{Political Dimension}

Voice and Accountability aims at capturing perceptions of "the extent to which a country's citizens are able to participate in selecting their government, as well as freedom of expression, freedom of association, and a free media" (World Bank 2006, p. 2).

Political Stability and Absence of Violence aims at capturing perceptions of the "likelihood that the government will be destabilized or overthrown by unconstitutional or violent means, including politically-motivated violence and terrorism" (ibid. p. 2).

Economic Dimension

Government Effectiveness aims at capturing perceptions of "the quality of public services, the quality of the civil service and the degree of its independence from political pressures, the quality of policy formulation and implementation, and the credibility of the government's commitment to such policies" (ibid. p. 2). 
Regulatory Quality aims at capturing perceptions of "the ability of the government to formulate and implement sound policies and regulations that permit and promote private sector development" (ibid. p. 3).

Institutional Dimension

Rule of Law aims at capturing perceptions of "the extent to which agents have confidence in and abide by the rules of society, and in particular the quality of contract enforcement, property rights, the police, and the courts, as well as the likelihood of crime and violence" (ibid. p. 3).

Control of Corruption aims at capturing perceptions of "the extent to which public power is exercised for private gain, including both petty and grand forms of corruption, as well as 'capture' of the state by elites and private interests" (ibid. p. 3).

The aggregated indicators are constructed from individual variables which are drawn from different data sources provided by other organizations including international financial institutions and other international organizations, political and business risk rating agencies, think tanks, and non-governmental organizations. Some of the variables relate to the existence of rules of governance, such as existence of specific anti-corruption legislation, while some refer to governance outcomes such as the actual enforcement of the legislation against corruption. The underlying variables differ also in terms of their specificity: some attempt to capture broad concerns of governance such as perceptions on the strength of the rule of law, whereas others focus on specific issues such as the cost of using the court system. The authors of the WGI point out that the aggregate indicators are inter-related, and that the classification of individual variables to the six aggregate indicators reflects on their subjective views rather than any well-defined criteria.

\section{Methodology}

The aggregation procedure used for constructing the six composite indicators is based on a statistical model known as the "unobserved components model" which aims at estimating the governance of a given country as a weighted average of all the indicators available for that country. The unobserved components model is used to account for the fact that "true governance" can only be approximated by aggregating the scores of individual indicators. The model, as described by the authors of the WGI, entails the following main phases: first, the individual indicators from each underlying data source are rescaled in order to make them comparable across data sources. Second, a weighted average of each of the rescaled data sources is constructed to arrive at an aggregate indicator of governance. The weights assigned to each data source are based 
on the estimates of the precision of each source that are produced by the unobserved components model (Kaufman, Kraay and Zoido-Lobatón, 2008).

The assumption underlying the statistical approach is that each of the individual data sources can only provide an imperfect signal of the broad notion of governance which cannot be measured directly. It is, therefore, necessary to aggregate the various data sources to get the best possible signal of governance in a country. According to Kaufmann et al., the unobserved components model assumes "that any observed correlation between two measures of corruption, for example, is due to their common, but unobserved, signal of corruption", and therefore, "data sources that are more correlated with each other provide more reliable information, and so receive greater weight" (Kaufman et al., 2008, p. 13). The units in which governance is measured follow a normal distribution with a mean zero and a standard deviation of one in each assessment period which implies that the WGI governance scores virtually always fall between -2.5 and 2.5 with higher values indicating better governance ratings. By setting the world average governance to zero in each period, the aggregate estimates do not provide information about trends in global averages of governance, but they are informative about changes in individual countries' relative positions over time (ibid., p.15).

The WGI estimates of governance are complemented by margins for error which indicate the measurement error embodied in the point estimates of "true governance". Kaufman et al. use $90 \%$ confidence intervals on the reported margins for error for the point estimates of governance of a given country. These intervals indicate the range in which it is $90 \%$ likely that the "true governance" score falls. Accordingly, Kaufman et al. point out that small differences in estimates of governance across countries, or changes within a country, are not likely to be statistically significant, since the $90 \%$ confidence intervals may overlap (for a detailed description of the model, see for example Kaufman, Kraay and Mastruzzi, 2004; for an in-depth critique of the WGI, see Arndt and Oman, 2006 and Arndt, 2009).

The number of variables and data sources used to compose each of the six aggregate the indicators has significantly increased over time. For example, the WGI covering the period 1997-98 were constructed on the basis of some 170 individual variables, drawn from 13 data sources compiled by 12 different organizations, whereas the 2009 update of the WGI was based on over 300 individual variables obtained from 31 data sources produced by 30 different organizations. The providers of the data sources are categorized in four groups: 1) commercial and business information providers; 2) surveys of firms or households; 3) non-governmental organizations; and 4) public sector data providers. The data sources are distinguished also according to the extent to which the sample of countries included in the sources is representative of the world as a whole. All the data sources used to construct the six aggregate indicators are perception-based, 
which means that they provide information on perceptions of certain aspects of governance as reported by survey respondents, civil society organizations, and private and public sector actors. Although the absolute number of survey-based data sources has increased over time, the WGI still largely rely on expert assessments (Kaufman et al., 2002; Kaufman et al., 2008, Kaufman et al., 2010).

\section{Reporting and Dissemination of Results}

The WGI results together with the underlying methodology as well as information on any changes in terms of data sources or other methodological issues are made public through the World Bank's web site (http://info.worldbank.org/governance/wgi/ sc_country.asp). The country-specific Country Data Report provides a summary of the six aggregate indicators, in the form of quantitative scores, together with the publicly-available, disaggregated data on which these indicators are based. The report further shows by aggregate indictor each country's percentile rank which indicates the percentage of countries worldwide that rate below a specific country. The margins for error are displayed at the $90 \%$ confidence intervals. Finally, the Country Data Report displays data from all the underlying data sources used for a given indicator.

Despite the open disclosure policy concerning the WGI country-specific results, methodology and data sources, there is no formal mechanism for any policy dialogue on the WGI between the World Bank Institute and the partner country authorities or other local actors. The use and dissemination of the WGI results at country level is thus dependent on the possibility to access the WGI data and on the interest by the local stakeholders.

\section{Partner Country Ownership}

The countries subject to the governance assessment through the WGI have no role in designing or implementing the assessment. The fact that the number of survey-based data sources used for the rating has increased over time indicates that more emphasis is given to the "voice" of local stakeholders at country level. These include households, private and public sector actors as well as civil society organization. However, as mentioned above, the WGI still largely rely on expert assessments and most of the new data sources are expert assessments.

A Fact Sheet summarizing the key characteristics of the WGI is presented below: 


\section{FACT SHEET}

Tool Worldwide Governance Indictors (WGI)

Agency World Bank Institute

\begin{tabular}{|c|c|c|}
\hline WHY & $\begin{array}{l}\text { Primary purpose of } \\
\text { assessment }\end{array}$ & $\begin{array}{l}\text { To guide policy dialogue and serve as a tool for broad cross-country comparisons } \\
\text { and for evaluating broad trends over time. }\end{array}$ \\
\hline \multirow[t]{3}{*}{ WHAT } & Conceptual approach & $\begin{array}{l}\text { Public Administration, New Public Management, Power and Political Economy } \\
\text { Perspective }\end{array}$ \\
\hline & Definition of governance & $\begin{array}{l}\text { "Governance is defined broadly as the traditions and institutions by which author- } \\
\text { ity in a country is exercised. This includes the process by which governments are } \\
\text { selected, monitored and replaced; the capacity of the government to effectively } \\
\text { formulate and implement sound policies; and the respect of citizens and the state } \\
\text { for the institutions that govern economic and social interactions among them." } \\
\text { (World Bank 2008b) }\end{array}$ \\
\hline & Focus of analysis & $\begin{array}{l}\text { Six aggregate dimensions of governance: } \\
\text { 1. Voice and Accountability } \\
\text { - ability by the citizens to participate in selection of government } \\
\text { - freedom of expression } \\
\text { - freedom of association } \\
\text { - freedom of media } \\
\text { 2. Political Stability and Absence of Violence } \\
\text { - likelihood of unconstitutional or violent overthrow of the government } \\
\text { - politically motivated violence and terrorism } \\
\text { 3. Government Effectiveness } \\
\text { - quality of public services } \\
\text { - quality of the civil service and its independence from political pressures } \\
\text { - quality of policy formulation and implementation } \\
\text { - credibility of governments commitment } \\
\text { 4. Regulatory Quality } \\
\text { - ability of the government to formulate and implement sound policies and } \\
\text { regulations to promote private sector development } \\
\text { 5. Rule of Law } \\
\text { - confidence by the citizens in the rules of the society } \\
\text { - quality of contract enforcement, property rights, policy and the courts } \\
\text { - likelihood of crime and violence } \\
\text { 6. Control of Corruption } \\
\text { - extent to which public power is exercised for private gain } \\
\text { - "capture" of the state by elites and private interests }\end{array}$ \\
\hline \multirow[t]{2}{*}{ HOW } & Methodology & $\begin{array}{l}\text { The six aggregate indicators consist of } 340 \text { individual variables (WGI 2007) } \\
\text { measuring the different dimensions of governance. The data sources ( } 35 \text { data } \\
\text { sources in 2007) provide information on the perceptions of governance by } \\
\text { different stakeholders. A statistical model is used for constructing the aggregate } \\
\text { governance indicators for individual countries. }\end{array}$ \\
\hline & Reporting of results & $\begin{array}{l}\text { Quantitative reporting, cross-country comparable set of indicators, individual } \\
\text { ratings publicly available }\end{array}$ \\
\hline WHERE & Coverage & 212 countries, annually since 2002 . \\
\hline OWNERSHIP & Role of partner country & $\begin{array}{l}\text { Partner country stakeholders not involved in assessment. Some data collection } \\
\text { carried out at country level (household/firm surveys). }\end{array}$ \\
\hline
\end{tabular}

\section{Sources:}

OECD DAC 2009, Donor Approaches to Governance Assessments, Sourcebook 2009, Paris.

World Bank 2008b, Governance Matters VII: Aggregate and Individual Governance Indicators 1996-2007, Washington D.C., see also (www.govindicators.org). 


\subsection{Country Policy and Institutional Assessment; The World Bank}

The Country Policy and Institutional Assessment (CPIA) is the core of the World Bank's performance-based allocation mechanism (PBA) which itself forms the basis for the resource allocation of the International Development Association (IDA), the World Bank's concessional lending window. ${ }^{99}$ The CPIA was known as the Country Performance Rating until 1998 when rating system was redesigned to give greater emphasis to institutional issues. The change in name of the tool further reflected the fact that the main purpose of the assessment is to assess policies rather than development outcomes (World Bank, 2001). As an IDA-eligible country, Mozambique is subject to the CPIA assessment conducted annually.

\section{$\square$ Conceptual Approach}

Since its introduction in the late 1970s, the approach of the CPIA has been expanded from macro-economic policies to covering a wide range of issues and processes related to a country's economic and public sector management, institutional framework, and structural and social policies. These policy areas are divided into four clusters: 1) Economic Management; 2) Structural Policies; 3) Policies for Social Inclusions/Equity; and 4) Public Sector Management and Institutions. A more specific criteria and set of indicators are defined for each of the four clusters.

While the CPIA is not based on any explicit definition of governance, its approach, and the criteria defined for each cluster, reflect the general governance definition adopted by the World Bank: "Governance refers to the manner in which public officials and institutions acquire and exercise the authority to shape public policy and provide public goods and services" (World Bank, 2007, p. 3). In other words, the CPIA attempts to analyze the state of a country' economic, institutional and social policies as well as the capacity of its public sector to implement these policies.

99. International Development Association (IDA), established in 1960, is the concessional lending arm of the World Bank. It provides interest free credits and grants to poorest developing countries. Eligibility for IDA support depends primarily on a country's relative poverty, defined as GNI per capita below a threshold, which is updated annually (USD 1.135 in 2010). Several small island economies as well as large economies such as Pakistan and India are also eligible to IDA funding. In 2010 , in all 70 countries were eligible for IDA resources. 
Consistent with the World Bank's Articles of Agreement ${ }^{100}$, which explicitly forbid the Bank and its staff to address political issues of its member countries, the CPIA does not address issues which are directly linked to political dimensions of governance, such as the nature of the political system, human rights situation etc. Although the Bank's mandate has been expanded over time to cover issues related to political governance, the CPIA is based on a more narrow approach with focus a on the economic and institutional dimensions of governance. ${ }^{101}$

Hence, using the framework developed by the OECD DAC, the conceptual approach underpinning the CPIA is rooted, first and foremost, in the theories of traditional public administration and new public management. Institutional aspects of governance, which were given additional emphasis in the CPIA in the late 1990s, mirror the influence of the new institutional economics in shaping the development discourse (OECD 2009, p. 13). This approach is, however, not aligned with the Bank's explicit emphasis on political governance as outlined in its pioneering study on the "crisis of governance" in Sub-Saharan Africa (World Bank, 1989). The CPIA approach to governance also differs significantly from the approach adopted by the WGI which makes an attempt to address issues related to political governance. As argued by Santiso, with the CPIA the Bank has framed governance in technical and functional terms which justifies the Bank's involvement in governance issues without violating its mandate (Santiso, 2001).

\section{Stated Purpose}

The development of the CPIA has been motivated by two main factors: first, by the World Bank's belief that a country's policy and institutional framework is of key importance for the achievement of development outcomes and the effective use of aid, and second, by the need to have a mechanism to guide the country-specific allocation

100. The Article IV (section 10) of the Articles of Agreement state that "The Bank and its officers shall not interfere in the political affairs of any member; nor shall they be influenced in their decisions by the political character of the member or members concerned. Only economic considerations shall be relevant to their decisions, and these considerations shall be weighed impartially in order to achieve the purposes stated in Article I". (IBRD Articles of Agreement as amended effective 16 February 1989. Retrieved March 3, 2011, from the World Wide Web: http://web.worldbank.org/WBSITE/ EXTERNAL/EXTABOUTUS.

101. In a legal opinion prepared for the Board of Directors, the Bank's General Counsel stated that "the Bank is prohibited from taking political factors into account in all its decisions. However, when such political factors lead to direct and obvious economic results relevant to the Bank's work, the Bank may properly take such results into account as economic considerations which only happen to have political causes or origins". (World Bank 2001a). Issues of "Governance" in Borrowing Members - The Extent of Their Relevance under the Bank's Article of Agreement, 1991; quoted in Governance - The Critical factor IDA 10-12, 2001, p. 3). 
of IDA resources. The primary purpose of the assessment is to help the Bank to determine the relative size of its concessional lending and grants to IDA-eligible countries based on their CPIA ratings (World Bank, 2001, World Bank, 2009b).

The economic performance of a borrowing country has been one of the principal criteria to determine the eligibility of a country for IDA support since the creation of the IDA in 1960. Although the performance assessment was initially not based on exact criteria, there were countries which were deemed ineligible due to their poor performance, and in some cases IDA-supported operations were suspended (World Bank, 1982, p. 23-24). ${ }^{102}$ A formal link between the IDA lending allocations and annual policy performance assessments was established in 1977, and since 1980 the allocation of IDA resources has been guided, primarily, by the CPIA (World Bank, 2001a).

\section{․ Focus of the Assessment}

The CPIA is a composite index which aims at assessing each IDA country's policy and institutional framework for fostering poverty reduction, sustainable growth and ability to effectively use development assistance. The CPIA further serves the Bank's aid programming and policy dialogue with its partner countries by providing comparable data on policy performance across a wide range of issues. The CPIA data are also widely used for research within the World Bank and in the wider research community (World Bank, 2009a).

As noted above, the CPIA consists of 16 criteria grouped into four clusters which, according to the World Bank, constitute the key determinants of economic growth and poverty reduction: Economic Management, Structural Policies, Policies for Social Inclusion and Equity, and Public Sector Management and Institutions. For each cluster, several specific criteria with more detailed indicators have been defined with the objective of assessing the country performance within a given cluster. The CPIA clusters and the criteria for each cluster are listed in Box 6.1 below:

102. Performance assessment was initially carried out by the World Bank field office staff based on quantitative indicators, such as GNP growth and savings rates, as well as on qualitative assessments of administration and economic management. In addition, performance assessment took into account the extent to which economic growth was broad-based, and the willingness of the recipient country government to carry out policy dialogue with IDA (World Bank 1982, p. 23-24). 


\section{Box 6.1 | The CPIA Clusters and Criteria}

A. Economic Management

1. Macroeconomic Management

2. Fiscal Policy

3. Debt Policy

B. Structural Policies
4. Trade
5. Financial Sector
6. Business Regulatory Environment

C. Policies for Social Inclusion/Equity

7. Gender Equality

8. Equity of Public Resource Use

9. Building Human Resources

10. Social Protection and Labor

11. Policies and Institutions for Environmental Sustainability

D. Public Sector Management and Institutions

12. Property Rights and Rule-based Governance

13. Quality of Budgetary and Financial Management

14. Efficiency of Revenue Mobilization

15. Quality of Public Administration

16. Transparency, Accountability, and Corruption in the Public Sector

Source: World Bank, 2009b.

The specific meaning of each criterion is defined in an Assessment Questionnaire which is prepared annually by the Bank at the headquarters level. The definition of the criteria has remained largely unchanged during the period 2005-2009. For the 2009 CPIA, the criteria were defined as follows (based on the CPIA 2009 Assessment Questionnaire, World Bank, 2009):

\section{Economic Management}

Macro-Economic Management "assesses the quality of the monetary/exchange rate and aggregate demand policy framework" (ibid. p. 6).

Fiscal Policy "assesses the short- and medium-term sustainability of fiscal policy (taking into account monetary and exchange rate policy and the sustainability of the public debt) and its impact on growth" (ibid. p. 7).

Debt Policy "assesses whether the debt management strategy is conducive to minimize budgetary risks and ensure long-term debt sustainability" (ibid. p. 8). 


\section{Structural Policies}

Trade criterion "assesses how the policy framework fosters trade in goods. Two areas are covered: (a) trade regime restrictiveness... and (b) customs and trade facilitation" (ibid. p. 10).

Financial Sector "assesses the structure of the financial sector and the policies and regulations that affect it. Three dimensions are covered; (a) financial stability; (b) the sector's efficiency, depth, and resource mobilization strength; and (c) access to financial services" (ibid. p. 13).

Business Regulatory Environment "assesses the extent to which the legal, regulatory, and policy environment helps or hinders private business in investing, creating jobs, and becoming more productive... Three sub-components are measured: (a) regulations affecting entry, exit, and competition; (b) regulations of ongoing business operations; and (c) regulations of factor markets (labor and land)" (ibid. p. 16).

\section{Policies for Social Inclusion and Equity}

Gender criterion "assesses the extent to which the country has enacted and put in place institutions and programs to enforce laws and policies that (a) promote equal access for men and women to human capital development; (b) promote equal access for men and women to productive and economic resources; and (c) give men and women equal status and protection under the law" (ibid. p. 19).

Equity of Public Resource Use "assesses the extent to which the pattern of public expenditures and revenue collection affects the poor and is consistent with national poverty reduction priorities" (ibid. p. 21).

Building Human Resources "assesses the national policies and public and private sector service delivery that affect access to and quality of: (a) health and nutrition services, including population and reproductive health, (b) education, early childhood development, training and literacy programs, and (c) prevention and treatment of HIV/AIDS, tuberculosis, and malaria" (ibid. p. 23).

Social Protection and Labour "assesses government policies in the area of social protection and labor market regulation, which reduce the risk of becoming poor, assist those who are poor to better manage further risks, and ensure a minimal level of welfare to all people" (ibid. p. 27). 
Policies and Institutions for Environmental Sustainability "assesses the extent to which environmental policies foster the protection and sustainable use of natural resources, and the management of pollution" (ibid. p. 30).

\section{Public Sector Management and Institutions (the Governance Cluster)}

Property Rights and Rule-based Governance assesses "the extent to which private economic activity is facilitated by an effective legal system and rule-based governance structure in which property and contract rights are reliably respected and enforced" (ibid. p. $31)$.

Quality of Budgetary and Financial Management "assesses the extent to which there is: (a) a comprehensive and credible budget, linked to policy priorities; (b) effective financial management systems to ensure that the budget is implemented as intended in a controlled and predictable way; and (c) timely and accurate accounting and fiscal reporting, including timely and audited public accounts and effective arrangements for follow up" (ibid. p. 35).

Efficiency of Revenue Mobilization "assesses the overall pattern of revenue mobilization--not only the tax structure as it exists on paper, but revenue from all sources as they are actually collected. Separate sub-ratings should be provided for (a) tax policy and; (b) tax administration." (ibid. p. 36).

Quality of Public Administration "assesses the extent to which civilian central government staffs (including teachers, health workers, and police) are structured to design and implement government policy and deliver services effectively" (ibid. p. 38).

Transparency, Accountability, and Corruption in the Public Sector "assesses the extent to which the executive can be held accountable for its use of funds and the results of its actions by the electorate and by the legislature and judiciary, and the extent to which public employees within the executive are required to account for the use of resources, administrative decisions, and results obtained" (ibid. p. 41).

For the purpose of this research, the content of the Cluster D covering Public Sector Management and Institutions is the most important as this cluster is defined as the "governance cluster" of the CPIA. As can be seen from the above definition of the criteria, the governance cluster focuses on the quality of a country's public financial management, public administration, property rights, or public sector corruption without taking into account issues related directly to political governance. In the course of the evolution of the CPIA over time, this cluster has been given increasing emphasis, reflecting the belief of the World Bank and its member countries that governance is of 
fundamental importance for country performance and aid effectiveness. For example, during the IDA 15 replenishment cycle covering 2009-2011, the governance cluster had 8,5 times the weight of each of the other three clusters when calculating the Country Performance Rating (World Bank, 2009a).

\section{$\square$ Methodology}

As described above, the three main components of the World Bank's performance based allocation system (PBA) mechanism guiding the bulk of the country-specific allocation of IDA resources are: 1) country performance rating (CPR) as measured by the CPIA; 2) size of population; and 3) Gross National Income per capita. The Country Performance Rating itself involves three processes: first, the Country Policy and Institutional Assessment (CPIA); second, the assessment of a country portfolio performance; and third, the adjustment for governance on the basis of a country's rating on the governance cluster (see Cluster D. Public Sector Management and Institutions). The CPIA constitutes the core of the PBA. ${ }^{103}$

In conducting the CPIA, countries are rated on a scale from 1 (low performance) to 6 (high performance) against the 16 CPIA criteria by the World Bank country teams. Each of the four clusters is given equal weight of $25 \%$ in the overall country performance rating. Similarly, within each cluster, all criteria receive an equal weight although the indicators used for a specific criterion may be weighted differently. The overall score, which is the CPIA rating, is obtained by calculating the average of the scores for each cluster (World Bank, 2009b).

The CPIA rating is guided by an Assessment Questionnaire which provides instructions, so called guideposts, for the scoring so as to enhance the consistency of the scores within and across regions. Although the Assessment Questionnaire suggests some data sources that can be used to assist in determining the country scores, it is emphasized that the scoring is not a mechanical process, but rather the "staff's professional judgment of country performance against the CPIA criteria should continue

103. For example, during the IDA15 replenishment cycle, $84 \%$ of the IDA 15 resources (total IDA15 replenishment SDR 27.3 billion, equivalent to USD 41.6 billion) were allocated through the PBA system. The rest of the funds were allocated taking into consideration the needs of the blend countries with large populations (notably India and Pakistan), special needs of post-conflict countries, provisions for arrears clearance, regional projects and exceptional natural disasters. In addition, each IDA eligible country received annually a fixed minimum allocation ("base allocation") set at SDR 1.5 million during the IDA15 replenishment (World Bank, 2010, p. 3: IDA's Performance Based Allocation System: Review of the Current System and Key Issues for IDA16; World Bank 2008, p. 32: IDA15 Report from the Executive Directors of the International Development Association To the Board of Governors). 
to be the key input in determining country scores" (World Bank, 2009b, p. 5). The assessment should focus on a country's economic and social policies, and institutions implementing the agreed policies, rather than on policy outcomes.

The primary responsibility for the assessment process at country level thus lies with the World Bank country teams who are expected to provide a written justification for their rating proposals for each criterion. In addition, a Bank-wide review is carried out on the basis of a number of selected benchmark countries which serve as reference points for the rating of other countries in the region. This is followed by a review of all country ratings before they are finalized and submitted for the endorsement by the Bank's Board of Directors (World Bank, 2007; World Bank, 2009b).

Since its introduction, both the formula for calculating the PBA and the contents of the CPIA have undergone significant changes, reflecting the increasing importance of country performance as a criterion for aid selectivity and, in particular, the growing emphasis given to governance issues as a determinant of policy performance. While a detailed discussion on the evolution of the PBA and the CPIA is beyond the scope of this research, the most fundamental changes that have taken place during the period 2006-2009 are summarized below. Hence, the following sections will outline the methodology as applied during the IDA14 replenishment cycle (2006-2008) and during the IDA15 replenishment cycle (2009-2011). ${ }^{104}$ For a detailed analysis of the changes over time, see Hout, 2007; World Bank, 2009a; Nissanke, 2010 as well as the successive World Bank IDA Replenishment Reports, in particular IDA10 Replenishment Report, 1992; IDA11 Replenishment Report, 1995; IDA12 Replenishment Report, 1998; IDA13 Replenishment Report, 2002; IDA14 Replenishment Report, 2005; and IDA15 Replenishment Report, 2008b.

For the IDA14 replenishment cycle, the country performance rating (CPR) was calculated by first constructing a composite index wherein the CPIA rating is given a weight of $80 \%$ and the country portfolio performance rating (PPR) a weight of $20 \%$. The portfolio performance rating of a given country, derived from the Bank's Annual Report on Portfolio Performance, reflects the percentage of IDA-funded projects considered at risk in the country. The composite index was then multiplied by the so called "governance factor".

The equation for calculating the CPR for each country during the IDA14 replenishment is shown below:

104. IDA is funded, primarily, by donor contributions negotiated in 3-year replenishment cycles. The most recent replenishment cycle, IDA16, which was finalized in 2011, covers the funding period 2012-2015. 
Country Performance Rating $=(0.8 \times$ CPIA $+0.2 \times$ PPR $) \times$ Governance Factor

The governance factor was derived from the five criteria in the CPIA's governance cluster (Cluster D) and from one element of the Bank's Annual Report of Portfolio Performance, the so called "procurement flag". It was calculated on the basis of the average score of the five governance criteria and the "procurement flag", divided by 3.5 (the mid-point of the 1-6 scale of the CPIA) and then raised to the exponent of 1.5. This means than for governance scores above 3.5 the rating is increased, whereas for scores below 3.5 the rating is decreased. The formula for calculating the governance factor is illustrated below:

\section{Governance Factor $=(\text { average governance score } / 3.5)^{1.5}$}

Source: World Bank, 2005, p. 46 (Additions to IDA Resources: 14 Replenishment; Working Together to Achieve the Millennium Development Goals; Report from the Executive Directors of the International Development Association to the Board of Governors)

The governance factor, which is applied as a multiplier, greatly increased the sensitivity of Country Performance Ratings to changes in governance. First, it entailed a double counting of governance in calculating the country performance ratings through the CPIA governance cluster and the governance factor. Second, the governance factor was raised to the exponent of 1.5. Therefore, during the period of IDA 14, the effective weight of governance (Cluster D) accounted for $66 \%$ of the overall country performance rating (World Bank, 2006c, p. 8). The justification for the emphasis on governance was the "strong evidence of a link between the quality of a country's governance system and its development performance" (ibid., p. 121). The emphasis on governance was also driven by the need to mitigate fiduciary risks to IDA funds posed by weak governance in IDA countries.

Figure 6.1 below provides an illustration of the various components of the Performance-Based Allocation system during the IDA 14 period. 


\section{Figure 6.1 | Performance-Based Allocation System; IDA14 (2006-2008)}

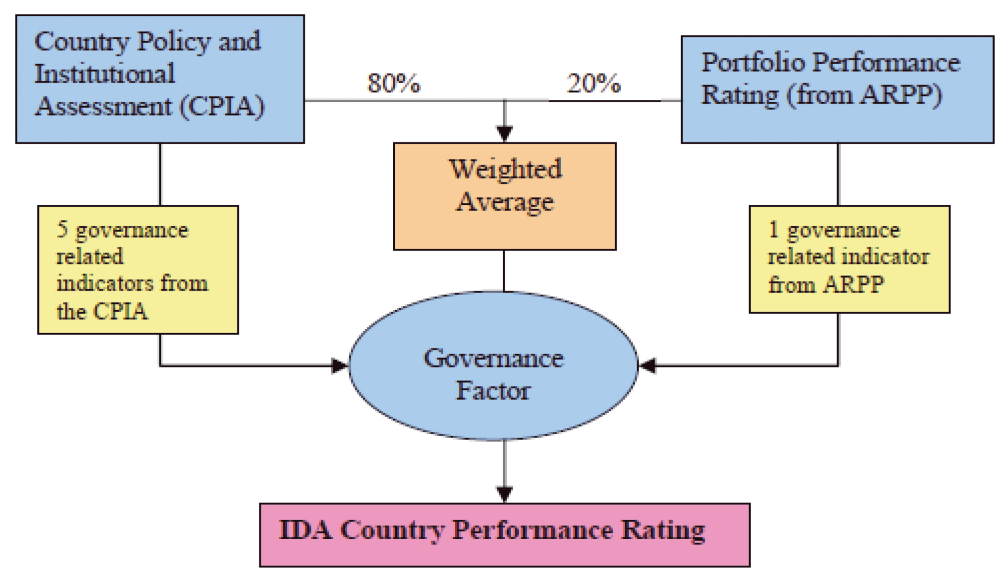

Source: Based on Annex 1 of the IDA14 Deputies' Report

Source: World Bank/IDA: IDA's Performance-Based Allocation System: A Review of the Governance Factor, 2006c, p. 3.

In response to the criticism by both IDA borrowing countries and donors about the complexity of the mechanism for calculating the country performance rating and, in particular, the double-counting of the governance cluster, the PBA mechanism was revised during the negotiation process for the IDA15 replenishment (2009-2011). First, the formula for calculating the CPR was simplified by removing the governance factor as a multiplier. Second, the weights of the different CPIA clusters were made more explicit. The weight of the average of the ratings for the three clusters A (Economic Management), B (Structural Policies) and C (Policies for Social Inclusion and Equity) was set at $24 \%{ }^{105}$ whereas the weight of the rating for the Cluster D (Public Sector Management and Policies) was set at 68\%. The Portfolio Performance Rating was given a weight of $8 \%$ (World Bank, 2009c, p. 9).

The equation for calculating the CPR, applied as of the beginning of the IDA15 (20092011), is illustrated below:

Country Performance Rating $=\left(0.24 \times \mathrm{CPIA}_{A-C}+0.68 \times C P I A_{D}+0.08 \times P P R\right)$

In addition to the country performance ratings calculated as described above, IDA also uses measures of population and GNI per capita in allocating resources. Population

105. In this procedure, one first takes the un-weighted average of the three clusters. It is this unweighted average that subsequently receives a weight of $24 \%$. 
affects allocations significantly: the relationship is linear with the population term, whereby a higher population results in a proportionately increased allocation. Moreover, while all IDA-eligible countries are poor there is an additional bias towards countries with lower GNI per capita. Hence the relationship between the country-specific IDA country allocation and the Country Performance Rating, size of population and the GNI per capita in a given country can be illustrated as follows:

IDA country allocation $=f\left(\right.$ Country performance rating ${ }^{5.0}$, Population $^{1.0}$, GNI/capita $\left.{ }^{-0.125}\right)$

Source: World Bank/IDA’s Performance-Based Allocation System: Simplification of the Formula and Other Outstanding Issues, 2007c, p. 10.

The PBA mechanism for the IDA15 replenishment with its various components is illustrated below in Figure 6.2:

Figure 6.2 | Performance-Based Allocation System; IDA15 (2009-2011)

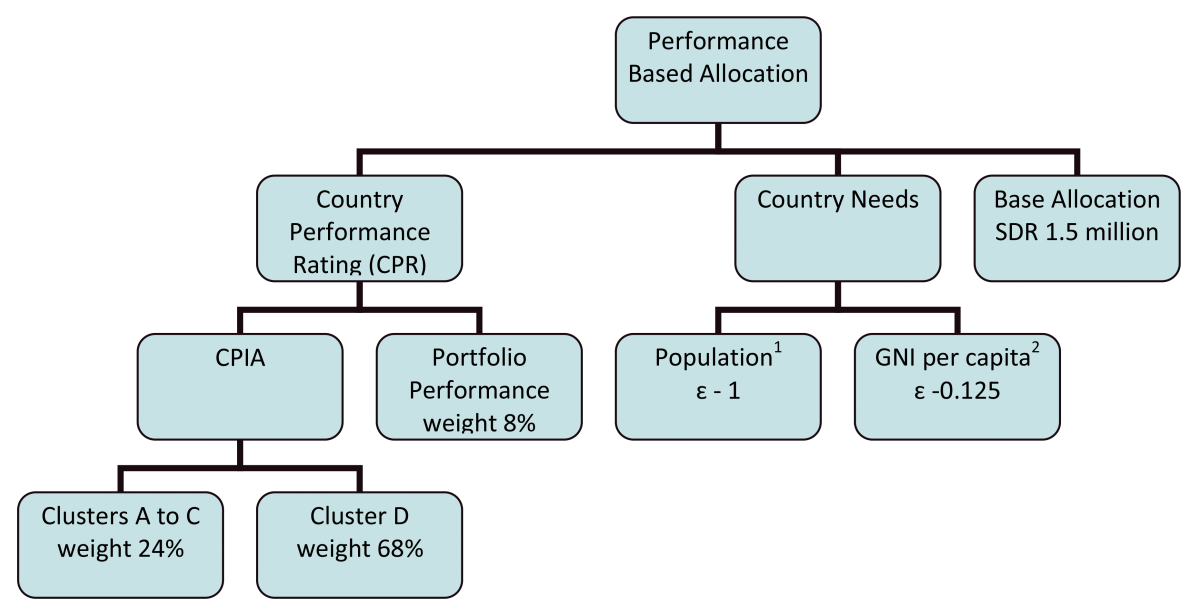

${ }^{1}$ The relationship between the IDA allocation and the size of a given country is linear whereby a higher population results in a proportionately increased allocation.

${ }^{2}$ The GNI per capita exponent indicates a modest bias towards countries with lower GNI per capita.

Source: Adapted from World Bank, 2010, p. 3 (IDA’s Performance Based Allocation System: Review of the Current System and Key Issues for IDA16). 


\section{Reporting and Dissemination of Results}

The country-specific CPIA ratings are presented in a quantitative format on the 1- 6 scale, with intermediate scores of 1.5, 2.5, 3.5, 4.5 and 5.5. Overtime the Bank's policy in disclosing the CPIA ratings has changed significantly in response to a growing criticism - by the IDA borrowing members, the donors and development scholars alike - of a lack of transparency with regard to the CPIA. Up to the year 2000, the CPIA ratings were not made publicly available, but in 2000 the World Bank began disclosing the CPIA relative ratings in a quintile format for IDA-eligible countries. In 2005, the World Bank's Board of Directors approved the disclosure of the numerical scores for all IDA-eligible countries, and since 2006 the CPIA results have been disclosed annually. The criteria and the methodology of the performance-based allocation system have also been made publicly available. To underscore the central role of the CPIA in the IDA allocation process, the disclosed scores for the IDA-eligible countries have been designated as the IDA Resource Allocation Index (IRAI).

\section{$\square$ Partner Country Ownership}

The Performance Based Allocation system with its different components is a standardized mechanism designed by the World Bank, in consultation with the IDA donor countries. The government authorities of a given country are engaged in the process of conducting the CPIA at two stages.

First, the World Bank country teams meet with the respective the government authorities when preparing the rating proposals and before submitting the proposals for the Bank-wide review. The main purpose of the discussions is to ensure that the country teams have taken into consideration all the relevant information when preparing their ratings. The discussions also provide an opportunity for the government to express its views concerning the progress - or a lack of progress - made in comparison with the previous years' CPIA ratings, and to help to identify areas where the Bank's assessment may differ from those of the country authorities. The discussions are meant to serve as part of a consultation process rather than a negotiation over the ratings. This consultation process does not involve other country-level stakeholder groups such as parliamentarians and civil society actors. The second stage involving the partner country takes place at the end of the CPIA process when the World Bank country teams report to the government authorities the results of the assessment. Again, the Bank's formal discussions are limited to the government authorities although with the public disclose of the CPIA ratings the information including the different scores is made available to wider stakeholder groups (information based on personal communication).

A Fact Sheet summarizing the key characteristics of the CPIA is presented below. 


\section{FACT SHEET}

Tool Country Policy and Institutional Assessment (CPIA)

Agency World Bank

\begin{tabular}{|c|c|c|}
\hline WHY & $\begin{array}{l}\text { Primary purpose of } \\
\text { assessment }\end{array}$ & $\begin{array}{l}\text { To guide the allocation of World Bank IDA resources among the IDA-eligible } \\
\text { countries. }\end{array}$ \\
\hline \multirow[t]{3}{*}{ WHAT } & Conceptual approach & Public Administration, New Public Management, \\
\hline & Definition of governance & $\begin{array}{l}\text { "Governance refers to the manner in which public officials and institutions acquire } \\
\text { and exercise the authority to shape public policy and provide public goods and } \\
\text { services" (World Bank 2007) }\end{array}$ \\
\hline & Focus of analysis & $\begin{array}{l}16 \text { Criteria, grouped in } 4 \text { clusters: } \\
\text { A. Economic Management } \\
\text { - macroeconomic management } \\
\text { - fiscal policy } \\
\text { - debt policy } \\
\text { B. Structural Policies } \\
\text { - trade } \\
\text { - financial sector } \\
\text { - business regulatory framework } \\
\text { C. Policies for Social Inclusion and Equity } \\
\text { - gender equality } \\
\text { - equity of public resources use } \\
\text { - building human resources } \\
\text { - social protection and labor } \\
\text { - environmental sustainability } \\
\text { D. Public Sector Management and Institutions } \\
\text { - property rights and rule-based governance } \\
\text { - quality of budgetary and financial management } \\
\text { - efficiency of revenue mobilization } \\
\text { - quality of public administration } \\
\text { - transparency, accountability and corruption in the public sector }\end{array}$ \\
\hline \multirow[t]{2}{*}{ HOW } & Methodology & $\begin{array}{l}\text { For each of the } 16 \text { criteria, countries are rated on a scale of } 1 \text { (low) to } 6 \text { (high) by } \\
\text { World Bank staff. Detailed questions and definitions are provided to the Bank's } \\
\text { country teams for each of the six rating levels for each of the } 16 \text { criteria. A number } \\
\text { of benchmark countries representing all IDA regions are chosen on the basis } \\
\text { of a bank-wide rating process. All country-ratings are reviewed against these } \\
\text { benchmark countries before the country-specific ratings are finalized. }\end{array}$ \\
\hline & Reporting of results & $\begin{array}{l}\text { Quantitative reporting, cross-country comparable set of indicators, individual } \\
\text { ratings publicly available. }\end{array}$ \\
\hline WHERE & Coverage & All countries eligible for World Bank IDA assistance \\
\hline OWNERSHIP & Role of partner country & $\begin{array}{l}\text { Partner country consulted during the assessment process and informed about } \\
\text { the results. }\end{array}$ \\
\hline
\end{tabular}

\section{Sources:}

OECD DAC 2009, Donor Approaches to Governance Assessments, Sourcebook 2009, Paris.

World Bank 2007b, Strengthening World Bank Group Engagement on Governance and Anticorruption, Washington D.C.

World Bank 2007c, IDA's Performance-Based Allocation System: Options for Simplifying the Formula and Reducing Volatility, Washington, D.C. 


\subsection{Country Policy and Institutional Assessment; The African Development Bank}

The Country Policy and Institutional Assessment (CPIA) carried out by the African Development Bank (AfDB) is very similar to the CPIA of the World Bank. The AfDB conducts the CPIA annually in all countries eligible for funding through the Bank's concessional lending window, the African Development Fund (ADF). The ADF-eligibility is based on the same criteria as applied by the World Bank IDA. The conceptual approach and the motivation underpinning the AfDB's CPIA, the process of conducting the assessments, as well as other methodological choices, including the reporting and dissemination policy largely mirror those of the World Bank's CPIA. However, despite harmonization efforts, some differences remain between these two assessment tools. ${ }^{106}$ The following sections briefly describe the CPIA tool as applied by the AfDB with emphasis on the key differences.

\section{$\square$ Conceptual Approach of the CPIA}

The CPIA of the African Development Bank attempts to assess the quality of a country's policy and institutional framework to ensure the efficient utilization of AfDB resources to support growth and poverty reduction. The main policy areas covered by the AfDB CPIA are identical to those of the World Bank: 1) Economic Management; 2) Structural Policies; 3) Policies for Social Inclusions/Equity; and 4) Public Sector Management and Institutions. Accordingly, the AfDB shares the same conceptual approach as the World Bank CPIA, derived from the theories of traditional public administration, new public management and institutional economics (OECD, 2009, p. 13).

As in the case of the World Bank CPIA, the cluster on Public Sector Management and Institutions aims to capture key issues related to a country's governance. However, the definition of governance, as outlined by the African Development Bank Group in 2000, is broader: "Governance is a process referring to the manner in which power is exercised in the management of the affairs of a nation, and its relations with other nations" (AfDB, 2000, p. 2). It is further stated that "governance is the exercise of power or authority - political, administrative and economic or any other kind - to manage resources and affairs" (ibid.). Governance is thus not defined only in terms of the administrative and institutional processes within the national boundaries of a

106. Following concerted efforts made by the multilateral development banks to harmonize their Performance Based Allocation systems, the mechanisms used by the Asian Development Bank, Inter-American Development Bank, the International Fund for Agricultural Development and the Global Environment Facility to guide their resource allocation are very similar (AfDB, 2010). 
given country. Yet, this wider approach is not reflected in the narrow focus adopted for the CPIA which, like the World Bank CPIA, excludes issues related to political governance.

\section{$\square$ Stated Purpose}

The CPIA is the key element of the AfDB's Performance Based Allocation (PBA) mechanism to determine the allocation of ADF resources. The main purpose of the CPIA is thus to assess the policy and institutional framework of a given country "in terms of how conducive such a framework is to ensuring the efficient utilization of scarce development resources in the pursuit of sustainable and poverty reducing development in the Regional Member Countries" (AfDB, 2009, p. 4-6).

As with the World Bank IDA, the AfDB is largely funded by donor contributions in 3 -year replenishment cycles. The bulk of the ADF resources, approximately $75 \%$ during the AFDB-11 (2008-2010), are allocated through the PBA mechanism. ${ }^{107}$ During the ADF-10 replenishment cycle (2005-2007), the share of funds allocated strictly under the PBA mechanism was even higher, at the level of $80 \%$ of total resources. The countries with highest CPIA ratings receive the highest share of the ADF resources. For example, in 2009 (ADF-11 replenishment cycle), 64\% of the resources were channelled to countries rated in the two strongest performing quintiles (AfDB, 2009, p. 4-6). The results of the CPIA further serve as an input in the aid programming and policy dialogue between the AfDB and its partner country authorities.

\section{$\square$ Focus of the Assessment}

Like the World Bank CPIA, the AfDB CPIA consists of 16 criteria grouped into four clusters: Economic Management (Cluster A); Structural Policies (Cluster B); Policies for Social Inclusion and Equity (Cluster C); and Public Sector Management and Institutions (Cluster D). The specific criteria and indicators for each cluster are, in terms of their content, practically identical to those of the World Bank. However, the AfDB divides the criteria into two distinct groups which are assessed separately: the Clusters $\mathrm{A}, \mathrm{B}$ and $\mathrm{C}$, with 11 individual criteria make up one group, the CPIA A-C, while Cluster D, with five individual criteria, the CPIA-D, is constructed as the "governance

107. The ADF-11 replenishment cycle, with total resources amounting to UA 5.9 billion (equivalent of USD8.9 billion at the time), covers the years 2008-2010. The most recent ADF replenishment cycle, ADF12, which covers the period 2011-2013, was finalized in 2011. Total resources available for the AFDB-12 period (2011-2013) amount to UA 6.097 billion (equivalent USD 9.5 billion) (AfDB, 2009; AfDB 2010). 
rating". The implications of the separation of the assessments of performance on CPIA (A-C) and on CPIA-D will be discussed in more detail in the section on methodology. The emphasis of the assessment is on the quality of policies and "tangible results from implementing policies" rather than on intended policies (AfDB, 2010, p. 2). The CPIA clusters and the criteria for each cluster are illustrated below:

\section{Box 6.2 | The CPIA (A-C) Clusters and Criteria}

A. Economic Management

1. Macroeconomic Management

2. Fiscal Policy

3. Debt Policy

B. Structural Policies

4. Policies and Institutions for Economic Cooperation, Regional Integration and Trade

5. Financial Sector

6. Business Regulatory Environment

C. Policies for Social Inclusion/Equity

7. Gender Equality

8. Equity of Public Resource Use

9. Building Human Resources

10. Social Protection and Labor

11. Policies and Institutions for Environmental Sustainability

Source: African Development Bank, 2009.

\section{Box 6.3 | The CPIA (D) Cluster and Criteria}

D. Governance Rating: Public Sector Management and Institutions

12. Property Rights and Rule-based Governance

13. Quality of Budgetary and Financial Management

14. Efficiency of Revenue Mobilization

15. Quality of Public Administration

16. Transparency, Accountability, and Corruption in the Public Sector

Source: African Development Bank, 2009.

As to the specific indicators, the only difference between the World Bank and the AfDB CPIA relates to the criterion concerning trade. (Structural Policies, Cluster B, criterion 4). In the case of the AfDB, this criterion explicitly takes policies and institutions for economic cooperation and regional integration into account, whereas the World Bank approach is more focused on the internal trade issues of a given country. Hence, the AfDB defines the criterion as follows: 


\section{B. Structural Policies}

Policies and Institutions for Economic Cooperation, Regional Integration and Trade "assesses how the policy framework fosters regional integration (bold added by the author) and trade in goods. Two areas are covered: (a) trade regime restrictiveness... and (b) customs and trade facilitation" (AfDB, 2009, p. 7).

The most fundamental difference between the CPIA of the Word Bank and the AfDB relates to the method for calculating the country-specific country performance scores and, in particular, to the way in which the rating of the Cluster D on governance is taken into account to arrive at the final scores.

\section{Methodology}

The Performance Based Allocation (PBA) of the AfDB contains the same three components as the World Bank's PBA: 1) country performance assessment; 2) size of population; and 3) Gross National Income per capita (AfDB, 2009, p. 16).

In conducting the country performance assessments the AfDB applies the same rating scale from 1 (low performance) to 6 (high performance) as the World Bank, but the AfDB's weighting of the four clusters in calculating the overall CPIA rating differs from that of the World Bank. The formula used for the calculation of the CPA score is as follows:

$$
C P A=0.26 \operatorname{CPIA}_{(A-C)}+0.58 G R+0.16 C P R R
$$

where CPIA ${ }_{(A-C)}$ refers to the average rating of a given country on the Clusters A, B and C, GR to the governance rating for the Cluster D, and CPRR to the Country Portfolio Rating based on projects considered to be problematic (ibid., p. 16).

The AfDB has developed a separate Guidance Note on Governance Rating to guide the rating of the five criteria in Cluster D. The Guidance Note lists various sources of information and indicators to inform the assessment of each area emphasizing that "using and combining a variety of sources of information, while taking into account country's specificities, is critical in order to determine trends and justify judgments made on progress or regression on governance" (AfDB 2009, p. 4). As an example, the guidance provided for assessing the Quality of Public Administration, which is one of the governance indicators in the Cluster $\mathrm{D}$, is presented below ${ }^{108}$ : 


\section{Box 6.4 | Operational Guidance Note: Assessing the Quality of Public Administration}

\begin{tabular}{|c|c|c|}
\hline Area of Assessment & Evidence Source & Specific Indicator \\
\hline General governance & $\begin{array}{l}\text { African Governance Report; } \\
\text { Chapter } 5 \text { on Effectiveness and } \\
\text { Accountability }\end{array}$ & No specific indicators \\
\hline \multirow[t]{2}{*}{$\begin{array}{l}\text { Policy coordination and responsi- } \\
\text { veness: } \\
\text { "Effectiveness of policy coordination } \\
\text { mechanisms and policy consistency across } \\
\text { departmental boundaries" }\end{array}$} & $\begin{array}{l}\text { Afrobarometer; Section on } \\
\text { Government Performance }\end{array}$ & $\begin{array}{l}\text { Central Governance Performance - } \\
\text { economic issues; } \\
\text { Central Governance Performance - } \\
\text { social issues and services; } \\
\text { Local Government Performance; } \\
\text { the Quality of Local Governance }\end{array}$ \\
\hline & $\begin{array}{l}\text { Bertelsmann Transformation } \\
\text { Index }\end{array}$ & Status Index and Management Index \\
\hline \multirow{2}{*}{$\begin{array}{l}\text { Service delivery and operational } \\
\text { efficiency: "Efficiency of administrative } \\
\text { structures and business processes" }\end{array}$} & $\begin{array}{l}\text { Worldwide Governance } \\
\text { Indicators }\end{array}$ & Government effectiveness \\
\hline & $\begin{array}{l}\text { African Competitiveness Report; } \\
\text { Section on Institutions }\end{array}$ & Burden of government regulation \\
\hline \multirow[t]{2}{*}{$\begin{array}{l}\text { Merit and ethics: "Merit and per- } \\
\text { formance based hiring and promotion; } \\
\text { bribe seeking behaviors" }\end{array}$} & $\begin{array}{l}\text { Global Integrity Report; Section } \\
\text { on Administration and Civil } \\
\text { Service }\end{array}$ & Civil Service Regulation \\
\hline & $\begin{array}{l}\text { Africa Peer Review Mechanism; } \\
\text { Section on Democracy and } \\
\text { Political Governance }\end{array}$ & \\
\hline $\begin{array}{l}\text { Pay adequacy and management of } \\
\text { the wage bill: "Sustainability of the } \\
\text { wage bill; Pay and benefit levels" }\end{array}$ & World Bank Civil Service website & no specific indicators \\
\hline
\end{tabular}

Source: Adapted from the Operational Guidance Note; Staff Guidance Note on the Governance Ratings of the Bank's Country Performance Assessment, AfDB 2009.

The rating is of the CPIA (comprising Clusters A, B and C) as well as the governance rating are carried out by the $\mathrm{AfDB}$ country teams in coordination with the headquarter

to design and implement government policy and deliver services effectively" (AfDB 2009, p. 31). The key dimensions to be assessed include the following: Policy Coordination and Responsiveness; Service Delivery and Operational Efficiency; Merit and Ethics; Pay Adequacy and Management of the Wage Bill (ibid. p. 31). The AfDB's definition of the indicators and its key dimensions is identical with that of the World Bank. 
staff (AfDB, 2009, p. 1). The annual CPIA process starts with the ratings of a number of countries selected as benchmark countries which serve as reference points for the rating of other countries. ${ }^{109}$ This is followed by the rating of the remaining countries and a Bank-wide peer review of ratings, along with the associated written justifications. Before the country ratings are submitted for endorsement by the Bank's Board of Directors, they are reviewed by the Bank's Quality Control with the objective of checking the consistency of the ratings with those of the World Bank CPIA.

The so called "guide posts", which the AfDB Assessment Questionnaire lists as suggested data sources or reference points to guide the ratings, are very similar to those of the World Bank. Generally, both the World Bank and the AfDB rely on data produced by the IMF and the World Bank Group, in particular, on the World Development Indicators, the Worldwide Governance Indicators and the IFC data. Concerning the assessment of country performance on socio-economic indicators (Policies for Social Inclusion and Equity, Cluster C), both agencies refer to various UN data sources as relevant reference points. However, some differences can be identified, for example, the AfDB guide posts concerning the criterion on trade are somewhat different due to the broader definition underlying this criterion. Furthermore, the AfDB seems to give more emphasis on African-based data sources such as the Afrobarometer and the African Peer Review Mechanism. The AfDB underlines the fact that any measurement of governance involves margins for error and that governance indicators provide only partial indication of country performance and trends in quality of governance.

Overtime the PBA and the formula for calculating the country performance rating as applied by the AfDB have changed, mirroring the changes in the World Bank PBA. The governance component was initially introduced in 2002 as a reflection of the increasing emphasis on governance-related issues among the aid agencies. For the AfDB, the rationale was three-fold: first, the new component signalled concerns about weak governance in the AfDB's borrowing countries; second, it made governance a key focus for policy dialogue and policy reform at country level; and third, it provided an incentive for good governance by linking it to the allocation of resources (AfDB 2008, p. 5). A country's performance in the area of governance was to be assessed by the criteria within the Cluster $D$ of the CPIA, and the four clusters were all given an equal weight of $25 \%$. The governance factor, similar to that of the World Bank, was calculated by dividing the country's average rating for the governance criteria by 3.5, the mid-point of the assessment range. The overall CPIA score was then multiplied by this factor. The purpose of the double-counting

109. In 2009, the benchmark countries included Botswana, Burkina Faso, Chad, Congo Republic, Malawi, Nigeria, Sierra Leone, Tanzania and Tunisia. The countries are deemed to represent "strong performing countries" (CPIA above 3.75$)$, "medium performing countries" $(3.25<$ CPIA $<3.75)$ and "poor performing countries" (CPIA below 3.25). For reference, the list of bench mark countries includes also countries that are not AfDB-eligible such as Botswana and Tunisia). 
of the governance cluster in the CPIA was to further strengthen the weight assigned to governance issues and thereby enhance the effective use of the ADF resources.

In line with the revision of the World Bank PBA formula for the IDA15 resource allocation (the period covering the years 2009-2011), the AfDB approach was modified and Cluster D was dropped from the CPIA and reformulated as the "governance rating". According to the AfDB, "this reflects the importance the Bank places on good governance for the achievement of inclusive and sustained economic growth in its Regional Member Countries" (http://www.afdb.org/en/about-us/african-development-fund-AfDB/ country-resource-allocation/governance-rating/). Hence, as of ADF-11 (2008-10), the CPIA rating only includes the first three Clusters A, B and C, and the "governance rating" comprising Cluster D is carried out separately.

\section{$\square$ Reporting and Dissemination of Results}

The AfDB reports the CPIA results in a format similar to that of the World Bank. The Bank's policy on reporting and dissemination of the results of the CPIA has evolved in tandem with that of the World Bank. Hence, in 2005, the full disclosure of the numerical CPIA scores for all the ADF-eligible countries was approved by the Bank's Board of Directors.

\section{Partner Country Ownership}

The AfDB's Performance Based Allocation system with its different components is a standardized mechanism applied in all AfDB-eligible countries. The partner country government is informed about the final CPIA scores of that country only after all the scores have been endorsed by the Bank's Board of Directors. The tentative CPIA ratings are not discussed or shared with the government authorities during the assessment process in order to avoid any pressure from the government side. Although there is no collaboration with local civil society organizations during the assessment process, data generated locally can be used an input in the ratings (information based on personal communication).

The AfDB thus seems to follow even stricter policy in carrying out its CPIA than does the World Bank. While the World Bank country teams meet with their respective government authorities when preparing the rating proposals, in the case of the AfDB, the discussions with partner country authorities take placed only after the ratings have been peer- reviewed and endorsed by the AfDB's Board of Directors.

A Fact Sheet summarizing the key characteristics of the AfDB's CPIA is presented below: 


\section{FACT SHEET}

Tool African Development Bank

Agency Country Policy and Institutional Assessment (CPIA)

\begin{tabular}{|c|c|c|}
\hline WHY & $\begin{array}{l}\text { Stated purpose of assess- } \\
\text { ment }\end{array}$ & $\begin{array}{l}\text { To guide the allocation of resources among the countries eligible for the African } \\
\text { Development Fund financing. }\end{array}$ \\
\hline \multirow[t]{4}{*}{ WHAT } & Conceptual approach & Public Administration, New Public Management \\
\hline & Definition of governance & $\begin{array}{l}\text { "Governance is a process that refers to the manner in which power is exercised in } \\
\text { the management of the affairs of a nation and its relations with other nations." } \\
\text { (AfDB 2000) }\end{array}$ \\
\hline & \multirow[t]{2}{*}{ Focus of analysis } & $\begin{array}{l}\text { CPIA Clusters A-C, 11criteria: } \\
\text { A. Economic Management } \\
\text { - macroeconomic management } \\
\text { - fiscal policy } \\
\text { - debt policy } \\
\text { B. Structural Policies } \\
\text { - policies and institutions for economic cooperation, regional integration } \\
\text { and trade } \\
\text { - financial sector } \\
\text { - business regulatory framework } \\
\text { C. Policies for Social Inclusion and Equity } \\
\text { - gender equality } \\
\text { - equity of public resources use } \\
\text { - building human resources } \\
\text { - social protection and labor } \\
\text { - environmental sustainability }\end{array}$ \\
\hline & & $\begin{array}{l}\text { CPIA Cluster D (Governance Rating), } 5 \text { criteria: } \\
\text { A. Public Sector Management and Institutions } \\
\text { - property rights and rule-based governance } \\
\text { - quality of budgetary and financial management } \\
\text { - efficiency of revenue mobilization } \\
\text { - quality of public administration } \\
\text { - transparency, accountability and corruption in the public sector }\end{array}$ \\
\hline \multirow[t]{2}{*}{ HOW } & Methodology & $\begin{array}{l}\text { For each of the } 16 \text { criteria, countries are rated on a scale of } 1 \text { (low) to } 6 \text { (high) } \\
\text { by AfDB country teams. Detailed questions and definitions are provided to the } \\
\text { Bank's country teams for each of the six rating levels for each of the } 16 \text { criteria. In } \\
\text { addition, for the CPIA Cluster D, a separate Guidance Note is provided to provide } \\
\text { additional reference points for assessment. A number of benchmark countries } \\
\text { representing all AfDB Regional Member Countries are chosen on the basis of a } \\
\text { bank-wide rating process. All country-ratings are peer-reviewed against these } \\
\text { benchmark countries before country-specific ratings are finalized. }\end{array}$ \\
\hline & Reporting of results & $\begin{array}{l}\text { Quantitative reporting, cross-country comparable set of indicators, individual } \\
\text { ratings publicly available. }\end{array}$ \\
\hline WHERE & Coverage & All countries eligible for ADF resources. \\
\hline OWNERSHIP & Role of partner country & $\begin{array}{l}\text { Partner country not involved in the assessment but informed about the results. } \\
\text { Some data underlying the assessment generated at local level. }\end{array}$ \\
\hline
\end{tabular}

\section{Sources:}

AfDB (2000), Bank Group Policy on Good Governance; AfDB (2008), The Bank Group's Contribution to Governance in Africa: Strategic Directions (2008-2012); AfDB (2009), ADF-11 Resource Allocation; OECD DAC (2009), Donor Approaches to Governance Assessments, Sourcebook, Paris. 


\subsection{Governance Profile; The European Union}

The European Union's instrument for assessing governance in the countries that are signatories of the EU-ACP Cotonou Partnership Agreement, the Governance Profile, was initially outlined in the European Commission's Communication of 2006 (Governance in the European Consensus -Towards a harmonized approach within the European Union, COM (2006)). The Communication together with the related Council Conclusions on Governance in the European Consensus for Development, adopted the same year by the EU Council of Ministers, entailed a new approach to supporting governance reforms in the African, Caribbean and Pacific (ACP) countries by explicitly linking EU funding to the governance situation in its partner countries. In line with the Council Conclusions, a country-specific Governance Profile was to be prepared for each ACP country which would determine its access to financing through the so called Governance Incentive Tranche. As a party to the EU-ACP Cotonou Partnership Agreement, Mozambique has also been subject to the governance assessment within the framework of the EU's new approach.

\section{$\square$ Conceptual Approach}

As discussed in Section 2.3.1, the concept of governance underlying the EU's contemporary approach to addressing governance in developing countries is defined in very broad terms in the European Commission's Communication of 2006 (COM 2006, 421 final, p. 3; see also Section 2.3.1). Building on the notion of "democratic governance", the Communication notes that "processes of democratic governance cannot be imposed from outside" but countries can be encouraged to carry out reforms through dialogue and incentive-based approaches (ibid., p. 7). The emphasis on a partner country's responsibility for improving its governance is thus embedded in the EU's conceptual and operational approach to assessing governance.

The EU approach to governance differs from that adopted by the World Bank and the AfDB with its explicit reference to political dimension of governance, such as human rights, democracy, the rule of law, and the nature of the political system of a given country. The political dimension of the EU governance approach is underlined by the fact that the concepts of governance and "democratic governance" are used as synonyms, with the latter gaining increasing prominence in the EU's development policy documents. Applying the OECD analysis of donor approaches to governance, the EU's approach is firmly rooted not only in the theories of public administration and new public management, but also in political economy analysis (OECD, 2009, p. 13).

\section{Stated Purpose}

The main objective of the EU's Governance Profile is to assess the "political will" of given ACP country to carry out governance reforms, and to provide financial 
incentives in the form of a "Governance Incentive Tranche" to countries showing such a willingness. Unlike the World Bank and the AfDB CPIAs, the Governance Profile is not aimed at ranking countries according to their governance performance. On the contrary, it is explicitly stated that "the main purpose of assessing a country's governance is not to establish a ranking but chiefly to help identify the most appropriate reforms and support measures" (COM (2006), p. 7).

The funding made available to support the new governance initiative, a total of $€ 2.7$ billion, forms part of the EU's assistance to the ACP countries under the $10^{\text {th }}$ European Development Fund (EDF) for the period 2008-2013. The Governance Incentive Tranche is provided on top of the country-specific allocation of EDF resources, which are agreed upon within the framework of the EU's National Indicative Programme with a given country. The outcome of the governance assessment related to the governance initiative determines only the volume of the financial incentive without impacting upon the initial EDF allocation.

It is worth noting that although the Governance Incentive Tranche is dependent on the political will of a given country to carry out reforms in the field of governance, the Incentive Tranche is not earmarked for governance reforms. However, "the EU expects ACP partners to embark on reforms necessary for development aid and international cooperation to bring lasting benefits" $(\operatorname{COM}(2006), \mathrm{p}$. 10). The governance assessment carried out within the framework of the Governance Initiative is further aimed at contributing to the Political Dialogue ${ }^{110}$ that takes place at country level between the EU and a given ACP country, in line with the Article 8 of the EU-ACP Cotonou Partnership Agreement (SEC2009) 58 final, p. 4).

\section{$\square$ Focus of the Assessment}

The EU governance assessment approach requires the drafting of a country-specific governance profile. The governance profile is meant to provide an overview of the governance situation in a given country, indicate general trends in governance and, furthermore, to assess the government's commitment to reforming governance. It aims at capturing the political, economic and institutional dimensions of governance through the following nine focus areas:

1. Political governance

2. The rule of law

3. Control of corruption

110. The Political Dialogue constitutes the highest level of structured and regular communication between the EU and an ACP country. The mechanism for Political Dialogue is laid down in the Article 8 of the ACP-EU Partnership Agreement (commonly known as the Cotonou Agreement). 
4. Government effectiveness

5. Economic governance

6. Internal and external security

7. Social governance

8. International and regional context

9. Quality of partnerships

The first six areas of correspond to the six composite indicators of the WGI. For the remaining three areas, the following sub-components have been identified:

Social governance: decent work, gender, HIV/AIDS

International/regional context: regional integration, involvement in regional initiatives, migration

Quality of partnership: political and programming dialogue

The EU aims at arriving at a holistic assessment of the governance situation in a given country by assessing the quality of governance in terms of the above nine focus areas. Compared with the focus areas of the World Bank and the AfDB CPIA, the EU addresses a broad range of issues some of which are beyond country-specific concerns. In fact, some of the sub-components, such as migration, clearly are more a reflection of the EU's governance concerns rather than governance concerns of developing countries in general. A detailed questionnaire designed by the Commission of the $\mathrm{EU}$ is provided to all $\mathrm{EU}$ country delegations to guide the drafting of the governance profile. The EU seems to take a rather flexible approach concerning the indicators and data sources to be used as the basis of the governance profile. While national indicators are considered useful in establishing national standards based on the priorities of a specific country, the use of international data sources and indicators is recommended so as to facilitate cross-country comparisons. There is no pre-established weighting of the different areas of governance or of the indicators used (ibid., p. 7-8).

\section{Methodology}

The EU's governance assessment process involves both qualitative and quantitative assessment methods. First, the governance profile of a given country is drafted at country level by the respective EU delegation in cooperation with the EU Member States present in the country. They are expected to present their qualitative assessment of governance for all nine areas, including an assessment of the main weaknesses of governance. As to the six areas of governance corresponding to the WGI composite indicators, the WGI scores are used as a reference point. The EU's governance profile is thus a qualitative narrative of the state of affairs in the nine focus areas of governance. All governance profiles are reviewed by the Commission to ensure consistency and comparability of the assessment across the ACP countries (Molanaers and Nijs, 2009, p. 567). 
After the EU-wide review process, the governance profile of a given country is shared, "as appropriate", with the country's government authorities as the basis for a dialogue on governance reforms. As an outcome of this dialogue, the partner country is expected to draft its own "Governance Action Plan" which outlines its planned measures to address the weaknesses identified in the governance profile. This Governance Action Plan, assuming that the partner country has agreed to prepare one, is forwarded to the EU headquarters for assessment on three criteria:

- relevance: refers to the links between the weaknesses identified in the governance profile and the Governance Action Plan;

- ambition: refers to the political will of the partner country government to address the weaknesses in the Governance Action Plan;

- credibility: refers to the capacity of the partner country to carry out the reforms suggested in the Governance Action Plan.

With the assessment of the Governance Action Plans, the process turns quantitative as each of the above three criteria is given a numeric score on the scale from 1 to 3 (basic $=<1$; intermediate $=1$ to 1.49 ; high $=1.5$ to 2.49 ; very high $=2.5$ to 3 ). The quantification of the Governance Action Plans serves as the basis for cross-country comparability, and for the differentiation of the volume of the Governance Incentive Tranche. This, the scoring of the Governance Action Plans determines the volume of the Governance Incentive Tranche. It can be granted at four different levels depending of the performance of a given country (all the percentages refer to the ratio of the Governance Incentive Tranche to the initial EDF allocation of a given country):

Initial level (10\%): basic or intermediate score on all three criteria

Second level (20\%) one or two criteria assessed as basic or intermediate; at least one criterion assessed as high

Third level (25\%): the three criteria assessed as high/very high

Fourth level (30\%): the three criteria assessed as very high

Source: European Commission (DG DEV), Governance Incentive Tranche, unpublished document.

In addition to the above four levels of Incentive Trance, a 5\% top-up is provided to: 1) countries that have concluded the African Peer Review Mechanism; 2) Portuguese-speaking African countries (PALOP) that have agreed to supplementary commitments in the field of "democratic governance"; and 3) to fragile states. In practice, only countries that opt not to prepare a Governance Action Plan are left without any governance incentive. This approach somewhat undermines the incentive function of the governance assessment process (Molanaers and Nijs, 2009, p. 567-568). 


\section{Dissemination of Reporting of Results}

The governance profile of a given country is not made public at the country level, although the conclusions of the governance profile can be shared "as appropriate" with the partner country government, and will be integrated into the aid programming dialogue. The EU's perceptions of the main weaknesses of governance, as outlined in the governance profile, are also discussed with the partner country government so as to provide the basis for the government to prepare its own response, the Governance Action Plan. The conclusions derived from the governance profile are further used as an input in the political dialogue conducted according to the Article 8 of the Cotonou Partnership Agreement between the EU and a given country. There is no mentioning of special efforts to share the outcome of the discussions related to the governance profile with other local stakeholders.

The Governance Action Plan itself is included as an annex to the EU's Country Strategy Paper, which is the country-specific programme document signed between the EU and a given country. The integration of the Action Plan into the Country Strategy Paper is seen as a contract between the EU and the partner country on governance reforms (SEC2009, p. 8). For example in the case of Mozambique, the Governance Action Plan prepared by the Government of Mozambique is annexed to the Country Strategy Paper 2008-2013 signed by the Government and the EU (Republic of Mozambique - European Community: Country Strategy Paper and National Indicative Programme 2008-2013).

\section{Partner Country Ownership}

Despite the EU's explicit emphasis on country ownership, the process of drafting the governance profile is in the hands of the EU delegation, and the EU Member States present in the country. The EU delegation may carry out key informant interviews with local stakeholders to clarify some issues or to complement existing data, but the governance profile is not negotiated with the government (information based on personal communication). The Governance Action Plan, with commitments to reforming governance, is prepared by the government of a given country. The implementation of the Governance Action Plan is supposed to be jointly monitored by the EU and the partner country. However, no explicit mechanism for monitoring the implementation has been set up, apart from the mechanism for political dialogue carried out under Article 8 of the Cotonou Partnership Agreement.

A Fact Sheet summarizing the key characteristics of the EU Governance Initiative is presented below: 


\section{FACT SHEET}

\begin{tabular}{|c|c|c|}
\hline WHY & $\begin{array}{l}\text { Primary purpose of assess- } \\
\text { ment }\end{array}$ & To guide policy dialogue, aid programming and resource allocation. \\
\hline \multirow[t]{3}{*}{ WHAT } & Conceptual approach & Public Administration, New Public Management, Political Economy Analysis. \\
\hline & Definition of governance & $\begin{array}{l}\text { "Governance concerns the State's ability to serve its citizens. It refers to the rules, } \\
\text { processes and behaviour of by which interests are articulated, resources are } \\
\text { managed, and power is exercised in society. The way public functions are carried } \\
\text { out, public resources are managed and public regulatory powers are exercised is } \\
\text { the major issue to be addressed in that context. Governance is a basic measure of } \\
\text { the stability and performance of a society. (EC 2003). }\end{array}$ \\
\hline & Focus of analysis & $\begin{array}{l}\text { Nine areas of governance: } \\
\text { 1. Political Governance } \\
\text { - human rights, fundamental freedoms } \\
\text { - electoral process, constitutional democracy } \\
\text { 2. Rule of Law } \\
\text { - judicial and law enforcement system } \\
\text { 3. Control of Corruption } \\
\text { 4. Government Effectiveness } \\
\text { - institutional capacity } \\
\text { - public financial management } \\
\text { 5. Economic governance } \\
\text { - private sector/market-friendly policies } \\
\text { - management of natural resources } \\
\text { 6. Internal and External Security } \\
\text { 7. Social Governance } \\
\text { - decent work } \\
\text { - gender } \\
\text { - HIV/AlDS } \\
\text { 8. International and Regional Context } \\
\text { - regional integration,involvement in regional initiatives } \\
\text { - migration } \\
\text { 9. Quality of partnership } \\
\text { - political and programming dialogue }\end{array}$ \\
\hline \multirow[t]{2}{*}{ HOW } & Methodology & $\begin{array}{l}\text { The Governance Profile is drafted, locally, by the EC delegation in cooperation } \\
\text { with the Member States, according to a detailed questionnaire that has been } \\
\text { prepared by the Commission headquarters. The Profile is comprised of both qual- } \\
\text { itative and quantitative indicators. The World Governance Indicators by the WBI } \\
\text { are used as reference points where applicable. To ensure a standardized approach } \\
\text { and comparability of results, the governance profiles are "harmonized" by the } \\
\text { Commission headquarters. Joint analysis with other donors is encouraged. }\end{array}$ \\
\hline & Reporting of results & $\begin{array}{l}\text { Descriptive summary which is complemented by cross-country comparable } \\
\text { indicators from third-party sources. }\end{array}$ \\
\hline WHERE & Coverage & $\begin{array}{l}\text { For all ACP countries as part of the preparation of Country Assistance Strategy } \\
\text { under the EDF } 10 .\end{array}$ \\
\hline OWNERSHIP & Role of partner country & The Governance Profile is shared, "as appropriate", with the partner country. \\
\hline
\end{tabular}

\section{Sources:}

EC (2003), Communication on Governance and Development, COM (2003) 615 DFID (2008), Brussels.

EC (2006), Communication on Governance in the European Consensus on Development, COM (2006) 421, Brussels 2006.

OECD DAC (2009), Donor Approaches to Governance Assessments, 2009 Sourcebook, Paris. 


\subsection{Millennium Challenge Scorecard; The USA}

The Millennium Challenge Scorecard was designed as a tool to determine the eligibility of a given country to receive development assistance from the USA under the framework of the Millennium Challenge Account (MCA). The MCA was launched as a new initiative in 2002 by the then President George Bush, with the objective of increasing the US support to developing countries. Through the MCA the US government was to provide an additional USD 5 billion per year, as of 2006, to developing countries that meet the eligibility criteria defined specifically for this funding instrument. The implementation mechanism of the MCA, the Millennium Challenge Corporation (MCC), was created by the US Congress in January 2004. Mozambique was first subjected to an assessment by the MCC in 2004.

\section{$\square$ Conceptual Approach}

The Millennium Challenge Act of 2003 provides the legal basis for both the Millennium Challenge Account and the Millennium Challenge Corporation and outlines the criteria for US support through the new financing instrument. According to the eligibility criteria stipulated in the Act, a country could be considered eligible if it has demonstrated commitment to: 1) just and democratic governance; 2) investments in the people; and 3) economic freedom (Millennium Challenge Act 2003. Retrieved from the World Wide Web, June 29, 2011. http://www.cfr.org/ poverty/millennium-challenge-act-2003/p16232). To highlight the importance of the criteria in guiding the allocation of funding through the MCA, the MCC was established as an organization independent of the US Agency for International Development (USAID).

Although the Millennium Challenge Corporation was set up as a separate organization to the USAID and has its own legal base ${ }^{111}$, they seem to share the same approach to governance according to which "governance issues pertain to the ability of government to develop and implement an efficient, effective and accountable public management process that is open to citizen participation and that strengthens rather than weakens a democratic system of government" (http://www.usaid.gov/our_work/

111. The decision to create a new organization for the MCA was one of the most debated issues during early congressional deliberations on the initiative. Some believed that USAID, the principal U.S. aid agency, should manage the programme, while others said that it should remain within the State Department to avoid the fragmentation of policy development. The Bush Administration argued that because the initiative represents a new concept in aid delivery, it should have its own organizational structure. Accordingly, the Millennium Corporation Act established the Millennium Challenge Corporation (MCC) as the implementing agency for the MCA (Tarnoff 2010, p. 2). 
democracy_and_governance/technical_areas/dg_office/gov.html. Retrieved May 14, 2011 from the World Wide Web).

A country can be considered eligible for support from the MCC if it has demonstrated a commitment to policies and reforms in the three areas identified above. The MCC criteria for eligibility reflect the US government's view that the quality of governance of a given country is critical for the successful implementation of development policies, and for the impact of external assistance in support of these policies. In line with the enhanced attention to political issues, transparency of government procedures and a government's accountability towards its citizens are highlighted as central components when assessing country performance. Consequently, in light of the OECD DAC conceptual framework, the MCC shares the same approach to governance as the EU, i.e. an approach rooted in power and political economy, traditional public administration and new public management approaches to governance (OECD 2009, p. 13).

\section{Stated Purpose}

The main objective of the governance assessments conducted within the framework of the MCC is outlined in the Millennium Challenge Act of 2003, which states that the MCC is "based on the principle that aid is most effective when it reinforces good governance, economic freedom and investments in people" (www.cfr.org/poverty/ millennium-challenge-act-2003/p16232. Retrieved from the World Wide Web, May 14, 2011). Accordingly, the MCC aims at enhancing the effectiveness of the growing US aid by selecting countries that are pursuing reforms in the three focus areas of just and democratic governance, investments in people and economic freedom. ${ }^{112}$

\section{$\square$ Focus of the Assessment}

The assessment conducted within the MCC framework results in a country-specific Millennium Challenge Scorecard which initially consisted of 16 indicators grouped into three categories: 1) Ruling Justly; 2) Investing in People; and 3) Fostering Economic Freedom. Since 2007, two additional indictors have been included (Natural Resource Management Land Rights and Access to Land as of 2008), while 2 of the original

112. In addition to the concerns related to aid effectiveness, the creation of the MCC was motivated by the heightened security considerations of the Bush administration following the terrorist attacks of September 11, 2001, and the role given to development cooperation in the US "war on terrorism". The MCC must also be seen in the context of the International Conference on Financing for Development, held in 2002 in Monterrey (Mexico), which called for additional funding to support developing countries to achieve the Millennium Development Goals (Hout, 2007, p. 70-71). 
indicators have been merged into one indicator (Cost of Starting Business and Days to Start-Up Business have been merged into Business Start-Up). The indicators for each category are listed in the box below:

\section{Box 6.5 | Focus of the MCC Country Performance Assessment}

\begin{tabular}{|c|c|c|c|}
\hline Category & Ruling Justly & Investing in People & $\begin{array}{l}\text { Encouraging Economic } \\
\text { Freedom }\end{array}$ \\
\hline Indicator & $\begin{array}{l}\text { 1. Civil Liberties } \\
\text { 2. Political Rights } \\
\text { 3. Voice and Accountability } \\
\text { 4. Government Effective- } \\
\text { ness } \\
\text { 5. Rule of Law } \\
\text { 6. Control of Corruption }\end{array}$ & $\begin{array}{l}\text { 1. Public Expenditures on Health as } \\
\text { Percent of GDP } \\
\text { 2. Public Primary Education Spending } \\
\text { as Percent of GDP } \\
\text { 3. Immunization Rates: DPT3 and } \\
\text { Measles } \\
\text { 4. Primary Education Completion Rate } \\
\text { 5. Natural Resource Management } \\
\text { (included for 2008) }\end{array}$ & $\begin{array}{l}\text { 1. Regulatory Quality } \\
\text { 2. Inflation } \\
\text { 3. Fiscal Policy } \\
\text { 4. Business Start-Up } \\
\text { 5. Land Rights and Access to } \\
\text { Land (included for 2008) } \\
\text { 6. Trade Policy }\end{array}$ \\
\hline
\end{tabular}

Source: MCC 2004, MCC 2007, MCC 2008, MCC 2009.

The definition of the indicators chosen for each category and the data sources are described below:

The Ruling Justly category, comprising 6 indicators, attempts to capture a country's commitment to democratic governance, rule of law, respect for human rights, government's transparency and accountability vis-à-vis its citizens, as well as the status of private property rights.

Civil Liberties indicator measures country performance on "freedom of expression, association and organizational rights, rule of law and human rights, and personal autonomy and economic rights" (MCC, 2004, p. 5; MCC, 2009, p. 8). Data Source: Freedom House

Political Rights indicator measures country performance "on the quality of electoral process, political pluralism and participation, government corruption and transparency and fair political treatment of ethnic groups" (MCC, 2004, p. 5; MCC, 2009, p. 10). Data Source: Freedom House.

Voice and Accountability indicator measures "the extent to which citizens of a country are able to participate in the selection of governments, and the independence of the media" (MCC, 2004, p. 5; MCC, 2009, p. 11). Source: World Bank Institute. 
Government Effectiveness indicator measures "the quality of public service provision, civil services' competency and independence from political pressures, and the government's ability to plan and implement sound policies" (MCC, 2004, p. 5; MCC, 2009, p. 13). Source: World Bank Institute.

Rule of Law indicator measures "the extent to which individuals and firms have confidence in an abide by the rules of society, and in particular the quality of contract enforcement, the police and he courts, as well as the likelihood of crime and violence" (MCC, 2004, p. 5; MCC, 2009, p. 16). Source: World Bank Institute.

Control of Corruption measures "the extent to which public power is exercised for private gain, including both petty and grand forms of corruption, as well as 'capture' of the state by elites and private interests" (MCC, 2004, p. 5; MCC, 2009, p. 18). Source: World Bank Institute.

The Investing in People category initially consisted of four indicators aimed at capturing a government's commitment to investing in, or providing services, in the field of the education and health, particularly for women and children. These indicators are measured either in terms of public expenditure or progress achieved. For the 2008 MCC country performance assessment, an indicator on national resource management was added. The indicators are described as follows (MCC, 2004, p. 6; MCC, 2009, p. 21-24):

Public Expenditure on Health measures the general government health expenditure as a percentage of GDP (MCC, 2004, p. 5, see also MCC, 2009, p. 21). Data Source: National Governments.

Public Expenditure on Primary Education measures the total public expenditure on primary education (MCC, 2004, p. 5; MCC, 2009, p. 22). Data Source: National Governments.

Immunization indicator measures the average of the diphtheria-pertussis-tetanuts $\mathrm{DPT}_{3)}$ and measles vaccination rates (MCC, 2004, p. 5; MCC, 2009, p. 23). Data Source: The World Health Organization WHO.

Primary Completion Rate measures the number of students completing primary education divided by the population in the relevant age cohort (MCC, 2004, p. 5; MCC, 2009, p. 23.) Data Source: World Bank and UNESCO. 
Natural Resource Management indicator measures "a government's commitment to sound management of water resources and water systems, proper sewage disposal and sanitary control, air quality standards, habitat preservation, and biodiversity protection" (MCC, 2009, p. 25). Data Sources: Columbia University's Center for International Earth Science Information Network and the Yale Center for Environmental Law and Policy.

The indicators on Encouraging Economic Freedom attempt to capture the commitment of a government to encouraging economic freedom and to pursuing policies that strengthen sound macro-economic management and private sector development in the country. An indicator on land rights and access to land was added for the 2008 MCC assessment. The five indicators are described as follows:

Regulatory Quality indicator measures "the ability of a government to formulate and implement sound policies and regulations that permit and promote private sector development" (MCC, 2004, p. 6; MCC, 2009, p. 26). Data Source: World Bank Institute.

Inflation indicator aims to capture a government's "commitment to sound monetary policy and private sector growth", measured by the most recent 1-year change in consumer prices (MCC, 2004, p. 6; MCC, 2009, p. 28). Data Source: IMF World Economic Outlook.

Fiscal Policy indicator assesses a government's "commitment to prudent fiscal management and private sector growth", measured by the overall budget deficit divided by GDP, averaged over a three-year period. (MCC, 2004, p. 6; MCC, 2009, p. 29). Data Source: National Governments (cross checked with the IMF sources).

Business Start-Up indicator measures "the time and cost of complying with all procedures officially required for an entrepreneur to start up and formally operate an industrial or commercial business" (MCC 2004, p. 6; MCC 2009, p. 30) Data Source: World Bank/International Finance Corporation, Doing Business Report).

Land Rights and Access (to land) indicator aims to assess "whether and to what extent a government is investing in secure land tenure” (MCC 2007, p. 6; MCC 2009, p. 30). Data Sources: International Fund for Agricultural Development, IFAD.

Trade Policy indicator measures a country's "openness to international trade based on average tariff rates and non-tariff barriers to trade" (MCC 2004, p. 5; MCC 2009, p. 34). Data Source: The Heritage Foundation's Index of Economic Freedom. 
As mentioned earlier, the indicators of the MCC are intended to assess the degree to which the political and economic conditions in a country serve to promote broadbased sustainable economic growth and thereby provide an appropriate policy framework for the use of the funds under this initiative. The choice of the indicators has been carefully justified in the MCC documentation by summarizing the research evidence on the impact of each indicator on economic growth and poverty reduction, with references to original data sources. The assessment is intended to focus exclusively on development goals without being influenced by other U.S. foreign policy and geo-strategic objectives.

The indicators are not considered as goals in themselves but they are used to measure policies considered as necessary preconditions for a country to achieve broad-based and sustainable economic growth. The MCC "favours indicators developed by independent third parties, which utilize rigorous methodology and objective data, are publicly available, have broad country-coverage and are comparable across countries, have a clear theoretical or empirical link to economic growth and poverty reduction, are policy-linked and have a broad consistency over results from year to year" (MCC 2009, p. 8). In other words, the MCC uses indicators developed by other development agencies. For example, the aggregated indicators on "voice and accountability", "government effectiveness" and "the rule of law", developed by the World Bank Institute for the WGI, constitute three of the five MCC indicators for the category of Ruling Justly. At the same time, the MCC uses additional indicators, such as the "civil liberties" indicator and "political rights" indicator, to capture specific aspects of the category of Ruling Justly. Both of the additional indicators are based on data produced by the Freedom House, which is also used by the WGI to construct the composite indicator of "voice and accountability" (Arndt 2009).

\section{$\square$ Methodology}

The MCC applies a globally standardized assessment methodology. The process for selecting the countries that could potentially receive financial assistance through the MCC is laid down in the Millennium Challenge Act. This process involves three main steps: first, the initial identification of "candidate countries" for MCC support; second, the assessment of the "candidate countries" on the basis of the MCC criteria listed above; and third, the selection amongst the group of "candidate countries" those countries that meet the eligibility criteria. The final decision on the eligibility is taken by the Board of Directors of the MCC.

Candidate countries for each fiscal year are identified on the basis of their per capita income using the World Bank IDA's income per capita ceiling for low-income country 
as the as the benchmark for candidacy. Hence a country can be considered a candidate country if "the per capita income of the country is equal to or less than the historical ceiling of the International Development Association for the fiscal year involved, as defined by the International Bank for Reconstruction and Development". The category of lower middle-income countries, as classified by the World Bank, was included in the group of potential candidate countries as of fiscal year 2006. According to the Act, a lower middle income country could receive up to $25 \%$ of all funds available though the Millennium Challenge Account. All candidate countries compete within their respective income groups. The Act further states that, apart from the per capita income ceilings, a country may be considered a candidate only if it is not statutorily prohibited from receiving U.S. economic assistance (Millennium Challenge Act 2003. Retrieved from the World Wide Web, May 14, 2011.

http://www.cfr.org/poverty/millennium-challenge-act-2003/p16232).

The Millennium Challenge Act does not specify in detail the methodology for assessing the eligibility of a given country, but states that the countries eligible for MCC support must meet the MCC criteria. The assessment methodology is described in a separate report, submitted annually by the MCC to the US Congress for approval. In addition to this report, the MCC provides a technical guidance note with detailed information on the indicators, the underlying data sources, as well as the formulas used to calculate the performance of a given country on each of the indicators. The technical guidance note further describes how to arrive at the country-specific scoring of the candidate countries, the Millennium Challenge Scorecard, which shows a country's percentile ranking in its respective income group (low-income/lower middle-income country), with the zero indicating the lowest, 50\% the median and $100 \%$ the best ranking. The Millennium Challenge Scorecard also indicates a country's score on each of the 17 indicators included in the assessment. The scale of the scores applied for the different indicators varies according to the units of measurement used by the original data providers. The data sources and specific indicators underlying the performance assessment are reviewed annually by the MCC, and over the years some minor changes have taken place (for a detailed description of the methodology to calculate the score of each indicator, see www.mcc.gov).

In general, to be eligible for MCC support, a candidate country must perform above the median in its income peer group on at least half of the indicators in each of the three policy category, and (bold added by the author) above the median on the Control of Corruption indicator. The indicator on corruption is thus treated as a threshold indicator. Concerning the indicator on Inflation, a country's inflation rate needs to be under a fixed ceiling of $15 \%$. 
The Board of Directors of the MCC, which is mandated by the Act to finally determine whether a country meets the criteria, has a certain degree of discretion in deciding upon country eligibility and "may also consider information to address gaps, time lags, measurement error, or other weaknesses in the indicators to assist in assessing whether MCC funds might reduce poverty and promote economic growth in a country" (MCC 2009, p. 4). Furthermore, countries that in view of the MCC Board demonstrate commitment to meet the eligibility criteria but fail in some policy areas, can be provided financial support through the so called Millennium Challenge Threshold Programmes aimed at supporting countries to improve their performance in the specific policy areas (www.mcc.gov).

The countries meeting the eligibility criteria are not automatically guaranteed assistance but are invited to submit programme proposals for consideration by the MCC Board. For example, as a low-income country Mozambique was identified as a candidate country and deemed eligible for MCC support already in 2004. However, the first cooperation agreement between the Government of Mozambique and the MCC, the so called MCC Compact, was signed only in 2007. Mozambique had received funding through the MCC in the form of a pre-compact grant since 2005 (www.mcc.gov; MCC, 2005, Press Release 9.9.2005).

\section{$\square$ Reporting and dissemination of results}

The country-specific Millennium Challenge Scorecards, as well as information on the underlying data sources, indicators and methodology, are publicly available on the MCC website. The scores are presented in a quantitative format. The lists of candidate countries, including countries excluded for legal reasons, are also made public. The MCC thus seems to have opted for a disclosure policy which allows the various stakeholders in the USA, in the wider development community, as well as in developing countries, to have access to all information on the results of the performance assessment. The MCC does not, however, consult the authorities of the candidate countries during the assessment process. Consultation with country authorities are initiated only at the stage of the preparation of the programme proposals for the Millennium Challenge Compact and Millennium Challenge Threshold Programme (information based on personal communication).

\section{Partner Country Ownership}

The notion of partner country ownership does not seem to be central to the MCC assessment process. While the countries subject to MCC assessment have wide access 
to all the information concerning the MCC, they are not involved or consulted during the assessment process, and the Millennium Challenge Scorecards are not formally used to mobilize wider policy dialogue (information based on private communication). Despite its strong emphasis on the political dimensions of governance, the MCC largely relies on external expert assessments such as the Freedom House and Worldwide Governance Indicators rather than on country-level data sources. However, it must be pointed out that some of the data underlying the Millennium Challenge Scorecards are collected at national level, in particular, data concerning the category of "Investing in People". The extent the to which the outcome of the assessment, i.e. the Millennium Challenge Scorecard, is discussed with the authorities of a given candidate country remains unclear. As pointed out above, the consultations with the country authorities start only after the decision on country eligibility has been taken by the Board of Directors of the MCC.

A Fact Sheet summarizing the key characteristics of the Millennium Challenges Scorecard is presented below: 


\section{FACT SHEET}

Tool Millennium Challenge Scorecard

Agency Millennium Challenge Corporation; United States

\begin{tabular}{|c|c|c|}
\hline WHY & $\begin{array}{l}\text { Primary purpose of assess- } \\
\text { ment }\end{array}$ & $\begin{array}{l}\text { To select countries eligible for assistance through the MCA and to provide } \\
\text { information on performance monitoring and policy reforms. }\end{array}$ \\
\hline \multirow[t]{3}{*}{ WHAT } & Conceptual approach & $\begin{array}{l}\text { New Public Management, Public Administration, Power and Political Economy } \\
\text { Perspective }\end{array}$ \\
\hline & Definition of governance & $\begin{array}{l}\text { "Governance is a broad concept, encompassing the capacity of the state, the } \\
\text { commitment to the public good, the rule of law, the degree of transparency and } \\
\text { accountability, the level of popular participation, and the stock of social capital." } \\
\text { (USAID 2002) }\end{array}$ \\
\hline & Focus of analysis & $\begin{array}{l}\text { Three main categories, measured with } 16 \text { indicators. As of 2007, } 2 \text { supplemen- } \\
\text { tary indicators include: } \\
\text { 1. Ruling Justly } \\
\text { - civil liberties } \\
\text { - political rights } \\
\text { - voice and accountability } \\
\text { - government effectiveness } \\
\text { - rule of law } \\
\text { - control of corruption } \\
\text { 2. Investing in People } \\
\text { - public expenditure on health } \\
\text { - immunization rates } \\
\text { - public expenditure on primary education } \\
\text { - girls' primary education completion rate } \\
\text { 3. Encouraging Economic Freedom } \\
\text { - cost of starting business } \\
\text { - inflation } \\
\text { - fiscal policy } \\
\text { - days to start business } \\
\text { - trade policy } \\
\text { - regulatory quality } \\
\text { 4. Supplementary indicators (as of 2007) } \\
\text { - natural resources management } \\
\text { - land rights and access }\end{array}$ \\
\hline \multirow[t]{2}{*}{ HOW } & Methodology & $\begin{array}{l}\text { The } 18 \text { indicators are measured by using information collected from publicly } \\
\text { available third-party data sources and complied by the MCC. Data sources are } \\
\text { determined by the MCC Board of Directors. A country is considered eligible for } \\
\text { MCC funding if it scores above the median (in its respective income peer group) } \\
\text { on at least half of the indicators in each of the three policy categories, and above } \\
\text { the median on the corruption indicator. The inflation indicator is set at a fixed } \\
\text { ceiling of } 15 \% \text {. The MCC Board may also consider supplemental information and } \\
\text { take into account factors such as data gaps or time lags to review eligibility. }\end{array}$ \\
\hline & Reporting of results & $\begin{array}{l}\text { Quantitative reporting, cross-country comparable set of indicators, individual } \\
\text { ratings publicly available }\end{array}$ \\
\hline WHERE & Coverage & Annual since 2004 (63 countries in 2004, 98 countries 2007) \\
\hline OWNERSHIP & Role of partner country & $\begin{array}{l}\text { Partner country stakeholders partly involved as some data collection carried out } \\
\text { at country level (household/firm surveys). }\end{array}$ \\
\hline
\end{tabular}

\section{Sources:}

Millennium Challenge Corporation 2007, 2007 Country Scorebook, Washington D.C.

OECD DAC (2009), Donor Approaches to Governance Assessments, Sourcebook, Paris.

USAID (2002), Foreign Aid in the National Interest: Promoting Freedom, Security and Opportunity, Washington. 


\subsection{Country Governance Analysis; The United Kingdom}

The Country Governance Analysis (CGA) has its origin in the UK Government's White Paper of 2006, entitled Eliminating world poverty: making governance work for the poor people (Crown Copyright, 2006), which defined governance as a central component for poverty reduction and wider socio-economic development. The White Paper mandated the UK government's aid agency, the Department for International Development (DFID), to assess and monitor governance in its partner countries, and to use this assessment to guide the UK's aid policies and programming. To this effect, the Country Governance Analysis was introduced in 2007. Since then the analysis has been conducted in several developing countries, including in Mozambique, in the context of the planning of the DFID's country assistance programmes.

\section{Conceptual Approach}

The Country Governance Analysis was developed as a tool to support the implementation of the governance agenda outlined in the White Paper. The CGA is not explicit about its conceptual underpinnings. Neither does it refer to a specific definition of the notion of governance. The White Paper itself is also operational in its approach. While stating that "the fight against poverty cannot be won without good governance" (Department for International Development, 2006, p. xi), it does not provide any theoretical justifications for the argument. According to the White Paper "Good governance requires: capability the extent to which government has the money, people, will and legitimacy to get things done; responsiveness - the degree to which government listens to what people want and acts on it; and accountability - the process by which people are able to hold government to account" (ibid., p. 20). The notion of good governance is defined in terms of "good politics" which "determines how resources are used and policies are made" (ibid., p. 23). While the state is given a central role in governance, the White Paper underlines that governance is not only about governments but entails also the participation by political parties, parliament, the judiciary, the media, private sectors actors as well as civil society (ibid., 2006).

As discussed by Moore and Unsworth (2006), the White Paper recognizes the historical roots of governance problems in developing countries. It acknowledges, on the one hand, the need to help governments to become more democratic, participatory and law-abiding, and on the other hand, the limits to solving the governance problems through direct donor interventions. Furthermore, the White Paper highlights the impact of global political and economic forces beyond the control of developing countries as an important element affecting the quality of their governance, and calls for shared responsibility to tackle governance issues at international level (Moore and Unsworth, 2006, p. 706-707). 
Hence, the UK approach to governance underlying the CGA is very broad comprising historical, political, economic and social dimensions of governance not only within a specific country context but also global governance concerns. In its historical and global approach it is clearly more holistic than any of the tools discussed above. Using the OECD DAC analysis, the conceptual approach of the CGA is firmly rooted in political economy and historical analysis related to governance. With its emphasis on public service delivery and the accountability of the state to its citizens, the CGA also builds on theories of traditional public administration, new public management and network governance (OECD, 2009, p.13-14).

\section{Stated Purpose}

The strategic objective of the CGA is defined as putting a "comprehensive governance and conflict assessment at the heart of the DFID's country planning process" (DFID, 2008, p.3). Through the CGA, the DFID aims to assess whether a given country meets the three criteria set for UK's aid partnerships: 1) commitment to poverty reduction and the MDGs; 2) commitment to respecting human rights and other international obligations, as well as to strengthening financial management; and 3) accountability to reduce the risk of misuse of funds (Department for International Development (DFID)/Foreign and Commonwealth Office and HM Treasury, 2005. Partnerships for Poverty Reduction: Rethinking Conditionality. Retrieved in June 15, 2011 from the World Wide Web, http://www.dfid.gov.uk).

In operational terms, the CGA has four main objectives:

1) to reach a judgment on both the broad trajectory of development and change in governance, as well as on trends in critical and specific aspects, and on the key short and medium term political and conflict risks;

2) to inform DFID ministers and senior management's understanding of the historical and strategic contents of governance in any particular country;

3) to inform the nature, content and direction of donor governance dialogue in-country in countries where such a process exists, or to help initiate one where it does not;

4) to inform the design of DFID's country programme and the British government's strategy.

Source: DFID, 2008, p. 5

The CGA is thus aimed at guiding the preparation of the DFID country assistance strategy for a given country and informing the choice of partner institutions, priority sectors and aid modalities for cooperation. However, the CGA is not (bold added by the author) used to rank countries, to trigger disbursement of aid, to set minimum 
threshold for particular aid instruments or to draw final conclusions on the three partnership commitments cited above.

\section{$\square$ Focus of the Assessment}

The focus of the governance assessment under the CGA framework is shaped by the White Paper's definition of good governance which involves three components: 1) State Capability; 2) State Responsiveness; and 3) State Accountability. State capability refers to the effectiveness of a given partner country government in delivering public services and carrying out public sector functions. The assessment of state responsiveness aims to capture the extent to which a given state, as well as the policies promoted by its public sector institutions, respond to the needs of citizens and support them in exercising their rights as citizens. Under accountability, the CGA aims to assess the ability of citizens, civil society and the private sector to scrutinize the government and public institutions as well as hold them to account for their work.

The CGA is expected to provide a robust analysis of the quality of governance within the above three broad focus areas while paying to potential trends in these areas. The analysis aims to cover not only the formal mechanisms of governance, but also the informal mechanisms which impact upon state capability, responsiveness and accountability. The key issues to be addressed within the framework of the CGA are presented in Box 6.6:

\section{Box 6.6 | Focus of the CGA}

\section{State Capability}

- Political Stability and Personal Security

- Economic and Social Policy Management Capability

- Government Effectiveness and Service Delivery

- Revenue Mobilization and Public Financial Management

- Conditions for Investment, Trade and Private Sector Development

\section{Responsiveness}

- Human Rights and Civil Liberties

- Pro-Poor Policy

- Inequality, Discrimination and Gender Equality

- Regulatory Quality

- Corruption

\section{Accountability}

- Political Freedoms and Rights

- Transparency and Media

- Political participation and Checks

- Rule of Law and Access to Justice

- Civil Society

Source: DFID, 2008, p. 8 . 
The main focus areas and the specific issues to be addressed within the framework of the CGA are thus very similar to those of the Worldwide Governance Indicators and the Millennium Challenge Scorecard, albeit structured somewhat differently.

\section{Methodology}

According to the DFID, the "CGA aims to combine simplicity and flexibility" (DFID, 2008, p. 7). Hence, the DFID has opted for an approach that gives its country offices a "maximum flexibility" in defining the specific focus of the analysis - within the boundaries of the three main focus areas -as well as in selecting the indicators and data sources underpinning the analysis. The analysis "should centre on data produced or endorsed by the government and other local sources", and "the CGA should pull together a balanced data set: local, national and international; quantitative and qualitative data; expert and citizen-led" (DFIF 2008, p. 13).

The principle of flexibility is also applied to methods for conducting the CGA. The DFID encourages its country offices to support and use, to the extent possible, existing or emerging country-level assessment and dialogue processes. This means that, in cases where the government of a given country, or any of the other donors present in that country, have already produced a governance assessment which is considered sufficiently rigorous and robust by the DFID country office, that assessment can be put forward as the CGA. If necessary, the assessment can then be supplemented by additional data and analysis (DFID, 2008, p. 15-16).

In most simple terms, the CGA thus entails the collection, analysis and interpretation of existing data, whether quantitative or qualitative on the above set of issues, grouped under the headings of state capability, responsiveness and accountability. The CGA does not require any scoring or quantification of qualitative data. It relies on qualitative narratives produced by the DFID country offices on the basis of their own analysis and discussions with government and civil society, as well as with other donor agencies. In its flexibility, the CGA clearly differs from the standardized approach applied in the other governance assessments discussed earlier.

Before finalization, the CGAs are submitted to the DFID headquarters for a peer review so as to ensure that the process of conducting the CGA has been aligned with the existing assessment processes within a country, and that the analysis is based on a robust and balanced set of data. The peer review further aims at providing some consistency and comparability of the outcomes of the assessments. 


\section{Reporting and Dissemination of Results}

Although the main purpose of the CGA is to inform the DFID's policy dialogue and country programming processes, the results of the CGA should be shared with partner country governments, civil society actors and other donor agencies. However, the sharing of the analysis can mean various things ranging "from joint production, endorsement, consultation through merely handing over a final document" (DFID, 2008, p. 13). Transparency is considered desirable and, therefore, whenever possible the outcome of the CGA should be shared and actively disseminated.

The extent to which the practices of conducting the assessments and disseminating the outcomes of country-specific CGAs follow the principles of sharing and transparency remains debatable. Although the DFID calls for sharing the information, it also recommends that the dissemination of the final governance analysis be handled pragmatically based on a country context. It is thus acknowledged that the dissemination of the final CGA document may not be possible "in sensitive contexts", and there may be different versions submitted internally and for public communication purposes. All countries are instructed, however, to publicize some version of the governance analysis. For example in the case of Mozambique, the draft CGA of 2007 can be retrieved from the DFID web page. However, no reference can be found to the final version of the document. It thus remains unclear whether a revised final version was produced, or whether the draft document should be treated as the final CGA.

\section{Partner Country Ownership}

Following the recommendation to use existing government assessment processes in conducting the CGA, it can be assumed that, at least in principle, DFID's partner countries are involved in the CGA. The emphasis on a country-specific analysis of historical, structural and political factors impacting upon governance implies that the CGA builds on indicators considered relevant for a given country and relies on data generated at the country level. In this respect the CGA allows for a stronger partner country ownership than, for example, the World Bank, the African Development Bank and the MCC, which rely on a standardised approach. However, the extent to which a given partner country can exercise ownership concerning the analysis of the data and the drafting of the CGA outcome document remains questionable.

The DFID guidance note underlines that the CGA should be conducted in consultation with other stakeholders, including the partner country government, but it does not outline any mechanism for negotiating the final CGA document. As pointed out above, the dissemination of the outcome of the CGA remains in the hands of the 
country office. "In sensitive contexts" the final document does not have to be published. The ownership by a partner country of the CGA thus seems to be dependent on the perceived quality of governance in a given country: arguably, if the state of governance is considered poor, the CGA remains confidential, whereas if the country is considered a good performer, the outcome of the CGA is freely shared.

A Fact Sheet summarizing the key characteristics of the CGA is presented below. 


\section{FACT SHEET}

$\begin{array}{ll}\text { Tool } & \text { Country Governance Analysis } \\ \text { Agency } & \text { DFID (UK) }\end{array}$

\begin{tabular}{|c|c|c|}
\hline WHY & $\begin{array}{l}\text { Primary purpose of } \\
\text { assessment }\end{array}$ & To guide policy dialogue, aid programming and performance and assessment. \\
\hline \multirow[t]{3}{*}{ WHAT } & Conceptual approach & $\begin{array}{l}\text { Historical and Political Economy Analysis, Network Governance, New Public } \\
\text { Management, Public Administration, }\end{array}$ \\
\hline & Definition of governance & $\begin{array}{l}\text { "Governance is about the use of power and authority and how a country } \\
\text { manages its affairs..... Governance analysis considers all the mechanisms, } \\
\text { processes, relationships and institutions through which citizens and groups } \\
\text { articulate their interests and exercise their rights and obligations." (DFID 2007). } \\
\text { "Good governance is to be found where states are capable, accountable and } \\
\text { responsive". (DFID 2008) }\end{array}$ \\
\hline & Focus of analysis & $\begin{array}{l}\text { Three categories comprise } 15 \text { main criteria ("information points"). Additional } \\
\text { context-specific criteria may be included. : } \\
\text { 1. State Capability } \\
\text { - political stability and personal security } \\
\text { - economic and social policy management capability } \\
\text { - government effectiveness and service delivery } \\
\text { - revenue mobilization and public financial management } \\
\text { - conditions for investment, trade and private sector development } \\
\text { 2. Accountability } \\
\text { - political freedoms and rights } \\
\text { - transparency and media } \\
\text { - political participation and checks } \\
\text { - rule of law and access to justice } \\
\text { - civil society } \\
\text { 3. Responsiveness } \\
\text { - human rights and civil liberties } \\
\text { - pro-poor policy } \\
\text { - inequality, discrimination and gender equality } \\
\text { - regulatory quality } \\
\text { - corruption }\end{array}$ \\
\hline \multirow[t]{2}{*}{ HOW } & Methodology & $\begin{array}{l}\text { Methodology non-prescriptive, but a mix of qualitative and quantitative } \\
\text { indicators suggested. The choice of indictors done by DFID country offices } \\
\text { which prepare the analysis by using publicly available data organized along } \\
\text { DFID's framework for good governance. Existing partner country government, } \\
\text { donor-partner country dialogues or processes serve as the starting point for the } \\
\text { CGA. Joint analysis with other donors encouraged. }\end{array}$ \\
\hline & Reporting of results & $\begin{array}{l}\text { Descriptive summary complemented by cross-country comparable indicators } \\
\text { from third-party sources. Transparent reporting and publication of results is } \\
\text { considered desirable, but subject to country context. }\end{array}$ \\
\hline WHERE & Coverage & $\begin{array}{l}\text { Mandatory for all programme countries in the preparation of their Country } \\
\text { Assistance Plans (CAPs). }\end{array}$ \\
\hline OWNERSHIP & Role of partner country & $\begin{array}{l}\text { Dialogue with country stakeholders to arrive at "shared understanding of quality } \\
\text { of governance". Some data collection carried out at country level (household/ } \\
\text { firm surveys). Assessment to be peer reviewed by DFID's Quality Assurance } \\
\text { Group. }\end{array}$ \\
\hline
\end{tabular}

\section{Sources:}

DFID (2008), How to Note; Country Governance Analysis, London

OECD DAC (2009), Donor Approaches to Governance Assessments, Sourcebook, Paris

University of Essex and UNDP (2007), Preliminary Survey on Donor use of Governance Assessments, Online, www.undp.org/oslocentre/docs07/bergen_2007 (accessed 19 July 2010) 


\subsection{Strategic Governance and Corruption Analysis; The Netherlands}

The Strategic Governance and Corruption Analysis (SGACA) was introduced by the Ministry for Foreign Affairs of the Netherlands in 2008 as a tool for assessing the quality of governance of countries receiving Dutch development assistance. Since then, a Strategic Governance and Corruption Analysis has been conducted in several developing countries, including Mozambique, in the context of the preparing the Multi-Annual Strategic Plans for the Netherlands' partner countries.

The formulation of the SGACA was motivated by the recognition that much of the aid channelled to developing countries had failed to bring expected results, largely due to insufficient understanding of the country context: the historical, political, social and economic factors which contribute to a change in a given country. At the same time, the need to show results was mounting in order to justify the high volumes of Dutch development assistance. It was argued that "after almost five decades of aid, donors have to admit that their way of thinking must be pushed to the background and that instead they have to start looking at development from the perspective of the developing countries" (Hazenberg, 2008, p. 405). The SGACA was designed with the specific objective of shedding light on the multitude of formal and informal factors that shape governance in a particular country.

\section{Conceptual Approach}

The documentation on the SGACA outlines, explicitly, that the governance processes of a given country need to be examined through the "lens" of political economy. Within the SGACA framework, the term "political economy", in itself a very broad and multi-faceted notion, is used to refer "to the interaction between institutions and human behaviour, the way in which the former shape choices and how the latter changes institutional frameworks" (Hazenberg 2009, p. 403). ${ }^{113}$ The objective of the SGACA is to explore the underlying factors that shape the formal and informal relations between the state and organized groups in society. It aims at looking "behind the façade", that is, behind the formal structures and rules of governance so as to provide an in-depth understanding of the different historical, political and economic forces

113. According to the OECD, political economy analysis is "concerned with the interaction of political and economic processes in a society: the distribution of power and wealth between different groups and individuals; and the processes that create, sustain and transform these relationships over time." (www.oecd.org/dac/governance-development/politicaleconomyanalysis.htm). 
shaping the state of governance in a particular country (Waltmans, 2008; Hazenberg, 2009).

The explicit reference to a political economy approach distinguishes the SGACA from the other assessment tools under consideration in this research. Although the conceptual basis of the SGACA seems very similar to that of the UK's CGA, the SGACA highlights the importance of the interaction of various formal and informal factors which shape the governance in a given country. Following the OECD DAC conceptual framework, the SGACA has its roots, primarily, in the traditions of historical and political economy analysis. It also contains elements of the new public management and network governance by looking into public sector efficiency and the role of country-specific social and political processes for achieving better governance (OECD DAC, 2009, p. 14).

\section{口 Stated Purpose}

The SGACA was designed as a tool to enhance the efforts by the Dutch government to analyze the quality of governance in its partner countries. Its main purpose is to deepen the understanding of the country-specific context for governance and, specifically, for corruption. To this effect, it aims at analyzing the national and local political processes in a given country and their impact on the development of that country. It further aims at explaining what determines the nature and dynamics of these political processes. Enhanced attention is paid to informal institutions and factors that underlie formal political processes and set the rules of local/national politics. Apart from generating knowledge of the governance situation in a particular country, the objective of the SGACA is to improve the Dutch and other donor interventions by shedding light on the question of what really drives - or blocks - development in a given country. It is assumed that with its political economy approach the SGACA can contribute to more effective and realistic development aid in terms of planning, programming, risk assessment and dialogue.

In operational terms, the objective of the SGACA is to serve as an input to the formulation of the Netherlands' Multi-Annual Strategic Plans for its partner countries. The outcome of the SGACA impacts upon the allocation of Dutch aid resources between and within developing countries, as well as upon the choice of aid modalities. However, as in the case of the UK's CGA, the objective of the SGACA is not to rank countries or to determine whether a country is eligible for official development assistance by the Netherlands. 


\section{$\square$ Focus of the Assessment}

The core of the SGACA assessment is referred to as the Power and Change Analysis (PCA) which aims at identifying the factors and actors which may help to explain both strong/weak governance and strong/poor development performance. Furthermore, the PCA aims to shed light on the potential opportunities and constraints for changes in governance, or in wider development trends.

The PCA follows a guideline, developed by the Ministry for Foreign Affairs of the Netherlands, which defines the process of the analysis and outlines the set of issues to the addressed. These issues are grouped into three broad dimensions named as: 1) Foundational Factors; 2) Rules of the Game; and 3) Here and Now. The first dimension, the Foundational Factors, comprises issues which are considered to be the fundamental parameters shaping the nature of the political system of a given country. The Rules of the Game refers to those aspects of a country's political system - both formal and informal - which are seen as determining the quality of governance, irrespective of the formal structure and rules of governance. The third dimension, the Here and Now, refers to issues which are likely to have an imminent impact on state-society relations and are likely to contribute to changes in governance (The Netherlands Ministry for Foreign Affairs, 2008, p. 10). The issues to be addressed within each dimension are listed in Box 6.7.

\section{Box 6.7 Focus of the SGACA}

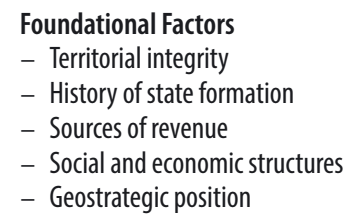

Rules of the Game

- Formal legal and administrative framework

- Political competition

- Institutionalization of state, civil society and private sector organizations

- Distribution of power

- State-society relations

- Identification of key trends

\section{Here and Now}

- Context

- Actors and Stakeholders

Source: The Netherlands Ministry for Foreign Affairs 2008. 
The above list of issues illustrates the Netherlands' attempt to capture a range of country-specific historical, geographic etc. factors which, while beyond the immediate control of a given country, can strongly influence the state of governance of that country. In particular, the category of Foundational Factors covers a number of very broad topics which are largely beyond the control of a country's formal governance structures, but set the political and economic parameters for the country's governance agenda. The issues to be addressed under the Rules of Game, as well as under the Here and Now, aim at capturing governance concerns which are more likely to fall within the control of the state and other stakeholders of a given country.

In order to ensure consistency, a set of suggested questions is provided to guide the analysis. For example, on "territorial integrity", "the starting point is to know whether the government broadly exercises authority over its population and territory, and controls its borders or whether there are parts of the territory which remain outside government control". To address these topics, the following questions are suggested: "Does the national government have the monopoly of violence? Are there disputed territories? Do tax collection, policing and justice systems cover all area of the country? Is there a serious challenge to public authority from armed insurgents, social movements or local power holders?" (The Netherlands Ministry for Foreign Affairs, 2008, p. 11). (For a more detailed description of the contents of the three dimensions and the "suggested questions", see The Netherlands Ministry for Foreign Affairs 2008, p. 11-26).

The objective of the PCA is not only to identify the formal institutions, rules and procedures which shape the political economy of a given country, but also the informal institutions, structures, patterns of behaviour which remain behind the façade. Therefore, although the overall scope of the Power and Change Analysis is defined in terms of the above three main dimensions, each with an agreed set of specific issues, the focus of the assessment and the individual questions to be raised in a given country can be tailored according to the country context. The teams responsible for conducting the PCA are thus given flexibility to fine-tune the focus of the assessment in order to ensure maximal relevance of the analysis (ibid., 2008).

\section{Methodology}

The methodology for conducting the SGACA entails a four-stage process. It starts with the regular monitoring and reporting work carried out by the Dutch embassy in a given country. This leads to the establishment of a so called "Track Record" for that country which provides the basis for the Power and Change Analysis (PCA). Once the PCA is completed, a country-level workshop (or 1-2 workshops) is organized to discuss the outcome of the PCA. The workshop is meant, primarily, for internal 
discussion but it can be opened to other stakeholders such as other donors, representatives of the partner country government, the private sector and civil society. The SGACA ends with the process of summarizing the key findings of the analysis, and identification of policy choices available for the Dutch government. The final stage of the SGACA feeds into the preparation of the Dutch Multi-Annual Strategic Plan for a given country (the Netherlands Ministry for Foreign Affairs, 2008).

As mentioned above, the central component of the SGACA exercise is the PCA. According to guideline for the PCA, the analysis should preferably be conducted by an external consultancy team comprising both international and local consultants, together with the staff of the Dutch embassy in a given country. First the Foundational Factors, i.e. the fundamental factors shaping the state of the political system are mapped out, largely, on the basis of available information collected at the country level. Second, the formal and informal Rules of the Game of the political system that are likely to affect the quality of governance are identified with the objective of explaining what really drives or prevents changes in governance or, in more general terms, development in the country. Finally, concerning the last, vaguely named category, Here and Now, the focus of the analysis is on those development trends and events which are likely to bring about changes in the relations between the state and society (ibid., 2008).

The results of the PCA are presented in a qualitative narrative of the state of governance and corruption. The outcome document includes an analysis of the reasons underlying the prevailing situation, and further outlines emerging changes in a country's governance trajectories. The PCA does not aim at ranking of countries, and there is no automatic link between outcome of the PCA and any specific aid interventions. However, the PCA feeds into the discussion on the Netherlands' aid strategy and its wider foreign policy choices (ibid., 2008).

\section{$\square$ Reporting and Dissemination of Results}

The Netherlands seems to apply a policy similar to the UK concerning its CGA in the reporting and the dissemination of the SGACA. The outcome of the SGACA, including the PCA, should be shared with partner country governments, civil society actors and other donor agencies. However, as in the case of the CGA, the level of sharing of the output documents of SGACA may mean different things, and the dissemination of the outcome of the SGACA seems to remain very restricted. For example, the final outcome of the PCA in Mozambique was shared with the representatives of the Mozambican government and other donor agencies. However, no formal discussions were held with the representatives of the government, and there was no feedback from the government on the PCA (information based on personal communication). The 
PCA cannot be accessed through the web page of the Dutch Embassy in the country or through the Foreign Ministry's web page.

\section{Partner Country Ownership}

Although the main purpose of the SGACA is to gain in-depth understanding of the formal and informal political, economic, social etc. processes in a given country, the involvement of the local stakeholders of the country in the formulation and implementation of SGACA is marginal. However, in the course of the various phases of the SGACA, countries subject to the assessment are consulted. First, the Track Record, which is drafted by the Dutch embassy in a given country, builds on the data generated at the local level. Second, the PCA is normally carried out by a consultancy team, which includes local stakeholders such as civil society actors. During the third phase, which entails the workshop discussions on the outcome of the PCA, representatives of government and other stakeholder groups may be invited, together with representatives of other donors. However, the extent to which the local stakeholders, whether government or civil society representatives, have access to the final outcome documents of the SGACA is less clear.

A Fact Sheet summarizing the key characteristics of the SGACA is presented below: 


\section{FACT SHEET}

Tool Strategic Governance and Corruption Analysis

Agency The Netherlands, Ministry for Foreign Affairs

\begin{tabular}{|c|c|c|}
\hline WHY & $\begin{array}{l}\text { Primary purpose of } \\
\text { assessment }\end{array}$ & To guide policy dialogue and aid programming. \\
\hline \multirow[t]{3}{*}{ WHAT } & Conceptual approach & $\begin{array}{l}\text { Historical, Power and Political Economy Perspectives, New Public Administration, } \\
\text { Institutional Economics, Network Governance. }\end{array}$ \\
\hline & Definition of governance & $\begin{array}{l}\text { "In the context of a political and institutional environment that upholds human } \\
\text { rights, democratic principles and the rule of law, good governance is the trans- } \\
\text { parent and accountable management of human, natural, economic and financial } \\
\text { resources for the purposes of equitable and sustainable development" } \\
\text { (http://www.minbuza.nl) }\end{array}$ \\
\hline & Focus of analysis & $\begin{array}{l}\text { Power and Change Analysis focusing on non-formal practices and relationships, } \\
\text { links between formal and informal institutions. Three main dimensions: } \\
\text { 1. Foundational Factors } \\
\text { - territorial integrity } \\
\text { - history of state formation } \\
\text { - sources of revenue } \\
\text { - social and economic structures } \\
\text { - geostrategic position } \\
\text { 2. Rules of the Game - Analysis of the Political System } \\
\text { - formal legal and administrative framework } \\
\text { - political competition } \\
\text { - institutionalization of state, civil society and private sector organizations } \\
\text { - distribution of power } \\
\text { - state-society relations } \\
\text { - identification of key trends } \\
\text { 3. Here and Now - Analysis of the Current Context and Key Actors }\end{array}$ \\
\hline \multirow[t]{2}{*}{ HOW } & Methodology & $\begin{array}{l}\text { The SGACA entails an in-depth political economy analysis (the Power and Change } \\
\text { Analysis, PCA) of various spheres of governance, with focus on non-formal } \\
\text { governance practices and relations, and linkages between formal and informal } \\
\text { institutions. While governance performance is not measured against precon- } \\
\text { ceived, standardized governance indicators, the PCA follows a template covering } \\
\text { the above three dimensions and their sub-components. The PCA builds on data } \\
\text { collected by the country office, while the PCA itself is carried out by external con- } \\
\text { sultant. The PCA is complemented by a workshop held at local level. Other donors } \\
\text { and partner country representatives may be invited to the workshop. }\end{array}$ \\
\hline & Reporting of results & $\begin{array}{l}\text { Qualitative political economy analysis of the above topics, grouped into the three } \\
\text { dimensions. No scoring or ranking. Final PCA report shared with partners but not } \\
\text { publicly available. }\end{array}$ \\
\hline WHERE & Coverage & $\begin{array}{l}\text { Mandatory for all programme countries in the preparation of their Country } \\
\text { Assistance Plans (CAPs). }\end{array}$ \\
\hline OWNERSHIP & Role of partner country & $\begin{array}{l}\text { Some data collection carried out at country level (household/firm surveys) and } \\
\text { use of local consultants. Workshop discussions involving local stakeholders. No } \\
\text { consultation on final report. }\end{array}$ \\
\hline
\end{tabular}

Sources:

Hazenberg, J. (2008), The SGACA Experience: incentives, interests and raw power: Making development aid more realistic and less technical (http://www.minbuza.nl, Retrieved July 19, 2011).

The Ministry for Foreign Affairs (2008), Framework for Strategic Governance and Corruption Analysis (SGACA), The Hague.

OECD DAC (2009), Donor Approaches to Governance Assessments, Sourcebook, Paris.

Waltmans, J. (2008), Behind the Façade: From analysis to action (http://www.minbuza.nl, Retrieved July 19, 2011). 


\subsection{Power Analysis; Sweden}

The Power Analysis is a tool developed by the Swedish International Development Agency (SIDA), Sweden's principal governmental aid agency, to analyze formal and informal political, economic and institutional factors that are likely to shape the development outcomes of a given country. The development of the tool was initiated in 2002, and since the mid-2000s a Power Analysis has been carried out in several of the Sweden's partner countries. In Mozambique a Power Analysis was initiated in 2006, with focus on the northernmost province of Niassa. While the initial objective was to expand the analysis to cover the entire country, the process was discontinued after the completion of the analysis on Niassa in 2006. The results of the Power Analysis concerning Mozambique are thus available only for one province. ${ }^{114}$

\section{Conceptual Approach}

The Power Analysis builds on SIDA's definition of the notion of "good governance" which embraces political, economic and institutional dimensions of governance: "On the whole, good governance implies an efficient and predictable public sector incorporating the participation and the rule of law, i.e. with the characteristics of democratic governance" (SIDA 2002, p. 6). According to SIDA, the Power Analysis approach "gravitates to political analysis", with the notion of "power" as the key analytical concept (Bjuremalm 2006, p. 3). The Power Analysis thus shares, to a large extent, the same conceptual political economy approach to assessing governance as, in particular, the Dutch Strategic Governance and Corruption Analysis and the UK Country Governance Analysis and the (OECD 2009, p. 14). Each of the three assessment tools makes an attempt to analyze the formal and informal political, institutional and structural factors which shape the governance structures in a given country. However, the explicit emphasis on power relations as the core of governance distinguishes the Power Analysis from the two other tools that build on historical and political economy approach to governance.

Although the notion of power is at the centre of SIDA's assessment, the Power Analysis is not based on a fixed definition of power, and each of the Power Analysis studies is carried out with its own understanding of the concept. It is, however, acknowledged that power has a multitude of meanings. Therefore an attempt is made to provide a common ground for the Power Analysis studies by making a distinction between

114. The Power Analysis is being replaced by another approach referred to as Reality Check. At the time of conducting this research, a Reality Check assessment on Mozambique was under preparation but not yet finalized (information based on personal communication). 
controlling power and constructive power, or between power over and power to (SIDA, 2008, p. 24, Moore, 2005, p. 8). The Power Analysis further assumes that in most developing countries progress towards democracy tends to require both (a) some reduction in the controlling power of the central state executive, and (b) increases in the constructive power of various parts of the state apparatus. Yet, as noted by SIDA (2006), and even more forcefully by the critics of the Power Analysis (e.g. Moore, 2005), the use of power as the key analytical tool creates a number of difficulties for conducting the analysis, interpreting the results and, in particular, for drawing operational conclusions of the analysis. In SIDA's own words "we could have commissioned alternative studies of the same country at the same moment from different people, and end up with very different products" (SIDA, 2008, p. 22).

\section{$\square$ Stated Purpose}

The development of the Power Analysis was motivated by several factors: first, by SIDA's experience from supporting political institutions and democratic processes; second, the perceived need for a thorough analysis of the country context as the basis for preparing SIDA's country assistance strategies; and third, by the enhanced emphasis on poverty as a multidimensional concept that highlighted the lack of power, security and opportunities/resources as fundamental causes of poverty. Among other factors, the need to make progress towards the Millennium Development Goals, a shift towards new aid modalities, and SIDA's commitment to the Paris Declaration on Aid Effectiveness contributed to the development of the new tool for assessing governance (Bjuremalm 2006).

The primary rationale for the Power Analysis is the belief that, for poverty to be reduced, questions related to the distribution of formal and informal power, access to resources and influence over politics must be addressed. The Power Analysis is expected to enhance the understanding of the underlying structural factors impeding poverty reduction as well as of the incentives and disincentives for pro-poor development. Furthermore, the Power Analysis is used to identify agents of change that can drive "pro-poor development". As stated by SIDA: "What we want to achieve is to try another way of painting the political landscape, with more shades and nuances including formal and informal power relations and structures, as well as another way of understanding how these factors affect and are affected by development cooperation. The analysis of actors, interest groups and structures will ideally show where real power in a society lies and how power is distributed" (Bjuremalm, 2006, p. 14, emphasis in the original). 
Building on the results of the Power Analysis, SIDA hopes to make its aid programmes more relevant for a given country, to improve its dialogue with the partner country authorities and other local actors, and finally, to enhance the effectiveness of its aid interventions. On a more operational level, the Power Analysis aims at supporting the planning of SIDA's country strategies and at analyzing the risks and opportunities of different aid programmes (SIDA 2005, SIDA 2006).

\section{$\square$ Focus of the Assessment}

In order to paint the political landscape of a given country, the Power Analysis starts with the mapping of various governance structures, actors and interest groups with the objective of showing where the "real power" in society lies. The mapping process is aimed at enhancing the understanding of how the prevailing power structures impact upon on poverty reduction. While the Power Analysis is deemed to be country-specific without a rigid list of issues to be addressed, it is suggested that the following broad topics be considered:

\section{Box 6.8 | Focus of the Power Analysis}

\section{Basic Country Analysis}

Formal and informal social, political, economic and institutional factors affecting pro-poor development (including history of state formation, demography, natural resources etc.)

Formal and informal actors, structures and institutions of power in society

Medium-Term Dynamics of Change

Analysis of the incentives and capacities of pro-poor agents for change operating within formal or informal domains

Role of External Forces

Donor interventions through various modalities of aid

Link between Change and Poverty Reduction

Analysis of expected changes and their impact on poverty including an analysis of the impact of HIV/AIDS

Operational Implications

Translation of the (understanding of) underlying interests and power relationships into strategies and actions in the Country Assistance Plan

"How we work?"

Assessment of the need for incentives for SIDA staff to gain deep understanding of country context

Source: Bjuremalm, 2006. 
The main topics to be covered by the Power Analysis are again rather similar to those addressed by the UK and the Dutch assessment tools. Acknowledging the similarities, collaboration with other donors is encouraged by SIDA.

To guide the analysis of the distribution of power in a given country, SIDA provides a list of questions which should be raised during the process. The questions are formulated in very general terms, for example:

- How is formal and informal power distributed in society?

- How is formal and informal power distributed in society according to gender?

- How power relations are distributed in the private sphere?

- What kind of formal and informal power is being exercised, how is it exercised and how is this understood or perceived, and by whom?

- What types of hidden dimensions of power exist, especially but not only, relating to gender?

- How do belief systems and cultural practices legitimize and reinforce material power structures?

Source: Bjuremalm, 2006, p. 15-16.

Within the framework of the Power Analysis, countries are not assessed according to a specific set of indicators but rather in terms of their environment for poverty reduction, rights-based development, and ultimately, for democratic governance. Therefore, in the course of the analysis, an attempt is made to assess the ability of the poor to voice their concerns in the prevailing political situation, and of the existence of a legal framework for protecting the rights of the poor.

\section{Methodology}

Power Analysis studies are initiated by SIDA's country offices which also have the primary responsibility for conducting the analysis. In practice external consultants, including local experts, are hired to carry out parts of the study. Concerning the methodology, very little guidance is provided by the SIDA headquarters, and therefore, there is much scope for the analysts at country level to adapt the approach and define the areas of focus. According to SIDA, the local context largely determines the process, methods and purpose of the analysis. While the analysis seems to be centred on desk reviews and secondary research, it is often complemented by interviews and questionnaires. The methods for collecting data about power - its constitution, distribution, exercise and control -range from the use of panels of independent experts, surveys, and public opinion polls, to focus group discussions (SIDA 2005, SIDA 2006). 
Since the Power Analysis is explicitly looking into power relations in a given country and analyzing the dynamics of the political landscape, the stability of the prevailing political situation in a given country needs to be paid attention to. As emphasized by SIDA "it is important that we as donors think about why we are interested in politics. It is natural for donors to be interested - we are participants. But we should also, or perhaps primarily, be reflecting on what our routine and strategic actions do in the political arena - what effects they have for political relations, institutions, processes and above all agency" (Bjuremalm 2005, p. 21). The policy of "do no harm" is underlined as the guiding principle of the Power Analysis (SIDA 2005, SIDA 2006).

\section{口 Reporting and Dissemination of Results}

The outcome of a Power Analysis is presented as a qualitative report which does not allow for cross-country comparison. The dissemination practices vary greatly from one Power Analysis to another. The most common practice seems to be that the final reports are made available to those involved in the analysis. It is, however, acknowledged that wider and more active dissemination of the reports would create opportunities for joint learning both among donors and between donors and various partner country representatives. In the case of the Power Analysis on the Niassa Province in Mozambique, the assessment process itself was very participatory and the outcome of the assessment was widely shared and discussed at the local level (information based on personal communication).

\section{Partner Country Ownership}

According to SIDA, the involvement of the government and other local actors of a given country in the Power Analysis is determined by the primary objective of the study and the perceived state of the political situation of the country. Therefore the level of participation by local stakeholders in the Power Analysis has varied considerably across countries. In Niassa, local stakeholders representing local government authorities, traditional leaders and various interest groups were deeply involved throughout the process (information based on personal communication). In general it is emphasized that a balance should be found between SIDA's need for information to improve its understanding of the political landscape of a given country, and its desire to support the democratic processes within that country (SIDA 2005; SIDA 2006).

A Fact Sheet summarizing the key characteristics of the Power Analysis is presented below: 


\section{FACT SHEET}

Tool Power Analysis

Agency Swedish International Development Authority (SIDA)

\begin{tabular}{|c|c|c|}
\hline WHY & $\begin{array}{l}\text { Primary purpose of assess- } \\
\text { ment }\end{array}$ & To guide policy dialogue and aid programming. \\
\hline \multirow[t]{3}{*}{ WHAT } & Conceptual approach & $\begin{array}{l}\text { Historical, Power and Political Economy Perspective, Institutional Economics, } \\
\text { Network Governance }\end{array}$ \\
\hline & Definition of governance & $\begin{array}{l}\text { "On the whole, good governance implies an efficient and predictable public } \\
\text { sector incorporating participation and the rule of law, i.e. with the characteristics } \\
\text { of democratic governance. In the concept of democratic governance, a stronger } \\
\text { emphasis is placed on central democratic institutions like a democratic constitu- } \\
\text { tion, a parliament, general elections, participation and an active civil society as } \\
\text { well as human rights." (SIDA 2002) }\end{array}$ \\
\hline & Focus of analysis & $\begin{array}{l}\text { Basic Country Analysis } \\
\text { Formal and informal social, political, economic and institutional factors } \\
\text { Formal and informal actors, structures and institutions of power in society } \\
\text { Medium-Term Dynamics of Change } \\
\text { Incentives and capacities of pro-poor agents for change operating within formal } \\
\text { or informal domains } \\
\text { Role of External Forces } \\
\text { Donor interventions } \\
\text { Link between Change and Poverty Reduction } \\
\text { Expected changes and their impact on poverty including an analysis of the } \\
\text { impact of HIV/AIDS } \\
\text { Operational Implications } \\
\text { Translation of the (understanding of) underlying interests and power relation- } \\
\text { ships into the Country Assistance Plan } \\
\text { "How we work?" } \\
\text { Creation of an incentive mechanism for staff. }\end{array}$ \\
\hline \multirow[t]{2}{*}{ HOW } & Methodology & $\begin{array}{l}\text { Very flexible approach in terms of data collection, sources and methods with } \\
\text { much scope for adapting the approach and defining the areas of focus. The anal- } \\
\text { ysis centred on desk reviews and secondary research, but often complemented } \\
\text { by interviews and questionnaires. }\end{array}$ \\
\hline & Reporting of results & $\begin{array}{l}\text { Qualitative political economy analysis addressing above topics. However, focus } \\
\text { varies according to country context. No scoring or ranking. Final report shared } \\
\text { with partners but not publicly available. }\end{array}$ \\
\hline WHERE & Coverage & $\begin{array}{l}\text { Bangladesh, Burkina Faso, Ethiopia, Kenya, Mozambique (focus on one region } \\
\text { only), Tanzania }\end{array}$ \\
\hline OWNERSHIP & Role of partner country & $\begin{array}{l}\text { Some data collection carried out at country level (household/firm surveys) and } \\
\text { use of local consultants. Extensive discussion and consultations with local stake- } \\
\text { holders representing various groups of actors. No consultation on final report. }\end{array}$ \\
\hline
\end{tabular}

\section{Sources:}

Helena Bjuremalm: SIDA Power Analysis - experiences and challenges, 2006 (Edita Communication Ab). OECD DAC (2005) 'Lessons Learned on the Use of Power and Drivers of Change Analyses in Development Cooperation', DAC Network on Governance (GovNet), OECD, Paris, online at http://www.gsdrc.org/docs/open/DOC82.pdf.

OECD DAC (2009), Donor Approaches to Governance Assessments, Sourcebook, Paris.

SIDA 2002: Good Governance.

Sida (2005) 'Methods of Analyzing Power - A Workshop Report, Division for Democratic Governance, Sida, online at http://www.sida.se/shared/jsp/download.jsp?f=SIDA4712en_Methods+web.pdfanda=3485. 


\subsection{Concluding Remarks}

The outcome of the analysis of the governance assessment tools developed and used by the largest donor agencies in Mozambique during the period of 2006-2010 echoes the key message of the OECD DAC survey: aid agencies apply diverse conceptual and operational approaches to assessing the quality of governance in their partner countries in an attempt to ensure effective use of aid resources (OECD DAC, 2009). The key findings of the analysis of the assessment tools selected as unit of analysis are summarized below. The findings are structured according to the conceptual framework developed by the OECD DAC Governance Network's which was used to guide the analysis.

\section{$\square$ Conceptual Approach}

The conceptual approach underlying the different assessment tools, while generally not explicitly spelled out, can be derived from the aid agencies' conceptualization of the notion of governance. In light of the analysis, the Country Policy and Institutional Assessments conducted by the World Bank and the African Development Bank are rooted, primarily, in the thinking of traditional public administration and new public management. The Worldwide Governance Indicators (World Bank Institute), the Millennium Challenge Scorecard (USA) and the Governance Profile (EU) have all adopted a broader approach which entails elements of power and political economy analysis. The Country Governance Analysis (UK), the Strategic Governance and Corruption Analysis (NL) and the Power Analysis (Sweden) originate, primarily, from the tradition of political economy analysis as explicitly stated in the case of the assessment tools by the Netherlands and Sweden. The latter three assessment tools also reflect an attempt to approach governance from a historical perspective. However, despite the similarities in their conceptual underpinnings, some differences can be identified. For example, the importance of interaction between the informal and formal factors underlying governance is highlighted in the SGACA approach whereas the Power Analysis - as its name suggests - approaches governance from the perspective of power relations. Yet, the Power Analysis lacks a clear conceptualization of the notion of power underlying the assessment tool. The emphasis on institutions and administrative framework, characteristic to all the assessment tools under consideration, is an indication of the influence of the new institutional economics in their conceptual approach to assessing governance. 


\section{$\square$ Stated purpose}

The stated purpose of the assessment tools varies from providing the basis for determining the eligibility for assistance (Millennium Challenge Scorecard) and the volume of aid (CPIA), to informing policy dialogue and aid programming of a given donor agency with the Government of Mozambique (Governance Profile, Country Governance Analysis, Strategic Governance and Corruption Analysis, Power Analysis). The common denominator for all assessment tools is the underlying assumption that the quality of governance impacts upon the effectiveness of the use of aid resources. This assumed relationship between the quality of governance and aid effectiveness is explicitly stated in the case of all assessment tools. Reflecting the aid agencies' focus on poverty reduction as the primary objective of development cooperation, the stated purpose of the assessments also refers to the need for assessing the quality of governance in Mozambique as an instrument to enhance the poverty impact of aid.

The objective of contributing to governance reforms is not outlined as an explicit purpose of the assessments. However, the fact that all assessment tools aim at identifying the strengths and weaknesses of governance in Mozambique. In the case of the British, Dutch and the Swedish assessments, the identification of the "drivers of change" for reforming governance, implies that the results of the assessments serve as an instrument for the aid agencies to address governance issues in the country. The use of the assessment results either as a determinant of the eligibility for aid, or the volume of aid, or more generally as the basis for aid programming, further implies that aid is, to a varying degree, conditioned on reforming governance. The Worldwide Governance Indicators are an exception in the sense that they are not formally used by the World Bank for any decision-making purposes. However, as discussed above, the Worldwide Governance Indicators are widely used as the reference point in the other assessment tools and therefore have also operational implications.

\section{$\square$ Focus of the assessment}

The focus of the selected assessment tools varies reflecting their conceptual approaches and stated purposes. Hence, the CPIA by the World Bank and the African Development Bank concentrate on economic and institutional dimensions of governance, while the rest of the assessment tools also take into account the political dimension of governance. Despite the diversity of the specific issues addressed within each of the three dimensions of governance, the following focus areas seem to be common to all assessment tools but the CPIA: the nature of the political system; the quality of public administration, particularly public financial administration and corruption; the inclusiveness of economic and social policies regarding public service delivery, income distribution and gender; and 
the environment for private sector operations. With regard to the political dimensions of governance, the scope of the analysis ranges from an assessment of the formal political system and political rights (Worldwide Governance Indicators, Millennium Challenge Scorecard) to an in-depth analysis of the formal and informal power relations at different levels of governance, including issues such as the human rights situation, the role civil society organizations etc. (Governance Profile, Country Governance Analysis, Strategic Governance and Corruption Analysis, Power Analysis). The Power Analysis stands out in its attempt to also analyze the role of the traditional leaders in the contemporary context of governance in Mozambique.

\section{Methodology and data}

The methodological choices adopted by the different assessment tools can be divided into two main groups i.e.: quantitative assessments (CPIA, Millennium Challenge Scorecard) and qualitative assessments (Governance Profile, Country Governance Analysis, Strategic Governance and Corruption Analysis, Power Analysis). Some assessment tools combine both quantitative and qualitative methods. The quantitative assessments rely on a standardized approach (standardized either globally or across countries subject to the assessment) so as to allow for cross-country comparisons of the assessment results. The qualitative assessments tend to tailor the assessments according to the specific context of Mozambique, even when following a unified approach agreed upon at headquarter level. The data sources underpinning the assessments vary somewhat similarly: where the quantitative assessments tend to build on data generated by international organizations and external experts, the qualitative assessments rely more on locally produced data and use, to a varying degree, local expertise for conducting the assessment.

\section{Reporting and dissemination of results}

The reporting and dissemination practices applied by the different assessment tools can also be grouped into two categories, which reflect the methodological choices underlying the assessments. The results of assessments which are reported in numeric format, are generally made available through the agencies' web pages. The results of the assessments based on qualitative analysis are presented in a format of lengthy reports or narratives which are shared, to varying degrees, with the Government of Mozambique and other donors. Apart from the Power Analysis, the results of the assessments are not actively disseminated to the government or other local stakeholders. In fact, contrary to the stated disclosure policies by the agencies, the distribution of the results of the qualitative assessments seems to remain very restricted. 


\section{Partner Country Ownership}

In light of the analysis, the ownership and participation of Mozambican stakeholders, the Government or others, in designing and implementing the assessments seems rather limited. In the case of the quantitative assessments, in particular the World Bank CPIA, some consultations take place with the government authorities concerning the scores but the final results are not negotiated with the government. With respect to the qualitative assessments, the participation of the local stakeholders is greater because of the reliance of these assessments on local expertise and locally generated data. The design of the assessment tools including the identification of the focus of the assessments, remains, however, in the hands of the aid agencies. Furthermore, due to the lack of both a formal consultation mechanism and an active dissemination policy, the qualitative assessments cannot be characterized as being locally owned or country-led. The Power Analysis stands out, again, as an exception because of its systematic involvement of local stakeholders throughout the assessment process.

In conclusion, the findings based on the analysis of the conceptual and operational approaches of the selected assessments tools seem to mirror the outcome of the OECD DAC survey of a wider range of assessment tools, albeit with some differences. In the case of Mozambique, the majority of the assessment tools approach governance from a broad perspective which is rooted in historical, political economy and power analyses. The Country Policy and Institutional Assessments, conducted by the World Bank and the African Development Bank, stand out in their relatively narrow approach derived from the theories of traditional public administration and new public management. The common denominator for all assessment tools relates to the objective of enhancing the effectiveness of the use of aid resources, in particular, for economic growth and poverty reduction. At the same time the assessments also serve several different purposes: some assessment tools are used to determine the eligibility for or the volume of aid and others provide a basis for a wider policy dialogue and aid programming. The use of the results of the governance assessments as an instrument for reforming governance is implicit: the assessments aim to identify the strength and weaknesses as well as potential the "drivers of change" in the field of governance, and indirectly impact upon the allocation and modalities of aid. The methodological choices vary from globally standardized, quantitative methods to qualitative approaches that allow for taking into account the country-specific governance context in Mozambique. The data sources underlying the assessments vary accordingly: the quantitative assessments tend to rely on external expert assessments and data available globally, while the qualitative assessments make more use of local expertise and locally generated data. The methodological choices seem to impact upon the practices for disseminating and reporting the results. Hence the results reported in quantitative formats are generally made publicly available on the aid agencies web pages, while the results of 
the qualitative assessments are presented in the form of narratives which are generally shared only, if at all, with the Government of Mozambique. Active dissemination of the results is exceptional. Finally, the partner country ownership remains limited in the case of all but one of the selected assessment tools. Neither the Government of Mozambique nor other local stakeholders are truly involved in designing and conducting the assessments. The participation by local stakeholders is, at best, limited to the use of local experts in carrying out the assessments - with the exception of one assessment tool, i.e. the Power Analysis developed and applied by SIDA. 


\section{Consistency of the Assessments of Governance in Mozambique}

In the previous chapter, the different governance assessment tools applied by the largest donors to Mozambique have been examined following the analytical framework developed by the OECD DAC. In this chapter, the focus is on the outcomes of the assessments. The main purpose of the chapter is to analyze and compare the results of the governance assessments with the objective of understanding whether the different assessments arrive at similar conclusions about the quality of governance in Mozambique. The chapter aims thus at answering the research question concerning the consistency of the results of the selected governance assessments which have been carried out in Mozambique over the period 2006-2010 by the "top ten" donors. The notion of consistency is addressed from three angles: first, in view of country-specific assessment results for Mozambique at a specific point of time; second, in view of Mozambique's results compared to other low-income countries within the region; and third, in view of changes and trends in governance as measured by the selected assessment tools.

The results of the governance assessments on Mozambique will be analyzed, whenever possible, in a wider regional context, depending on the availability of data generated through the same assessment tools. Mozambique's most important regional peer group is the Southern African Development Community (SADC), which currently includes 15 countries. ${ }^{115}$ Within SADC, the most relevant reference group for Mozambique is the group of countries classified as low-income countries (SADC LICs) which are likely to share similar developmental challenges with Mozambique. Hence, Mozambique's performance in terms of its political, economic and institutional governance will be discussed in comparison with the SADC low-income countries which, in addition to Mozambique, include the Democratic Republic of Congo, Madagascar, Malawi, Tanzania, Zambia and Zimbabwe.

115. SADC, initially established in 1980 by the Frontline States with the politico-economic motivation of reducing their dependence on minority-ruled South Africa, currently includes 15 countries with different political and economic prospects. According to the World Bank classification based on GNI per capita, the following countries fall into the groups of lower middle-income countries: Angola, Botswana, Lesotho, Mauritius, Namibia, Seychelles, South Africa and Swaziland. The rest of the countries, classified as low-income countries include Democratic Republic of Congo, Madagascar, Malawi, Mozambique, Tanzania, Zambia and Zimbabwe. 
The detailed analysis of the results presented in a quantitative format, i.e. the results of the Worldwide Governance Indicators, the Country Policy and Institutional Assessment of the World Bank and the African Development Bank as well as the Millennium Challenge Scorecard, will be limited to the years 2007 and 2010. The justification for the choice of these two years is two-fold. First, the year 2007 overlaps relatively well with the timing of the qualitative assessments conducted, on an ad hoc basis, by the European Union (2008), the UK (in 2007), the Netherlands (in 2008) and Sweden (in 2006). Although the EU, UK, Dutch and Swedish assessments do not cover exactly the same year, it can be argued that changes in the policy framework, institutions and governance performance are normally slow processes, and therefore the changes in the year-to-year results are likely to be relatively marginal (except in a case of radical changes such as a revolution, outbreak of a violent conflict, etc.). Second, the 2010 assessment results are of special interest, in particular, from the point of view of the evolution of political governance in Mozambique. As has been discussed earlier, following the intense debate on the lack of transparency of the electoral process prior to the 2009 presidential, parliamentary and municipal elections in Mozambique, the donors providing general budget support, the G19, opted for an exceptionally strong policy measure and imposed a temporary freeze on budget support disbursements. The question of the extent to which the donor governance assessments capture this type of county-specific changes, particularly in the field of political governance, can thus be discussed in light of the 2010 assessment results. The inclusion of the year 2010 is justified also due to the fact that the field work for this study was carried out primarily in 2010.

The chapter starts with a discussion on the comparability of the results of the different governance assessment tools. The second section describes the methods used for analyzing the consistency of the results of the assessments. The third section of the chapter examines the results of the governance assessments reported in quantitative format. These include the WGI, the CPIA of the WB and the AfDB, and the Millennium Challenge Scorecard of the MCC. The fourth section looks at the results of the assessments of the European Union, the UK, the Netherlands and Sweden, which are presented primarily in a qualitative format, or in a format combining both quantitative and qualitative data. The last two sections focus on the consistency of the results.

In sum, this chapter aims at assessing the consistency of the governance assessments from the perspective of a single country with the objective to identify whether different methods of assessing governance contribute to different perceptions of the quality of governance. It also provides insights as to what can be learned by comparing the outcomes of donor governance assessments characterized by different conceptual approaches, purposes, foci and methodological choices as well as by different levels of partner country participation in the assessment processes. 


\subsection{Comparing the Results of Governance Assessments - Comparing Pears with Apples?}

An analysis of the consistency of the results of the governance assessments carried out in Mozambique entails comparisons between assessments which differ both conceptually and methodologically. In addition, as has been discussed above, the outcomes of these assessments are reported in various formats. The results of the WGI, the World Bank and the AfDB CPIA, and the MCC's Millennium Challenge Scorecard, are reported only in a quantitative format with numeric scores, whereas the EU's Governance Profile, the Dutch Power and Change Analysis and the Power Analysis by the Swedish SIDA are qualitative analyses. The UK Country Governance Analysis combines quantitative data and qualitative analysis which are summarized in a qualitative narrative. The main common denominator of the assessments is their stated objective of examining the quality of governance in Mozambique.

The limitations concerning the comparability of the results of the governance assessments, or even a complete lack of comparability, have been a topic of intense debate among academics as well as within the agencies conducting these assessments. The debate has focused, in particular, on the WGI and the CPIA (see e.g. Arndt and Oman, 2006; Arndt, 2009; Knack, 2006; Kaufman and Kraay, 2007; Kaufman, Kraay and Mastruzzi, 2007; AfDB, 2008, World Bank, 2009).

The cross-country and overtime comparability of the WGI scores is disputed by Arndt and Oman (2006) and Arndt (2009), who argue that a change in the quality of governance, as recorded by the WGI, is only one of four possible reasons for a change in a country's governance score. A change in the ratings may also result from a change in the perceptions by those who provide the data underlying the scores, without an actual change in a given country. Similarly, a change in a given country's governance scores may simply reflect changes in other countries' ratings. As pointed out by Arndt, since the WGI "composite indicators are constructed in such a way that the average value of an indicator across all countries is always zero and its standard deviation is always one, changes in one country's rating change the ratings of other countries, other things equal" (Arndt, 2009, p. 143). Finally, a change in the number and composition of the data sources from one year to the next may lead to a change in a country's rating.

While the authors of the WGI claim that their scores allow for comparisons, they emphasize the need to take into account the standard errors when making direct comparisons across countries and over time. According to Kaufman et al., "a useful rule of thumb" is that when confidence intervals on the reported standard errors overlap in a comparison of two countries or in a single country over time, the data do not reveal statistically significant differences (Kaufman et al., 2008, p. 1). 
The comparability of the results of the World Bank CPIA has been questioned for similar reasons. First, the lack of access to the CPIA results has been highlighted as one of the key problems preventing comparisons over time (the CPIA ratings have been published only since 2006). The CPIA has also been criticized for not providing systematic estimates on the margins for error of its ratings, unlike the WGI. An evaluation report of the World Bank CPIA (2009a) acknowledges the problems concerning the comparability of the CPIA results stating that "there is a degree of imprecision in CPIA measurement of the quality of the policies and institutions" and, therefore, the CPIA scores can be interpreted only as estimates with a margin for error. ${ }^{116}$ According to the report, "assessing the reliability of the CPIA ratings is an intrinsically difficult if not impossible task, given that a benchmark (that is, the "true" rating) does not exist" (World Bank 2009a, p. 49). It is further noted that, given the CPIA criteria's focus on the quality of policies and institutions that are likely to change gradually, little change can be expected in the ratings from one year to the next. Due to the imprecision of the measurement and the complexity of the policy and institutional framework of any given country, the World Bank calls for caution in ranking countries according to their CPIA scores. According to the Bank, high-, middle-, and low-performing countries can be distinguished, but attempts to position countries on a more precise scale will likely result in some of them being misclassified. Despite this warning, the Bank itself provides the data on country rankings on its web page

(http://data.worldbank.org/indicator/IQ.CPA.IRAI.XQ/countries?order=wbapi data_value_2009\%20wbapi_data_value\%20wbapi_data_value-last\&sort=asc\&display=default. In the case of the AfDB CPIA, similar questions about the comparability of the results can be raised as both CPIAs apply the same assessment methodology.

The comparison of the results of all the selected eight governance assessments under consideration in this research is even more problematic due to the significant differences in their approach. The World Bank and the AfDB CPIAs are conceptually and methodologically closest to each other. They apply an identical set of indicators, rely on same data sources, use the same rating scales and present their results in a comparable format. Yet, even in the case of the World Bank and the AfDB, the comparison of the CPIA results is not straightforward. Firstly, the ratings primarily reflect the professional judgments by the staff of each agency, and secondly, the timing of the assessment processes varies due to the agencies' different fiscal years. Therefore, while a

116. The 2005 Global Monitoring Report cites estimates of a standard error of 0.24 for the overall scores on the 1-6 scale. This means that small annual changes from one year to the next may not be necessarily significant (World Bank, 2005). 
close correlation has been found between the World Bank and the AfDB CPIA ratings at a global level, there are also some differences. ${ }^{117}$

The comparison of the results of the assessments presented as qualitative narratives, namely the EU Governance Profile, the UK Country Governance Analysis, the Dutch Power and Change Analysis and the Power Analysis by SIDA, presents additional challenges. They share, to a large extent, the same political economy approach to assessing governance and aim at analyzing the formal and informal political, institutional and structural factors which shape the governance structures in Mozambique. However, the set of issues addressed under the notion of governance as well as the methodological choices vary from one assessment tool to another which is likely to impact upon the overall perceptions of the quality of governance in Mozambique. Furthermore, in the case of the Power Analysis by SIDA, the geographic scope of the assessment is limited, primarily, to one province only, and therefore, the results are highly context-specific.

Despite the above difficulties inherent in comparing the results of various governance assessment tools, an attempt has been made to analyze the consistency of the results of the eight governance assessments on Mozambique. It is argued that, notwithstanding the differences, there are a number of common denominators which create a sufficient basis for the comparison of the outcomes of the assessments. First, all the governance assessments are carried out with the general objective of enhancing the effectiveness of aid provided to Mozambique and, implicitly, of supporting of governance reforms. Second, the outcomes of the assessments impact upon the aid policy dialogue and decision-making of the donor agencies - irrespective of the stated purpose of a specific assessment. In some cases the results are explicitly used to determine Mozambique's eligibility for assistance or the volume of assistance, whereas in other cases the impact is more subtle influencing mainly the choice of priorities and instruments of aid. Third, the governance assessments under consideration rely, to a large extent, on the same data sources with much of the data generated either by the international

117. According to the comparison of the level of the World Bank and the AfDB CPIA ratings for the year 2007, which covered 50 countries, the average correlation coefficient for 15 of the total of 16 CPIA criterion was 0.79 , with the correlation coefficient for different criteria ranging from 0.66 (Gender Equality, Cluster C) to 0.89 (Quality of Budgetary and Financial Management, Cluster D). The criterion on Regional Integration and Trade (Cluster B) of the AfDB was excluded as it is not exactly identical with the equivalent criterion of the World Bank CPIA. A comparison of the direction of the changes in the quality of governance from 2006 to 2007 indicated that, for 10 out of the 15 criteria, none of the 50 countries in the analysis had ratings move in the opposite direction. For the criteria on Fiscal Policy (Cluster A), Gender Equality and Equity of Public Resource Use (Cluster C) and Quality of Budgetary and Financial management (Cluster D), the ratings moved in opposite direction in one out of 50 countries. Concerning Macro-Economic Management (Cluster A), the rating moved in opposite direction in 2 out of 50 countries (World Bank, 2009, p. 50-54). 
organizations, such as the World Bank and various UN agencies, and to lesser degree by the Government of Mozambique and other Mozambican actors.

\subsection{Comparison Methods}

The comparison of the results of the eight governance assessments is done in two phases. In the first phase Mozambique's governance performance is analyzed following, as strictly as possible, the methodological approaches and reporting formats of each governance assessment. In the second phase the results are quantified using the CPIA scale from 1 to 6 so as to allow for a more systematic analysis of the consistency.

\subsubsection{Comparison of Results as Reported by Aid Agencies}

For the first phase of the analysis, the consistency of the results of the different assessments is compared on the basis of the scores and qualitative judgments that can be extracted from the original reports presented in quantitative or qualitative format.

In the case of the results of the quantitative assessments, reported in numeric scores (the WGI, the World Bank and the AfDB CPIA and the Millennium Challenges Scorecard), the scores for Mozambique and other SADC low-income countries for the years 2007 and 2010 are drawn from the datasets generated by the agencies themselves. The publicly available data is further used to calculate the average scores for the SADC low-income countries so as to create a basis for the comparison between Mozambique and its peer group within the region. In this first phase, the consistency - or inconsistency - of the results is analyzed by examining the governance performance of Mozambique on the chosen set of governance indicators, as embodied in the scores generated by each assessment tool. In view of the close conceptual and methodological similarity between the World Bank and the AfDB CPIA, the consistency of the CPIA scores is examined in more detail. Furthermore, the results on Mozambique's governance performance relative to those of the SADC low-income countries are compared so as to see whether its performance within its peer group is judged to be the same irrespective of a specific assessment tool. The analysis also includes an assessment of the consistency of the perceptions concerning potential trends of governance in Mozambique.

With respect to the results qualitative assessments conducted by the EU, the UK, the Netherlands and Sweden, the initial analysis is done on the basis of the original assessment reports which are publicly available (the EU Governance Profile and the UK Country Governance Analysis) or were obtained from the agencies for the purpose of 
this research (the Power and Change Analysis by the Netherlands and the Power Analysis by the Swedish SIDA). The main contents of each report have been summarized in a table format in order to facilitate the comparison of the outcomes with the results of the quantitative assessments.

\subsubsection{Comparison of Results Based on Quantification}

In order to allow for a more systematic comparison of the consistency of results of the governance assessments on Mozambique the results of the governance assessments by the WGI, the World Bank, the AfDB, the MCC, the EU, the UK and the Netherlands are quantified on a rating scale of 1 to 6 which is used in the CPIA of the World Bank and the AFDB. The quantification of the findings of the Power Analysis by SIDA was not considered appropriate in view of its limited geographic focus, and the largely historical, non-normative approach underlying the analysis. The Power Analysis will, however, be used as a complementary reference point whenever appropriate.

The quantification of the results of the qualitative governance assessments entails my interpretation of the results as the researcher, and therefore the reliability and the validity of the scores generated for the comparison purposes can obviously be questioned. To justify this approach, the following points can be made. First, every quantitative statement is a qualitative statement in disguise. In other words, the numeric scores generated by the WGI, the World Bank and the AfDB, as well as the MCC, are themselves constructed on the basis of qualitative assessments. Even in the case of the so called fact-based indicators, such as the rate of economic growth, debt sustainability, access to health and education services, receipt/payment of bribes etc., the assessment itself is based on a qualitative judgment by the reviewers of what is perceived to be "weak/poor" or "strong/good" performance. As explicitly stated in the note guiding the World Bank and the AfDB CPIA, the professional judgment by the Banks' own staff is the key input in determining the scores. The qualitative judgments on country performance are turned into numeric scores and presented on a standardized scale so as to facilitate comparisons cross countries and over time.

The same logic of quantifying qualitative statements is applied to the quantification of the results of the qualitative assessments, conducted by the EU, the UK, the Netherlands. The qualitative judgments of Mozambique's performance in a given area of governance, as summarized in the assessment reports, have first been analyzed by the researcher following, as strictly as possible, the original governance criteria, indicators or benchmarks used by the agencies. The qualitative judgments are then turned into numeric scores using as the basis the scale from 1 ("very weak") to 6 ("very strong") with the score 3.5 as the mid-point in line with the CPIA. 
The justification for using the CPIA scale from 1 to 6 as the basis for the quantification and comparison of the results of all the selected governance assessments can be summarized as follows. Firstly, the scale from 1 to 6 is applied by the World Bank and the AFDB CPIA, both of which are included in this research. They apply an identical set of indicators, and provide the same definitions for each scoring level, which would imply a close comparability and a high degree of consistency between the two assessments. Second, the CPIA scores for Mozambique, particularly those of the World Bank, are frequently used as points of reference by the WGI, the MCC, the EU and the UK. Third, the CPIA scale from 1 (defined as "very weak") to 6 (defined as "very strong") provides a reasonable proxy for the quantification of the qualitative statements, such as "very weak", "weak"/"poor", "largely operational", that are commonly used in the assessment reports by the EU, the UK, the Netherlands, and to a lesser degree by the Swedish SIDA.

One of the key problems inherent in comparing the results of the governance assessments under consideration in this research relates to the choice of indicators to be used as the basis for comparison. As discussed earlier, apart from the World Bank and the AfDB CPIA, the focus of the assessments on Mozambique differs according to the conceptual approach underlying the assessment. As a result, the sets of issues addressed as governance concerns and the specific indicators used to capture the performance on these issues vary greatly. Even the terminology differs: within the framework of the CPIA, the key governance issues are defined as "criteria", the WGI and the MCC refer to "indicators" whereas the qualitative assessments use more vague terms such as "thematic areas" or "issues of governance". However, the overview in Chapter 6 of the eight governance assessments on Mozambique illustrates that, irrespective of the terminology used, similar questions are considered critical for "good governance" across the spectrum and therefore are addressed in most assessments. These include the political and economic stability of the country, the effectiveness of the government to provide public services to its citizens, and the protection of the rule of law, including the fight against corruption. Again, these questions largely correspond to the six aggregate indicators constructed by the WGI. Even the CPIAs by World Bank and the AfDB, while excluding questions directly related to political systems, addresses public sector transparency and accountability which can be considered to be one indication of the functioning of the political system in a given country.

Accordingly, for the purpose of comparing the consistency of results of the governance assessments, the wide range of issues included in these assessments have been clustered into political, economic and institutional dimension of governance, and further grouped into six aggregate indicators in line with the WGI:

Political dimension: 1) Voice and Accountability; 2) Political Stability and Absence of Violence 
Economic dimension: 3) Government Effectiveness; 4) Regulatory Quality

Institutional dimension: 5) Rule of Law; 6) Control of Corruption

In the process of quantification, I have taken the liberty of concentrating on those issues which are common to all, or most, governance assessment tools. Accordingly, some issues that are specific only to one assessment tool, without obvious links to governance concerns in Mozambique, have not been included in the quantified results. For example, within the framework of the EU Governance Profile, the indicators on "EU Programming Dialogue" refer specifically to the partnership relations between the EU and Mozambique. Therefore, these have not been taken into account in the quantification process. Concerning the selection of the issues addressed by the MCC, only the five aggregate indicators derived from the WGI, as well as the indicator on fiscal policy, have been included. The systematic quantification of all indicators on a scale from 1 to 6 was not considered feasible due to the different units of measurement and the different scales applied by the MCC. ${ }^{118}$

\subsubsection{Rescaling the Original Scores}

As has been described above, the numeric scales applied in the quantitative assessments to determine whether performance is "weak/poor" or "good/strong" or something inbetween differ significantly: the WGI apply systematically a scale from -2.5 to +2.5; the World Bank and the AfDB CPIA a scale from 1 to 6; and the MCC has opted not only for different scales for different indicators, but also for different units of measurement. Therefore, in order to compare the results of the quantitative assessments of the WGI and the Millennium Challenge Scorecard against the numeric scale from 1 to 6 , the original scores have to be rescaled.

The rescaling of the WGI scores on Mozambique entails a simple calculation. As discussed earlier, the WGI scores on all indicators are presented on the scale from -2.5 ("poor governance") to 2.5 ("good governance"). To rescale the scores according to the scale from 1 to 6 , a value of 3.5 is added to each score $(-2.5+3.5=1 ; 2.5+3.5=6)$. For example, to rescale Mozambique's WGI score on the composite indicator for Voice

118. The MCC uses two units of measurement to assess the performance on health (total expenditure on health per GDP of a given country and specific immunization rates), and applies a different scale on measurements. The same applies to the assessment on education where the units of measurement include total expenditure on primary education per GDP and girls' primary school completion, with each based on a different scale. Concerning the indicators aimed at capturing economic governance, such as inflation, fiscal policy, regulatory framework for private sector, the units of measurement and the performance assessment scales are all different. 
and Accountability on the scale from 1 to 6 , the value of 3.5 is added to the original score of -0.81 (year 2007) to arrive at the new score.

With regard to the scores of the Millennium Challenge Scorecard, the process of rescaling is more problematic because the units of measurement and the scale applied by the MCC vary greatly from one indicator to another, apart from those indicators that are derived from the WGI. For the five aggregate indicators derived from the WGI, the MCC takes the original WGI scores as the starting point of the assessment but rescales scores so that the median for the low-income countries included in the MCC assessment is adjusted to zero for each indicator.

Hence, for the purpose of comparing the scores of the Millennium Challenge Scorecard for Mozambique on the five aggregate WGI indicators using the scale from 1 to 6 , the following steps were taken. First, Mozambique's original WGI scores for the years 2005 and 2008, which formed the basis for MCC 2007 and 2010 respectively (information based on personal communication), have been used as the reference point. Second, consistent with the rescaling of the WGI scores, the value of 3.5 has been added to the original scores in order to arrive at new scores on the scale from 1 to 6 . Concerning the indicator on Fiscal Policy, the rescaling was done on the basis of Mozambique's percentile ranking (zero\% worst, $50 \%$ median and $100 \%$ best) which the MCC reports for each indicator and each country (in its respective income group). Mozambique's percentile score on Fiscal Policy in 2007 and 2010 was thus used as a proxy to arrive at respective scores for 2007 and 2010 on the scale from 1 to $6 .{ }^{119}$

\subsection{Quality of Governance in Mozambique: Quantitative Assessments}

\subsubsection{Worldwide Governance Indicators}

As discussed in the Chapter 6, the WGI construct six aggregate grouped into three broad dimensions of governance. The scale used measuring governance on each of the six aggregate ranges from -2.5 to +2.5 , with higher scores corresponding to better outcomes.

Unlike the World Bank and the AfDB, the WGI do not provide definitions for the different levels of scores which could be used as the guidance for a more detailed

119. The MCC presents the percentile ranking in five quintiles that can be rescaled on the scale from 1 to 6 as follows: below 10\% (equals 1), 10-25\% (equals 2), 25-50\% (equals 3), 50-75\% (equals 4), $75-90 \%$ (equals 5 ) and above $90 \%$ (equals 6 ). To arrive at a score on scale from 1 to 6 , the following calculations were made: MCC value/ $100 * 5+1$. 
interpretation of the perceived quality of governance embodied in the scores. However, the WGI classify countries in percentile ranks according to the governance scores. Countries falling into the bottom $10^{\text {th }}$ percentile are perceived as being in "governance crisis", whereas countries between the $90^{\text {th }}$ and $100^{\text {th }}$ percentile are perceived to have "exemplary governance". The percentile ranks are reported separately for each aggregate indicator for all countries included the WGI data set (Kaufman et al., 2008).

Table 7.1 summarizes Mozambique's scores on each of the six aggregate indicators of governance based on the WGI updates of 2007 and 2010. The table also shows Mozambique's percentile rank, on the scale from zero to 100, indicating the percentage of countries worldwide that rate below Mozambique among the countries covered by WGI in 2007 and in 2010. The range in Mozambique's percentile rank, when taking into consideration the margin for error, is indicated in the figures in brackets. ${ }^{120}$

Table 7.1 | Governance Performance; WGI Scores 2007 and 2010

\begin{tabular}{|c|c|c|c|c|c|c|c|}
\hline \multirow[b]{2}{*}{ 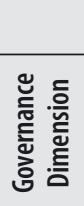 } & \multirow[b]{2}{*}{ Aggregate Indicator } & \multicolumn{3}{|c|}{$2007^{1}$} & \multicolumn{3}{|c|}{$2010^{1}$} \\
\hline & & $\begin{array}{c}\text { Score } \\
\text { Scale }-2.5 \\
\text { to }+2.5\end{array}$ & $\begin{array}{c}\text { Percentile } \\
\text { Rank }^{2} \\
0-100\end{array}$ & $\begin{array}{l}\text { Standard } \\
\text { Error }\end{array}$ & $\begin{array}{c}\text { Score } \\
\text { Scale }-2.5 \\
\text { to }+2.5\end{array}$ & $\begin{array}{c}\text { Percentile } \\
\text { Rank }^{2} \\
(0-100)\end{array}$ & $\begin{array}{l}\text { Standard } \\
\text { Error }\end{array}$ \\
\hline \multirow{2}{*}{ 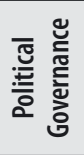 } & $\begin{array}{l}\text { 1. Voice and Account- } \\
\text { ability }\end{array}$ & -0.08 & $\begin{array}{c}46.6 \\
(39.2-51.2) \\
\end{array}$ & 0.11 & -0.12 & $\begin{array}{c}45.0 \\
(37.3-51.4)\end{array}$ & 0.11 \\
\hline & $\begin{array}{l}\text { 2. Political Stability and } \\
\text { Absence of Violence }\end{array}$ & +0.31 & $\begin{array}{c}55.3 \\
(40.2-70.8)\end{array}$ & 0.24 & +0.32 & $\begin{array}{c}57.1 \\
(42.2-70.9)\end{array}$ & 0.23 \\
\hline \multirow{2}{*}{ 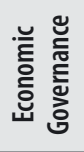 } & $\begin{array}{l}\text { 3. Government Effec- } \\
\text { tiveness }\end{array}$ & -0.49 & $\begin{array}{c}37.4 \\
(23.2-47.3)\end{array}$ & 0.18 & -0.47 & $\begin{array}{c}38.8 \\
(26.2-48.1)\end{array}$ & 0.17 \\
\hline & 4. Regulatory Quality & -0.51 & $\begin{array}{c}31.6 \\
(22.2-47.3) \\
\end{array}$ & 0.16 & -0.37 & $\begin{array}{c}40.7 \\
(28.6-50.4) \\
\end{array}$ & 0.16 \\
\hline \multirow{2}{*}{ 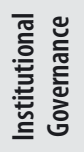 } & 5. Rule of Law & -0.59 & $\begin{array}{c}33.5 \\
(22.5-45.2) \\
\end{array}$ & 0.15 & -0.50 & $\begin{array}{c}37.0 \\
28.8-47.1 \\
\end{array}$ & 0.13 \\
\hline & 6. Control of Corruption & -0.53 & $\begin{array}{c}36.4 \\
(21.7-49.3)\end{array}$ & 0.16 & -0.40 & $\begin{array}{c}42.6 \\
(31.4-54.3)\end{array}$ & 0.16 \\
\hline
\end{tabular}

${ }^{1}$ The number of countries covered by the WGI increased from 212 in 2007 to 213 in 2010.

${ }^{2}$ The figures in brackets indicate the lower and upper bound of Mozambique's percentile ranking, at $90 \%$ confidence interval.

Source: http://info.worldbank.org/governance/wgi/pdf_country.asp, adapted by the author.

120. The WGI report the standard error, or margins for error, for each aggregate indicator and for all countries. The standard error reflects the measurement error embodied in the point estimates for each country in a given year. Standard errors are reported at $90 \%$ confidence intervals with lower values indicating higher precision of the estimate. The 90 percent confidence intervals indicate the range in which it is 90 percent likely that the "true governance" score falls. The $90 \%$ confidence intervals reported by the WGI are the point estimate plus or minus 1.64 times the standard error. (Kaufman et al., 2008, p. 16-18). 
At the outset, it can be noted that Mozambique scores below the midpoint (zero) on all aggregated indicators, both in 2007 and in 2010, apart from one of the aggregate indicators of political governance, namely Political Stability and Absence of Violence. Even on this aggregate indicator, with scores of 0.31 and 0.32 for 2007 and 2010 respectively, Mozambique scores only slightly above the midpoint of the scale.

Mozambique is perceived to perform worst, both in 2007 and in 2010, on the two aggregate indicators for institutional governance, namely on the Rule of Law and Control of Corruption. In 2007 Mozambique's scored -0.59 on the Rule of Law and -0.53 on the Control of Corruption. Although the scores for these two aggregate indicators slightly improved for 2010, the changes are not statistically significant using the Kaufman et al. "rule of thumb" concerning the confidence intervals on the reported standard errors. On economic governance, measured by the aggregate indicators of Government Effectiveness and Regulatory Quality, Mozambique also scores well below the midpoint of the scale. On Regulatory Quality Mozambique is perceived to have made progress from 2007 to 2010 with scores of -0.51 and -0.37 respectively, although even in this case the change is not statistically significant.

Mozambique's governance performance in terms of its percentile ranking, compared with all countries covered by the WGI in 2007 and $2010^{121}$, is illustrated in the Figure 7.1. The confidence intervals are shown as a thin black line in each bar.

121. The number of countries covered by the WGI increased from 212 in 2007 to 213 in 2010. 
Figure 7.1 | Governance Performance 2007 and 2010; WGI Percentile Ranking

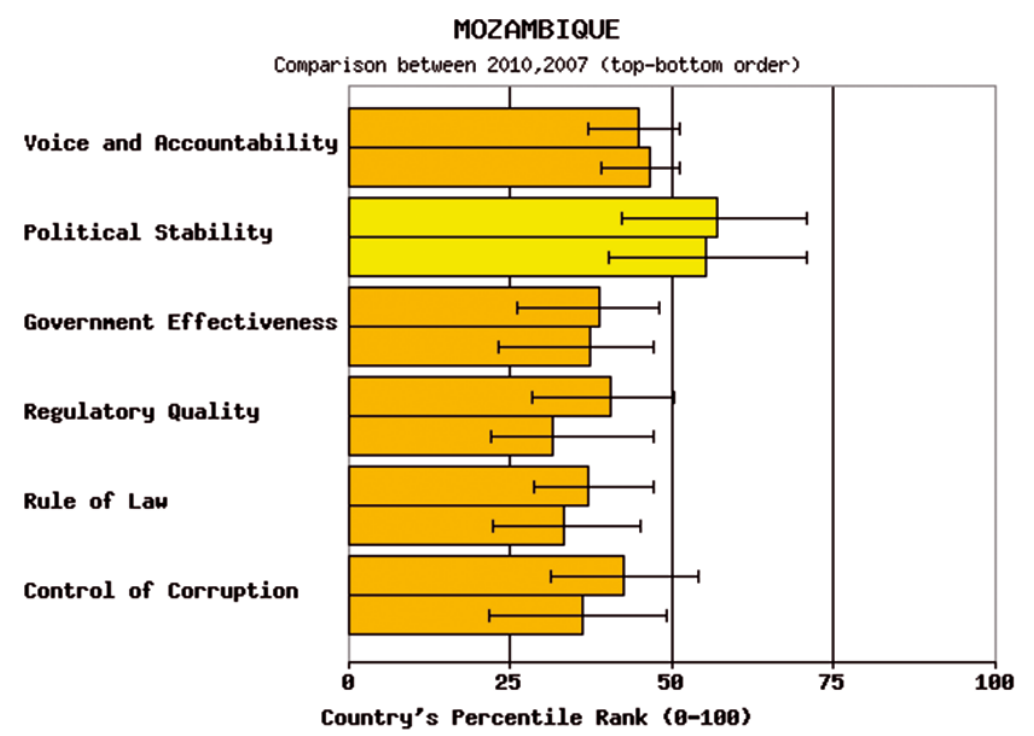

Source: Kaufmann D., A. Kraay, and M. Mastruzzi (2010), The Worldwide Governance Indicators:

Source: Kaufman et al, 2010 (http://info.worldbank.org/governance/wgi/sc_chart.asp\#. Retrieved from the World Wide Web, September 15, 2011).

According to the WGI scores more than half of the countries covered by the WGI rate below Mozambique on Political Stability and Absence of Violence. However, it is important to note that the standard error is highest on Political Stability and Absence of Violence. According to Kaufman et al., this reflects "somewhat smaller number of data sources available for this aggregate indicator" (Kaufman et al., 2008, p. 17). The country is also perceived to perform relatively well in comparison to other countries on Voice and Accountability with a percentile ranking close to 50. Concerning the aggregate indicators measuring economic and institutional governance, Mozambique's percentile ranking remains below half of the countries covered by the WGI both in 2007 and 2010. Comparing the changes in the ranking from 2007 to 2010, Mozambique's performance is perceived to improve, in particular, on Regulatory Quality and Control of Corruption. However, the changes in the ranking are not statistically significant when taking into account the margins for error.

Mozambique's performance vis-à-vis the other SADC of low-income countries, as perceived through the lens of the WGI, is illustrated below in Table 7.2. For comparison purposes, the scores for Mozambique and the average scores for the other SADC LICs are presented on the six aggregate indicators for both 2007 and 2010 (based on the World Bank data sources, calculations by the author). As the margin for error reported 
for a given aggregate indicator is practically the same across all countries, the Table does not provide this information for the SADC LICs.

Table 7.2 | Governance Performance - Mozambique and SADC LICs; WGI 2007 and 2010

\begin{tabular}{|c|c|c|c|c|c|}
\hline & & \multicolumn{2}{|c|}{$2007^{1}$} & \multicolumn{2}{|c|}{$2010^{1}$} \\
\hline & & MOZ & $\begin{array}{l}\text { Average } \\
\text { SADC LICS }\end{array}$ & MOZ & $\begin{array}{l}\text { Average } \\
\text { SADC LICs }\end{array}$ \\
\hline 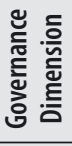 & Aggregate Indicator & $\begin{array}{c}\text { Score } \\
\text { Scale }-2.5 \text { to } \\
+2.5\end{array}$ & $\begin{array}{c}\text { Score } \\
\text { Scale }-2.5 \text { to } \\
+2.5\end{array}$ & $\begin{array}{c}\text { Score } \\
\text { Scale }-2.5 \text { to } \\
+2.5\end{array}$ & $\begin{array}{c}\text { Score } \\
\text { Scale }-2.5 \text { to } \\
+2.5\end{array}$ \\
\hline \multirow{2}{*}{ 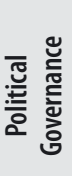 } & 1. Voice and Accountability & -0.08 & -0.59 & -0.12 & -0.71 \\
\hline & $\begin{array}{l}\text { 2. Political Stability and Absence of } \\
\text { Violence }\end{array}$ & +0.31 & -0.56 & +0.32 & -0.67 \\
\hline \multirow{2}{*}{ 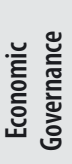 } & 3. Government Effectiveness & -0.49 & -0.84 & -0.47 & -0.97 \\
\hline & 4. Regulatory Quality & -0.51 & -0.84 & -0.37 & -0.95 \\
\hline \multirow{2}{*}{ 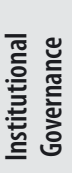 } & 5. Rule of Law & -0.59 & -0.83 & -0.50 & -0.90 \\
\hline & 6. Control of Corruption & -0.53 & -0.75 & -0.40 & -0.75 \\
\hline
\end{tabular}

${ }^{1}$ The number of countries covered by the WGI increased from 212 in 2007 to 213 in 2010.

Source: http://info.worldbank.org/governance/wgi/pdf_country.as, calculations by the author.

In view of the above data, Mozambique is seen to perform better than the rest of the SADC LICs on all aggregate indicators. The difference is obviously greatest in the area of political governance where Mozambique is performing above the mid-point when compared to all countries included in the WGI, but it is worth noting that Mozambique's scores are also better than the average scores on economic and institutional governance of the SADC LICs. Even concerning the aggregate indicators on the Rule of Law and Control of Corruption, which are seen as the most critical for Mozambique, its scores are higher than the average scores for the rest of the SADC LICs.

To sum up, Mozambique scores below the midpoint on the WGI scale both in 2007 and in 2010 on all aggregate indicators apart from one aggregate indicator on Political Stability and Absence of Violence. Although the WGI depict a positive trend, the changes 
are not statistically significant taking into consideration the estimated margins of error in the measurement. Despite the fact that Mozambique's WGI scores remain below the mid-point on all aggregate indicators but one, it is seen to perform better than the rest of the SADC LICs on all dimensions of governance.

\subsubsection{Country Policy and Institutional Assessment (The World Bank)}

The World Bank CPIA looks at the policy and institutional framework of a given country with the objective of assessing the extent to which the country creates the conditions for poverty reduction, sustainable growth and effective use of development assistance.

An overview of Mozambique's policy and institutional performance in 2007 and in 2010, as perceived through the lens of the World Bank CPIA, is summarized in the Table 7.3 in accordance with the four CPIA clusters. The Table shows Mozambique's scores on each of the aggregate indicator within a cluster, the average score on each cluster and the overall CPIA rating (formally referred to as the IDA Resource Allocation Index, IRAI). The same information is provided for the SADC low-income countries and for all IDA-eligible countries (based on the World Bank data sources, calculations by the author). The CPIA scores range from 1 to 6 , with the score 3.5 defined as the mid-point (1="very weak/low", $3=$ "moderately weak" $6=$ "very good/strong").

The summary of the CPIA for Mozambique indicates that the country is perceived to perform above the mid-point of the CPIA scale, with overall CPIA scores of 3.6 and 3.7 for 2007 and 2010 respectively. Mozambique scores best in Economic Management (Cluster A) with an average score of 4.2 in 2007 and 4.5 in 2010 (good performance). It is rated above the mid-point of the scale also on Structural Policies (Cluster B), whereas the average scores on Policies for Social Inclusion (Cluster C) and Public Sector Management and Institutions (Cluster D, the governance cluster) remain below the mid-point of the CPIA scale both in 2007 and 2010. It is worth noting that Mozambique's average score on the governance cluster remains below 3.5, although it is perceived to perform well on the indicator for Efficiency of Resource Mobilization (criterion 14, score 4.0 in 2007 and 2010) and Quality of Budgetary and Financial Management (criterion 13, score 4.0 in 2010). 
Table 7.3 | Governance Performance - Mozambique, SADC LICs and IDA-eligible countries; World Bank CPIA 2007 and 2010

\begin{tabular}{|c|c|c|c|c|c|c|}
\hline \multirow{2}{*}{$\begin{array}{c}\text { CPIA CRITERIA } \\
\text { Governance Dimension / Criterion }\end{array}$} & \multicolumn{2}{|c|}{ MOZ } & \multicolumn{2}{|c|}{$\begin{array}{l}\text { Average } \\
\text { SADC LICs }\end{array}$} & \multicolumn{2}{|c|}{$\begin{array}{l}\text { Average } \\
\text { IDA }^{4}\end{array}$} \\
\hline & 2007 & 2010 & 2007 & 2010 & 2007 & 2010 \\
\hline $\begin{array}{l}\text { CPIA Cluster A: Economic Management } \\
\text { 1. Macroeconomic Management } \\
\text { 2. Fiscal Policy } \\
\text { 3. Debt Policy }\end{array}$ & $\begin{array}{l}4.0 \\
4.0 \\
4.5\end{array}$ & $\begin{array}{l}4.5 \\
4.5 \\
4.5\end{array}$ & $\begin{array}{l}3.4 \\
3.2 \\
3.0\end{array}$ & $\begin{array}{l}3.4 \\
3.2 \\
3.1\end{array}$ & $\begin{array}{l}3.7 \\
3.4 \\
3.5\end{array}$ & $\begin{array}{l}3.7 \\
3.5 \\
3.4\end{array}$ \\
\hline Average Cluster $A^{1}$ & 4.2 & 4.5 & 3.2 & 3.2 & 3.5 & 3.5 \\
\hline $\begin{array}{l}\text { CPIA Cluster B: Structural Policies } \\
\text { 4. Trade } \\
\text { 5. Financial Sector } \\
\text { 6. Business Regulatory Environment }\end{array}$ & $\begin{array}{l}4.5 \\
3.5 \\
3.0\end{array}$ & $\begin{array}{l}4.5 \\
3.5 \\
3.0\end{array}$ & $\begin{array}{l}3.7 \\
3.0 \\
3.2\end{array}$ & $\begin{array}{l}3.6 \\
2.9 \\
2.8\end{array}$ & $\begin{array}{l}3.8 \\
3.2 \\
3.3\end{array}$ & $\begin{array}{l}3.8 \\
3.1 \\
3.2\end{array}$ \\
\hline Average Cluster $B^{1}$ & 3.7 & 3.7 & 3.3 & 3.1 & 3.4 & 3.4 \\
\hline $\begin{array}{l}\text { CPIA Cluster C: Policies for Social Inclusion/Equity } \\
\text { 7. Gender Equality } \\
\text { 8. Equity of Public Resource Use } \\
\text { 9. Building Human Resources } \\
\text { 10. Social Protection and Labor } \\
\text { 11. Policies and Institutions for Environmental } \\
\quad \text { Sustainability }\end{array}$ & $\begin{array}{l}3.5 \\
3.5 \\
3.5 \\
3.0 \\
3.0\end{array}$ & $\begin{array}{l}3.5 \\
3.5 \\
3.5 \\
3.0 \\
3.5\end{array}$ & $\begin{array}{l}3.3 \\
3.3 \\
3.1 \\
2.9 \\
3.3\end{array}$ & $\begin{array}{l}3.2 \\
3.3 \\
3 . .3 \\
2.9 \\
3.1\end{array}$ & $\begin{array}{l}3.4 \\
3.4 \\
3.4 \\
3.1 \\
3.1\end{array}$ & $\begin{array}{l}3.4 \\
3.5 \\
3.5 \\
3.1 \\
3.1\end{array}$ \\
\hline Average Cluster $\mathrm{C}^{1}$ & 3.3 & 3.4 & 3.2 & 3.2 & 3.3 & 3.3 \\
\hline $\begin{array}{l}\text { CPIA Cluster D: Public Sector Management and } \\
\text { Institutions } \\
\text { 12. Property Rights and Rule-based Governance } \\
\text { 13. Quality of Budgetary and Financial Management } \\
\text { 14. Efficiency of Revenue Mobilization } \\
\text { 15. Quality of Public Administration } \\
\text { 16. Transparency, Accountability and Corruption in the } \\
\text { Public Sector }\end{array}$ & $\begin{array}{l}3.0 \\
3.5 \\
4.0 \\
3.0 \\
3.0\end{array}$ & $\begin{array}{l}3.0 \\
4.0 \\
4.0 \\
3.0 \\
3.0\end{array}$ & $\begin{array}{l}2.8 \\
3.1 \\
3.5 \\
2.9 \\
2.7\end{array}$ & $\begin{array}{l}2.8 \\
2.8 \\
3.5 \\
2.8 \\
2.3\end{array}$ & $\begin{array}{l}2.9 \\
3.2 \\
3.4 \\
3.0 \\
2.9\end{array}$ & $\begin{array}{l}2.9 \\
3.3 \\
3.5 \\
3.0 \\
2.9\end{array}$ \\
\hline Average Cluster $D^{1}$ & 3.3 & 3.4 & 3.0 & 2.9 & 3.1 & 3.1 \\
\hline Overall CPIA² (=IDA Resource Allocation Index, IRAI) & 3.6 & 3.7 & 3.2 & 3.1 & 3.3 & 3.3 \\
\hline Average Clusters A, B and C & 3.7 & 3.9 & 3.2 & 3.2 & 3.4 & 3.4 \\
\hline Average Cluster D & 3.3 & 3.4 & 3.3 & 2.9 & 3.1 & 3.1 \\
\hline
\end{tabular}

${ }^{1}$ For calculation of the cluster averages, all criteria are equally weighted within a cluster.

${ }^{2}$ Overall CPIA rating is calculated as the mean of the score of the Cluster A, B, C and D.

${ }^{3}$ SADC LICs: DRC, Madagascar, Malawi, Tanzania, Zambia, Zimbabwe.

${ }^{4}$ The number of IDA eligible countries: 75 countries in 2007 and 77 countries in 2010.

\section{Sources:}

http://www.worldbank.org/ida 
http://siteresources.worldbank.org/IDA/Resources/73153-1181752621336/IRAI2007table1.pdf (accessed July 14, 2008).

http://www1.worldbank.org/operations/CPIA2010/IRAI2010table1.xls (accessed July 21, 2011)

http://www1.worldbank.org/operations/CPIA2010/MOZ.pdf (accessed July 21, 2011)

Calculations by the author.

The comparison of the average scores by cluster over the years 2007-2010 indicates that Mozambique's performance is perceived to have slightly improved from 2007 to 2010, as measured by criteria for Economic Management (higher score on Macroeconomic Management, criterion 1, Cluster A), Policies for Social Inclusion (higher score on Policies and Institutions for Environmental Sustainability, criterion 11, Cluster C) and for Public Sector Management and Institutions (higher score on Quality of Budgetary and Financial Management, criterion 13, Cluster D). Although the changes in the scores on individual criteria do not exceed 0.5 , they result in marginal improvement in the overall CPIA scores between the years 2007 and 2010 (3.6 in 2007 and 3.7 in 2010).

In comparison with the SADC LICs, Mozambique is perceived to perform better in all four clusters both in 2007 and 2010. The difference is most notable on Economic Management where the SADC LICs score below the mid-point, with average scores of 3.2. and 3.2. (2007 and 2010 respectively). Concerning Structural Policies (Cluster C) Mozambique is perceived to perform significantly better, in particular on the criterion related to trade policy (criterion 4, score 4.5). Mozambique is also seen to perform better than its SADC peer group on all the indicators measuring Public Sector Management and Institutions (Cluster D, the governance cluster). Finally, over the period 2007 and 2010, Mozambique's scores improve slightly, whereas the SADC LICs' scores indicate an opposite trend, albeit with the changes being marginal in both cases.

The above overview further illustrates that Mozambique's scores are systematically slightly higher than the average for its wider low-income country reference group, the IDA eligible countries. This is reflected also in its ranking among the IDA countries: in 2007, only 27 of the 75 IDA eligible countries obtained a higher average score than Mozambique, while only 23 countries received a higher score in governance cluster (Cluster D) - albeit with a number of countries sharing the same ranking. The 2010 CPIA results indicate that Mozambique's ranking within its reference groups has improved: of the 77 countries included in the 2010 CPIA assessment 16 received higher overall CPIA scores while only 17 countries received higher average scores in the governance cluster (calculations based on data retrieved from http://siteresources.worldbank.org/IDA/Resources/73153-1181752621336/IRAI2007table1.pdf; and 
http://www1.worldbank.org/operations/CPIA2010/MOZ.pdf). In order to translate the scores into qualitative judgments on Mozambique's governance performance, a detailed examination of the meaning of the scores in Cluster D is presented in Annex 3.

While the World Bank CPIA does not, by its own definition, address political governance in Mozambique, some of the indictors measuring the Quality of Public Administration (criterion 15) and Transparency, Accountability and Corruption in the Public Sector (criterion 16) touch upon political governance. For example, the indicator concerning the existence of merit-based recruitment processes for public service, and the indicator on accountability of the government vis-à-vis the citizens are closely linked to the political governance of the country. However, the 2009 developments in the political sphere in Mozambique, which led to a temporary freeze of general budget support disbursements, are not reflected in the CPIA results. Contrary to the common view among the general budget support donors, of which the World Bank is one, the average CPIA ratings including the score on the governance cluster indicate a slightly positive development trend in Mozambique's policy and institutional framework.

\subsubsection{Country Policy and Institutional Assessment (The African Development Bank)}

An overview of Mozambique's policy and institutional performance in 2007 and 2010, as perceived through the lens of the AfDB CPIA is summarized in Table 7.4. The scores for the criteria on Public Sector Management and Institutions are presented separately in line with the structure followed by the AfDB. In addition, the table presents a summary of the performance of the SADC LICs as well as of the AfDB eligible countries (calculations by the author based on the African Development Bank data sources). 
Table 7.4 | Governance Performance - Mozambique, SADC LICs and ADF-eligible countries; The AfDB CPIA 2007 and 2010

\begin{tabular}{|c|c|c|c|c|c|c|}
\hline \multirow{2}{*}{$\begin{array}{l}\text { CPIA CRITERIA (Clusters A, B and C) } \\
\text { Governance Dimension / Criterion }\end{array}$} & \multicolumn{2}{|c|}{$\mathrm{MOZ}$} & \multicolumn{2}{|c|}{ SADC LICs ${ }^{3}$} & \multicolumn{2}{|c|}{ AFDB Eligible $^{4}$} \\
\hline & 2007 & 2010 & 2007 & 2010 & 2007 & 2010 \\
\hline $\begin{array}{l}\text { CPIA Cluster A: Economic Management } \\
\text { 1. Macroeconomic Management } \\
\text { 2. Fiscal Policy } \\
\text { 3. Debt Policy }\end{array}$ & $\begin{array}{l}4.5 \\
4.0 \\
4.5\end{array}$ & $\begin{array}{l}4.0 \\
3.5 \\
4.0\end{array}$ & $\begin{array}{l}3.6 \\
3.4 \\
3.4\end{array}$ & $\begin{array}{l}3.8 \\
3.5 \\
3.5\end{array}$ & $\begin{array}{l}3.6 \\
3.4 \\
3.2\end{array}$ & $\begin{array}{l}3.9 \\
3.6 \\
3.5\end{array}$ \\
\hline Average Cluster $\mathrm{A}^{1}$ & 4.3 & 3.8 & 3.5 & 3.6 & 3.4 & 3.7 \\
\hline $\begin{array}{l}\text { CPIA Cluster B: Structural Policies } \\
\text { 4. Reg. Integration and Trade } \\
\text { 5. Financial Sector } \\
\text { 6. Business Regulatory Environment }\end{array}$ & $\begin{array}{l}3.5 \\
3.0 \\
3.0\end{array}$ & $\begin{array}{l}3.5 \\
3.5 \\
3.5\end{array}$ & $\begin{array}{l}3.4 \\
3.3 \\
3.3\end{array}$ & $\begin{array}{l}3.3 \\
3.3 \\
3.1\end{array}$ & $\begin{array}{l}3.6 \\
3.1 \\
3.0\end{array}$ & $\begin{array}{l}3.6 \\
3.3 \\
3.2\end{array}$ \\
\hline Average Cluster $B^{1}$ & 3.2 & 3.5 & 3.3 & 3.3 & 3.2 & 3.4 \\
\hline $\begin{array}{l}\text { CPIA Cluster C: Policies for Social Inclusion/Equity } \\
\text { 7. Gender Equality } \\
\text { 8. Equity of Public Resource Use } \\
\text { 9. Building Human Resources } \\
\text { 10. Social Protection and Labor } \\
\text { 11. Policies and Institutions for Environmental Sustainability }\end{array}$ & $\begin{array}{l}4.0 \\
4.5 \\
3.0 \\
3.0 \\
4.0\end{array}$ & $\begin{array}{l}4.0 \\
4.0 \\
3.0 \\
3.0 \\
4.0\end{array}$ & $\begin{array}{l}3.1 \\
3.4 \\
3.0 \\
3.2 \\
3.3\end{array}$ & $\begin{array}{l}3.3 \\
3.2 \\
3.2 \\
3.3 \\
3.1\end{array}$ & $\begin{array}{l}3.3 \\
3.3 \\
3.2 \\
3.0 \\
3.2\end{array}$ & $\begin{array}{l}3.4 \\
3.5 \\
3.3 \\
3.1 \\
3.3\end{array}$ \\
\hline Average Cluster $\mathrm{C}^{1}$ & 3.7 & 3.6 & 3.2 & 3.2 & 3.2 & 3.3 \\
\hline CPIA $^{2}$ & 3.7 & 3.6 & 3.3 & 3.3 & 3.3 & 3.5 \\
\hline
\end{tabular}

${ }^{1}$ For calculation of the cluster averages, all criteria are equally weighted within a cluster.

${ }^{2}$ The overall CPIA rating is calculated as the mean of the score of the Cluster A, B and C.

${ }^{3}$ SADC LICs: DRC, Madagascar, Malawi, Tanzania, Zambia, Zimbabwe.

${ }^{4}$ ADF-eligible countries: 51 countries in 2007, 39 countries in 2010.

\begin{tabular}{|c|c|c|c|c|c|c|}
\hline \multirow{2}{*}{$\begin{array}{c}\text { CPIA CRITERIA (Cluster D) } \\
\text { Governance Dimension / Indicator }\end{array}$} & \multicolumn{2}{|c|}{ MOZ } & \multicolumn{2}{|c|}{ SADC LICs } & \multicolumn{2}{|c|}{ AFDB Eligible } \\
\hline & 2007 & 2010 & 2007 & 2010 & 2007 & 2010 \\
\hline $\begin{array}{l}\text { CPIA Cluster D (the Governance Rating) : Public Sector Management } \\
\text { and Institutions }\end{array}$ & & & & & & \\
\hline 12. Property Rights and Rule-based Governance & 3.0 & 3.0 & 3.1 & 3.1 & 3.0 & 3.1 \\
\hline 13. Quality of Budgetary and Financial Management & 3.5 & 3.5 & 3.3 & 3.3 & 3.2 & 3.5 \\
\hline 14. Efficiency of Revenue Mobilization & 3.0 & 4.0 & 3.5 & 3.3 & 3.4 & 3.5 \\
\hline 15. Quality of Public Administration & 3.5 & 3.5 & 3.1 & 3.0 & 3.0 & 3.0 \\
\hline 16. Transparency, Accountability and Corruption in the Public Sector & 3.0 & 2.5 & 3.0 & 2.9 & 2.9 & 3.0 \\
\hline Average Cluster $D^{1}$ & 3.2 & 3.3 & 3.2 & 3.1 & 3.2 & 3.2 \\
\hline
\end{tabular}

${ }^{1}$ The average rating for Cluster $\mathrm{D}$ is the Governance Rating.

\section{Sources:}

http://www.afdb.org/fileadmin/uploads/afdb/Documents/Project-and-0perations/AFDB\%20-\%202007\%20CPIA.xls http://www.afdb.org/fileadmin/uploads/afdb/Documents/Project-and-Operations/

2010\%20Detailed\%20CPIA-FOR\%20DISCLOSURE_.xls.

Calculations by the author. 
Again, while bearing in mind the imprecision of the CPIA measurements and the problems inherent in comparing scores over time, a number of tentative conclusions can be drawn from the above overview.

First, in general terms Mozambique is perceived to perform not unsatisfactorily in terms of Economic Management (Cluster A), Structural Policies (Cluster B) and Policies for Social Inclusion and Equity (Cluster C), which constitute overall CPIA scoring in the case of the AfDB. Mozambique's scores slightly exceed the mid-point of the scale both in 2007 and 2010 with scores of 3.7 and 3.6 respectively. Mozambique receives its best ratings in Economic Management (Cluster A) and Policies for Social Inclusion/Equity (Cluster C) where it scores 4 and 4.5 on several criteria, both in 2007 and 2010. Concerning Structural Policies (Cluster B), Mozambique's performance was rated below the mid-point in 2007 (average score 3.2) but by 2010 it reached the midpoint of the scale on all the 3 criteria. However, looking at the changes in the scores of individual criteria within clusters and in the cluster averages, it can be noted that Mozambique's performance is perceived to have deteriorated between 2007 and 2010 in Economic Management (lower scores in Macro-Economic Management and Debt Management (criterion 1 and 3 respectively, Cluster A) and in Policies for Social Inclusions/Equity (lower score on Equity of Public Resource Use, criterion 8, Cluster C).

Concerning Mozambique's performance on Public Sector Management and Institutions (Cluster D), i.e. its governance rating, average scores remain below the midpoint of scale for both years under consideration (3.2 for 2007 and 3.3 for 2010). The slightly better average rating hides opposite trends concerning two criteria: Mozambique's score on Efficiency of Revenue Mobilization (criterion 14) increased from 3.0 in 2007 to 4.0 in 2010; and on Transparency, Accountability and Corruption in Public Sector (criterion 16) its rating changed from 3.0 in 2007 to 2.5 in 2010. On the criteria measuring the Quality of Budgetary and Financial Management (criterion 13) and Quality of Public Administration (criterion 15), Mozambique scores at mid-point both in 2007 and 2010. The AfDB itself concluded that "the Country Performance and Institutional Assessment (CPIA) rating for Mozambique over the period 2007-2010 remains stable", but highlights the need for improvements in Debt Policies and Equity in Public Resource Management (AfDB, 2011, p. 26, Country Assistance Strategy for Mozambique for 2011-2015).

A comparison of Mozambique's average CPIA scores (Clusters A, B and C) with those of the SADC LICs and the rest of the AFD-eligible countries shows that Mozambique is perceived to perform slightly, but only slightly, better than its SADC and other African peers. Concerning governance cluster, the ratings are practically identical. The only area where Mozambique is perceived to perform worse than its peers is Transparency, Accountability and Corruption in Public Sector (criterion 16). In particular, 
with the 2010 score of 2.5 Mozambique falls behind the average of the AFDB-eligible countries (3.0) as well as the average SADC LICs score (2.9).

Table 7.5 provides an overview of the CPIA results of the World Bank and the AfDB for 2007 and 2010. While both assessments seem to paint, in general terms, a very similar picture of Mozambique's policy and institutional framework, a more detailed analysis of the scores shows some differences. In 2007, Mozambique received a different score in all on 7 criteria out of the total 16 CPIA criteria, and in 2010, the scores differ on 8 criteria. In some cases, the World Bank and the AfDB scores also indicate conflicting perceptions on the trend of the performance. For example, concerning Fiscal Policy (criterion 2, Cluster A), the World Bank scores improve (4.0 in 2007 and 4.5 in 2010) whereas the AfDB scores indicate a negative trend with (4.0 in 2007 and 3.5 in 2010). Concerning the criterion aimed at assessing Transparency, Accountability and Corruption in Public Sector (criterion 16, Cluster D), the World Bank CPIA rates Mozambique at the level of 3.0 both in 2007 and 2010, whereas the AfDB CPIA score drops from 3.0 in 2007 to 2.5 in 2010. For the interpretation of the difference between the score of 3.0 and 2.5, see Annex 1.

The variation in scores on individual criteria leads to variation in cluster averages. On Economic Management (Cluster A) and Policies for Social Inclusion/Equity (Cluster C), not only are Mozambique's average scores for 2007 and 2010 different in both clusters, but also the trend is perceived to be different: according to the World Bank CPIA, Mozambique's performance has improved from 2007 to 2010, whereas in the case of the AfDB the performance is seen to have deteriorated. Even though they are marginal, these differences imply that even very similar governance assessment tools with virtually identical assessment criteria, data sources and methodology, can arrive at different performance results. As discussed earlier, apart from giving somewhat conflicting signals of the Mozambique's performance, the differences in the CPIA ratings also impact upon the volume of aid provided by the two agencies to Mozambique.

As in the case of the World Bank, the AfDB CPIA does not explicitly address the state of political governance in Mozambique. However, the AfDB concludes that "corruption remains a challenging issue mostly due to weaknesses in internal control systems, slow pace of implementation of reforms in the justice system and the prevailing stateparty conflict of interest which results in inefficiency in the use of public resources" (AfDB, 2011, p. 3-4). This qualitative judgment, underlying Mozambique's score of 2.5 on the criterion concerning Transparency, Accountability and Corruption in Public Sector (Cluster D), seems to reflect more the views expressed by the general budget support donors discussed in Chapter 5. The "lack of political will" to carry out the specific reforms, including fight against corruption, was highlighted as one of the risks for the successful implementation of the Bank's Poverty Reduction Support Loan already 
in 2008 (AfDB, 2008, p. 23). The Poverty Reduction Support Loan is the Bank's funding instrument for general budget support programmes.

Table 7.5 | Governance Performance; The World Bank and the AfDB CPIA for 2007 and 2010

\begin{tabular}{|c|c|c|c|c|}
\hline \multirow{2}{*}{$\begin{array}{c}\text { CPIA CRITERIA } \\
\text { Governance Dimension / Indicator }\end{array}$} & \multicolumn{2}{|c|}{2007} & \multicolumn{2}{|c|}{2010} \\
\hline & WB & AfDB & WB & AfDB \\
\hline $\begin{array}{l}\text { CPIA Cluster A: Economic Management } \\
\text { 1. Macroeconomic Management } \\
\text { 2. Fiscal Policy } \\
\text { 3. Debt Policy }\end{array}$ & $\begin{array}{l}4.0 \\
4.0 \\
4.5\end{array}$ & $\begin{array}{l}4.5 \\
4.0 \\
4.5\end{array}$ & $\begin{array}{l}4.5 \\
4.5 \\
4.5\end{array}$ & $\begin{array}{l}4.0 \\
3.5 \\
4.0\end{array}$ \\
\hline Average Cluster $\mathrm{A}^{1}$ & 4.2 & 4.3 & 4.5 & 3.8 \\
\hline $\begin{array}{l}\text { CPIA Cluster B: Structural Policies } \\
\text { 4. Trade } \\
\text { 5. Financial Sector } \\
\text { 6. Business Regulatory Environment }\end{array}$ & $\begin{array}{l}4.5 \\
3.5 \\
3.0\end{array}$ & $\begin{array}{l}3.5 \\
3.0 \\
3.0\end{array}$ & $\begin{array}{l}4.5 \\
3.5 \\
3.0\end{array}$ & $\begin{array}{l}3.5 \\
3.5 \\
3.5\end{array}$ \\
\hline Average Cluster $\mathrm{B}^{1}$ & 3.7 & 3.2 & 3.7 & 3.5 \\
\hline $\begin{array}{l}\text { CPIA Cluster C: Policies for Social Inclusion/Equity } \\
\text { 7. Gender Equality } \\
\text { 8. Equity of Public Resource Use } \\
\text { 9. Building Human Resources } \\
\text { 10. Social Protection and Labor } \\
\text { 11. Policies and Institutions for Environmental Sustainability }\end{array}$ & $\begin{array}{l}3.5 \\
3.5 \\
3.5 \\
3.0 \\
3.0\end{array}$ & $\begin{array}{l}4.0 \\
4.5 \\
3.0 \\
3.0 \\
4.0\end{array}$ & $\begin{array}{l}3.5 \\
3.5 \\
3.5 \\
3.0 \\
3.5\end{array}$ & $\begin{array}{l}4.0 \\
4.0 \\
3.0 \\
3.0 \\
4.0\end{array}$ \\
\hline Average Cluster $\mathrm{C}^{1}$ & 3.3 & 3.7 & 3.4 & 3.6 \\
\hline $\begin{array}{l}\text { CPIA Cluster D: Public Sector Management and Institutions } \\
\text { 12. Property Rights and Rule-based Governance } \\
\text { 13. Quality of Budgetary and Financial Management } \\
\text { 14. Efficiency of Revenue Mobilization } \\
\text { 15. Quality of Public Administration } \\
\text { 16. Transparency, Accountability and Corruption in the Public Sector }\end{array}$ & $\begin{array}{l}3.0 \\
3.5 \\
4.0 \\
3.0 \\
3.0\end{array}$ & $\begin{array}{l}3.0 \\
3.5 \\
3.0 \\
3.5 \\
3.0\end{array}$ & $\begin{array}{l}3.0 \\
4.0 \\
4.0 \\
3.0 \\
3.0\end{array}$ & $\begin{array}{l}3.0 \\
3.5 \\
4.0 \\
3.5 \\
2.5\end{array}$ \\
\hline Average Cluster D¹ & 3.3 & 3.2 & 3.4 & 3.3 \\
\hline Average Cluster A, B, C, D & 3.6 & 3.6 & 3.7 & 3.5 \\
\hline
\end{tabular}

${ }^{1}$ For purposes of the calculation of the cluster averages, all criteria are equally weighted within a cluster.

\section{Sources:}

http://www.worldbank.org/ida

http://siteresources.worldbank.org/IDA/Resources/73153-1181752621336/IRAI2007table1.pdf (accessed July 14, 2008)

http://www1.worldbank.org/operations/CPIA2010/IRAI2010table1.xls (accessed July 21, 2011)

http://wwwl.worldbank.org/operations/CPIA2010/MOZ.pdf (accessed July 21, 2011)

Sources: 
http://www.afdb.org/fileadmin/uploads/afdb/Documents/Project-and-Operations/ AFDB\%20-\%202007\%20CPIA.xls

http://www.afdb.org/fileadmin/uploads/afdb/Documents/Project-and-Operations/ 2010\%20Detailed\%20CPIA-FOR\%20DISCLOSURE_.xls

To conclude, the outcome of the AfDB assessment on Mozambique's policy and institutional performance is, in general terms, very similar to that of the World Bank. However, a more detailed analysis of the scores on specific criterion point to several inconsistencies. Although the differences in the scores are not significant, they indicate conflicting signals of the trends in Mozambique's performance. Furthermore, in comparison with the results of the World Bank CPIA, the AfDB scores indicate slightly more variation between the years, and even contradictory trends.

Comparing the results of the three governance assessments of the WGI, the World Bank and the AfDB, it seems that the WGI portrays slightly more critical views of Mozambique's governance performance than the World Bank and the AfDB CPIA.

\subsubsection{The Millennium Challenge Scorecard}

The governance assessments conducted by the Millennium Challenge Corporation (MCC) are summarized in quantitative reports known as Millennium Challenge Scorecards which aim at capturing the quality of governance through 18 indicators, grouped into three categories: "Ruling Justly", "Investing in People" and "Fostering Economic Freedom". ${ }^{122}$

Five of the indicators used by the MCC correspond to the aggregate indicators developed by the WGI, albeit with somewhat different classification. MCC's Ruling Justly comprises WGI's aggregate indicators of Voice and Accountability, Government Effectiveness, the Rule of Law and Control of Corruption whereas Encouraging Economic Freedom includes the indicators of Regulatory Quality. The scores generated through the WGI are used as the basis of the MCC assessment, but the scores are rescaled. Furthermore, due to the different timing of the annual assessments, the scores used by the MCC refer to the WGI scores of two years earlier. Hence, the scores of the Millennium Challenge Scorecard for the 2007 are based on the WGI scores 2005, and the scores for

122. Ruling Justly: Civil Liberties, Political Rights, Voice and Accountability, Government Effectiveness, Rule of Law and Control of Corruption; Investing in People: Public Expenditures on Health as Percent of GDP, Public Primary Education Spending as Percent of GDP, Immunization Rates for DPT3 and Measles, Primary Education Completion Rate, Natural Resource Management (as of 2007), Fostering Economic Freedom: Regulatory Quality, Inflation, Fiscal Policy, Business Start-Up, Land Rights and Access to Land (as of 2007), Trade Policy. 
2010 are based on WGI scores 2008 (http://www.mcc.gov/pages/selection/scorecards; information based on personal communication). Within the framework of the MCC assessment, the question of the margin of error is not specifically addressed, but the Millennium Challenge Scorecards indicate the margin of error for the scores derived from the WGI. The rest of the indicators are developed by third parties such as the UN agencies, US-based research institutions organizations and international non-governmental organizations. All of the indicators rely on publicly available data.

Table 7.6 below presents an overview of the assessment results for Mozambique and the rest of the SADC LICs as derived from the Millennium Challenge Scorecards for 2007 and 2010. Calculation of the average scores for SADC LICs is made by the author based on the country-specific Scorecards. The table also shows the respective median scores for all the MCC candidate countries belonging to the category of low-income countries. As described earlier, to qualify for MCC support a candidate country must perform above the median on at least half of the indicators in each of the three policy categories and (emphasis by the author) above the median on the Control of Corruption indicator. Concerning the indicator on Inflation, the MCC sets a fixed ceiling of $15 \%$ as a threshold. 
Table 7.6 | Governance Performance - Mozambique and SADC LICs; Millennium Challenge Scorecard 2007 and 2010

\begin{tabular}{|c|c|c|c|c|c|c|c|c|}
\hline \multirow{2}{*}{$\begin{array}{l}\text { MCC CRITERIA } \\
\text { Governance Dimension / Indicator }\end{array}$} & \multicolumn{2}{|c|}{$\begin{array}{l}\text { MCC Scale/Unit of } \\
\text { Measurement }\end{array}$} & \multicolumn{2}{|c|}{ MOZ } & \multicolumn{2}{|c|}{$\begin{array}{l}\text { Average } \\
\text { SADC LICs }\end{array}$} & \multicolumn{2}{|c|}{$\begin{array}{c}\text { Median MCC } \\
\text { LICs }^{2}\end{array}$} \\
\hline & Scale & Unit & 2007 & 2010 & 2007 & 2010 & 2007 & 2010 \\
\hline $\begin{array}{l}\text { Ruling Justly } \\
\text { 1. Civil Liberties } \\
\text { 2. Political Rights } \\
\text { 3. Voice and Accountability } \\
\text { 4. Government Effectiveness } \\
\\
\text { 5. Rule of Law } \\
\text { 6. Control of Corruption }\end{array}$ & $\begin{array}{c}0-60 \\
0-40 \\
-2.5 \text { to }+2.5 \\
-2.5 \text { to }+2.5 \\
-2.5 \text { to }+2.5 \\
-2.5 \text { to }+2.5\end{array}$ & $\begin{array}{l}\text { Score } \\
\text { Score } \\
\text { Score } \\
\text { Score } \\
\text { Score } \\
\text { Score }\end{array}$ & $\begin{array}{l}31.0 \\
25.0 \\
0.65 \\
0.55 \\
0.12 \\
0.14\end{array}$ & $\begin{array}{l}36.0 \\
25.0 \\
0.64 \\
0.41 \\
0.23 \\
0.23\end{array}$ & $\begin{array}{c}27.0 \\
17.3 \\
-0.02 \\
0.02 \\
0.04 \\
-0.01\end{array}$ & $\begin{array}{r}26.7 \\
18.0 \\
0.07 \\
-0.17 \\
0.06 \\
0.05\end{array}$ & $\begin{array}{l}30.0 \\
17.0 \\
0.0 \\
0.0 \\
0.0 \\
0.0\end{array}$ & $\begin{array}{l}29.0 \\
18.0 \\
0.0 \\
0.0 \\
0.0 \\
0.0\end{array}$ \\
\hline $\begin{array}{l}\text { Investing in People } \\
\text { 7. Public Expenditure on Health } \\
\text { 8. Immunization Rate } \\
\text { 9. Public Expenditure on Education } \\
\text { 10. Girls'Prim. Education Comple- } \\
\text { tion Rate }\end{array}$ & $\begin{array}{c}0-15 \\
20-100 \\
0-10 \\
10-130\end{array}$ & $\begin{array}{l}\text { Total exp./GDP } \\
\text { Score } \\
\text { Total exp./GDP } \\
\text { Compl.rate/ } \\
\text { Cohort }\end{array}$ & $\begin{array}{l}2.77 \\
74.5 \\
2.63 \\
23.4\end{array}$ & $\begin{array}{l}3.66 \\
74.5 \\
2.89 \\
52.1\end{array}$ & $\begin{array}{l}2.51 \\
79.8 \\
3.34 \\
55.2\end{array}$ & $\begin{array}{l}3.12 \\
77.6 \\
2.65 \\
68.2\end{array}$ & $\begin{array}{l}2.22 \\
81.0 \\
2.07 \\
66.7\end{array}$ & $\begin{array}{c}2.25 \\
81.8 \\
1.6 \\
66.5\end{array}$ \\
\hline $\begin{array}{l}\text { Encouraging Economic Freedom } \\
\text { 11. Inflation } \\
\text { 12. Fiscal Policy } \\
\text { 13. Cost of Starting Business }{ }^{4} \\
\text { 14. Days to Start-up Business } \\
\text { 15. Trade Policy } \\
\text { 16. Regulatory Quality } \\
\text { 17. Business Start-Up }\end{array}$ & $\begin{array}{c}0-15 \\
-8 \text { to } 4 \\
200-0 \\
200-0 \\
20-100 \\
-2.5 \text { to }+2.5 \\
0-1\end{array}$ & \begin{tabular}{|c|} 
Inflation over $12 \mathrm{mths}$ \\
Budget def./GDP \\
$\%$ of income $\mathrm{p.c.}$ \\
No of days \\
Av. tariff rates \\
Score \\
Score
\end{tabular} & $\begin{array}{c}10.1 \\
-3.49 \\
85.7 \\
113 \\
60.2 \\
0.16 \\
\text { n.a. }\end{array}$ & $\begin{array}{c}10.3 \\
-3.20 \\
\text { n.a. } \\
\text { n.a. } \\
74.5 \\
0.16 \\
0.96\end{array}$ & $\begin{array}{c}52.6 \\
-4.34 \\
134.7 \\
62.3 \\
50.7 \\
-0.22 \\
\text { n.a. }\end{array}$ & $\begin{array}{r}35.8 \\
0.55 \\
\text { n.a. } \\
\text { n.a. } \\
57.0 \\
-0.23 \\
0.76\end{array}$ & $\begin{array}{c}\text { n.a. } \\
-2.52 \\
85.7 \\
43.0 \\
59.1 \\
0.0 \\
\text { n.a. }\end{array}$ & $\begin{array}{c}\text { n.a. } \\
-1.4 \\
\text { n.a. } \\
\text { n.a. } \\
67.9 \\
0.0 \\
0.92\end{array}$ \\
\hline $\begin{array}{l}\text { Supplemental Information } \\
\text { 18. Lands Rights and Access to Land } \\
\text { 19. Natural Resource Management }\end{array}$ & $\begin{array}{c}0-1 \\
0-100\end{array}$ & $\begin{array}{l}\text { Score } \\
\text { Score }\end{array}$ & $\begin{array}{l}0.81 \\
54.8\end{array}$ & $\begin{array}{l}0.69 \\
55.3\end{array}$ & $\begin{array}{l}0.59 \\
62.7\end{array}$ & $\begin{array}{l}0.63 \\
62.3\end{array}$ & $\begin{array}{l}0.62 \\
64.1\end{array}$ & $\begin{array}{l}0.61 \\
61.6\end{array}$ \\
\hline
\end{tabular}

${ }^{1}$ The SADC LICs: DRC, Madagascar, Malawi, Tanzania, Zambia and Zimbabwe. The average scores are calculated by the author.

${ }^{2}$ In 2007, the number of MCC candidate countries (LIC group) was 79; in 2010 the number was 63.

${ }^{3}$ The WGI scale (originally from $-2,5$ to $+2,5$ ) is rescaled by the MCC so that the median for LICs is adjusted to zero for all of the World Governance Indicators (by indicator). Country scores are calculated by taking the difference between actual scores and the median. E.g., if the unadjusted median for LICs on Voice and Accountability is -0.70 , the MCC adds 0.70 to each country's score in order to set the median at zero.

${ }^{4}$ Indicators merged into a single indicator on Business Start-Up.

\section{Sources:}

http://www.mcc.gov

Fiscal Year 2007 Data Notes

Fiscal Year 2010 Data Notes

As the above table illustrates, the interpretation of the scores of the Millennium Challenge Scorecards is problematic due to the fact that the scale and units for measurement 
vary from one indicator to another. The median score for a respective income group, calculated by the MCC for each indicator, is the only comparator that can be used across all indicators and all countries. ${ }^{123}$ The analysis of Mozambique's performance is therefore based on a comparison of its scores with the median scores of all low-income countries covered by the MCC, and with the median scores of its SADC peer group. The focus on the median scores can be justified taking into consideration the fact that the median scores serve as the benchmark against which the eligibility of Mozambique is assessed. The only exception to this rule is the indicator on Inflation where a fixed ceiling of $15 \%$ has been set.

Concerning the category Ruling Justly, which is aimed at measuring the quality of political governance, Mozambique scores above the median of the MCC LIC candidate countries on all the six indicators, in both 2007 and 2010. This includes the Control of Corruption criterion, which is used as threshold indicator for MCC eligibility. Mozambique thus qualifies for the MCC support on all these indicators. The Millennium Challenge Scorecards also indicate some changes from 2007 to 2010 in Mozambique's political governance with higher scores on indicators measuring Civil Liberties, the Rule of Law and Control of Corruption, and with a lower score on Government Effectiveness.

Comparing Mozambique's scores with the average scores of the SADC LICs in the indicators for the Ruling Justly category, Mozambique is perceived to be significantly better. However, it must be pointed out that the low average scores of the SADC LICs are due to the very low scores given to the Democratic Republic of Congo and Zimbabwe. The rest of the SADC LICs (Madagascar, Malawi, Tanzania and Zambia) are perceived to perform at the level of Mozambique with scores above the respective median scores of the MCC LICs.

Looking at the indicators aimed at measuring service delivery in health and education, grouped in the category Investing in People, the outcome of the MCC is not as positive. Mozambique's scores on Immunization Rates and on Girls' Primary Education Completion Rate remain below the respective median scores of the MCC LICs both in 2007 and 2010. Mozambique's performance is perceived to be particularly critical concerning the primary school completion rate of girls, where it falls well below the MCC median. As to the indicators on Public Expenditure on Health and on Primary Education, Mozambique scores above the MCC LIC median. The scores for 2007 and 2010 are by and large identical, except on Girls' Primary Education Completion Rate, where Mozambique's performance is perceived to have improved considerably, albeit

123. Comparison based on the deviation from the median is a fairly standard procedure to compare different indicators. For example, the UNDP Human Development Index (HDI) uses the deviation from the median as a way of standardization. 
still failing to pass the MCC LIC median. Mozambique's performance, as perceived through the MCC, is poor also in comparison with its SADC peer group. Apart from the indicator on Public Expenditure on Health, Mozambique's scores are lower than the respective average scores of the SADC LICs.

On Economic Freedom Mozambique is perceived to perform at the level of, or slightly above, the median score of the MCC LICs on two indictors, namely on Regulatory Quality and Trade Policy. Mozambique passes the MCC eligibility criteria also on Inflation. However, Mozambique's performance is perceived to be very poor on indicators related to the regulatory framework for private sector development, and it fails to score above the median on the respective indicators used by the MCC in 2007 (Cost of Starting Business and Days to Start-up Business). On Fiscal Policy, with scores well below the MCC LICs median and even the average for the SADC LICs, Mozambique fails to pass the eligibility criteria both in 2007 and 2010.

Looking at the changes in respective scores for 2007 and 2010, Mozambique's performance does not indicate major changes in either direction, apart from the indicators related to business environment. While Mozambique failed both in the Cost of Starting Business and Days to Start-up Business indictors in 2007, it is perceived to have performed among the best within its peer groups on the new (merged) indicator measuring Business Start-Up in 2010 (the Cost of Starting Business and Days to Start-up Business indicators were merged into a single indicator Business Start-Up in 2008, all derived from the World Bank Doing Business report). Whether the change is an indication of improving regulatory framework for private sector operations, or a result of the change of the indicator remains uncertain.

The indicators on Land Rights and Access to Land and on Natural Resource Management, included in the Millennium Challenge Scorecard as of 2007, were initially treated as "Supplemental Information", and are therefore discussed under this sub-heading. ${ }^{124}$ As illustrated in the table above, Mozambique is perceived to perform well above the median of the MCC LICs on the indicator measuring land rights and access to land both in 2007 and 2010. While exceeding the median also in 2010, its score together lowered considerably during the period from 2007 to 2010. Concerning the indicator on Natural Resource Management, Mozambique scores remain below the median of the MCC LICs both in 2007 and 2010 without major change in direction.

124. As of 2008, the indicator on Land Rights and Access to Land was included in the category on Investing in People, and the indicator on Natural Resource Management was included in the category on Economic Freedom. 
In comparison with the SADC LICs, Mozambique' performance follows the same pattern as in comparison with all the MCC LICs: Mozambique scores on Land Rights and Access to Land are higher than the average scores of the SADC LICs both in 2007 and 2010, whereas on Natural Resource Management its scores are below the average SADC LICs.

In conclusion, while the Millennium Challenge Scorecards portray a more critical different image of the quality of governance in Mozambique than the CPIAs and the WGI, the key findings concerning the main strengths and the weaknesses are very similar. Mozambique scores above the median of the MCC LIC candidate countries on all the six indicators aimed at measuring the quality of political governance of the country (category Ruling Justly) both in 2007 and 2010. Looking at the performance with respect to service delivery in social sectors, particularly in health and education (category Investing in People), the outcome of the MCC is critical. Concerning the environment for private sector development, and macro-economic policies (cluster Economic Freedom), Mozambique's performance is perceived to be weak relative to other LICs subject to the MCC assessment. However, although in 2007 Mozambique scored below the median on more than half of the indicators in the category of Economic Freedom, and in 2010 in the category of Investing in People, it was deemed eligible for assistance by the MCC Board of Directors both in 2007 and in 2010. The MCC Board thereby used its discretionary power to determine Mozambique's eligibility.

\subsection{Quality of Governance in Mozambique: Qualitative Assessments ${ }^{125}$}

\subsubsection{Governance Profile ${ }^{126}$}

The EU Governance Profile on Mozambique was drawn up in 2008 by the EU country delegation in consultation with the EU Member States present in the country. It contains a qualitative analysis of governance in terms of following nine thematic areas, each divided into sub-components with more detailed indicators:

1. Political and democratic governance (WGI/Voice and Accountability)

2. Political governance and the rule of law (WGI/Rule of Law)

125. With respect to the qualitative assessments, the comparison of the results of the governance assessments on Mozambique with those of the SADC LICs cannot be made because of the lack of comparable data. The agencies under consideration have either not conducted governance assessments in other the SADC LICs or the assessments have not been conducted during the period under consideration in this study.

126. Source: European Community - Republic of Mozambique Country Strategy Paper and National Indicative Programme 2008-2013; EU Governance Profile June 2007-May 2009. 
3. Control of corruption (WGI/Control of Corruption)

4. Government effectiveness (WGI/ Government Effectiveness)

5. Economic governance (WGI/Regulatory Quality)

6. Internal and external security (WGI/Political Stability and Absence of Violence)

7. Social governance

8. International and regional context

9. Quality of Partnerships

The Governance Profile is presented in a format of a matrix. Apart from providing an assessment of the prevailing governance situation, it sketches the general trends in political, economic and institutional dimensions of governance, as perceived through the lens of the EU. As described earlier, the Governance Profile does not entail any scoring or ranking of countries according to their governance performance. However, the WGI scores are used as reference points in the analysis. The key messages on each of the nine areas extracted from the Profile are summarized below.

Political Governance (WGI/Voice and Accountability)

The state of Political Governance in Mozambique is assessed through four sub-components: 1) Human Rights; 2) Fundamental Freedoms; ${ }^{127}$ 3) Electoral Process; and 4) Principles for Constitutional Democracy. According to the EU's perception, the legal and administrative framework necessary for political governance is largely in place, but the implementation of the legislation and related administrative regulations is inefficient and slow in all sub-components. Mozambique is perceived to perform best as to Fundamental Freedoms, whereas it is seen to face greatest challenges in respecting the Principles of Constitutional Democracy. ${ }^{128}$

\section{The Rule of Law (WGI/Rule of Law)}

The respect for the Rule of Law, particularly, the functioning of the justice sector, is perceived to be weak or even very weak. Although the Constitution and the subsequent legislation provides a solid legal framework for the Rule of Law, the inefficiency of the system is seen as an impediment to the country's overall development. For example, the principles of equal access to justice and a fair trial are perceived to be violated, and corruption in the justice sector is deemed to be endemic. Law enforcement is perceived to be very weak, and violations of citizens' rights common.

127. The EU Governance Profile lists the following rights as fundamental freedoms: freedom of movement, freedom of religion, freedom of expression, freedom of information and freedom of assembly.

128. For the EU, the Principles of Constitutional Democracy entail the following components: Separation of the Executive, Legislative and Judiciary; Power of the Parliament; Existence of MultiParty System; Functioning of Political Pluralism; Existence of Democratic Control of Security Mechanisms. 
Control of Corruption (WGI/Control of Corruption)

On Control of Corruption, Mozambique's performance is perceived to be very weak with widespread corruption across public, private and CSO sectors. Although Mozambique has ratified a number of international conventions on anti-corruption (such as the UN Convention on Anti-Corruption, the African Union African Charter on the Values and Principles of Public Service and the SADC Protocol against Corruption), they have not been incorporated into national anti-corruption legislation. The existing legislation is considered ineffective and in need of major revisions. While the space for pretty corruption is perceived to be reducing, large-scale corruption is seen to be getting worse.

\section{Government Effectiveness (WGI/Government Effectiveness)}

The effectiveness of the government is assessed in terms of: 1) Institutional Capacity; 2) Public Financial Management; and 3) Decentralization. Institutional Capacity addresses questions related to the mandates and resources of public institutions as well as their planning and implementation capacity. While the mandates of public institutions are considered well defined, the financial and human resources base is perceived to be very low. Planning and implementation capacity suffers from over-bureaucratic administrative mechanisms and weak over-sight.

Mozambique is seen to perform better on Public Financial Management. According to the Governance Profile, the necessary reforms to enhance budget planning, execution and control are in place and their implementation is on track. The sustainability of the reforms is perceived to be a major challenge, particularly with respect to mainstreaming the reforms across the government.

With regard to the decentralization of power and authority to lower levels of administration, the legal framework is deemed to be in place but the process is perceived to be slow and inefficient. Financial resources transferred to lower administrative levels are considered insufficient in relation to the needs, and the capacity to use these resources at municipal and district level is very weak.

\section{Economic Governance (WGI/ Regulatory Quality)}

The two sub-components for assessing Economic Governance and Regulatory Quality include the Policy Framework for the Private Sector and the Management of Natural Resources. The first sub-component addresses a broad range of issues such as access to capital markets, respect for property rights, access to land, need to pay bribes and quality of labour regulations. Concerning the Management of Natural Resources, the assessment covers the existing legislation and a number of specific issues including Mozambique's involvement in the Extractive Industries Transparency Initiative (EITI) and the Forest Law Enforcement, Governance and Trade (FLEGT) programme. 
On Policy Framework for the Private Sector, Mozambique's performance is perceived to be poor, despite the government's increasing emphasis on private sector development. In view of the EU, access to funding is highly restricted, and the processes for the registration of property rights are complex and costly. The customs service is perceived to be improving but still inefficient, and smuggling is thought to be common. Labour regulations are also considered to be complex and costly. While bribery is rarely punished, the need to pay bribes is perceived to be increasing. In conclusion, the EU governance profile sees the business environment in Mozambique as "highcost and high-risk", with slow processes of reforms. As to the Management of Natural Resources, the legislative framework is perceived to be inadequate and its implementation inefficient. However, the government's willingness to seek a compliant status with the EITI, and for a membership in the FLEGT programme are seen as positive signs of its commitment to enhance natural resource management.

Internal and External Stability (WGI/Political Stability and Absence of Violence) Seen through the lens of the EU, Mozambique performs well in relation to both internal and external stability. It is noted, nevertheless, that although Mozambique is not involved in any internal or regional conflicts, there is a potential for localized political and social conflicts to arise, largely due to increasing inequality. Concerning external stability, the government is seen to be strongly committed to enhancing global security through its involvement in regional and global peace keeping and peace mediation efforts.

In addition to the above six areas of governance, drawn from the WGI, the EU governance profile includes an assessment of the quality of social governance, the dynamics of the country's regional and international context and the quality of partnerships.

\section{Social Governance}

Social governance is addressed in view of two specific areas of government policies: first, the fight against HIV/AIDS; and second, the promotion of gender equality. With respect to HIV/AIDS, the commitment of the government to fight the disease is perceived to be inadequate. This is illustrated, for example, by the limited state funding for the implementation of the HIV/AIDS strategy. It is highlighted that Mozambique ranks among the 10 most HIV/AIDS affected countries in the world.

On gender equality the situation is perceived to be mixed. While Mozambique has ratified most of the international conventions and declarations on gender equality, and gender issues are mainstreamed in the national development strategy and in sectoral strategies, gender discrimination and domestic violence remain common. 
International and Regional Context

Mozambique's international and regional context is assessed in terms of its participation in regional and global initiatives aimed at enhancing economic integration and political governance. Mozambique is perceived to perform well in both areas. Concerning economic integration, it is pointed out that Mozambique has implemented all legal and financial commitments to enforce the regional integration within SADC. On political governance, Mozambique is commended for its active participation in NEPAD and in the African Peer Review Mechanism (APRM). The Governance Profile further notes that Mozambique's participation in specific EU-supported regional initiatives, namely the Economic Partnership Agreements (EPA) and the Joint Africa-EU Strategy, is progressing satisfactorily.

The question of migration is included in the EU assessment as a specific sub-component of Mozambique's international and regional governance situation. The focus on migration reflects, primarily, the EU's own concerns related to the influx of illegal migrants from many African countries. From this perspective, the Governance Profile looks at Mozambique's willingness to collaborate with the EU in controlling illegal migration, and concludes that illegal migration from Mozambique to the EU countries is not a major concern. However, migration from Mozambique to neighbouring countries, and vice versa, is identified as an important issue from economic and political points of view, and it is seen as a potential cause for conflicts. The question of human trafficking is perceived to be another area of concern due to Mozambique's vulnerability to organized criminal networks.

Quality of Aid Partnerships

The last thematic area addressed within the framework of the Governance Profile refers to a very EU-specific issue: the quality of the aid partnerships between the EU and Mozambique. These partnerships are assessed in view of three sub-components: 1) the quality of the EU's Political Dialogue with the Government of Mozambique; 2) the quality of the EU's development policy programming; and 3) the level of participation of the non-state actors in Mozambique's national development planning.

On Political Dialogue, Mozambique's performance is considered to be very good with an open and constructive approach to the dialogue process. Mozambique is perceived to perform satisfactorily with regards to the "essential elements" (i.e. human rights, democratic principles and the rule of law) and the "fundamental element" which constitute the foundation of Cotonou Agreement between the EU and the ACP countries (ACP-EU Partnership Agreement 2006, Article 8).

The assessment is more critical concerning the quality of the EU's own development policy programming in Mozambique, particularly due to the limited involvement of the parliament and non-state actors in the preparation of the EU's Country Strategy 
for Mozambique. The programming process is characterized as a Commission-driven exercise without consultations with Mozambican stakeholders. This criticism is targeted, primarily, at the EU's failure to engage other stakeholders in the programming process. However, the Mozambican government's performance in engaging non-state actors in the formulation and monitoring of national development strategies is also perceived to be mixed. While non-state actors are formally involved in these processes, in practice their participation varies greatly across sectors. The need to strengthen broad-based participation at lower administrative levels is highlighted as a key development challenge for the government.

To conclude, the key messages derived from the EU's Governance Profile concerning the quality of political, economic and institutional governance in Mozambique can be summarized as follows.

Concerning political governance, Mozambique's legal and administrative framework is perceived to be satisfactory but the implementation of legislation and related administrative regulations is lagging behind. The weakest link in political governance relates to the enforcement of the principles of constitutional democracy. However, Mozambique's political stability is perceived to be strong both internally and externally. On economic governance, Mozambique's performance is deemed to be mixed. The institutional capacity of the government is generally weak across all sectors and at all levels of public administration, yet in the specific area of public financial management Mozambique's performance is perceived to be relatively satisfactory. The environment for private sector development is considered poor with a complex regulatory framework, exacerbated by an inefficient bureaucracy and endemic corruption. Weaknesses are also identified in the government's capacity to provide public services and promote gender equality. Furthermore, the involvement of non-state actors in policy-making is highlighted as a key development challenge for the government. Through the lens of the EU, Mozambique faces its greatest problems in terms of institutional governance. Mozambique's performance is perceived to be weak with regard to the respect for the rule of law, and very poor as to the control of corruption.

\subsubsection{Country Governance Analysis ${ }^{129}$}

The UK Country Governance Analysis (CGA) on Mozambique, which was carried out by the DFID field office in 2007, entails an assessment of three aspects related to the functioning of the state, i.e. the capability, accountability and responsiveness of the state. As described earlier, each of the three broad headings comprises several 
components which broaden the assessment beyond the attributes of the state to the state-society relations at large.

The results of the CGA are presented as a qualitative narrative drawn up at the field level, but the analysis is based on both quantitative and qualitative data produced by third parties, including documents produced by the Government of Mozambique and by local non-state actors. As explicitly stated by the UK, the objective of the CGA is not to rank countries according to their performance and the outcome of the assessment is not used to trigger any disbursement of aid. However, the outcome of the CGA guides the UK government's policy dialogue and aid programming with Mozambique.

The quality of governance in Mozambique as perceived through the CGA is summarized in the sections below. The sections correspond to the three broad thematic areas of the CGA, which are divided into specific indicators as deemed appropriate in the Mozambican context by the DFID field office. Again, the summary is limited to the key messages of the DFID's report.

State Capability

The main areas addressed under the notion of state capability include: 1) Political Stability and Post-conflict Transition; 2) Public Sector Effectiveness; 3) Public Financial Management; and 4) Environment for Private Sector Development. These areas correspond, to a large extent, to the aggregate indicators applied by the WGI and the World Bank and the AfDB CPIA. Although the CGA does not provide scores, the CPIA and WGI scores on respective indicators are used as reference points for the qualitative analysis.

On Political Stability and Post-conflict Transition Mozambique is seen to perform well, particularly at the national level. However risks of localized political conflicts are perceived to remain high due the slow progress of electoral reform. Mozambique is also seen to have made progress in improving its Public Financial Management. Other related areas, where the CGA notes improved performance, include enhanced legislation on tax administration and public procurement.

Concerning Public Sector Effectiveness, Mozambique's performance is perceived to be relatively poor across all sectors and at all levels of public administration. Public service delivery is highlighted as the most critical area, especially at district level. While the Environment for Private Sector Development is also deemed to be poor, the CGA commends the government for its commitment to pursuing, with some success, difficult reforms in this area. 


\section{State accountability}

The accountability of the Mozambican state is assessed in terms of five components: 1) Political Environment; 2) Decentralization; 3) Access to Information and Media Freedom; 4) Justice Sector; and 5) the Role of Civil Society.

In general, the CGA identifies major gaps between the legislative framework and law enforcement which are perceived to undermine the accountability of the state. Concerning the political environment, the performance of Mozambique is characterized as mixed. The necessary legislation for a multi-party democracy is deemed to be in place but the implementation of the legislation is perceived to be poor. The CGA notes, for example, that although the Constitution guarantees the separation of the powers between the executive, the judiciary and legislature, in practice the lines between the three institutions are blurred. The state and public sector institutions are seen to be largely dominated by Frelimo. Furthermore, Frelimo's grip on power is perceived to be getting tighter.

With regard to the process of decentralization, the same mismatch between the existing legislation and the actual practice is identified. The Government of Mozambique is commended for its legislative reforms aimed at decentralizing planning and budgetary powers to provincial and municipal authorities. However, the implementation of the legislation is perceived to have created a system of dual accountability: the elected provincial authorities are accountable to their electorate and, at the same time, to the central level administration.

As to the transparency and access to information, the Government of Mozambique is perceived to have made progress towards wider dissemination of information on the management of public resources and towards greater engagement of local communities in resource utilization. Despite progress, the access to information by average citizens, the media and even by opposition political parties, is considered limited. Concerning the freedom of the media, particularly press freedom, Mozambique is perceived to perform well in comparison with the other countries in the region. Even the state-owned media is seen to play a very valuable role in holding the government accountable for its work. The role of the media in promoting state accountability is seen to be weakened by insufficient resources, low technical capacity, and interestingly, by the media self-censorship.

The Justice Sector comprising the Ministry of Justice, the Attorney General's Office, the Courts and the Police is perceived to be the weakest link in the accountability of the state. The sector is deemed to suffer from a lack of sufficient financial and human resources at all levels, and the reform processes are undermined by a lack of coordination. The judiciary is characterized as being biased, inefficient and corrupt. 
The CGA judgment on the role of the civil society can be summarized as follows: first, the accountability of the civil society organizations (CSOs) to their constituencies is very weak; second, their technical capacity and financial resource bases are very low; and third, internal governance mechanisms are inadequate. In addition, due to the political environment in the country, many of the CSOs are co-opted by the ruling party which undermines their credibility to act as watchdogs of the government. These weaknesses are seen as indications of the fact that non-partisan CSOs are a relatively new, post-1992 war phenomenon in Mozambique, and of the fact that many CSOs have been established in response to the funding opportunities made available by donor agencies.

\section{State Responsiveness}

The assessment of the responsiveness of the Mozambican state addresses the human rights situation, the government's policies to promote economic, social and gender equality, and the government's measures to combat corruption. As in the case with State Accountability, Mozambique's performance is considered mixed. Adequate legislation and government policies to enhance the capacity of the state to respond to the needs of the citizens are, by and large, in place, but the enforcement of the legislation and the policy implementation are deemed to be inefficient.

Mozambique is perceived to perform relatively poorly in the area of human rights despite the fact that human rights, and the justice sector at large, are defined as the government's priorities for democratic governance. The harmonization of domestic legislation with the international human rights conventions which Mozambique has ratified is lacking, and human rights violations are frequently reported. Mozambique is identified as a point of origin for organized crime, including trafficking of women and children. On a positive note, the government is perceived to have initiated reforms with the objective of improving the human rights situation. With respect to constitutional civil liberties, such as freedom of movement, freedom of expression, and freedom of assembly, Mozambique is perceived to perform relatively well.

In relation to the promotion of the economic, social and gender equality, Mozambique is perceived to perform better than many other African countries. Investments in social protection programmes for the most vulnerable groups of the society, albeit limited in scope and funding, are an indication of the government's commitment to respond to the needs of disadvantaged citizens. On gender equality, Mozambique's performance is perceived to be mixed. On the one hand, the proportion of women in the parliament is very high in comparison with most African countries and even globally, and the number of women in the ministerial positions is significant. On the other hand, women and children are seen to face systematic discrimination and exclusion in daily life in all aspects of development. Domestic violence is reported to be widespread. Legislative 
reforms to promote gender equality are seen as an indication of the government's commitment to enhance its responsiveness to the needs of women.

Within the framework of the CGA, corruption is addressed as one aspect of State Responsiveness. Referring to Mozambique's scores on the Transparency International Corruption Perception Index measuring perceptions of public sector corruption, the CGA notes that Mozambique has stagnated at a score 2.8 on a scale from 0 (very corrupt) to 10 (very clean) over the period from 2004 to 2007. The CGA further cites the national survey on Governance and Corruption of 2004, according to which public sector corruption was highlighted as a serious problem, albeit not the most pressing concern for most households. On a more positive note, the Government of Mozambique is seen to have initiated a number of reforms to enhance the fight against corruption, such as approval of a new Anti-Corruption legislation, an Anti-Corruption Strategy and a National Action Plan. The anti-corruption rhetoric by the President of the Republic, followed by some concrete actions, is seen by the CGA as an indication of the government's commitment to strengthen its fight against corruption in the public sector. At the same time it is pointed out that the new anti-corruption measures are likely to remain unsuccessful without greater accountability of the state. Hence, despite the increased emphasis on corruption, Mozambique is perceived to perform very poorly in combating corruption.

To conclude, the UK Country Governance Analysis assesses the capability of the state, to a large extent, on the basis of the criteria developed within the framework of the WGI and the CPIA. Accordingly, the CGA looks at political stability, public sector effectiveness, public financial management and the environment for private sector operations in Mozambique. Mirroring the outcome of the WGI and the EU Governance Profile, Mozambique is perceived to perform best in political stability, whereas the effectiveness of the public sector in terms of administrative capacity and service delivery is perceived to be relatively poor across all sectors, and at all levels of public administration. The policy framework for private sector development is characterized as poor.

The accountability of the Mozambican state vis-à-vis its citizens is perceived to be undermined by inefficient implementation of the existing the legislative framework. Although the necessary legislation for a multi-party democracy is deemed to be in place, its implementation is perceived to be poor. Due to the dominant position of the ruling party, the space for political competition is small and it is judged to be getting smaller. The separation of powers between the executive, the judiciary and legislature is not institutionalized. Access to information by average citizens, the media and the opposition parties remains limited. As in the case of the EU Governance Profile, Mozambique's performance is perceived to be very poor with respect to the justice sector, which is characterized as being 
the weakest link in the accountability relations between the state and the society at large. The role of the civil society is understood to being undermined because of capacity weaknesses and limited independence from the ruling party.

Concerning the responsiveness of the state, the performance of Mozambique is considered mixed. The legal and policy framework of the state for responding to the needs of the citizens is considered to be satisfactory, but its implementation is lagging behind. In relation to the promotion of the economic, social and gender equality, Mozambique is perceived to perform better than many other African countries. With regards to corruption Mozambique is perceived to perform very poorly, despite the government's enhanced anti-corruption rhetoric.

\subsubsection{Strategic Governance and Corruption Analysis ${ }^{130}$}

The outcome of the Netherlands' Power and Change Analysis is presented as a qualitative narrative which builds on the analytical work of the Dutch Embassy in Mozambique, as well as on quantitative and qualitative data generated by third parties, including the Government of Mozambique and Mozambican non-state actors. As in the case of the UK CGA, the Dutch PCA does rank countries according to their performance, but the outcome of the analysis is used as an input in the formulation of the Netherlands' Multi-Annual Country Strategies.

The quality of governance in Mozambique as perceived through the lens of the PCA is summarized in the sections below. The discussion, which will be limited only to the key messages on each of the three clusters, does not do full justice to the comprehensiveness of the analysis of the PCA report.

Foundational Factors ${ }^{131}$

The territorial integrity of Mozambique is characterized as fragile, and the country is perceived to be extremely vulnerable to organized crime. While the national boundaries are not contested, weak border control together with an increasingly open economy are deemed to entail risks to sustained socio-economic development. The legacy of colonial administration, which has resulted in a highly centralized state structure under the leadership of Frelimo, has shaped the history of state formation. The state, and the entire political economy of the country, is perceived to have been captured

130. Source: Netherlands Ministry of Foreign Affairs (2008). Power and Change Analysis: Mozambique 2008 (not publicly available, copy received for research purpose only).

131. Foundational factors: Territorial integrity; History of state formation; Sources of revenue; Social and economic structures; Geostrategic position 
by Frelimo, which maintains power through patron-client relationships. Despite the transition to a market economy and the constitutional separation of powers, the state, economy and the ruling party are seen to be effectively merged.

The structure of the government, based on line ministries, is perceived to be inadequate to meet the needs for efficient governance and service delivery. Public administration is characterized as highly centralized, over-regulated, inefficient and institutionally weak. While significant potential for domestic resources mobilization through improved tax policies and tax administration exists, it remains unexplored due to lack of both political will and technical and administrative capacity. Hence, tax revenues to the state budget as percentage of GNP are below those of other LICs in the region.

The social and economic structures of Mozambique are considered to be fragmented, comprising four inter-dependent sub-economies: 1) informal economy; 2) formal economy; 3) economy built around the mega-projects financed through foreign direct investments; and 4) illegal economy run by criminal networks. In general, the economy is characterized as "an economy of consumption rather than an economy of investment for production". The PCA notes that even though Mozambique's GNP has more than doubled over the ten-year period from 1994 to 2003, the impact of this expansion on the country's socio-economic development has been mixed. While the national poverty level has been reduced during the period from 1996/97 to 2002/03, income inequality has increased and job creation has remained limited.

Rules of the Game ${ }^{132}$

The Rules of Game cluster entails an assessment of Mozambique's formal legal and administrative framework, space for political competition, and the distribution of power within the state and between the state and non-state actors. Special attention is paid to corruption.

The legal and administrative framework, enshrined in the 1990 Constitution and subsequent legislation, is perceived to provide the basis for liberal democracy in Mozambique. However, the control of state resources by the ruling party and the nature of the electoral legislation undermine political competition, and consequently, the country is seen to be moving towards a system with one party dominance. The political system is further deemed to be characterized by a mechanism of informal negotiations between the ruling party and the opposition, outside the formal and legal institutional framework, with both parties committed to preserving the status quo.

132. Rules of the game: Formal legal and administrative framework; Political competition; Institutionalization of state, civil society and private sector organizations; Distribution of power; State-society relations; and Identification of key trends. 
The political dynamics between the ruling party and the opposition are perceived to impact upon the society at large. In view of the PCA, the state-society relations are shaped by two significant factors: first, the victory of the liberation struggle led by Frelimo; and second, the peace process with the transition to multi-party democracy led by Renamo. Although the legitimacy of the leading role of Frelimo in the liberation struggle is not contested, the opposition, although weak, constitutes a challenge to the legitimacy to Frelimo's claim to lead the post-war state.

The separation of the executive, legislative and judiciary powers of the state, while enshrined in the Constitution, is perceived to remain a challenge. The institutionalization of key state functions, in particular of the judiciary, police and military, is considered weak. Despite the weaknesses identified in the performance of many public sector institutions, Mozambique is commended for the progress made in improving public financial management. With respect to corruption, the PCA concludes that although anti-corruption legislation has been approved by the government, the enforcement of the legislation is inefficient and corruption is perceived to be increasing.

The legal framework for distribution of power and resources between the different levels of state administration is perceived to be, for the most part, in place but the implementation of the legislation is considered very weak, which is reflected, for example, in the allocation of the state budget. Concerning the role of the civil society and private sector the PCA concludes that both groups of the non-state actors are weak vis-à-vis the state, whereas the media is perceived to a significant player in the state-society relations.

The Rules of the Game cluster also includes an assessment of the emerging trends and the underlying endogenous and exogenous factors which are likely to impact upon the quality of governance in Mozambique. The development of the political system, management of land and other natural resources, capacity development and risks of increasing social unrest are highlighted as the key endogenous factors which are likely to influence the governance context. Among the exogenous factors, which are considered relevant for the rules of the game, the PCA identifies issues such as potential discovery of major oil and gas resources, regional economic integration, increasing cooperation with China, as well trends in international trade and commodity markets. The evolution of the situation in Zimbabwe is also seen as an important exogenous factor which may impact upon developments in Mozambique.

Through the lens of the PCA, the emerging trends driven by the endogenous factors are gloomy. The PCA concludes that Frelimo's tendency to strengthen its dominance over the state and the economy is likely to enhance the cooption of Renamo and other opposition parties, and subsequently, to reduce the space for political competition. Despite the reform of the electoral legislation aimed at consolidating pluralist political 
system, Mozambique is perceived as remaining a de facto dominant party system. The decentralization process is largely seen as an attempt by the ruling party to extend and consolidate its control over the state and resources, despite the allocation of some resources to the district level administration. Conflicts over the use of land and other natural resources are likely to increase. Due the heightened sense of class differentiation among the population at large, the risks of social protests are also likely to increase. Apart from some exceptions, the CSOs are perceived to be prone to rent-seeking and rent-sharing with those in power elite.

Among the positive trends, the PCA highlights the increase in critical thinking amongst various groups, such as the youth, intellectuals and some CSOs. This can create pressure for alternative, more broad-based and inclusive development driven by local stakeholders rather than by donors. Furthermore, the accountability of the government vis-à-vis other stakeholders, as well as transparency in public financial management, including the use of foreign aid, are expected to improve.

The emerging trends related to the exogenous factors are perceived to be very similar. In view of the PCA, the discovery of natural resources and the consequent increase in domestic revenues is likely to undermine the role of OECD DAC donors, and to lead to the end of the government's drive for good governance. ${ }^{133}$ In parallel, the emerging role of China as the preferred international partner for Mozambique is likely to promote cooperation with less emphasis on anti-corruption, accountability and democracy. Furthermore, according to the PCA regional economic integration and the creation of the SADC common market may weaken Mozambique's regional competitiveness in terms of production and employment, which can feed social unrest. Global trends are also perceived to have negative implications for Mozambique: the volatility of international markets, exacerbated by budgetary crises in donor countries and reduced aid levels, is likely to increase social pressures inside the country. Finally, the development scenarios for Zimbabwe are likely to encourage Frelimo to further strengthen its control mechanisms.

Here and Now ${ }^{134}$

The third PCA cluster focuses on three issues identified at the time of the 2008 assessment as the key events likely to contribute to changes in the quality of governance in Mozambique. These include, first, the (then) forthcoming presidential, parliamentary and provincial elections in 2009; second, the 2008 joint Annual Review of general budget support; and third, the detention of several senior government official accused

133. As pointed out in the introductory chapter, significant coal deposits and natural gas reserves have been found in Mozambique (see Chapter 1).

134. Here and now: Analysis of current context in view of governance and corruption with focus on events likely to impact upon quality of governance. 
of embezzlement. The choice of this specific set of issues relates to the PCA's emphasis on accountability between the state and the citizens and on fight against corruption as key elements of good governance.

Concerning the 2009 presidential, parliamentary and provincial elections, the PCA concludes that Frelimo is determined to gain the majority in all the elections. It further highlights the possibility of a manipulation of the election results in favour of the ruling party, given the electoral track record in Mozambique. With respect to general budget support as an aid modality, the PCA notes that high level of aid channelled as general budget support entail risks to the Government of Mozambique, to the CSOs, as well as to the donors themselves. ${ }^{135}$

The detention of a former minister and senior government officials accused of embezzlement is the third event addressed under the Here and Now cluster. The detention process is characterized mainly as a strategic measure by Frelimo, which is targeted at several audiences. In view of the PCA, the detention serves the purpose of assuring Mozambican citizens and donors that the government is committed to combatting corruption. It is also seen as an attempt to respond to the budget support donors' request for increased transparency and improved law enforcement. Finally, the detention is perceived to serve as a warning to the emerging internal fractions within Frelimo.

To conclude, through the lens of the PCA, Mozambique faces major challenges in terms of its political, economic and institutional governance. The image portrayed by the PCA seems more critical than the ones portrayed by any of the other governance assessments. The key messages emerging from the analysis can be summarized as follows. Firstly, there is a mismatch between the formal legislative and administrative framework and the "reality" of the political system. While constitutionally a multi-party democracy, Mozambique is seen to be moving towards a one-party state. Secondly, apart from public financial management, public sector institutions are perceived to be inefficient, due largely to a lack of political will and of the technical capacity to embark upon reforms. The justice sector in particular is considered very weak, which also undermines the fight against corruption. Thirdly, in contrast with the

135. Risks for the GoM: potential failure by the government to meet the GBS targets involves the risk of significant reduction of aid; the deep involvement of the GBS donors in the core planning and budgeting processes of the GoM likely to undermine the government's sovereignty;

Risks for the CSOs: high level of GBS entails the risk of enhancing the accountability of the government to the donors at the cost of its accountability to the parliament and the citizens of the country;

Risks for the Donors: in light of the 2008 GBS Annual Review process, the GBS donors' enhanced emphasis on good governance may undermine the efforts of donor harmonization, which is one of the fundamental objectives of general budget support. 
stated policy of decentralization, the political power and financial resources remain in the hands of the central administration and the ruling party. The emerging civil society and private sector actors are weak and, with some exceptions, fail to play the "watch dog" role in relation to the state. On the positive side, freedom of the press, and of the media in general, is deemed to be widely respected.

The emerging trends, whether related to endogenous or exogenous factors, are perceived to be gloomy, in particular with respect to political governance. Mozambique is likely to remain a de facto dominant party system with the ruling party consolidating its power. The risks of social protests are perceived to be increasing due to the widening gap between the poor and the rich in the society. The potential discovery of natural resources, the increasing role of the emerging economies and regional economic integration, are likely to enhance the risk-prone trends in governance. The role of the OECD DAC donors is perceived to be weakening vis-à-vis the new donors, such as China, which is deemed to bring to an end the government's efforts to enhance transparency, accountability and fight against corruption.

\subsubsection{Power Analysis ${ }^{136}$}

The Power Analysis on Mozambique, conducted by the Swedish government's aid agency SIDA, focuses on the northern most province of the country, the Province of Niassa. However, much of the analysis builds on country wide research concerning Mozambique's colonial legacy and the political, economic and social developments after independence which underlie the contemporary governance structures at national, provincial and district levels. The evolution of the power-relations and governance structures at national level is seen as having shaped the framework for the emerging power relations and governance at lower levels of administration. This approach is highlighted in the title of the final report of the assessment: National Governance and Local Chieftaincy; A Multi-level Power Assessment for Mozambique from Niassa's Perspective (Åkesson and Nilsson, 2006) ${ }^{137}$.

As described earlier, the notion of "power" constitutes the key analytical concept for the Power Analysis. In the case of the Niassa Power Analysis, the notion of power is approached from three angles: first, what power is; second, how power is manifested;

136. Source: Åkesson G. and Nilsson A. (2006), National Governance and Local Chieftaincy; A Multi-level Power Assessment for Mozambique from Niassa's Perspective.

137. The Power Analysis was conducted, on behalf of SIDA, by two Swedish researchers, Gunilla Åkesson and Anders Nilsson, both of whom have long practical and research experience from Mozambique, including from the Province of Niassa. 
and third, how power is exercised. The explicit elaboration of the conceptual approach sets the Power Analysis apart from the other governance assessments under consideration in this research. As the conceptual approach is central not only in determining the focus of the analysis, but also for interpreting the outcome of the analysis, the approach developed for the Niassa assessment will be briefly described below ( $\AA$ kesson and Nilsson, 2006, p. 22-27 138 ):

First, the concept of power is defined as a means to change or to maintain a status quo in a specific societal situation. Second, concerning the manifestation of power, a distinction is made between "political power" and "social power". Political power refers to control over the politico-administrative apparatus, including control over the resource allocation, policy making and policy implementation which underlie the prevailing political system. Social power refers to the capacity and resources that people in a given society have to influence and change their own situation. The question of legality and legitimacy of power is seen as being closely linked to the manifestation of power: what is legal in the political sphere of the society may not be perceived to be legitimate in the social sphere, and vice versa. Third, three different ways to exercise power are distinguished: "controlling power" (or "power over"), "constructive power" (or "power to") and "collaborative power" (or the "power with"). Controlling power is seen as the capacity of an actor to reinforce its will on other actors. Constructive power refers to the capacity of an actor to use resources for the benefit of other actors. Collaborative power implies that power is exercised with a high degree of local participation in the identification of needs, mobilization of resources, making of investment decisions, etc. Åkesson and Nilsson argue that all three forms of power should be exercised simultaneously in order to improve democratic governance in the country.

Finally, as an attempt to understand the dynamics of power relations beyond the formal rules enshrined in legislation (political power), and the informal rules rooted in social norms (social power), the authors put forward the notion "willing compliance" as one way of exercising power. Willing compliance refers to power relations where the subordinates seem to comply with the status quo even when it is not in their interests to do so. According to the authors, the notion of willing compliance contributes to the understanding of how the elites in a given society manage to shape subordinates' visions and perceived needs as well as to the understanding of how the subordinates view their place and role in society.

Although the approach is in line with SIDA's general guidelines for conducting the Power Analysis, the interpretation of the notion of power, the scope of the analysis, the

138. The conceptual framework developed by Åkesson and Nilsson builds on the discussion on power relations by Mick Moore (2005) and Steven Lukes (2005). 
set of issues, and the methodology for the Niassa Analysis, have been adapted taking into account the specific country and regional contexts. This is reflected, in particular, in the emphasis on the role of the traditional authorities in shaping governance, particularly at community level, in Mozambique. The explicit attempt to shed light on the traditional governance structures and their impact upon the prevailing power relations is another aspect which distinguishes the Power Analysis from the rest of the governance assessments under consideration.

Building on the above conceptual approach, the Niassa Power Analysis addresses governance in terms of three broad focus areas: first, politico-economic transformations in Mozambique since independence; second, the development of the state-society relations at large; and third, the role of the international donor community in the evolution Mozambique's power relations.

The outcome of the Power Analysis is summarized below. At the outset, it must be underlined that the Power Analysis was initially developed with the objective of enhancing the understanding of the structural factors impeding poverty reduction in a given country. Accordingly, the main purpose of the Power Analysis on Mozambique is to unbundle the web of political, economic and social power structures and their implications for poverty reduction, with focus on the Province of Niassa. It does not, as such, assess the quality of governance in Mozambique on the normative scale from "weak/poor" or "strong/good" governance, but aims at analyzing whether the prevailing governance structures create conditions for poverty reduction. The final report on Niassa is thus an analysis of the evolution of governance structures in the province against the background of Mozambique's politico-economic transformation and the development of the state-society relations rather than a normative assessment based on pre-defined benchmarks. It has served as a tool for the implementation of the aid programmes supported by SIDA in the Niassa Province (information based on personal communication).

Politico-Economic Transformation

The Power Analysis distinguishes three main periods in Mozambique's politico-economic transformation which have impacted upon the prevailing governance structures at all levels of administration: first, the period of top-down colonial administration characterized by forced labour and extensive migrant work; second, the early post-independence period of the one-party state with central economic planning; and third, the constitutional transition to multi-party system and market economy. The role of Frelimo has been critical in all the transitions, first, as the leader of the national liberation struggle and, since independence, as the ruling party.

According to the Analysis, the common denominator of the three periods is the reliance on a top-down "functional development principle" with emphasis on large-scale 
investments aimed at promoting changes at the macro-level of the economy ( $\AA$ kesson and Nilsson, 2006, p. 28). ${ }^{139}$ It is further argued that, in contradiction with the "territorial development principle", the policies pursued during these three periods have ignored the development needs and opportunities at the local level. Therefore, despite past politico-economic transformations, the contemporary governance structures in Mozambique continue to be based on a rigid, vertical hierarchy, i.e. on a high degree of controlling power by the state and Frelimo. Although the abolition of traditional authorities caused discontent among certain population groups, and probably contributed to prolonging the war, the vertical power relations based on the controlling power by Frelimo have been institutionalized and largely accepted in the society. The power relations are thus also characterized by a high degree of willing compliance in the Mozambican society.

The Power Analysis views legislative reforms, such as the 2003 legislation on local state structures initiated in the early years of 2000, as signs of a transition towards more horizontal and collaborative governance structures. ${ }^{140}$ The implementation of the reform process, is however, perceived to be characterized by two contradictory tendencies. On one hand there is an attempt to decentralize power and authority to lower levels of administration and, on the other, there is a trend of systematic concentration of power in the hands of the Frelimo. The role of the community authorities, while acknowledged, remains consultative, and their power is perceived to be limited to social power rather than political power. According to the Power Analysis, the key challenge concerning the transition relates to the question whether the political elite, that is Frelimo, is willing to give up some of its controlling power and to create a space for constructive and collaborative power to be exercised by other stakeholders in the society.

Development of the State-Society relations

The development of the relations between the state and the Mozambican society at large are analyzed from two angles: the relationship between the state and the Frelimo; and the relationship between state and civil society. ${ }^{141}$

139. The functional development principle is defined as a top-down policy approach concentrating on macro-level of the economy in which performance is measured at the aggregate level, whereas territorial development principle is puts emphasis on community participation, equitable distribution of, and access to, resources in all parts of a given country (Åkesson and Nilsson 2006, p. 26).

140. The 2003 legislation provides for the decentralization of political and budgetary authority to provincial and district levels as well as for the participation of community authorities in development planning and decision-making. The community authorities are composed of traditional leaders, secretaries of the villages or suburbs, and other leaders legitimated as such by local communities (Åkesson and Nilsson 2006, p. 38).

141. Civil society is defined as "wide range of societal expressions and groups, represented by traditional as well as contemporary networks and organizations" (Åkesson and Nilsson 2006, p. 109). 
The relationship between the state apparatus and Frelimo is perceived to be the "area most resistant to change" (Åkesson and Nilsson, 2006, p. 57). Despite constitutional changes, the "culture of governance", within which the Frelimo leadership always holds important positions in the state apparatus, has remained unchanged. According to the Power Analysis, the combination of Frelimo's deep entrenchment in, and total control over, the state apparatus is the main problem for developing more constructive and collaborative power relations. The decentralization process is perceived to be at risk because of the tendency by the ruling party to de-concentrate power into its own hands, and the relations between the state and the party are in fact seen to be reinforced. The space for political opposition and critical CSO action is limited, as the loyalty to Frelimo party is perceived to be the main criterion for employment in the state apparatus, or for a fair treatment by the state. Frelimo's institutionalized power position has created a situation of a "willing compliance" in which the status quo is accepted. ${ }^{142}$

The Power Analysis starts its analysis of the relationship between the state and the civil society from a proposition that states that a civil society action is not necessarily in contradiction to the state but it can serve as a means to enhance social power. It is further stated that the various civil society organizations should be assessed "in relation to their possible contribution to good and legitimate governance" (Åkesson and Nilsson, 2006, p. 64). The Power Analysis on the state-civil society relationships is largely limited to Niassa province, and with focus on two districts. It entails a rich socio-economic analysis and research on the formal and informal power relations at community level. In view of context-specificity of the findings, the discussion here is limited to the findings which can be considered relevant for understanding the state-society relations at national level.

The Power Analysis notes that the dominant role of Frelimo as the ruling party, and as the de facto state, has impacted upon the development of the civil society and its relations with the state. Hence, civil society operates within a framework of the Frelimo-controlled governance structures with limited space and resources for independent action. However, civil society is perceived to have gained more space as a result of the decentralization process which has legitimized the traditional authorities and other community leaders. While this process is considered a step towards more

142. The prevailing "culture of governance" is perceived to be reflected in the evolution of the neopatrimonial system in the Mozambican society, characterized by two parallel networks. According to the Power Analysis, the networks created within Frelimo during the liberation war are at the core of the prevailing neo-patrimonial system in Mozambique. However, in parallel, the different ethnolinguistic groups in the society, often deeply rooted in local history and pre-colonial power structures, are still active and determine power relations within these groups. While the two patrimonial systems are intertwined, the Frelimo system is perceived to be dominant. The Power Analysis argues that the relative political stability in Mozambique is "a consequence of the double nature of the patrimonial system and a skilful management between the two realms" (Åkesson and Nilsson, 2006, p. 62). 
horizontal and collaborative governance structures at district and community levels, a contradictory tendency of the consolidation of political power by the ruling party is perceived to be underway. Making a distinction between locally rooted civil society and non-governmental organizations, most of which are financed by donors, the Power Analysis argues that the latter very rarely are democratic member-based organizations with local constituencies. Their role in contributing to more collaborative local governance structures is therefore perceived to be limited. It is further argued that donors can strongly influence the balance of power at community level by selecting which local non-governmental organizations to support. The role of donors is discussed in more detail below.

\section{Role of the Donors}

The Power Analysis examines the role of donors in the context of Mozambican power relations in view of two questions. The first question relates to the asymmetry of the power relations between donors and the Government of Mozambique, and the second concerns public sector corruption and abuse of power by the Mozambican state.

It is argued that the asymmetrical power relations between the donors and the government are so deeply institutionalized that the relationship can be characterized as "willing compliance" by both parties. According to the Power Analysis, the dialogue between the donors and their Mozambican counterparts is coloured by a strong mutual distrust, contrary to the public statements by both parties. Nevertheless, both parties are perceived to be willing to comply with the prevailing situation in order to maintain the status quo.

The power relations between donors and the Government of Mozambique are analyzed also in view of the debate on public sector corruption. It is pointed out that corruption is deemed to be endemic by many donors - as well as by Mozambican citizens - and the anti-corruption rhetoric is strong both among donors and within the government. However, despite the inefficiency of the government's fight against corruption, donors continue supporting the state with increasing amount of aid. According to the Analysis, this is interpreted by many non-state Mozambican actors as an implicit acceptance of corruption and abuse of power by the state. Donors are thus seen to exercise their power in contradiction to their stated objectives, which in turn is interpreted as an indication of shared interests between the donors and the government.

In addition to analyzing the historical factors underlying the established governance structures and the main features of the current governance context, the Power Analysis outlines the emerging trajectory of power relations in Mozambique. Two contradictory tendencies are identified. On the one hand a number of reform processes are seen to be underway with the objective of enhancing poverty reduction and increasing the 
participation of local communities in the development process. On the other hand, a trend characterized by an increasingly centralized power structure, generalized corruption and the abuse of power by the state, and by diminishing room for opposition and civil society action outside Frelimo's control can be identified. It is argued that the two tendencies are "both palpable and recognized, at least informally, by the social and political forces in Mozambique" (Åkesson and Nilsson, 2006, p. 111).

According to the Power Analysis, these contradictory tendencies can coexist because they satisfy the interests of the civil society, the state, and the donors simultaneously. First, the on-going reforms concerning decentralization and the broadening of the participation of community leaders respond to the interests of the local communities by increasing their access to power and resources. Furthermore, poverty reduction and improved access to public services contributes to enhancing the legitimacy of the state and the ruling party. Second, the ruling party benefits from the increasing legitimacy of the political system, which is constitutionally a multi-party democracy, and allows for a political competition. The Frelimo led government is perceived to be a force for change, although the political opposition is weakened, largely as a result of the formal recognition - and co-option - of traditional authorities and other community leaders by Frelimo. Third, the donor community is perceived to benefit from the status quo because of the progress made in the political sphere with the transition to a multi-party system, and because of the strong macro-economic performance and positive socio-economic developments in the country. The fight against corruption, while central in the dialogue between the donors and the Government, is not acted upon by the donors because of the political and economic achievements under the current regime. The Power Analysis does point out that the two contradictory tendencies entail a risk to political stability in Mozambique and, therefore, calls for "mainstreaming conflict-awareness" in the development processes (Åkesson and Nilsson 2006, p. 106).

In conclusion, the Swedish Power Analysis on Mozambique approaches governance from the point of view of formal and informal power relations. The Power Analysis explores the evolution of the power relations in the country from a historical and political economy perspective highlighting the importance of the country's successive politico-economic transformation in shaping the framework for the existing governance structures.

The Power Analysis concludes that the contemporary governance structures in Mozambique continue to be based on a rigid, vertical hierarchy under the leadership of Frelimo, despite the various politico-economic transformations which have occurred since the country's independence. At the same time it identifies trends which may lead to more horizontal structures of governance. The decentralization process, initiated in the early years of 2000, is highlighted as an important element of this transition. According to the Power Analysis, the transition process is characterized by two contradictory tendencies: 
on the one hand, there is an attempt to decentralize power and authority to lower levels of administration, on the other hand, there is a trend of systematic de-concentration of power in the hands of the Frelimo. The key question for the transition to succeed relates to the willingness of the political elite to give up some of its power and create a space for power to be exercised by other stakeholders in the society.

The development of the state-society relations is perceived to have resulted in a "culture of governance" in which the leadership of the Frelimo party always holds important positions in the state apparatus. Frelimo's power hegemony, initially built on its legitimacy as the leader of the national liberation struggle, has remained unchanged despite the constitutional change to multi-party democracy. While civil society is perceived to have gained more space as a result of the decentralization process, its role visà-vis the state is limited within the Frelimo-controlled governance structures. By legitimizing the traditional authorities and other community leaders, the decentralization process may contribute towards more horizontal governance structures at district and community level - if not undermined by the contradictory tendency to de-concentrate power into the hands of the ruling party.

The relationship between the donors and their Mozambican counterparts is characterized by a strong mutual distrust, contrary to the public statements by both parties. The Power Analysis refers to the official donor discourse according to which the Government of Mozambique has the ownership of national agenda-setting and policy-making. At the same time, the same donors criticize the government for exercising too much controlling power. From the Mozambican point of view, the government's room for manoeuvre is undermined by the donors through their economic power and deep involvement in policy-making. However, both parties are perceived to be willing to comply with the prevailing situation in order to maintain the status quo.

\subsection{Consistency of the Assessment Results: The Emerging Landscape}

In view of the above analysis, the selected governance assessments portray a relatively similar, yet nuanced, image of the quality of governance in Mozambique. Despite the differences in their conceptual approaches, focus of the analysis and methodology, the general conclusions that can be extracted from these assessments are rather consistent concerning the perceptions of the main strengths and weaknesses of governance in the country. Using the broad WGI definition of governance comprising political, economic and institutional dimensions as an organizing framework, the key messages emerging from the governance assessments can be summarized as follows. 
First, it can be said that Mozambique is perceived to perform relatively well in the area of political governance, particularly concerning the political stability of the state - notwithstanding the fact that this dimension of governance is not addressed by the World Bank and the AfDB CPIA. The findings are more diverse with respect to fundamental freedoms, transparency of the political system, and in particular, the accountability of the state vis-à-vis the citizens. These issues are highlighted as significant governance concerns in the Governance Profile (EU), the Country Governance Analysis (UK) and the Power and Change Analysis (NL). While the Swedish Power Analysis identifies somewhat similar challenges, it also underlines that there are signs of increasing openness of the political system with increasing accountability of the state.

Irrespective of the governance assessment tool Mozambique is perceived to be facing its greatest challenges in the area of institutional governance, particularly, concerning the rule of law and corruption. Mozambique's weak performance in respect of the rule of law, with the poor functioning of the entire justice sector, is underscored in all assessments as the fundamental weakness of the governance situation. Endemic corruption in the public sector, which partly reflects the inefficiency of the justice sector, is another issue where Mozambique's performance is considered critical. In the qualitative assessment reports, the gap between the legal framework and the law enforcement is highlighted as a significant factor behind Mozambique's poor performance. While the legislation and government policies concerning the rule of law and the fight against corruption are perceived to be, by and large, in place, their implementation is seen as being slow and inefficient.

With regard to economic governance, the performance record is perceived to be mixed. While all governance assessments highlight various weaknesses in government effectiveness, particularly concerning the quality of public administration and public service delivery, there is a common perception that Mozambique has made significant progress in improving public financial management. The quality of public administration and public service delivery is perceived to be undermined because of the lack of human and financial resources. At the same time, the improvements in public financial management at the level of central administration, in particular with regard to the planning and execution of the state budget, as well as the state audit function, are acknowledged in all assessment reports. Concerning the regulatory framework for the private sector, the perceptions are very similar - and very critical: Mozambique's performance is characterized as very weak or weak in terms of private sector development. While the failure to create an enabling business environment is seen, partly, as a remnant of the period of the central planned economy, it is also seen as a reflection of the lack of political will by those in power, and the general lack of competence to implement necessary reforms.

The seemingly consistent general conclusions about the quality of governance in Mozambique may be explained by various factors. The consistency may indicate that the different 
assessments in fact succeed in capturing essential elements of the "true governance" in Mozambique, which is then reflected in the relatively uniform image portrayed by these assessments. It may also merely reflect the fact that the selected governance assessments tend to draw on the same external data sources. The scores generated through the WGI and the World Bank CPIA, in particular, are often cited as key reference points by the other assessments. In other words, the "beast feeds itself". It can also be argued that the efforts by the international donor community to coordinate and harmonize its aid policies contribute to the harmonized view of the governance situation, irrespective of the specific assessment tool. The only exception to the rule seems to be the Niassa Power Analysis which relies, primarily, on the data collected at country level for the specific purpose of the Analysis. All in all, the tentative general conclusion that be drawn from the results of the eight governance assessments points at a rather uniform perception of the strengths and weaknesses of the quality of governance in Mozambique.

\subsection{Consistency of the Results Based on Quantification}

In this section the question of the consistency of the results of the governance assessments is analyzed more systematically in order to find out whether the common general perceptions hide systematic differences. To this effect, an attempt has been made to quantify and compare results of the governance assessments on the scale of 1 to 6 , based on the method described in section 7.2 of this chapter. To facilitate the quantification and comparison, the results of the assessments are presented in accordance with the six aggregate indicators of the WGI, grouped in three dimensions of governance. The grouping of the issues according to the WGI classification is based on the researcher's subjective interpretation of rich and multi-faceted reports, guided by the definitions that each donor has provided for its own set of indicators. ${ }^{143}$

The quantified results of the seven governance assessments on Mozambique are summarized below in Table 7.7. The classification of the set of issues addressed as Mozambique's governance concerns in the different assessments is based on the researcher's interpretation of the original datasets and assessment reports, apart from the World Bank and the AfDB CPIA where the scores are derived from the datasets provided by the agencies. However, due to the re-grouping of the indicators in accordance with the WGI classification, the average governance scores calculated by the researcher differ

143. The quantification is limited to the results of the WGI, the World Bank and the AfDB CPIA, the Millennium Challenge Scorecard, the Governance Profile, the Country Governance Analysis and the Strategic Governance and Corruption Analysis. As described in the Section 7.2.2, the quantification of the findings of the Power Analysis by SIDA was not considered appropriate in view of its narrow geographic focus, and the largely historical, non-normative approach. 
slightly from the original CPIA averages. The quantification of the qualitative judgments, and the rescaling of the original scores generated by the WGI and the MCC, is done by the researcher.
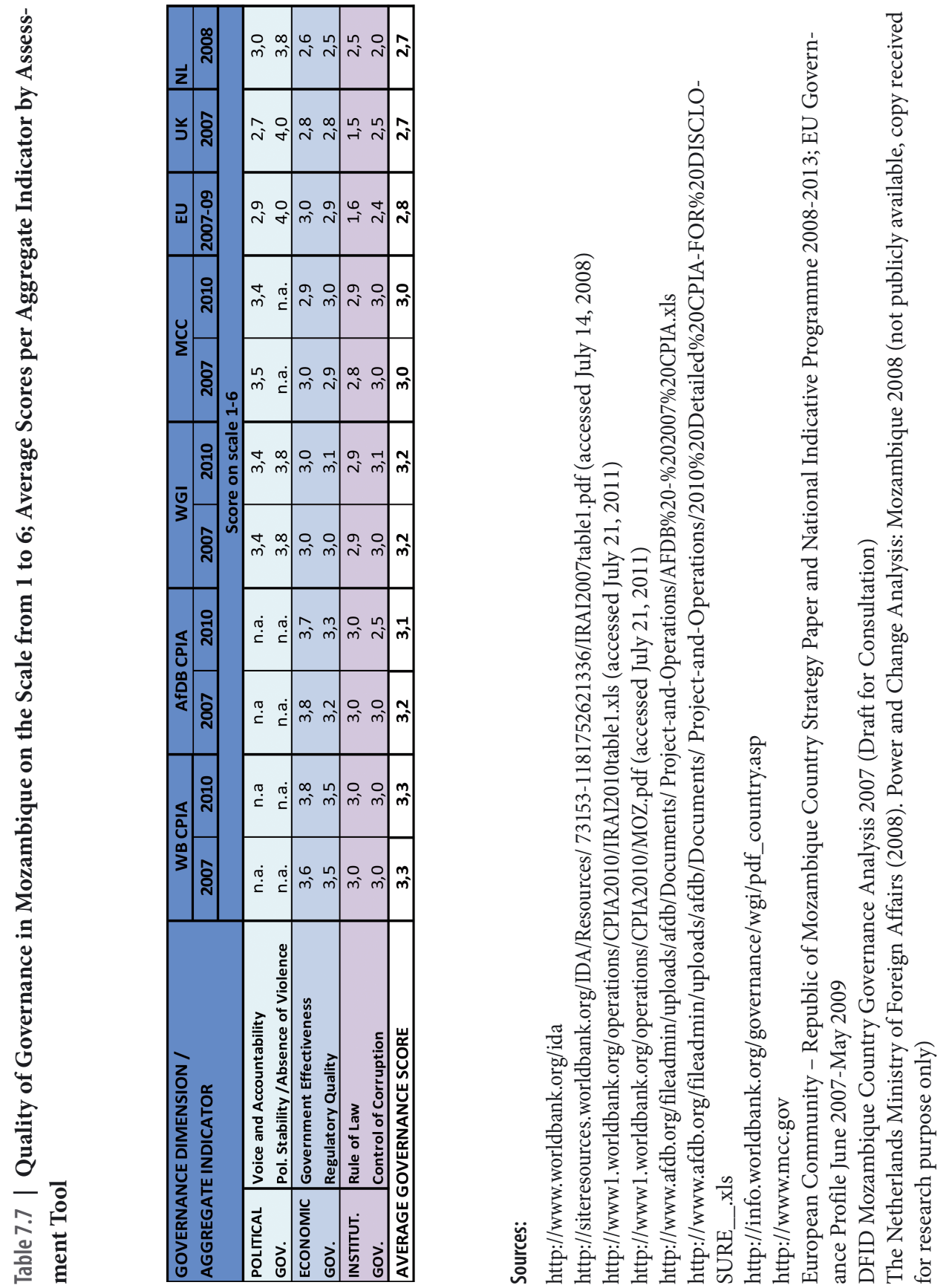
Table 7.8 provides a more detailed overview of the governance landscape in Mozambique as distilled from the different methods for assessing governance there (data sources as listed above). Apart from classifying the issues under the WGI headings of political, economic and institutional governance, the table presents a summary of the results for the set of issues addressed as central governance concerns through different assessment tools, following as closely as possible the original assessment reports by the donor agencies. Using the concepts developed by the OECD DAC Governance Network, the central governance concerns can be considered to be as the focus areas of the different governance assessments (OECD DAC, 2009).

While bearing in mind the problems related to the quantification of the qualitative assessments and the rescaling of the original scores, a number of points can be raised for discussion on the basis of the overviews presented in Tables 7.7 and 7.8.

First, the summary of the quantified results seems to confirm the tentative conclusions, drawn from the initial analysis of the original assessment reports: the perceptions of the main strengths and weaknesses of governance in Mozambique are rather consistent irrespective of the governance assessment tool.

The political dimension of governance, particularly concerning the aggregate indicator on Political Stability and Absence of Violence, appears to be the strongest area of governance in Mozambique, notwithstanding the fact that the political dimension of governance is not explicitly addressed within the CPIA framework. With all the scores above the mid-point of the scale, ranging from 3.8 (WGI in 2007 and 2010; SGACA/ $\mathrm{NL}$ ) to 4.0 (Governance Profile/EU and CGA/UK), indicate that Mozambique is considered a relatively stable partner for cooperation. The successful post-conflict transition, together with the constitutional change from one-party state to a multiparty democracy, are consistently highlighted as the major achievements in all the qualitative assessments, including the Swedish Power Analysis. The perceptions on Voice and Accountability are less consistent with the scores ranging from 2.7 (CGA/UK) to 3.4 (WGI in 2007 and 2010; MCS/MCC in 2007). The lower scores reflect the perceived weaknesses in the consolidation of the constitutional democracy and accountability of the state vis-à-vis the citizens. The scores constructed on the basis of the qualitative assessments seem to be systematically slightly lower than the scores derived from the quantitative assessments. 


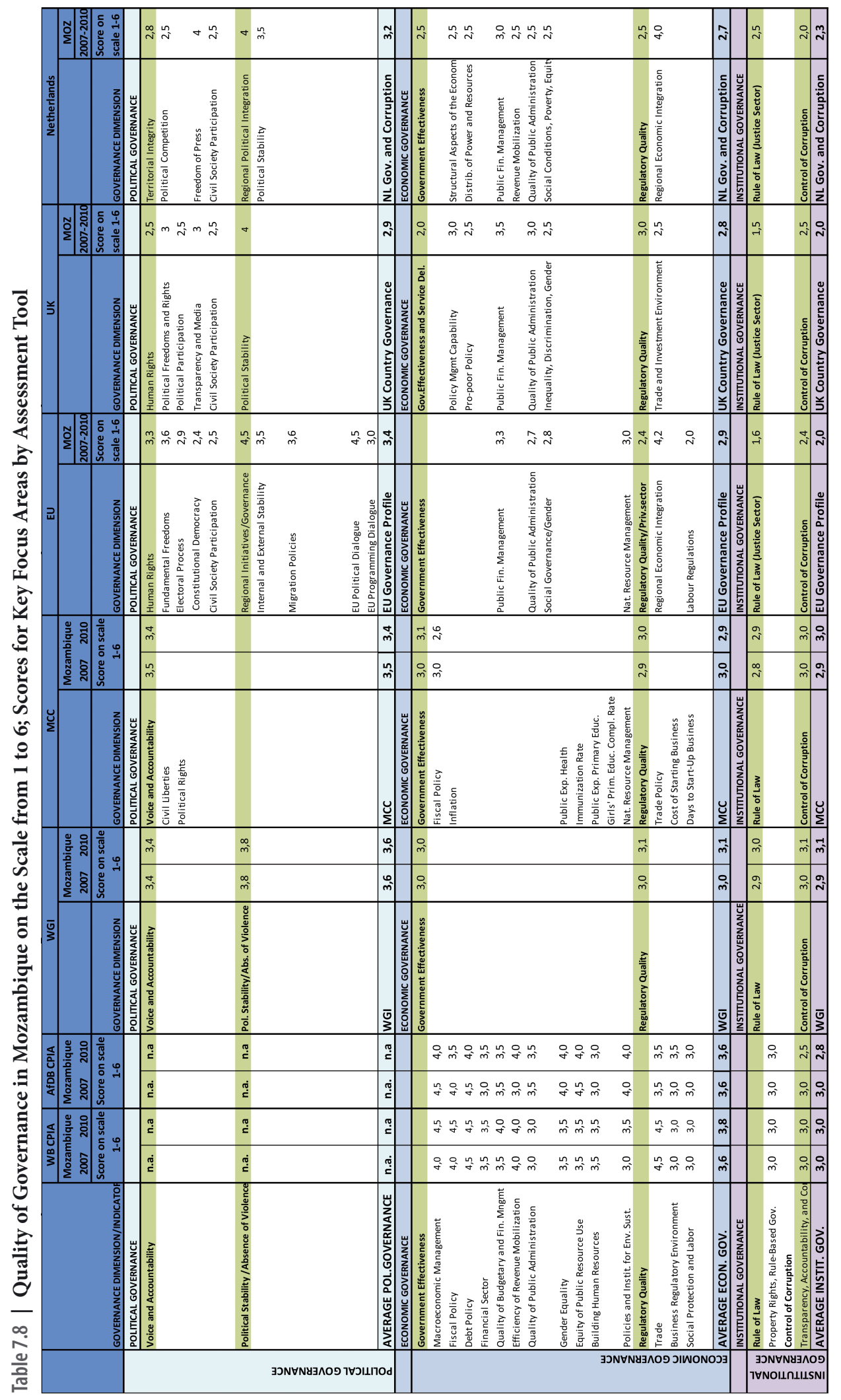


Similarly, consistent with the initial analysis of the outcomes of the assessment tools, institutional governance, captured by the aggregate indicators on the Rule of Law and Control of Corruption, emerges as the weakest area of governance when looking at the scores on a unified scale. Irrespective of the governance assessment tool, Mozambique's scores remain below the mid-point of 3.5 on both of these aggregate indicators. The greatest problems are identified with respect to the Rule of Law where Mozambique's scores range from 1.5 (CGA/UK) and 1.6 (SGACA/NL) to 3.0 (World Bank and AfDB CPIA, in 2007 and 2010). Mozambique's performance is perceived to be equally weak concerning Control of Corruption with scores ranging from 2.0 (SGACA/NL) to 3.1 (WGI 2010). While institutional governance is perceived to be the weakest area in all assessments, the great variation in the scores indicates that the perceptions of the magnitudes of the problems differ significantly depending on the assessment tool. As the Tables 7.6 and 7.8 illustrate, the scores constructed on the basis of the qualitative assessments are systematically lower than those originally presented on a numeric scale. Weaknesses related to the rule of law and the fight against corruption are highlighted as a critical governance concerns in the Swedish Power Analysis also.

As to the two aggregate indicators on economic governance, namely Government Effectiveness and Regulatory Quality, the overall perception emerging from the quantified results appears to be closely consistent with the conclusion based on the initial analysis: Mozambique's performance on economic governance is mixed. For example, with respect to Government Effectiveness, Mozambique is rated at the level of 4.0 and 4.5 on Macro-Economic Management and Debt Policy indicators, whereas its scores remain below the mid-point of 3.5 on the criterion related to the quality of public administration (with the exception of the AfDB CPIA score of 3.5 for both 2007 and 2010). Mozambique's performance is also perceived to be relatively poor concerning social and gender equality. Weaknesses in the government's capacity to provide public services and to promote equality are also highlighted in the Swedish Power Analysis. Concerning the indicators aimed at measuring Regulatory Quality, such as Trade and Regional Economic Integration, Mozambique obtains scores in the range of 3.5 to 4.5, whereas it is perceived to perform poorly on indictors related to the environment for private sector operations.

Second, a closer examination of Mozambique's scores on specific indicators measuring Government Effectiveness and Regulatory Quality, generated by the different assessment tools, points to a number of inconsistencies which are reflected in the average scores on these two aggregate indicators. The above tables show that, on Government Effectiveness, Mozambique's scores range from 2.6 (SGACA/NL) to 3.8 (World Bank CPIA, in 2010; AfDB in 2007), and on Regulatory Quality from 2.5 (SGACA/ NL) to 3.5 (World Bank CPIA, in 2007 and 2010). In view of the World Bank and the AfDB CPIA, Mozambique is perceived to perform relatively well on Government 
Effectiveness, with scores above the mid-point of the scale, whereas through the lenses of the rest of the assessment tools Mozambique's performance remains below the midpoint. The qualitative assessments conducted by the UK and the Netherlands arrive at the most critical judgments of the government's effectiveness, with scores of 2.8 and 2.7 respectively. Similar differences can be identified in the perceptions on Mozambique's Regulatory Quality with scores ranging from 2.5 (SGACA/NL) to 3.5 (World Bank CPIA). While the World Bank CPIA scores reach the mid-point of 3.5 (in 2007 and 2010), the scores generated through all the other assessment tools - including those of the AfDB - remain below the mid-point. On the basis of the comparison of the quantified results, the greatest variation in the perceptions on Mozambique's performance can thus be identified in the field of economic governance.

Third, looking at the changes in Mozambique's quality governance between 2007 and 2010, as portrayed through the scores of the World Bank and AfDB CPIA, the WGI and the MCS, which provide data for both years, the perceptions of the trends seem to be rather consistent with little variation between the years. However, a closer look at the scores on specific indicators shows several inconsistencies within the same year, and between the two years under consideration. The most notable difference relates to the aggregate indicator on Control of Corruption where the AfDB score falls from 3.0 in 2007 to 2.5 in 2010 while the World Bank CPIA score remains unchanged. In light of the banks' identical definition of the ranking levels 2 and 3 respectively, this change can be interpreted as somewhat significant. Some inconsistencies can be identified in the perceptions of the direction of the change on specific aggregate indictors but, by and large, scores either change in tandem or remain unchanged. The stable picture of the governance landscape is also reflected in the average scores for 2007 and 2010.

The fourth tentative conclusion than can be drawn from the quantified results relates to the seemingly systematic difference between the outcomes of the quantitative and qualitative assessments. The quantitative assessments seem to paint a more positive image of Mozambique's governance performance than the qualitative assessments, with the World Bank CPIA generating the highest overall score. The qualitative assessments conducted by the EU, UK, the Netherlands and Sweden arrive, in general, at more critical perceptions about Mozambique's governance performance, and identify serious concerns in some specific areas of governance such as the Rule of Law and Control of Corruption. Furthermore, the quantitative assessments seem to provide a more uniform image with very little variation in the scores on the six aggregate indicators, whereas the scores generated from the qualitative assessments point to more significant differences in perceptions on Mozambique's performance in these six areas of governance. 
Although the results of the Swedish Power Analysis are not included in the quantified summary, the conclusions derived from the original assessment report are rather similar to those of the other qualitative assessments. The most significant difference between the results of the Swedish Power Analysis and the rest of the qualitative assessments relates to the perceived trend in Mozambique's political governance: while the other assessments highlight challenges with respect to the consolidation of the democratic principles, the Power Analysis depicts signs of change towards more vertical and democratic distribution of power, albeit with contradictory tendencies.

The emerging systematic differences between the quantitative and qualitative assessments may, of course, have resulted from the process of interpreting and quantifying the qualitative statements by the researcher rather than reflect differences in perceptions. Yet, the qualitative statements such as "very weak", "poor", "weak" etc. do correspond to the low scores on the scale from 1 to 6 without leaving much room for subjective interpretation. I would argue that there are other factors which contribute to the seemingly systematic differences between the outcomes of the quantitative and qualitative assessments. These are likely to include the differences in the conceptual approach, stated purpose and focus of a specific assessment tool as well as in the methodological choices made in conducting assessment. In addition, the participation - or lack of participation - of local stakeholders may be one factor underlying the different perceptions of governance emerging from the assessments. The next section will explore these factors in more detail.

\subsection{Inconsistencies in the Assessment Results; An Attempt of Explanation}

In view of the results of the selected governance assessments on Mozambique, it appears that the conceptual approach underlying a specific assessment tool impacts upon not only the focus of the assessment, but also on the general image of the quality of governance generated through the given tool. As discussed earlier, the conceptual approach determines, to a large extent, the focus and the choice of the set of specific issues included in each assessment. In light of the above overviews, the perspective through which governance is addressed seems to impact upon the overall perceptions on the quality of governance. The qualitative assessments conducted by the EU, UK, the Netherlands and Sweden, all of which approach governance through political economy and power perspectives highlighting political issues as the core component of governance, seem to arrive at more critical conclusions than do the World Bank and the AfDB CPIAs which exclude this dimension. As illustrated in the above Tables 7.7 and 7.8, Mozambique is perceived to perform best on all indicators through the lenses 
of the World Bank and the AfDB which explicitly exclude issues related to political dimension of governance. Even corruption, which is considered to be one of the key indicators of the quality of governance irrespective of the assessment tool, seems to be given more weight in the qualitative assessments building on political economy and power analyses.

The stated purpose of a specific governance assessment is arguably an even more important factor contributing to the differences in the outcomes of these assessments. As has been discussed in Chapter 6, the results of the CPIA conducted by the World Bank and the AfDB as well as of the Millennium Challenge Scorecard, have a direct impact on the amount of aid allocated to a specific country. The country-specific CPIA ratings determine the relative size of the Banks' financing to low-income countries, whereas in the case of the MCC the eligibility of a given country to receive any assistance is de facto determined by its scores. In contrast, while the EU, the UK, the Netherlands and Sweden use the results of their assessments for aid programming and policy dialogue, they explicitly state that the results are not directly linked to decisions on the volume of aid.

Therefore it could be argued that the governance assessments, which automatically trigger fundamental decisions concerning aid tend to arrive at more subtle findings so as to secure the continuation of aid flows, while the more indirect link between the assessment results and the aid relationship allows for more critical views on the governance situation. In the end, it seems to be in the interest of the donor agencies to maintain the status quo in terms of their aid flows despite their rhetoric on the need to reduce Mozambique's aid dependency. Pressures to disburse the budgeted ODA funds are common among many donor agencies, and in some agencies the rate of the disbursements is interpreted as an indication of successful programme implementation.

Methodological choices appear to explain some of the differences in the governance perceptions on Mozambique. In light of the above overviews, qualitative analysis involving the use of local expertise and reliance on local data sources, such as community and household level assessments, seem to result in more critical perceptions of the governance situation. As has been described in Chapter 6, in the case of the Governance Profile/EU, the CGA/UK, the SGACA/NL and the Power Analysis/Sweden, there is an explicit emphasis on the importance of using also Mozambican data sources, including data produced by CSOs.

The level of participation by the Mozambican stakeholders in the governance assessments is also likely to influence the perceptions on the quality of governance. The involvement of partner country stakeholders in the design and implementation of the assessments, whether government authorities, private sector or civil society actors, 
determines the extent to which the focus of an assessment is fine-tuned to capture country-specific issues of governance. It also impacts upon the extent of the use of locally generated data sources and local expertise in conducting the assessment. On the basis of the above comparison, the governance assessments carried out by the WGI, the World Bank, the AfDB, and the MCC, based on globally standardized approaches with standardized reporting formats and reliance on external expertise, seem to arrive at more positive perceptions of governance. It may be argued that, due to the standardized approaches, these assessments fail to capture some of the governance concerns specific to the reality in Mozambique. The qualitative assessments of the UK, the Netherlands and Sweden, and to a lesser degree that of the EU, which are designed and conducted taking into account the local context, may be better tuned to identifying the complexities of the governance situation in the country.

Finally, the decision whether the final outcome of a specific governance assessment is shared with the Government of Mozambique and local non-state actors is likely to impact upon the reported perceptions. In view of the above comparison, it can be argued that the relatively easy access to and availability of the reports of the governance assessments, such as the reports by the World Bank, the AfDB, the WGI and the MCC, is likely to portray more favourable perceptions of the governance situation, whereas the reports that are shared in only "if appropriate" tend to contain more critical findings.

The above cautious explanations of the differences in the outcomes of the governance assessments can, to some extent, be traced to the discourses on the theoretical foundations of governance assessments and the effectiveness of donor interventions. The main value of the findings lies, however, in their potential relevance for aid agencies designing and conducting governance assessments and, therefore, these tentative explanations merit further investigation.

\subsection{Consistency of the Results of Governance Assessments - Concluding Remarks}

The image of the quality of governance in Mozambique portrayed by the selected donor governance assessments is relatively uniform yet nuanced. First, irrespective of the assessment tool, the perceptions about the main strengths and weaknesses in the quality of governance in Mozambique are very consistent. Mozambique is perceived to be politically stable, albeit with challenges related to the consolidation of democratic governance and to the respect of the fundamental freedoms enshrined in the Constitution. The economic governance of the country is characterized by both achievements 
and weaknesses: on one hand the government is perceived to perform relatively well with respect to the implementation of macro-economic policies and public financial management, and on the other the government's effectiveness in public administration, service delivery and creation of an enabling environment for private sector development is perceived to remain poor. In light of all the assessments, Mozambique faces its greatest challenges with regard to the institutional dimension of governance. Its performance is weak or even very weak regarding respect for the rule of law and fight against corruption which are considered to be the two key elements related to institutional governance.

Second, the above analysis indicates that the overall consistency of the results hides several somewhat significant differences in perceptions on the quality of governance in certain areas, as well as on the magnitude of the challenges confronted by Mozambique in these areas. Hence, while the results are very uniform concerning political stability in Mozambique, the perceptions vary notably concerning Mozambique's performance on indicators related to economic and institutional governance. For example, the scores derived from the qualitative assessments on issues such as the rule of law and corruption are significantly more critical than those generated through the quantitative assessments.

Third, in view of the above analysis, the perceptions on the changes and trends in Mozambique's governance performance are rather consistent. The assessment results of the WGI, the World Bank and AfDB CPIAs, and of the MCC showed little - if any variation between the two years included in the analysis. The most notable difference emerges when comparing the results of the quantitative and qualitative assessments, in particular, concerning political governance: while the quantitative assessments either exclude this dimension from their analysis, or fail to identify any changes, most of the qualitative assessments point to increasing challenges in the field of political governance. The only assessment which provides a slightly more optimistic outlook is the Swedish Power Analysis.

Fourth, methodological choices seem to contribute to systematic difference between the outcomes of the assessments. The quantitative assessments tend to portray a more positive and a more uniform image of Mozambique's governance performance than the qualitative assessments. The qualitative assessments conducted by the EU, the UK, the Netherlands and Sweden arrive at more critical perceptions on the quality of governance both at general level and at the level of specific areas of governance.

Finally, concerning the perceptions of Mozambique' performance relative to the SADC low-income countries, the assessment results are very consistent: Mozambique is perceived to perform better than - or at least at the same level of -its peer group on all 
the six aggregate indicators, irrespective of the assessment tool. Also the perceptions of the changes in the different areas of governance in Mozambique and in the SADC LICs are, by and large, very similar.

In conclusion, despite the different conceptual basis, purpose, focus and methodology for conducting the governance assessments, and the different level of the involvement of Mozambican stakeholders in these assessments, the results of the eight assessments under consideration in this research point to relatively consistent perceptions of the quality of governance in the country. At the same time, the analysis of the results generated by different assessments point to a number of factors which contribute to the variations and inconsistencies identified. The most important factor appears to be the choice of methodology: qualitative assessments adapted to the Mozambican context and conducted with greater reliance on locally generated data and local expertise tend to arrive at more critical perceptions of governance than quantitative assessments based on a globally standardized "one size fits all" approach to assessing governance. 


\section{Donor Governance Assessments: Mozambican Perceptions}

The analysis in the previous chapter of the results of the selected governance assessments indicates that the donor perceptions of the quality of governance in Mozambique are, by and large, consistent irrespective of the assessment tool. The question whether the consistency of the outcomes indicates that the assessments succeed in capturing the "true governance" in Mozambique, or whether the consistency merely reflects the fact that many of the assessments rely on same data sources and frequently cite each other without further triangulation of data, cannot be fully answered within the scope of this research. However, in view of the operational implications of the assessment results, the uniform image of governance portrayed by the donor assessments renders the research questions related to the Mozambican perceptions about the relevance and impact of the donor assessments even more important.

Against this background, the purpose of this chapter is to seek answers to the two remaining research questions set out in the Introduction:

- Are the governance assessments perceived by the Mozambican stakeholders as succeeding in addressing governance issues that are considered relevant in the specific governance context of Mozambique?

- Are the governance assessments perceived as contributing to improved governance in Mozambique?

In order to answer these questions, a field study was conducted in Mozambique. The primary purpose of the field work was to collect data on the perceptions by Mozambican stakeholders about the relevance of the donor governance assessments and their potential impact on improving governance in the specific context of Mozambique. The field study further aimed to shed light on the question concerning the participation of local stakeholders in donor governance assessments. In addition to Mozambican stakeholders, representatives of donor agencies conducting governance assessments were interviewed with the objective of complementing the desk analysis of these assessments.

The chapter starts with a discussion of the methods for collecting data, selecting respondents to be interviewed, and for analyzing the data generated though the field study. The second section focuses on the question of the perceived relevance of the donor governance assessments and the third section looks at the question of the impact of the assessments from the local stakeholders' point of view. The last section of the chapter presents the tentative conclusions based on the field study. 


\subsection{Field Study}

\subsubsection{Data Collection}

The field study was carried out over the period of 2010 - 2012. I started the field work during my two visits to Mozambique in 2010, and completed the work in 20112012 when I was based in the country for a period of 12 months. The field study was conducted by using the methods of semi-structured interviews with 28 Mozambican and 11 donor key informants as well as 8 focus groups involving 58 participants. The category of key informants thus comprised representatives of both local stakeholder groups and donor agencies. The focus group interviews involved only Mozambicans, primarily family farmers, informal sector micro-entrepreneurs and community-level civil society actors.

The main groups of local stakeholders were identified following the UNDP's definition of the key actors involved in governance in a country-specific context: the government, the private sector and civil society (UNDP, 1997). This approach is shared by most other multilateral and bilateral donor agencies which emphasize, increasingly, the importance of the participation of the private sector and civil society, along with the government, in addressing governance concerns of a given country. Based on this, the following six Mozambican stakeholder groups were identified for the purpose of this research:

- Members of Parliament (MP)

- Senior Civil Servants in Public Administration (SCS)

- Private Sector Actors (PS) ${ }^{144}$

- Media (MED)

- Academia (ACA) ${ }^{145}$

- Civil Society Organizations (CSO $)^{146}$

It needs to be pointed out that the above stakeholder groups overlap and individuals are often associated with several groups simultaneously. In the case of Mozambique, Members of Parliament and Senior Civil Servants are often also engaged in teaching, and so can also be closely linked with the academia. Similarly, civil society actors often play an

144. Includes representatives from large formal sector enterprises to informal sector microentrepreneurs.

145. Includes academic staff employed by universities, research institutions and independent researchers.

146. Civil society consists of many different actors from small informal activist group to big institutionalised organizations. In this chapter, civil society organization (CSO) is used as a concept to cover those actors and groups that are registered in Mozambique. Most of the CSOs receive external funding for their programmes even if the management of the organizations are fully Mozambican. 
important role in the media as reporters and commentators. Through consultancy assignments, many civil society actors have personal experience also from the private sector.

The respondents in each stakeholder group were selected on the basis of their involvement in governance discourse in Mozambique through their specific professional role in society or through their relations with donor agencies. The respondents are thus considered expert sources of information, or in other words "key informants", ${ }^{147}$ concerning donor governance assessments. According to the literature, the key informant interview is used as "a technique of collecting information on a social setting by interviewing a selected number of participants. The informants are chosen not on a random basis but because they possess special qualifications such as particular status, specialized knowledge, or accessibility to the researcher" (Phillips and Bagozzi, 1986, p. 313). In the case of this research, the principal criteria for selecting key informants was their "specialized knowledge" of, and "status", in governance discourse in Mozambique. Having lived in Mozambique for several years and having worked in different positions, I had developed a relatively extensive social network which facilitated the identification of respondents who met the criteria of a key informant. Apart from few exceptions, the key informants interviewed for the research were not my personal friends or colleagues. In all, 28 key informant interviews were conducted with Mozambican stakeholders.

The breakdown of the key informants by stakeholder groups is presented in Table 8.1 below:

Table 8.1 | Breakdown of the Respondents: Key Informants

\begin{tabular}{|l|c|c|c|c|c|}
\hline \multirow{2}{*}{ Stakeholder Group } & \multirow{2}{*}{$\begin{array}{c}\text { Number of } \\
\text { Informants }\end{array}$} & \multicolumn{2}{|c|}{ Gender } & \multicolumn{2}{c|}{ Locality } \\
\cline { 4 - 6 } & & M & F & Urban & Rural \\
\hline Members of Parliament & 3 & 2 & 1 & Maputo & \\
\hline Senior Civil Servants & 5 & 3 & 2 & Maputo & \\
\hline Private Sector & 5 & 3 & 2 & Maputo, Pemba, National & Pemba, Mocuba \\
\hline Media & 3 & 2 & 1 & Maputo, National & \\
\hline Academia & 4 & 2 & 2 & Maputo, National & \\
\hline The Civil Society/NG0s & 8 & 5 & 3 & Maputo, Pemba & Pemba, Mocuba \\
\hline TOTAL & 28 & 17 & 11 & & \\
\hline
\end{tabular}

${ }^{1}$ The respondents were not asked to provide information on their level of education or socio-economic status due to the potential sensitivities related to these questions.

147. Characteristics of an "ideal" key informant include the following: Role in community, Knowledge, Willingness, Communicability, Impartiality. 
As the above breakdown of the key informants shows, the respondents affiliated with civil society organizations are overrepresented in comparison with other stakeholder groups. I would argue that the overrepresentation of civil society actors is justified as they work closely with local communities. They are, therefore, more likely to be in a better position to transmit the "ordinary" Mozambican citizens' views and perceptions about the relevance and impact of the donor governance assessments than are senior civil servants, members of academia and Members of Parliament who, in the Mozambican context, form part of the elite of the society.

The data obtained through key informant interviews was complemented by conducting "focus group interviews and discussions", which can be defined as "carefully planned discussions designed to obtain perceptions in a defined area of interest in a permissive, non-threatening environment" (Kreuger, 1994, p. 6). Focus groups are considered useful for learning about participants' conceptualisations of particular phenomena and the language they use to describe them (Stewart and Shamdasani, 1990, p.15). For the purpose of this research, the focus group discussion method was primarily used for collecting data among those members of community and grass root organizations who are not necessarily familiar with the donor governance assessments but take part in governance discourse in their own locality.

The focus groups were selected on the basis of their roles as interlocutors, in their specific field of activity, between the local government authorities and their constituencies. The focus groups included in the research represented professional associations in rural and semi-urban areas, such as peasants' organizations and informal sector micro-entrepreneurs' associations, as well as interest groups such as women's organizations. The concentration on family sector farmers and informal sector micro-entrepreneurs is, in my view, justified by the fact that family sector farming provides the livelihood for some $75-80 \%$ of the Mozambican population, and the informal sector accounts for the bulk of non-agricultural jobs. An attempt was made to include women in the focus groups. In the identification of the focus groups and in setting up of the group discussions, I was assisted by colleagues affiliated with a Finnish non-governmental organization based in Mozambique. In some cases, they attended the focus group discussions as observers, and to some extent, as facilitators. In all, 8 focus group interviews/discussions were conducted involving 58 discussants. Each focus group consisted of the people from a given field of activity. The groups varied in size from 3 to 13 people. The focus group discussions with several discussants lasted from one hour to two hours whereas the discussions with three discussants lasted on average one hour or less.

The breakdown of the focus groups by affiliation is presented in Table 8.2 below: 
Table 8.2 | Breakdown of the Respondents: Focus Groups

\begin{tabular}{|l|c|c|c|c|}
\hline \multicolumn{1}{|c|}{ Focus Groups } & \multirow{2}{*}{$\begin{array}{c}\text { Number of } \\
\text { Respondents }\end{array}$} & \multicolumn{2}{c|}{ Gender } & \multirow{2}{*}{ Locality } \\
\cline { 3 - 4 } & & M & F & \\
\hline 1. Provincial Peasants' Association & 13 & 7 & 6 & Pemba \\
\hline 2. Mozambique Debt Group and Women's Group & 7 & 3 & 4 & Pemba \\
\hline 3. Provincial Forum for CS0s & 3 & 1 & 2 & Pemba \\
\hline 4. Environmental Association & 3 & 2 & 1 & Pemba \\
\hline 5. Association of Informal Sector Traders & 9 & 5 & 4 & Pemba \\
\hline 6. Various civil society actors incl. media & 11 & 7 & 4 & Mocuba \\
\hline 7. Farmers'Union & 9 & 3 & 6 & Mocuba \\
\hline 8. Association of Informal Sector Artisans/Traders & 3 & 1 & 2 & Maputo \\
\hline TOTAL & 58 & 29 & 29 & \\
\hline
\end{tabular}

While respecting the anonymity of the focus group discussants, the key characteristics of the selected focus groups are summarized below. Starting from the focus groups in Pemba:

The Provincial Peasants' Association (União Provincial dos Camponeses, UPC) represents family sector farmers in Cabo Delgado and aims at promoting agricultural production, productivity and access to markets. Farmers belonging to the Association are formally registered members. The Association is the provincial arm of the National Union of Peasants, which was established in 1987 to represent the family sector farmers and promote their political, economic and social rights at the national level.

Mozambican Debt Group (Grupo Moçambicano da Divida, GMD) is the provincial arm of the national Mozambique Debt Group. The Group identifies itself as an alliance which brings together civil society organizations, academic institutions and individual members. Established after Mozambique's access to the HIPC debt relief programme (1996-97), it first focused primarily on debt issues. Its thematic areas of interest have expanded to cover wider governance questions such as monitoring the implementation of Government's poverty reduction strategy (PARPA), public financial management and state-civil society relationship. GMD also serves as a forum for dialogue between the Government of Mozambique, civil society and the donors.

The Women's Forum is the local member of the national forum of women's organizations, Forum Mulher. Forum Mulher was established in 1993 with the objective of bringing together various groups, associations and organizations that work for gender 
equality and rights of women. The participation in the Women's Group does not require formal registration and is open to both women and men.

The Provincial Forum for Civil Society Organization in Cabo Delgado Province was founded as a CSO network in 1998. The aim of the Forum is to coordinate and improve the efforts of the different CSOs in the province and thereby enhance the role of civil society. The programme of work of the Forum is largely determined by the programmes of its member organizations. At present, the Forum has 55 member associations and organizations the majority of which (47) are Mozambican.

The Environmental Association was established in 1990 in Pemba to work, initially, in the field of environmental protection. The membership in the association is based on individual members with a wide range of educational and professional background. The Environmental Association is a member of the Provincial Forum for Civil Society Organizations in Cabo Delgado Province, and through this membership its field of work has expanded beyond environmental issues and covers now wider governance concerns in the province.

The Associations of Informal Sector Traders in Pemba belongs to a nation-wide organization of market vendors, hawkers and informal sector workers, established at the national level in 1999. The Association is an affiliate of the national trade union federation, the Organization of Mozambican Workers (OTM). The members of the Association pay a monthly fee for the services provided by the Association. One of the main initiatives of the Association has been to establish market committees in the town marketplaces. The committees collect fees from stallholders and provide basic infrastructure such as water and toilets, carry out maintenance work, organize cleaning, security, and access to selling space, and solve labour conflicts.

The nature and composition of the two focus groups interviewed in Mocuba differ significantly from those in Pemba. The groups were not very formally established organizations or associations but more loosely connected groups of individuals with different professional background and affiliations of their own. One of the groups included civil society actors affiliated with various local organizations, involved, mainly in agriculture, community training and media (community radio). The second focus group discussion involved a small group of family farmers who had organized themselves into a small producers' association albeit not a formally constituted association.

The focus group in Maputo included informal sector artisans and handicraft vendors who belong to an association that was created with the establishment of a market space, FEIMA, for small scale handicraft artisans. FEIMA has a formal administration which provides for a fenced-in, protected area with basic infrastructure such as water 
and sanitation, security, and to some extent, covered market stalls. The members of FEIMA pay a fee for the services provided by the Association. Prior to the establishment of FEIMA, the artisans worked from home and sold their products themselves as street or market vendors or through intermediaries.

In addition to the local stakeholder groups, representatives of the donor agencies, whose governance assessments are under consideration in this research, were interviewed. The objective of interviewing this group of respondents was to triangulate and complement the information obtained through written documentation and internet-based data sources. In addition, representatives of donor agencies that had played a central role in the donor community concerning the governance discourse as chairs of the G19, the general budget support donor, were selected for the interviews. Accordingly, the following donor representatives were interviewed (listed in the order of the volume of aid to Mozambique):

Table 8.3 | Breakdown of Respondents: Donor Agencies

\begin{tabular}{|l|c|c|c|}
\hline Donor Agency & Governance Assessment & $\begin{array}{c}\text { No of } \\
\text { Interviewees }\end{array}$ & Locality \\
\hline World Bank & CPIA & 1 & Maputo \\
\hline AfDB & CPIA & 1 & Maputo \\
\hline European Union & Governance Initiative & 1 & Maputo \\
\hline USA (USAID) & MCC & 1 & Maputo \\
\hline Sweden & Power Analysis & 2 & Maputo \\
\hline NL & SCAGA & 1 & Maputo \\
\hline UK & Drivers of Change & 2 & Maputo \\
\hline Chair of the GBS Group 2009-10149 & GBS Performance Assessment & 1 & Maputo \\
\hline Chair of the GBS Group 2008-09150 & GBS Performance Assessment & 1 & Maputo \\
\hline TOTAL & & 11 & \\
\hline
\end{tabular}

${ }^{1}$ The breakdown by gender not indicated in order to protect anonymity of the interviewees. In all, three of the key informants were female.

As mentioned above, the different categories of respondents, namely the key informants, focus groups and donor representatives, were interviewed following the methods of semi-structured interviews and focus group discussions. Interview guides were designed by the author for the three groups. In the case of the two categories of local

148. Interviewed in its capacity as the Chair of the General Budget Support donors (2009-10)

149. Interviewed in its capacity as the Chair of the General Budget Support donors (2008-09) 
informants, the interview guides were very similar addressing, by and large, the same set of questions. However, assuming that the key informants and the participants in the focus group interviews/discussions have different levels of knowledge of governance assessments in general, and of the donor governance assessments in particular, the interview guides were tailored somewhat according to the characteristics of the two main groups of respondents. Accordingly, the interviews with the key informants focused more directly on questions related to donor governance assessments, whereas the focus group interviews addressed the topic from a broader perspective on assessing governance. The interview guide used for the local stakeholder groups is annexed (Annex 2). As the interviews were carried out as semi-structured interviews, the guides were not meant to be used as a rigid tool but rather as guidance to ensure that a similar same set of issues was raised in all interviews.

The interviews with the key informants were structured around the following five main themes:

1. Meanings of governance in the context of Mozambique;

2. Knowledge of donor governance assessments;

3. Relevance of the issues addressed in donor governance assessments in of view of the respondents' perceptions of the governance context in Mozambique;

4. Local participation in donor governance assessments;

5. Perceptions of the impact of donor governance assessments in improving governance in Mozambique.

Each question consisted of a set of more specific questions related to the main topic of interest so as to generate data for answering the research questions related to the relevance and impact of donor assessments as perceived from the Mozambican perspective. The purpose of the first question was to provide information on how the notion of governance is understood by different stakeholder groups in Mozambique and, thereby, to feed into the analysis of whether the donor governance assessments succeed in addressing issues which are considered central governance concerns in the country. The second set of questions on the respondents' knowledge of governance assessments aimed, firstly, to explore their familiarity with the specific donor assessments included in the study, and secondly, to provide information on the availability and dissemination of results of the governance assessments. The third set of questions addressed directly the relevance of the donor governance assessments from the Mozambican perspective. The question of relevance was approached from two angles: first, whether the donor governance assessments are perceived to capture governance issues which are considered important in the Mozambican context; and second, what are perceived to be the most pressing governance challenges from the perspective of the Mozambican stakeholders. The purpose of the fourth and fifth question was to seek information, respectively, on the respondents' views about local participation 
in donor governance assessments, and their perceptions about the impact of these assessments on improving governance in Mozambique. The interviews ended with an open question to allow the respondents to raise question or provide any additional information.

The focus group interviews were guided, for the most part, by a similar set of questions. However, the interviews did not concentrate explicitly on governance assessments carried out by donor agencies, but addressed the questions of the relevance and impact of governance assessments in more general terms, including assessments conducted by national or local actors. Furthermore, in the focus groups more attention was paid to the respondents' interpretation of the notion of governance and the meaning of "good" or "bad" governance in the Mozambican context as, following my own assumption, these rather vague and abstract concepts may be understood very differently by people who are not so closely involved in governance discourse with the donor agencies as the key informants.

Concerning the interviews with the representatives of the selected donor agencies, the focus of the discussions was on the governance assessments conducted by each agency. The main purpose of the interviews was to complement the desk analysis of the assessment tools. The interview guide for the donor interviews was designed following the structure of the desk analysis of the donor assessment tools (Chapter 6). Hence, the key questions addressed in the interviews with donor representatives concerned the rationale ("why"), the focus ("what") and the methodology ("how") of the governance assessment of each agency. The questions of the involvement of local stakeholders ("ownership") and dissemination of the results of the assessments were also raised. Furthermore, the informants were invited to express their views as to how their governance assessments could be improved. An interview guide formulated to structure the interviews of donor agencies is annexed (Annex 3). Again, the interview guide was not used as a rigid tool but rather to ensure that a similar set of issues was covered in all interviews.

The key informant and focus group interviews among the local stakeholders took place in different localities in three geographic regions of the country (south, centre and north), including urban, rural and semi-urban areas. One interview was conducted via "Skype". Each interview or focus group discussion lasted from one hour to two hours. The interviews with the focus groups tended to last slightly longer. The interviews with donor representatives were all conducted in Maputo where all the agencies have their headquarters.

The interviews with the local stakeholders were conducted in Portuguese apart from few exceptions, and subject to permission by the interviewees, recorded. It is worth 
noting that while the recording of the interviews and focus group discussions was permitted in all cases, in some cases the recording was not possible for other reasons (discussants speaking very quietly, lot of background noise such as laughter in the group, interview via Skype, etc.). The interviews with donor representatives were carried out mainly in English and recorded apart from two interviews where the recording was not permitted by the interviewees. All taped interviews have been transcribed by the researcher or by research assistants hired for this purpose. Translations to English, as well as the identification of the key messages distilled from the interviews, are based on the researcher's interpretation of what was said by the respondents. In addition to the interviews, field notes were taken by the researcher during all the interviews and focus group discussions. All interviews and focus group discussions were carried out on the understanding that the anonymity of the individual respondents will be respected. The recordings and transcriptions can be provided upon request.

\subsubsection{Data Analysis}

The main body of the data consists of a total of 28 key informant interviews, 8 focus group discussions involving 58 participants with Mozambican stakeholders, and 11 interviews with representatives of donors involved in the governance assessments. The taped and transcribed interviews amount to some 350 pages of text. The data gathered through semi-structured interviews were complemented by information obtained through newspapers and other media, as well as through informal, non-structured discussions on topics related to the research questions.

The method used for analyzing the interview data is content analysis, which constitutes one of the basic approaches to data analysis in the tradition of qualitative research. In the case of this research, content analysis is used as a method for the systematic qualitative analysis of the data gathered through the interviews with Mozambican stakeholders and donor representatives. While the analysis is based on empirical data, the process is supported by the concepts derived from the governance discourse which have guided the organization and classification of the data. In other words, the approach to data analysis follows the tradition of a theory-guided approach that "allows the data to speak", but links the data with what is already known of the phenomena of interest.

Data analysis in qualitative research consists of organizing the data for analysis, then reducing the data into themes through classification and interpretation and finally representing the findings. Miles and Huberman (1994) classify the process of data analysis into three broad phases which include reducing, clustering and conceptualizing the data. The process of data analysis applied in this research followed the description by Creswell (2013, p. 182-188), consisting of the following mains steps: 
1. careful listening and transcription of the interviews

2. preliminary reading of the transcribed material and preliminary familiarization with the material

3. organization, classification and interpretation of the data into themes

4. representation of the findings

As pointed out by Creswell, the steps or the phases of the process vary according to the specific method of analysis. In general, data collection, data analysis and report writing are interrelated. According to Creswell, the process can be characterized as a "data analysis spiral" in which "the researcher engages in the process of moving in analytic circles rather than using a fixed linear approach" (Creswell, 2013, p. 182).

In this research, the preliminary organization and classification of the data was done on the basis of the interview guides, following the first steps of studying the field notes, repeated listening and transcribing the interviews. Further categorization of data and the development of themes and subthemes emerging from the data were guided by the concepts applied in the analysis of the donor governance assessments in previous chapters. These concepts were also used to support the interpretation of the data obtained through the interviews. Of particular importance for the data analysis were the conceptual frameworks formulated by the Worldwide Governance Indicators (WGI) and the OECD DAC Governance Network, which have been applied in Chapter 6 (Overview of Governance Assessment Tools) and Chapter 7 (Analysis of the Outcomes of the Donor Governance Assessments).

The data analysis relies on extensive use of citations from the interviews, which provide the basis for drawing preliminary conclusions concerning the research questions on relevance and impact of donor governance assessments. The citations are used, primarily, to enhance the understanding of the Mozambican perceptions of the purpose of the governance assessments, their focus and methodological approach in the specific case of Mozambique. The citations from the interviews with donors are used to identify areas which, from the donor perspective, require revisiting. Respecting the confidentiality of the interviews, the respondents are not identified even in case of direct quotations.

As the selection of the respondents for this research was purposive rather than random, the data do not allow any statistically representative generalizations. It must, furthermore, be pointed out that although the set of questions presented to both key informants and focus groups were rather identical, the respondents approached these questions differently depending on their socio-economic status, rural/urban origin, educational background, familiarity with the governance discourse etc. It is also important to bear in mind the different dynamics of the key informant interviews and 
focus group discussions. In key informant interviews the interviewer can guide the discussion more closely and keep it focused on the main themes having thus more control of the interview. In focus group discussions the participants interact with each other taking into account the views of other discussants, while the role of the interviewer is to encourage and moderate the discussion along the main themes (Kitzinger, 1995). The data generated through the key informant interviews and focus group discussions are, therefore, not fully comparable but should rather be seen as complementary data sources (Pietilä, 2010). With regard to the focus group discussions, it is worth noting that the discussants' participation in the debates was generally very active, which meant that the role of the facilitator was limited to guiding the discussions and ensuring that the main topics of the discussions were addressed. While in some mixed groups men appeared as more vocal discussants, in others the participation of women was very strong and spontaneous. Many of the focus groups discussions were rather intense with the discussants presenting very critical views about the quality of governance in the country. Compared with the key informant interviews, the tone of the discussions in the focus groups was generally more critical concerning the state of governance with the discussants sharing their thoughts and experiences very freely. This is somewhat in line with the general findings concerning focus group discussions, which indicate that in groups people find it easier to express criticism than in individual interviews (Kitzinger, 1995; Pietilä, 2010).

For the purpose of this research, I have analyzed the data generated through the key informant interviews and focus group discussions separately by identifying the specific sources of data. In other words by indicating whether the speaker is a key informant or focus group discussant. In my view, the data gathered through these different sources provide deeper insights into the country-specific interpretations of the complex notion of governance, and serve as a basis for analyzing the relevance of the donor governance assessments including their potential impact on improving governance in the case of Mozambique.

Finally, although I explained at the beginning of each interview and focus group discussion that the primary purpose of the interview was to learn about the respondents views about the donor governance assessments and not to collect data on the quality of governance in Mozambique, the key informants, as well as the participants in focus groups, seemed to share very freely their perceptions and experiences of various aspects of governance in the country. To some degree, the perceptions of the quality of governance were brought up also in the interviews with the donor representatives. However, as the purpose of the field study was not to arrive at any statement of the quality of governance in Mozambique, these views are referred to only when directly related to the research questions of relevance and the impact of donor assessments. 


\subsection{Relevance of Donor Governance Assessments}

The research question on the relevance of the donor governance assessments was approached through three separate sets of questions. The first set of questions concerned the respondents' interpretations of the notion of governance, including the notions of "good" and "bad" governance. The second set of questions focused on their knowledge of donor governance assessments, and the third set of questions aimed at exploring their views on the significance of the specific issues addressed by the donor governance assessments in the Mozambican context. The outcome of the discussion around these questions will be analyzed in the following sections.

\subsubsection{Meaning of Governance in the Mozambican Context}

As discussed earlier in Chapter 2, there is no shared interpretation of the concept of governance, and the conceptual approach underlying the donor governance assessments varies. The analysis of the governance assessments under consideration in this research (Chapter 6) confirms the diversity of conceptual approaches. For example, the CPIAs of the World Bank and the AfDB build on a relatively narrow public administration approach to governance with emphasis on economic and institutional dimensions. The CPIAs explicitly avoid political aspects, whereas other assessments tend to address governance from broader political economy and power perspectives. In this section, the focus will be on the Mozambican interpretations of the concept of governance. To support the analysis of the multiple meanings of governance, the broad World Governance Indicator (WGI) definition of governance comprising political, economic and institutional dimensions, has been used for the classification of the interview data, and for the identification of the main themes emerging from the interviews.

\subsubsection{Interpretation of Governance in the Context of Mozambique}

First, what does governance mean to the Mozambican stakeholders? The discussion starts with the views expressed by various key informants belonging to different stakeholder groups, followed by the discussion on the views raised by the focus group discussants.

As in the case of donors, governance means somewhat different things to different people in Mozambique. Many of the key informants started the discussion by stating that the concept of governance is "very complex" or "very broad", and "difficult to define in exact terms". However, the analysis of the data also points at a number of specific 
themes which can be classified according to the broad WGI classification of governance in terms of political, economic and institutional governance.

Among the key informants, governance seems to be understood, first and foremost, in terms of economic governance, particularly in terms of "government effectiveness", using the WGI concept. When answering the question of the meaning of governance, most key informants, irrespective of their stakeholder group, mentioned issues related to public administration, the government's capacity to provide access to public good and services for all, and to ensure prudent management of public resources. In this context, the importance of broad-based participation by the people themselves in the process of public administration and service provision was highlighted by several key informants.

For example, one of the key informants from Pemba, affiliated with a CSO which supports community level development planning, first pointed out the complexity of the concept but then narrowed it down to the management of public matters, or "the interests of the collective":

Key Informant No. 9 (CSO, Pemba)

"In principle, I think that the concept of governance is very complex. For me, what comes immediately to my mind when talking about governance is what we can also call public administration, how the matters or interests of the collective are managed. This question of the management of public interests is in my view what characterizes this concept of governance".

A similar interpretation was made by another key informant from Pemba, associated with a CSO involved in community training. According to him governance means, above all, access to public goods and services. He further emphasized that the process of providing these services requires broad-based participation by the people themselves because public goods belong to the Mozambican people:

Key Informant No. 10 (CSO, Pemba)

"When we talk about governance...I will not go directly to the concept of governance as it is a very broad question and covers many issues. But what we understand by governance is that people have access to public services. And we understand that public goods belong to the population, they are public. And what I also understand is that people shall participate in all processes of governance. That means, if it is a question of building a road, for what purpose the road is going to be built, this infrastructure; and they should say that "we are in this village, we have these products and what not, we produce this and we need this type of infrastructure...". 
The above views were echoed by one of the Members of the Parliament who underlined the capacity of the government to define the interests and needs of the population as the starting-point for governance:

Key Informant No. 18 (MP, Maputo)

"I believe that governance in our understanding should entail, in the first place, a clear definition of what we want to do, of what we plan to do as a service or as better service delivery for those who need to be served, as the English would say "how to deliver". Therefore, to analyze the concept of governance we first must have the capacity to define in a precise form the basic necessities of the population.... So in the Mozambican reality we have to define governance starting from the needs."

The government's capacity to deliver was defined as the key characteristic of governance also by an academic cum journalist with very extensive experience in the field of both education and media. In his perception, while governance is based on the relationship between the ruling party constituting the government and the electorate, it is the capacity of the government to fulfil its electoral promises that finally defines governance:

Key Informant No. 17 (ACA/MED, Maputo)

"For me, governance is the capacity that a government, a group of the representatives of the government, has to accomplish the programmes which its parties represent... To conclude, in order to define governance I would look into the manifests of the Frelimo party, which is the party constituting the government, and to find out if the programmes that the government has to accomplish, the programmes of the party, can be put into practice. Therefore, I would define governance as the capacity that a government has to execute the programmes and the resources that the party supporting the programmes has."

For the Mozambican key informants governance thus seems to mean, primarily, effectiveness of the government in public administration and the quality of service provision which, within the WGI framework, form part of the economic dimension of governance. However, the notions of participation and collectiveness, and the emphasis on governance "for the benefit of the people", while mentioned by most of the key informants, are not explicitly addressed through the WGI's definition of Government Effectiveness.

Issues related to Regulatory Quality, the second component of economic governance by the WGI, were not raised in the initial responses to the question of the meaning of governance apart from one private sector actor who works for a large international company. Instead of responding to the question of the meaning of the concept of governance, he addressed the topic from the point of view of the governance practices 
by the various private sector actors in Mozambique. The central theme that can be distilled from his account refers to transparency, a notion closely related to regulatory quality. He elaborated his views as follows:

Key Informant No. 25 (Maputo/National)

"The private sector in Mozambique has various levels as you know. We have the multinationals as the corporate sector, and then, lower down the order, you have the informal sector. In between you have varying categories of different types of businesses, the small ones and the medium, the SMEs so to say. In my opinion, we are in so far as governance issues are concerned, we are close to South Africa.... In other words, good governance and transparency is lifted to very good heights.

Now, the other chunk of Mozambican businesses, which are small and medium scale enterprises, they go by what they have been taught or inherited as practices run by either their forefathers in case of family businesses or by the Portuguese exporters which could have been part of the exodus of 1975 or those who stayed behind. Business practices and governance issues and transparency are questionable in these sectors. The informal sector and small businesses sometimes pretend to overlook governance issues in their pursuit of profit."(interview in English)

The interpretation of the concept of governance among the key informants is, however, not limited to the economic dimension of governance only. Another key theme emerging from the data relates to the political dimension of governance. The academic cum journalist cited above referred to the political nature of the relationship between the government and the voters as the basis for governance in Mozambique. This notion of accountability between those who govern and those who are governed was emphasized by several of the key informants, who characterized governance in terms of a relationship or contract between the government and the citizens. In this context, again, the participation by all stakeholders in the Mozambican society was highlighted as a key element of the accountability relationship. Following the WGI conceptualization of the dimension of political governance, it can be said that the Mozambican interpretation of governance entails the notion of Voice and Accountability. Somewhat surprisingly, issues related to the other component of political governance, namely Political Stability and Absence of Violence, were not raised by any of the key informants.

For example, a high-level senior civil servant, employed by one of the ministries in Maputo, defined governance as a contract between the government and citizens which is based, on the one hand, on the country's legislation and, on the other hand, on electoral processes: 
Key Informant No. 21 (SCS, Maputo)

"...governance has to do with the relationship between the authorities and the citizen. It should be managed according to the rules and principles, and legislation and principles. And this interaction is made, in principle, keeping in mind common objectives. If we talk about governance, for example at national level, the common objective has to do with what is formulated in the Constitution. The common objective has to do with the contract which the government signs with its people during the election campaign... the programme which the government presents and which is accepted by the voters. In the sense, what governance has to do with is the relationship of interests between two entities, the governor and those governed, to achieve the package of objectives."

A somewhat similar interpretation of governance was given by another senior civil servant from Maputo who defined governance as "a politico-administrative management of a territory", emphasizing the participatory nature of the governance process. In his view, "governance, especially in Mozambique, would entail creating a favourable environment for implementing all of those aspects that lead to the development of the country" (Key Informant No. 20, SCS, Maputo).

The political dimension of governance related to citizens' participation and mutual accountability between the government and the citizens, were highlighted also by several key informants from civil society. For example, one civil society actor, who leads a national organization working on governance issues, described his understanding of governance as follows:

Key Informant No. 24 (CSO/SCS, Maputo/National)

"Personally, I think, when you ask me what is governance, what is good governance, I associate this with the involvement, participation and accountability between those who govern and those governed. These are, these two are the key issues. Participation in the sense that people contribute to decision-making, people are free to express their opinions, people are free to question and they participate in all these forums, for example, for monitoring the exercise of governance. This is one issue. Another issue is that of mutual accountability. The government is there to govern, isn't it? This is done through, for example, the Assembly of the Republic as the more formal forum. But there are other forums which involve civil society organizations etc.... So it is in this sense that I understand governance: participation and mutual accountability."

Perhaps one of the most eloquent interpretations of governance as a participatory political process was presented by a civil society actor working closely with the parliament. In his view, governance can be defined as follows: 
Key Informant No. 22 (CSO/Parliament, Maputo)

"I understand governance as the set of activities and processes related to the political power to conduct the affairs of state. For me, all the processes involved in this arena are governance. And in my understanding of the concept of governance, I don't simply say that it is the government which in itself corresponds to that entity responsible for governance. In my view, the government of the day, which is the executive, leads the process, but around the government there are the state and non-state actors that also participate in the process of governance. For me it is a wide process involving different actors. Civil society is also part of the governance process, the parliament is part of the process of governance, other powers - one can say - are also part of governance, in general, because all these are involved in the process of conducting the affairs related to the governance of the state. This is my broad understanding of what is meant by governance."

Some civil society actors affiliated with sector-specific organizations approached the question of participation and accountability from the point of view of their own work. For example, a civil society activist involved in environmental issues in Pemba said that:

Key Informant No. 11 (CSO, Pemba)

"when we are thinking about governance ... we are saying that - I am explaining not trying to define - we are saying that ' $O K$, the government has policies, plans and strategies to implement in the country, to solve the problems of citizens'. And it has, for example, laws that guide the functioning of institutions. We think, we want the government to do better what it has promised to do"

Similar sector-specific accounts were provided by a number of other civil society activists.

Although "good governance" is identified as one the key pillars for development in the Government of Mozambique's national poverty reduction strategy (Plano de Acção Para Redução de Pobreza Absoluta, PARPA II), only one of the key informants, associated with a CSO cum research institute focusing on governance issues in Mozambique, approached the question of the meaning of governance specifically from the perspective of PARPA. He identified justice, public sector reform and decentralization as the central components in the governance debate of his organization:

Key Informant No. 6 (ACA/CSO, Maputo/National)

"When we talk about governance, it is very important that we are very concrete about what we are talking about because we have a governance framework within the poverty reduction strategy (PARPA). When talking about governance in Mozambique, we talk 
about the governance indicators, which are in PARPA, which include justice, public sector reform and decentralization. We concentrate the debate on this area of PARPA."

The PARPA-based approach to governance, with specific indicators for assessing e.g. the justice sector and enforcement of legislation, broadens the interpretation of the concept to the third WGI dimension of governance, namely institutional governance. The institutional dimension of governance, which within the WGI framework includes the notions of the Rule of Law and Control of Corruption, aims at addressing similar issues. It should, however, be noted that the key informant further pointed out that "governance could be defined as cross-cutting pillar for PARPA as it affects all sectors included in PARPA". In his view governance thus encompasses elements of political, economic and institutional dimensions.

In summing up the main messages from the key informant interviews, it can be concluded that the concept of governance is understood in terms of the government's effectiveness in managing the "public interests", and in providing public goods and services, as well as in terms of the accountability between state authorities and citizens. Following the WGI three-dimensional classification of governance, the economic and political dimensions of governance emerge as the key themes, whereas institutional governance seems to play a less significant role. However, the most central theme emerging from the interviews relates to broad-based participation, which is not fully captured by the WGI: expressing themselves in various ways, practically all key informants refer to the participation by all strata of the society as the fundamental component of governance. While the WGI notion of Voice and Accountability includes issues such as electoral rights, freedom of speech and freedom of association, it does not specifically address questions related to popular participation in governance.

The analysis of the focus group discussions brings additional nuances to the meaning of the concept of governance in the Mozambican context, and highlights the importance of participation as the key element of governance even further. At first it should be pointed out that while the key informants were, by and large, willing to embark upon a conceptual definition of governance, the focus group discussants preferred to approach the question by mentioning specific issues which, in their view, characterized governance. Accordingly, they elaborated their understanding of the complex notion of governance on the basis of their own experience rather than on an abstract level illustrating with vivid examples the problems they had encountered in the governance process. The key messages that can be distilled from the focus group discussions will be discussed below using the WGI conceptual framework as guidance for the analysis.

The issue that emerged as the core of governance among the focus group discussants, particularly in the semi-urban and rural settings of Pemba and Mocuba, related to the 
involvement of local communities in the government's planning and decision-making. Without exception, the question of participation was raised in one way or another in all focus group discussion. The discussants, whether subsistence farmers or micro-entrepreneurs in the informal sector, seemed very well informed about the legislation on decentralization, which outlines the structures and processes for their participation in the planning and monitoring of government actions. The excerpts below aim at illustrating the crucial importance of community participation as the key element of governance.

In the beginning of one of the focus group discussions in Mocuba, one of the discussants described in detail the legislation on decentralization which provides for community consultations and participation in all aspects of local development processes creating thus a space for broad-based participation. At the same time, he noted that there are problems in the implementation of the legislation.

\section{Focus Group F, Discussant No. 1 (male, Mocuba)}

"We are talking about the legislation, we have this law on local organs. The process of planning, I am talking in terms of documentation, the planning process starts from the bottom, which means that people starting from a district, for example a district headquarters, will go locality by locality to the villages for consultation, to consult the people on what exactly they want to be able to improve their lives in those villages which are the basis of the country. Each one of the things I will mention has its problems.

And we have also created the Consultative Councils. According to the legislation, the LOLE [Lei de Orgãos Locais, LOLE, added by the author], there are Consultative Councils from the level of a village to the level of a district. That is, the Consultative Council serves for consultation on all aspects. There are problems with these Consultative Councils but they exist. And with this development trend, which adheres to the district as the basis of development, the communities, the people, are given the right to express themselves, to say whether, in the final analysis, what is being done here will help to develop my community, my district, my country."

He further gave an example of how the legislations calls for community participation in the use of natural resources, noting again the problems in the implementation:

"And then concerning, for example, the management of natural resources where we work, there is a process of consultation, it was not there before. Anyone who wants to use the resources, although the resources belong to the state, anyone who wants to use the resources, the first thing he has to do is talk to the communities which are nearby these resources. And there is a negotiation between the explorer, who would like to make use of the resource, the communities and the government, and they have to come to a conclusion. Communities can say 'no, we do not want this operator here in this community'. There is nothing to say, if they don't want, the explorer will have to leave... All this has its problems. I am saying that the documentation, which exists in this country, provides for this." 
The legislation on decentralization was referred to in all focus group discussions in Pemba, Mocuba and Maputo. While it was seen as a central element of governance at the local level, and as a positive step towards improving governance, the situation in reality was perceived to be very different - as hinted at by the discussant cited above. Critical comments were made by several discussants, in particular, concerning the representativeness of the Consultative Councils as a forum for participation. To some extent, even the true commitment of the government to give voice to local communities and civil society was questioned.

The problem of the representativeness of the Consultative Councils was highlighted both in Mocuba and Pemba. In the words of one discussant in Mocuba:

\section{Focus Group F, Discussant No. 2 (male, Mocuba)}

"I also take up this whole thing that my colleague was talking about. These are really good things that the government provides for the citizens. But when talking about aspects where there are constraints, we have, for example, the members of the Consultative Councils who come from various levels starting from the village to the district. When looking at the district level, we find the Administrator [the highest-level civil servant at the level of district administration, added by the author] as the chairman of the Consultative Council. And what is then the problem? The Administrator is the person who will preside over the meetings of the members of the Consultative Council. And looking at the people who are part of the Consultative Council, there is the Chief of the Administrative Post, there is the Chief of the Locality and the regulos [the traditional leaders, added by the author], and probably these people are individuals who always look to the Administrator as their superior. And therefore, what I have seen many times, the big problems of the communities are not addressed."

His views were echoed by another discussant from the same group who also pointed out the mismatch between the legislation and the reality on the ground. In his view the Consultative Councils are not truly representative of the communities because:

Focus Group F, Discussant 3 (male, Mocuba)

"when the Consultative Council takes place, the forum for decision-making and approval of documents, there you have the whole apparatus of the government. The communities are there and they can elect the regulo to be the vice-president... they are all there, but the president controls everything.... On paper it is all well. It is true that our papers receive the grade 10 [means excellent, added by the author] but the process of implementation is invisible."

Very similar frustrations were expressed also in the focus group discussions in Pemba. A discussant from the peasants association explained his views as follows: 
Focus Group A, Discussant No. 1 (male, Pemba)

"...it creates difficulties for people to understand what this decentralization means, if it means decision-making by the government and influencing the communities. This can be seen also in the case of the Consultative Councils. When looking at the Consultative Councils, many people do not understand what it is, what is the role of the Consultative Council. And then in the Consultative Councils we have the village chief, the head of the local administration office, the head of the secretariat, but do these form part of the civil society? No, they don't. And when they go to a meeting to analyze the development on the ground, nobody says anything. The president on top of everything is the Administrator and they can never, never deny the Administrator because he is the Administrator, and they have the risk of losing their bread. ... We also want to participate in Consultative Councils to give our contribution to the community level, but they don't accept, they do not accept."

The above views were echoed by the discussants in the Mozambican Debt Group (Grupo Moçambicano da Divida, GMD). One of the discussants listed three specific problems concerning the Consultative Councils, namely, the limited focus of the Consultative Council discussions, the low level of civil society and female representation in the Councils. He justified his critique on the basis of legislation which, in his view, is very clear on these issues. For example, concerning the participation of women he said that:

Focus Group C, Discussant No.1 (male, Pemba)

"We have also raised the issue of women's participation... Because if you look around, in most Consultative Councils women are not well represented, but the law sets 30\% as the target for the participation and representation of women"

One of the challenges raised concerning the representativeness of the Consultative Councils related to the perceived lack of clarity between the government and party politics. Several discussants referred to the ambiguous division of responsibilities between the local authorities representing the state and the representatives elected by the citizens. In the word of one discussant from the focus group in Mocuba, with participants from the civil society, media, etc.:

Focus Group F, Discussant No. 2 (male, Mocuba)

"In the Consultative Council of the village - according to the norm - the president should be a regulo and his deputy should be a First Secretary [of the Frelimo party, added by the author]. And the one who has the power to deal with or to solve the problems of the community is the regulo, who is the representative of the state at the level of community. But before it was not like that, it was not the regulo that had the power to solve the problems. It was the Secretary of Frelimo who solved the problems. So there is this major constraint 
between the regulo and the Secretary of the Frelimo party. The Secretary of Frelimo party has the power on matters of the party but on matters of the state is the regulo who represents the state. In our governance, there is a poor understanding of these two areas. And therefore today, in my analysis, we are not doing well but we are making progress, this is a process."

In light of the focus group discussions, broad-based community participation seems to constitute the core of the concept of governance. Furthermore, the discussants seem to view governance as a process underlining that, despite various problems, positive changes have taken place in the relationship between the government and local communities. In their perception, communities have been given more space in the process of governance, even by the highest rank of the political authority, namely the president of the country. For example, one of the discussants noted as follows:

Focus Group F, Discussant No. 3 (male, Mocuba)

"It is not easy to reach the optimal point, to say that this is good governance. We want more. But governance is now developing, because at least the community has a voice and this is very positive."

Referring to the past he noted that "I think we are in a good situation to improve, and we have a long way to go, but comparing with the 1980s we are developing".

In this context, several discussants also talked about the so called "open presidency", initiated by President Guebuza, in the beginning of his second term in office in 2009. As stated by one of the focus group discussants in Mocuba:

Focus Group F, Discussant No. 1 (male, Mocuba)

"The open presidency also provides a space, that is the President of the Republic has opened a space. He cannot speak with the whole world but at least he asks 10 people who can express the views of the community. And already there have been situations where results can be seen. The communities are pointing out government people who are governing badly. We had a case, for example in the district $X$, where communities said about the Administrator that he should go with the President: 'Mister President, when you leave from here and go back to your office, take this Administrator with you. We do not want him. This did not happen before, nobody could talk like that. And he [the President, added by the author] said, 'fine, we will do an investigation' and this Administrator, he was removed. So there are positive things."

In the focus group discussion in Maputo, involving micro-entrepreneurs working with handicrafts, the notion of governance was approached from a slightly different perspective. While community participation emerged as the core issue defining governance 
among the focus groups in Pemba and Mocuba, the focus group discussants in Maputo seemed to interpret governance in a manner somewhat similar to many of the key informants. That is in terms of the capacity of the political leaders of the country. The importance of governance as securing the basic needs was highlighted again:

Focus Group H, Discussant No. 1 (female, Matola/Maputo)

"For me and my work, governance means having a leadership to satisfy the needs of the people, that is our Mozambican people. So, I consider this as good governance when a person can satisfy his needs, perhaps not all, because that is not easy, but the minimum for the well-being of the people."

And in the words of another discussant "Governance means that the governors understand us well, our way of working" Focus Group H, Discussant No. 2 (male, Maputo).

The involvement of local communities in planning and decision-making as an important element of governance was, however, mentioned also by one of the focus group discussants in Maputo. In contrast with the focus group discussants from Pemba and Maputo, her perception of the reality of community participation was much more positive - with positive impact on the situation of governance. She elaborated her views about the evolving relationship between the government authorities and the citizens as follows:

\section{Focus Group H, Discussant No.1 (female, Matola/Maputo)}

"Nowadays the leaders of the communities are taken into account. Everything starts from the bottom. There are better solutions because they began to respect the people at the grass root. There was a time when things started from the top and it was not easy to find a solution. Even in the case of robberies and thieves, they can catch the thief when they go to the bottom.

Governance starts from the Head of the Administrative Post, then we have those who in former times were called the regulos, also the rainhas [Queens, female traditional leaders, added by the author], they are the leaders of the communities, they know their neighbourhoods, they were born there and live there, and now these people are taken into account. This helps a lot. I would say that nowadays things no longer start from the top, everything starts from the bottom."

To sum up, the defining factor of governance for the focus group discussants seems to be the question of the involvement of local communities in the planning, decision-making and monitoring of programmes and actions financed by the government of Mozambique. The emphasis on participation may of course reflect the fact that discussants shared the same interest in community participation. As noted by Alasuutari (1999), in focus groups the participants tend to concentrate on issues which they share as a group. 
Another key message that can be distilled from the focus group discussions relates to the notion of governance as a process. The discussants' views clearly indicate that governance is interpreted within the framework of Mozambique's political history. For example, when referring to the legislation on decentralization as a positive step towards enhanced community participation and improved governance, the discussants point out the changing historical context of the country. The comments on the ambiguous composition of the Consultative Councils, the merging of the government and Frelimo, and the poor understanding by the people in communities of their role in the process of decentralization, highlighted as major constraints for genuine community participation, point at the perceived lack of open and democratic governance.

Using the WGI concepts as the guidance of the analysis, it can be argued that among the focus group discussants governance is understood, primarily, from the perspective of political governance with emphasis on Voice and Accountability. The notion of community participation appears as the key theme and, in fact, the defining factor of governance. The focus group discussants' interpretation of governance seems to include also elements closely related to the institutional dimension of governance. For example, the views presented by the discussants about the implementation of the existing legislation on decentralization are addressed through the WGI indicators concerning the Rule of Law. On the other hand, only two discussants from Maputo mentioned issues such as the quality of public administration and service delivery, which according to WGI classification form part of the economic dimension of governance.

The analysis of the focus group discussions brings additional nuances to the notion of Voice and Accountability. Whereas the set of WGI indicators on Voice and Accountability focus on issues such as citizens' rights to elect their government, freedom of association, freedom of expression and independence of media, the focus group discussants emphasize the importance of direct participation by local communities as the basis of accountability relations between citizens and government authorities. From the perspective of focus groups, accountability entails not only periodic elections and civic freedoms. It is, in addition, founded on bottom-up involvement of citizens and communities in all processes related to management of public affairs. The discussants' calls for public consultations at community level, broad representativeness of local administrative bodies such as the Consultative Councils, and direct involvement by communities in planning and monitoring the implementation of public affairs, are issues that go beyond the meaning of Voice and Accountability of the WGI. To some extent, their understanding of participatory governance reflects the UNDP's notion of "democratic governance" which entails "institutions and processes that are responsive to the needs of ordinary citizens, including the poor, and that promote development" and "building effective and capable states that are accountable and transparent, inclusive and responsive - from elections to participation of women and the poor". 
(http://www.undp.org/content/undp/en/home/ourwork/democraticgovernance/overview.html, accessed December 9, 2012). The approach to governance among the focus group discussants bears similarities also with the "upside down view of governance" which calls for exploring with an open mind how governance can be built through the bargaining between the actors of the state and the society at large, and through the interaction between formal and informal institutions (IDS, 2010).

In conclusion, the preliminary analysis of the key informants' and focus group discussants' interpretation of the concept of governance indicates that governance has multiple meanings in the Mozambican context, just as amongst the donors. While the complexity and multi-dimensionality of the concept of governance was explicitly highlighted by several respondents, the analysis also points to a number of common themes or issues which are perceived as the key elements of governance from the perspective of Mozambique.

First, in general terms, governance in Mozambique is understood as a broad, multi-dimensional notion related to the political, economic and institutional processes in the country. Second, governance is interpreted, primarily, as the management of public affairs to achieve common goals and to meet the interests of the collective. The process of managing public affairs is perceived to be based on a relationship of accountability or a contract between the government and the citizens which is rooted in the country's legislation. The elected government together with the state authorities at various level of public administration bear the responsibility for fulfilling their electoral promises by implementing publicly financed programmes and putting into practice legislation adopted by the parliament. Fourth, in the Mozambican context governance is seen to entail a broad-based participation by all stakeholders in the society in the processes that affect their lives. The involvement of local communities, private sector actors and civil society in the management of public affairs is highlighted as a core component of the governance in the country.

Following the WGI conceptual framework, in the Mozambican context governance is understood as a broad concept comprising political, economic and institutional dimensions. However, the analysis of the data points at an additional dimension of governance which is not fully captured by the WGI conceptual framework. Building on the UNDP's notion of "democratic governance", this additional dimension can be conceptualized as "participatory democracy". 


\subsubsection{Perceptions on "Good" and "Bad" Governance}

In order to go beyond the general interpretations of governance, the informants were invited to express their views about what constitutes good or bad governance in Mozambique. The purpose of discussions was not to explore the informants' judgments about the quality of governance, but rather to enhance the understanding of what these concepts mean for different stakeholders in the specific context of Mozambique. The outcome of the discussions is presented below, starting again with the key messages emerging from the key informant interviews, followed by the outcomes from the focus group discussions. The analysis of the interviews is supported by the conceptual framework developed by the WGI.

At the outset it can be said that the key informants' views about good and bad governance reflect, by and large, their interpretations of the concept of governance. Accordingly, the effectiveness of the government, the accountability of the government and state authorities vis-à-vis citizens, and broad-based community participation were identified as characteristics of good governance. At the same time, the discussions on the specific positive or negative attributes on governance shed new light on the meaning of the concept in the Mozambican context.

Perhaps the most comprehensive account of what constitutes good governance in Mozambique was provided by one of the key informants from Pemba who works for a CSO involved in advocacy and in the training of communities and other CSOs at the provincial level (underlining by the author):

Key Informant No. 13 (CSO, Pemba)

"There are of course several elements that you can consider, but in my field and practical work in the communities, the fundamental elements include, first, participation. It is important to ensure the involvement of all strata of society so as to achieve fair and good governance... In my view the participation of all strata of society is important, whether as organized groups or on an individual basis as citizens; that they are invited to participate from the process of consultation to the process of planning the programmes of the government. And finally they must be involved in the process of monitoring so as to see how far the government is implementing its policies and programmes. And they should jointly analyze the impacts to see whether people are satisfied or not.

Another important element for the process of governance is, in my view, the issue of transparency that we have been talking about. Governance where the different processes are not clear and open, where information is not accessible to everyone, so that everyone can comment, to criticize, to express whether they are satisfied or not - in my opinion that is not fair and good governance. ...So above all, this transparency in planning, implementation 
and management, not only of funds but of all other resources belonging to Mozambique, is in my opinion very important.

We have also another element that is the accountability, which very often fails. I think good governance requires accountability because governance presupposes the existence of a society that is guided according to the rules, laws, principles and institutions in various sectors. We have the question of responsibility which is very important in the process of governance. It is important that whoever is responsible for governance, whether we talk politically or of governance of a company or of a corporation, that this person, assumes responsibility for his duties and for the rights that people have, and is in charge of the process.

The question of the rule of law is also very important for good governance, that is, for the governance processes of any country. In Mozambique, in particular, it is important to respect the Constitution and the separation of powers embodied in the Constitution. And it is important that anyone can see that everything that is decided by the government in Mozambique is in accordance with the laws, not vacillating or jumping around, crossing the borders of the laws. Every word and every decision that comes out of the Assembly of the Republic has to comply with the law, our Constitution. And for the three fundamental powers involved in this process of governance, there must be a 'check and balance'. So there has to be rule of law.

There are other important elements but, from the point of the work that I have been doing, I would in general consider these. And also consensus in putting things into practice, the unilateralism of the issues and decisions. Leaving certain strata of society at the margin, they don't allow it, and at some point people would be discontent, that is not very good. So I think these may be some essential elements for a fair governance, good governance".

Another key informant from Pemba, affiliated with a local environmental association, described good governance in almost identical terms (underlining by the author):

Key Informant No. 11 (CSO, Pemba)

"When we are talking about good governance, what are we talking about? That there is access to information without any problems, because one of the things we have noticed is that it is not easy, for example, to have the budget and the government's plans, even at the district level. ... Because whatever the government actually plans to do is done with public funds, and in the end the money comes from the citizens....taxes, all those things which provide this money for the government to do something. The government therefore has an obligation to show and say 'ok, this year in this municipality, for example, we plan to do this and spend this, this much and this much of the money we want to spend in this way'. So for us this issue of transparency is one of the basic pillars of good governance. But apart from transparency, accountability is also extremely important. It is related with the planning: $O K$, this was planned, and at the end of the year we have the possibility to 
assess what has been done. The government has to say what it has planned, whether it has accomplished the plan or failed and so on.

Also the question of participation in these processes is of interest because we think that civil society and citizens in general have to be involved in these processes. In my view these are for us the basic pillars of good governance.

There is another interesting issue which, I think, has something to do with corruption. In our view there has to be respect for the law and legality. Many times we have the legislation, the laws are good, they are there, but they are not implemented. So things are done in an arbitrary manner. Therefore this issue is law enforcement is a very interesting question. There are of course other components, for example, in the area of provision, let's say public service delivery. There are these several components that one can discuss. One can also discuss the issue of access to justice, to see the extent to which citizens have access justice. So these are other issues that can also enter into discussion on the question of good governance."

Similar issues were raised by practically all key informants, albeit not in such a systematic manner. In particular, questions related to access to information, transparency and accountability of the government, and prudent management of public resources were among the most frequently mentioned characteristics of good governance. In the words of two key informants from Pemba both working with at community level organizations:

Key Informant No. 9 (CSO, Pemba)

"For me, the major preconditions for good governance are necessarily linked to accountability, for example, transparency and the question of management, or better management of the public goods. All these elements are, in my view, major preconditions for good governance... On the other hand, I think that bad governance would be characterized, for example, by lack of accountability, lack of transparency, for example, by harmful management of public assets. We can also add here, for example, the question related to corruption. All these elements would, in my opinion, be those which can characterize bad governance."

\section{Key Informant No 10 (CSO, Pemba)}

"Good governance, what we understand by good governance - there is a lot of talk about good governance in Mozambique, I don't know if there is much talk about this abroad - what we understand, and what I understand as I cannot generalize, it means that the government should be transparent, that is good governance to me. The government should be transparent in all that it does both in planning and in the implementation of government programmes, people should know. Also in budgeting, people should know what was spent, and what has not been spent and why it has not been spent. All this to me is good governance, for the government to be transparent in its actions." 
One of the specific issues concerns transparency, which was raised by several key informants particularly in relation to transparency in the use of natural resources. For example, as stated by one key informant from Maputo working for a CSO with focus on corruption issues:

Key Informant No. 6 (ACA/CSO, Maputo/National)

"The question of the extractive industry - we are working on it now - it is very important because there are indications that oil will be discovered in Mozambique, we already have a plenty of gas, and the management of the revenues from the extractive industry must be done within a framework of greater transparency. Not only concerning what companies pay to the state but, above all, concerning what goes back to communities and how communities are prepared to receive these funds and to implement local development programmes. We don't have a clear legal framework for this."

As discussed above in the section 8.2.1.1 broad-based participation and involvement of local communities and civil society in the management of public affairs and public resources, provided for by the legislation on decentralization, emerged as one of the defining factors of governance in Mozambique. Not surprisingly, the participatory nature of governance was again highlighted as a key characteristic of good governance. However, instead of just highlighting decentralization and broad-based community participation as an element of good governance, several key informants expressed their frustration with the situation on the ground pointing at failures in the participatory process. As stated by an academic cum civil society actor from Maputo:

Key Informant No. 7 (ACA/CSO, Maputo/Nampula)

"The question of decentralization; there is talk about decentralization, but Laura if you go to a rural area, there everything comes from top to bottom. It is a process, very well, but it is necessary to create conditions for these processes because now all the people there go around without any direction."

The above frustration was echoed by another key informant, also from Maputo:

Key Informant No. 6 (ACA/CSO, Maputo/National)

"In our view, this idea that the district is the unit of planning and budgeting, it has not yet materialized in Mozambique because the state budget is both conceived and executed at the central level whereas the planning is done at the local level. Therefore there is no connection."

Although the problems in moving forward with decentralization were largely perceived to be the fault of the government, some of the key informants pointed their fingers at the civil society actors themselves. For example, one civil society actor heading 
an organization which is deeply involved in governance discourse but which works in close cooperation with the government, argued that the government has provided the space for broad-based participation. However, it is the civil society itself that lacks the capacity to participate with the government and fails to hold the government accountable. Approaching the question from a historical perspective, he stated the following:

\section{Key Informant No. 24 (CSO/SCS, Maputo)}

"In line with the already well defined and standardized big pillars for governance, the government is trying to create a space, or has created a space - after the peace in -92 for the practice of multiparty politics - for the creation of civil society organizations, and it has also created the specific spaces where people can monitor and express their ideas. It is a process that is in construction in Mozambique, it is in construction. And this process has a very interesting characteristic. As you know, the state in Mozambique, which in the 80's was a police state, a strongly authoritarian state, suddenly changed in the late 90's, it created a space; the government opened up all the spaces. Suddenly there was an opening, and the interesting phenomenon in Mozambique was that the civil society actors could not fill those spaces. Mozambique has this specificity. As if all the windows of the house had suddenly been opened up, and those outside could not enter all those places that have been opened. We have this problem now. And that is not the fault of the government, it is not a function of government, how should I put it, to create capacity for the civil society. The civil society has to organize itself, to find mechanisms to organize itself, to be the interlocutor of the government. I think Mozambique is still in this phase of construction. We still have this problem. And often, it seems that the government is, how should I put it, high-jacking the civil society but this is not so... there is a lack of capacity by the civil society to occupy the space, not just to participate. But not only to occupy, but to occupy but with quality, to be able to be on the same level with the interlocutors from the side of the government. So the other side of the coin is that the civil society is not able.

It seems that it is a process, also because the history of the civil society participation is recent. So, good governance is not only understood as the ability of the government to be accountable but also the ability of the other actors to interact with government in all these areas, to have this balance, to have these checks and balance, in fact this is good governance."

A similar point was made by a Member of Parliament from Maputo. Using as an example the role of civil society in the debate on human rights he argued that:

Key Informant No. 19 (MP, Maputo)

"We don't have a strong civil society which is a great problem.... When we organize a meeting to elect members for a national Human Rights Commission and only 7 organizations show up - where does all the money go that the international community allocates to civil society if only 7 organizations are able to present candidates for such an important 
commission as the Human Rights Commission? What has gone wrong if human rights are not on the agenda of the civil society organizations? If the human rights were on the agenda of the civil society, we would have had 100 organizations presenting their candidates at the meeting."

Access to public services, which had been identified as one of the defining factors of governance in general, was also frequently mentioned as a characteristic of good governance. From the point of view of a Member of Parliament, good governance in the Mozambican context entails not only meeting the basic needs of the people, but also creating the conditions people need to improve their own lives:

Key Informant No. 18 (MP, Maputo)

"In Mozambique, the concept of good governance should be interpreted, first not only as meeting the basic needs of the population but also as raising the quality of life, because in the Mozambican context, governance goes from the meeting the basic needs of the population, raising the level of the quality of their to creating also the conditions for the people to find mechanisms and means to solve their own problems.

Another key informant, identified as an academic cum journalist, approached the question from a personal point of view stating the following:

Key Informant No. 17 (ACA/MED, Maputo)

"In my day-to-day life governance is measured by the quality of public service that is provided. When I, belonging to the so called higher economic class, look for public services in health or education, I don't find solutions for myself... And also concerning the public services provided by various ministries, if I need a document, how long does it take to get that document, would it be necessary to try to impress the official by other means so as to get my document in reasonable time. All this allows me to assess whether governance is good or bad."

Access to justice, and in general, the implementation of the existing legislation, both of which can be considered elements of the rule of law, were also identified as important attributes of good governance. However, instead of just referring to the significance of the rule of law, several key informants approached the issue more generally by presenting critical views about the enforcement of the existing legislation. For example, one of the key informants, categorized as an academic cum civil society actor, elaborated her views as follows:

Key Informant No. 7 (ACA/CSO, Maputo/Nampula)

"...there seems to be a willingness to change things, but this willingness is not reflected in practice. It is not that we don't have laws and instruments, in fact, we have many 
instruments, but the process from theory to practice does not work. In my view, this is closely linked with the lack of political will, because they say 'OK, let's fight against corruption', but the politicians are the most corrupt, the main leaders are corrupt."

A very different approach to the question of the meaning of good governance in Mozambique was presented by a key informant, an academic, who emphasized the political dimension of governance as the core of good governance (interview in English):

Key Informant No. 23 (ACA, Maputo)

"By governance I mean political governance. And in the context of Mozambique, from this angle, it means the elections and the quality of elections, the issues of intersection between party and the government machinery, and also the issue of corruption. So these are the key issues, we can also include human rights etc."

He further argued that the good governance agenda promoted by the government of Mozambique excludes politically sensitive issues in order to protect its privileged position (interview in English):

These are the key issues that the government is not, or has not ever been open to compromise, with the donors. The government is much more open to compromise on several other issues, including public financial management where there have been a number of reforms, but when it comes to political governance, there is a lot of resistance. It's also understandable, because many of the people that can be called the political elite, their social mobility, it was also enabled through corrupted mechanisms, so for them to be open, and discuss some of the issues and importantly accept the good governance and discourse in this field, that would mean for them to shoot themselves in their own feet, so that they tend not to be open for this discussion, let alone to compromise."

Analyzing the key messages emerging from the key informant interviews within the framework of the WGI conceptual framework, a number of general remarks can be made. First, the discussion on the attributes of good and bad governance sharpens the interpretation of the concept of governance. In addition to issues related to economic and political governance, which had emerged as the core components in the general definitions of governance, particularly transparency in the management of public affairs and the accountability of the state authorities, the discussion on the characteristics of good governance puts emphasis on institutional governance. The respect for the rule of law, in particular the need to implement existing legislation and to ensure access to justice, are highlighted as key features of good governance. The emphasis on broad-based community participation as a core component of governance in the Mozambican context also runs through in the discussions on the characteristics of good governance. However, the key informants' call for creating a space and providing the mechanisms for broad-based community participation sharpens the meaning 
of participatory governance. The importance of access to information by the communities regarding matters of public interest, and of an open dialogue between the state authorities and the communities, emerges as an additional component of good governance. This call for a free flow of information and the creation of bargaining mechanisms for power sharing between the state and the citizens can be interpreted as elements of what has been referred to as "participatory democracy". The notion of participatory democracy can be detected also in the statement by the key informant with an academic background who approached the good governance question from the point of view of the political processes in the country.

When turning to the focus group discussants, a similar consistency between the meaning of governance and of the attributes of good governance can be identified. In line with their interpretation of governance, expressed mainly in terms of local involvement and bottom-up community participation in the planning, implementation and monitoring of government interventions, the focus group discussants stressed the nature of the relationship between the state and the society at large as the key criterion for the quality of governance. Without exception, the discussants in the focus groups in Pemba, Mocuba and Maputo raised issues related to this topic, often talking on the basis of their experiences as a group or as a collective. The specific issues mentioned range from the implementation of the existing legislation on decentralization to creating mechanisms for participation and sharing information. The tone of the discussions was again much more critical when compared to those with the key informants. The excerpts below aim at illustrating the messages emerging from the focus group discussions.

The emphasis on broad-based community involvement and participatory governance that was highlighted not only as a core component of governance, but also a key attribute of good governance among the focus groups, is well captured by one of the focus group discussants from the provincial CSO forum in Pemba who elaborated her views in a simple but straightforward manner as follows:

Focus Group D, Discussant No. 2 (female, Pemba):

"For us, from the perspective of the Forum, good governance would be a situation where the government and the civil society share almost everything. There are joint planning processes for the benefit of the people, there is accountability, activities are planned jointly, and this would be good governance."

Approaching the question of community participation from the perspective of the formal decentralization process, one discussant from the provincial peasants' association in Pemba expressed his views as follows: 
Focus Group A, Discussant No. 1 (male, Pemba)

"And if we look at what this decentralization means in practice, it is still not good. For us it is premature language. Because the Mozambique where we live now is not the one where we used to live. I would even say that we are totally lost with this decentralization. What is this decentralization? For me it would mean participating in the planning process. But if we look at the plans that are made at the district level, the civil society is not involved, it is not. Therefore, even today there are many, many problems, and at the community level they are annoyed because there is no planning, and even less decentralization."

A somewhat similar point was made by one of the focus group discussants from Mocuba. He elaborated on the problems confronted at the level of communities in more detail, also pointing out the consequences of the failures of the participatory processes:

\section{Focus Group E, Discussant 2 (male, Mocuba)}

"I would like to talk a bit about planning. The national planning begins in mid-February, that means, the consultations with the communities concerning their needs start in mid-February. The issues are discussed at the level of the localities, then channelled to the Administrative Post and so on, everything goes according to the legislation and the deadlines for the submission of the plans. What happens, at the moment, is that someone from the Provincial Directorate of Finance arrives, stays here for two days for the elaboration of the District Development Plan, PESOD [Programa Económico e Social do Distrito, PESOD]. Two days is enough for him to get an idea of the plan. They talk about infrastructure that requires financing to be completed this year, financing for the same infrastructure to be completed next year, and financing for the completion of the same work for the third year. There are such problems because of the consultation process.

...And what happens often when the government does not consult the communities - this happens sometimes also with the NGOs - they dig a borehole but the communities won't stop going to the river. People see the borehole but since they were not consulted they continue fetching water from far away, from 10,15,20 kilometres distance. If you ask 'to whom does the borehole belong' they say 'well, it belongs to the men who came to dig it'. These things happen in our communities."

Another topic that was frequently raised in the discussions on good - or bad - governance relates to law enforcement, in particular, concerning the access to land and other natural resources. One of the discussants of the provincial peasants' association in Pemba illustrated the concerns of the family or subsistence farmers with specific reference to the implementation of the legislation on the use of land:

Focus Group A, Discussant 1 (male, Pemba).

"With regard to the question of the land law; the land law is approved, and we know that in Mozambique our land is not sold nor leased. But what is happening now: the land is 
being taken a bit politically. Because what they do: if you stop along the road, you can see many fields. But if you'd like to know whom the fields belong to, it is said that they belong to director of $X$ or director $X$. But when a farmer wants to make use of these fields, what they say: 'you cannot have cattle here because there is tse tse fly'. I do not know what type of a fly can choose who is a director and will not sting a director but stings a peasant."

Approaching the problem on the basis of their own experience, the discussants also frequently referred to the perceived failure in implementing the legislation concerning the community involvement in natural resources management and the communities' rights to the income accrued from exploiting natural resources (commonly referred to as the "law on the 20\%"). The passage of the discussion in the focus group in Pemba summarizes well the views expressed by several discussants:

Focus Group A, Discussant No. 1 (male, Pemba)

"Let's look at the large companies. When we see where they are established, what is their benefit for the community, we do not understand. We can say that in Cabo Delgado there is a lot of exploitation of wood. We can ask where do the $20 \%$ go, because there is lot of talk about that money going to the communities. We can go and check, what year the operations started, what are the changes in this community where the operations take play, and we will not see anything."

Focus Group A, Discussant No. 2 (female, Pemba)

"I can also contribute to this question of logging... the 20\% for the communities. In the communities, it is only the village chief who knows about these funds, the community does not even know about them. There are no consultations."

Focus Group A, Discussant No. 3 (female, Pemba)

"Another thing still is that people exploit sand in our area. The make use of the sand without the knowledge of the people, of the community. There are so many potholes that people are even afraid when they go to those areas because of the water."

The same problem was raised by a focus group discussant in Mocuba who explained in detail what the law says and what happens in practice:

Focus Group E, Discussant No. 2 (male, Mocuba)

"We see, for example, in relation to the problems of natural resource management. The law says that, first, before channelling the $20 \%$ you should create a management committee, there in the area. Second, you must open a bank account on behalf of those communities. Third, the regulo cannot be member of the committee, it is written in the law. The regulo is not a member of that committee. No state employee should be part of the committee. But if we were to go and look for one of those committees, we would see that 
the functionary of the local administration acts as the president, the teacher is the treasurer and the regulo is probably the secretary. And often the community is called in 'you go, you go, you go', and they come up with 10 members. The requirement of the legislation of 10 members is fulfilled but, in essence, there are only 3 people. So this is also one problem that we have in the governance process."

Last but not least, the question of access to information emerged as one of the key characteristics of good governance. It was raised by several discussants in the context of both law enforcement and community participation. The key message that can be distilled from the discussions is well captured by one discussant in a focus group representing local civil society associations in Pemba:

Focus Group C, Discussant No. 6 (male, Pemba)

"What often happens, when a law is adopted in our country, is that the law ends up in drawers. I say this, I'm not afraid to say this, it always stays in the drawer. People who are in towns don't even know that there is a land law, because the law is still in the drawer, there is no disclosure. And as my colleague said about family law, many people in the villages don't have knowledge of the legislation because there is no disclosure, the law is still kept in the drawer. There is a lack of information and lack dissemination of the laws."

His views were supported by two or three other discussants from the same group who spoke with one voice of the limited access to legislation by the population. One discussant even argued that the dissemination and the implementation of the existing legislation remains poor because withholding information serves the interest of those in power:

Focus Group C, Discussant No. 3 (male, Pemba)

"It should be so [that the government shares information about new legislation, added by the author], but that's not what happens because, I believe... I don't know how to put it... in order to govern as I want I have to keep people uninformed. I don't know if you understand what I am saying. In order to govern, I have to leave people uninformed so that I can rule as I want. Now who is interested at the moment, so to speak, to inform the civil society is the civil society itself. That is what we have seen. Yes, we know the government is the legitimate channel for disseminating the laws but this is not what happens."

A somewhat similar point was made by one discussant in a focus group comprising of small scale and micro entrepreneurs in Pemba:

Focus Group B, Discussant No. 1 (male, Pemba).

"I have to say that the national policy of governance for us working on our own account, it is extremely bad. It is bad in the sense that the government does not engage in a dialogue 
with us, for example, when the season of festivities approach. ... In my view, the most important elements of good governance would be information and dialogue with the government, or with those institutions that are part of the government."

Poor access to information as a barrier to community participation was mentioned by several discussants. For example, according to a discussant from the peasants' association in Pemba:

Focus Group A, Discussant No. 1 (male, Pemba)

"They look for ways which they could call civil society participation or participation by the peasant. But let us see what tools they give to the civil society to better participate in all these processes. It has been a bit difficult. Just to have the Economic and Social Plan is a problem."

While the importance of access to information was also highlighted by the focus group discussants in Mocuba, it was also pointed out that the free flow of information and the dialogue between the government and communities is hampered by the low level of education of the population:

Focus Group C, Discussant No. 5 (male), Mocuba)

"Information should reach the bottom. People who need information don't have access to information. Many people are not aware of their rights, they do not really know what they are entitled to. In the communities, I bet $90 \%$ of the people there don't know that they have the freedom of expression, they still have that education. If we were to look into... we spoke for example of visits by the President of the Republic. It's not just anyone who stands up to speak. They are usually people who have had access to information, people academically ... But people who are there in the communities, they still have the old education. There is still some work to be done."

However, on a more positive note, one of the discussants in a focus group involved in provincial development planning and monitoring in Pemba pointed out that the situation is improving:

Focus Group D, Discussant No. 1 (female, Pemba)

"Since last year here, the dialogue between civil society and the government is not on a satisfactory level for us as civil society but now we are moving forward. There has been an opening since the last Observatory [Development Observatory, added by the author] in the sense that that government has agreed that there has to be a space for the coordination of information sharing between civil society and the government. And the dialogue has now been a little more open. What is missing is creating a space outside this Observatory where the government itself would share out plans and strategies at the beginning of each 
year so that civil society can follow-up and monitor public policies more closely... What we have noticed is that this opening exists only at the provincial level, at the level of a district and administrative posts, that impasse still exists."

In summing up the messages emerging from the focus group discussions, it can be concluded that community participation and the dialogue between the government and the citizens constitutes the key characteristic of good governance. Another central theme relates to the respect for the rule of law, and closely related to this, to the free flow of information. Looking at these themes within the framework of the WGI, it can be argued that the notion of good governance among the focus group discussants is interpreted, first and foremost, in terms of the institutional aspects of governance, notably in terms of the Rule of Law. The emphasis on the free flow of information and accountability also points at the political dimension of governance, notable to Voice and Accountability. However, again the most important theme emerging from the focus group discussions is the need for bottom-up participatory governance, which relates to the principle of "participatory democracy".

To conclude, the discussions with the key informants and focus groups on the characteristics of good - and bad - governance reveal a high degree of frustration with the state of affairs in Mozambique. Most of the respondents pointed at the gap between the existing legislation on community participation, in particular the legislation on decentralization, and the reality on the ground. While the legislation was seen as having created the space for community participation, and thereby, provided the basis for good governance, in practice very little, if any, progress had been made. The involvement of the local communities in managing the use of natural resources and in having access to the benefits accrued from these resources, while protected by legislation, was questioned by several interviewees in different stakeholder groups. The same applied to the respondents' perceptions concerning the free flow of information as well as the transparency and accountability of the government authorities vis-à-vis citizens. All these issues were highlighted as key aspects of good governance, yet in reality they were seen as unfulfilled promises.

\subsubsection{Greatest Challenges of Governance for Mozambique}

The third set of questions related to the Mozambican interpretations of the notion of governance focused on the perceptions of the greatest governance challenges facing the country. The question was raised towards the end of the interviews with the objective of seeing whether the respondents' views about what is good or bad governance in the Mozambican context are consistent with their perceptions of the most central challenges for governance. This discussion was also aimed at providing an input for 
analyzing whether the donor governance assessments on Mozambique succeed in capturing those governance concerns which are considered most important by local stakeholders. The outcome of the discussion on the greatest concerns for governance as perceived by the Mozambican stakeholders is summarized below. As above, the discussion starts with the analysis of the key informant interviews followed by the analysis of the focus group discussions.

In light of the key informant interviews, the issues related to transparency and accountability and access to public services, which had been mentioned as the key characteristics of good/bad governance, were perceived to be among the greatest challenges for Mozambique, irrespective of a stakeholder group. However, the discussion on the greatest challenges brought the question of corruption to the centre of the governance debate, and corruption was singled out by most informants as the underlying challenge for governance in Mozambique. The emphasis on corruption was somewhat unexpected as this issue had not emerged as a central theme in the discussions on the concept of good or bad governance. The views about the greatest challenges are well captured by one key informant affiliated with a CSO in Pemba (underlining by the author):

Key Informant No. 9 (CSO, Pemba)

"In my view the big challenge in Mozambique is to fight against corruption - and the government is aware of this - which, I think, is an evil that pervades our society. ... On the other hand, we have the question of accountability which I think is essential. We come from a culture where accountability perhaps was not the way we saw things, but as a precondition for good governance it is necessary that the government be sensitized concerning the issue of accountability so that an ordinary citizen knows what is happening and how and why.

Then there is the question of the provision of basic services to citizens which somehow reflects the recent phenomena. I think the government has worked on this, and it has to work on this, because it is their obligation to increasingly improve the standard of living of Mozambicans. So I think these are the major challenges."

The above views were echoed by several other key informants. For example, one key informant heading a nationwide CSO from Maputo stated that "corruption is always a challenge for good governance, the reform of the legislation, we have the issue of conflict of interests, the issue of the management of public goods" (Key Informant No. 6, Maputo).

Many of the key informants made the point that while corruption is endemic, it hits the poor most. For example, one of the key informants working as a senior civil servant in the health sector in Maputo argued that "Corruption is big problem, seriously.... 
It is really an evil that pervades our country" (Key Informant 5). Another key informant from civil society made the following point:

Key Informant No. 15 (Maputo/Pemba)

"When we talk about corruption, well $\mathrm{OK}$, there is a lot of money going around and we don't even know how much and for whom etc., and of course, that money is also away from the people. But what hurts most the ordinary people is the petty corruption, that is, the police, school, hospital and all public offices, all offices."

The discussion on the greatest governance challenges seems to broaden the interpretation of the notion of governance to the entire political economy of the country, beyond the specific attributes of good or bad governance. According to several key informants, the governance situation in Mozambique is ultimately framed by the nature of political governance which impacts upon the perception of the legitimacy of the government and the sense of citizenship among the population. For example, the challenges related to poverty and corruption, or transparency and accountability, in themselves perceived as major governance concerns, were seen as closely linked to the political economy of Mozambique. In other words, the discussions revealed that, from the Mozambican stakeholder perspective, the political dimension of governance is perceived to be the most critical area of governance which underlies the challenges identified in other dimensions of governance. The narratives below illustrate the perceptions of the various respondents concerning the complex relationship between the political context and its implication for governance.

First an account by a key informant affiliated with a Maputo-based CSO engaged in community training and advocacy:

Key Informant No. 2 (CSO, Maputo)

"The biggest challenge is poverty, but the big problem is that politics and poverty are not separate issues. They are interlinked in such a way that their boundaries are minimal, and to fight against corruption means fighting against poverty, and making the political process more democratic and free would probably have implications for poverty, I don't know..... The political control of the country by Frelimo means also economic control, and the economic control is corrupt. The political process, the political dominance, means economic dominance. Therefore it has all the power of corruption with this dominance."

The blurring of the boundaries between the state, the government, the citizens and the ruling party as the key challenge for governance in Mozambique was pointed out also by another key informant from Maputo, identified as an academic cum private sector actor: 
Key Informant No. 3 (ACA/PS, Maputo)

"I think the most sensitive point is the sense of citizenship at all levels, including the economic elites, intellectuals and even worse at the grass root level. I think people still don't have a sense of citizenship, it is still very low. But why? Because the relationship between the political sphere and the economic sphere - we have no independence between the various spheres. I cannot see a sphere of markets that is clear, a sphere of the state that is clear or a sphere of civil society that is clear. The spheres are not clear. And above all this you have a party, which is the state, and which has tentacles in all these areas so that you have elites which end up being the same in all these circles."

His views were echoed by another academic cum civil society actor from Maputo who also highlighted the poor sense of citizenship in Mozambique, and further questioned the state's interest in having informed citizens that know their rights and responsibilities:

\section{Key Informant No. 7 (ACA/CSO, Maputo/Nampula)}

"I believe there are issues that are related to the fact that we do not have citizens, because people don't know their rights, they don't exercise their rights, they don't demand, they exercise neither their rights nor duties. In my view there is a big problem of ignorance, and this closely linked with the way this state functions. I don't even know whether the state wants people to know their rights or not, because knowing their rights would mean exercising the right, to demand etc. In my view there is a serious problem in this regard."

The discussion on the greatest governance challenges also brought up the question of the role of the parliament. While some of the informants expressed their concern about the lack of political competition, some referred to the weakness of the parliament in playing its oversight role vis-à-vis the government. According to a key informant working as a coordinator of an NGO forum:

Key Informant No. 6 (CSO, Maputo/National)

"The question of the power of the Assembly of the Republic is the most important, the question of political parties in terms of a multi-party democracy. It is fundamental that Mozambique has very strong political parties and not only the tendency towards one party which we are seeing - you can say that the great challenge is this.... We are moving towards a single party and our space as civil society is also becoming more and more limited."

A similar view was expressed by one of the Members of the Parliament who stated that:

Key Informant No. 18 (MP, Maputo).

"We need a functional state structure, we need a state that can meet all these challenges.... We need a country that begins to think seriously that if 'A' governs the country today, 
tomorrow also ' $B$ ' can govern the country. We also need to eliminate all ideological burdens from the state apparatus, the state cannot be mixed with one political party, the state must be a public thing."

One of the key informants affiliated both with the academia and the civil society went further, arguing that the nature of the political governance presents a risk to the stability of the country:

Key Informant No. 8 (ACA/CSO, Maputo/National)

"The democratic process is one of them, the issue of urban poverty is another, the issue of HIV-AIDS is another challenge because it has very profound implications both political and economic, social and all that...Another question, facing all this, is how to gain the legitimacy to govern, when $60 \%$ of the population is outside the system and does not recognize you as a legitimate leader; population that at any moment can be mobilized to destroy all this that the donors call a success story, success 'for whom, by whom'."

In this context the question of the respect for the rule of law, which had been identified as a key characteristic of good governance, was brought up again, now with a specific reference to the political governance of the country. According to a key informant from Pemba:

Key Informant No. 13 (CSO, Pemba)

"There may be many challenges, but the question of implementing the decisions or activities of governance within the rule of law is central. The question, for example, there are some issues related to electoral laws, the process of elections, which do not follow the procedures of our electoral law in our country, and end up undermining the survival of other opposition parties."

The key messages emerging from the focus group discussions echo, to a large extent, those distilled from the key informant interviews. The issues related to transparency and accountability, and even more explicitly to corruption, were highlighted as the greatest challenges of governance for Mozambique. Again, the emphasis on corruption as the single most serious governance challenge was somewhat surprising as corruption had not emerged as a central theme in the discussions on the concept of good or bad governance.

The passage from the exchange of views in one of the focus groups in Pemba (Focus Group D) captures well the concerns related to corruption. The focus group discussants are civil society activists dealing in environmental protection and community training: 
Focus Group D, Discussant No. 2 (female)

"One of them is corruption, that is the most important that has triggered all others."

Focus Group D, Discussant No. 1 (male)

"The fraud of public funds, this is one thing. That is, in fact, theft of public funds that we are talking about is because corruption manifests itself in various ways. But one issue which is of concern is the issue of misuse of public funds for personal purposes. This is something that happens a lot. In the area of public services for citizens, for example if we look at the health institutions, the treatment of the patients in the health centres is poor and you even have to pay to get proper treatment. Because of this situation, for example pregnant woman, everybody knows that when she goes to have the baby, she has to take some 200 or 300 or 500 [meticais, added by the author] in capulana [the traditional clothing, added by author], because if she cannot take out this money at the time of the delivery, she may run the risk of dying."

Focus Group D, Discussant No. 2 (female)

"It is everywhere, the government authorities just don't want to admit that this goes on in all places of civil service but it does. Even in the notary..."

Focus Group D, Discussant No.1 (male)

"I believe this problem of bad service in public institutions, they have the habit, for example, with regard to dealing with simple process - like when you need to get an identity card or if you need a statement - sometimes it can take a long time. This still happens, it is a challenge."

Focus Group D, Discussant No. 2 (female)

"And this slowness practiced by public officials, it is deliberate slowness in all public services because they know that the more worried the citizen is, that is when they can practice that mini-corruption, a deliberate slowness in health centres."

Focus Group D, Discussant No. 1 (male) and Discussant 2 (female)

"And finally, you need to go and beg for a favour from the public official... (Discussant 1 (M) ...to advance your service and..." (Discussant 2 (F))

\section{Focus Group D, Discussant No. 1 (male)}

"But now we have already reached the situation where your process will be forgotten if you don't pay anything. And if you cannot pay, because most people cannot, you have a big problem. We are a poor country where most people don't have even the minimum, not even food." 
The problem of corruption was perceived to be the core challenge for governance by several discussants in other focus group discussions in Pemba as well as in Mocuba.

However, like many of the key informants cited above, the focus group discussants in Mocuba, involving civil society activists, small scale farmers and local media members, approached the question of greatest governance concerns from a wider perspective of democratic governance pointing out problems related to the blurring boundaries between the state and the party in power, the inability to exercise civic rights and poor law enforcement. The excerpts from the discussion in the Focus Group F (Mocuba) illustrate the perceptions by the discussants:

\section{Focus Group F, Discussant No. 8 (female)}

"For me, corruption is a big cancer in our communities, our country will not progress while corruption continues at this level. And another question is to use the word democracy in its real terms, to put it in practice and not just use as a blasphemy in public assemblies or say that we are democratic, because democracy itself, implemented, it is good. Therefore, we must have political parties, which we can trust and which we can elect; and I can say that I am Renamo without being humiliated, I can vote for whom I want, I can trust that my vote will actually make have a weight in that place where I vote."

"There is no difference between government and Frelimo. We're mixing things up and no one knows that there is difference between party and government. But here there is no difference. When you speak about the party, it is the government, it is the same."

Another discussant from the same group made a similar point by saying that "From my point of view one of the challenges is that there are perhaps many citizens who cannot differentiate between the Frelimo party and the government. Because people do not realize exactly what the party is and what the government is... it is a very big challenge." (Discussant No. 12 (male))

The above views were echoed by several other discussants with some pointing at the high level of illiteracy as the factor contributing to the lack of democratic governance. For example, one of the discussants argued that "a big challenge that still needs to be overcome is the high incidence of illiteracy. Because to govern illiterate people is 'very easy'. But to govern people who think for themselves, they will always contradict that what you think in order to improve things. If you govern illiterate, uninformed people, they will just accept what you say but there is no action, no reaction." (Discussant No. 11 (male)).

As in the case of the key informants, the focus group discussants in Mocuba raised the question of access to information and the respect for the rule of law as major challenges for governance. In the words of one discussant: 
Focus Group E, Discussant No. 8 (female)

"... there is a lack of knowledge: the laws are fantastic, I've read the Constitution, it is fantastic. If the country functioned according to what has been written, it would be fantastic. But information, the laws are made in Maputo and remain there in drawers, in the archives....the less people know, the better I can govern. In other words, it is misinformation; corruption has already become a culture and we think misinformation is in our own benefit."

In contrast with the focus group discussants in Pemba and Mocuba, who rather consistently raised corruption and the lack of transparency of the political process as the greatest concerns for governance in Mozambique, the discussants in Maputo approached the question from the point of view of concrete problems mentioning issues such as the lack of transport, lack of a sufficient shelter in their working environments. The question of corruption did not enter into the discussion.

To conclude, the outcome of the key informant interviews and focus group discussions indicates that the greatest governance challenges in Mozambique relate to the political economy of the country, characterized by the political and economic dominance of the party in power since independence. For example, the question of corruption, singled out by many informants as the biggest challenge, was seen as an indication of the political dynamics of the country. Expressing themselves in various ways, the respondents referred to the need to strengthen democratic processes and citizens' rights, while others raised their concerns about the perceived trend towards a one party system. The dominance of the Frelimo was seen as having resulted in the capture by the party of the state apparatus, the private sector, and to some extent, civil society. This undermines attempts to reform governance in specific areas such as transparency and accountability, the fight against corruption and the respect for the rule of law.

Analyzing the outcome of the interviews against the framework of the WGI, it can be argued that from the Mozambican stakeholders' perspective, the core challenges for governance relate not only to political governance, but also more specifically, to democratic governance of the country. Issues concerning the perceived shift towards a oneparty state, merging of the state and the party, weak sense of citizenship and endemic corruption point to a "democratic deficit" as the core component of governance among the Mozambican stakeholders. The concept of democratic deficit, which refers to "any situation in which there is believed to be a lack of democratic accountability and control over the decision-making" ${ }^{\prime 50}$, has been widely used with reference to the functioning of the European Union, but also, for example, with reference to the political system of the USA. In his critique of USA politics, Chomsky refers to democratic deficit as

150. Source: http://www.collinsdictionary.com/dictionary/english/democratic-deficit 
"that feeling of helplessness, impotence, everything is run by somebody else, I can't do anything about it" (video recording, August 18, 2009. Retrieved from the World Wide Web http://bigthink.com/videos/the-democratic-deficit, August 14, 2012).

Similar views can be detected from the interviews among the Mozambican stakeholders. The issues related to democratic deficit are not fully captured by the WGI notion of political governance, which focuses only on the rights to participate in elections and the respect for fundamental freedoms such as freedom of association, freedom of speech etc. which are guaranteed by Mozambique's Constitution.

Another related theme that emerges from the discussions on the greatest governance challenges concerns the sense of citizenship and the difference between having rights in theory and being able to exercise those rights in practice. The views expressed by several of the key informants and focus group discussants about the weak sense of citizenship among the Mozambicans, and about the low level of understanding of the citizens rights and responsibilities, can be best understood using the concepts of "formal citizenship" and "substantive citizenship", developed by Glenn (2010). Building on the work of the British sociologist T.H. Marshall on the evolution of citizenship, Glenn argues that citizenship is not only a formal legal status (formal citizenship), but also a fluid conception that is constructed through every day practices and interactions between the members of a given community (substantive citizenship). The analysis of the data gathered through the interviews points at the challenges faced by the Mozambican citizens to exercise their rights as individual citizens and as members of a community. Although their rights and responsibilities are laid out in the Constitution and related legislation, in practice their possibilities to participate as full-fledged members are challenged. This aspect of governance, which is perceived to be the core element of governance in the Mozambican contexts, is not captured by the WGI approach to governance.

At the same time, it can be concluded that the interpretation of the concept of governance among the various Mozambican stakeholders, including their views about the characteristics of good governance, is rather consistent with the WGI classification of governance. In light of the analysis, governance seems to be understood, first and foremost, in terms of the management of public affairs involving the government, the private sector and civil society. The attributes of good governance, such as transparency and accountability of the state, the fight against corruption, access to justice, delivery of public services and the dialogue between the government and civil society, which feature high on the donor governance agenda, are highlighted as the key elements for good governance also in the Mozambican context. However, despite the largely shared interpretation of the meaning of governance by the Mozambican stakeholders and the donor agencies, there seems to be one important difference, which 
relates to the emphasis given to the political dimension of governance. On the basis of the interviews, from the Mozambican perspective, the most fundamental element of governance pertains to the political context, which is seen as the underlying factor contributing to good or bad governance in the country.

\subsubsection{Knowledge of Donor Governance Assessments}

The shared understanding of the concept of governance, including the notions of good or bad governance, among the donors and Mozambican stakeholders, can be considered as one of the key preconditions for the relevance of the donor assessments for the governance discourse in the country. It can also be assumed that the Mozambican stakeholders' knowledge of the donor assessments impacts upon the significance of these assessments at the country level. If the local stakeholders are not aware of the donor assessments, and have no access to the assessment reports, the relevance of these assessments for the governance discourse in the country is likely to remain limited. As an input to the analysis of the relevance of the donor governance assessments, the country-level knowledge of the assessments was explored through a series of questions related to the local stakeholders' familiarity with the assessments.

To this effect, the informants were asked if they had heard about any governance assessments carried out by the donor agencies operating in Mozambique. If the answer was affirmative, additional questions were made about the informants' knowledge of the topics covered by these assessments, and their access to the assessments reports. The informants were also asked whether they had been involved in the assessment processes. In case the informants were not aware of any donor governance assessments, they were invited to share their knowledge of any other governance assessments, including those carried out by Mozambican organizations.

The analysis of the field data starts with the information provided by the key informants, followed by the analysis of the focus group discussions. The analysis is supported by the OECD DAC conceptual framework applied to the overview of the donor governance assessments (Chapter 6), with focus on the questions related to the reporting and dissemination practices and partner country ownership of the assessments.

As to the key informants, the level of awareness of donor governance assessments varied widely from relatively detailed knowledge of the topics covered by the assessments, the methodology used in conducting the assessments, and the results of the assessment reports, to just general ideas about the assessments. The key informants who had participated in donor governance assessments as team members, had been subject to assessments due to their professional roles, or had acted as sources of information for 
donor assessments, were, rather obviously, among the best informed. They were able to refer to specific assessments and name at least some topics covered by the assessments. Some of the key informants also volunteered their views of the methodological choices and accessibility of the assessments.

The quote below from an interview with an academic cum private sector actor based in Maputo represents the level of knowledge among the best-informed key informants. He had firsthand experience from some donor governance assessments, although not necessarily from any of the assessments under consideration in this research, and was able to mention a number of specific topics that, in his view, are normally addressed in the donor assessments. It is worth noting that the informant used the English words when referring to the topics of the assessments although the interview was otherwise conducted in Portuguese (underlined words were used in English):

Key Informant No. 3 (ACA/PS, Maputo)

"To my understanding, accountability is an important part. Voice is also important in the sense of participation and that is an area which has been addressed a lot. Also public service delivery is a very important area. Accountability in the broadest sense, not only vertically but also horizontally between institutions, in other words, questions concerning public administration are addressed in relation to other state organs etc. These are normally the main topics, at least as far as I can think of...... the main topic of the World Bank and the IMF."

The topics listed by the key informant correspond, by and large, to the aggregate indicators used by the World Governance Indictors, although the WGI as a specific governance assessment tool was not mentioned by the informant.

Another key informant affiliated with a Mozambican research cum CSO made reference to the World Bank CPIA and the IMF assessments, albeit pointing out difficulties in accessing the reports:

Key Informant No. 6 (ACA/CSO, Maputo)

"There are assessments which are clearly intended for reforms. For example, the World Bank's CPIA is oriented to the reforms and goals where the government should make progress. The CPIA is not a document known to the public, nor are the indicators of the World Bank to disclose this assessment. There are other assessments that are made ... what I follow closely are the indicators of the IMF, but I don't have much access to the assessments of the IMF in the area of governance. It is certain that the reports of the Fund cover cross-cutting issues such as the issue of extractive industry." 
The above two key informants were exceptional with their relatively specific knowledge of some of the governance assessments carried out by the donor agencies. The rest of the key informants responded to the question in more general terms. While mentioning one or two donor agencies by name, they mainly share their perceptions about the problems related to the assessments. For example, one of the senior civil servants described his knowledge as follows:

Key Informant No. 21 (SCS, Maputo)

"We have, for example, those periodic assessments made by the World Bank and USAID, and sometimes they are a bit controversial. And somehow, although called external assessment, it is a judgment made by people following the order of the partners, or donors... in some cases they are called 'partners' but often they are 'donors'. They make their judgments on what is called performance but it is of our internal dynamics, using some kind of standards and benchmarks on the basis of which they give an opinion of whether our governance is better or worse. In other words, I have heard about them."

Somewhat similar accounts were provided by several other key informants. One key informant, affiliated with the Mozambican academia and media, described his knowledge as follows:

Key Informant No. 17 (ACA/MED, Maputo)

"I don't know well many of the assessments but I know one assessment made by DFID which recruited a well-known Mozambican sociologist, Elísio Macamo, to participate in the study. And I know also another assessment by Ireland that hired a researcher Joseph Hanlon as a senior evaluator. I know the APRM review, and yes, I know some things of CIP.

From what I've seen in most of assessments that I know, the assessments are highly subjective, there is no access to assessment tools and there are no clearly defined indicators that can be quantified and used for assessing a specific issue under discussion, and this is a cause of some concern for me."

His views were echoed by one academic cum CSO activist:

Key Informant No.7 (ACA/CSO, Maputo/Nampula)

"In my view the assessment reports are not known. I know some of them because of my work. The one that is most publicized is the one of the U.S. State Department on the issue of justice. It is the only one and there is always confusion, because they make a copy and paste' of the previous report. This is it the only one that is discussed in the newspapers and for many years it is the one that has been commented on... I don't know them and even the government itself says that it does not know of them. But all do their assessments." 
I think they are known by people who deal most directly with this. I do not think they are discussed, perhaps even the Assembly [of the Republic, added by the author] should discuss such assessments because it is there where these issues are also debated. I don't know if the Council of Ministers discusses them or not, but even in terms of civil society, in my view, they are not distributed for people to study them and to know them."

The level of knowledge among the Members of Parliament interviewed for this research did not differ fundamentally from that of the other key informants. There was no indication of the parliament's engagement with the assessments at any stage of the assessment processes, although the parliamentarians were fully aware of the assessments. One of the Members of Parliament provided an interesting interpretation of the donor assessments from a historical perspective:

Key Informant No. 19 (MP, Maputo)

"The period immediately after the war, the first multiparty elections, the period after -94, the phase until the end of the Chissano government... At that time the assessments that were made were not very impartial, the primary objective of all partners was to give some protection. This was a country coming out of the war, a country taking its first steps towards a democracy, and therefore a bit of paternalism was necessary, the paternalistic tendency was necessary. Whether it was good or bad, only time will tell, but I believe that, at that time, there were not many options and therefore the development cooperation partners ended up protecting the government to push forward with reforms, whether flawed or not. If they had been very hard in their assessments - I believe - the reforms would have stalled without progress.

Then we entered into the later phase which is the phase of the government of Guebuza. Initially he came out as a very authoritarian person which also caused some of the cooperation partners to harden a bit. And I think there was, let's say, more pressure, and he himself also adopted this discourse of the fight against poverty, corruption, bureaucracy which, in the end, was the framework required also by the donors."

The above excerpts illustrate the level of knowledge among the best informed key informants. Having been involved, in one way or another, in the assessment processes or having had some access to the assessment reports, they were able to refer to at least some specific donor assessments. However only 2 of the key informants seemed to be familiar with the assessments conducted by the World Bank (the CPIA and the WGI), while one of the key informants referred to the assessment conducted by the DFID. The assessments conducted, for example, by the African Development Bank and the EU, or by the other bilateral agencies included in this research, did not enter into the discussion. This outcome is surprisingly low in comparison to the donors' own description of their reporting and dissemination practices and of partner country involvement in the assessment processes. 
Outside Maputo the level of knowledge of donor governance assessments among the key informants turned out to be even much lower. The interviews conducted with the key informants in Pemba showed that they had very little, if any, knowledge of the governance assessments conducted by donors. At the same time the key informants seemed very familiar with the practice of governance assessments carried out by Mozambican CSOs. When asked about the donor assessments, they tended to approach the question immediately from the perspective of local assessments, whereas the donor governance assessments hardly entered into the discussion.

The excerpt below from an interview with a key informant affiliated with a CSO active throughout the country reflects well the general knowledge:

\section{Key Informant No. 9 (CSO, Pemba)}

"I have some knowledge, though not very good, of the work of CIP [Centro de Integridade Publica, added by the author] and some other organizations that have done almost periodic assessments of governance in Mozambique. At the local level in Cabo Delgado we have the Christian Council of Mozambique and we have the Human Rights League which have made an assessment, for example, of local governance, in particular, of the district development plans at the level of province. ... The results are published in reports, and usually there is a workshop to present the results and share the information. In other words I know some who have done this kind of work."

When asked specifically about the governance assessments carried out, for example, by the World Bank or the USA, the answer was "I don't have very deep knowledge of the assessments made, for example, by the World Bank or by the United States."

Similar responses were given by several other key informants in Pemba. While some of the informants referred in passing to the governance assessments conducted by donors, their level of knowledge of specific donor assessments seemed marginal. However, most of the informants seemed to have been involved in some local assessments. They were able to describe with some detail the issues addressed in these assessments as well as the reporting and dissemination mechanisms applied by the local actors. For example, the key informant cited above elaborated his understanding of what the local assessments entail as follows:

Key Informant No. 9 (CSO, Pemba)

Concerning the organizations such as the CIP, and the reports that have been presented, the main topics issues that are included, I think, are more related to the questions of reform, for example, the question of corruption and the question of the provision of basic services to people. These have been the focus or the topics that have been often covered when the assessing the process or aspects of governance, at least here in Mozambique." 
His views were echoed by another key informant working at a CSO that is involved in community training and advocacy:

Key Informant No. 10 (CSO, Pemba)

The topics that are addressed are related to transparency, proper management of funds, the question of corruption, the question of the provision of social services, these are the topics that are often addressed at least in the assessments by the CIP and the GMD [Grupo Mocambicano de Divida, added by the author].”

While the key informants in Pemba seemed, in general, relatively knowledgeable of the local assessments related to governance issues, some of the informants did not seem to be familiar with any governance assessments at all. For example, the informal sector traders seemed largely unaware of these assessments. As stated by the Key Informant No. 12 affiliated with the informal sector traders' association: "I am not able to answer this question. I have not yet heard [of these assessments, added by the author]."

To conclude, in light of the key informant interviews, there is some knowledge of donor governance assessments, at least in Maputo. The best-informed respondents were able to mention 2 or 3 donor assessments and identify some topics included in the assessments. However, the key message that can be distilled from the analysis implies that the reporting and dissemination of the donor governance assessments remains very limited, despite the fact that the majority of the eight donor agencies under consideration claim that they are willing to share their assessment reports. Hence, even among the best-informed respondents, i.e. among those who through their work or professional roles had been involved in some assessment processes, the level of knowledge of the specific assessment tools was limited. It is also important to note that the best-informed key informants were all based in Maputo where the donor agencies, central government authorities and the media are centered. Outside Maputo, the level of knowledge of the selected donor governance assessments was practically nonexistent, and the donor assessments in general barely entered into the discussion. However, most of the informants seemed to be very familiar with the governance assessments conducted by local organizations, particularly with those that focus on corruption and on the government's performance in programme implementation.

The focus group discussions, which were held primarily outside Maputo, revealed a somewhat similar picture as the one emerging from the key informant interviews in Pemba. Many of the focus group discussants had been directly involved in local governance assessments within their own field of work or in their specific geographic location. The discussants thus responded to the question about their knowledge of the assessments on the basis of their own participation in the assessments, often highlighting the problems they had encountered in the assessments. As stated by one of 
the discussants from the peasants' association: "the UPC is always involved in these meetings on assessing the performance of the government" (Focus Group A, Discussant No. 1 (male).

In most cases, the assessments seemed to have been initiated and carried out by local actors, with a focus on the performance of the local or central government authorities. Having themselves been involved in the assessments, either as individuals or as a group, the discussants were able to describe well the issues addressed. In light of the discussions, the assessments seemed to have focused on the government's performance concerning issues that are central for the livelihood of the local population. The excerpt from the discussion among the peasants illustrates well the multitude of issues captured by their assessments:

Focus Group A, Discussant No. 1 (male, Pemba)

"There are many questions that are raised, the question of domestic violence, which the government also takes to its heart, there is the question of the land law... Then there is the question of getting access to equipment, we know what we need to produce....

We can see in our province some districts which are suffering about the conflict between humans and animals. I believe there is a law that protects wildlife but I think they are now defending more animals than the people who pay taxes. I do not know what contribution they bring, these animals, to people because it is difficult to put elephants with people, I don't know how you can do it. These are more or less the questions... We can look at the large companies, we have here the company $X$, if we were to go where it has been established and see what is its benefit to the community we would not find anything...

Therefore, there are several issues that we raise. There are the questions about the work of the Consultative Councils. There are several issues that we can mention here, it is a long list... There are serious problems."

Two female discussants from the same group added to the "long list" and made specific reference to issues related to the use of natural resources which appeared to be one of the critical issues addressed in the local assessments:

"I can also contribute to this question of logging... the $20 \%$ for the communities. In the communities, it is only the village chief who knows about these funds, the community does not even know about them. There are no consultations." Discussant No. 2 (female, Pemba) .... "Another thing still is that people exploit sand in our area. The make use of the sand without the knowledge of the people, of the community. There are so many potholes that people are even afraid when they go to those areas because of the water." Discussant No. 3 (female, Pemba) 
The key findings emerging from other focus group discussions in Pemba pointed to a similar situation: the focus group discussants had themselves been directly involved in assessing the government's performance in terms of the implementation of the provincial and district level development programmes. The level of knowledge of the discussants was determined, largely, by their personal participation in these assessments. As described by one of the focus group discussants:

Focus Group C, Discussant No. 1 (male, Pemba)

Even the GMD has made these assessments, but not from the provincial level, they were carried out from the central level. The work was done together with the Christian Council of Mozambique and AMODE, I don't know if there were others, they did the work together. They visited all the municipalities here in Cabo Delgado.

The discussants seemed well informed not only about the topics covered by the assessments but were also able to elaborate on the processes for conducting the assessments in detail. For example, one of the discussants described the assessment process his organization as follows:

Focus Group C, Discussant No. 2 (male), Pemba

"As ... [name of the person left unidentified] just said, and this is often the case with AMODE, this is what we have done in the districts of Chiurre, Montepuez and Mocimboa da Praia. What do we do? We have our activists there, they follow-up the programmes day after day, and after the assessment, after a year, we call all administrators of those districts where the monitoring takes place and start to inform them that 'this is what you have promised to do and what would accomplish last year and this what you have achieved and this is what you have not achieved'... And it is not only AMODE, now we have another organization that has also participated, a faith-based organization, a religious organization. It chose the districts of Namuno and Mocímboa da Praia. And as I just explained, when we get there, we collect the information, we start to look what the government has promised to do over the year and whether they fulfilled that."

The level of knowledge among the focus group discussants in Mocuba did not seem to differ from that in Pemba: the discussants were very familiar with assessments conducted by local or national organizations but their awareness of the donor governance assessments seemed marginal. The discussants approached again the question on the basis of their experience from assessments describing at length the focus of and the processes for conducting the assessments. The governance assessments carried out by donor agencies did not enter into the discussion.

In conclusion, the key findings concerning the level of knowledge among the Mozambican stakeholders interviewed for the research indicate that while many of the key 
informants are aware of the practice of donor governance assessments, very few are familiar with specific assessment tools. Among the focus group discussants, the level of knowledge of donor assessments is very limited although they are very knowledgeable of the various assessments conducted by Mozambican civil society organizations and other local actors.

This outcome is somewhat surprising in light of the donor agencies' descriptions of their reporting and dissemination practices. As discussed in Chapter 6, apart from the assessments by the UK and the Netherlands, the results of the governance assessments under consideration in this research are made available to the local stakeholders, albeit accessible only through the internet. Even in the case of the UK and the Netherlands, the reports can be shared with the partner country authorities subject to a consideration by the respective field offices. However, despite the formal disclosure policies, the reports of the governance assessments seem to remain within very restricted circles in Maputo, and fail to reach local stakeholders beyond the capital. While the limited knowledge by the local stakeholders of these assessments may in itself be interpreted as an indication of their significance at country level, it is not necessarily so. The question of the relevance of the governance assessments is therefore explored further in the next section.

\subsubsection{Relevance of Donor Governance Assessments in Mozambique}

The discussion in the section 8.2.1 concerning the interpretation of the concept of governance, including perceptions of good and bad governance, points to a relatively similar understanding of these complex notions among the Mozambican stakeholders and donors. At the same time, the above analysis of the stakeholders' knowledge of the donor governance assessments indicates that the awareness of the donor assessments is limited even among the key informants, and practically non-existent among the focus group discussants. While the shared understanding of what constitutes governance provides a good starting point for addressing relevant issues, the limited knowledge among the stakeholders of the donor assessments can be seen as a factor that undermines the relevance of these assessments.

In order to explore this question, the informants were asked to express their views on the relevance of the donor governance assessments, including the topics addressed in the assessments, from the perspective of the governance context in Mozambique. This question was raised only among those informants, in all 22 informants, who had some knowledge or experience of donor assessments. The main purpose of the discussion was to shed light on the question of whether or not the donor governance assessments 
succeed in capturing governance concerns considered relevant by local stakeholders in the specific case of Mozambique.

The key messages emerging from the interviews indicate that the answer to the question of the relevance of the donor governance assessments is not clear-cut. The informants approached the question from various angles, some commenting on the topics addressed, some on the methodological choices, and some reverting to the question of the accessibility of the assessments. According to the informants, all these aspects impact upon the relevance of the donor assessments.

Concerning the relevance of the topics, it seems that many of the issues addressed in all the selected donor governance assessments, such as transparency and accountability, delivery of public services, public financial management and corruption, are perceived to be central in the governance discussion in Mozambique. As expressed by one of the key informants: "the issues relevant for governance are the same all over the world, in China, in Europe, in Mozambique: corruption, transparency, accountability" (Key Informant No. 4, ACA, Maputo). Similar views were presented by most of the other key informants.

At a more specific level, it was pointed out that some of the donor governance assessments use the national poverty reduction strategy, PARPA, as the frame of reference and, therefore, touch upon issues which are perceived to be relevant also for Mozambique. As stated by one of the key informants affiliated with a Mozambican CSO which focuses on governance questions:

Key Informant No. 6 (ACA/CSO, Maputo)

"The CPIA is somewhat aligned with the indicators of PARPA, and surely it addresses many other concerns related to public sector reform. Therefore, in my opinion, it is one way of the World Bank to assess whether the government is implementing the reforms included in the PARPA. There are other assessments... I follow closely the letters of instructions by the International Monetary Fund (IMF) but I don't have access to the assessments carried out by the IMF in the area of governance."

Some of the key informants pointed out issues which, in their view, were not sufficiently addressed in the donor assessments, such as economic inequality, gender equality and human rights, particularly the rights of women. The failure to address these specific issues was seen as a limitation of the relevance of the governance assessments in the context of Mozambique.

For example one of the key informants, with long experience from both academia and civil society, criticized the World Bank for not addressing the question of inequality: 
Key Informant No. 7 (ACA/CSO, Maputo/Nampula)

"What matters to the World Bank, is not how wealth is distributed, they often are not at all concerned about it...It is not enough to know that the income per capita increased, but how is it increased, how is it distributed? In my view, very often there is no such an analysis, and even less any concern about it."

Several informants, both men and women, argued that gender issues are often not taken into account at all. Even when gender issues are addressed, they are addressed only within the framework of specific assessments on the position of women, and therefore remain isolated from the general discussion on governance. In their view, the position of women is paid attention only in assessments which focus on areas such as education and health which are traditionally considered to be areas involving women.

However, as discussed in section 8.2.2, the interpretation of governance by the Mozambican stakeholders includes one additional dimension, conceptualized as participatory democracy, which is not fully captured by the donor approaches to governance. This notion of participatory democracy, characterized as broad-based community participation with a strong sense of citizenship, emerges again as the critical element missing from the donor assessments. When responding to the question of the relevance of the donor assessments, most of the key informants mentioned issues which can be identified as aspects of participatory democracy. Expressing themselves in different ways, the key informants spoke about the wider political environment in Mozambique which, in their view, is not sufficiently taken into account in the donor governance assessments. As formulated by one of the informants, identified as an academic cum civil society actor:

Key Informant No. 8 (ACA/CSO, Maputo)

"Most donors prefer to focus on less sensitive areas such as education and health. Questions related to justice, question of elections, for example the question of political participation, the question related to decentralization, for example what are the reasons for a country like Mozambique not to increase the number of municipalities and to adopt the strategy of gradualism, the freedom of expression, the space for public debate, the media; these do not enter into the agenda. The question of the capture of the state by a political party does not enter into the agenda either."

Another key informant, with a background both in the academia and media, argued even more forcefully that the governance assessments fail to address the question of the state of democratic governance in Mozambique. In his view:

"there is one thing that is important, and it seems to me that this is not sufficiently raised when making an assessment of the quality of governance - although it is a perfectly bureaucratic and we cannot criticize because one party is systematically chosen to govern 
- the idea of a dominant party in countries with a citizenship deficit and weak national identity, i.e. where the institutions are not strong enough, what happens? It is always the same party that rules....You have a parliament that has been in power for the past 15 years, and having the mandate, has always been unanimous." Key Informant No. 17, ACA/MED, Maputo

One of the most critical judgments of the donor assessments was made by an academic cum civil society actor who argued that the donors deliberately close their eyes to the political processes in the country, and that the assessments are just a play between the government and the donors:

Key Informant No. 8 (ACA/CSO, Maputo)

"The most painful part of this whole process is that I see how the Netherlands, Sweden, Switzerland, all those countries which strongly supported the national liberation movements, have now completely changed their discourses. Today they say that they cannot interfere in internal affairs, that today you already have your sovereignty... At that time they had the courage to stand side by side with the process of national liberation, and today there are not side by side with the process and pro-democracy movements in the country, with the basic principles that guide much of the philosophy of the rights of the citizens in Europe.

My mother says, 'My son, haven't you yet realized that this is a game of two elephants, and therefore it is you who will suffer as you are the grass'. She is a woman with primary education only but as she watches television she can see that it is a game. And she also says 'why do you want to get involved just to suffer in this game of these elephants, let them drink their water, it is their business and their problem, go on with your own life."'

It was further argued that even when issues related to the political dimension of governance are addressed, the assessments fail to capture the specific dynamics between the state and the citizens in Mozambique because of their standardized approach. In the words of one of the key informants with firsthand experience of donor assessments:

Key Informant No. 3 (ACA/PS, Maputo)

"I don't know but I think there are sometimes assumptions about the state and about citizenship which do not reflect well the status or the specific reality as to how the issues are seen either by the actors of the state or by the individuals themselves...I think that something does not make sense, and as a result, you often have an assessment which covers all the issues but does not reflect the essence of the dynamics of the relationship between the state and the society in the specific context of our country. In my view this excessive standardization of the assessments ends up hiding the essence." 
According to the key informant cited above, the failure to address the core problems embedded in the state-society relations in Mozambique results from the "one size fits all" approach applied in many of the donor assessments. Elaborating his critique of the approach he pointed out that:

"In my understanding these assessments are very standardized, and well, for an organization like the World Bank or the IMF it is important to have frameworks because they operate in various parts of the world. But sometimes, as they are too standardized, there are specific issues that are not captured in these studies, and this is their great weakness. Often when I pick up stories of some studies I am confused about what they want because there are issues that don't make sense. But why? Because these are assessments that are conducted within the framework of global studies and have to follow a certain line, and sometimes the result does not reflect the most sensitive questions of a given country." (Key Informant No. 3, ACA/PS, Maputo)

In other words, in his view one of the root causes for the limited relevance of many of the donor assessments relates to methodological issues. Similarly critical views about the methodology applied in the donor assessments were presented by several other key informants. Some raised questions about the terms of reference of the donor assessments while some challenged the type of indicators used for assessing governance performance. As stated by one of the informants affiliated with both the academia and civil society: "in my view the problem lies in the terms of reference for the assessments, they have nothing to do with the reality of the country" (Key Informant No. 7, ACA/ CSO, female, Maputo/Nampula).

Her views were somewhat echoed by another key informant, working as a senior civil servant for the government, who argued that the terms of reference set by the donors fail to take into account the context-specificity of the governance situation:

Key Informant No. 21 (SCS, Maputo)

"Well, these assessments... often arise from the point of view of those who call for the assessments. The donor is the one who often initiates the assessment exercise. This means that he already has his own understanding of what is good governance. He comes here to study, to analyze a situation in reality, based on his references, not on our references".

The following statement made by one of the key informants illustrates well the general thinking about the quality of the indicators: "I don't doubt the legitimacy and good intentions of the donors. That is not the issue and that is not what I want to say. What concerns me, and what in my view is not well defined is the basis for defining an indicator." (Key Informant No. 17, ACA/MED, Maputo). 
He elaborated his concerns by using the area of justice as an example - a central area for governance in all donor assessments - pointing out that the justice sector covers a wide range of actors and issues which cannot be fully addressed by only looking at the performance of the Ministry of Justice.

Another key informant pointed out that often indicators used in donor assessments measure only output without further analysis of the related processes. He noted, using corruption as an example, that many governance assessments give a country a top mark in the area of corruption if the country has an anti-corruption legislation in place, irrespective of whether the legislation is adequate or whether it is implemented:

Key Informant No. 3 (ACA/PS, Maputo)

"Whether the legislation is adequate or not, whether it is implemented or not, whether complementary legislation exists - this type of information is not available and, therefore, the results will always be good. It is this methodological and technical analysis that I would do concerning all these indicators."

A very similar critique was raised by an academic cum civil society actor who not only questioned the relevance of the indicators, but also hinted at the deliberate bias in defining the indictors:

Key Informant No. 8 (ACA/CSO, Maputo)

"A major constraint of the assessments is that there is a big contradiction and a lack of strategic vision among donors themselves on this mechanism that they have developed for the assessments. ....First, in the definitions of the specific indicators that can monitor progress, what it is that symbolizes success in terms of political reform? For example, to build another 4 or 5 prisons... for example, there were not enough prisons or judges in the districts, and now there are 10, does this indicate success? Is this progress? Would this increase access to justice? The dialogue of the deaf begins already here, as some donors say 'there were no judges before, but now there are 10, so let's give more opportunities'.

I used to call the assessment mechanism as a little tennis match between two clubs that have the same agenda, and the agenda is simply to provide more money to Mozambique."

He summarized his critique of the methodology of the donor assessments as follows: "I've already seen many of these assessments, some of them with more consistent analysis, others with less consistent. Some of these assessments are often simply a replication of models developed outside Mozambique, and they simply try to readjust those indicators to this reality. Very often these indicators don't tell anything." (Key Informant No. 8, ACA/CSO, Maputo) 
In addition to the above concerns related to the topics and methodology, some of the key informants raised questions about the purpose of the assessments as factors undermining the relevance of the assessments at country level. It was argued that the main purpose of the assessments is not to analyze the quality of governance in the country but rather to justify the continuation of the aid programmes. The governance assessments are carried out because it is "the fashion of the development industry which in itself is used as a justification for the exercise" (Key Informant No. 17, ACA/MED, Maputo).

It was further pointed out, in more specific terms, that the purpose by some donors to rank countries according to their governance performance renders the results of the governance assessments irrelevant from the perspective of an individual country. The quote below summarizes well the views presented by some of the key informants:

Key Informant No. 3 (ACA/PS, Maputo)

"Many of the governance assessments in the world start from the idea of ranking things. One can question whether this is useful from a practical point of view. All well, this serves the World Bank or its IDA because with the ranking they define how to allocate funds - it can be useful for them. But from the point of view of interventions to improve the governance of a country, the ranking is increasingly irrelevant. And many of these studies aim at ranking in order to have a greater comparability. Although comparability is not bad, it is good, but to rank countries is very impressionistic, and from the point of view of usefulness, I don't know if it helps anything else other than IDA."

In conclusion, the key message emerging from the interviews with key informants familiar with the donor assessments indicates that, despite the shared understanding of the concept of governance, the donor governance assessments are deemed to have rather limited relevance at the country level. The lack of understanding of the political dynamics and the relationship between the state and the citizens in Mozambique, together with the "one size fits all" approach of the assessments, were mentioned as the main reasons why the donor assessments tend to "miss the target". The informants referred to the political processes in the context of Mozambique which, in their view, set the parameters for the entire governance discourse in the country. It was pointed out that the donor governance assessments tend to deal with questions related to less sensitive issues such as public service delivery - in themselves seen as relevant governance issues - but tend to avoid addressing political issues which are perceived to be the core concerns for governance in Mozambique. Even when the donor governance assessments address issues related to political governance, they fail to capture 
the core problems embedded in the state-society relations because of their standardized approach, which does not take into account the country-specific factors. In other words, according to the informants, the assessments fail to address the key governance challenge for the country, i.e. the challenge concerning Mozambique's political environment and the perceived trends in the country's political context.

\subsection{Impact of Donor Governance Assessments}

The question of the perceived impact of donor governance assessments on reforming governance in Mozambique constitutes the fourth research question outlined for this research project. To seek answers to the question, the informants were asked to explore their views on this issue. The outcome of the discussions is summarized below.

The question of perceived impact of governance assessments is closely related to the discussion on the relevance of these assessments at country level. Hence, to some extent the views presented by the Mozambican stakeholders about the relevance of the donor assessments can be revisited through the question of the impact of the assessments. It can be argued that if the assessments are seen as an input to the governance discourse in Mozambique they are, by definition, perceived to be somewhat relevant. The donor assessments may encourage public debate on governance even if they fail to fully capture the "true governance concerns" in the country. It can be further argued that the donor assessments may be seen as a valuable contribution even by those who are not very familiar with the selected assessments under consideration in this research. With this in mind, the question of the impact of donor assessments was initially raised with all key informants and focus groups irrespective of their level of knowledge of the specific assessment tools.

The analysis of the data generated through interviews indicates that there is no straightforward answer to the question of the impact of the donor assessments. Although the donor assessments are criticized by the local stakeholders for various conceptual and methodological reasons, most of them seem to consider these assessments as an important instrument for mobilizing a country-level discussion on governance, providing a voice for local concerns, and for putting pressure on the government and state authorities. At the same time, the limited involvement of local actors, restricted dissemination of the assessment reports and therefore poor knowledge of the assessments, are highlighted as factors which undermine the potential impact of the assessments.

The key message emerging from the interviews was expressed in a nut shell by a civil society actor working with the parliament who said that "the assessments carry weight, 
because they create all this dynamics" while pointing out at the same time that "let's not forget that about $80 \%$ of the population do not enter this dialogue. A lot has changed, many good things have happened but from the point of view of the 80\%, nothing. For the $80 \%$ all is still 'top-down', they just react to the processes." (Key Informant No. 22 Maputo/National).

His views were echoed by several others. According to one academic cum private sector actor, the assessments are good because they systematize the reality that is known and discussed by the people, but they "are normally addressed to very restricted audiences, at the level of the elite" (Key Informant No. 3, Maputo/National). Another academic cum civil society elaborated her views as follows:

"From what I understand, the assessments are important. They are discussed at some level, they start appearing in newspapers - whoever has access to newspapers and television! But in my view they are not yet widely discussed, and they are often limited to macro analysis." Key Informant No. 7 (ACA/CSO, Maputo/Nampula)

The role of the donor assessments in informing public opinion and, in particular, giving a voice to the population at large, was mentioned by several respondents as an important outcome of the assessments. According to one of the Members of the Parliament, "Any assessment is always a call for attention and an assessment also helps to form public opinion.... the assessments that are made and are read by those in power, by academics, they serve as a basis for a debate". (Key Informant No. 18, MP, Maputo)

In a similar manner a civil society actor from Maputo argued that:

"they must have an impact and have an impact. I believe that what is discussed in the press, on television, what is discussed by civil society is based on these assessments. There is a general discontent but these assessments should consolidate this general discontent... One can see that a lot has been done in this country thanks to these assessments, but it takes time." (Key Informant No 2, Maputo/National)

Another civil society actor from Pemba said that:

"in my view, the role of international organizations has been very great in the construction or support of the fortification of our civil society in Mozambique. And also in creating an opening for the people themselves, for freedom of expression by the people. Today it is already very common to see people even at community level to stand up in public and ask for their rights. Perhaps not in the right forum but they dare to speak, they dare to express their discontent." (Key Informant No. 13, Pemba).

A similar point was made by a key informant from Maputo, associated with a nationwide CSO who argued that the "assessments raise the level of popular debate to a more academic and coherent level". In his view "the assessments give weight to the complaints 
of the people. We know that the institutions of justice are slow and that they are mixed with the party, and who rules in the justice is Guebuza. This is how people talk. Reading these assessments one can see that they say the same thing that is said in the street but in a more elaborate form." (Key Informant No. 2, CSO, Maputo/National)

A number of the respondents also mentioned specific issues, such as the process of decentralization, strengthened public financial management, access to justice, human rights etc., which in their view confirmed the impact of the donor assessments. For example, the key informant cited above continued by saying that "Sometimes we see studies which spoke about decentralization already in the 90s' when decentralization had not yet been implemented. But there were people who were promoting this, there were already assessments about this. It takes time, sometimes the assessments are proposals which have their process of maturing."(Key Informant No. 2, CSO, Maputo/National)

Another key informant from Maputo pointed out public financial management as an area that has benefitted from governance assessments:

Key Informant No. 24 (SCS/CSO, Maputo/National)

Of course they do [have an impact, added by the author]. Remember what the management of public finances was like 10 years ago. The whole reform process, starting 10-15 years ago, it was a result of the assessments which the partners were doing, the suggestions to improve the system. Today we have this level of financial management, which is by far much better than we had years ago. Now, it did not appear from nowhere. This is a result of studies, assessments and recommendations that have been made over the years.

According to another civil society actor from Pemba, the impact of donor assessments can be seen both in the process of decentralization and in the fight against corruption:

Key Informant No. 9 (CSO, Pemba)

"Yes, they have an impact, perhaps not the desired impact because this is gradual process. I think these things are not solved from one day to another. If we were to compare a governance assessment that was made 5 years ago in Mozambique with today we would see that some things are already somewhat different.... I could mention two things, on the one hand, this question of corruption - it is clear that today there are anti-corruption offices, at least at regional level, which try to stop this evil and there are cases that have been taken to the court etc. This is one question which shows that there are signs, albeit small, emerging in an attempt to combat this evil. On the other hand, we have the question of decentralization, all this about the devolution of powers that empowers districts to play a different role compared with the past. In my view these things illustrates a bit the impact of this type of assessment". 
Human rights, including women's rights, were also mentioned by several respondents as areas that had gained from the donor governance assessments which had brought these topics to the public debate.

One of the most forceful arguments concerning the positive impact the donor assessments was made by an academic whose own research focuses on governance issues in Mozambique. In his view, the donor assessments enhance the capacity and the voice of the Mozambican civil society, as well as other actors, to engage in the governance discourse (interview in English):

Key Informant No. 23 (ACA, Maputo)

"The Mozambican civil society lacks conceptual and methodological instruments to assess the quality of governance on its own. So it relies more on the research done by donors. So these instruments, they became important so as to inform the work by civil society, on the one hand, and more importantly, they are also sort of back-up to civil society. Back-up in the sense that they make civil society arguments strong, because they are based on evidence, on proven evidence, from more credible instruments, such as these ones, the ones that are meant to measure the quality of government.

On the other hand it informs the public debate. The Mozambican government is very much good in neglecting the evidence produced locally. Why? Because the Mozambican institutions I know, including academic institutions, and most of the people that are in the academia, they got the scholarships from the government. So their research on its own, sometimes, is not taken strongly - well because 'we know him' - but when it comes from the donors, it is taken seriously at least in the sense that the government feels obliged to respond to it. So by responding to it, it is engaging in the dialogue. The quality of the response may be disappointing but there is some debate, they tend to disregard the methodologies etc. We have seen that several times, but there is some sort of debate. And you would see the media, the academia, they all sustain much of the arguments using these instruments.

Many of the respondents who argued in favour of the donor assessments pointed out in very explicit terms that the restricted dissemination of the assessments undermines the potential impact of the assessments. In the words of the above key informant from the academia (interview in English):

Key Informant No. 23 (ACA, Maputo)

However, they are not widely known, they are only known in the Julius Nyerere Avenue [many of the Embassies are located on Julius Nyerere Avenue, added by the author], in the university and around this area. There are even MP's that are not aware of these instruments. Well this is partially true, because not all of these instruments, are public, are made available to the public. For instance, the more qualitative types, from the Dutch, 
from the Swedes, they did not make it public. So the ones that are more widely known, are those from the World Bank and African Development Bank. And these ones, they are more quantitative, and the quantitative tend to say less in terms of the dynamics; what does a composed indicator mean, quality of governance, and some of the indicators, if you look at the Freedom House indicators, the WB indicators, there are some differences. But people would very much be keen to receive in the public the more qualitative ones that deal more in the contextualized manner with the issues. "

One of the Members of Parliament referred to the same problem from the perspective of the functioning of the administrative system in the country and the capacity at the lower levels of administration:

Key Informant No. 18 (MP, Maputo)

"The big problem lies in knowing whether those who govern are willing to use these assessments as a basis for real change. Because what we have noticed is that, when talking at the central level, the assessments are discussed and accepted completely peacefully but at the local level that is where the problem begins. Often the Administrator does not have access to these assessments, the Head of the Post [lowest administrative unit at local level, added by the author] has no access to the assessments, and therefore, the Administrator and the Head of the Post are not properly informed about the aspects of good governance, he does not understand."

Although most of the informants seemed to see the donor assessments in rather positive light pointing out their contribution to mobilizing governance debate and even improving governance in practice, some of the informants also expressed more sceptical views. The main reasons raised by the sceptics related not only to the restricted access to the assessments but also, and perhaps more importantly, to the donor-driven and top-down approach underlying the assessments. The donor assessments were seen as instruments aimed at serving the interests of the donor agencies themselves rather than as an input to the governance discourse in the country. Even some of the informants, who considered the assessments as an instrument to hold the government accountable, questioned their significance for reforming governance in practice. The quote below, from a discussion with an informant with a background both in the media and academia, summarizes well the thinking among the sceptics:

Key Informant No. 17 (ACA/MED, Maputo)

"In my view these assessments serve primarily the institutions that conduct them so that they have an instrument to put pressure on the government. If you ask me whether these assessments are reflected in my life in terms of improved governance, my answer is no. Furthermore, these assessments are disclosed within a small selected group, including the evaluators themselves, the government and a handful of academics and members of civil 
society, but not all. So the dissemination and the discussion either of the results or of the recommendations of the assessments are completely ignored by the population in general."

According to another key informant with relatively profound knowledge of specific assessments tools:

Key Informant No. 3 (ACA/PS, Maputo)

"They are used by restricted audiences such as NGOs, the IMF, the World Bank, donors, and they have no implications for citizens at community level. These assessments are produced and used at that level, and few actually reach the base so as to provoke any transformation. And instead of being bottom-up they are always top- down."

Some of the respondents expressed their doubts about the impact of donor assessments in very cynical terms arguing that even the donors themselves are not truly concerned about governance in Mozambique. It was argued that donors are looking for "success stories" that justify the continuation of development cooperation with Mozambique and, therefore, are willing to compromise on governance issues. For example one of the key informants, who did not deny the value of the assessments in mobilizing public debate, questioned the motives of the donors. She elaborated her views as follows:

Key Informant No. 7 (ACA/CSO, Maputo/Nampula)

"You donors give money to this country, and most of the time you don't demand anything although you have the right to demand. But why, because you also... what interests you is to have success cases, and in spite of everything, Mozambique is a success case for you. And therefore you do these assessments but this does not result in anything, this is the fashion of assessments."

One of the most cynical views about the impact of the donor assessments was made by an academic cum civil society actor heading a Mozambican civil society forum who argued that:

Key Informant No. 8 (ACA/CSO, Maputo/National)

"...the ruling party realized it all, and knows that the donors will never withdraw money so as to impose drastic measures. The reforms are just 'for the English to see' as the popular saying goes".

In his view the impact of donor assessments on improving governance remains marginal because of the shared objective between the donors and the government to maintain the status quo. 
Finally, while most of the sceptics mentioned the top-down and largely donor-driven approach of the assessments as the main factors undermining their impact at country level, some of the respondents raised questions concerning the willingness and capacity of the government and state authorities to act upon governance assessments. Due to a lack of a culture of assessments, critical assessments in particular are kept in the drawer by those in charge rather than disseminated for public debate. For example, according to one of the senior civil servants "We are afraid of taking a photograph of ourselves, we like to have a beautiful photograph. I think the fear is institutional, there is no culture to accept assessments." (Key Informant No. 19, Maputo).

In summing up the outcome of the discussion on the perceived impact of donor assessments on improving governance, it can be concluded that the messages are somewhat conflicting. On the one hand the assessments are seen as having succeeded in mobilizing public debate on governance, in consolidating common perceptions in a systematic manner, in giving legitimacy to common complaints and in providing an instrument to local actors to move forward with governance issues. Although reforming governance was seen as a slow and gradual process, the governance assessments were perceived to have contributed to improving governance in several areas. On the other hand, because of the limited accessibility, restricted dissemination and topdown approach, the country-level impact of the donor assessments was seen as being severely undermined. In view of some informants, the impact of donor assessments on governance in Mozambique may even be harmful if the donor assessments are used merely to justify the maintaining of the status quo in the relationship between the government and the donors. The limited impact of the assessments was also perceived to be a reflection of the lack of willingness by the government and state authorities to follow-up the issues emerging from the governance assessments.

\subsection{Mozambican Perceptions on Donor Governance Assessment- Concluding Remarks}

In the previous sections, the research questions concerning the relevance and impact of the donor governance assessments from the perspective of Mozambican stakeholders were approached from different angles, including questions related to local interpretations of the notion of governance, familiarity of local stakeholders with the donor assessments, relevance of the topics covered by the assessments, and finally, perceptions about the impact of donor assessments on improving governance. The analysis of the data points to a number of key findings which serve as the basis for answering the research questions. 
First, concerning the question about the meaning of the concept of governance and of what constitutes good and bad governance, the analysis indicates that the Mozambican interpretations are rather similar to those of the donors. Governance is understood as a multi-dimensional, complex concept which, following the WGI definition, involves political, economic and institutional dimensions. As in the case of donors, there are variations concerning the perceptions of the relative importance of the different dimensions and aspects of good and bad governance. Some stakeholders highlight the importance of political aspects of governance whereas some put more emphasis on economic and institutional aspects of governance. In general, broad-based popular participation, government accountability and effectiveness and the respect for the rule of law emerged as central elements of governance.

However, the discussion with the local stakeholders brings an additional element to the notion of governance, which is related to the nature of the political and democratic processes of the country. From the Mozambican perspective, the biggest governance concerns are perceived to be related to low sense of citizenship and lack of truly participatory or "bottom-up" governance. Building on the UNDP's notion of democratic governance, these issues can be conceptualized as participatory democracy. While the concept of participatory democracy is closely related to the political dimension of governance that is covered by many of the donor assessments, it appears that the donor assessments under consideration in this research fail to address the dimension fully.

Second, the analysis of the data on the familiarity of local stakeholders with donor governance assessments indicates that the level of knowledge varies greatly between the key informants and the focus group discussants. The best-informed respondents, who were able to mention 2 or 3 donor assessments and identify some topics included in the assessments, are all from Maputo. Even among these best-informed respondents, the level of knowledge of the specific assessment tools is limited. As to the key informants outside Maputo, the level of knowledge of donor assessments appears to be very limited. However, most of them are very familiar with the governance assessments conducted by local organizations. Among the focus group discussants, the level of knowledge of donor assessments is practically non-existent. However, the focus group discussants also seem to be very knowledgeable about the various assessments conducted by Mozambican civil society organizations and other local actors.

Third, concerning the relevance of the focus of the donor governance assessments - a question addressed only to those key informants familiar with the donor assessments - the perceptions are somewhat conflicting: on one hand, the governance assessments seem to capture several aspects of governance that are considered highly relevant in the Mozambican context, whereas on the other hand, they seem to miss some of the most fundamental governance concerns for the country. In light of the interview data, 
the emphasis of the donor assessments on transparency, accountability, government effectiveness, the rule of law and corruption is fully justified in view of the governance issues considered to be relevant in the Mozambican context. However issues related to the notion of participatory democracy, in particular questions of political processes, citizenship and bottom-up participation, which emerge as the core challenges for governance in Mozambique, are deemed to fall outside the conceptual framework of donor governance assessments.

Fourth, the analysis of the data concerning local perceptions about the impact of the donor assessment on improving governance points at two key findings. On one hand, the assessments are seen as having succeeded in mobilizing public debate on governance issues, in consolidating common perceptions in a systematic manner, in giving legitimacy to common complaints and in providing an instrument to local actors to move forward with governance issues. On the other hand, the country-level impact of the donor assessments is seen as being seriously undermined because of their limited accessibility, restricted dissemination and top-down approach. Furthermore, the impact of the donor assessments on governance in Mozambique may even be harmful if they are used by the donors merely as a justification for maintaining the status quo in the relationship with the government. However the general sense among the local stakeholders suggests that the donor governance assessments contribute positively to reforming governance in Mozambique.

In light of the above key findings, the answer to question of the relevance of the donor assessments from the perspective of Mozambican stakeholders is not clear-cut. Despite the largely shared understanding of the meaning of governance, the donor approaches to governance and, subsequently, the assessments conducted by donors seem to miss one fundamental aspect of governance, namely participatory democracy. In the Mozambican context this aspect is perceived as being of critical importance. The lack of involvement by local stakeholders in the donor assessments, along with the restricted sharing of the results of the assessments, is reflected in the relatively limited knowledge of the donor assessments among the local stakeholders. This, in turn, is likely to undermine the relevance of the assessments at the country level. Even still, despite their various conceptual and methodological weaknesses, the donor assessments are seen as making an important contribution to the governance discourse in the country, as having a positive impact on governance reforms in specific areas. 



\section{Ways Forward in Assessing Governance}

Building on the analysis of local perceptions of the relevance of donor assessments, this chapter aims at generating recommendations for improving the current donor practices in assessing governance in a specific country context. The discussion draws on the data gathered through the fieldwork, including the interviews with the donor representatives.

At the outset it needs to be pointed out that the specific question as to how to move forward with donor governance assessments was not systematically raised with the key informants and focus group discussants. However, the views presented by the informants about the donor assessments in the course of the interviews - whether critical or positive - provide a basis for exploring this question further. Bearing in mind the limited knowledge of the donor governance assessments among the focus group discussants, the discussion below draws primarily on the interviews with the key informants.

One of the themes emerging from the analysis of the relevance of the donor assessments concerns the need to enhance the knowledge among local stakeholders of these assessments. From the key informants' point of view, wider access to and, active dissemination of, the outcome of the assessments would enable the local stakeholders to further enhance their own understanding of the governance situation, and to strengthen their dialogue with the government and state authorities on governance challenges. Hence, one of the most obvious recommendations concerns the development of the disclosure policies and dissemination practices applied by the donors.

Another theme that can be derived from the interviews relates to the question of the involvement of local actors in assessing governance. As indicated above, broad-based participation in governance is one, if not the most important, factor in defining good governance in the Mozambican context. In the course of the interviews, the question of the involvement of local stakeholders was approached by the informants from several different perspectives: while some talked about the importance of using local knowledge at the level of communities or expert institutions in the assessment processes, others referred to the importance of tailoring the focus of assessments taking into account the specific governance concerns in Mozambique. Some of the key informants argued in favour of the joint assessment mechanisms, such as the periodic joint reviews structured around the general budget support as the way forward in improving the relevance of the governance assessments. Some of the informants 
highlighted the merits of the African Peer Review Mechanism (APRM) as the most comprehensive, country-owned approach to assessing governance in Mozambique. All in all, from the local stakeholders' perspective, the way forward in assessing governance entails a shift towards assessments which build on country-specific knowledge and broad-based local participation. The key messages stemming from the discussion will be summarized below.

\subsection{Context-Specificity with Local Participation}

First, the question of using community level knowledge in assessing governance was mentioned by several key informants as an important starting point for enhancing the relevance of the assessments. It was argued that the current donor assessments fail to capture the reality of governance problems as seen and experienced by the citizens at the level of communities. The following quote from an interview with one academic cum civil society actor illustrates rather well the frustration expressed by several respondents:

Key Informant No. 7 (ACA/CSO, Maputo/Nampula)

"I'm telling you what was said to the Dutch ambassador, and this has been said to many others: you speak and speak and conduct assessments but these are assessments where people don't go to really see how things are on the ground. They make a text review and chat with one or persons but they don't go to the field".

According to another academic cum civil society actor:

Key Informant No. 8 (ACA/CSO, Maputo/National)

"There are few mechanisms that allow the citizen to assess his own government. Of the few mechanisms that exist the Afrobarometer is an example of an assessment which is done by ordinary citizens about governance, democratic system, political and economic reform. It is the only instrument available right now that has the perspective of the common citizen."

Moving already towards a recommendation, one civil society actor elaborated his views as follows:

Key Informant No. 22 (CSO, Maputo)

"If we could understand how they [people in the communities, added by the author] think, we could see that they perhaps think differently about reforming governance because of the experience they have from participating in governance reforms, and we 
would develop a policy or programmes which builds on their perceptions about a new model for governance, in other words, we would discuss and negotiate."

It was further pointed out that Mozambican civil society organizations and research institutions have developed expertise on governance issues in the country and can provide valuable information for donor assessments. As argued by one civil society actor from Pemba: "Donors have representation in this country, but they are not here all the time. I'm sure that CIP (Centro de Integridade Publica, CIP, added by the author) has more capacity to develop contact with people in a given district than the World Bank representative has."(Key Informant No. 13, CSO, Pemba). According to another civil society actor cum academic from Maputo, affiliated with a nation-wide civil society forum, there are a few local institutions and CSOs that have the capacity to conduct assessments with focus on key governance challenges for the country. In his view, however, these assessments are not taken into account either by the government or the donors.

Key Informant No. 8 (ACA/CSO, Maputo/National)

"There are a few research institutions that do systematic analysis on the major challenges facing Mozambique in the area of political reform, economic and social reform....IESE has technical and analytical capacity, also some civil society organizations such as WLSA in the field of gender has contributed to some extent to the development of a strong capacity to assess gender issues in Mozambique, the CIP in the area of corruption and local governance has produced some reports on democracy and local governance, with the support of Swiss cooperation, the League of Human Rights has produced reports on human rights issue. Large part of this type of assessments is not taken into account by donors or by the government itself."

According to some of the informants wider use of local data sources and better, context-specific understanding of the governance situation could enhance the credibility, and thereby potential impact, of governance assessments. From the point of view of an academic, closer collaboration with universities and research institutions would be the best way to improve governance assessments and overcome the assessments as a donor-driven exercise. He elaborated his views as follows (interview in English):

Key Informant No. 23 (ACA, Maputo)

"I think the donors would need to link up with the universities, at the moment they don't really. One thing is to commission analyses to IESE and other types of independent institutions. But the other is to gradually also involve the universities. I think these would, to some extent, make a difference. Because the universities, they are the ones who produce knowledge. And I think, by using the university, it is also a way of making the knowledge available to be used, and to expand the debate to other people and other actors.... As it 
stands now, most people tend to look at these instruments as donor-driven, also aimed at pointing out to mistakes and weaknesses, and doing little justice to some of the improvements that take place. ... Our government is also, in terms of behaviour, it suspects some of the things coming from the donors. So if a way could be found to involve other actors, that would also help."

Similar points were raised by several other informants. According to one the civil servant, for example, there is general impression that the assessments are imposed on Mozambique "by donors who give us money" (Key Informant No. 20, Maputo). In order to change this perception and to create an environment where assessments would be seen as an instrument for reform it would be important, in his view, to include Mozambicans in the assessment teams "so as not to give an impression that we have a police, a foreign police who wants to know how we operate". At the same time he also stressed that "You need people from outside, it has to be a panel. If you have only nationals in the team, people will think that they are from the party."

According to another senior civil servant, the involvement of local actors in governance assessments impacts upon the overall objective underlying a given assessment. In his perception, assessments conducted by donors alone tend to focus on errors and failures in Mozambique's performance, based on some international standards used as a benchmark. The assessments involving local partners approach the quality of governance with the objective of indicating what the key challenges are for governance, and of identifying ways for overcoming these challenges taking into consideration the past development of the country. In his words:

Key Informant No. 21 (SCS, Maputo)

"The point is that, if the assessment is internal or carried out in partnership, then we are looking for challenges that we need to overcome, but once the assessment is conducted by a donor, it all depends on many things. Because if we already are looking for mistakes which show that a certain model does not work, which show that this underdeveloped country is doomed, it has no way out, it depends a bit on this. Perhaps it will help, but the more the assessments are carried out in partnership, the more they have a shared objective, that is, if we have a partner who comes to support us, supports us with resources and also support us in the assessment, then it will indeed direct us to the challenges. An assessment conducted by a donor often shows that the situation is bad rather than the way to overcome the problem, it shows that we have a problem, and this is what is complicated... In other words, a good assessment shows us the areas where we need to take action, and in taking action the country receiving aid will gain, but we all gain as partners in cooperation."

When talking about the involvement of local institutions in governance assessment processes, several informants singled out the national parliament as one of the most 
important institutions that should be involved in the debate. It was argued that the parliament should be the one that plays a central role in the governance assessment processes because of its constitutional mandate to monitor the performance of the government. In the words of one of the civil servants: "it should be the parliament that requests these assessments because the parliament is the one that assesses the performance of the government". (Key Informant No. 21, Maputo). From the point of view of one of the civil society actors the lessons learned from the governance assessments are not translated into policy actions because the assessments are not debated at the appropriate political level, that is, at the level of the parliament. Similar views were presented by many civil society actors as well as by informants linked to academia.

However, while stressing the oversight function of the parliament vis-à-vis the government, the informants also expressed their doubts about the capacity of the parliament to play this role effectively. The parliament was perceived to be weak and lacking capacity and resources to engage in a meaningful debate either with the government, or civil society organizations, or with the donors. Partly thanks to the support by the international donor community, the government and civil society had gained much more competence than parliament which, according to the constitution, has the mandate to hold the government accountable. As stated by one of the senior civil servants:

Key Informant No. 20 (SCS, Maputo)

"The parliament has an important role but it needs more capacity. I often think that, in our case, the speed of the changes is very rapid and that the government is always getting ahead. The government is interacting with partners and investors while parliamentarians are sleeping."

One of the civil society actors elaborated the problem of the perceived lack of capacity from the wider perspective of the collaboration between the parliament, civil society and donors in Mozambique as follows:

Key Informant No. 22 (CSO, Maputo)

"Remember that you have a civil society that is perhaps somewhat weak because it has never seen a well-functioning parliament. Hence the international development partners also play an important role. On the one hand, to work with civil society organizations to help them to understand what is the role of an effective parliament, and how a parliament can function. But, on the other hand, to work also with the parliament itself so as to support the parliament to enhance its capacity to monitor the state."

Although the involvement of local organizations, including the parliament, was seen as one way to enhance the relevance of the governance assessments, this was not considered as a solution in the short-term. In addition to the capacity problems, the 
prevailing nature of state-society relations was seen as an impediment to rapid change. As argued by one academic cum private sector actor:

Key Informant No. 3 (ACA/PS, Maputo)

"The room for manoeuvring is very limited, that is, the space between the market, the state and civil society, it is very limited. And as long as we are in this situation of lack of independence [between the different spheres, added by the author], there are no conditions for an effective basis for citizenship, accountability and governance in this country."

Second, as has been discussed earlier, some of the informants questioned the standardized approach applied in many assessments, such as the WGI and the CPIA. One of the informants illustrated the importance of country-specific understanding by saying that "Maybe the model that is used in Ghana does not work here. Ghana, for example, has different level of democracy and development processes, perhaps higher than ours. So perhaps some of the standard indicators do not apply here. So perhaps there is a need to try to domesticate, in a manner of speaking, the assessment processes." (Key Informant No. 24, SCS/CSO, Maputo).

It was further pointed out that, due to the lack of context-specificity, important aspects of governance, such as the questions of political dynamics and citizenship, are missed by the donor assessments. Even when these issues are addressed, the approach remains too standardized to capture the core questions. The quote below from an interview with an academic cum private sector actor illustrates the thinking among some of the informants:

Key Informant No. 3 (ACA/PS, Maputo)

"I wouldn't say that they don't address this aspect [sense of citizenship, added by the author], they do, but the way the donors address this aspect is very standardized and sometimes they don't capture the specificities and don't go to the heart of the problem. In my view it is more a matter of approach, they don't say that it is not an important aspect."

Similar views were presented by some other informants. For example, one senior civil servant elaborated his views as follows:

Key Informant No. 21 (SCS, Maputo)

"As I said there are a number of values that are common - when talking about peace, stability, or about hunger, nutrition, health - and if we are talking about how to make things better, a good assessment shows us where we are with all these things and helps us see the way forward to reach a solution. There are challenges for those who make the assessments, one of the biggest challenge is to use their knowledge and their experience, but adapted and fitted to the context." 
The above views are somewhat challenged by arguments put forward by some of the informants who questioned the importance of who is responsible for a given assessments. It was pointed out that assessments conducted by both local and external actors can be relevant. The key question was perceived to be the focus of the assessment rather than the actor conducting the assessment. As stated by an informant heading a national CSO working on governance issues:

Key Informant No. 6 (ACA/CSO, Maputo/National)

"I think they can all make a contribution, I don't see that as a question of relevance. I prefer to talk about processes, which are the processes and reforms that are relevant. Now, who are the relevant actors, I think all actors are relevant, there is no hierarchy; the donors, the civil society as well as political parties, each of them has its role to play."

A somewhat similar point was made by another civil society actor from Maputo who said that "I never understood this differentiation, about the details concerning who participates in this or that assessment" (Key Informant No. 2, CSO, Maputo). Furthermore, in his understanding, shared by some other informants, donors also employ local researchers in their assessments assuming that they have the necessary capacity: "international organizations also use local resources and researchers to do the work when they realize that there is a person that can do the work." The collaboration between local research institutions and donors in assessing governance was elaborated further by one of the civil society actors from Pemba who approached the question from the point of view of "whose word counts more". In his view, the government is more responsive to the critique coming from the donors than from the local actors without realizing that the donors base their assessments, to large extent, on the analysis carried out by local research institutions.

\section{Key Informant No. 13 (CSO, Pemba)}

"Those reports or criticisms made by the World Bank or other multilateral or bilateral donors, they can have a somewhat stronger influence. Because our government is still, unfortunately, in the dark and looks simply at those providing external financial support, and forgets that often the criticisms made by the World Bank, they focus on some studies done internally by the CIP [Centre for Public Integrity, added by the author]. Because the CIP presents an analysis and on the basis of this internal analysis the World Bank and other donors act. And on the basis of many information channels, many independent television channels such as STV, Miramar, they are critical. On the basis of this information, which they broadcast on television or on radio, the donors also pay attention."

In conclusion, from the Mozambican perspective, the use of community level knowledge and experiences of governance, together with the wider involvement of local institutions, in particular the CSOs, research institutions and the parliament, would 
enhance not only the relevance of the governance assessments but also the credibility of the assessments, and their potential impact for reforming governance. Yet, there is also need for external actors: the donors play an important role by increasing the independence of the assessment teams as well as by providing support for building local capacity. Finally, because of the government's dependence on external financial support, the assessments conducted by donors may carry more weight than those carried out by local institutions.

In the discussion on the strengths and weaknesses of donor governance assessments, two specific assessment mechanisms were mentioned as a way forward towards improving the relevance of governance assessments. One of these is the Joint Review mechanism developed within the framework of the general budget support programme supported by the G19. The other one is the African Peer Review Mechanism (APRM). Both of these assessment mechanisms are considered locally-driven with a strong involvement of local stakeholders in the design and implementation of the assessment processes.

While a profound analysis of either of the mechanisms is beyond the scope of this research, their main characteristics will be discussed below with emphasis on the informants' perceptions concerning the relevance of these assessment tools.

\subsubsection{Joint Review of the General Budget Support}

The general budget support programme (GBS) and the implications of the multi-layered GBS planning and monitoring mechanism for the aid relationships in Mozambique has been discussed in some detail in Chapter 5. In this section, the focus is on the Mozambican stakeholders' perceptions concerning the relevance of the Joint Review as a tool for assessing governance. It needs to be pointed out that the joint review was not specifically raised by the author but it was mentioned by some of the informants in their reflections upon the donor governance assessments. However, it was raised only by a handful of key informants who had gained knowledge about the mechanism through the media or through personal involvement in the review process.

As described in Chapter 5, the general budget support programme (GBS), formally entitled the Programme Aid Partnership (PAP), is based on a Memorandum of Understanding (MoU) signed in 2009 between the Government of Mozambique and the donors providing non-earmarked funding to the state budget. The MoU further ooutlines the mechanism for planning and monitoring the performance of both the government and the donors in meeting their commitments. The annual Joint Review constitutes the core component of this monitoring mechanism. 
The Joint Review is conducted on the basis of a set of performance indicators, the Performance Assessment Framework (PAF), which is negotiated and agreed jointly between the government and the donors. The PAF includes indicators for measuring the progress by both the government and the donors. The CSOs are invited to participate in the Joint Review and they contribute to the assessment of the government's performance in implementing the national poverty reduction strategy. While the PAF indicators for measuring progress on the side of government are derived from Mozambique's development strategies, the MoU entails a number of other conditions related to the political governance in Mozambique. These include the government's commitment to:

1) safeguarding peace and promoting free, credible and democratic political processes, independence of the judiciary, rule of law, respect for human rights, good governance and probity in public life, including the fight against corruption;

2) prioritizing fighting poverty through its [GoM, added by the authro] policies and plans and in its patterns of public expenditure; and 3) pursuing sound macro-economic policies and public financial management systems (Memorandum of Understanding 2009, p. 6).

In the course of the annual Joint Review, the government and the donors verify whether the targets set in PAF have been met and whether the government has complied with the underlying principles outlined in MoU. The CSO participation in the Joint Review is structured through the nation-wide Development Observatory (formerly known as Poverty Observatory). The Development Observatory collects data at provincial, and to some extent, at district level, and provides feedback on the progress made by the government in implementing its development programmes, in particular the Economic and Social Plan and the poverty reduction strategy. ${ }^{151}$

In light of the interviews, a number of themes can be derived concerning the Joint Review as a tool for assessing governance. First, although the Joint Review is a mechanism that has been formally jointly agreed upon by the government and the budget support donors, it is still seen, to some extent, as a donor-driven assessment tool. Hence, the Joint Review is perceived to be biased towards issues that are central from the perspective of the donors such as public financial management. As stated by one civil society actor, with direct experience from the Joint Review process:

151. The Development Observatory was initially created in response to the request by donors to involve CSOs in the preparation of the PARPA, but has since then established itself as a credible forum for the dialogue between the government, donors and the CSOs. The contributions from the Development Observatory are often considered as a "second opinion" in comparison with the official progress reports by the state authorities. 
Key Informant No. 22 (CSO, Maputo)

"On the donor side I have analyzed quite a bit the use of the instrument, the Performance Assessment Framework [referred to in English by the informant], or PAF, as one way that the donors have found in order to agree with the government upon some indicators that could be used to assess the quality of governance.... Although it includes indicators that reflect the component of service delivery, the focus has mainly been on the financial dimensions."

Nevertheless, despite its somewhat limited focus, the Joint Review has is seen as having contributed to wider governance reforms, such as increased accountability by the government and involvement of civil society in the process of governance. The quote below summarizes a number of the positive comments made by several key informants about the Joint Review.

\section{Key Informant No. 22 (CSO, Maputo)}

"Each donor is anxious to see how its money is spent. But on the positive side, I think it [the Joint Review, added by the author] is positive, although not ideal, because starting from the monitoring of public spending there are many governance reforms that are being implemented, and these in fact will improve the quality of governance. Therefore, this financial dimension, and the role of donors, has been very positive, not just in terms of the financial administration but also in educating the Mozambican government to be accountable and to spend money in a responsible manner, and to include civil society in the process of governance.

Hence, from the year 2000 to today we can see that the government has made quite significant progress on governance issues, and this is a result of these assessments conducted within the framework of the meetings with partners. I am talking about the Poverty Observatories, about the Consultative Councils: in 2003, we had the first session of the Poverty Observatory, and in 2003 we also had the approval of the law 8/2003 for the Consultative Councils. This is also a result of the set reforms that the government has introduced through donor pressure."

The impact of the Joint Review on pushing forward governance reforms was referred to by several other civil society actors both from Maputo and from Pemba as well as by the Members of Parliament. For example, one of the Members of Parliament elaborated on the role of the G19 in Mozambique's governance discourse during President Guebuza's second term in office (2009-2014).

Key Informant No. 19 (MP, Maputo)

"But during the mandate [second term of President Guebuza, added by the author] it became apparent that the reforms were not moving forward as rapidly as expected. Therefore, there were always frictions concerning the Memorandum of Understanding between 
the G19 and the government - although not all information comes into public but a lot comes out - there were many frictions and these frictions were apparently good because they forced the government to speed up some reforms that were not moving fast."

$\mathrm{He}$, together with some others, even argued that the G19 has become the real watch dog vis-à-vis the government: "So what happens, we'll all wait for the analysis that comes from the G19, but we ourselves, we don't have the capacity, this is missing."

In a similar manner, one of the civil society actors from Maputo, affiliated with a CSO closely involved in the Joint Review processes, argued that the Joint Review is the "official assessment mechanism" whereas the assessments carried out by donors are "parallel mechanisms". In his view, despite its weaknesses, the impact of the Joint Reviews on improving governance has been "irreversible":

\section{Key Informant No. 14 (CSO, Maputo)}

"The government has been forced to create platforms through the donors who push; the government has to allow people to participate, it has to open up. This is creating a culture of accountability, impressive, perhaps one of the best examples in the subcontinent - Mozambique is doing very well in this."

Second, the Joint Review was seen by some of the informants as a mechanism that has succeeded in addressing core issues related to the political and democratic processes in the country. One of the civil society actors described at length the incident related to Joint Review of 2009 which led to the temporary freeze of general budget support disbursements in 2010 by several GBS donors (discussed in Chapter 5):

\section{Key Informant No.2 (CSO, Maputo/Pemba)}

"I think you know about the last crisis with donors, the negotiations for financing, there was a serious problem. In my opinion that happened because the donor understood the climate of the country, the political climate, and the governance situation of the country and that's why they intervened. They would not have intervened if they had not noticed it. They realized that they could interfere because they had the support of a large part of Mozambicans, it was not a foreign interference. They interfered because they realized that Mozambicans wanted them to interfere, that's my perception. They would not have intervened if they had not realized that the Mozambicans wanted it. Then there were talks about interference here and there, but the bottom line is that they realized that Mozambicans were protesting against this tightening in governance and therefore called for a reform of the electoral process, more effective fight against corruption, and for other that are part of what we are talking in the street." 
However, the Joint Review was also criticized for a number of reasons. Apart from the perceived biased focus of the assessment, the lack of involvement by the parliament was highlighted as a major weakness of the mechanism, just as in the case of the governance assessments conducted by donors. As argued by one of the civil society actors from Maputo:

Key Informant No. 6 (ACA/CSO, Maputo)

"The Joint Review should take place within the Assembly of the Republic and not outside. Because what we say is that the Assembly of the Republic makes its assessment of the balance [progress, added by the author] of PES [the Economic and Social Programme which is the government's annual programme approved by the Parliament, added by the author], but our experience from participating in the Joint Review shows that there is a whole set of sectoral reports which are not part of the balance of the PES. They are shared with donors but they are not shared with the Members of the Parliament. Therefore, more information is needed in the Parliament, and then the debates between the donors and the government at technical level could gradually be transmitted to the Members of the Parliament."

A similar comment on the exclusion of the Parliament from the Joint Review was made by another civil society actor, also based in Maputo:

Key Informant No. 22 (CSO, Maputo )

"in the Joint Reviews you discuss different issues than in the Parliament. There you discuss the MDGs, the PARPA, a range of other issues whereas in the Parliament you discuss the Economic and Social Programme and the budget. Now, here is the big problem: when you ask the Parliament to make an assessment of PARPA, this assessment will never be efficient because they don't know what PARPA says."

In summing up the key messages, the following conclusions can be made. Firstly, the Joint Review is recognized as a mechanism that allows broader participation by local stakeholders in the assessment process. It has brought the general budget support donors, the government and civil society to the same negotiation table. It serves as a forum for joint assessment of the performance of both the government and the G19 donors against a common set of PAF indicators, including indicators related to political and democratic governance. Secondly, although the emphasis of the Joint Review is perceived to be narrow and biased towards donor concerns, it is also seen as an instrument that has triggered wider governance reforms. Thirdly, the relevance of the Joint Review as an assessment mechanism is undermined because it excludes the parliament, which has the constitutional mandate to assess the government's performance. 


\subsubsection{African Peer Review Mechanism}

The African Peer Review Mechanism (APRM) is another governance assessment tool that was raised by some of the informants, along with the Joint Review, in their reflections upon the strengths and weakness of the donor assessments. It needs to be pointed out that the APRM was mentioned only by a handful of the key informants (in all 6 of all the 28 Key Informants). Before proceeding with the discussion on Mozambican perceptions on the merits of the APRM, the main principles of the mechanism will be outlined below.

The African Peer Review Mechanism has its origin in the inaugural summit of the African Union (AU) in 2001 when the African Heads of State and Government adopted the New Partnership for Africa's Development (NEPAD) as the new framework for development for the continent (Petlane and Gruzd 2011, p. 6). Good governance was identified as a fundamental prerequisite for achieving the objectives of NEPAD, and to this effect, in 2002, the AU adopted the Declaration on Democracy, Political, Economic and Corporate Governance (AU/NEPAD AHG/235 XXXVIII, Annex I). The Declaration commits African countries to promoting four broad objectives: democracy; and political governance; economic and corporate governance; socio-economic development and the African Peer Review Mechanism (APRM). The APRM was conceived as an instrument to monitor and evaluate the performance of AU Member States by the member countries themselves in areas of political, economic and corporate governance. While the AU has urged all Member States to subject themselves to the peer review process, the participation is voluntary. Mozambique acceded to the APRM in 2003.

According to its mandate, the primary purpose of the APRM is "to foster the adoption of policies, standards and practices that lead to political stability, high economic growth, sustainable development and accelerated sub-regional and continental economic integration through sharing of experiences and reinforcement of successful and best practice, including identifying deficiencies and assessing the needs for capacity building" (AU/NEPAD, APRM 2003, p. 1).

The APRM is essentially both a self-assessment and a peer review mechanism. It entails a self-assessment of the governance performance by the country under the review, and a parallel assessment conducted by 2-3 AU Member States elected as the peer reviewers. It does not aim to rank countries as to their governance performance but, as a peer review mechanism, it seeks to promote learning and capacity building among the countries participating in the review process. 
The focus areas of the APRM are derived from the objectives of the AU Declaration on Democracy, Political, Economic and Corporate Governance. The APRM Guideline, adopted in 2003, defines the focus of the assessment in terms of four broad areas as follows:
a) Democracy and Good Political Governance
b) Economic Governance and Management
c) Corporate Governance
d) Socio-Economic Development

Source: AU/NEPAD HSGIC, 2003; APRM Guideline

For each of the four focus areas, a set of more specific components to be assessed is defined in the APRM Guideline, which also spells out the codes and standards, criteria and indicators for conducting the review at country level. The Guideline underlines the importance of taking into account the specific context of a country under review, and states that the development of country-specific criteria and indicators "is best undertaken by those involved in the assessment at country level in close consultation with the APRM Secretariat (AU/NEPAD HSGIC 2003, p. 3-4). The process of conducting the APRM in a specific country entails five stages. Apart from the last stage (Stage Five), which provides six months for the final report to be made public, the time frames for the process are not specified.

In Mozambique the APRM was initiated in 2005 although Mozambique had been among the first countries joining the APRM in 2003. The operationalisation of the review process was postponed due to the general elections in 2004 and, delays in creating the necessary institutional structures for conducting the review. The Self-Assessment Report (Relatório de Auto-Avaliação) was finalized in 2008, based on extensive consultations with the local stakeholders at the provincial and district levels over the period of 2006-2007. This self-assessment process was mobilized and organized, primarily, by Mozambican civil society organizations. The Self-Assessment Report amounting to some 700 pages, was published, together with the government's preliminary National Programme of Action, in February 2009 when the African Country Review Team with 18 representatives from different African countries visited the country. The launch ceremony was a high-profile occasion attended by the President of the Republic.

The analysis of the entire APR process in Mozambique and its outcome, the Country Review Report, is beyond the scope of this research. However, to allow comparison with the outcome of the donor governance assessments, the key messages emerging from the Country Review Report can be summarized in two findings. First, on a positive note, the Report points out that, despite its "traumatic" colonial past and 
protracted war, Mozambique can be considered as a successful post-conflict country with major achievements in political stability, socio-economic and private sector development. Second, according to the Report, the positive development trend is overshadowed by the consistent high rate of poverty, the multifaceted inequalities in the society, and the blurred boundaries between the party in power, the government and the economic elite. One of the often quoted lines from the report states that: "In Mozambique, senior FRELIMO politicians are the party; the party is the government; the government is the state." (GoM, APRM Country Review Report 2010, p. 21). The Review Report also addresses a number of cross-cutting and special issues which are considered as having wider implications for governance and calls for a comprehensive approach in addressing these challenges. ${ }^{152}$ As summarized by Mosse and Pohlman: "In fact, the Country Review Report offers a comprehensive and useful synthesis of the key challenges for Mozambique to continue the process of democratic development." (Mosse M. and Pohlman J.F. 2011, p. 17).

In view of the APRM's mandate and the principles and the procedures guiding the implementation of APR, it is by far the most locally-driven governance assessment process that has been conducted at a national level in Mozambique in recent years. Compared with the donor governance assessments under consideration in this research, as well as with the Joint Review, the ownership of the APRM lies firmly in the hands of the Mozambicans stakeholders. The local participation encompasses the government, the parliament, private sector, media, academia, civil society actors, and last but not least, private citizens. The APRM could therefore be characterized as an instrument which builds on Mozambican interpretations of governance, and allows for assessing governance by taking into account not only the country-specific governance challenges, but also local perceptions and experiences of governance. The question of whether the APRM is seen as having realized this potential will be discussed below in light of the views presented by some of the informants familiar with this assessment mechanism.

The APRM was highlighted, first and foremost, as a unique tool for assessing governance because it was conducted with the full endorsement by the Government of Mozambique, and with broad participation by various Mozambican stakeholders.

152. Cross-cutting issues addressed in the Review report include: Poverty and inequality; Interwovenness of party, government and business; HIV/Aids; Land ownership; High levels of illiteracy; High aid dependency; Information flow and paucity of data; Political inclusivity; Crime, safety and security; Gender-based violence; Capacity constraints and implementation challenges; Elections and Corruption. As special issues the Review Report takes up the following: Climate change; Landmines and Environmental situation in Beira (APRM Country Review Report, 2010, p. 19; 34-36). 
One of the senior civil servants elaborated his views on the APRM in Mozambique as follows:

Key Informant No. 20 (SCS, Maputo)

"In my view, this was one of the best exercises conducted in the country. It was hard, it was not easy in Mozambique to submit this document directed by an academic Lourenco Rosario who had major shocks and frustrations with the government because of this document. I know very well, there was no consensus. I think it is the only document that the government agreed to do, perhaps at the level of the United Nations, the government agreed to do the assessment, it is a zoom."

He further noted that

"judging by the process, it was very transparent, very comprehensive. There was much involvement, many discussions, sometimes heated discussions because the purpose of the document was not well understood, and at first many of us did not understand either why it was needed. But I cannot imagine that a peasant knows about it. But it was a very comprehensive exercise."

According to another senior civil servant the value of the APRM lies in the fact that it builds on a more systematic analysis of a large number of different stakeholders. In his opinion the APRM "is very valuable and helps to form, crystallize the views of Mozambicans" that can then be presented in a systematic format to the government. (Key Informant No. 21, Maputo)

One of the academic cum CSO actor (Key Informant No. 6, Maputo/Nampula) described the APRM as the first assessment that broadly involved also the civil society. She further pointed out that the APR builds on the data collected at the community level and succeeds in addressing a number of relevant issues related to governance. In her view the fact that the APR Country Report was presented to the President of the Republic by the peer review countries has created a pressure for the government to tackle the governance challenges, although the outcome of the APRM does not, as such, tie the government to any reforms.

The most comprehensive account of the APRM was presented by one of the informants who is affiliated with the national APRM structure. In line with the official APRM documentation, he outlined the main principles guiding the assessment as follows:

Key Informant No. 24 (SCS/CSO, Maputo)

"The APRM is a unique mechanism, it was established by the African Union, by the Africans for the Africans. The novelty is already there. In other words, it is an internal effort 
by the country, not by the government or by whomever, and the entire country is assessed. The country is the one that conducts the self-assessment, and the most interesting thing is that this self-assessment is done by the Mozambicans. And therefore, there is immediately a difference because there are no people from outside doing this exercise, the donors do not enter into this."

In my view this process of self-assessment is also an exercise to strengthen those pillars of democracy, freedom of expression and freedom of opinions. I think this is what the APRM is about. It's the people that expose the truth, it is the country itself, the people, and it is important because of this. And the result is indeed the mirror of the country."

He praised the participatory nature of the assessment process even more explicitly than the previous speakers by saying that "the APRM is not based on a poll or a household survey, it builds on extensive consultations involving all strata of the society irrespective whether you are from the government, a Christian, a Muslim, a disabled". In his view, the relevance of the APRM was enhanced by tailoring its focus according to the specific context of the country, while respecting the overarching objective of the APRM. His perceptions about the impact of the APRM on improving governance in practice were, however, more cautious. He pointed out some specific reforms, such as the reform of the electoral legislation and the nomination of the first ombudsman, but emphasized the gradual process of reforming governance. With regard to the potential impact of the APR in general he made the point that, for example in Kenya and South Africa, the respective APR Country Reports had indicated the problems which - when left unresolved - lead to the outbreak of post-election violence in Kenya (2008) and the xenophobic attacks in South Africa (2010). In his perception, the strong national ownership and broad local participation in the assessment process deemed the APRM very relevant, with potentially significant impact on reforming governance, albeit gradually.

Contrary to the above positive views about the APRM, some of the key informants questioned the real impact of the APRM on improving governance. For example, one of the informants affiliated with academia cum media, who had been involved in the APRM process, questioned the objectivity of the assessment by pointing out that

Key Informant No. 17 (ACA/MED, Maputo)

"The APRM was structured like a branch paid by the Ministry of Planning. It does not have its own budget. Who pays for the conducting of the APRM is the government itself. Considering that 'the one who pays the orchestra orders the music', this is probably less transparent and less desirable for an independent exercise, and the APRM must be independent."

A very similar comment was made by one of the CSO actors for whom "the great peer review ends up being a process which is dominated by the government itself, it is driven 
by the government simply to legitimize the fact that it is having a peer review."(Key Informant No. 22, CSO, Maputo)

Some concerns were also raised about the rigor of process of data collected for the APRM. According to the Key Informant No. 17, quoted above, the APR Country Review Report repeats what has been presented in other reports: "I must also say that I think that there is a 'cut and paste', a cut and paste from almost all the assessments done in the country which then result in the creation of instruments such as the PARPA, the actual APR. They all rely on one document that has been extremely little publicized, that is the Agenda 2025. ${ }^{153}$ "

The limited access to the outcome of the APRM beyond the urban elite was mentioned as one of the issues undermining its potential impact:

Key Informant No. 17 (ACA/MED, Maputo)

"So if you ask me if I think these documents are sufficiently disseminated explicit, perhaps there is a large dissemination at the level of the city of Maputo, that is Polana, Baixa and Sommerschield [the luxury parts of Maputo city with concentration of foreigners, added by the author], but if you were to go to Xipamanine, or Chamamculo or Mafalala [poorer neighbourhoods] and ask someone what the APRM is, nobody can respond."

The above view echoes the comment made by one of the civil servants (cited earlier) about the peasant not knowing anything about the APRM.

One of the most critical accounts of the APRM was presented by an academic who has been closely involved in the APRM in Mozambique. In his view, the relevance of the APRM is undermined by because of the lack of real commitment by the government to implement the National Programme of Action accompanying the Country Review Report (the interview in English):

Key Informant No. 23 (ACA, Maputo)

"They send some progress reports with barely no information at all, and yes, to me that was something that they needed to do, to show some sort of commitment and political will. And also to improve some of the indicators, in terms of good governance, but in terms of commitment to push forward some of the issues, I don't really see that much."

In contrast to all the other informants speaking about the APRM, he also questioned the merits of the strong national ownership and the voluntary nature of the Mozambique as adopted by the government in 2003 following a broad-based consultative process. 
mechanism, which are generally considered the cornerstones of the APRM: "I don't look at it [the APRM, added by the author] with the same weight that does have, for instance, CPIA or other instruments, because those instruments come from those who give part of the money to spend in this country." In fact, in his view, the APRM as an instrument for assessing governance is "gradually losing momentum", not only in the case of Mozambique but in other countries as well, because of the lack of political will by the governments to move forward with their National Programmes of Action.

Bearing in mind the small number of informants who referred to the APRM, some tentative conclusions can be made about its merits as an instrument for assessing governance in Mozambique. First, the APRM process is generally seen as the most locally-driven assessment process with strong national ownership. Second, because of its consultative approach, the outcome of the assessment, particularly the Self-Assessment Report, is perceived to reflect the views of a wide range of Mozambicans about the achievements and challenges concerning governance in the country. Yet, despite the consultative process, the APRM is not widely known in the country. Third, the strong ownership of the APRM by the Government of Mozambique has its shortcomings: the relevance and potential impact of the assessment is greatly compromised because the mechanism is institutionally integrated into the government structures and is dependent on state financing. For some of the informants, the lack of institutional and financial independence of the APRM is reflected in the slow implementation of the National Programme of Action, which is aimed at responding to the governance concerns identified through the assessment. In other words, despite the participatory and context-specific approach to assessing governance, the APRM with its different reports, may remain yet another set of reports without significant relevance and impact on the ground.

\subsection{Revisiting Donor Governance Assessments; Donor Perspectives}

Following the above preliminary recommendations for enhancing the relevance and impact of donor governance assessments, formulated on the basis of the interviews with the Mozambican informants, this section turns to the views expressed by the donors about the strengths and weaknesses of their governance assessments.

At the outset it is import to recall that the main purpose of the interviews with the representatives of the selected donor agencies was to complement the desk study of the assessment tools under consideration in this research. Accordingly, the key questions addressed with donor representatives concerned the rationale, the focus and the methodology of the governance assessment of each agency. However, the informants were also invited to 
share their views as to how their governance assessments could be improved. The interview data thus provide some basis for identifying ways forward in assessing governance.

Following the conceptual framework developed by the Governance Network of the OECD DAC which was used to structure the desk study presented in Chapter 6, the analysis here focuses on the informants' views in respect of the conceptual approaches and methodological choices, including the involvement of local stakeholders in the assessments, as well as on the reporting and dissemination practices applied by the donors. The identity of the informants will not be disclosed, although the aid agencies may be identified in some cases.

First, as discussed out in Chapter 6, the conceptual approach underlying the different governance assessments varies from one agency to another. Due to different conceptual approaches, some assessments concentrate on the economic and institutional dimensions of governance while others adopt a wider power and political economy approach to governance, with emphasis on political governance. This lack of a common conceptual framework and a common set of indicators for good governance emerged as one of most debated topics among the donors. Some of the informants saw this conceptual puzzle as a major problem for conducting a coherent dialogue within the donor community and with the Mozambican government on governance. On the other hand, other donor informants considered the differences to be purely a matter of prioritisation by a given agency. According to one informant:

\section{Donor Representative No. 1}

"there definitely is a problem how governance is used in the development world or community. And what I mean by that is that there doesn't seem to be a rational assessment, and well a consensus, it's often such that it becomes a more emotional rather than factual.... have seen some ambassadors and agencies going to one extreme, which is that things are terrible, and it's a complete nepotistic, authoritarian, I don't know what else, bad, violent regime, to the opposite where they say everything is hunky-dory and wonderful. This schizophrenia is not easy for the government to understand, it doesn't help the dialogue basically on these difficult issues."

A very similar account was presented by another donor representative who elaborated his views on the situation as follows:

Donor Representative No. 6

"One of the difficulties of not having a shared a analytical framework or view point is that lot of elements in governance are not uniquely defined. The democratic process in .... (country reference deleted by the author) is completely different form that in .... (country reference deleted by the author) but still we consider them as very highly democratic 
countries. But we cannot say to Mozambique, you should adopt our system because it's better; that is not the case, so you don't have, in that sense, criteria to say what good governance is. Good governance becomes then, it should be certain principles, but even these principles are always debatable factors."

The problems of the different donor interpretations of what governance means, and what a governance assessments should entail, were brought into the limelight by the clash among the general budget support donors, the G19, in the context of the 2009 Joint Review. With each agency defending its own interpretation of what the Joint Review should entail, there was no consensus among the G19 donors as to how to tackle the problem of the alleged electoral fraud, which was the core question at the time. This incident had clearly left a mark on all the donors interviewed for this research, all of them members of the G19, because it was spontaneously raised by all informants irrespective of their position vis-àvis the freeze. The quote from the interview with one of the informants summarizes well the heated debate within the donor group:

Donor Representative No. 10

I think the approach taken by the G19 was good in the sense that political governance was not excluded in that situation - despite the attempt by the Commission - but it was brought to the core. It was kind of a schizophrenic situation, the Commission and the World Bank for a long time arguing that we cannot engage in a dialogue on matters which are in any way of political nature, such as elections and the position of Frelimo. They said we can only talk about economic governance. There were times when, for example, the World Bank said that they would have to leave the meeting room when we discuss issues related to political governance. We said that 'this is really absurd, you cannot act like this, at least you can be present, and stay quiet if you so wish if you don't want to participate."”

The quote below addressed the same incident - and the donor behaviour - from another perspective:

Donor Representative No. 1

"a lot of our colleague agencies focus very much on the last part, the conflict of interest, accountability in the political sense of Frelimo dominance, the anti-corruption which has been very weak...it is interesting because then those concerns, I guess combined with the recent contracts about the electoral process, lead to the extreme, if I can use this word, extreme reaction, and the threat of stopping aid, and the escalation of the political dialogue, which I think the government found difficult to understand. They genuinely don't see themselves... they don't think they are dictators, yes, they have the power and they use it. More important, it was strange, almost like a cold shower in Mozambique. I'm not saying those agencies were wrong, that the concerns are not right, but there is this sort of dichotomy often." 
The disagreement in the context of the Joint Review also highlighted the fact that even among the EU Member States, the approach to assess governance was interpreted somewhat differently. The EU Governance Profile, which in principle had been drafted jointly by the Commission and the $13 \mathrm{EU}$ Member States then present in the country, all of them members of the G19, could not be used as the common framework for assessing governance.

Donor Representative No. 9

"...we did try to get the G19 to accept the governance the EU governance profile as the monitoring tool, and that met with resistance, most resistance from the Commission itself. As they said, they were happy to share the final assessment but they were not happy to share with non-members the process of reaching these assessments."

From the perspective of another informant, the limitations of the EU Governance Profile reflected, first and foremost, the lack of commitment by the EU Member States to this assessment:

Donor Representative No. 10

"For example, the EU has an assessment, the Governance Profile which in itself should guide all EU countries, but in reality it does not. And I think that the reason why it does not do so, and why it has not been used even for example in this G19 process, is that even when you look at the Governance Profile, it lists the right things as the weaknesses - as far as I can remember - but I don't know whether, for example,.... [country reference left out, added by the author] does read the paper. And countries, or at least many countries, seem to act according to their own national interests."

From the point of view of some of the donors, this disagreement clearly undermined the commitment of the G19 to the principles of the Joint Review of the general budget support. For example, one of the informants challenged the G19 position by the arguing that it lead to the duplication of instruments for monitoring performance, increasing secrecy and unpredictability:

\section{Donor Representative No.7}

"We think there's something fundamentally problematic if there's an agreed plan between the donors and the government which is not public, transparently shared, and it's not linked to any local civil society. I refer to the GAP, the Governance Action Plan ${ }^{154}$. Because in the end we know you can't bomb countries to peace, and you can't really drive governance

154. The Government of Mozambique was requested by the G19 to prepare the so called Governance Action Plan as a precondition for the release of budget support funding for 2010. The GAP comprised a set of time-bound targets with specific indicators for measuring progress. 
reforms by donors conditionality... It [the GAP, added by the author] hasn't necessarily even been agreed, I think, with the line ministries. So suddenly you have to work out a strategy for land use, in six months, which no line ministry knows about, they don't know where it came from, they are not conscious about the Plan. So this is going to be a headache. But I think it's a consequence of a closed discussion between the government and donors."

The question of methodological choices, particularly questions concerning the reliability of the assessments, data sources and the involvement of local actors in the governance assessments, emerged as another debated topic among the donors themselves. Questions about the reliability and subjectivity of the CPIA ratings were raised by several informants. While it was pointed out that the CPIA ratings remain "ultimately a subjective interpretation and absorption of those analyses" it was also argued that the CPIA consultation and benchmarking process (described in Chapter 6) can quite effectively minimize any personal bias in the scoring:

Donor Representative No. 1

“... the degree of error is more on the half of a point; if it is 3 or 3,5 or if it is 3.5 or 4 . It is very hard that a country that is rated 3, should actually be at 4 , or country rated at 5 should be 4. That one point is actually a big jump and I haven't seen many cases where people have been able to say this was terribly wrong. Half a point I think is much more difficult if there is a subjectivity element."

One of the informants commented on the data sources commonly used in governance assessments, such as the CPIA or the EU Governance Profile, as follows:

\section{Donor Representative No. 7}

"I think we do use them and do read them, but we try to rely maybe more also on local assessments, our contacts with local NGOs. Because a lot of the information is just running around, you have a lot of these endogeneity problems. If you look at the CPI [Corruption Perception Index, added by the author], it's really funny, for example the Transparency International Index is a function of various governance indicators, so it's the function of CPI, and the CPI refers to the Transparency. So you know, I have a feeling sometimes you have the same information and expectations running under the system, and it doesn't always help us. Sometimes it's high level, sometimes it's fairly superficial and it's difficult to get this touch. I think we could see this with what happened a couple of weeks ago, no one expected, no one saw it coming." (reference to violent riots that took place in Maputo in September 2010, added by the author).

To be meaningful a governance assessment should, in his view, start from identifying what are the governance issues that matter at the level of communities rather than 
build on any global interpretation of governance. He shared his own experience as an illustration of the importance of a bottom-up approach for understanding what is considered relevant at community level:

"So last week I was out in ... [district reference deleted by the author] and I asked them what are the biggest local governance concerns. And they said the elephants eat the papaya trees, and the local district administration doesn't listen'. So I think there's a great risk that we all rely on this high-level global instruments."

A very similar argument in favour of a context-specific approach was made by another informant who said that "I don't believe in these top-down approaches any more. I think it is much better to say these are the dimensions to look at, in general. But you have to start from the country-specific characteristics and see to what extent you can influence there"(Donor Representative No. 6).

It was further pointed out that the donors may not be capable of making effective use of all the data and information that have been produced either by the donors themselves or by local actors:

Donor Representative No. 6

"... And I also agree that these governance indicators, the CPIA indexes, they are very useful statistical information and we should keep on using it. But if you do not understand the political processes behind it, and do not discuss it, then you are missing the point. It has to be a combination of the two, and it reinforces each other to get a better analysis of what is going on."

But what also comes into play is that various countries look at the same data from different viewpoints as if they want to prove something different. That is possible because we don't have a shared analytical viewpoint when looking at governance."

The third topic, which from the donor perspective calls rethinking, concerns the prevailing practices of sharing of information, and reporting and dissemination of the result of the governance assessments. Although some of the donors seemed to be willing to share their governance assessments among themselves, and to some extent also with the government authorities, there was no consensus as to how to share the results with wider stakeholder groups. For example, the Donor Representative No. 6 explained that:

"We knew that country $X$ [country references deleted by the author] had done their operation, and we also knew that country $Y$ had done one [country references deleted by the author]. What we did do, the three of us, as a result of our study and their studies as well, is to sit down, that was done before the elections of last year, to see how can we use these reports to stimulate a debate amongst Mozambicans here in Mozambique." 
In the case of some donors, the governance assessments involved consultations not only with other donors but also with selected government authorities. As discussed in Chapter 6, the CPIA of the World Bank entails, at least in the case of Mozambique, relatively extensive exchange of views and consultations with government authorities. Although the AfDB's CPIA is generally almost identical to that of the World Bank in all respects, in Mozambique the actual process of conducting the assessment appeared to be somewhat different. While the World Bank seems to be even encouraged to consult the government authorities about the Bank staff's initial ratings and the written justifications, in the case of the AfDB the initial ratings and write-ups are not supposed to be shared with the government.

As in the case of the World Bank CPIA, the Millennium Challenges Scorecard and the Governance Profile seem to be shared, and to some extent discussed with the government authorities. According to the informant at the EU Commission, the Governance Profile is shared with the government but it is not negotiated (information based on personal communication). The practice adopted by the MCC seems a bit more open for negotiation:

Donor Representative No. 3

"At the MCC they use it [the Scorecard, added by the author] as a form of dialogue so, for example, they have been telling the government that because they are below on girls primary education and immunization rates - and I think there's also one on access to water - they have basically informed the government that if they are interested in a second compact, they would have to be moving to address those areas, or they won't be considered for a second compact."

As pointed out in Chapter 6, the Power Analysis carried out by Sweden in the Niassa Province, stands out as the most participatory assessment. The assessments starts at the community level and ends up with active debates of the results at community level. As explained by the informant affiliated with the process:

Donor Representative No. 8

"I know that several of my colleagues and several of the organizations that we are working wit, were consulted during the writing of the report [the Power Analysis, added by the author]. ...And also if you look at how the study has been used after, I think that is also a sign that it was actually involving process. Because there are so many studies done in Mozambique, and I mean people really don't care so much when they come out, because it's just yet another study. But what happened when this came out, they organized a seminar, they organized a seminar to launch the study where they invited people from all the districts, like the administrator, but also civil society members, and traditional leaders, where they had a discussion on some of the topics from the study." 
According to her account, the launching seminar further served as a forum for collecting feedback for the communities involved, and for elaborating recommendations for tackling the problems outlined in the report. Therefore, in her view the Power Analysis is "like a 'how' document. It's not about to work or not to work in Niassa in Mozambique, it's about how to improve our work in Niassa."

The possibility of harmonizing the various governance assessment tools was brought up some of the informants. For example, the EU Governance Profile was considered by some of the EU Member States, although not by all, as a sufficient governance assessment framework. As stated by one of the donor representatives: "we believe that the tools that are already there, are sufficient for us to make our own decision now. I am primarily talking about the EU governance profile" (Donor Representative No. 9). According to another informant a joint assessment could be a feasible option, even desirable, "if you agree with the terms of reference" (Donor Representative No. 6). However, it was also pointed out that the diversity of governance assessments has its merits exactly because the different assessments bring out different views and "second opinions".

Although the African Peer Review Mechanism (APRM) did not emerge as a central point of reference among the donors, it seemed to have served as the common framework and the basis of discussion at least in the context of the 2009 Joint Review. As said by one of the informants:

Donor Representative No. 10

"In fact in the G19 dialogue we probably referred mostly to the APRM assessment, because we felt that it included many of the same elements that we saw as concerns on the basis of our knowledge, and we thought that it is better to take the APRM, an assessment made by Africans themselves of Mozambique, as the basis rather than to refer to an EU or any other assessment."

Concerning the World Bank, the AfDB and the MCC, the room for manoeuvring at the field level seems very limited. The agencies' legislative and regulatory frameworks call for independent, agency-specific assessments as a precondition for the decision-making on financial allocations and therefore, harmonization of the governance assessments does not seem to be an option at least for the foreseeable future.

Finally, although the question of the potential impact of the governance assessments on improving governance was not directly raised with the informants. However, some of them did volunteer their views on this issue. In light of the interviews, the expectations among the donors are very modest in comparison with the perceptions by many of the Mozambican informants. As stated by the Donor Representative No. 10: "I don't 
have any information that they [the governance assessments, added by the author] would impact upon governance. In my view, they remain internal assessments."

In most cases the governance assessments appeared to be conducted mainly for the agencies' internal purposes, and the outcomes of the assessments are used for justifying budgetary allocations made at the headquarter level. The primary objective is to convince the agencies' domestic constituencies rather than to influence the governance situation in Mozambique. The key assumption underlying the assessments thus relates to the argument that aid is effective in countries that perform well - whatever the performance assessment criteria a given agency may use. Even the CPIA's possibility to impact upon the wider governance context in Mozambique was perceived to be very limited, despite its direct financial implications:

\section{Donor Representative No. 1}

"Now government obviously, they know that the money is linked to this. So they want to try and see if there is any way in which they can take measures, or do something to help to improve some of the indicators. But it's difficult for them, because the instrument doesn't suit itself to that type of response. It really has to be a broader progress and more systematic effort to improve the environment. The CPIA doesn't really respond, I mean it does respond here or there by half a point, but it doesn't really respond much to these specific limited initiatives."

The most sceptical view about the donor influence was expressed by one of the donor representatives who seemed to argue that the donors fool themselves in thinking that they can really impact upon what happens in the country:

\section{Donor Representative No. 6}

"I don't think we can determine the way Mozambique is going to develop. We cannot, even as G19. We can only influence it to a certain extent, but we keep on acting as if we can determine, it's very strange, we are very arrogant and very stupid in that sense."

In conclusion, on the basis of the interviews with the selected donor representatives, the donor community is very aware of the fact that different interpretations of the concept of governance, and subsequently, their different approaches to assessing governance are problematic from the point of view of the government and other local stakeholders. The conflicting signals generated through the different assessments are seen as a cause of concern by many of the donors. Although while there seems to be some willingness to move towards a common assessment framework and harmonization of the multitude of assessments, this is hardly a viable option, at least in the short term. 
Several donors pointed out methodological weaknesses in their own assessments, whether in terms of the element of subjectivity, the use and interpretation of the data, and the limited use of local expertise in conducting the assessments. Concerning the sharing of information and dissemination of the results of the assessments, the donor agencies seem to have policy of sharing information about their governance assessments among themselves, but there is no common practice as to how to interact with the government or with non-state actors. The parliament did not enter into the discussion at all. In several cases the assessments seemed to be conducted mainly for the agencies' own internal purposes, and therefore the active dissemination of the results of the assessments was not considered an important issue. However, particularly in the case of the assessments with direct financial implications, such as the World Bank CPIA and the Millenniums Challenge Scorecard, the results were subject to some consultation with the government authorities. The Power Analysis of Sweden stands out as an exception in its bottom-up approach, strong reliance on local participation in conducting the assessments, and the active dissemination of the results with the local stakeholders engaged in the assessment.

Finally, in light of the interviews, the donor perceptions about the impact of their assessments on improving governance are very modest. The assessments play a role in the dialogue between the donors and the government on a range of governance issues and, after all, impact upon the donors' aid programming. But the contribution of the assessments to reforming governance is perceived to be limited, in contrast with the views of many of the Mozambican stakeholders.

\subsection{Ways Forward - Concluding Remarks}

On the basis of key themes emerging from the above discussion, a number of cautious recommendations can be suggested for enhancing the relevance and potential impact of governance assessments. Bearing in mind that the recommendations are generated from the views and perceptions expressed by only a relatively small number of all the key informants interviewed for the research, they must be considered as preliminary suggestions only for the way forward with assessing governance.

The first recommendation, from the perspective of the Mozambican stakeholders, concerns the broader involvement of local stakeholders in the design of the donor governance assessments. In the key informants' view the participation by local stakeholders would strengthen the relevance of the donor assessments by ensuring that issues considered significant for the specific governance context in Mozambique will be captured by the assessments. The second recommendation, closely related 
to the first one, relates to the engagement of local expertise, such as the Mozambican research institutions, academia and CSOs, in conducting the assessments. Local expertise could help sharpen the focus of the assessments on context-specific governance challenges and strengthen the analysis of the formal and informal structures and processes that underlie the prevailing governance context. Using local expertise could provide access to data sources and knowledge which are hidden from donor-led assessments. The restrictive disclosure policy and lack of active dissemination of the results of the donor assessments emerges as the third area that requires revisiting. One of the key messages points to the need to broaden the access to the governance assessment reports and to expand the dissemination level beyond the limited circles of the donor themselves and the government. The fourth recommendation that can be generated from the interviews concerns the involvement of the political decision-makers, notably the parliament, in the governance discourse. The parliament, which has the constitutional mandate to monitor the government's performance, cannot be excluded from the discourse. The perceived marginalization of the parliament appears as one of the fundamental shortcomings in the governance discourse in the country. The fourth recommendation concerning the parliament's participation leads to the fifth recommendation, which is related to the need for capacity building. In order to promote broad-based and informed engagement by the parliamentarians, CSOs, communities, and citizens at large, the donors are encouraged to invest in strengthening the capacity of all stakeholders to take part in governance discourse. Finally, based on the lessons learned from the Joint Review and the APRM, the dialogue between the external actors, the government and civil society, based on a shared reform agenda, provides a solid framework for improving governance in practice. However, successful implementation of the reform agenda requires systematic monitoring of performance by all parties, including by the donors who can play an important role because of their financial leverage.

From the perspective of the donors, the key issue that needs revisiting seems to relate to the lack of common framework for assessing governance. The multitude of conceptual and operational approaches to assessing governance is generally seen as problematic amongst the donors, not least because it can results in conflicting messages about the quality of governance in the country. However, while there seems to be some willingness to move towards the harmonization of the assessment tools, and to a common analytical framework, this is not seen as a viable option in the short term. Concerning the potential impact of the governance assessments on improving governance, the donor perceptions are very modest despite the fact that the governance assessments impact upon the agencies' aid programming. In the view of the donors, the governance assessments may play a role in the dialogue between the donors and the government on a range of governance issues, but their contribution to reforming governance is perceived to be limited. It is worth highlighting that the donor view appears to be in 
clear contrast with the views of many of the Mozambican stakeholders, which implies that the donors are not fully aware of the consequences - positive and negative - of their governance assessments. 


\section{Conclusions}

This concluding chapter recaptures the background and the purpose of the research, presents a summary of the main findings, discusses the relevance of the findings of the research, and finally, suggests some areas for further research.

The research builds on contemporary development discourse which identifies governance, or in normative terms, "good" governance, as one of the main building blocks for poverty reduction and sustainable socio-economic development. The conceptual framework of the research, outlined in Chapter 2, traces the emergence of governance as a fundamental component of the development discourse and the debate on aid effectiveness. Despite the aid agencies' shared belief in the importance of governance for effective aid and for the achievement of development objectives, there is no shared understanding as to what governance means or how it can be assessed in a specific country setting. In the absence of a common conceptual and operational approach to assessing governance, developing countries are subjected to multiple governance assessments conducted by the aid agencies in their attempt to ensure effective use of aid resources. The involvement of the developing countries themselves in designing and implementing the governance assessments has remained limited regardless of the aid agencies' declared commitment to respect partner country ownership.

In an attempt to contribute to this discourse, the main purpose of this case study on Mozambique has been to examine what the governance assessments conducted by aid agencies entail in the specific country context of Mozambique, and how the assessments are perceived from the Mozambican perspective. The evolving governance context in Mozambique, and the role of aid agencies in the country's political, economic and social transformation since independence, has been discussed in detail so as to provide a background for understanding the setting within which contemporary governance assessments take place. The discussion illustrates that Mozambique has, in fact, been "in a state of unfinished transitions" since independence, driven by both internal and external factors (Åkesson and Nilsson, 2006, p. 34). The aid agencies have contributed to these transitions, and impacted upon Mozambique's development trajectory, by providing significant amounts of technical and financial assistance to the country over the years. The governance assessments conducted by the donor agencies can be seen as one of the instruments that influence Mozambique's development processes.

Against this background, the research set out to seek answers to four research questions. The first research question aimed to explore how the aid agencies operating 
in Mozambique define and assess governance. In seeking answers to this question, the governance assessment tools formulated and used by the ten largest aid agencies (by volume of aid) in Mozambique were selected as the units of analysis for the case study. The analysis focused on the assessments conducted over the period of 20062010. In all, eight specific assessment tools have been analyzed in detail. The analysis of the conceptual and operational approaches applied in the selected assessment tools was conducted as a desk study based, primarily, on written documentation and internet-based data. To complement the desk analysis, representatives of the donor agencies that conducted these assessments were interviewed. The analysis was guided by the conceptual framework developed by the OECD DAC Governance Network.

The second research question concerned the consistency of the results generated by the selected governance assessment tools. The main purpose of the analysis was to identify similarities and potential differences in the quality of governance, as portrayed by the selected assessments. The analysis entailed, firstly, an in-depth examination of the results as presented in the assessment reports provided by the agencies themselves. Secondly, to allow for a more systematic analysis of the consistency, the results distilled from the original assessment reports were quantified using a single numeric scale as the benchmark for the comparison. For the quantification, the scale from 1 to 6 , which is used in two of the selected assessment tools (the Country Policy and Institutional Assessment of the World Bank and the African Development Bank), was applied.

The third and fourth research questions aimed to explore the perceptions by the Mozambican stakeholders about the donor governance assessments: the third research question focused on the perceived relevance of assessments from the Mozambican perspective, and the fourth question focused on the perceived impact of the governance assessments on improving governance in the country. In seeking answers to the questions on the relevance and impact of the assessment, a field study was conducted in Mozambique over the period of 2010-2011. The research material generated through the field study consisted of semi-structured interviews with 28 Mozambican key informants and 8 focus group discussions involving 58 participants.

\subsection{Conceptual and Operational Approaches to Assessing Governance}

The outcome of analysis of the selected governance assessment tools, developed and used by the largest donor agencies in Mozambique during the period of 2006-2010, mirrors the findings of the OECD DAC survey of a wider range of assessment tools, albeit with some differences. The aid agencies do apply different conceptual and 
operational approaches to assessing the quality of governance. In the case of Mozambique, most of the assessment tools build on conceptual approaches rooted in the traditions of historical, political economy and power analyses. The Country Policy and Institutional Assessments, conducted by the World Bank and the African Development Bank, stand out in their relatively narrow approach derived from the theories of traditional public administration and new public management. The common denominator for all the assessment tools relates to the stated purpose of enhancing the effective use of aid resources for economic growth and poverty reduction. At the same time, the assessments serve several other purposes: some assessment tools are used to determine the eligibility for, or the volume, of aid while others provide a basis for a wider policy dialogue and aid programming. The use of the results of the governance assessments as an instrument for reforming governance is implicit: the assessments aim to identify the strength and weaknesses as well as the potential "drivers of change" in the field of governance, and to provide a basis for resource allocation and choice of aid modalities. The methodological choices adopted by the selected tools vary from globally standardized quantitative methods to qualitative approaches that allow for tailoring the assessment to the country-specific governance context in Mozambique. The data sources underlying the assessments vary accordingly: the quantitative assessments tend to rely on globally available data and external expert assessments, whereas the qualitative assessments make more use of locally generated data and local expertise. The methodological choices seem to impact upon the practices for disseminating and reporting the results. The results reported in a quantitative format are made publicly available on the aid agencies' web pages, whereas the results of the qualitative assessments are presented in the form of narratives which are generally shared only - if at all - with the Government of Mozambique. Active dissemination of the results by the aid agencies is exceptional. Finally, the partner country ownership remains limited in the case of all but one of the selected assessment tools. Neither the Government of Mozambique nor other local stakeholders are truly involved in designing and conducting the assessments. The participation by local stakeholders is, at best, limited to the use of local experts in carrying out the assessments - with the exception of one assessment tool, i.e., the Power Analysis developed and applied by SIDA.

\subsection{Consistency of the Results of the Governance Assessments}

Despite the differences in their conceptual approach, stated purpose, foci, methodological choices, and the level of the involvement of Mozambican stakeholders in the assessments, the results of the eight assessments selected for analysis in this research point to relatively consistent, yet nuanced, perceptions of the quality of governance in 
Mozambique. Using the governance assessment approach developed by the Worldwide Governance Indicators (WGI) as an organizing framework, the key findings emerging from the eight governance assessments can be summarized in the following.

First, irrespective of the assessment tool, the perceptions about the main strengths and weaknesses in the quality of governance in Mozambique are very consistent. Mozambique is perceived to be politically stable, although with challenges related to the consolidation of democratic governance and the respecting of the fundamental freedoms enshrined in the Constitution. The economic governance of the country is characterized by both achievements and weaknesses: on the one hand, the government is perceived to perform relatively well with respect to the implementation of macro-economic policies and public financial management; on the other hand, the government's effectiveness in public administration, service delivery and in creation of an enabling environment for private sector development is perceived to remain poor. In the view of all the assessments, Mozambique faces its greatest challenges in the area of the institutional dimension of governance. Mozambique's performance is perceived to be weak, or even very weak, with respect for the rule of law and control of corruption. In other words, irrespective of the assessment tool, Mozambique is perceived to perform best in the field of political governance and worst in the field of institutional governance. In the field of economic governance, Mozambique's performance is perceived to be mixed in all the assessments.

Second, the analysis indicates that the consistency of the perceptions about the main strengths and weaknesses hides several differences in the perceptions of the quality of governance in specific areas, and in the perceptions of the magnitude of the challenges confronted in these areas. Hence, while the results are very uniform concerning the political stability in Mozambique, the perceptions vary notably concerning Mozambique's performance on issues related to economic and institutional governance. The key messages distilled from the qualitative assessments, for example the Governance Profile (EU), the Strategic Country Governance and Corruption Analysis (the Netherlands) and the Country Governance Analysis (the UK), concerning issues such as the rule of law and control of corruption, are significantly more critical than the perceptions generated through the quantitative assessments. The Country Policy and Institutional Assessments conducted by the World Bank and the African Development Bank seem to portray the most positive image in these areas of governance.

Third, the perceptions about the changes and trends in Mozambique's governance performance are rather consistent. The assessment results of the WGI, the World Bank and AfDB CPIAs and of the MCC, which are presented in quantitative formats and provide comparable data sets, show little - if any - variation between the years 2007 and 2010 included in the analysis. The most notable difference emerges when 
comparing the results between the quantitative and qualitative assessments, in particular, with respect to political governance. While the quantitative assessments either exclude this dimension from their analysis, or fail to identify any changes, most of the qualitative assessments point to increasing challenges in the field of political governance. The only assessment which arrives at a slightly more positive outlook is the Swedish Power Analysis.

Fourth, the perceptions generated through the WGI, the World Bank and the AfDB CPIAs and the MCS about Mozambique's performance relative to the group of the SADC low-income countries, i.e. to its closest peer group, are very consistent. Irrespective of the assessment tool, Mozambique is perceived to perform better than - or at least at the same level as - its peer group on all the six aggregate indicators of the WGI. Also the perceptions of changes or evolution in governance in Mozambique and in the SADC low-income countries are, for the most part, very similar.

Finally, methodological choices seem to contribute to systematic differences between the outcomes of the governance assessments. The results of the quantitative assessments seem to portray a more positive image of Mozambique's governance performance than the results distilled from qualitative assessments. In light of the analysis, the qualitative assessments adapted to the Mozambican context and conducted at the country level, with greater reliance on local data sources and local expertise, tend to arrive at more critical perceptions about the quality of governance than do the quantitative assessments based on a standardized, "one size fits all" approach to assessing governance. The quantitative assessments tend to provide not only a more positive view, but also a more uniform image of the governance context in the country.

\subsection{Perceptions about the Relevance of the Governance Assessments}

The research question on the relevance of the selected governance assessments from the perspective of Mozambican stakeholders was approached from three different angles by exploring: firstly, the local interpretations of the notion of governance; secondly, the familiarity of local stakeholders with the donor assessments; and lastly, the relevance of the specific topics covered by these assessments. The key findings emerging from the analysis are summarized in the following:

First, the Mozambican interpretations of the notion of governance and of "good" and "bad" governance are rather similar to those underlying the donor governance assessments. 
Governance is generally understood to be a multi-dimensional and complex concept which, following the WGI definition, involves political, economic and institutional dimensions. There are variations concerning the perceptions of the relative importance of the different dimensions, and of the aspects of good and bad governance, just as there are among the selected assessment tools. Some stakeholders highlight the importance of the political aspects of governance, while others put more emphasis on the economic and institutional aspects of governance. In general, broad-based popular participation, government accountability and effectiveness, and the respect for the rule of law, emerge as the central elements of good governance in the Mozambican context.

Within the broadly shared understanding of the notion of governance among the Mozambican stakeholders and the donors, one important difference stands out: in the Mozambican context governance is defined, first and foremost, in terms of the political processes of the country. The political realm is perceived to underlie all other dimensions of governance in the country. From the Mozambican perspective, the biggest governance concerns relate to the lack of truly democratic governance, weak sense of citizenship and the merging of the state and the party in power. Building on the UNDP's notion of democratic governance, this dimension of governance is conceptualized as "participatory democracy". Although the notion of "participatory democracy" is closely related to the political dimension of governance of the WGI, which is covered by many of the selected assessment tools, the analysis indicates that the donor governance assessment tools fail to fully capture this, from the Mozambican perspective fundamental, dimension of governance.

Second, the analysis indicates that the level of knowledge regarding donor governance assessments varies greatly between the key informants and the focus group discussants. The best-informed respondents, who were able to mention 2 or 3 donor assessments, and identify some of the topics included in the assessments, were all from the capital city, Maputo. Even among the best-informed respondents the level of knowledge of the specific assessment tools remains rather limited. Outside Maputo, the level of knowledge of any donor governance assessment is very limited. At the same time, there is extensive knowledge about various the governance assessments conducted by local organizations. Among the focus group discussants, the level of knowledge of the donor assessments is practically non-existent, although they also seem very knowledgeable of the various assessments conducted by the Mozambican CSOs and other local actors.

Third, the analysis of the perceptions about the relevance of the donor governance assessments points at somewhat conflicting findings. In view of the limited knowledge of donor governance assessments among the Mozambican stakeholders interviewed for the research, this question was presented only to those key informants familiar with the governance assessments conducted by aid agencies. On one hand, the governance 
assessments are perceived to capture several aspects of governance which are considered highly relevant in the Mozambican context. The common focus areas included in all the selected donor assessments, notably transparency, accountability, government effectiveness, the rule of law and corruption, are considered to be very relevant in the specific context of Mozambique. On the other hand, the assessments miss some of the most fundamental governance concerns for the country. In particular, challenges which are considered to be the core challenges for governance in the country, i.e. those related to the lack of broad-based popular participation in the political arena, the weak sense of citizenship, and generally, to the political dynamics in Mozambique, are perceived to be excluded from the donor governance assessments. In view of the best-informed local stakeholders, the failure to address the county-specific challenges in the political realm renders the donor governance assessments on Mozambique somewhat irrelevant - except that the assessments impact upon Mozambique's access to aid.

\subsection{Perceptions about the Impact of Governance Assessments}

Based on the case study on the selected governance assessments in Mozambique, the answer to the research question concerning the impact of the assessments in improving governance is not clear-cut. In light of the analysis, the assessments have succeeded in mobilizing public debate on governance issues, consolidating existing perceptions in a systematic manner, legitimizing popular complaints, and in providing an instrument for local actors to press for governance reforms. At the same time the country-level impact of the governance assessments is perceived to be seriously undermined because of the restricted dissemination policies and top-down approaches adopted by most of the aid agencies conducting the assessments. Besides, if the assessments are used by donors merely as a justification of maintaining the status quo in the relationship between the government and the donors, the impact of the assessments on governance in Mozambique may even be potentially harmful. The key finding emerging from the analysis implies, however, that in view of the Mozambican stakeholders the donor governance assessments have contributed positively to governance in Mozambique, particularly by broadening the space for non-state actors to take part in the governance discourse, by enhancing their voice, and by legitimizing their concerns. Hence, despite various conceptual and methodological weaknesses, the donor assessments are generally seen as an important contribution to the governance discourse in the country which have a positive impact on governance reforms in some specific areas of governance.

The key findings emerging from this research, summarized in the above sections, indicate that the critical assumptions (Chapter 1, p.7) underlying the research questions 
cannot be fully supported in light of the case study on the selected governance assessments in Mozambique. Although the aid agencies define and assess governance in various ways, several of the selected assessment tools take into account the specific governance context in Mozambique. The landscape of governance portrayed by the selected assessment tools is relatively uniform with consistent perceptions of the main strengths and weaknesses in Mozambique's governance performance. However, the case study indicates that the governance assessments fail to capture the concerns related to political processes which are considered the greatest governance challenges in the Mozambican context. The failure to address issues related to the aspect of participatory democracy undermines the relevance of the selected governance assessments. Finally, whereas the case study indicates that the governance assessments conducted by the aid agencies are perceived to contribute to improved governance in Mozambique, the lack involvement by Mozambican stakeholders in the governance assessments, and the limited dissemination of the assessment reports, greatly undermines their potential impact.

\subsection{Relevance of the Research}

This case study based on a limited number of donor governance assessments and purposive sample of informants does not allow for any empirical generalization of the findings across the multitude of governance assessments conducted by aid agencies in different parts of the developing world. However, from a theoretical perspective, the findings seem to validate much of the critical literature on governance discourse, and have "wider resonance" (Mason, 1996, p. 153) outside the specific context of Mozambique. In view of the analysis, the concept of governance as applied by the aid agencies has, indeed, become a "catch-all concept" which makes it difficult to distinguish where governance begins and where it ends (Hyden and Court, 2002, p. 18). The concept of governance is used, even within a single assessment tool, in reference to both governance structures and governance processes as well as to formal and informal patterns of rule. The normative agenda for "good" governance underlying the selected assessment tools covers, with some variations, at least, the ten elements identified by Smith as being the common elements of the donor agenda: political accountability; human rights; the rule of law; decentralization of political power; political pluralism; participation; eradicating corruption, transparent and accountable public administration; efficient public management; economic reform and poverty alleviation (Smith, 2007). The long list of "good" things to be achieved by developing countries like Mozambique underlines the importance of the question raised by Grindle about "good enough governance" (Grindle, 2002). In view of the real capacity and resource constrains faced by many developing countries, including Mozambique, the call for moving away from 
the all-embracing governance agenda to creating the minimal, country-specific conditions deemed necessary for poverty reduction and wider socio-economic development seems very valid.

However, in light of this research the argument that the governance agenda promoted by the aid agencies is ethnocentric remains debatable. As argued by one of the Mozambican key informants: "the issues relevant for governance are the same all over the world, in China, in Europe, in Mozambique: corruption, transparency, accountability" (Key Informant No. 4). Furthermore, most of the selected governance assessments on Mozambique, with the exception of the CPIAs by the World Bank and the AfDB, make an attempt to "look beyond the facade", and seek an understanding of the formal and informal structures rooted in the social fabric and power relations in Mozambique.

The conceptual approach underpinning a given governance assessment tool turns out to be of fundamental importance for identifying the critical, country-specific governance challenges as indicated by the survey conducted by the OECD DAC Governance network (OECD 2009). The findings of this research imply that, from the local stakeholders' perspective, the assessments rooted in historical, political economy and power analyses succeed better in capturing the "true governance" in Mozambique than the assessments which build on traditional public administration and new public management approaches to governance. Furthermore, as argued by the proponents of the "upside-down view of governance", the assessments need to build on a deep analysis of the context-specific political, economic and social dynamics so as to identify not only the formal but also the informal local governance institutions and relationships that are "pervasive and powerful", and can contribute to building effective, rule-based and accountable public authority (IDS, 2010, p. 70-71).

The conclusions drawn by Ferguson from his case study on Lesotho, with focus on a large rural development project, open new perspectives for analyzing - and for assessing - the country-level implications of the donor governance assessments. Following the argumentation by Ferguson, governance discourse has, to a large extent, been generated by the aid agencies, and has become an integral part of the "development apparatus" in Mozambique. This governance discourse has created a structure of knowledge in the country around the notion of good governance, and the aid interventions supported by the donors are organized on the basis of this structure of knowledge. As argued by Ferguson, these interventions contribute to significant structural changes even when failing to achieve the intended objectives because "ideas and discourses have important and very real social consequences" (Ferguson, 1994, p. xv). From the perspective of this research, it can be argued that the governance discourse promoted by the aid agencies may not have achieved its objectives related to enhanced aid effectiveness or improved governance, but it has certainly succeeded in bringing 
governance to the core of public debates in Mozambique, also amongst the Mozambicans. Using the World Bank expression, governance has become "everybody's business" (World Bank, 2011, p. 8).

The governance discourse has brought about significant structural changes in the field of governance in the form of legislative reforms, the creation of numerous new interest groups particularly among the civil society actors, and in the opening of space for non-state actors to take part in the discourse. The findings from this case study seem to further resonate with Ferguson's argument according to which the development discourse turns sensitive political issues into "development issues" which then remain outside the realm of politics. The governance discourse generated by the aid agencies and operationalized through the various governance assessment tools seems to have translated political questions, such as participatory democracy, citizenship, access to resources, public service provision etc., into technical questions debated between the aid agencies, the Government of Mozambique and, to a varying degree, civil society. Yet, one of the key findings of this research indicates that the donor governance assessments fail to capture the complexities of the political dynamics in Mozambique. Furthermore, as pointed out by several of the Mozambican respondents, the national parliament is practically excluded from the governance discourse, despite its constitutional mandate to monitor the performance of the government. In other words, the governance discourse generated by the donors seems to have de-politicized the essentially political debates in Mozambique by transforming them into the largely context-independent and globally standardized development discourse, as argued by Ferguson. From the Mozambican perspective, the the de-politicization of the governance discourse turns out to be the key factor that undermines the country-level relevance of the governance assessments.

Some tentative generalizations can be made also from the perspective of the policy debate on governance assessments. The findings of the research highlight the importance of context-specific approach to assessing governance. The research further indicates that the involvement of local stakeholders is critical for the identification of the key challenges for governance, not only as data providers but also as active partners in the governance assessment processes. If the donor assessments of the quality of governance aim to enhance the effectiveness of aid by enhancing the understanding of the formal and informal structures and institutions that impede poverty reduction and of the incentives and disincentives for "pro-poor development", the participation of the local stakeholders in the assessment processes is of utmost importance. Furthermore, efforts by the aid agencies to improve governance without the commitment by the wide spectrum of local stakeholders to carry out reforms are likely to fail to bring sustainable results. As noted by one of the donor representatives, "we cannot, even as the G19 [determine the way Mozambique is going to develop], we can only influence to 
a certain extent but we keep on acting as if we can determine" (Donor Representative No. 6). Or in even more direct terms by another donor representative: “...in the end we can't bomb countries to peace, and you can't really drive governance reforms by donor conditionality" (Donor Representative No. 7).

\subsection{Emerging Questions for Future Research}

The outcome of this case study suggests that the way forward with assessing governance requires a shift from donor-led governance assessment towards country-led joint assessments that build on country-specific analyses of what governance means, and on a broad-based country ownership of the assessments processes and the results of the governance assessments. However, the case study also indicates that the aid agencies themselves are part of the governance realm in Mozambique and cannot be seen as neutral a-political "development experts" in the country's governance structures and processes. Furthermore, in a developing country context like Mozambique with high dependence on external aid, it is impossible to conceptualize governance only in national or local terms. On the contrary, the country-specific governance context in Mozambique, as in any developing country, is influenced also by the supranational factors which interact with the national and local factors.

From this perspective, a number of questions can be suggested for further research. First, while the question of how the concept of governance is defined remains relevant for assessing governance, the question needs to be approached bearing in mind that governance is fundamentally contextual. Instead of searching for a universally accepted definition of the concept of governance, there is a need to formulate a common analytical framework for approaching governance from a perspective that entails context-specificity. Hence, further research is needed to conceptualize the "context-specific approach" to assessing governance. What does context-specificity mean beyond an attempt to "look beyond the facade"?

Second, the call for enhancing the broad-based participation by local stakeholders in identifying the context-specific, evolving governance concerns, and in assessing governance leads to the question of how to identify the relevant stakeholders in the myriad of formal and informal power relations and interest groups in any given society. Nationwide consultations, as adopted by the APRM in Mozambique, are hardly a viable option. The common practice of inviting representatives of the government, private sector and civil society, followed by many aid agencies, does not ensure the representation of the broad spectrum of national and local actors who have a stake in the governance discourse in their own society. For example, in a governance context such as Mozambique, 
characterized by the hegemony of the party in power, the representatives of the different stakeholder groups may in the end represent interests of the political and economic elite despite their different constituency. As argued by one of the Mozambican key informants: "there are no conditions for an effective basis for citizenship, accountability and governance in this country" (Key Informants No. 3). Therefore, the question of how to ensure truly broad-based local participation in a specific country context merits further research. The lessons learned from the World Governance Assessments programme provide a basis for exploring this question further.

Third, this case study on assessing governance assessments in Mozambique indicates that many of the governance challenges, as identified through the lenses of the various assessment tools, can be traced to the country's colonial legacy, the formal and informal governance structures created during the period of the war triggered by outside forces, as well as the emerging economic opportunities, particularly in relation to natural resources. The governance context of Mozambique cannot be fully understood without a deeper analysis of the inter-linkages between the various external and internal factors impact upon the national and local governance context in a given country. Hence, any analytical framework for assessing governance in a country-specific context should entail a broad perspective that allows taking into account the fact that governance is shaped by a number of supranational forces that impact upon the national and local governance context.

Fourth, the problematic of "good enough governance" conceptualized by Grindle already a decade ago requires further research. The all-embracing good governance agenda, which seems to have become part of the rhetoric not only amongst the donors but also amongst many of the political leaders in developing countries, needs to be disaggregated and prioritized taking into account the perceived urgency of specific reforms and the capacity and resource constraints in a given country. Hence, further research is needed to identify the critical areas for action, the sequencing of reforms and the key actors to be engaged in the reform processes bearing in mind that all these questions entail political choices.

Finally, in light of this case study, the role and impact of donors in generating governance discourse and contributing to changes in governance in developing countries requires further research. The aid agencies have become an integral part of the formal and informal governance structures and processes in their partner countries. The governance assessments conducted by the agencies have direct and indirect financial and other policy-related implications which shape the governance context beyond the aid relationships. The aid agencies play an important political role even when claiming to be neutral, a-political "development experts" providing financial and technical support to a given partner country. Therefore the question of how the aid agencies influence 
governance through the multitude of governance assessments merits further analysis. The often stated policy of "do no harm" is meaningless as the aid agencies are part of the "development apparatus" in their partner countries, and cannot be abstracted out from the governance discourse.

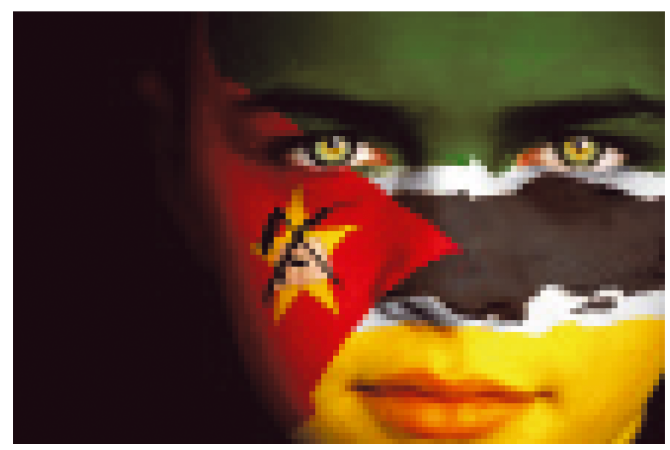

Source:

http://www.portaldogoverno.gov.mz/Mozambique 



\section{References}

Abrahamsen, R. (2000). Disciplining Democracy: Development Discourse and Good Governance in Africa. London: Zed Books.

Abrahamsson, H. \& Nilsson, A. (1994). Moçambique em Transição - Estudo da História de Desenvolvimento durante o Periodo 1974-1992. Maputo: CEEI-ISRI and Padrigau.

Adam, Y., Goodyear R., Greeley, M., Moore, M., Munguambe, J., Neves, M., Roberts, P., Taju, G. \& Vieira S. (1991). Aid Under Fire. SIDA Evaluation Report 1991\&1. Stockholm: SIDA.

Addison T., Mavrotas G. \& McGillivray M. (2005). Aid to Africa. Journal of International Development 17, 990-991.

African Union/NEPAD (2003). African Peer Review Mechanism. NEPAD/HSGIC/03-2003/ APRM/MOU.

African Union/NEPAD (2002). Declaration on Democracy, Political, Economic and Corporate Governance. AHG/235 XXXVIII.

African Development Bank Group (2009). The 2010 Country Policy and Institutional Assessment (CPIA). 2009 CPIA Questionnaire. Tunis: African Development Bank Group.

African Development Bank Group (2009). Operational Guidance Note. Assessing Governance. Staff Guidance Note on the Governance Rating of the Bank's Performance Assessment. Tunis: African Development Bank Group.

African Development Fund (2009). AFDB-11 Resource Allocation. Discussion Paper. ADF11 Mid Term Review. Helsinki: African Development Fund.

African Development Fund (2010). Issues Concerning the AFDB Resource Allocation Framework. Discussion Paper. ADF-12 Replenishment. Cape Town: African Development Fund.

Agencia de Informação de Moçambique (1984). AIM Bulletin. Issues No. 92, 93, 94, 100, 101. Maputo.

Åkesson, G. \& Nilsson, A. (2006). National Governance and Local Chieftaincy; A Multi-level Power Assessment for Mozambique from Niassa's Perspective. Unpublished document.

Alasuutari, P. (1999). Laadullinen tutkimus. Tampere: Vastapaino.

Alasuutari, P. (2001). Johdatus yhteiskuntatutkimukseen. Helsinki: Gaudeamus.

Andrews, M. (2008). The Good Governance Agenda: Beyond Indicators without Theory. Oxford Development Studies, 36 (4), 379-407). International Development Centre. Oxford. 
Appolinario, U. (2010). Breaking the Aid Trap: Between Aid Dependency, Governance and Institutions in Mozambique. Geneva: Graduate Institute of International and Development Studies.

Arndt, C. (2009): Governance Indicators. Maastricht: Boekenplan.

Arndt, C., Hussain, A.M., Jones, S.E., Nhate, V., Tarp, F. \& Thurlow, J. (2011). Explaining Poverty Evolution. The Case of Mozambique. WIDER Discussion Paper No. 2001/64. Helsinki: WIDER.

Arndt, C., Jensen H.T. \& Tarp F. (2000). Stabilization and Structural Adjustment in Mozambique. An Appraisal. Journal of International Development 12 (3), 299-323.

Arndt, C., Jones, S. \& Tarp, F. (2006). Aid and Development: The Mozambican Case. Discussion Papers 06-13. University of Copenhagen.

Arndt, C. \& Oman, C. (2006). Uses and Abuse of Governance Indicators. OECD Development Centre Studies. Paris: OECD.

Astill-Brown, J. \& Weimer, M. (2010). Mozambique - Balancing Development, Politics and Security. London: Chatham House.

Baran, P.A. (1982). A Morphology of Backwardness. In Alavi H. and Shanin T. (Eds.), Sociology of "Developing Societies" (pp. 195-204). Hong Kong: Macmillan Publishers.

Batley, R., Bjornestad, L. \& Cumbi, A. (2006). Joint Evaluation of General Budget Support 1994-2004. Mozambique Country Report. University of Birmingham.

Bauer, P.T. (1981). Equality, the Third World and Economic Delusion. London: Weidenfeld and Nicholson.

Bevir, M. (2011). Governance. In M. Bevir (Ed.). The Sage Handbook of Governance. London: Sage.

Bjuremalm, H. (2006). SIDA Power Analysis - experiences and challenges. Stockholm: SIDA.

Blomström, M. \& Hettne, B. (1984). Development Theory in Transition. London: Zed Books.

Booth, D. (2011). Aid, Institutions and Governance: What Have We Learned? Development Policy Review 29 (s1), s5-s26.

Bosworth, B. \& Collins, M. S. (2003). Empirics of Growth: An Update. Brookings Papers on Economic Activity, Vol. 34 (2), 113-206.

Bourguignon, F. \& Sundberg. M. (2007). Aid Effectiveness - Opening the Black Box. (unpublished document).

Brito M. de (2008): Governance Assessments in Practice; Case Study on Mozambique. Retrieved from: www.oecd.org/dataoecd/21/11/40108254.pdf

Browne, S. (2006). Aid and Influence: Do Donors Help or Hinder? London: Earthscan.

Burnside, C. \& Dollar, D. (1997). Aid, Policies and Growth. World Bank Policy Research Working Paper 1777. Washington: World Bank.

Burnside, C. \& Dollar, D. (2000). Aid, Policies and Growth. American Economic Review 90 (4), 847-868.

Burnside C. \& Dollar D. (2004). Aid, Policies and Growth: Revisiting the Evidence. World Bank Policy Research Paper 3251. Washington: World Bank. 
Buur, L. \& Baloi, S.O. (2009). The Mozambican PRSP Initiative: Moorings, usage and future. DIIS Working Paper 2008 (35). Copenhagen: DIIS.

Buur, L. \& Kyed, M.H. (2006). Contested Sources of Authority: Re-claiming State Sovereignty by Formalizing Traditional Authority in Mozambique. Development and Change $37(4), 847-869$.

Cassen R. and Associates (1986). Does Aid Work? Report to an Inter-Governmental Task Force, $1^{\text {st }}$ edition ( $2^{\text {nd }}$ edition 1994). Oxford: Oxford University Press.

Castel-Branco, C.N. (2010). Desafios da Construção Democrática. In L. de Brito, C.N. Castel-Branco, S. Chichava \& A. Francisco (Eds.), Desafios para Moçambique, 2010 (pp.1729). Maputo: IESE.

Castel-Branco, C.N. (2011). Dependência da Ajuda Externa, Acumulação e Ownership. In L. de

Brito, C.N. Castel-Branco, S. Chichava \& A. Francisco (Eds.), Desafios para Moçambique, 2011 (pp. 401-466). Maputo: IESE.

Castel-Branco, C.N., Cramer, C. \& Hailu, D. (2001). Privatization and Economic Strategy in Mozambique. WIDER Discussion Paper No.2001/64. Helsinki: WIDER.

Castel-Branco, C.N. \& Ossemane, R. (2010). Crises Cíclicas e Desafios da Transformação do Padrão de Crescimento Económico em Moçambique. In L. de Brito, C.N. Castel-Branco, S. Chichava, S. \& A. Francisco (Eds.), Desafios para Moçambique, 2010 (pp.141-182). Maputo: IESE.

Chenery, H., Ahluvalia, S.M., Bell, C.L.G., Duloy, H.J. \& Jolly, R. (1974). Redistribution with Growth. World Bank and the Institute of Development Studies/University of Sussex. Oxford: Oxford University Press.

Chenery, H.B. \& Strout, A.M. (1966). Foreign Assistance and Economic Development. American Economic Review 56 (679-733).

Clemens, M.A., Radelet S. \& Bhavnani R. (2004). Counting Chickens When They Hatch: The Short Term Effect of Aid on Growth. Centre for Global Development Working Paper 44. Washington D.C.: Centre for Global Development.

Collier, P. (2007). The Bottom Billion. Oxford: Oxford University Press.

Collier P. \& Dollar D. (2004). Development Effectiveness: What Have We Learnt? The Economic Journal 114 (244-271).

Commission for Africa (2005). Our Common Interest: The Report of the Commission for Africa. London.

Cornia A.G., Jolly R. \& Stewart, F. (1987). Adjustment with Human Face: Protecting the Vulnerable and Promoting Growth. Oxford: Clarendon Press.

Creswell, W. J. (2013). Qualitative Inquiry and Research Design. USA: SAGE Publications.

Court J., (2006). Governance, Development and Aid Effectiveness: A Quick Guide to Complex Relationships. ODI Briefing Paper March 2006. Overseas Development Institute. London.

Court, J., Hyden, G. \& Mease, K.(2004). Making Sense of Governance. Boulder and London: Lynne Rienner Publishers. 
Dalgaard, C-J. \& Hansen, H. (2001). On Aid, Growth and Good Policies, Journal of Development Studies, 37 (6), 17-41.

Dahl-Ostergaard, T., Unsworth, S., Robinson, M. \&Jensen, R.I. (2005). Lessons Learned on the Use of Power and Drivers of Change Analyses in Development Cooperation. Paris: OECD DAC.

Davies, R., O'Meara, D. \& Dlamini, S. (1984). The Struggle for South Africa I. London: Zed.

Denzin N. \& Lincoln Y.S. (1978). Handbook of Qualitative Research (Eds.). USA: Sage Publications.

Department for International Development (2006). Eliminating World poverty; Making Governance Work for the Poor. London: Department for International Development. Norwich: HMSO.

Department for International Development (2006). Evaluation of General Budget Support: Synthesis Report. London: Department for International Development.

Department for International Development (2008). How to note. Country Governance Analysis.

London: DFID.

Development Policy Committee (2007). State of Finland's Development Policy III. Helsinki. Ministry for Foreign Affairs.

Doucouliagos H. \& Paldam M. (2005). The Aid Effectiveness Literature: The Sad Results of 40 Years of Research. University of Aarhus, Department of Economics Working Paper, 15. Aarhus: University of Aarhus.

Easterly W., Levine R. \& Roodman D. (2003). Aid, Policies and Growth: Comment. American Economic Review 94 , 774-781.

Economist Intelligence Unit (2008). Mozambique Country Profile 2008. London: Economist Intelligence Unit.

EISA Mozambique Election Archive. Retrieved April 15, 2010, from the World Wide Web http://www.eisa.org.za/WEP/mozelectarchive.htm

Eronen, J., Palmujoki, E. \& Virtanen, P. (2007). Trade Capacity, Poverty Reduction and Development Cooperation: Case Studies of Mozambique and Vietnam. In K. Brolén, K. Wilska, \& M von Bonsdorff (Eds.), Aid for Trade: from Policies to Practice (pp.102179). Helsinki: Ministry for Foreign Affairs of Finland.

Eskola, J. (2001). Laadullisen tutkimuksenjuhannustaiat. Laadullisen tutkimuksen analyysi vaihe vaiheelta. In J.Aaltola and R. Valli (Eds.), Ikkunoita tutkimusmetodeihin II (pp.133-157). Jyväskylä: PS-kustannus.

Eskola, J. and Suoranta, J. (1996). Johdatus ladulliseen tutkimukseen. Rovaniemi: Lapin yliopisto.

EU Election Observation Mission to Mozambique 2010. http://www.cip.org.mz/election2009/ndoc2009/294_Final_Report_EU_EOM_en.pdf

Eurodad, Cafod \& Trócaire (2008). Mozambique: An Independent Analysis of Ownership and Accountability of in the Development Aid System. Maputo. 
European Commission (2003). Governance and Development. Communication from the Commission to the Council, the European Parliament, the European Economic and Social Committee and the Committee of Regions COM(2003) 615 final. Brussels: European Commission.

European Commission (2006a). Governance in the European Consensus for Development. Towards a Harmonized Approach within the European Union. Communication from the Commission to the Council, the European Parliament, the European Economic and Social Committee and the Committee of Regions COM(2006) 421 final. Brussels: European Commission.

European Commission (2006b). The European Consensus on Development. Brussels: European Commission.

European Commission (2006c). Compendium on Development Cooperation Strategies. Brussels: European Commission.

European Union (2007). Official Journal of the European Union C306. Brussels: European Commission.

European Commission (2009). Supporting Democratic Governance Through the Governance Initiative. A Review and the Way Forward. Commission staff working paper. SEC(2009) 58 final. Brussels: European Commission.

Ferguson, J. (1994). The Anti-Politics Machine. "Development", De-politicization and Bureaucratic Power in Lesotho. Minneapolis: University of Minnesota Press.

Ferreira, E. de Sousa (1974). Portuguese Colonialism in Africa: the End of an Era. Paris: UNESCO Press.

Forquilha, S. C. (2010). Governação Distrital no Contexto da Reformas de Descentralização Administrativa em Moçambique. In L. de Brito, C.N. Castel-Branco, S. Chichava \& A. Francisco (Eds.), Desafios para Moçambique, 2010 (pp. 31-50). Maputo: IESE.

Francisco, A. (2010). Sociedade Civil em Moçambique. In L. de Brito, C.N. Castel-Branco, S. Chichava \& A. Francisco (Eds.), Desafios para Moçambique, 2010 (pp. 51-105). Maputo: IESE.

Frank, A.G. (1981). Crisis: In the Third World. London: Heinemann Educational Books.

Geffray, C. (1991). A Causa das Armas. Antropologia da Guerra Contemporânea em Moçambique. Porto: Litografia Ach. Brito.

Gerring, J. (2004). What Is a Case Study and What Is It Good For? American Political Science Review, 98 (2), 341-354).

Gersony, R. (1988). Summary of the Mozambican Refugee Accounts. (unpublished document).

Glenn, E.N., (2010). Constructing Citizenship: Exclusion, Subordination and Resistance. American Sociological Review 76 (1), 1-24.

Grindle, M. (2004): Good Enough Governance: Poverty Reduction and Reform in Developing Countries. Governance: An International Journal of Policy Administration and Institutions 17, 525-48. 
Grindle, M. (2011). Good Enough Governance Revisited. Development Policy Review 29 (s1), s199-s221.

Guba, E.G. \& Lincoln, Y.S. (1994). Competing Paradigms in Qualitative Research. In N.K. Denzin, N.K. (1978). The Research Art (3rd ed.). New York: McGraw-Hill.

Guillaumont P. \& Chauvet L. (2001). Aid and Performance: A Reassessment. Journal of Development Studies 37 (6), 66-92.

Government of Mozambique, Ministry of Planning and Development. (2010). Poverty and Wellbeing in Mozambique: Third National Poverty Assessment. Maputo.

Government of Mozambique and Programme Aid Partners. Memorandum of Understanding 2009. www.pap.org.mz

Government of Mozambique and UNDP (2010). Report on the Millennium Development Goals. Maputo.

Governo de Moçambique/Ministério de Plano e Finanças (2004). Pobreza e Bem-Estar em Moçambique: Segunda Avaliação Nacional (2002-2003). Instituto Internacional de Pesquisa em Políticas Alimentares (IFPRI). Universidade de Purdue.

Governo de Moçambique/Ministério de Planificação e Desenvolvimento (2010). Pobreza e Bem-Estar em Moçambique. Terceira Avaliação (2008-2009). Maputo.

Gwin C. (2002). IDA's Partnerships for Poverty Reduction, An Independent Evaluation of Fiscal Years 1994-2000. Washington D.C.: World Bank.

Haaparanta, L. \& Niiniluoto, I. (1991). Johdatus tieteelliseen ajatteluun (6. korjattu painos). Helsingin yliopiston filosofisen laitoksen julkaisuja No. 3. 1986.

Hall, M. \& Young T. (1997). Confronting the Leviathan: Mozambique Since Independence. London: Hurst \& Company.

Hanlon, J. (1991). Mozambique: Who Calls the Shots? London: James Currey.

Hanlon, J. (2002). Are donors to Mozambique promoting corruption? Sheffield conference paper:

Towards a New Political Economy of Development, University of Sheffield.

Hanlon, J. (2004). How Northern Donors Promote Corruption: Tales from the New Mozambique

Corner House Briefing 33. Dorset: The Corner House.

Hanlon, J. (2011). Mozambique News Reports \& Clippings. Number 178, Retrieved on March 12, 2011. from the World Wide Web: http://tinyurl.com/mozamb

Hanlon, J. \& Smart T. (2008). Há Mais Bicicletas - Mas Há Desenvolvimento? Maputo: Central Impressora e Editora de Maputo.

Harding, A \& Gerster, R. (2004). Learning Assessment of Joint Review 2004. Final Report to Programme Aid Partners and Government of Mozambique. Maputo.

Hansen H. \& Tarp F. (2000). Aid Effectiveness Disputed. Journal of International Development 12, 375-398.

Hansen H. \& Tarp F. (2001). Aid and Growth Regressions. Journal of Development Economics $64,547-570$. 
Hansen H. \& Tarp F. (2006). Aid and Development. Swedish Economic Policy Review 13, 9-61.

Hazenberg, J. (2008). The SGACA Experience: incentives, interests and raw power: Making development aid more realistic and less technical. Retrieved July 19, 2011. (http://www.minbuza.nl).

Heywood, A. (2007). Politics. Palgrave Macmillan (Third Edition).

Hout W. (2007). The Politics of Aid Selectivity: Good Governance Criteria in World Bank, US and Dutch Development Assistance. Abingdon: Routledge.

Hoyland, B., Moene, K. \& Willumsen, F. (2009). The tyranny of international index rankings. (http://www.lse.ac.uk/government/research/resgroups/PSPE/pdf/

2010conference_papers/Hoyland.pdf)

Hyden G., Court J. (2002). Better Governance and Public Policy. Kumarian Press.

Hyden G., Court J.\& Mease K. (2004). Making Sense of Governance: Empirical Evidence from Sixteen Developing Countries. Lynne Rienner.

Hyden G., Mease K. Foresti, M. \& Fritz, V. (2008). Governance assessments for local stakeholders: What the World Governance Assessment offers. Working Paper 287. ODI and Dag Hammarskjöld Foundation. London: ODI.

IMF (1998). Press Release No. 98/12. Washington D.C.: IMF.

IMF (2000). Press Release No. 00/28. Washington D.C.: IMF.

IMF (2013). Press Release No. 13/231. Washington D.C.: IMF.

IMF (2010). World Economic Outlook. Washington D.C.: IMF.

IMF (2011). Republic of Mozambique: 2011 Article IV consultation - staff report. Washington D.C.: IMF.

Institute of Development Studies (2010). An Upside-down View of Governance. Brighton: Institute of Development Studies.

Instituto Nacional de Estatística (2004). Inquérito aos Agregados Familiares sobre Orçamento Familiar 2002/3. Instituto Nacional de Estatística. Maputo.

Instituto Nacional de Estatística (2010). Inquérito sobre Orçamento Familiar 2008/9. Instituto Nacional de Estatística: Maputo.

Inter-Parliamentary Union, IPU. http://www.ipu.org/wmn-e/classif.htm

Isaacman, A. \& Isaacman, B. (1983). Mozambique. From Colonialism to Revolution. Harare: Zimbabwe Publishing House.

Kaufmann, D., \& Kraay, A.(2007). Governance Indicators: Where are We, Where Should We Be Going? World Bank Policy Research Working Paper No. 4370. Washington D.C.: World Bank.

Kaufmann, D., Kraay, A. \& Mastruzzi, M. (2007). The Worldwide Governance Indicators Project: Answering the Critics. Washington D.C.: World Bank.

Kaufman, K., Kraay, A. \& Zoido-Lobatón, P. (1999). Aggregating Governance Indicators. World Bank Policy Research Working Paper No. 2195. Washington D.C.: World Bank.

Kaufmann D., Kraay A. \& Zoido-Lobatón P. (1999). Governance Matters. Policy Research Working Paper 2196. Washington D.C.: World Bank. 
Kaufman, K., Kraay A. \& Zoido-Lobatón P. (2002). Governance Matters II. World Bank Policy Research Working Paper No. 2772. Washington D.C.: World Bank.

Kaufman, K., Kraay, A. \& Zoido-Lobatón P. (2008). Governance Matters VII. World Bank Policy Research Working Paper No. 4654. Washington D.C.: World Bank.

Kaufman, K., Kraay, A. \& Zoido-Lobatón (2010). Worldwide Governance Indicators. World Bank Policy Research Working Paper No. 5430. Washington D.C.: World Bank.

Keefer, P. (2009). Governance. In T. Landman and N. Robinson (Eds.). The Sage Handbook of Comparative Politics. ( $\mathrm{p}+$. 439-62). London: Sage.

Kelsall, T. (2008). Going with the Grain In African Development. Africa Power and Politics Programme Discussion Paper No. 1. London: Overseas Development Institute.

Khan, M.H. (2006a). Governance, Economic Growth and Development since the 1960s: Background paper for World Economic and Social Survey. New York: United Nations (DESA).

Khan, M.H. (2006). Governance and Anti-Corruption Reforms in Developing Countries: Policies, Evidence and Ways Forward. G-24 Discussion Papers No. 24. Geneva: United Nations (UNCTAD)

Killick, T., Castel Branco \& C.N., Gerster, R. (2005). Perfect Partners? The performance of Programme Aid Partners in Mozambique. Report to the Programme Aid Partners and Government of Mozambique. Maputo.

Kitzinger, J. (1995). Qualitative Research: Introducing Focus Groups. British Medical Journal, 311 (7000), 299-302.

Kjaer A.M. (2004). Governance. Cambridge: Polity Press.

Klerk, F. W. de. (1998). The Last Trek - A New Beginning. London: Macmillan.

Knack, S. (2006). Measuring Corruption in Eastern Europe and Central Asia: A Critique of the Cross-Country Indicators. World Bank Policy Research Working Paper WPS3968. Washington D.C.: World Bank.

KPMG/Ministry of Planning and Development (2010). Final Report - Paris Declaration Evaluation Phase 2. Mozambique. Maputo.

Krueger, R. A. (1994). Focus Groups: A Practical Guide for Applied Research. London: SAGE Publications.

Kulipossa F.P. (2007). Mozambique. IDS Bulletin 37 (2), 20-54. Brighton: Institute of Development Studies.

Langbein, L. \& Knack, S. (2008). The Worldwide Governance Indicators: Six, One or None? Journal of Development Studies, 46 (2), 350-370.

Lawson, A., Renzio, P. de \& Umarji, M. (2006). Assessment of Public Finance Management in Mozambique 2004/05. (Final Report). Maputo.

Lawson, A., Umarji, M., Guilherme, J. \& Chacine, C. (2008). Assessment of Public Finance Management in Mozambique 2006. (Final Report). Maputo.

Leftwich, A. (2000). States of Development. On the Primacy of Politics in Development. Cambridge: Polity. 
Lensink R. \& White H. (2000). Assessing Aid: A Manifesto for the $21^{\text {st }}$ Century?. Oxford Development Studies 28 (1), 5-18.

Manning, C.L. (2002). The Politics of Peace in Mozambique. Post-Conflict Democratization, 1992-2000. Westport: Prager.

Mason, J. (1996). Qualitative Researching. Great Britain: SAGE Publications.

McGillivray M. (2004). Aid Effectiveness. WIDER research paper. Helsinki: UNU/WIDER. Meneses, M.P. \& Sousa Santos (de), B. (2009). Mozambique: The Rise of a Micro Dual State.

Africa Development, Vol. XXXIV, No. 3 and 4, 129-166.

Miles, M.B. \& Huberman A.A. (1994). Qualitative Data Analysis (2 $\left.2^{\text {nd }} e d.\right)$. USA: SAGE Publication.

Ministry for Foreign Affairs (2008). Framework for Strategic Governance and Corruption Analysis (SGACA). The Hague: Ministry for Foreign Affairs.

Ministry of Foreign Affairs of the Netherlands (2008). Power and Change Analysis: Mozambique 2008. Unpublished document.

Ministry for Foreign Affairs of Finland (2002). Evaluation of the Bilateral Development Co-Operation between Mozambique and Finland. Evaluation Report 2002:2. Helsinki: Ministry for Foreign Affairs of Finland.

Minter, W. (1994). Apartheid's Contras. An Inquiry into the Roots of War in Angola and Mozambique. London: Zed Books.

Molanaers, N., \& Nijs, L. (2009). From the Theory of Aid Effectiveness to the Practice: The European Commission's Governance Incentive Tranche. Development Policy Review, 27 (5), 561-580.

Moore, M. \& Unsworth, S. (2006). Britain's New White paper: Making Governance Work for the Poor. Development Policy Review, 24 (6), 706-707.

Morrisey, O. (2004). Conditionality and Aid Effectiveness Re-evaluated. The World Economy, Vol. 2 (2), 153-171.

Mo Ibrahim Foundation. http://www.moibrahimfoundation.org

Moore M. (1993). Good Government? IDS Bulletin 24, reproduced in IDS Bulletin 37 (4) 50-56. Brighton: Institute of Development Studies.

Mosley P., Harrigan J. \& Toye J. (1991). Aid and Power: The World Bank and Policy Based Lending. Routledge: London.

Mosse, M.. \& Pohlman. F.J. (2011). O MARP em Moçambique. Open Society Foundations. Johannesburg: OSISA.

Newitt, M. (1994). A History of Mozambique. London: Hurst \& Company.

Nissanke, M. (2010). Reconstructing the Aid Effectiveness Debate. In Mavrotas, G., Foreign Aid for Development (pp. 63-93). Oxford: Oxford University Press for UNU-WIDER.

OECD. (2005). Survey on Progress in Harmonisation and Alignment. Mozambique Country Report. Paris: OECD.

OECD. (2003). Rome Declaration on Harmonization. Paris: OECD. 
OECD. (2005). Paris Declaration on Aid Effectiveness. Paris: OECD. www.oecd.org/dataoecd/11/41/34428351.pdf.

OECD. (2008). Accra Agenda for Action. Paris: OECD. www.oecd.org/dataoecd/11/41/34428351.pdf.

OECD (2007). Survey on Monitoring the Paris Declaration: Overview of the Results. Journal on Development 2007 (8). Paris: OECD.

OECD DAC (2007). DAC Statistical Reporting Directives. Paris: OECD.

OECD DAC (2008). Is this ODA? http://www.oecd.org/document/0/ 0,3746,en_2649_34447_42398912_1_1_1_1,00.html

OECD (2008). Survey on Donor Approaches to Governance Assessments. Final Report. www.oecd.org/dataoecd/26/5/40049776.pdf.

OECD DAC (2009). Donor Approaches to Governance Assessments, Sourcebook, Paris: OECD DAC.

OECD DAC (2010). Inside the DAC. A Guide to the OECD Development Assistance Committee 2009-2010. Paris: OECD.

OECD DAC. (2011). 2011 DAC Report on Multilateral Aid. Paris: OECD.

OECD DAC International Development Statistics Databases. Available from www.oecd.org/dac/stats/idsonline

Pearson L. and others (1969). Partners in Development: Report of the Commission on International Development. New York: Praeger Publishers.

Petlane, T. \& Gruzd, S.(2011). African Solutions: Best Practices from the African Peer Review Mechanism. Johannesburg: Jacana

Phillips, L.W. \& Bagozzi, R.P. (1986) “On Measuring Organizational Properties of Distributional Channels: Methodology Issues in the Use of Key Informants”. Research in Marketing, Vol. 8 ,313-369.

Pierre, J. (1999). Debating Governance; Authority, Steering and Democracy. Oxford: Oxford University Press.

Pierre J. \& Peters, B. G. (2000). Governance, Politics and the State. Macmillan Press.

Pietilä, I. (2010). Ryhmä- ja yksilöhaastattelun diskursiivinen analyysi. In Ruusuvuori, J., Nikander, P. \& Hyvärinen, M (toim.), Haastattelun analyysi (pp. 212-241). Tampere: Vastapaino.

Rajan R. G. \& Subramanian A. (2005a). What Undermines Aid's Impact on Growth? IMF Working Paper 126. Washington: International Monetary Fund.

Rajan R. G. \& Subramanian A. (2005b). Aid and Growth: What does the Cross-Country Evidence Really Show? IMF Working Paper 127. Washington:. International Monetary Fund.

Rakner, L. \& Wang, V. (2007). Governance Assessments and the Paris Declaration. A CMI Issues Paper R2007:10. Bergen: CMI.

Republic of Mozambique \& UNDP (2005). Report on the Millennium Development Goals. Maputo. 
Republic of Mozambique (2001). Action Plan for the Reduction of Absolute Poverty 20012005 (PARPA). Maputo.

Republic of Mozambique (2006). Action Plan for the Reduction of Absolute Poverty 20062009 (PARPA II). Maputo.

Republic of Mozambique, Ministry of Planning and Development (2010). Report on the Millennium Development Goals - Mozambique. Maputo.

Republic of Mozambique, Ministry of Planning and Development (2010). Poverty and Wellbeing in Mozambique: Third National Poverty Assessment. Maputo.

República Popular de Moçambique (1975). Constituição da República Popular de Moçambique. Maputo.

República de Moçambique (1990). Constituição da República - Moçambique. Maputo.

República de Moçambique (2004). Constituição da República - Moçambique. Texto Aprovado na Assembleia da República em 16 de Novembro 2004. Maputo: Escolar Editora.

República de Moçambique (2011). Plano de Acção para Redução da Pobreza 2011-2014. Maputo.

Renzio, P. de \& Hanlon, J. (2007). Contested Sovereignty in Mozambique: The Dilemmas of Aid Dependence. Global Economic Governance Programme Working Paper. Oxford: University College Oxford.

Rhodes, R.A.W. (1997). Understanding Governance: Policy Networks, Governance, Reflexivity and Accountability. Open University Press.

Riddell R. (1987). Foreign Aid Reconsidered. Baltimore: John Hopkins University Press.

Riddell R. (2007). Does Foreign Aid Really Work? Oxford: Oxford University Press.

Rosenstein-Rodan P. (1961). International Aid for Underdeveloped Countries. Review of Economics and Statistics, 43, 107-138.

Rostow W. W. (1956). The Take-Off Into Self-Sustained Growth. The Economic Journal, $66,25-48$.

Roxborough, I. (1983). Theories of Underdevelopment. London: Macmillan Press.

Santiso, C. (2001). Good Governance and Aid Effectiveness: The World Bank and Conditionality.

The Georgetown Public Policy Review, Vol. 7 (1), 1-22.

Sellström, T. (1999). Liberation in Southern Africa - Regional and Swedish Voices. Interviews from Angola, Mozambique, Namibia, South Africa, Zimbabwe, the Frontline and Sweden. Uppsala: Nordic Africa Institute.

Sen, A.K. (1999). Development as Freedom. New York: Anchor Books.

Siitonen, L. (2005). Aid and Identity Policy. Small Donors and Aid Regime Norms. Turun yliopiston julkaisuja. Sarja B.Turku: Turun yliopisto.

Silverman, A. (2010). Doing Qualitative Research ( $3^{\text {rd }} e d$.). London: SAGE Publications.

Smith, B.C. (2007). Good Governance and Development. New York: Palgrave Macmillan.

Soiri, I. \& Peltola, P. (1999). Finland and National Liberation in Southern Africa. Uppsala: Nordic Africa Institute. 
Stewart, D.W. \& Shamdasani, P.N. (1990). Focus Groups Theory and Practice. London: SAGE Publications.

Stiglitz, J. (2008). Is there a Post-Washington Consensus. In N. Serra and J. Stiglitz (Eds.), The Washington Consensus Revisited: Towards a New Global Governance. Oxford: Oxford University Press.

Strauss, A. and Corbin, J. (1990). Basics of Qualitative Research. USA: SAGE Publications. Swedish International Development Agency (2002). Good Governance. Stockholm: SIDA.

Swedish International Development Agency (2005). Methods of Analyzing Power - A Workshop Report. Stockholm: SIDA.

Szirmai, A. (2005). The Dynamics of Socio-Economic Development; An Introduction. Cambridge: Cambridge University Press.

Tarnoff, C. (2010). Millennium Challenge Corporation. Congressional Research Service. RL 32427. www.crs.gov.

Tarp, F. (2010). Aid Growth and Development. In G. Mavrotas (Ed.), Foreign Aid for Development (pp. 20-53). New York: Oxford University Press for UNU-WIDER.

Thomas, M.A. (2007). What do the Worldwide Governance Indicators Measure? John Hopkins University. School of Advanced International Studies. Washington DC.

Transparency International. http://www.transparency.org

Tuomi, J. \& Sarajärvi, A. (2012). Laadullinen tutkimus ja sisällönanalyysi (9.uudistettu laitos). Helsinki: Tammi.

UNAIDS (2009). Country Fact Sheet on Mozambique. Maputo.

UNDP (1997). UNDP Strategy Note on Governance for Human Development. New York: UN.

UNDP (2001). Mozambique Human National Development Report. New York: UN.

UNDP (2007a). Governance Indicators - User's handbook. New York: UN.

UNDP (2007b). UNDP Human Development Report. New York: UN.

UNDP (2011). Mozambique Country Profile of Human Development Indicators. http://hdrstats.undp.org/en/countries/profiles/MOZ.html

UNICEF (1989). Children on the Front Line. New York: UNICEF.

United Nations (1997). Governance for sustainable human development. A UNDP policy document. New York: UN.

United Nations (2000). United Nations Millennium Declaration. Retrieved from: www.un.org/millennium/declaration/ares552e.htm.

United Nations (2002). Report of the International Financing Conference in Monterrey. New York: UN.

United Nations (2005). Millennium Project; Investing in Development. Report to the UN Secretary General. New York: UN.

United Nations (2008). Human Development Indices. http://hdr.undp.org/en/media/ HDI_2008_EN_Tables.pdf.

United Nations General Assembly Resolution 2626 (XXV), 24 October, 1970.

United Nations General Assembly Resolution 1701 (XVI), 19 December 19, 1961. 
University of Essex \& UNDP (2007). Preliminary Survey on Donor use of Governance Assessments.( www.undp.org/oslocentre/docs07/bergen_2007)

Voipio, T. (2011). From Poverty Economics to Global Social Policy. Kuopio: University of Eastern Finland. Dissertations in Social Sciences and Business Studies No 11.

Wahlroos, B. (2010). Kehitysapu syytä lopettaa. In Suomen Kuvalehti 11/2010 (19.3.2010). Helsinki: Otavamedia.

Waltmans, J. (2008). Behind the Façade: From analysis to action. (http://www.minbuza.nl).

White, G. (1983). Revolutionary Socialist Development in the Third World: An Overview. In $\mathrm{G}$.

White, R. Murray \& C. White (Eds.), Revolutionary Socialist Development in the Third World (pp. 1-34). Brighton: Wheatsheaf Books Ltd.

Wield, D. (1983). Mozambique - Late Colonialism and Early Problems of Transition. In G. White, R. Murray \& C. White (Eds.), Revolutionary Socialist Development in the Third World (pp. 75-113). Brigton: Wheatsheaf Books Ltd.

Williamson, J. (2002). Did the Washington Consensus Fail? (http://www2.econ.iastate.edu/ classes/econ502/tesfatsion/WashingtonConsensus.JWilliamson2002.pdf)

World Bank (1982). IDA in Retrospect: The First Two Decades of the International Development Association. Washington D.C.: World Bank.

World Bank (1989). Sub-Saharan Africa: From Crisis to Sustainable Growth. Washington: World Bank.

World Bank (1998). Assessing Aid: What Works, What Doesn't and Why. Washington: World Bank.

World Bank (1992). Governance and Development. Washington D.C.: World Bank.

World Bank (1994). Adjustment in Africa: Reforms, Results and the Road Ahead. World Bank Policy Research Unit, Washington: World Bank

World Bank (1997). The State in a Changing World. World Development Report 1997. Washington: World Bank.

World Bank (2000a). Attacking Poverty: Opportunities, Empowerment, and Security. 2000/2011. World Development Report 2000/2001. Washington: World Bank.

World Bank (2000b). Reforming Public Institutions and Strengthening Governance. Washington: World Bank.

World Bank (2001a). Review of the Performance-Based Allocation System, IDA 10-12. Washington. D.C.: World Bank.

World Bank (2001b). Governance - The Critical Factor, IDA 10-12. Washington. D.C.: World Bank.

World Bank (2002). A Case for Aid. Washington: World Bank.

World Bank (2003). Country Assistance Strategy for the Republic of Mozambique. Washington D.C.: World Bank.

World Bank (2005). Lesson Learned from the Decade of Development. Washington: World Bank. 
World Bank (2006a). Global Monitoring Report 2006; Strengthening Mutual Accountability. Washington: World Bank.

World Bank (2006b). Worldwide Governance Indicators. Washington: World Bank.

World Bank (2006c). A Decade of Measuring the Quality of Governance. Washington D.C. World Bank.

World Bank (2006d). IDA's Performance Based Allocation System: A Review of the Governance Factor. Washington. D.C.: World Bank.

World Bank (2007a). Governance and Anti-Corruption Strategy. Washington: World Bank.

World Bank (2007b). Strengthening the World Bank Group Engagement on Governance and Anti-Corruption. Washington. D.C.: World Bank.

World Bank (2007c). IDA's Performance Based Allocation System: Options for Simplifying the Formula and Reducing Volatility. Washington. D.C.: World Bank.

World Bank (2007d). Selectivity and Performance. IDA's Country Assessment and Development Effectiveness. Washington. D.C: World Bank.

World Bank (2008a). Aid Architecture; An Overview of the Main Trends in Official Development Assistance Flows. Washington D.C.: World Bank.

World Bank (2008b), Governance Matters VII: Aggregate and Individual Governance Indicators 1996-2007.Washington D.C.: World Bank.

World Bank (2008c). Report from the Executive Directors to the Board of Governors. Additions to IDA Resources. Fifteenth Replenishment. Washington D.C.: World Bank.

World Bank (2009a). The World Bank's Country Policy and Institutional Assessment, An Evaluation. Independent Evaluation Group. Washington D.C.: World Bank.

World Bank (2009b). Country Policy and Institutional Assessments. 2009 Assessment Questionnaire. Washington D.C.: World Bank.

World Bank (2009c). IDA’s Performance Based Allocation and Development Results: An Update. Washington D.C.: World Bank.

World Bank (2010). IDA's Performance Based Allocation System: Review of the Current System and Key Issues for IDA16. Washington D.C.: World Bank.

World Bank (2011). An Evaluation of the 2007 Strategy and Implementation Plan. World Bank Country-Level Engagement on Governance and Anticorruption. IEG Evaluation Report. Washington D.C. World Bank.

World Bank (2012). Strengthening Governance: Tackling Corruption. Washington: World Bank.

World Bank \& UNDP (1989). Africa's Adjustment in the 1980s. Washington: World Bank. Wuyts, M. E. (1989). Money and Planning for Socialist Transition: The Mozambican Experience. Aldershot: Gower Publishing Company Ltd.

Yin, K. R. (2009). Case Study Research: design and methods (4 $4^{\text {th }}$ ed.). USA: SAGE Publications. 


\section{WEBPAGES}

www.afdb.org/fileadmin/uploads/afdb/Documents/Project-and-Operations/

AFDB\%20-\%202007\%20CPIA.xls

www.afdb.org/fileadmin/uploads/afdb/Documents/Project-and-Operations/

2010\%20Detailed\%20CPIA-FOR\%20DISCLOSURE_.xls

www.eisa.org.za/WEP/mozelectarchive.htm

http://hdrstats.undp.org/en/countries/profiles/MOZ.html

www.mcc.gov

www.minbuza.nl

www.oecd.org/dac

www.oecd.org/dac/aid-architecture

www.oecd.org/dac/effectiveness/parisdeclarationandaccraagendaforaction.htm www.oecd.org/dac/effectiveness/busanpartnership.htm.

www.oecd.org/dataoecd/21/11/40108254.pdf

www.oecd.org/dataoecd/11/41/34428351.pdf.

www.oecd.org/document/0/0,3746,en_2649_34447_42398912_1_1_1_1,00.html

www.oecd.org/dac/stats/idsonline

www.oecd.org/dataoecd/26/5/40049776.pdf.

www.pap.org.mz

www.transparency.org

www.un.org/millennium/declaration/ares552e.htm.

www.un.org/millenniumgoals

www.un.org/esa/ffd/ffdconf/hdr.undp.org/en/media/HDI_2008_EN_Tables.pdf.

www.undp.org/oslocentre/docs07/bergen_2007

www.worldbank.org/ida/country/mozambique.html

http://info.worldbank.org/governance/wgi/pdf_country.asp

http://info.worldbank.org/governance/wgi/index.asp

http://siteresources.worldbank.org/IDA/

Resources/73153-1181752621336/3878278-1277241699178/moz.pdf

www.worldbank.org/ida

http://siteresources.worldbank.org/IDA/Resources/

73153-1181752621336/IRAI2007table1.pdf

www1.worldbank.org/operations/CPIA2010/IRAI2010table1.xls

www1.worldbank.org/operations/CPIA2010/MOZ.pdf 



\section{Annexes}

\section{Annex 1. CPIA Cluster D}

\section{Qualitative Judgments behind the World Bank and the AfDB CPIA Scores; Mozambique's Performance on Public Sector Management and Institutions, 2007 and 2010}

In order to interpret CPIA scores and translate them into qualitative judgments about Mozambique's performance, it is necessary to revert to the World Bank's own definitions of the 16 CPIA criteria and of benchmarks for the different rating levels (on scale from 1 to 6) established for each criterion. These are outlined in the CPIA Assessment Questionnaire which is provided annually by the World Bank headquarters as guidance for the CPIA conducted at country level. In view of the weight of the governance rating (Cluster D, Public Management and Institutions) in the calculation of the overall CPIA score - and the specific focus on governance of this research - the discussion is limited to Mozambique's scores related to the Public Sector Management and Institutions (Cluster D).

The five criteria within the Cluster $\mathrm{D}$ are equally weighted, with each criterion given a weight of 0.05. However, as stated in the Assessment Questionnaire, each of the five criterion is multi-dimensional and the composite indicators for each criterion should be rated separately. The Assessment Questionnaire defines the rating levels for each of the composite indicators.

\section{Cluster D. Public Sector Management and Institutions}

\section{Criterion 12. Property Rights and Rule-Based Governance}

Purpose: to assess "the extent to which private economic activity is facilitated by an effective legal system and rule-based governance structure in which property and contract rights are reliably respected and enforced" (CPIA 2009 Assessment Questionnaire, World Bank 2009, p. 31) 
As shown in Table 7.3, Mozambique's score remained unchanged, at the level of 3.0, on the criterion on Property Rights and Rule-Based Governance. The criterion is multi-dimensional with three composite indicators ( $\mathrm{a}, \mathrm{b}$ and $\mathrm{c}$ ) which aim at assessing a) the legal basis for secure property and contract rights; b) the predictability, transparency and impartiality of laws and regulations affecting economic activity and c) the extent to which crime and violence impede economic activity.

For score 3, the following descriptions are given (the letters a, b and $\mathrm{c}$ in brackets refer to the three composite indicators):

(a) The law protects property rights in theory, but in fact registries and other institutions required to make this protection effective function poorly, making the protection of private property uncertain.

(b) Laws and regulations are not changed arbitrarily, but may not be publicly available. Courts are costly and time-consuming to use. Delays are common, but generally are not pretext for bribes. Judicial decisions are sometimes publicly available.

(c) The state is able to provide a modicum of protection against crime and violence. Most citizens view the police on balance as an impediment to crime and violence rather than a source.

(Source: World Bank 2007, 2009)

Criterion 13. Quality of Budgetary and Financial Management

Purpose: to assess "the extent to which there is: (a) a comprehensive and credible budget, linked to policy priorities; (b) effective financial management systems to ensure that the budget is implemented as intended in a controlled and predictable way; and (c) timely and accurate accounting and fiscal reporting, including timely and audited public accounts and effective arrangements for follow up" (ibid. p. 35).

On the criterion measuring the quality of budgetary and financial management, Mozambique is perceived to have improved its performance between 2007 and 2010: in 2007 Mozambique scored 3.5 whereas in 2010 it scored 4.0. This criterion is also multi-dimensional with three composite indicators: a) comprehensive and credible budget linked to policy priorities; b) financial management and c) fiscal reporting. Concerning the scores 3 and 4 , the following descriptions are given:

Definitions for score 3 are:

(a) Policies or priorities are explicit, but are not linked to the budget. There is no forward look in the budget. The budget is formulated in consultation with spending ministries The budget classification system does not provide an adequate picture of general government activities. A significant amount of funds controlled by the executive is outside the budget (e.g., 10-25\%), and a number of donor activities bypass the budget. 
(b) Expenditures deviate from the amounts budgeted by more than 20 percent overall, or on many broad budget categories. Budget monitoring and control systems are inadequate. Payment arrears are 5-10\% of total expenditures.

(c) Reconciliation of banking and fiscal records is undertaken less frequently than mont$h l y$, or discrepancies are not always accounted for. In-year budget reports are prepared quarterly less than 8 weeks after the end of the period, but their usefulness is undermined somewhat by inaccurate data or reporting only at high levels of aggregation. There are significant delays (e.g., more than 10 months) in the preparation of public accounts. Accounts are not audited in a timely and adequate way, and few if any actions are taken on budget reports and audit findings.

(Source: World Bank 2007, 2009)

Concerning the score 4, the following definitions are provided:

(a) Policies and priorities are broadly reflected in the budget. Some elements of forward budget planning are in place. The budget is formulated in consultation with spending ministries, from a sufficiently early stage in the budget preparation process. The budget classification system is comprehensive, but different from international standards. Less than $10 \%$ of funds controlled by the executive are outside the budget.

(b) Actual expenditures deviate from the amounts budgeted by more than 10 percent on many broad budget categories. Budget monitoring and control systems exist, but there are some deficiencies. Payment arrears may exist but are less than 5\% of total expenditures.

(c) Reconciliation of banking and fiscal records is undertaken satisfactorily, on a monthly basis. In-year budget reports are prepared quarterly less than 6 weeks after the end of the period, with reasonably accurate data, broken down to at least programme or functional level. There are delays (e.g., more than 6 months) in preparation of the public accounts. The accounts are audited in a timely and professional manner, but few meaningful actions are taken on budget reports or audit findings.

(Source: World Bank 2007, 2009)

Criterion 14. Efficiency of Revenue Mobilization

Purpose: to assess "the overall pattern of revenue mobilization--not only the tax structure as it exists on paper, but revenue from all sources as they are actually collected. Separate sub-ratings should be provided for (a) tax policy and; (b) tax administration." (ibid. p. 36).

The criterion for measuring the efficiency of revenue mobilization comprises two composite indicators: a) tax policy and b) tax administration. The definitions for the score 4, which Mozambique achieved both in 2007 and 2010, are given below:

Definitions for score 4: 
(a) A significant amount of revenue is being generated by low-distortion taxes such as retail sales/VAT, property, etc. VAT has not been fully operational to include activities at the retail stage. Non-trivial amounts of revenue are generated from company and personal income taxes. Tax base is broad and exemptions are moderate and made time-bound, especially for promotion schemes. Trade taxes have few and low rates.

(b) Tax administration is solid, cost of revenue generation has been reduced and there are relatively few cases of corruption and political interference. Eligibility for preferential rates and exemptions is largely transparent.

(Source: World Bank 2007, 2009)

\section{Criterion 15. Quality of Public Administration}

Purpose: to assess "the extent to which civilian central government staffs (including teachers, health workers, and police) are structured to design and implement government policy and deliver services effectively" (ibid. p. 38).

This criterion concerning the quality of public administration is also multi-dimensional comprising the following four composite indicators: a) policy coordination and responsiveness; b) service delivery and operational efficiency; c) merits and ethics; d) pay adequacy and management of the wage bill. Mozambique scored 3 on this criterion both in 2007 and 2010. The score 3 for each of the indicators is defined as follows:

(a) Administrative structures are fragmented, and coordination mechanisms are generally inadequate to overcome parochial bureaucratic interests.

(b) Business processes can be overly complex, often causing unnecessary delays.

(c) Hiring and promotion formally merit-based, but there is extensive patronage in practice in several parts of government. Bribe seeking is accepted behavior in some agencies but not throughout government.

(d) Public employment as a share of total employment is higher than needed and unsustainable if adequate wages were paid. The wage bill represents an excessively large proportion of total government expenditure. Some sectors are overstaffed (particularly health and education). Pay and benefit levels are generally inadequate and there are major difficulties in attracting and retaining staff in key technical areas.

(Source: World Bank 2007, 2009)

Criterion 16. Transparency, Accountability, and Corruption in the Public Sector Purpose: to assess the extent to which the executive can be held accountable for its use of funds and the results of its actions by the electorate and by the legislature and judiciary, and the extent to which public employees within the executive are required to account for the use of resources, administrative decisions, and results obtained" (ibid. p. 41). 
Mozambique scored 3 also on the criterion concerning public sector transparency, accountability and corruption both in 2007 and 2010. This criterion consists of three dimensions which are defined in terms of the following composite indicators: a) accountability of the executive to oversight institutions and of public employees for their performance; b) access of civil society to information on public affairs; c) state capture by narrow vested interests. The score 3 for each composite indicators is defined as follows:

(a) External accountability mechanisms such as inspector-general, ombudsman, or independent audit may exist, but have inadequate resources or authority.

(b) Decision making is generally not transparent, and public dissemination of information on government policies and outcomes is a low priority. Restrictions on the media limit its potential for information gathering and scrutiny.

(c) Elected and other public officials often have private interests that conflict with their professional duties.

(Source: World Bank 2007, 2009)

The above definitions of the scoring levels provide a basis for interpreting the scores in more operational terms and for drawing some conclusions about the Mozambique's Public Sector Management and Institutions, as perceived through the CPIA. For example, it can be concluded that, with a score of 3, Mozambique still faces significant challenges concerning the respect for Property Rights and Rule-based Governance (criterion 12) with a major gap between the existence of appropriate legislation and the enforcement of this legislation. The same applies to the Quality of Public Administration (criterion 15) and Transparency, Accountability and Corruption in Public Sector (criterion 16) in the country. With the rating of 3.0 Mozambique is perceived to suffer from large, fragmented and ineffective public administration that is characterized, at least to some degree, by non-transparent patronage and bribe-seeking. Accountability mechanisms between the government and the citizens function poorly, if at all, and public officials often have private interests which are in conflict with their professional duties. Lack of transparency in government decision-making and restrictions on the media limit the citizens' access to information on government policies. The fact that these scores have remained unchanged implies that the situation is perceived to be constant, or that the changes are so small that a revision of the scores is not justified.

The CPIA results seem to indicate also a number of positive trends in Mozambique's Public Sector Management and Institutions. For example, the Quality of Budgetary and Financial Management (criterion 13), particularly the preparation and execution of state budget as well as fiscal reporting mechanisms, is perceived to have improved between 2007 and 2010. With the rating of 4.0 Mozambique has reached a relatively satisfactory level, at least in comparison with the average SADC LICs and all IDA eligible countries. Similar, relatively positive conclusions can be drawn from Mozambique's 
scores on the Efficiency of Revenue Collection (criterion 14): rating at level of 4 both in 2007 and 2010 implies that Mozambique is perceived to have a fiscal policy in place, has created a solid tax administration system and succeeds to generate significant domestic revenue through low-distortion taxes.

The difference in the World Bank and the AfDB perceptions on Mozambique's governance performance is notable concerning the criterion Transparency, Accountability, and Corruption in the Public Sector (criterion 16). In 2007, Mozambique was rated at the level of 3.0 both by the World Bank and the AfDB, however, in 2010, the Mozambique was rated at the level of 2.5 by the AfDB. Bearing in mind that both assessments rely, by and large, on same data sources, the difference is rather significant when translated into qualitative judgments underlying the scores. As has been described earlier, the AfDB and the World Bank use an identical set of criteria and define the different rating levels in exactly similar manner. The definition of the rating level 2 (in contrast to the rating level 3 outlined on page 5) is as follows:

Criterion 16. Transparency, Accountability, and Corruption in the Public Sector

The rating level 2 for each composite indicators is defined as follows:

(a) The are only ineffective audits and other checks and balances on executive power. Public officials are not sanctioned for failures in service delivery or for receiving bribes.

(b) Decision making is not transparent, and government withholds information needed by the public and civil society organizations to judge its performance. The media are not independent of government or powerful business interests.

(c) Boundaries between the public and private sector are ill-defined, and conflicts of interest abound. Laws and policies are bias towards narrow private interests. Implementation of laws and policies is distorted by corruption, and resources budgeted for public services are diverted to private gain.

In view of the AfDB, Mozambique thus faces a much more problematic situation in terms of public sector transparency, accountability and corruption than in view of the World Bank. According to the AfDB CPIA, there are no effective external accountability mechanisms, decision-making in the public sector is non-transparent and corruption is wide-spread. It is also worth noting that, according to the AfDB CPIA, the situation is perceived to have deteriorated from 2007 to 2010 whereas the World Bank CPIA does not reflect any changes over the same period. 


\section{Annex 2. Interview Guide: Key Informants and Focus Group Discussants}

Título da Investigação: Avaliação de Governação em Análise: o Caso de Moçambique

\section{Apresentação da Investigação}

Grupos de intervenientes (abordagem à governação por parte do PNUD: governo, sector privado, sociedade civil):

1. Membros (deputados) da Assembleia da República (AR)

2. Funcionários públicos superiores na Administração Pública (AP)

3. Intervenientes do Sector Privado (SP)

4. Membros dos meios de comunicação (MC)

5. Membros dos círculos académicos (ACAD)

6. Membros das Organizações da Sociedade Civil (OSC)

A entrevista focaliza os assuntos que se seguem:

1. Conhecimento das avaliações de governação

2. Relevância das avaliações de governação

3. Envolvimento nas avaliações de governação

4. Impacto das avaliações de governação

5. Questões adicionais

6. Quaisquer outras observações

\section{Grupo de Inter-} venientes:

\begin{tabular}{|c|c|c|c|c|c|}
\hline AR & AP & MC & SP & ACAD & OSC \\
\hline & & & & & \\
\hline
\end{tabular}

Data:

Perguntas de base relacionadas com a familiaridade do/da Entrevistado/a com a cooperação para o desenvolvimento

Caso não tenha muito conhecimento, dê destaque à Secção B (nível de conhecimento classificado entre 1 e 2).

\section{DEFINIÇÃO DO CONCEITO DE GOVERNAÇÃO}

1. Já conhece o conceito de "governação"? Como explicaria a palavra?

2. Como explicaria a conceito de 'boa governação'? E má governação, o que o conceito significa para si?

3. Como é que a qualidade de governação em Moçambique influencia a vossa vida e o trabalho quotidiano?

4. Quais são, na sua opinião, os elementos mais importantes de boa governação?

5. Quais são, na sua opinião, os elementos mais importantes de má governação? 


\section{A. ENTREVISTADOS - FAMILIARIZADOS COM AS AVALIAÇÕES DE GOVERNAÇÃO}

\section{CONHECIMENTO DAS AVALIAÇÕES DE GOVERNAÇÃO}

1. Enumere as avaliações de qualidade de governação (em Moçambique) de que está consciente:

2. Queira descrever como é que você soube destas avaliações de governação (por exemplo, por meio da rádio, televisão, jornal, a partir de amigos/colegas).

3. Pode dizer-me algo acerca destas avaliações de governação que foram realizadas em Moçambique?

4. Por que razão você acha que são realizadas as avaliações de governação?

5. Regra geral, quais são as questões que elas abrangem?

6. Você pode dizer-nos algo sobre os resultados de tais avaliações no caso de Moçambique? O que é que elas revelam a respeito da qualidade da governação em Moçambique?

\section{RELEVÂNCIA DAS AVALIAÇÕES DE GOVERNAÇÃO}

1. Quais são as questões mais importantes abrangidas nas avaliações de governação?

2. Pode por favor mencionar algumas questões que na sua opinião são importantes, mas não foram abrangidas?

3. Por que razão você acha que estas questões não são abrangidas?

4. Quais são as questões que você acrescentaria, se tivesse a oportunidade?

\section{PARTICIPAÇÃO NAS AVALIAÇÕES DE GOVERNAÇÃO}

1. Quem é que organizou estas avaliações de governação? (queira indicar isto para cada uma das avaliações que referiu)

2. Você sabe até que ponto estiveram envolvidos peritos do interior do país nas várias avaliações?

3. Você participou de alguma maneira nas avaliações de governação? Caso sim, de que forma? (por exemplo no desenho, realização, como entrevistado/a ou de outra maneira consultado/a no decorrer da avaliação)

4. Você conhece alguém que participou nas avaliações de governação?

5. Na sua opinião, quem é que deve participar nas avaliações de governação? Por que razão?

6. Na sua opinião, quem é que deve ter a responsabilidade definitiva pelo desenho da avaliação e pela interpretação dos resultados?

\section{IMPACTO DAS AVALIAÇÕES DE GOVERNAÇÃO}

1. Qual é o tipo de impacto que você acha que as avaliações de governação têm sobre a qualidade de governação ou sobre a reforma a nível de governação? 
2. Será que têm impactos positivos sobre a reforma a nível de governação, ou que têm pouco ou nenhum impacto?

3. Você acha que algumas avaliações de governação tem importância (esclareça de que avaliação as pessoas estão a falar)?

4. O que é que você acha pessoalmente destas avaliações de governação? Caso na sua opinião sejam úteis, especifique porque é que podem eventualmente ser úteis. Caso não, como é que elas podiam tornar-se mais úteis? (especifique as avaliações de governação referidas)

\section{PERGUNTAS E OBSERVAÇÕES ADICIONAIS}

1. Você acha que é importante que estas avaliações sejam efectuadas?

2. Você acha que as avaliações de governação prestam atenção aos assuntos certos (especifique as várias avaliações de governação em causa?

\section{QUAISQUER OUTRAS OBSERVAÇÕES}

\section{Obrigada!}

\section{B. ENTREVISTADOS - NÃO FAMILIARIZADOS COM AS AVALIAÇÕES DE GOVERNAÇÃO}

1. Você acha que é importante que estas avaliações sejam efectuadas?

2. Porque é que você acha que é importante que estas avaliações sejam efectuadas?

3. Quais são as questões mais importantes que devem ser abrangidas nas avaliações de governação?

4. Na sua opinião, quem é que deve participar nas avaliações de governação?

5. Quaisquer outras observações

\section{Obrigada!}




\section{Annex 3. Interview Guide: Donor Representatives}

\section{AID AGENCY INTERVIEWS}

\section{AID AGENCY:}

DATE:

\section{TOOL:}

\section{INTERVIEWEE:}

\begin{tabular}{|l|l|l|l|}
\hline WHY & $\begin{array}{l}\text { Definition of } \\
\text { governance }\end{array}$ & & \\
& $\begin{array}{l}\text { Primary purpose } \\
\text { of assessment }\end{array}$ & & \\
\hline & $\begin{array}{l}\text { Conceptual } \\
\text { approach }\end{array}$ & & \\
\hline WHAT & Focus of analysis & & \\
\hline HOW & Methodology & & \\
\hline & $\begin{array}{l}\text { Reporting of } \\
\text { results }\end{array}$ & & \\
\hline WHERE & Coverage & & \\
\hline OWNER- & $\begin{array}{l}\text { Role of the part- } \\
\text { ner country }\end{array}$ & & \\
\hline SHIP & & & \\
\hline & & & \\
\hline
\end{tabular}




\section{Summary in Dutch - Samenvatting}

Het kader voor dit onderzoek wordt gevormd door het hedendaagse ontwikkelingsdebat over de relaties tussen de kwaliteit van het bestuur (governance), de doeltreffendheid van ontwikkelingssamenwerking en het process van ontwikkeling. In dit debat worden bestuur - of in normatieve termen - "goed" bestuur gezien een van de belangrijk pijlers voor armoedebestrijding en duurzame ontwikkeling. Hoewel hulporganisaties in het algemeen overtuigd zijn van het belang van goed bestuur voor de doeltreffendheid van hulp en het realiseren van ontwikkelingsdoelstellingen, is er geen overeenstemming over de preciese betekenis van bestuur of hoe dit moet worden beoordeeld in de context van een specifiek land. Door de afwezigheid van een gemeenschappelijke conceptuele en operationele benadering voor de waardering van bestuur zijn ontwikkelingslanden onderworpen aan een veelvoud van bestuursevaluaties door verschillende hulpinstanties terwille van een doeltreffende gebruik van middelen. De betrokkenheid van de ontwikkelingslanden zelf bij het ontwerp en de uitvoering van de bestuursbeoordelingen is beperkt gebleven, ondanks de door hulporganisaties met de mond beleden respect voor partnerland 'eigendom' in het ontwikkelingsproces.

In een poging om bij te dragen tot dit debat, is het belangrijkste doel van de case study over Mozambique om te onderzoeken wat bestuursbeoordelingen, uitgevoerd door ontwikkelingshulporganisaties, inhouden in de context van een specifiek land en hoe die beoordelingen worden ervaren door lokale belanghebbenden. In dit onderzoek wordt de kwaliteit van het bestuur in Mozambique zelf niet beoordeeld, maar wordt veeleer geprobeerd vier vragen te beantwoorden: ten eerste, hoe definiëren en beoordelen hulporganisaties, die actief zijn in Mozambique, het verschijnsel bestuur; ten tweede, hoe consistent zijn de uitkomsten van de verschillende bestuursbeoordelingen; ten derde, hoe relevant zijn de bestuursbeoordelingen vanuit het Mozambikaanse perspectief; en ten vierde kunnen bestuursbeoordelingen worden beschouwd als een bijdrage tot beter bestuur.

Het proefschrift bestaat uit 10 hoofdstukken. In hoofdstuk 1 worden de achtergronden en de belangrijkste doelstellingen van het onderzoek beschreven en de onderzoeksvragen gedefinieerd. In hoofdstuk 2 wordt het conceptuele kader van het 
onderzoek geschetst. In hoofdstuk 3 worden de methodologische aanpak en primaire bronnen van het onderzoek beschreven. Hoofdstukken 4 en 5 vormen de achtergrond voor het onderzoek. Zij schetsen de evolutie van de bestuurlijke en politieke context en de ontwikkeling van de architectuur van ontwikkelingshulp in Mozambique sinds de onafhankelijkheid in 1975. In hoofdstuk 6 wordt onderzocht hoe ontwikkelingshulporganisaties, die actief zijn in Mozambique, bestuur definiëren en beoordelen. In hoofdstuk 7 wordt geprobeerd een antwoord te geven op de onderzoeksvraag over de consistentie van de uitkomsten van de geselecteerde bestuursbeoordelingen. In hoofdstuk 8 worden de bestuursbeoordelingen onderzocht vanuit het Mozambikaanse perspectief. In hoofdstuk 9 worden een aantal aanbevelingen geformuleerd om de huidige donorpraktijken voor de beoordeling van het bestuur in de context van een specifiek land te verbeteren. In hoofdstuk 10 wordt een samenvatting geboden van de belangrijkste bevindingen van het onderzoek, wordt de relevantie van de bevindingen besproken en worden gebieden voor verder onderzoek geïdentificeerd.

Het onderzoek wordt conceptueel omkaderd door drie onderling samenhangende debatten, die aan het veranderende ontwikkelingsparadigma ten grondslag liggen, hetgeen op zijn beurt wordt weerspiegeld in de steeds toenemende nadruk van hulporganisaties op bestuurlijke vraagstukken alsmede in hun inspanningen om de kwaliteit van bestuur in ontwikkelingslanden te beoordelen. In de discussie over het veranderende paradigma, wordt het toenemend belang van bestuur als een fundamenteel aspect van ontwikkeling en effectieve hulpverlening beschreven (hoofdstuk 2).

Het onderzoek is voornamelijk gebaseerd op twee soorten bronnen (hoofdstuk 3). Ten eerste werden, met het oog op het onderzoek naar de conceptuele en operationele benaderingen voor de beoordeling van bestuur en de consistentie van de resultaten van de verschillende beoordelingen, de beoordelingsinstrumenten die tussen 2006 en 2010 zijn ontwikkeld en toegepast door de tien grootste ontwikkelingshulporganisaties in Mozambique, geselecteerd als eenheden voor analyse. Dit zijn: de Worldwide Governance Indicators (Wereldbankinstituut), de Country Policy and Institutional Assessments (Wereldbank en de Afrikaanse Ontwikkelingsbank), Governance Profile (Europese Unie), Millennium Challenge Scorecard (VS), Country Governance Analysis (VK), Strategic Governance and Corruption Analysis (Nederland), Power Analysis (Zweden). De schriftelijke documentatie van elke beoordeling wordt aangevuld met gegevens uit interviews met de vertegenwoordigers van de respectievelijke hulporganisaties. Ten tweede werd in de loop van 2010-2011 een veldonderzoek uitgevoerd in Mozambique, in een poging om licht te werpen op de vragen over de lokale percepties van de relevantie van de beoordelingen en de impact van de beoordelingen op bestuurshervorming in Mozambique. De methoden voor gegevensverzameling omvatten interviews met sleutelinformanten (in het totaal 28 Mozambikaanse informanten en 11 donorinformanten) en interviews met focusgroepen (in totaal 8 focusgroepen 
met 58 deelnemers). Het veldonderzoek bestond uit het interviewen van verschillende types Mozambikaanse belanghebbenden (stakeholders). De methode voor de analyse van de gegevens steunt op begrippen die ontleend zijn aan de bestaande literatuur over bestuursbeoordelingen. Voor de analyse van de gegevens afkomstig uit het veldwerk werden inhoudsanalysemethoden gebruikt.

In de discussie over de veranderende context van het bestuur in Mozambique worden radicale cycli van economische en politieke veranderingen besproken, gedreven worden door zowel interne als externe factoren, waarmee het land sinds onafhankelijkheid te maken heeft. Ondanks haar succesvolle transformatie na het conflict en de snelle economische groei, vooral sinds 1992, wordt Mozambique geconfronteerd met grote uitdagingen op het gebied van het politiek bestuur (hoofdstuk 4). In het overzicht van de evolutie van de hulparchitectuur in Mozambique wordt aangetoond dat donoren een belangrijke rol gespeeld hebben in de politieke, economische en sociale transformatie van Mozambique. De hulp heeft bijgedragen tot armoedevermindering en bredere sociaal-economische ontwikkeling, maar heeft ook geleid tot onbedoelde, negatieve ontwikkelingsuitkomsten (hoofdstuk 5).

Bij de analyse van de geselecteerde bestuursbeoordelingsinstrumenten, die in Mozambique ontwikkeld en gebruikt werden door de grootste donoren in de periode tussen 2006 en 2010, wordt aangegeven dat het merendeel van de instrumenten voortbouwt op conceptuele benaderingen die geworteld zijn in de tradities van de historische, politiek-economische en machtanalyses (hoofdstuk 6). De aandachtsgebieden van de verschillende beoordelingen variëren als gevolg van de uiteenlopende conceptuele benaderingen waarop ze gestoeld zijn. De gemeenschappelijke noemer voor alle beoordelingsinstrumenten bestaat uit het streven om het doeltreffenheid van hulp voor economische groei en armoedevermindering te vergroten. Het gebruik van de resultaten van de bestuursbeoordelingen als instrument voor de bestuurshervorming is impliciet: de beoordelingen proberen de sterke en zwakke punten, alsook de potentiële "aandrijvers van verandering" op het gebied van bestuur te identificeren en proberen een grondslag te bieden voor de toewijzing van middelen en de selectie van hulpvormen. De methodologische keuzes die door de geselecteerde instrumenten aangenomen worden, variëren van wereldwijd gestandaardiseerde kwantitatieve methoden tot kwalitatieve benaderingen waarmee de beoordeling afgestemd kan worden op de landspecifieke bestuurlijke context in Mozambique. De methodologische keuzes lijken een invloed te hebben op de keuze van de gegevensbronnen, op de praktijken voor de verspreiding en het rapporteren van de resultaten van de beoordeling, alsook op de mate waarin de plaatselijke belanghebbenden deelnemen aan de uitvoering van de beoordelingen. Actieve verspreiding van de resultaten door de hulporganisaties is uitzonderlijk. Het eigendom van het partnerland van de beoordelingsprocessen blijft beperkt bij alle onderzochte beoordelingsinstrumenten, op één uitzondering na. 
Met betrekking tot de vraag naar de consistentie van de resultaten van de geselecteerde bestuursbeoordelingen wordt in deze case study gesuggereerd dat de acht beoordelingen een heel consistent, maar toch genuanceerd beeld van de kwaliteit van het bestuur in het land geven (hoofdstuk 7). Achter de algemene consistentie van de resultaten zitten een aantal verschillen verborgen in de perceptie van de kwaliteit van het bestuur in specifieke gebieden en in de perceptie van de uitdagingen op deze gebieden. Uit de case study wordt geconcludeerd dat kwalitatieve beoordelingen, die aangepast zijn aan de Mozambikaanse context en uitgevoerd worden met meer benutting van lokale gegevensbronnen en lokale expertise, meer kritische percepties leveren van de kwaliteit van het bestuur, dan kwantitatieve beoordelingen op basis van een gestandaardiseerde, algemene aanpak voor de beoordeling van bestuur.

De analyse van de relevantie van de geslecteerde bestuursbeoordelingen vanuit het perspectief van de Mozambikaanse belanghebbenden leidt tot enigszins tegenstrijdige bevindingen (hoofdstuk 8). Enerzijds vindt men dat de bestuursbeoordelingen tal van aspecten van het bestuur omvatten, die in de Mozambikaanse context als heel relevant beschouwd worden. De gemeenschappelijke nadruk in alle geselecteerde donorbeoordelingen, voor met name transparantie, rekenschap, effectiviteit van het overheidsoptreden, de rechtsstaat en corruptie, worden door lokale belanghebbenden beschouwd als heel relevante uitdagingen in de specifieke context van Mozambique. Anderzijds missen de beoordelingen sommige van de meest fundamentele bestuursproblemen van het land. Zaken zoals het ontbreken van een participatieve democratie, het zwak ontwikkelde gevoel van burgerschap, en de aard van de politieke dynamiek in het algemeen zijn, zo vindt men, in de beoordelingen door de donoren onderbelicht. Vanuit het perspectief van de lokale belanghebbenden worden de bestuursbeoordelingen door donoren daardoor minder relevant, omdat de specifieke uitdagingen in het politieke domein onvoldoende in kaart gebracht worden.

Met betrekking tot de vraag naar de impact van de beoordelingen op de kwaliteit van het bestuur is het antwoord in het licht van deze case studie niet eenduidig (hoofdstuk 9). Naar de mening van de meerderheid van de geinterviewde lokale belanghebbenden, dragen bestuursbeoordelingen door donoren op een positieve manier bij tot het bestuur in Mozambique, door de speelruimte voor niet-gouvernementele spelers om deel te nemen aan het debat over het bestuur te vergroten, door hun stem te versterken en door hun punten van zorg te legitimeren. Op nationaal niveau, wordt de impact van beoordelingen echter ernstig ondermijnd door de beperkte verspreiding van de resultaten en de top-down benaderingen van de meeste ontwikkelingshulporganisaties die beoordelingen uitvoeren. $\mathrm{Al}$ met al is men van mening dat de donorbeoordelingen een belangrijke bijdrage leveren aan de debatten over het bestuur in het land en dat ze op een aantal specifieke terrein een positieve invloed op bestuurshervormingen hebben. 
Voor de toekomst, suggereert deze studie dat een verschuiving gewenst is van door donoren gestuurde bestuursbeoordelingen naar door het land zelf gestuurde gemeenschappelijke beoordelingen gebaseerd op landspecifieke analyses van de betekenis van bestuur en naar een breed gedragen nationale betrokkenheid bij beoordelingen en eigendom van de uitkomsten hiervan. (hoofdstuk 10). In de case study wordt ook aangegeven dat de hulporganisaties in een van hulp afhankelijk land als Mozambique zelf een deel zijn van het bestuursdomein en niet gezien kunnen worden als neutrale, apolitieke "ontwikkelingsdeskundigen" in de algemene bestuurlijke context van het land. Verder kan bestuur niet alleen in nationale of plaatselijke termen geconceptualiseerd worden. De landspecifieke bestuurscontext in Mozambique wordt, zoals in elk land, ook beïnvloed door supranationale factoren die interacteren met de nationale en plaatselijke factoren.

Er worden een aantal vragen gesuggereerd voor vervolgonderzoek. Terwijl erkend moet worden dat bestuur fundamenteel contextueel is, verdient de vraag hoe de "contextspecifieke benadering" voor beoordeling van bestuur geconceptualiseerd moet worden nader onderzoek. Ten tweede, is er verder onderzoek nodig om te begrijpen hoe er een werkelijk brede participatieve benadering van de bestuursbeoordeling ontwikkeld kan worden in diverse landen. Ten derde, is er verder onderzoek nodig om een analytisch kader te ontwikkelen om de onderlinge verbanden te onderzoeken tussen de verschillende externe en interne factoren die van invloed zijn op de nationale en plaatselijke bestuurscontext in een gegeven land. In plaats van een allesomvattende, wereldwijd gestandaardiseerde "goede bestuursagenda" te bevorderen is het ten vierde noodzakelijk landspecifieke kritieke gebieden voor actie te identificeren en te prioriteren en moeten de voornaamste spelers geïdentificeerd worden die betrokken moeten worden bij de hervormingsprocessen in dat land. Er is verder onderzoek nodig om een aanpak te vinden die dit toelaat. Ten slotte is er verder onderzoek nodig naar de rol en de impact van donoren in de discussies over goed bestuur, die kunnen bijdragen tot bestuursveranderingen in ontwikkelingslanden. De hulporganisaties zijn onderdeel van het "ontwikkelingsapparaat" in hun partnerlanden en kunnen niet losgekoppeld worden van het lokale debat over bestuur. 



\section{Curriculum Vitae}

Laura Torvinen was born in Kalajoki, northern Finland, in 1954. She holds a Masters Degree in Economics from the Helsinki School of Economics and Business Administration (1978), now Aalto University, and a Master of Philosophy in Development Studies from the Institute of Development Studies, University of Sussex, UK (1986).

She has more than 30 years of work experience in the field of development policy and development cooperation, both in Finland and abroad. Her experience in Finland ranges from civil society organisations to the Ministries for Foreign Affairs and of Finance. She has long term field experience from Lesotho and Mozambique, and has made numerous short term field missions to various other developing countries. Currently she works as the Director of the Unit for Development Financing Institutions, Ministry for Foreign Affairs of Finland (Helsinki), which is responsible for i.a. Finland's collaboration with the World Bank and the regional development banks.

\section{Other Assignments}

- World Bank Team Leader, Ministry for Foreign Affairs of Finland (2012-2013)

- Head of Cooperation and Deputy Head of the Mission, Embassy of Finland to Mozambique (2011-2012)

- Senior Adviser, Ministry for Foreign Affairs of Finland (2007-2011)

- Counsellor, Permanent Representation of Finland to the European Union (2006, 1998-2000)

- Economic Adviser, Ministry for Foreign Affairs of Finland (2002-2006)

- Financial Adviser, Ministry of Finance of Finland (2000-2002)

- Economic Adviser, Ministry for Foreign Affairs of Finland (1998-2000)

- Field Representative, Service Centre for Development (KEPA), Mozambique (1993-1996)

- Economic Adviser, Ministry for Foreign Affairs of Finland (1991-1993)

Before joining the Ministry for Foreign Affairs of Finland she had worked for the UNDP in Lesotho (1981-1983), Finnchurchaid in Finland (1983-1987) and for the Ministry of Agriculture in Mozambique. She has been an active member of several Finnish development related non-governmental organizations. She has extensive experience from training and teaching in her field of expertise. 



\section{MGSoG Dissertation Series}

Biniam Egu Bedasso

Institutional Change in the Long Shadow of Elites

Essays on Institutions, Human Capital and Ethnicity in Developing Countries

MGSoG Dissertation Series, nr 35 (2013)

Sepideh Yousefzadeh Faal Deghati

Childhoods Embargoed

Constructing and Reconstructing Multidimensional Child Poverty in Iran 1984-2009

MGSoG Dissertation Series, nr 34 (2013)

Robert Bauchmüller

Investing in Early Childhood Care and Education:

The Impact of Quality on Inequality

MGSoG Dissertation Series, nr 33 (2013)

Martin Rehm

Unified Yet Separated

Empirical Study on the Impact of Hierarchical Positions within Communities of Learning MGSoG Dissertation Series, nr 32 (2013)

Dorcas Mbuvi

Utility Reforms and Performance of the Urban Water Sector in Africa

MGSoG Dissertation Series, nr 31 (2012)

Lina Salanauskaite

Distributional Impacts of Public Policies:

Essays in Ex-Ante and Ex-Post Evaluation

MGSoG Dissertation Series, nr 30 (2012)

Esther Schüring

To Condition or not - is that the Question?

An Analysis of the Effectiveness of Ex-Ante and Ex-Post Conditionality in Social Cash Transfer Programs 
MGSoG Dissertation Series, nr 29 (2012)

Joe Abah

Strong Organisations in Weak States

Atypical Public Sector Performance in Dysfunctional Environments

MGSoG Dissertation Series, nr 28 (2012)

Zina Samih Nimeh

Social Citizenship Rights: Inequality and Exclusion

MGSoG Dissertation Series, nr 27 (2012)

Lenka Eisenhamerová

Legitimacy of 'Humanitarian Military Intervention'

MGSoG Dissertation Series, nr 26 (2011)

Sonila Tomini

Informal Payments for Health Care Services in Albania

MGSoG Dissertation Series, nr 25 (2011)

Jinjing Li

Dynamic Microsimulation in Public Policy Evaluation

MGSoG Dissertation Series, nr 24 (2011)

Aziz Atamanov

Rural Nonfarm Employment and International Migration as Alternatives to Agricultural Employment: The Case of Kyrgyztan

MGSoG Dissertation Series, nr 23 (2011)

Frieda Vandeninden

Poverty Alleviation: Aid and Social Pensions

MGSoG Dissertation Series, nr 22 (2011)

Juliana Nyasha Tirivayi

The Welfare Effects of Integrating AIDS Treatment with Food Transfers:

Evidence from Zambia

MGSoG Dissertation Series, nr 21 (2011)

Agnieska Ewa Sowa

Who's Left Behind? Social Dimensions of Health Transition and Utilization of Medical Care in Poland

MGSoG Dissertation Series, nr 20 (2011) 
Emmanaouil Sfakianakis

The Role of Private Actors in the Provision of Public Goods with Applications to Infrastructure and Financial Stability

MGSoG Dissertation Series, nr 19 (2011)

Siu Hing Lo

White Collars Green Sleeves

An Interonganizational Compariso of Deteminants of Energie-Related Behaviors among Office Workers

MGSoG Dissertation Series, nr 18 (2011)

Treena $\mathrm{Wu}$

Constraints to Human Capital Investment in Developing Countries:

Using the Asian Financial Crisis in Indonesia as a Natural Experiment

MGSoG Dissertation Series, nr 17 (2011)

Henry Espinoza Peña

Impact Evaluation of a Job-Training Programme for Disadvantaged Youths:

The Case of Projoven

MGSoG Dissertation Series, nr 16 (2011)

Florian Tomini

Between Family and Friends

Understanding the Interdependency of Private Transfers

MGSoG Dissertation Series, nr 15 (2010)

Michał Polalowski

The Institutional Transformation of Social Policy in East Central Europe:

Poland and Hungary in comparative and historical perspective

MGSoG Dissertation Series, nr 14 (2010)

Maha Ahmed

Defining, Measuring and Adressing Vulnerability:

The Case of Post Conflict Environments

MGSoG Dissertation Series, nr 13 (2010)

Pascal Beckers

Local Space and Economic Success

The role of spatial segregation of migrants in the Netherlands

MGSoG Dissertation Series, nr 12 (2010) 
Victor Cebotari

Complicting Demands in Ethnically Diverse Societies

Ethnopolitical Contention and Identity Values in Europe

MGSoG Dissertation Series, nr 11 (2010)

Dennis Gyllensporre

Competing and Complementary Perspectives on the EU as a Crisis Management Actor:

An Examination of the Common Security and Defence Policy through the Lenses of Idealism and Realism

MGSoG Dissertation Series, nr 10 (2010)

Judit Vall Castello

Business Cycle and Policy Effects on Labour Market Transitions of Older and Disabled Workers in Spain

MGSoG Dissertation Series, nr. 9 (2010)

Keetie Roelen

False Positives or Hidden Dimentions: the definition and measurement of child poverty

MGSoG Dissertation Series, nr. 8 (2010)

Denisa Maria Sologon

Earning Dynamics in Europe

MGSoG Dissertation Series, nr. 7 (2010)

Melissa Siegel

Money and Mobility: Migration and Remittances

MGSoG Dissertation Series, nr. 6 (2010)

Jessica S. Hagen-Zanker

Modest Expectations: Causes and effects of migration on migrant households in source countries

MGSoG Dissertation Series, nr. 5 (2010)

Mirtha R. Muniz Castillo

Human Development and Autonomy in Project Aid: Experiences from four bilateral projects in Nigaragua and El Salvador

MGSoG Dissertation Series, nr. 4 (2009)

Christiane Arndt

Governance Indicators

MGSoG Dissertation Series, nr. 3 (2009) 
Britta Augsburg

Microfinance - Greater Good or Lesser Evil?

MGSoG Dissertation Series, nr. 2 (2009)

Geranda Notten

Measuring and Managing Poverty Risks

MGSoG Dissertation Series, nr. 1 (2008) 
